\title{
Rethinking Schooling
}

This book offers a vantage point for thinking about the worlds of schools and curricula. Focusing on the concept of seeing schools, curricula, and teaching in new ways, the editors have selected seminal articles from the Journal of Curriculum Studies. Each of the chapters seeks to shed fresh light on the ways of thinking about teaching, curricula, and schools. The themes include:

- classrooms and teaching

- pedagogy

- science and history education

- school and curriculum development, and

- students' lives in schools.

Written by an international group of distinguished scholars from Britain, North America, Sweden, and Germany, the chapters draw on the perspectives offered by curriculum and pedagogical theory, history, ethnography, sociology, psychology and organizational studies, and experiences in curriculum-making. Together they invite many questions about why teaching and curricula must be as they are.

With a specially-written introduction by the editors, Rethinking Schooling offers new futures for education and alternative ways of seeing them, and will be an important resource for students of curriculum studies.

This volume is from the Education Heritage series. For details of other titles in this series, please go to the website at www.routledge.com/education.

Ian Westbury is Professor of Curriculum and Instruction, University of Illinois at Urbana-Champaign, USA. Geoffrey Milburn is Professor Emeritus, Faculty of Education, the University of Western Ontario, Canada. 


\title{
Education Heritage series
}

Other titles in the series:

From Adult Education to the Learning Society

Twenty-one years from the International Journal of Lifelong Education

Peter Jarvis

\author{
A Feminist Critique of Education \\ Christine Skelton and Becky Francis \\ Overcoming Disabling Barriers \\ 18 years of Disability \& Society \\ Len Barton

\section{Tracing Education Policy} \\ Selections from the Oxford Review of Education \\ David Phillips and Geoffrey Walford
}

\section{Rethinking Schooling}

Twenty-five years of the Journal of Curriculum Studies

Ian Westbury and Geoffrey Milburn

Readings from the Journal of Education Policy

Stephen J. Ball, Ivor F. Goodson and Meg Maguire

Forty Years of Comparative Education

Changing contexts, issues and identities

Michael Crossley, Patricia Broadfoot and Michele Schweisfurth

Education and Society

Twenty-five years of the British Journal of Education

Len Barton 


\section{Rethinking Schooling}

Twenty-five years of the Journal of

Curriculum Studies

Edited by Ian Westbury and Geoffrey Milburn 
First published 2007

by Routledge

Published 2017 by Routledge

2 Park Square, Milton Park, Abingdon, Oxon OX14 4RN

711 Third Avenue, New York, NY 10017, USA

Routledge is an imprint of the Taylor \& Francis Group, an informa business

Copyright (C) 2007 Ian Westbury and Geoffrey Milburn

Typeset in Galliard by Wearset Ltd, Boldon, Tyne and Wear

The Open Access version of this book, available at www.tandfebooks.com, has been made available under a Creative Commons Attribution-Non Commercial-No Derivatives 4.0 license.

British Library Cataloguing in Publication Data

A catalogue record for this book is available from the British Library

Library of Congress Cataloging in Publication Data

A catalog record for this book has been requested

ISBN13: 978-0-415-40744-1 (hbk) 


\section{Contents}

Contributors vii

Acknowledgements $\quad$ x

Introduction: rethinking schooling - twenty-five years of the Journal of Curriculum Studies

IAN WESTBURY AND GEOFFREY MILBURN

PART I

Thinking about schools and the curriculum

1 Strange curricula: origins and development of the institutional categories of schooling

WILLIAM A. REID

2 Adam Smith and the moral economy of the classroom system

DAVID HAMILTON

3 The lesson as a pedagogic text: a case study of lesson designs

A GNETA LINNÉ

PART II

Thinking about pedagogy

4 Reflectivity and the pedagogical moment: the practicalethical nature of pedagogical thinking and acting 
vi Contents

5 Didaktik analysis as the core of the preparation of instruction

WOLFGANG KLAFKI

6 Effect of questions in education and other enterprises J.T. DILLON

PART III

Thinking about curriculum work and curriculum change

7 'There's always another agenda': marshalling resources for mathematics reform

JEREMY N. PRICE AND DEBORAH LOEWENBERG BALL

8 Towards a theory of leadership practice: a distributed perspective

JAMES P. SPILLANE, RICHARD HALVERSON, AND

JOHN B. DIAMOND

PART IV

Thinking about futures

9 Designing diversity: globalization, textbooks, and the story of nations

JAMES ANDREW LASPINA

10 Meta-scientific criticisms, curriculum innovation, and the propagation of scientific culture

JOAN SOLOMON

11 A curriculum for the study of human affairs: the contribution of Lawrence Stenhouse

JOHN ELLIOTT

12 Learning for anything everyday

SHIRLEY BRICE HEATH AND MILBREY WALLIN MCLAUGHLIN

13 Curriculum forms: on the assumed shapes of knowing and knowledge

BRENT DAVIS AND DENNIS J. SUMARA

Index 


\section{Contributors}

Deborah Loewenberg Ball is William H. Payne Collegiate Professor in Education of the School of Education at the University of Michigan, USA. Her areas of specialization include the study of efforts to improve teaching through policy, reform initiatives, teacher education, and mathematical knowledge for teaching.

Brent Davis is a professor of education at the University of Alberta, Canada. $\mathrm{He}$ is author of Inventions of Teaching: A Genealogy. His research is focused on the educational relevance of recent developments in the cognitive and complexity sciences.

John B. Diamond is an assistant professor of education at Harvard University, USA. His work focuses on how students' race and social class intersect with school practices, policies, and leadership to shape children's educational opportunities and outcomes.

J.T. Dillon is a professor of education at the University of California, Riverside, USA. His most recent books include Musonius Rufus and Education in the Good Life and a re-issue of Questioning and Teaching: A Manual of Practice.

John Elliott is an emeritus professor of education in the Centre for Applied Research in Education at the University of East Anglia, Norwich, UK. He is well known for his role in developing the theory and practice of action research. His books include Action Research for Curriculum Change, The Curriculum Experiment: Meeting the Challenge of Social Change, and an anthology of his essays, Reflecting Where the Action Is.

Richard Halverson is an assistant professor in the Department of Educational Leadership and Policy Analysis at the University of Wisconsin-Madison. His research investigates methods and theories to access, document, and communicate instructional leadership expertise.

David Hamilton retired in 2005 from a chair in education at Umeå University, Sweden. His books include Towards a Theory of Schooling and Learning about Education: An Unfinished Curriculum. 
Shirley Brice Heath is currently Professor at Large and Professor of Anthropology and Education at Brown University and Margery Bailey Professorship in English and Dramatic Literature and Professor of Linguistics Emerita at Stanford University. She is author of Ways with Words: Language, Life, and Work in Communities and Classrooms and an editor of the Handbook for Literacy Educators: Research in the Visual and Communicative Arts. Her research interests include later language development, social entrepreneurship, and youth involvement in community development.

Wolfgang Klafki is Emeritus Professor of Education at the Philipps-Universität Marburg, Germany. His recent books include Schultheorie, Schulforschung und Schulentwicklung im politisch-gesellschaftenlichen Kontext: Ausgewählte Studien [Theory of the School, School Research, and the Evolution of the School in a Political-Social Context: Selected Studies] and Gecsteswissenschaftliche Pädagogik und Nationalsozialismus: Herman Nohl und seine 'Göttinger Schule', 1932-1937: eine Individual- und Gruppenbiografische, Mentalitäts- und Theoriegeschichtliche Untersuchung [Pedagogy in the Geisteswissenschaften and National Socialism: Herman Nohl and his 'Göttingen School', 1932-1937: An investigation using individual- and groupbiographical methods and the methods of the history of group mentality and theory].

James Andrew LaSpina is a writer and educational researcher. He is currently involved in a project looking at the emergence of biculturalism in New Zealand and its impact on state educational policymaking and curriculum reform. He is author of The Visual Turn and the Transformation of the Textbook.

Agneta Linné is a professor of education at Örebro University, Sweden. She is author of Moralen, Barnet eller Vetenskapen? [Morality, the Child or Science? A Study of Tradition and Change in Teacher Education]. Her research interests focus on curriculum history, teacher education, and sociology of education.

Milbrey Wallin McLaughlin is the David Jacks Professor of Education and Public Policy in the Graduate School of Education at Stanford University, USA. Her interests focus on policy implementation, contexts for teaching and learning, and community youth development. Her publications include Professional Communities and the Work of High School Teaching (with Joan E. Talbert) and Urban Sanctuaries: Neighborhood Organizations in the Lives and Futures of Inner-city Youth (with Merita A. Irby and Juliet Langman).

Geoffrey Milburn is a professor emeritus of education at the University of Western Ontario and Editor (Canada) of the Journal of Curriculum Studies.

Jeremy N. Price is a professor in educational foundations at Montclair State University, Montclair, NJ, USA. His research interests focus on the potential of transformative pedagogies in schools and teacher education and issues of power, identity, and knowledge in the lives of school students and teachers. 
William A. Reid was a member of the editorial team of JCS for 27 years. He is author of The Pursuit of Curriculum and Curriculum as Institution and Practice.

Joan Solomon is Visiting Professor of Science Education at both the Open University and the University of Plymouth, UK. She has written books on Science, Technology and Society, and on pupils' understanding of energy: Getting to know about Energy. Her principal interests are in the areas of public understanding of science and the emerging spirituality in young children's responses to science.

James P. Spillane is the Olin Professor in Learning and Organizational Change at Northwestern University, USA. He is author of Standards Deviation: How Local Schools Misunderstand Education Policy and Distributed Leadership.

Dennis J. Sumara is a professor of education at the University of Alberta, Canada. He is interested in curriculum theory and literary education, and has written Why Reading Literature in School Still Matters: Imagination, Interpretation, Insight, which was awarded the 2003 Ed Fry Book Award by the National Reading Conference.

Max van Manen is a professor of curriculum, pedagogy, and qualitative research methods in the Faculty of Education at the University of Alberta, Canada. He is the author of The Tone of Teaching: The Language of Pedagogy; Researching Lived Experience: Human Science for an Action Sensitive Pedagogy; The Tact of Teaching: The Meaning of Pedagogical Thoughtfulness; Childhood's Secrets: Intimacy, Privacy, and the Self Reconsidered (with Bas Levering); and is the editor of Writing in the Dark: Phenomenological Studies in Interpretive Inquiry.

Ian Westbury is a professor of curriculum and instruction at the University of Illinois at Urbana-Champaign and General Editor of the Journal of Curriculum Studies. 


\section{Acknowledgements}

To prepare this book, each chapter was extracted from its printed format in the pages of the JCS via scans or file conversion. The authors of the individual chapters reviewed, and corrected, their texts, and in many cases undertook updating of their original texts and references. We are very grateful for this assistance.

We also thank Dean Allen Pearson, Danielle Brown, Katherine Butson, Beverley Tomlinson, the staff members of the Education Library in the Faculty of Education at the University of Western Ontario, Stefan Hopmann of the University of Vienna, and Selena Douglass of the University of Illinois at UrbanaChampaign for their valued assistance in the preparation of the manuscript.

All articles herein have been reproduced with the permission of the Taylor \& Francis Group Ltd., the publisher of the Journal of Curriculum Studies:

Davis, B. and Sumara, D.J. (2000) 'Curriculum forms: on the assumed shapes of knowing and knowledge', Journal of Curriculum Studies, 32 (6), 821-45.

Dillon, J.T. (1982) 'The effect of questions in education and other enterprises', Journal of Curriculum Studies, 14 (2), 127-52.

Elliott, J. (1983) 'A curriculum for the study of human affairs: the contribution of Lawrence Stenhouse', Journal of Curriculum Studies, 15 (2), 105-23.

Hamilton, D. (1980) 'Adam Smith and the moral economy of the classroom system', Journal of Curriculum Studies, 12 (4), 281-98.

Heath, S.B. and McLaughlin, M.W. (1994) 'Learning for anything everyday', Journal of Curriculum Studies, 26 (5), 471-89.

Klafki, W. (1995) 'Didaktik analysis as the core of preparation of instruction' (Didaktische Analyse als Kern der Unterrichtsvorbereitung). Journal of Curriculum Studies, 27 (1), 13-30.

LaSpina, J.A. (2003) 'Designing diversity: globalization, textbooks, and the story of nations', Journal of Curriculum Studies, 35 (6), 667-96.

Linné, A. (2001) 'The lesson as a pedagogic text: a case study of lesson designs', Journal of Curriculum Studies, 33 (2), 129-56.

Price, J.N. and Ball, D.L. (1997) “"There's always another agenda”: marshalling resources for mathematics reform', Journal of Curriculum Studies, 29 (6), 637-66.

Reid, W.A. (1990) 'Strange curricula: origins and development of the institutional categories of schooling', Journal of Curriculum Studies, 22 (3), 203-16.

Solomon, J. (1999) 'Meta-scientific criticisms, curriculum innovation and the propagation of scientific culture', Journal of Curriculum Studies, 31 (1), 1-15. 
Spillane, J.P., Halverson, R., and Diamond, J.B. (2004) 'Towards a theory of leadership practice: a distributed perspective', Journal of Curriculum Studies, 36 (1), 3-34.

van Manen, M. (1991) 'Reflectivity and the pedagogical moment: the normativity of pedagogical thinking and acting', Journal of Curriculum Studies, 23 (6), 507-36. 



\title{
Introduction
}

\section{Rethinking schooling - twenty-five years of the Journal of Curriculum Studies}

\author{
Ian Westbury and Geoffrey Milburn
}

This book is the outcome of a challenge - an invitation to present a view of curriculum studies by way of a selection of articles drawn from the pages of the Journal of Curriculum Studies (JCS). JCS has been published since 1968. Since 1987, the journal has appeared six times a year, with each annual volume containing more than 750 pages and about 40 articles. To keep this book to a reasonable size, we had to limit our selection to 14 articles!

The task of selection was the more difficult because of the character of both JCS and the field of curriculum studies. The pages of JCS are a busy street corner, a place where many ideas and issues pass by. It is a place with a distinctive character, but one that changes over the course of a year, years, and decades. The challenge we had was to present a view of this moving street corner, and depict it in a way that illuminated some of the major issues that face thought about the curriculum.

There is another problem. There are many, often contested, views on what the core questions around the curriculum are, how they can be addressed, and what the answers might look like. Those teaching in universities and the people they teach, who often identify themselves with the 'real world' of schools, (very) often have different understandings about what issues around the curriculum and teaching are important. In other words, as we contemplated the task of selection, we were all too aware that the choices we could make would necessarily present only one view of thinking about the curriculum - one drawn from the already selective view represented in the pages of JCS. Let us explain how our selection came about and its rationale as a contribution to curriculum studies.

As is the case with any academic journal, JCS mirrors its field in two ways: reactively, by virtue of the selection the editors of JCS make from the manuscripts submitted for publication; and proactively, by virtue of the editorial strategies the editors have pursued as they have sought to define a perspective on the broader, changing field. As we thought about the mirror on the field of curriculum studies that has emerged from these processes, we saw three, we think distinctive, features in the way JCS has presented curriculum studies: a focus on schools and school systems, that is, a concern for education as a praxis rather than an ideal, eclecticism, and an emphasis on cross-cultural dialogue. 


\section{I. Westbury and G. Milburn}

\section{Curriculum as a practice}

As a field with a raison d'être in the practice of education and its advancement, curriculum studies must seek to develop an understanding of the inner work of schools, and how they are and might be 'steered'. The topics that follow - the nature of classrooms, teaching practices, teachers, subjects, change, and, of course, curricula - have been persistent themes in the pages of JCS. The theory and research around such topics seek to open up the 'realities' of schooling, as a basis for thinking about the work and world of schools and for its improvement.

\section{Eclecticism}

Curriculum studies is an eclectic field, one that accommodates the host of issues that comes to bear as educators reflect on the most basic questions about schooling as a practice: 'What do we, i.e. as a community, as educators, as school leaders, as teachers, etc., want to do?' and 'How can we do it?'. In considering these questions, a vast array of topics and issues demand examination and inquiry: the nature of education and the missions of schools; the character of subjects; the nature of teaching and the classroom; curriculum-making; the political, social, and cultural contexts that determine how teaching, schools, and systems of schooling are structured. Ideas from many disciplinary traditions offer grist for the mills of discussion and inquiry on all of these topics: the history, philosophy, sociology, and politics of schooling; evaluations of successful and not-so-successful innovations and practices; what counts as best practices, and why; and, of course, curriculum research and theory. Similarly, the full range of traditional and emergent research methods is needed to secure the 'knowledge' that is the bedrock of effective deliberation: experiments and quasiexperiments, surveys, case studies, philosophical and theoretical analyses, narratives, etc. JCS has sought to offer a hospitable place for essays and articles reflecting all these kinds of work, and, as such, is a busy street corner. But it can be argued that such eclecticism mirrors what is necessary for the understanding of curriculum and teaching, both as ideas and ideals and as practices.

\section{Cross-cultural dialogue}

Most thinking and policy-making around the curriculum are inevitably national or regional, i.e. 'local', in scope. Policy-makers and researchers have, at times, looked to London, New York, Stockholm, or Tokyo for ideas, but the core issues that teachers, school leaders, and policy-makers have faced have been typically set in a time and place, and framed within the discourses of their immediate worlds.

However, although schools, curricula, and pedagogies are seen to be 'local', viewed cross-culturally, schooling - its subjects, classrooms, pedagogies, and schools, but not programmes of study - is more similar than different across 
societies. And in recent years the local has increasingly come to be seen to mirror the universal as problems, ideas, issues, policies, and curricula have moved across global networks. This has come about, in part, because the contexts and missions of schools have converged around such tasks as, for example, secondary and higher education for many or all, with the changes in curricula, subjects, and teaching practices that follow. International assessments seeking to provide a basis for the bench-marking of best practices impose their own universalism. Pervasive social forces, such as mass migration, contribute to concerns about how to incorporate an appropriate multiculturalism into the school and curriculum. National minorities are being seen in new ways, with the questions that follow about the place of minority cultures in the worlds of the majority. The state, and the state's 'instruments' for steering schooling, have come to loom large as new forces in the governance and management of school systems and curricula.

As individuals and school systems explore the range of questions and problems that follow, many conversations are sparked about 'our' schools and 'your' schools, about 'our' approaches and 'your' approaches, and about 'our' successes and failures and 'your' successes and failures. From its beginnings in the UK, JCS was engaged in such a conversation across the communities that looked to England and Scotland as important reference points for discussions of the curriculum. In the 1970s, the editors of JCS sought to expand this conversation across the English-speaking world and, in the 1980s and 1990s, across mainland Europe and beyond. But, as articles from authors from contexts that drew on different traditions of educational theory and research emerged, it became clear that there was another, prior conversation to be engaged with: about the concepts that cultures use as they think about education, schooling, and teaching.

Max van Manen's chapter, 'Reflectivity and the pedagogical moment: the practical-ethical nature of pedagogical thinking and acting' (Chapter 4) illustrates this 'problem', and the possibilities that flow from it. Van Manen is a Dutch-born Canadian scholar whose work is rooted in the European traditions of educational theorizing. In his chapter he asks whether English speakers should assume that the European field of (in German) Pädagogik, which has become assimilated into some English-language work as pedagogy, does in fact map onto the traditions of English-language discussion of pedagogy/teaching. He uses the term 'upbringing' to capture the different focus of this European tradition, and asks how adults, care-givers and teachers relate to the task of 'upbringing' children - and what this might mean for how we think about teaching. His chapter illustrates very clearly what such 'other' perspectives can bring to English-language discussions of 'teaching'.

Wolfgang Klafki's 'Didaktik analysis as the core of the preparation of instruction' (Chapter 5) raises parallel issues. There, Klafki, a German scholar, dismisses much of what the English-language world takes to be at the core of the preparation for teaching, the mastery of teaching methods; for Klafki, Didaktik analysis is the heart of the matter. But how can methods not be the heart of the 
matter? The recognition, and then the exploration, of the questions that follow such issues of language, holds the promise of enrichment of all conversations about education.

\section{Making curriculum strange}

How do these strands come together in the chapters that follow? First, we have a book that addresses the task of thinking about the 'What do we do?' and 'How do we do it?' questions - in classrooms, schools, and school systems. There are three parts entitled 'Thinking about ...': 'Schools and classrooms', 'Pedagogy', 'Curriculum work and curriculum change'. These are, of course, the central topics around schooling as an organized social institution and practice, and the core topics of curriculum studies. In addition, we have a fourth part entitled 'Thinking about futures' where the chapters seek to highlight some basic problems around the ways we think about curricula and schooling.

As we sought a theme that might pull together these topics, we returned, again and again, to a play on the words of the title of one of our early selections, William Reid's 'Strange curricula: origins and development of the institutional categories of schooling' (Chapter 1):

The lore of schooling and our familiarity with the world of the classroom can divert our attention from important questions we might be asking about the present functions of curricula and how new functions might be envisaged. One way to raise such questions is to turn away for a while from what is normal and to look instead at things and places which strike us as strange. (p. 9)

A knowledge of 'strange curricula' estranges the familiar, giving us the capacity to look at the familiar in new ways. Reid's word-play gave us the organizing principle for the selection of essays represented in this volume.

Thus, as we thought about the articles in JCS that had most firmly stamped themselves on our thinking, they were essays that explored fundamental topics around teaching, classrooms, and schools, the curriculum, futures, etc., but had thrown an estranging light on these topics. Reid's 'Strange curricula' (Chapter 1), David Hamilton's 'Adam Smith and the moral economy of the classroom system' (Chapter 2), and Agneta Linné's 'The lesson as a pedagogic text: a case study of lesson designs' (Chapter 3), do this from the viewpoint of history. They make it clear that the lessons and classrooms that teachers know so well must be seen as social inventions, constructed in particular times for particular purposes. The idea of invention opens the possibility of re-invention.

This insight is also implicit in James Dillon's very different chapter, 'Effect of questions in education and other enterprises' (Chapter 6). There he reviews the body of work on questions and questioning - to raise fundamental questions about one of the pervasive activities of teachers. As we have suggested, Max van Manen's chapter (Chapter 4) looks at teaching as a moral and ethical activity, 
not as 'instruction', and, in so doing, frames teachers and teaching in revealing ways.

Jeremy Price and Deborah Ball's “"There's always another agenda”: marshalling resources for mathematics reform' (Chapter 7) confronts curriculum change not by looking at the strange but at the familiar. In contexts in which there are aspirations for changes in what schools do, their portrait of a school system leaves a host of questions to be asked about how such aspirations are in fact supported. In the 'real' world of schools they describe, what can curriculum reform and change really mean? James Spillane, Richard Halverson, and John Diamond's 'Towards a theory of leadership practice: a distributed perspective' (Chapter 8) approach their question by drawing on both a wide-ranging review of the research literature and their own case studies to develop a new construct, distributed leadership, that has important implications for all thinking about how both the routine and the creative work of the school get accomplished.

The five chapters in Part IV, 'Thinking about futures', range widely. Three of the chapters explore subject-related issues, posing questions about the need for re-invention within science, history/social studies, and the humanities. Like classrooms, subjects are inventions, that is constructions of times and places; as such, they can be in need of reconstruction - but of what kind? James LaSpina's 'Designing diversity: globalization, textbooks, and the story of nations' (Chapter 9) raises the question of how the histories of the first peoples in the settler societies of the United States, Canada, Australia, and New Zealand can be embraced within 'national' histories. As his essay shows, notions of the nation as a 'land of immigrants' and/or as 'multicultural' miss the heart of the problem. The questions he asks drive to the very centre of the national narratives and the histories of these settler-nations. Finally, Joan Solomon's 'Metascientific criticisms, curriculum innovation and the propagation of scientific culture' (Chapter 10) and John Elliott's 'A curriculum for the study of human affairs' (Chapter 11), an exploration of the work of Lawrence Stenhouse, an English curriculum leader of the 1960s and 1970s, raise the central questions about the modern mass secondary school. For Elliott, mass secondary education has meant the hegemony of a credentialing, 'academic' school that has lost sight of the missions of education and educating that Stenhouse sought with his Humanities Curriculum Project. For Solomon the question is the same, although posed differently. How does science educate, and what does education in and for science mean? Is it the task of the school to teach science as scientists might understand it, for example, as 'inquiry' and 'discovery', or as the knowledge thought to be prerequisite to university science programmes, or should school science be the teaching about and the discussion of the outcomes of that science?

The final chapters in Part IV, Shirley Brice Heath and Milbrey Wallin McLaughlin's 'Learning for anything everyday' (Chapter 12) and Brent Davis and Dennis Sumara's 'Curriculum forms: on the assumed shapes of knowing and knowledge' (Chapter 13) pick up Elliott's concern in ways that extend its meaning. Heath and McLaughlin explore teaching and learning in the 


\section{I. Westbury and G. Milburn}

environment of formalized non-school programmes and describe what might be regarded as a form of the 'hands on/minds on' teaching and learning that was once the platform for the work of technical and vocational schools. The implications of this slogan might not have been fully realized in the practice of those schools, but it was their platform. Many would see it as an educational and curricular ideal that was lost as mass secondary education adopted the forms of 'academic', bookish education that Elliott sees defining contemporary secondary schools in England - and, of course, many other places. Davis and Sumara's curriculum theorizing explores and generalizes the issue Heath and McLaughlin open up. The metaphor of fractals lets them ask why schools are the way they are, and why the idea of hands-on/minds-on learning, with flexible time and a flexible organization, has been replaced by a 'rational', structured school.

As we have suggested, our goal in re-presenting this selection of essays from JCS has been to offer an invitation to rethink schooling by making curriculum strange and thus securing leverage over the familiar. The readers of this book will decide if estranging schools and the curriculum can be enlightening. 
Part I

Thinking about schools and the curriculum 



\title{
1 Strange curricula \\ Origins and development of the institutional categories of schooling
}

\author{
William A. Reid
}

\section{Introduction}

From Ash-Wednesday, unto the said Thursday, all the Commencers ... are to come to the Schools upon every Monday, Tuesday, Wednesday, Thursday \& Friday, at one of the Clock in the afternoon, \& to bring thither with them every one a Sophister ... [T] he said Commencers are there to be ready to define 2 or 3 theses, which they themselves shall make choice of, \& deliver unto those Bachelors of Arts, not of the same College, who shall think fit to come thither to reply upon them.

(University of Cambridge, Statutes of Elizabeth I, quoted in Costello 1958: 15)

Quotations such as the above have more than curiosity value: they provide us with an opportunity for improving our understanding of curriculum through the removal of taken-for-granted assumptions. The lore of schooling and our familiarity with the world of the classroom can divert our attention from important questions we might be asking about the present functions of curricula and how new functions might be envisaged. One way to raise such questions is to turn away for a while from what is normal and to look instead at things and places which strike us as strange. History offers us one medium for achieving this shift of vision. ${ }^{1}$ The quotation at the head of this paper refers to a method of instruction which was familiar to university students and teachers in the Elizabethan University of Cambridge: so familiar that conveyance of its meaning does not require explanatory phrases: the reiteration of key categories will suffice - 'Sophister', 'Commencer', 'Theses' - and documentation need only be concerned with administrative arrangements relating to those categories - 'From Ash-Wednesday', 'at one of the Clock in the afternoon'.

I am using the word 'category' here in the technical sense proposed by Meyer (1980). Meyer considers that much thought about schooling, and therefore curriculum, is misguided in that we are over-fascinated by modern administrative and political rationalizations of the work of education. The centrality which, since the mid-nineteenth century in Europe and North America, has been given to the idea of national educational systems has led us to base our understanding of how and why schooling is delivered on 
administratively-centred accounts which stress internal organization and decision-making, that is, under one aspect, the planning and creation of the 'categories' - subjects of the curriculum, for example - which figure in official descriptions of educational practice. These Meyer calls 'organizational categories'. Neglected, but more important, he suggests, are the 'institutional categories' which are the socially- or culturally-held conceptions of wider publics concerning significant features of schooling and curriculum. In the long run, or even the medium run, it is the extent of conformity to institutional categories which decides whether curricular evolution can come about, not the efficiency or directive power of the education system itself.

A small example will serve to illustrate this point. In the mid-1970s the Schools Council and the Department of Education and Science agreed that the public examination then taken by students in England and Wales at age $16(\mathrm{O}$ level) should cease to have its results reported on a pass/fail basis. Grades would be given, and it would be up to users of examination results to decide what these grades meant for their purposes. The general public - even most teachers - never accepted this: they continued to talk about 'passing' and 'failing', linking pass and fail to the grade scheme in the way it always had been. O level as an institutional category was inextricably intertwined with the idea of success and failure, and administrative changes in the organizational category could not alter this larger reality. ${ }^{2}$

The curricular categories which occur in the Elizabethan Statutes of the University of Cambridge are organizational. Quite a lot of people would also have had an institutional understanding of them, but these would almost all have been insiders in some sense, and this categorical understanding would have been unique to Cambridge - there was only one other university to be considered (if we exclude Scotland) and that had its own subtly different way of organizing things. ${ }^{3}$ So what has to happen in order that categories can exist which are predominantly institutional in the sense that they are culturally held and transcend any particular organizational location? How can we have a conception of O level (or GCSE) which is not tied to any individual place where courses are followed or examinations taken? Such is our familiarity with modern thinking and practice that it may not occur to us that such questions even arise. Looking at strange curricula can show us that these are indeed real questions with practical relevance.

In pursuing the puzzle of the origins and development of the institutional categories of curriculum and schooling, I shall look at three sub-questions. First, the issue of how ideas move from having a particular reference to a universal one, since it is only possible to talk about institutional categories under conditions where ideas which can form the basis of such categories are capable of bearing a universal meaning. I will examine the process by which 'curriculum' became a universal idea of this kind and look at some of the consequences of this shift. Second, I shall look at ways in which the reflection of universally-held ideas in particular organizational settings is recognized, and shall claim that this is mediated through the installation of appropriate 'inventions'. My example 
will be the classroom. Finally, I shall consider how the combination of universally-held ideas and categorically-appropriate inventions results in the creation of dominant institutional categories which then exert a powerful influence over what can or cannot be done by curriculum planners.

To conclude this introduction I offer another instance of a strange curriculum, this time from our side of the watershed of the English Renaissance and therefore somewhat more connected with modern understandings of schooling. We will be referring to it in later sections of this paper:

Afternoon school [at Winchester] lasted from two till six; in the vast schoolroom, lighted at that time only by candles in sconces; the boys sitting at their 'scobs' or movable desks, while the commoners were accommodated also at friendly scobs, or sat at two long 'commoner tables'. Against the walls were the 'Tabula Legum', or rules of the school, and the curious 'Aut disce' tablet offering a three-fold alternative of study, with a mitre as its reward; timely withdrawal to wield the lawyer's pen or the soldier's sword; [or] the 'sors tertia' of the rods, which stood throughout the school time in a compartment of the Headmaster's seat, and were used when school ended. Order was preserved by two prefects, the 'Ostarius' or doorkeeper, and the 'Bible-Clerk', exempted from lessons for police work, and armed each with his ground ash.

(Gosden 1969: 80. The period referred to is towards the end of the eighteenth century)

\section{Universal categories: curriculum}

There are certain terms in both our everyday and our theoretical discourse which we take to relate to concrete particulars. Thus, to take a curriculum example, if we talk about the McGuffey Readers, we understand that the matter at issue is a particular set of books which were used in particular schools in a particular epoch with particular students. We know that they could not have been part of a curriculum before their publication date, and we would not expect to find them in schools today. If we use a term like this, which we take to be particular, outside its historical context we are aware of the incongruity. Thus, Malcolm Seaborne in The English School: Its Architecture and Organization 1370-1870 (1971: 144) refers to the orthographical desk which was an aid to spelling and made its appearance in schools in the early-nineteenth century. In explaining what it was he uses the word 'teaching machine', but puts it in inverted commas to show that his usage is anachronistic. Whatever claims the orthographical desk might have had to be a teaching machine, it could not have been one since the conception 'teaching machine' did not exist in the early-nineteenth century. Seaborne, however, is a careful historian. It would not be surprising to find other writers talking about orthographical desks as teaching machines without discomfort, that is, treating the idea of a teaching machine as universal rather than particular. 


\section{William A. Reid}

Some terms, however, in spite of their particularist connotations, have achieved universal status even in the discourse of serious historians. One of these is 'curriculum'. As Hamilton (1989: 35) points out, historians of higher education often refer to the 'curriculum' of the medieval university whereby 'they unwittingly impose the language of the present onto the schooling of the past'. Typically, students at medieval universities, such as Paris or Bologna, attended to whatever learning they pleased, as made available by various masters, came and went as they liked and received no final degree or testimonial. It was, as Hamilton (1989: 38) says, 'a loose-textured organizational form' where student absenteeism or the fact that enrolment did not match attendance 'was not so much a failure (or breakdown) of school organization as a perfectly efficient response to the demands that were placed upon it'. No one in that situation would have described what they were doing as 'following a curriculum', yet so capacious has the term now become that it can be used retrospectively to refer to educational activities which predated the technical use of the word: activities showing all those characteristics of looseness and serendipity which the arrival on the scene of the concept of 'curriculum' was to mark as outdated.

For 'curriculum' signalled, through its entry into the vocabulary of education around the end of the sixteenth century, ${ }^{4}$ the arrival of a more closely-knit organization of educational activities, and particularly the fact that they had come to be conceived of as sequential and capable of completion. Significantly, the first references to curriculum occur in relation to the granting of degrees or testimonials. It was found, for example, at the University of Leiden in 1582 in the phrase 'having completed the curriculum of his studies' (Hamilton 1989: 45 ). A necessary condition of curriculum moving from its previous connotation of simply an elapse of time (at this time curriculum horae occurs just as readily as curriculum studiorum ${ }^{5}$ ) was that the time taken over studies began to have some enduring significance - such as marking a point of completion at which the award of a qualification was merited or permissible. This notion of completion was connected with the greater levels of organization of studies that came about as a result of growing student numbers and the efforts of Renaissance scholars to systematize teaching and learning through applications of 'method', a notion particularly associated with the name of Peter Ramus. The 1569 edition of his Dialectic offers this explanation: 'Method is the disposition by which that enunciation is placed first which is first in the absolute order of knowledge, that next which is next, and so on: and thus there is an unbroken progression' (quoted in Hamilton 1989: 46). Progression is the counterpart of completion and makes possible the idea of curriculum as an educational category. Thus, curriculum was, like the orthographical desk and the McGuffey Readers, launched upon the world at a particular time and place in history, and was associated with tendencies in learning and in the wider society which were peculiar to that time and place.

Where pedagogy was concerned, we should note, for example, that the move away from loosely-connected studies and towards curriculum went along with a shift from the first-hand study of texts to the use of textbooks, which became 
available with the invention of printing. Indeed, a condition of curriculummaking was the provision of printed books which enabled the 'unbroken progression' of learning to be uniformly paced and monitored. ('Turn to page 10, line l' would have been a strange instruction to possessors of copies of books written in different hands.) A concomitant implication was that students no longer had access, even via lectures, to the original texts of authors since these were now mediated by textbook writers who created forms of 'school knowledge' qualitatively different from the authorially-based arts and disciplines which had been at the heart of medieval learning. And, on an even wider stage, claims have been made that the rise of curriculum was intimately linked with the growth of administrative bureaucracy stimulated in Europe by the development of the nation state.

Thus, study of history suggests that, for some purposes, we should regard curriculum as a particular term, in the same way that Seaborne (1971) took 'teaching machine' to be a particular term. But, in modern usage, curriculum has attained an exclusively universal connotation and we happily apply it to all kinds of educational activities in many different times and places. Like all such terms, it has become decontextualized and prone to be regarded as definable rather than problematic (we note the frequency with which writers of curriculum textbooks insist on offering stipulative definitions of what curriculum is). Curriculum as a definable universal has become an assumption of the field.

Is this merely an academic point, or does it have practical or theoretic significance? First of all, from a practical point of view, if we assume the curriculum to be universal, we run into problems of international communication and research. Though curriculum as a term is treated as universal, actual discourse about it is, inevitably, particularistic and has, as reference points, 'specific actions within specific contexts' (Westbury 1985). In the case of the USA, for example, 'the localized and decentralized structure of the school curriculum puts a premium on the communication of ideas and technical solutions from centres to peripheries - and there are many centres and many peripheries'. Thus 'it is service-delivery rather than service-planning which offers the most visible and characteristic forms of real-world thought about the curriculum' (Westbury 1985: 9). Very different is the style of curriculum discourse, and therefore the implicit significance of the word 'curriculum', which prevails in countries such as Sweden or the UK where decision-making is much more centrally politicized. Mistakes and misconceptions can, and frequently do arise as nations strive to study and learn from each other's conduct of education systems because of misplaced assumptions about the universal nature of the term curriculum.

But even if we confine our considerations of curriculum to one location, we still risk adopting a myopic stance in our attempts to understand it if we regard it as an unproblematic category. Terms which are not really universal, though they are treated as such, become assimilated to the concrete circumstances in which they are used and we tend to see these circumstances - of style, control, and delivery - as having a much higher degree of centrality than a more flexible view might indicate is appropriate or necessary. An instance of this want of 


\section{William A. Reid}

flexibility is the current neglect, in studies of the effectiveness of curricula, of certain kinds of outcome which are not felt to be part of this implicit definition of the 'universal' curriculum. As Doyle (1986: 378) points out, classroom methods which are apparently ineffective under a definition which assumes effects to be immediate may, under less restrictive assumptions, turn out to be quite defensible:

The teacher ... emphasized problem-solving and reasoning skills in units on the metric system and laboratory measurement and on scientific research methods. The students completed only fourteen tasks (low for the sample of teachers we have observed), and $80 \%$ of the total class time was devoted to only six tasks. Moreover, engagement was not always high, productivity was sometimes low, and work was not always conducted efficiently. Yet, the logical progression or semantic thread of content was quite explicit and clear, and students were pushed to deal with some fundamental issues in science. In addition, many novel tasks were used in which students were required to discern relationships, assemble information and solve problems.

\section{Inventions: the classroom}

In presenting his example, Doyle wants to make a somewhat different point from the one which I have drawn from it. His focus is on the proposition that the form of the curriculum is essentially determined by the pedagogic arrangements through which it is embodied. The conclusion Doyle (1986: 337) arrives at is 'that certain types of task are suitable for classrooms, that is, they fit the constraints of teacher and student work systems in these environments'. But we can go further than this by enlisting the aid of history in attacking our problem. Just as we associate the idea of curriculum structure with certain taken-forgranted circumstances related to social and political beliefs and traditions, so one of the salient aspects of the curriculum process - the classroom - is conceptually linked with specific sets of socio-technical arrangements through which its pedagogic work is conventionally accomplished. This time, the strangeness comes about through the perception of these arrangements as historically created, and the leading idea is that of 'invention' (Westbury 1984).

As we look into history, we realize that, in spite of the way that current conceptions of curriculum are dominated by the apparatus of the classroom, teaching and learning went on before such a notion existed. The story of how classrooms evolved is somewhat different according to where one looks. I take my example from the English 'public' schools of the nineteenth century (which were, of course, private). Unlike curriculum, the work of schooling can be readily exemplified through images, and many images exist of teaching and learning in English public schools before the advent of classrooms. They typically show educational activity going on in a single large room accommodating up to about 200 students. The Winchester schoolroom of the 1680s, referred to in my earlier quotation, is a case in point (see Figure 1.1). The room is high 


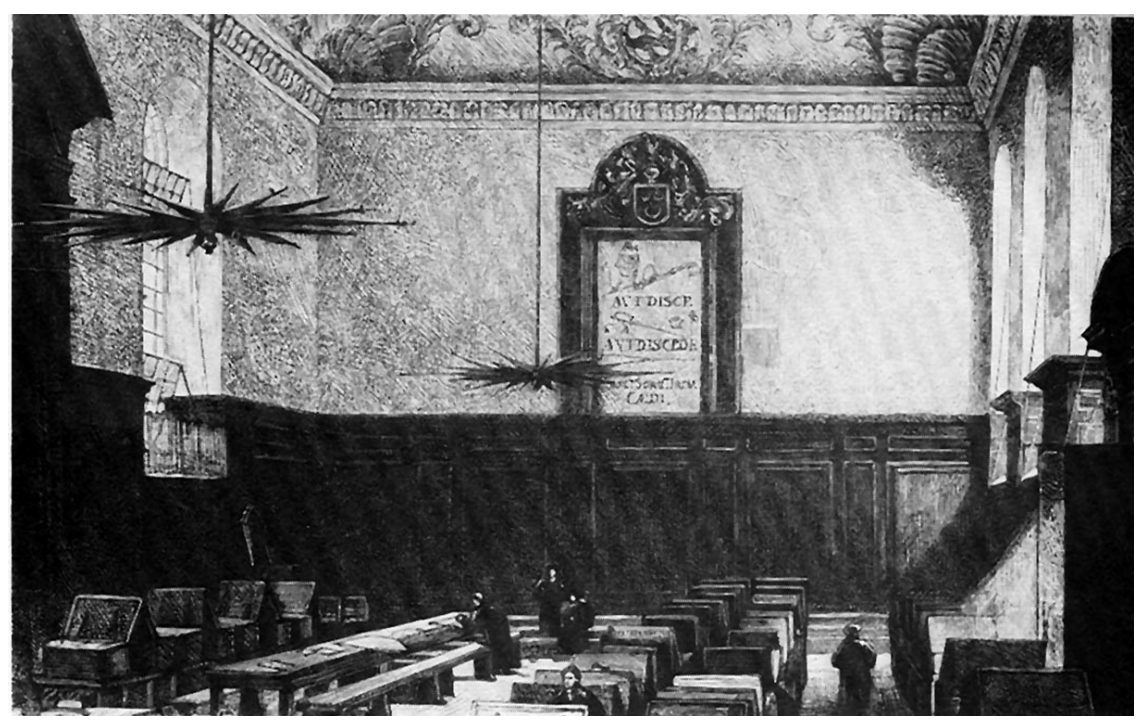

Figure 1.1 Winchester schoolroom of 1683-7 (from Pascoe 1881).

- probably about 30 feet to the ornate frieze which surrounds it - with dark panelling reaching about a third of the way up the walls and large windows admitting ample light without giving a view of the outside world. The scene is dominated by the famous 'Aut Disce' tablet on the end wall. Book boxes stand open along the sides of the room, while the well-lit centre is taken up by desks and tables. Few students appear in this picture, but others of similar schools show students and teachers standing, or seated at tables or desks (those of the teachers often more like thrones with elaborate canopies) in what to us is a random or even disorderly way (see Figure 1.2). It is not clear whether there are several lessons in progress, or perhaps none, for Ramist ideas were slow to penetrate these schools, and much of what we are looking at still reflects the 'loosetextured organizational form' to which Hamilton referred in his discussion of medieval universities. Hardly any of the attributes of the conventional classroom are present. Simultaneous instruction is not in evidence, nor a clear focus of student on teacher. What we are looking at here is a schoolroom, which tells us nothing more than that it is the place where members of a school meet. In fact, it was often referred to simply as 'the school'. This, to us, looks ambiguous, as we assume structurally-marked differentiation of space within a 'school'. However, structure can be as much within people's heads as in architecture. 'School' was certainly divided into 'forms' - though membership in these was not closely age-related (and so it would be anachronistic to refer to them as 'grades'). Often too, academic ranking within forms was signalled in some way. But most of this escapes us as we look into schoolrooms with modern eyes. The 


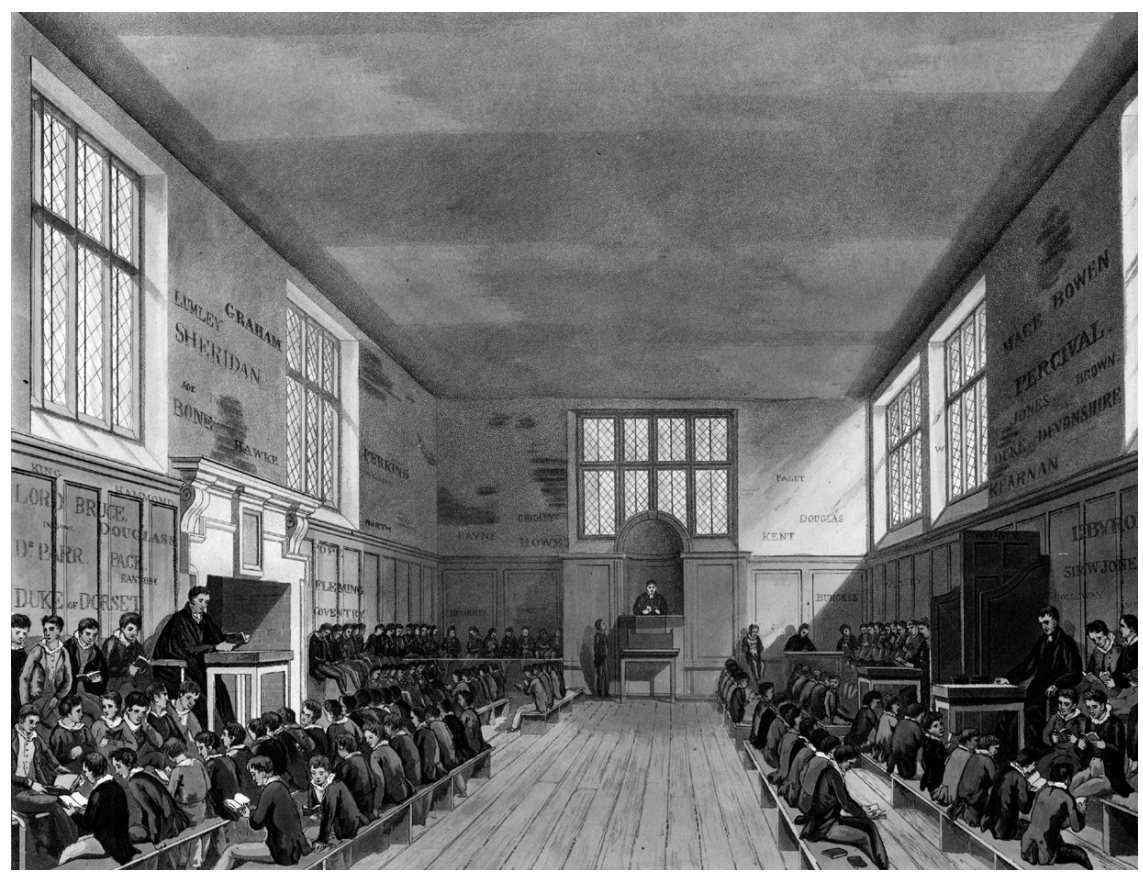

Figure 1.2 A. Pugin, 'Harrow School Room' (from Ackermann 1816).

fact is that, despite our extensive experience of teacher and student roles, if we were to step into the world of the picture we simply would not know how to act as either student or teacher: the technology of the schoolroom, so well known to the participants, is hidden from us so that we wonder how anyone could tolerate such strange arrangements.

One important reason why they were not just tolerated but even welcomed, is that educational settings are more than arenas for the deployment of technologies of teaching and learning, more even than functional constellations of sociocultural relationships: they are cultural microcosms which derive meaning from the macrocosmic institutions of the world of adult endeavour. This is how the Clarendon Commissioners saw the situation. In 1864 they were called upon to pass judgement on whether the public schools should move towards a system of classroom as opposed to schoolroom organization, and defended their coolness towards classrooms in their Report (Clarendon Commission 1864, Vol. 1: 287):

It may admit of doubt whether ... schools are not moving faster than the world, for which they are a preparation, has followed or will be able to follow them. It is necessary at the Bar, and in other careers in life, and in the Houses of Parliament, that much mental work should be done of all kinds, amidst many outward causes of distraction. 
The schoolroom was still alive in the English public schools of the 1860s because it was a form of organization which had meaning beyond the immediate tasks of the accomplishment of teaching and learning. But its days were numbered. Classrooms arrived on the scene with their own macro-cosmic resonances centring around collectivist sentiments of sympathy and emulation which were to be unlocked by the new teacher professionalism (see Chapter 2; Hamilton 1989). These had a stronger appeal for the new majority bound for lesser administrative posts in government and commerce. Not surprisingly, it was the more aristocratic schools which clung longest to the old traditions. But by 1885 even at Winchester the 'once-thronged room' was deserted. And when, in the 1890s, the Headmaster summoned his sixth form to meet him there he was 'shocked to find that it was no longer known where to sit or what to do in School' (Firth 1949: 155).

The strangeness of the schoolroom and the familiarity of the classroom both relate to their success as inventions. An invention is a new solution to a problem, but to be successful it has to be more than technically feasible. It has to fit with theories of practice and with social relations and conventions. More than this, if it is an educational invention it has to mesh with the meanings which the world outside schools projects upon it. Discarded inventions, such as schoolrooms, puzzle us, while living ones, such as classrooms, dull our imaginations with their excessive familiarity. Yet they too are inventions of their time, with a beginning and, we can confidently predict, an end. Though the classroom places constraints on the delivery of curriculum, we need not view these constraints as fixed for ever. Just as history can remove from our thinking the limiting assumption of curricular universality, so it can also remove the assumption of the immortality of inventions.

\section{Institutional categories: the universalization of invention}

The final stage of my present project is to draw together the ideas of 'universal' and 'invention' into a third notion: that of the 'institutional category'.

Looking at the strange curricula of previous epochs forces us to confront the question of how they acquired more than parochial significance when national and local governments were not involved in the provision of education and there was no apparatus of qualification or statutory enrolment to secure the legitimacy of schooling. As long as we are dealing with the loose-textured fabric of medieval education there is little problem. Learning was $a d$ hoc and on demand: it did not stand in need of legitimation. To put the matter very simply, no one was concerned in any practical sense about questions such as, 'What is a real education?' 'What is a real school?'. Education was something you picked up as you went along; it came in disconnected bits. Schools were sui generis; there was seldom any need to compare one with another. But, beginning in the eighteenth century, issues of the reality and authenticity of types of teaching and learning came to assume practical importance. There is visible evidence of this in, for example, the architectural styles adopted in the building of English 


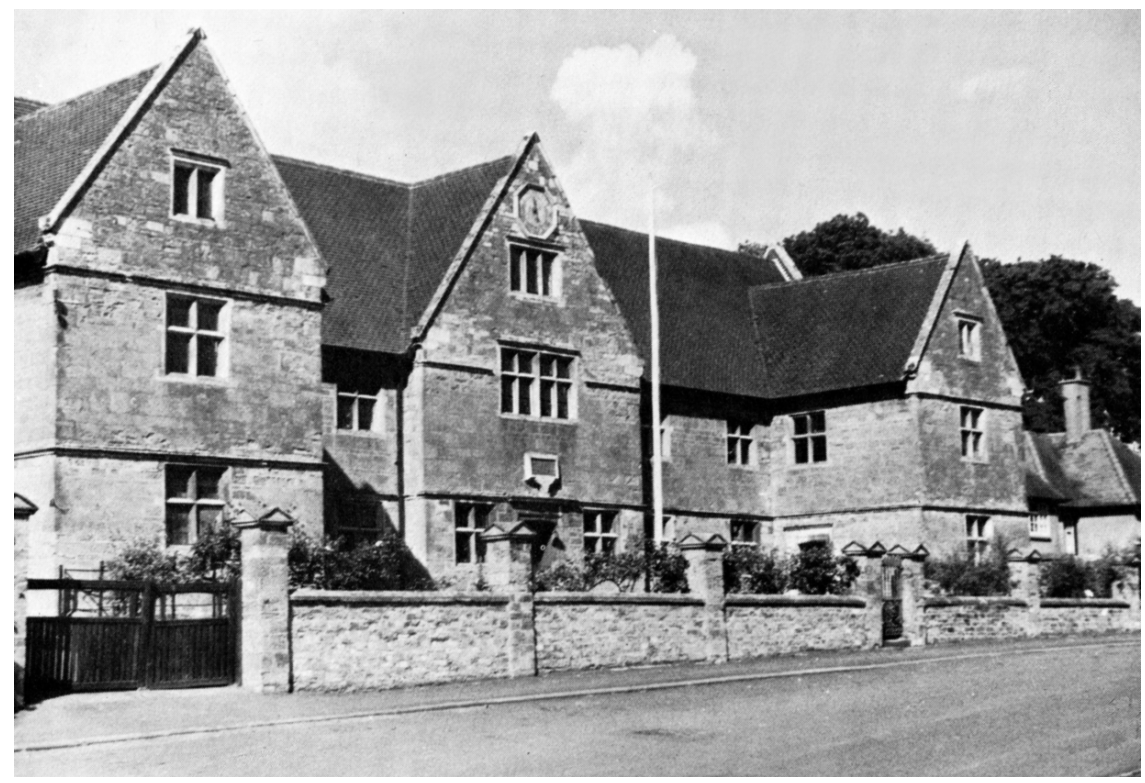

Figure 1.3 Clipston School, Northants, 1667 (from Seaborne 1971: Plate 62).

secondary schools. Before the eighteenth century, school buildings reflected the vernacular traditions of the area in which they were constructed (Figure 1.3). Some clues to their function may be externally present, but often we have to be told that it is a school. By the middle of the nineteenth century, the reverse is true. We know from their Elizabethan Gothic design that Liverpool Collegiate and Cheltenham College are secondary schools, but we would not be able to place them geographically (Figures 1.4 and 1.5). ${ }^{6}$

By the middle of the nineteenth century, the English public schools were beginning to exhibit not only architectural uniformity, but also uniformity in organization and curriculum. To take a minor, but significant example of this, Kennedy of Shrewsbury produced his Latin Primer when, in the 1830s, 'the public school headmasters decided on the desirability of a common textbook' (Oldham 1952). Once such a book was universally available there was an answer to the question 'How do we know we are doing proper Latin?' 'Because we are following Kennedy's Primer'. Previously a variety of texts had been used, some printed by the schools themselves. And uniformity spread even to details of dress and manner. As sequences of sporting photographs show, the casual individual poses (sometimes with pets) of the 1860s gradually gave way to more and more regimentation till, by the end of the century, teams appeared in identical kit and carefully ordered rows, all facing the camera (Figures 1.6 and 1.7). Through widespread adoption of inventions (the textbook, games played according to agreed rules, classrooms) what had been particular had 


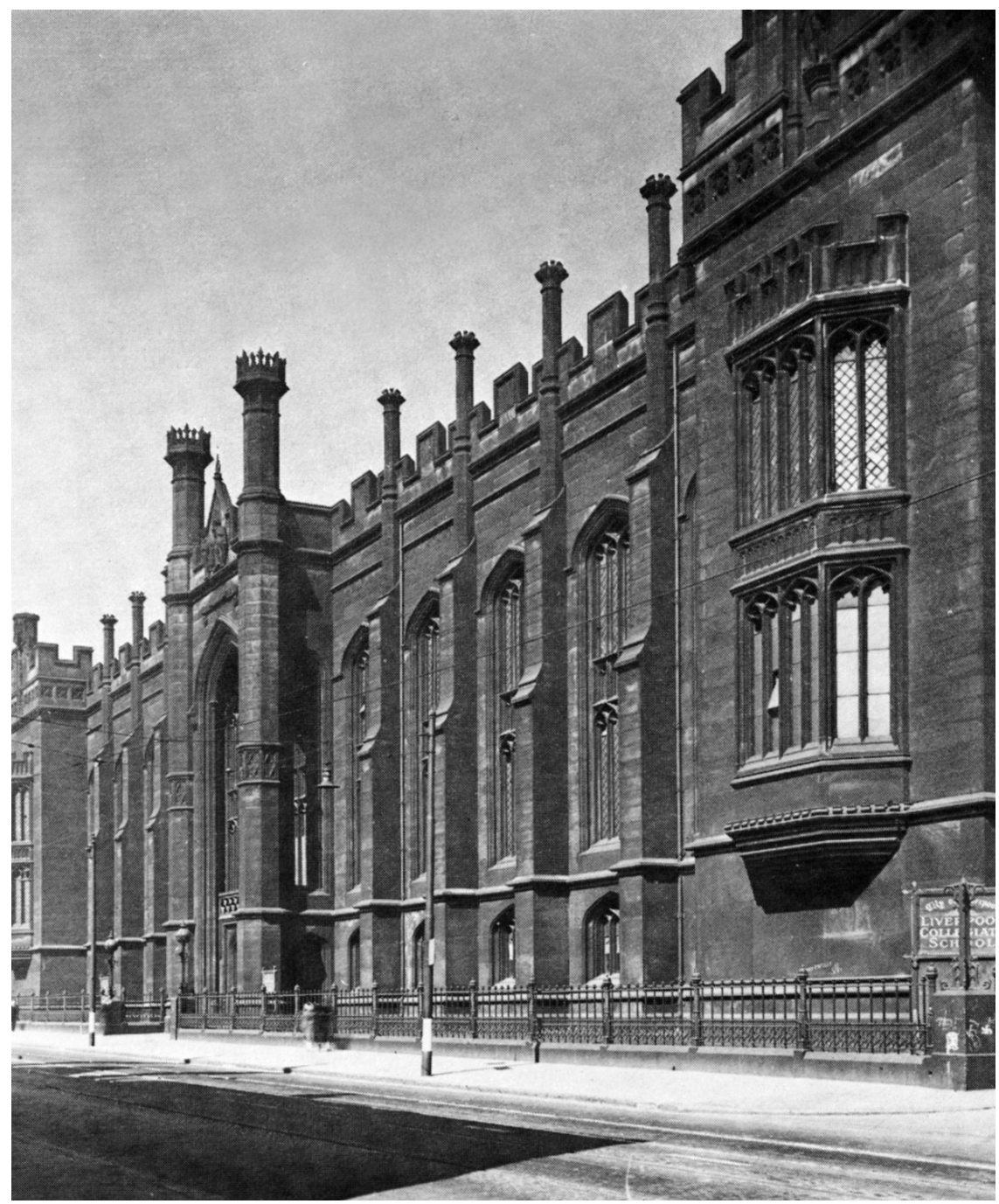

Figure 1.4 Liverpool Collegiate Institution, 1843 (National Monuments Record, B42/1940).

become universal. By such means, ideas like 'public school' became institutional categories. Their conscious moulding of internal organizational categories around the approved inventions won for the schools authenticity in the eyes of their public.

This movement from the particular to the universal through shows of categorical conformity based on the implementation of standard inventions can be represented diagrammatically (see Figure 1.8). We begin at the bottom with a 


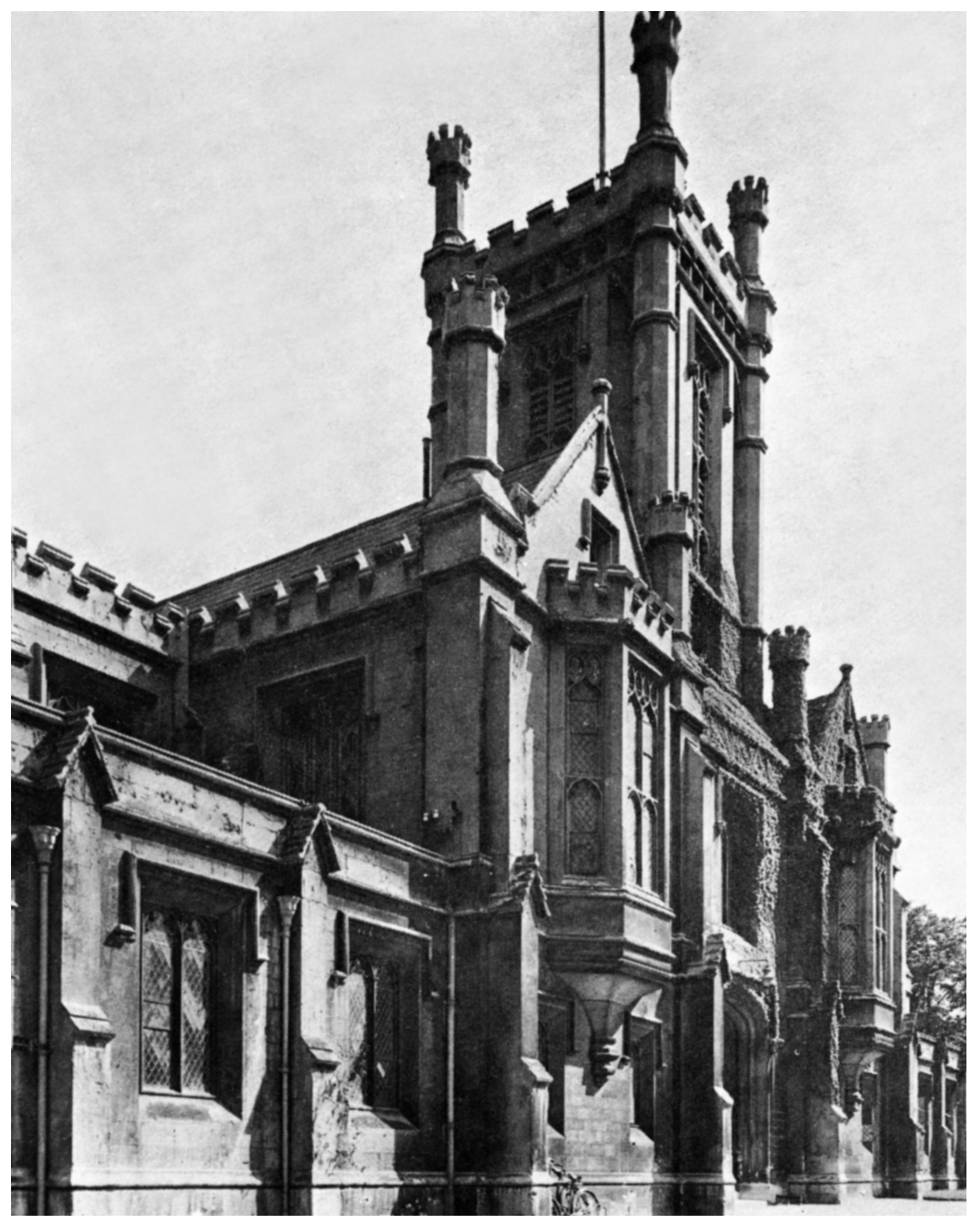

Figure 1.5 Cheltenham College, 1843-50 (National Monuments Record, A43/7083).

situation, such as that obtained in public schools into the early-nineteenth century where organization was specific to a particular establishment: Winchester College was a unique school with its own way of doing things and not especially to be compared with any other school. It had its own terminology (e.g. 'Ostarius') which might or might not be to some extent shared with, or familiar to other schools. In subsequent decades, through social and technological 


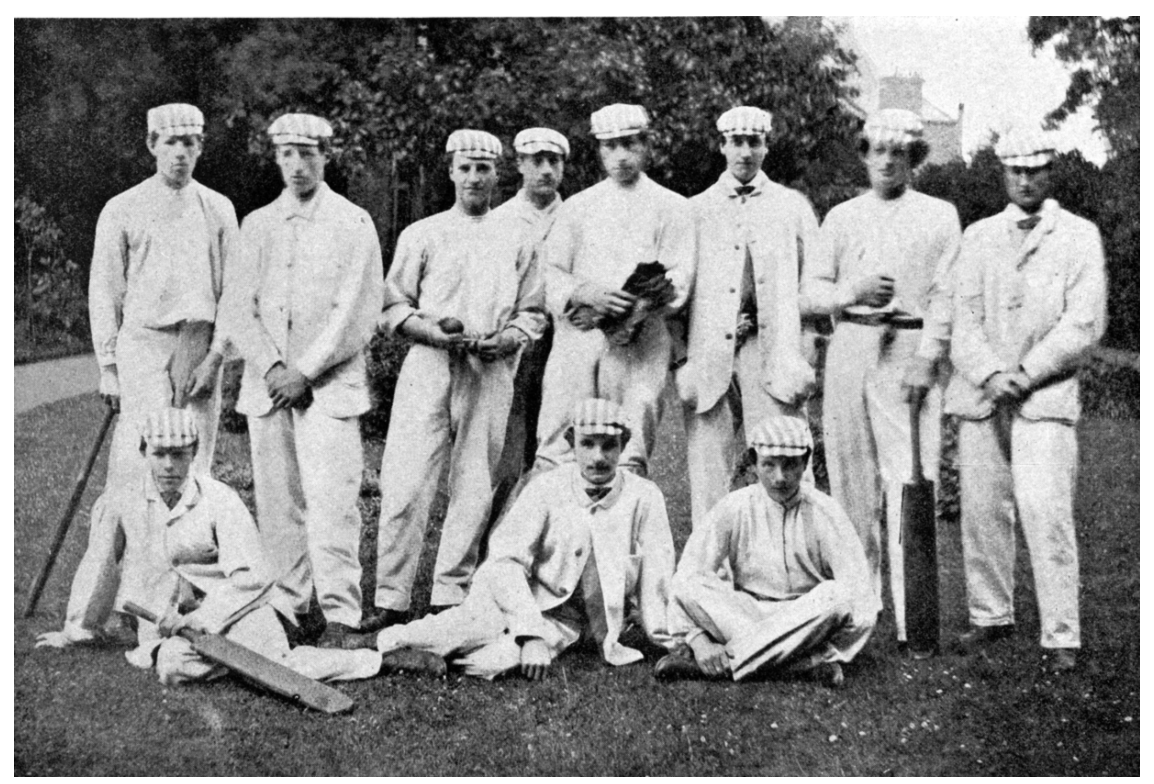

Figure 1.6 Harrow School cricket eleven, 1863 (from Lyttelton et al. 1922, p. 136).

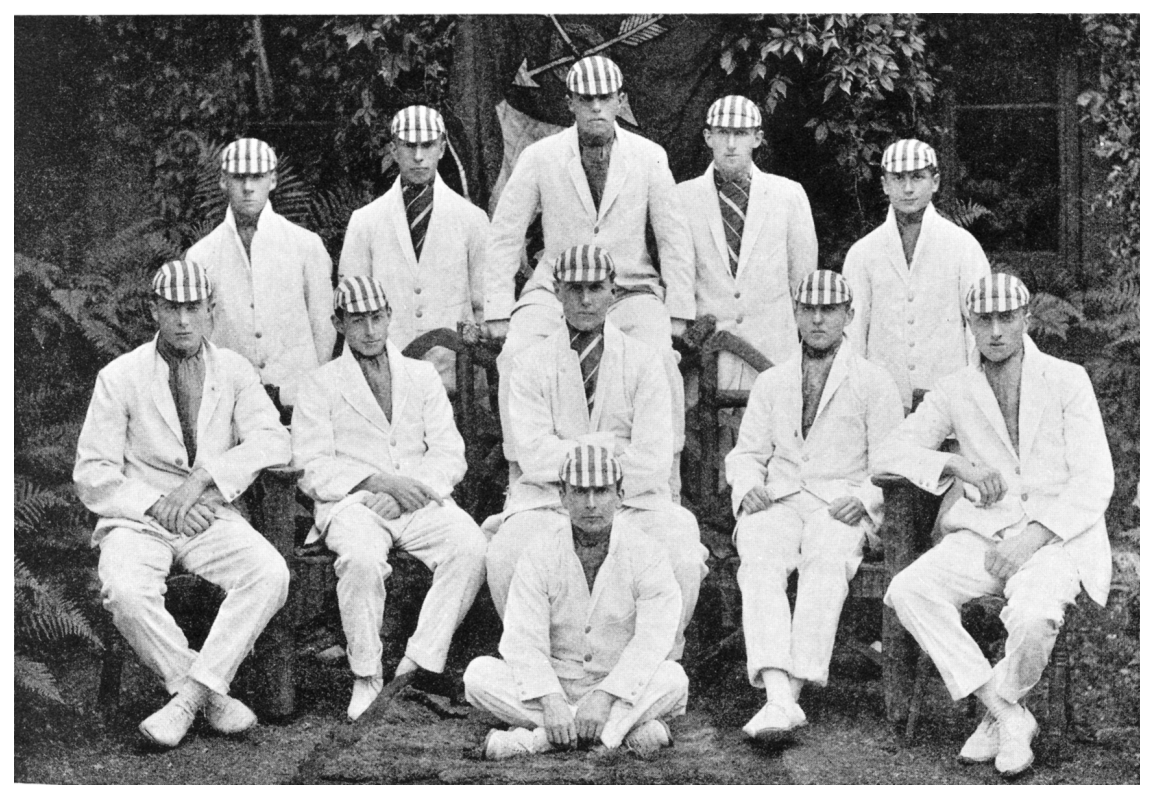

Figure 1.7 Harrow School cricket eleven, 1912 (from Lyttelton et al. 1922, p. 220). 
Superior

institutional category

('Public school')

Implementation

of inventions

Organization

(Winchester College)

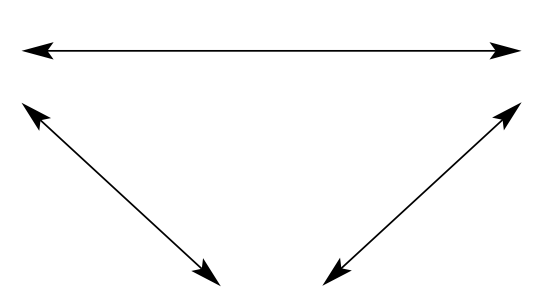

Subordinate institutional category

('Prefect')

Implementation

of inventions

Role

('Ostarius')

Figure 1.8 The evolution of institutional categories.

developments (some very simple and obvious: Tom Brown arrived at Rugby in a stagecoach, but left on a train), the clientele for these schools became national and general rather than local and particular. ${ }^{7}$ It was larger and more mobile, but grew to include people with little knowledge of the schools. Comparison within a secure frame of reference became an important issue and there was a shift of emphasis from what was unique to what was common and therefore comparable. 'Ostarius' becomes assimilated to the subordinate universal category 'prefect'; Winchester joins the superior category of 'public school' within which 'prefect' finds its meaning.

The essential mediating factor in this was the constituency of people who supported the schools as users of their services in one way or another. They became the bearers of the educational categories in their institutional aspect, making connections between category and invention and exercising judgement over questions of which inventions should be indicative of categorical membership and whether the implementation of inventions was genuine enough to sustain claims of categorical conformity.

Then, in a further development, the clientele became larger than the old schools could cope with and new ones were set up. This created a broader and more powerful impulse towards conformity. The older schools had been able to adopt a somewhat relaxed attitude towards orthodoxy. While other headmasters rushed to copy Arnold's combination of the office with that of school chaplain, the head of Eton declined to do so on the grounds that boys were so easily impressed with anything which is said from a pulpit that he should not presume to extend his authority in that way. And, as we have seen, Winchester felt com- 
fortable with its schoolroom till the 1880s. But newcomers had to be more careful and the categorical inventions were respected in excruciating detail. To be quite sure of its status, Marlborough, a new foundation of the 1860s, had before the turn of the century already acquired a school ghost. We learn this from one of several popular boys' magazines which, as well as features on real schools, also ran fictional accounts of school life dealing in categories so familiar to those who had never been near a public school that they needed no more explanation than did 'sophisters' or 'commencers' to bachelors of arts in sixteenth-century Cambridge (Reid and Filby 1982: 78-80).

\section{Conclusion}

The importance of this relationship between universal categories, implemented inventions, and educational constituencies tends to get lost as we look at modern education systems which are legally sanctioned. Yet much that is puzzling in the present-day curriculum may become explicable and even predictable if we ask the same kinds of questions about current arrangements that we are driven to ask as we look into the strange schools of the past. We can see, for example, why innovative programmes in the humanities have often failed while, in a very short time, programmes based on learning about or working with computers have become securely established. Media coverage of computers and ideas associated with computers, ensures their acceptance as part of the 'real' world that needs to be reflected in the microcosm of the school, while evidence that the work of schools reflects the universal category is readily available in the highly visible invention of the computer lab. 'Humanities' on the other hand, is an organizational category which is only dimly reflected in the institutional categories held by constituencies who are more familiar with 'English' or 'History', and has no readily recognizable invention to support it. Similarly, one can see why worries are expressed at grade inflation, since this strikes at one of the most important universals holding together constituency support for US high schools. And one has to wonder what light the analyses offered by the present chapter might shed on the arrival of a National Curriculum in England and Wales. How and why did categorical support for the schools become so weakened that legal intervention of this kind became possible or necessary?

Many questions of this sort, which we might not ask at all, or might not ask in quite the same way, are raised for us if we confront the strange curricula of the past with curiosity and with respect for those who taught them and followed them. For strange curricula were also, in their time, rational and appropriate. Such curiosity and respect also offer us tools for developing answers to our questions which are interestingly different from those we might arrive at if we had to depend solely on the confused alliance between a universal conception of curriculum and a preoccupation with the accidents of present-day practice which tends to dominate so much of our current thinking and writing. 


\section{Acknowledgements}

Figure 1.3 is taken from Malcolm Seaborne (1971) The English School: Its Architecture and Organization 1370-1870, and is reproduced with the permission of Malcolm Seaborne. Figures 1.4 and 1.5 are reproduced with the permission of the National Monuments Record and are Crown Copyright.

\section{Notes}

1 Other possibilities are comparative studies or futures studies. History offers the advantage when the questions being asked require examination of developmental sequences. For specific attempts to use history to study the evolution of institutional categories of schooling, see Reid (1985) and Reid and Filby (1982).

2 As I suggest later, political initiatives on the curriculum in England and Wales at the time this essay was first published, make interesting material for the kind of analysis proposed in this chapter. The general tendency of these initiatives was to move organizational categories closer to institutional ones. The structure of the then-new national curriculum reflected rather faithfully the institutional categories which have shaped public thinking on the secondary curriculum at least since the drawing up of the Board of Education Grant Regulations of 1904.

3 Educational organizations which prefer to preserve an image of uniqueness have many little strategies for avoiding submersion in universal categories. Detail becomes important: Oxford and Cambridge propel punts from different ends and have different styles of carrying umbrellas.

4 Enquiries into the use of the word 'curriculum' need to adopt a more sophisticated approach to the study of language. It is clear, as I point out in the text, that some early occurrences of the word simply refer to elapse of time. The important question is not about use of the word but about the intended meaning, and for that a considerable sensitivity to context is required. Nevertheless, in spite of my doubts about the data, I am sure that studies such as that of Hamilton (1989) are basically right in their conclusions.

5 'Curriculum horae' might be rendered as 'the passage of an hour' while 'curriculum studiorum' signifies 'course of (his) studies'. The later idea is an extension of the former, and the movement from one to another involves no sharp discontinuity of meaning.

6 It might be argued that changes in building style simply reflected the need to design on a larger scale as school populations grew. But there are many counter-instances. In Wolverley (Worcestershire), for example, the small room of the grammar school which never held more than about a dozen pupils was fronted by a large and structurally irrelevant neo-Gothic porch (Seaborne 1971: 194).

7 To say that the constituency moved from being local and specific to national and general is to cover up a good deal of complexity which there is no space to examine here. In one sense the clientele of the old schools was already national in that some of them drew students from the whole country, but it was also in a sense local in that families might preserve an automatic allegiance to one school. In other cases, schools which had been endowed with the local population in mind might, with doubtful legality, be opened up to a national clientele of those able to pay fees.

\section{References}

Ackermann, R. (1816) The History of the Colleges of Winchester, Eton, and Westminster: with the Charter House, the Schools of St. Paul's, Merchant Taylors, Harrow, and Rugby, and the Free-school of Christ's Hospital (London: R. Ackerman). 
Clarendon Commission (1864) Report of H.M. Commissioners appointed to inquire into the Revenues and Management of Certain Colleges and Schools, and the Studies Pursued Therein; with an Appendix and Evidence, 4 vols, 3288 HC 1864 xx, xxi.

Costello, W.T. (1958) The Scholastic Curriculum at Early Seventeenth-Century Cambridge (Cambridge, MA: Harvard University Press).

Doyle, W. (1986) 'Content representation in teachers' definitions of academic work', Journal of Curriculum Studies, 18 (4), 365-79.

Firth, J. D’E. (1949) Winchester College (London: Winchester Publications).

Gosden, P.H.J.H. (ed.) (1969) How They Were Taught: An Anthology of Contemporary Accounts of Teaching and Learning, 1850-1900 (Oxford: Basil Blackwell).

Hamilton, D. (1980) 'Adam Smith and moral economy of the classroom system', Journal of Curriculum Studies, 12 (4): 281-98.

Hamilton, D. (1989) Towards a Theory of Schooling (London: Falmer Press).

Lyttelton, R.H., Page, A., and Noel, E.B. (eds) (1922) Fifty Years of Sport at Oxford, Cambridge and the Great Public Schools: Eton, Harrow and Winchester, vol. 3 (London: Walter Southwood \& Co).

Meyer, J.W. (1980) 'Levels of the education system and schooling effects', in C.E. Bidwell and D.M. Windham (eds), The Analysis of Educational Productivity, Vol. 2: Issues in Macroanalysis (Cambridge, MA: Ballinger), 15-63.

Oldham, J.B. (1952) A History of Shrewsbury School, 1552-1952 (Oxford: Basil Blackwell).

Pascoe, C.E. (1881) Everyday Life in Our Public Schools: Sketched by Headscholars of Eton, Winchester, Westminster, Shrewsbury, Harrow, Rugby, Charterhouse (London: Griffith and Farran).

Reid, W.A. (1985) 'Curriculum change and the evolution of educational constituencies: the English sixth form in the nineteenth century', in I.F. Goodson (ed.), Social Histories of the Secondary Curriculum: Subjects for Study (London: Falmer Press), 289-311.

Reid, W.A. and Filby, J. (1982) The Sixth: An Essay in Education and Democracy (Lewes, UK: Falmer Press).

Seaborne, M. (1971) The English School: Its Architecture and Organization 1370-1870 (London: Routledge \& Kegan Paul).

Westbury, I. (1984) 'Invention of curricula', Paper presented at the Annual Meeting of the American Educational Research Association, New Orleans, LA (College of Education, University of Illinois at Urbana-Champaign).

Westbury, I. (1985) 'Curriculum research and curriculum theory in international perspective' (College of Education, University of Illinois at Urbana-Champaign). 


\title{
2 Adam Smith and the moral economy of the classroom system
}

\author{
David Hamilton
}

Domestic education is the institution of nature; public education, the contrivance of man.

(Smith 1976a: 222)

On 11 May 1762, a meeting of the Faculty of Glasgow University decided to convert a College 'Chamber' (living room) into a 'class room' for civil law. The appearance of the term 'classroom' in the Faculty minutes is historically noteworthy: indeed, its use is perhaps unprecedented in English-language sources. The term does not reappear in the minutes until 1774 yet, by the time the college opened a new suite of teaching rooms in 1813, the comparable medieval and Renaissance labels - 'school' and 'class' - had virtually disappeared. ${ }^{\text {' }}$

In 1762, Glasgow was a centre of educational and intellectual innovation. The 11 members of the May Faculty meeting included Joseph Black (1728-99), whose discovery of latent heat enabled James Watt to revolutionize the steam engine; John Anderson (1726-96), whose educational and social ideas helped to shape popular adult education in the nineteenth century; and not least, Adam Smith (1723-90), whose writings did much to establish the science of political economy.

Although Black, Anderson, and Smith achieved fame well beyond the boundaries of Glasgow University, their work also had an important local impact. Anderson's use of practical demonstrations in physics was sufficiently notorious to earn him the nickname 'Jolly Jack Phosphorous'. Smith's service as college quaestor (book-keeper) in the late 1750s coincided with a rapid growth of the university's library. And Black's earliest communications on latent heat were given a month before the May Faculty meeting to a college gathering of the Glasgow Literary Society. ${ }^{2}$

The presence of 'several gentlemen of the City' at the Literary Society's meeting and its subsequent change of name to the 'Literary and Commercial Society of Glasgow' underline the fact that the local trade in philosophic, economic, and social ideas embraced both town and gown. Furthermore, the same 'commerce intellectuel' continued through time - linking members of the 1762 Faculty with influential nineteenth-century figures such as Robert Owen 
(1771-1858) of New Lanark (who helped to introduce Pestalozzian ideas into British schooling); William Hamilton (1788-1856) of Edinburgh (who encouraged public support for a state-run system of education along Prussian lines); and David Stow (1793-1864) of Glasgow (who founded a 'normal seminary' which served as a prototype for teacher training in England and elsewhere).

This chapter examines the general ferment of educational and social ideas that, in Glasgow and beyond, was associated with the work of reformers like Smith, Owen, Hamilton, and Stow. Specifically, it is activated by three related assumptions. First, that the educational practices of Glasgow University had a direct influence on those adopted in the elementary schools of the nineteenth century. Second, that the change from class to classroom reflected a more general upheaval in schooling - the ultimate victory of group-based pedagogies over the more individualized forms of teaching and learning that had dominated previous centuries. And third, that the shift from class to classroom in the early days of the Industrial Revolution was as important to the administration of schooling as the concurrent shift from domestic to factory production was to the management of industry. ${ }^{3}$

Analytically, the chapter adopts the standpoint that educational practice lies at the intersection of economic history and the history of ideas. That is, the pedagogical practices of an epoch are expressions of both material and ideological resources. Taken independently, neither technologies (material resources) nor beliefs (ideological resources) are sufficient to account for the practices of schooling. For instance, the technological basis of chalk-and-talk teaching - the blackboard - did not become a commonplace item of school furniture until the nineteenth century, which is nearly 150 years after it had appeared in Comenius's Orbis Pictus. One explanation for the delay is that, prior to the nineteenth century, open-ended chalk-and-talk teaching was a much less acceptable mode of popular instruction than more closed forms of tuition such as catechesis. ${ }^{4}$

As an architectural unit, the classroom came to prominence in Britain after the 1830s with the gradual spread of state-supported (and state-supervised) schooling. By the twentieth century, the batch-production rhetoric of the 'classroom system'5 (e.g. lessons, subjects, timetables, grading, standardization, streaming) had become so pervasive that it successfully achieved a normative status - creating the standards against which all subsequent educational innovations came to be judged. Indeed, the widespread penetration of the classroom system had another important ideological effect. It obscured the fact that, before about 1800, schooling had been organized around a quite different vocabulary, and quite different assumptions, resources, and practices.

This chapter, then, has been written to excavate such differences. Its backcloth is the post-medieval context of education. Its foreground is the reformulation of ideas about universal (or mass) schooling that, with the shift from individualized to group mass instruction, came to a head in the late eighteenth and early nineteenth centuries. Like the associated shift in industry from tools to machines, the time-span of this pedagogical transformation is measured in 
decades rather than years. Nonetheless, schooling, like industry, eventually yielded to the dominance of new instruments of production (the mass-produced steel-nibbed pen, for example), new patterns of organization (e.g. the multiroom school) and new forms of management (e.g. payment by results). In short, the production and distribution of the educational 'goods' of nineteenthcentury popular schooling came to be governed by a new set of principles - the 'moral economy' ${ }^{6}$ of the classroom system.

Systems in many respects resemble machines.... A system is an imaginary machine, invented to connect together in the fancy those different movements and effects which are already in reality performed.

(Smith 1795: 44)

Insofar as the classroom system operated as a unified discipline of schooling, it was both a system of thought and a system of practice. Indeed, the fact that it was designated as a 'system' is itself historically significant.

The assumption that any group of phenomena can be systematized dates back at least to the late Renaissance when philosophers like Francis Bacon (author of the Novum Organum, 1620) sought to formulate the disparate teachings of the period into a unified science. Basically, the term 'system' came into use (e.g. in Hartlib's (1969) translation of Comenius's A Reformation of Schools, 1642) at about the same time as mechanistic views of the universe superseded more animistic ideologies. ${ }^{8}$ Isaac Newton (1642-1727) was a major figure in this general philosophical transformation. His eventual success in explaining the law-like workings of planetary and terrestrial motion (in the Principia, 1687) served both as a model and a motivation for thinkers in other fields.

Shortly after the appearance of the Principia, one of Newton's colleagues, John Locke (1632-1704), published an early venture in the systematization of the social world (An Essay Concerning Human Understanding, 1690). ${ }^{9}$ If Bacon's Novum Organum (1620) was about the systematization of scientific method (via an appeal to the priority of externally-derived sense experience), Locke's Essay was about the systematization of scientific analysis (via an appeal to the inner light of 'natural reason'). Collectively, philosophers like Bacon, Newton, and Locke strengthened the inner and outer workings of the mechanistic world view. In the process, the new levels of sophistication which they brought to human inquiry did much to validate the belief that nature was accessible, knowable, and controllable.

During the century that followed, such power-laden ideas about reason, nature, and law-like behaviour had a considerable influence upon those, like Adam Smith, who grappled with the social changes brought about, variously, by the extension of international trade, the improvement of agriculture, and the development of industry. Whereas Newton pivoted his natural universe around the unifying concept of gravity, Smith set out to construct an analogous ethical and economic cosmology around what he deemed to be the unchanging ethical 
and economic relationships of human life. His ethical system, A Theory of Moral Sentiments (first edition, 1759), was built around the 'natural principle' of 'sympathy' (or 'fellow feeling'); his economic system, The Wealth of Nations (first edition, 1776), was shaped around the human 'propensity' to 'truck, barter and exchange'. ${ }^{10}$ Smith's works consciously advanced elements of a general or Newtonian system of social philosophy and political economy. Their construction, however, was far from 'natural'. In his choice of concepts, Smith deliberately highlighted the virtues of economic liberty over those of trading restraint. Most notably, The Wealth of Nations harnessed the self-interested pursuit of gain to the belief that such activity would also benefit society at large.

Smith's ideas, of course, were the answer to every entrepreneur's prayer. They gave legitimacy, even sanctity, to the (then) marginal members of society who, outside the restrictive practices of the established merchant and craft guilds, were actively developing new forms of industrial production (e.g. the factory spinning of cotton fibre).

As shown in a later section of this chapter, Smith's harmonization of the ideas of self and collective interest was also crucial to the development and legitimation of simultaneous instruction.

There is a faculty inherent in the human mind ... which constitutes the Madras System, the organ desiderated by Lord Bacon, for the multiplication of power and the division of labour ... which like the principle of gravitation in the material world, pervades, actuates, invigorates, and sustains the entire scholastic system.

(Bell 1832a: 15)

One of the most successful Glasgow entrepreneurs was David Dale (1739-1806) who, in 1786, entered into partnership with Richard Arkwright (1732-92, inventor of the water-frame) to build a water-powered cotton mill on a fast-flowing stretch of the River Clyde near Lanark, about 25 miles upstream from Glasgow. Dale provided the appropriate finance and Arkwright supplied the relevant technical support. By 1800, the New Lanark mill was the largest in Scotland.

Early cotton mills such as New Lanark were a mechanical embodiment of the systematic ideas of Bacon, Newton, Locke, and Smith. Their production was organized around a series of separate processes, powered by a single energy source, and harmonized by a disciplined army of drive shafts, pulleys, gears, and 'hands'. Under optimum conditions - a surplus of water, raw materials, and labour - the production of cotton yarn was administered, quite literally, like clockwork.

Just as the first factory system began to replace the domestic (i.e. hand-spinning) production of cotton yarn, so the rhetoric and ideals of systematization began to penetrate other spheres of life. Some of the educational consequences of this accelerating social transformation can be readily traced out in the singlevolume Complete Works $(1832 \mathrm{~b})^{11}$ of Andrew Bell (1753-1832), the self-styled 'discoverer' of the monitorial system. In 1789 Bell, a Church of England 
Minister born and educated in Scotland, was appointed superintendent of the East India Company's Orphanage (or 'military male asylum') near Madras. His published writings commence in 1796 with a report to the Directors of the Company documenting the modifications that he had made to the form of schooling offered by the asylum (Bell 1797). On the basis of Bell's testimony, it seems that the Madras Orphanage had originally been modelled on the forms of charity (or pauper) schooling that had blossomed in early eighteenth-century England alongside the workhouse movement.

Socially and pedagogically, such charity schools were a transitional form of educational life. On the one hand they were an integral part of the domestic or craft economy of the sixteenth and seventeenth centuries; yet, on the other hand, they were also a response to the spread of wage labour (and its alter ego, unemployment). From the first perspective, charity schools pre-date the factory system. They were a surrogate of family life, not an alternative mode of existence. By the end of the eighteenth century, however, the second perspective dominated. Workhouse charity schools could no longer cope, educationally or financially, with the increasing numbers of indigent poor children who populated areas of urbanization and industrialization.

In this context of crisis, Bell's novel intervention in the affairs of the Madras asylum was as simple as it was time-honoured. He elevated to the level of a major educational principle the practice of employing pupils as teaching assistants. If the financial implications of such a strategy were not immediately evident, Bell (1797) was careful to draw attention to them. 'After this manner,' he wrote, 'THE SCHOOL TEACHES ITSELF' (p. 20, capitalization in original).

In the early nineteenth century Bell was encouraged to prepare his ideas for a wider audience. In the process, his writings gradually assimilated the language of the Industrial Revolution. For instance, the title-page of Elements of Tuition (1808) not only included the word 'system', but also echoed Adam Smith in noting that Bell's discovery achieved a 'multiplication of power and a division of labour' in the 'moral, religious and intellectual world'.

In the 1820s, Bell also attempted to turn his ideas from a technology into a science. The Brief Manual of Mutual Instruction and Moral Discipline (1823-7), for instance, refers to the 'code of laws', founded on the 'constitution of man' (p. 71), which, Bell argued, gave coherence to the 'Universal principle' of 'mutual tuition' (p. 74).

Bell's dual perspectives on mutual instruction - technological and scientific survived into his last writings. In the seventh edition of Mutual Tuition and Moral Discipline (1832a), Bell portrayed the mutual system as an 'entire economy'. At the same time, however, he characterized the workings of the system as a kind of muscular pedagogy. Its primary purpose was to 'prevent the waste of time' by 'call[ing] forth' the 'exertion' and fixing the 'attention' of the students (pp. 50, 51).

If Bell's later writings mask the charity-school origins of the monitorial system, a less clouded view can be gained from the early writings of his noncon- 
formist counterpart, Joseph Lancaster (1778-1838). Although the systems of Bell and Lancaster shared the same 'mechanical part[s]' (Trimmer 1805, quoted in Kaestle 1973: 101), the rhetoric of the machine is much less obtrusive in Lancaster's prose. In fact, Improvements in Education (1806) reflects a much older source of Lancaster's ideas. It is saturated, particularly in its early pages, with notions of militant piety and ascetic discipline that, like the concept 'division of labour', ${ }^{12}$ emerged in the Reformation and Counter-Reformation of the sixteenth and seventeenth centuries.

Like Andrew Bell, Joseph Lancaster started his experiments before the end of the eighteenth century. As a young man in Southwark he set up a small school in his father's house, later receiving financial support from a network of local Quakers. ${ }^{13}$ Although Improvements in Education gives no explicit indication of the source of Lancaster's ideas, the methods he used, like those of Bell, were firmly rooted in the urban charity-school tradition, which, in turn, was influenced by continental educational ideas brought over by Catholic and Protestant refugees. ${ }^{14}$

Although Lancaster may not have been aware of the connection, Improvements in Education had much in common with The Conduct of the Schools (1720), an educational treatise written (in French) by Jean-Baptiste de la Salle (1651-1719), founder of the Christian Brothers. ${ }^{15}$ De la Salle's efforts in Northern France were directed to the same ends as those of Bell and Lancaster; namely, the reorganization of pre-existing charity schools to cope more adequately with the salvation of the growing population of urban poor.

Like his British successors, de la Salle provided a system of vernacular and elementary instruction. His most noted contribution, however, was in the realm of school administration. As enrolments grew, de la Salle chose not to form new schools by a process of fission but, rather, to reorganize existing schools into a hierarchy of smaller administrative units of 'anything up to a hundred boys' (Battersby 1949: 79, Hamilton and Gibbons 1980) - known as 'classes'.

De la Salle's adoption of the Renaissance term 'class' brought a new metaphor to charity schooling. If a sense of order was invested in schooling in the industrial revolution through the notion of the 'machine', it was brought to earlier forms of schooling via the notion of the 'ladder'. By the nineteenth century, schooling in Scotland had assimilated both these metaphors. Each reinforced the sense of order - structural or sequential - advanced by the other; and, as shown in the next three sections, each was an essential element in the ideological underpinning of the classroom system.

It is a common practice for one class to try to excel another. The highest class, as to proficiency in learning, occupies the most honourable place in the school: a place not otherwise distinguished from the rest, than that it the customary seat of that class. When an inferior excels a superior class, the superior class quits its station, and goes down to the seat of the inferior. When this happens, the superior class finding itself excelled, and not liking the disgrace, usually works very hard to regain its former seat. 
One of the earliest known uses of the word 'class' appears in an account of life at the University of Paris printed in 1517. Before that time (and particularly during the early days of medieval foundations such as Bologna), university students followed a self-directed set of studies. That is, degree programmes took shape, year-by-year, according to the availability of students, teachers, and texts. By the beginning of the sixteenth century, however, the larger colleges at the University of Paris had adopted a different system. Their teaching was organized around groups (which gradually became known as classes), each of which comprised the students of one year and each of which was taught by a regent who accompanied the students through the different stages of the Master of Arts degree. This pedagogic form, known as the modus et ordo Parisiensis, became a prototype for both the establishment of new universities and for the reformation of medieval foundations.

In 1577, for instance, Glasgow University received a new Charter (the Nova Erectio) which supplanted its original, Bologna-derived constitution of 1451. The new foundation was consciously framed to advance the more 'definitely Protestant end[s]' (Mackie 1954: 63) of the Scottish Reformation. Residence in college was made compulsory for the Principal; courses were reduced in length; teaching was planned according to a 'rigid programme' (p. 76); examinations were more closely regulated; and teachers and students were expected to profess the Protestant faith and attend compulsory worship.

As the evidence of Paris and Glasgow suggests, the notion of classes came into prominence with the rise of sequential programmes of study which, in turn, resonated with various Renaissance and Reformation sentiments of upward mobility. In Calvinist countries (such as Scotland) these views found their expression, theologically, in the doctrine of predestination (the belief that only a pre-ordained minority could attain spiritual salvation) and, educationally, in the emergence of national but bipartite education systems where the 'elect' (i.e. predominantly those with the ability to pay) were offered the prospect of advanced schooling, while the remainder (predominantly the rural poor) were fitted to a more conservative curriculum (the appreciation of religious knowledge and secular virtue). ${ }^{16}$

In many respects, the reformation coexistence of conservative and meritocratic sentiments (i.e. of sponsorship versus maintenance of the status quo) survived in the pattern of charity schooling that emerged in the seventeenth and eighteenth centuries. ${ }^{17}$ In Glasgow, for instance, the earliest charity school (Hutcheson's Hospital, founded 1641) was set up deliberately to advance the orphan sons of 'burgesses' (Hutcheson's Hospital 1800: Appendix 3). At a later date, charity schools with more limited goals were also set up in rural areas (e.g. the Scottish Society for the Propagation of Christian Knowledge opened its first school - for the 'salvation of souls' (Mason 1954: 2) on St Kilda in 1711). And the first urban charity school for paupers (the Town's Hospital of Glasgow, founded 1733) was set up to both improve and civilize its inmates (Greer 1979).

These ideological variations, which were echoed in England and Europe (Mason 1954, Lis and Soly 1979), also survived into the era of the monitorial 
school. Bell and Lancaster, for instance, were both concerned to inculcate virtue (e.g. through good school attendance), but only Lancaster's use of an elaborate system of prize-giving gave full expression to the meritocratic ethic.

The reasons for this differential emphasis of sponsorship and conservatism are not difficult to uncover. Bell's system, supported predominantly by the established church and the landed classes, was more concerned with retaining the status quo. Its functioning and rhetoric were dedicated to the efficient maintenance of the social machine, rather than to the improvement of its human product. On the other hand, Lancaster's system, which stressed industry and achievement as much as virtue and salvation, was supported by the dissenting churches and financed by wealth derived from industry rather than from inheritance.

In turn, Bell's ideas hinged on a vision of an ordered, static, agricultural society; whereas Lancaster's system was built around a future-oriented technological and Utopian vision of the new moral world. Bell and his supporters sought to stem the flow of history; Lancaster and his colleagues struggled to channel its social energies along more profitable lines. For Bell, education was a static steam-engine; for Lancaster, it was a locomotive. ${ }^{18}$

In general, the larger the classes the greater the improvement.

(Bell 1823-7: 7lfn)

In 1751, Adam Smith became Professor of Logic at Glasgow University; his appointment was a direct reflection of a modernizing climate in Scottish life. To secure the services of this already-noted scholar, the Glasgow Faculty suspended the regular logic syllabus and allowed Smith to repeat a series of lectures on literature and economics given in Edinburgh between 1748 and 1751 . Although Smith's modern motions were not to the liking of all Faculty members, it was generally agreed that they would revive the flagging fortunes of the university by attracting students from 'industry and commerce' - a relatively new and untapped constituency. ${ }^{19}$

Adam Smith spent only one year as Professor of Logic. In 1752 he was transferred, following the death of the incumbent, to the Chair of Moral Philosophy, a position that accorded more reasonably with the content of his Edinburgh lectures. Gradually, Smith's moral philosophy course took shape in four parts: natural history, ethics, jurisprudence (legal theory), and political economy. The conceptual apparatus erected in the lectures had a direct influence on education, as it did upon other spheres of life. Specifically, Smith's ideas on the 'division of labour' (elaborated in The Wealth of Nations) and 'fellow-feeling' (elaborated in A Theory of Moral Sentiments) were to furnish a more sophisticated justification for the deployment of 'classing' in education.

Both $A$ Theory of Moral Sentiments and The Wealth of Nations began with a discussion of the origin of the 'distinction of ranks'. In the first of these works, Smith drew upon static images of social structure to describe the place of the individual in society. He used such terms as 'distinction', 'rank' and 'station'. ${ }^{20}$ 


\section{David Hamilton}

By the publication of The Wealth of Nations, however, Smith had refined his views on rank in three respects.

First, his discussion of 'the division of labour', in the early chapters of The Wealth of Nations (1976b), brought into focus the idea that society could be divided, not into many ranks, but into a smaller number of groupings (i.e. divisions). To identify such groupings, later writers (but not, apparently, Smith) ${ }^{21}$ borrowed the word 'class' from education where, as noted earlier, it had been used since the Renaissance to refer to cohorts of students at different levels on the same course of study.

Second, Smith advanced the claim that the distinction of ranks was due not to 'nature' (as was his argument in respect of 'species' differences) but, rather, due to differences in 'habit, custom and education' (Smith 1976b: 28-9). By apportioning the effects of heredity and experience in this way, Smith resolved a problem of social taxonomy. Inter-class/division/species differences were thus identified as fixed (and unalterable), while intra-class differences were identified as fluid (and open to influence).

Third, Smith pointed out that the clustering of ranks also had consequences for the mutual social and economic advancement of society. He argued that members of a social group (however labelled) shared a 'common stock' of 'talents' wherein even the most 'dissimilar' genius could, by 'barter, and exchange', purchase 'whatever part of the produce of other men's talents he has occasion for' (Smith 1976b: 29-30). In actuality, of course, Smith's ideas related principally to the economic exchange of commodities in the market place. Yet, the rhetoric of 'talents' and 'genius', together with Smith's predictions about the benefit of sharing the 'common stock', was easily translated from the economic to the academic market-place.

Overall, Smith's philosophy was both collectivist and market-oriented. The collectivism expressed itself educationally through the view that classing increased learning; the market orientation expressed itself through the view, discussed in the next section, that mutual educational benefit could only be realized through the association of classing with a meritocratic system of individual advancement.

Three children ... cannot by any possibility make the same progress as if there were thirty, and the reason is obvious; each one of the thirty sympathizes with those of the same age, and the example of each operates mutually.... This principle operates equally in regard to children of whatever rank in life. Sympathy and example are the most important auxiliaries of the infant system.

(Stow 1833: 11)

Besides highlighting the differences between divisions and ranks, Smith also challenged the associated belief that society could be regarded as a static entity. His attack took two forms - both typical of the general historical bias of the Scottish Enlightenment (Forbes 1954, Höpfl 1978). First, Smith offered an 
account of the changes that had taken place in human society since its origins (thus demonstrating the mutability of social forms); and second, he speculated about the forces that lay behind the dynamics of social evolution. This latter thrust was to prove very influential in education since the mechanisms proposed by Smith to account for the progress of the individual in society were equally applicable to the advancement of the individual through schooling. In both instances, promotion was deemed to occur not through isolated effort, but rather, through the group-based mechanisms of mutual 'sympathy' and 'emulation'.

As noted earlier, 'sympathy' (or 'fellow-feeling') was the pivotal concept of $A$ Theory of Moral Sentiments. Smith believed it to be the ethical relationship that existed among all members of society, irrespective of their wealth or rank. Previously, sympathy had been regarded by moral philosophers as some kind of spiritual essence that well-endowed people distributed, like alms, to the less fortunate (i.e. 'sympathy for'). In Smith's revised usage, sympathy became something that is shared, like common property (i.e. 'sympathy with'). To the extent, therefore, that individuals were in sympathy with each other, they could be regarded, in Smith's terms, as morally equal (i.e. the presumed economic equality of buyer and seller under conditions of free trade). ${ }^{22}$

If the concept of sympathy accorded all humans the same initial natural or moral status, then Smith deployed the concept of emulation to account for any subsequent differentiation. He argued that, through an appreciation of (or sympathy with) the achievements of the successful, the poor would be motivated to further their own self-improvement. In these terms, Smith and his supporters believed that the ethical sentiment of emulation, like the analogous economic sentiment of enlightened self-interest, would advance the collective interests of the rational, plentiful, and equitable society.

In Smith's cosmology, then, sympathy and emulation were to be regarded as collectivist principles - referring in the first instance to the basis of society's social cohesion and, in the second instance, to the source of society's continuous progress. Although later writers were prone to conflate competition and emulation, Smith regarded them differently. Emulation was not about rivalry, but about self-improvement. Furthermore, sympathy and emulation were not held to be in opposition like co-operation and competition. Rather, Smith assumed that without sympathy there could be no emulation. In a manner consistent with the early optimistic days of the Industrial Revolution, sympathy and emulation were seen as devices for the levelling up rather than for the differentiation of human beings. ${ }^{23}$

Despite its novel features, Smith's analysis of sympathy and emulation also served to refocus a long-standing debate about the merits of classing in education. In 1512, for instance, Erasmus's De Ratione Studii had drawn attention to the fact that group teaching (as opposed to individual tutoring) could be beneficially used to arouse a 'state of mutual rivalry' (Thompson 1978: 682).

Bacon and Locke advanced similar views in the seventeenth century. At that time, the supposedly sterile (medieval) methods and curricula of the grammar 
schools had led many wealthy parents to resort to home tuition. Locke was equally critical of medieval methods but also noted that if students were sent 'abroad' (i.e. away from home), they might be motivated, through the 'emulation of [their] school fellows', to put 'life and industry' into their learning. ${ }^{24}$

By the time of Adam Smith, the debate about grouping had, as shown earlier, become merged with the other issues. In turn, Smith's nineteenthcentury disciples tended to pull apart the concepts of sympathy and emulation and, presumably under the influence of Thomas Malthus (1766-1834), confuse them with notions about competition and co-operation. ${ }^{25}$ For instance, the individualized pedagogies of Bell and Lancaster placed greater emphasis on emulation and competition; whereas the Glasgow-linked pedagogies of Owen and Stow (whose sophistication leaned more to group teaching) placed more store by the concept of sympathy. Indeed, both Owen and Stow specifically eschewed the monitorial practice of prize-giving, preferring the alternative pedagogic strategy of using the 'sympathy of numbers' to 'animate and invigorate' (Stow 1850: 17) their pupils into 'friendly emulation' and 'going forward with their companions'. ${ }^{26}$

In these terms, the connection between Adam Smith and the legitimation, adoption, and dissemination of group teaching is more than merely coincidental. Yet, in the event, Smith's conceptual system came to be revised as the Industrial Revolution turned on periods of famine, slump, and social discontent. Just as it is certain that the ideas of Smith and his contemporaries were never fully articulated in educational terms, it is equally the case that many people took elements from them and built their own pedagogic systems. But association does not prove causality. How, then, did the constellation of pedagogical concepts that prefigured the classroom system enter the commonsense world of education? What specific intellectual genealogies, social networks, and cultural catalysts served to translate ideas into practice ${ }^{27}$

In a chronological sense, it is true that Owen and Stow succeeded Bell and Lancaster. Pedagogically, however, there is a sense in which the methods of group instruction did not evolve from within the monitorial system but, rather, from a different tradition. If Owen and Stow explicitly rejected the individualizing and competitive ethos of the monitorial system, what was the source of their alternative perspectives? Again, there are good grounds for looking towards events at the Scottish Universities.

In a class-room ... emulation and energy are found to result from the simple circumstance, that a number of young persons similarly situated as to age and advantages, are engaged in listening to the same things, and in receiving the same impressions. A sympathetic animation pervades the whole; the glow of zeal, and an expression of curiosity are perceived in almost every countenance; and the faculties of the mind are exerted, and powers unused before, are awakened into life and activity.

(Jardine 1825: 435) 
In the early eighteenth century, university teaching methods were still largely medieval in origin and style. The professors and lecturers at Glasgow University dictated their lectures in Latin, and examined their students through a version of the oral disputation. Their pedagogy assumed scarcity of texts, placed little emphasis on extempore writing, and reflected medieval assumptions about the nature of knowledge, the establishment of truth, and the philosophy (or psychology) of teaching and learning.

The eighteenth century saw a number of developments which foreshadowed a shift in the pedagogy of Scottish university teaching. The wider dissemination of printing increased Glasgow University Library's holdings (and opened up class libraries to undergraduates); the systematization of knowledge led to specialization among university teachers (the rise of subject professors over generalist 'regents'); the emergence of new ideas that could not easily be expressed in old languages gradually led to the substitution of English for Latin as the dominant medium of tuition; ${ }^{28}$ and finally, various factors led certain teachers, like Adam Smith, to adopt relatively extempore methods of teaching and examining.

Some of the most significant changes came at the end of the century and were developed by former pupils and successors of Adam Smith - John Millar (Professor of Law, 1761-1801); James Mylne (Professor of Moral Philosophy, 1797-1839) and most notably, George Jardine (Lecturer and Professor of Logic from 1774-1827). ${ }^{29}$

Towards the end of his career Jardine recorded - in Outlines of Philosophical Education (1818) - some of the developments that had taken place over his 67year connection with Glasgow as student and teacher. Jardine's particular contribution was to complete the transformation of the logic class set in train by Adam Smith and, in the process, to provide a pioneering rationale for what came to be known as 'simultaneous instruction'. Drawing on the ideas and direct influence of Smith, David Hume (1711-76), and Helvetius (1715-71) (whom Jardine had met through an introduction from Hume), Jardine's revision of the logic class encompassed both its content and organization. The new course, like the old one, focused on the processes of human thought but used ideas from the nascent field of psychology rather than from the traditional discipline of syllogistic logic. In turn, Jardine not only regarded learning as an active process, he also used the same psychological ideas as the basis of his teaching methods. In his own lectures, that is, he sought to cultivate 'all the powers of the intellect and taste' by calling them 'severally into action' (Jardine 1825: 31).

The first part (or 'division') of Jardine's lectures to the logic class was devoted to the 'study of mind' - the 'mother science ... from which all others derive at once their origin and nourishment' (p. 45).

Jardine chose the 'powers of the understanding' as his first topic and lectured, initially, on the 'faculties' of 'perception' and 'attention' (p. 47). Such a selection was probably deliberate. Jardine regarded perception as the primary mechanism of thought - the 'first and wonderful communication between mind 
and matter' (p. 5l) - and 'attention' as the focusing device which helped to discriminate among sense impressions.

Perception and attention also figured prominently in Jardine's educational practice. They were not new ideas, being an important element in Comenius's philosophy of education ${ }^{30}$ but Jardine gave them a new lease of life by linking them to late eighteenth-century notions about improvement and industry. For instance, echoing Adam Smith's ideas about emulation and the division of labour, he believed that, by 'deep and persevering attention to one subject' persons of 'moderate abilities' could attain 'remarkable degrees of eminence' (p. 105). ${ }^{31}$

If the first part of Jardine's 'practical system of discipline' ( $\mathrm{p}$. viii) embodied a philosophy of learning, the second part articulated a psychology of teaching. Notably, Jardine chose to bring together the processes of teaching and assessment which, hitherto, had been conducted separately. Together with his colleagues, Jardine gradually incorporated into (and alongside) his lectures an extempore system of questioning. According to Jardine's own account, such questioning gradually developed into a pedagogic system that consciously blended the requirements of both individual and group teaching. That is, questions were not 'put indiscriminately' (p. 282) but, instead, tailored to the 'particular circumstances of each individual' (p. 284). Nevertheless, such a pedagogy also had consequences for the group. Its 'active discipline' (p. 290), as Jardine recognized, placed 'constant demands' upon the 'attention' of all students (p. 284). Like Erasmus, Bacon, Locke, and Smith, Jardine believed that classing could, at the same time, serve the interests of the individual student.

External evidence for the introduction of a new group-based system of teaching at Glasgow can be gleaned from the gradual spread of endowed prizes, following their initiation in 1776. Prizes given solely for achievement had been known since the Reformation (if not earlier) but Jardine pioneered a broader approach which rewarded effort ('regular and spirited exertion' (p. 378)) as well as achievement ('genius or proficiency' (p. 377)). By bringing prizes within the 'reach of every degree of talent and industry' (p. 378), Jardine hoped to promote a general 'spirit of emulation' (p. 377) and, thereby, activate all the members of the logic class.

Jardine's system of prize-giving, unlike earlier variants in Glasgow, emphasized the homogeneity of the student group. His classes, that is, were analogous to Smith's 'division'.32 Overall, Jardine and his colleagues transformed the medieval lecture. In its new form it was to be construed not as a 'dictate' (as it had been known earlier) but as a vernacular discourse - an 'easy dialogue'33 between a teacher and a group of 'not more than thirty or forty' students (Jardine 1825: 426). Although the term 'lecture' was retained, Jardine's teaching represented, as he acknowledged, a convergence of tutorial and lecturing methods. Thus, despite their different labels, Jardine's university lectures, 'properly so called' (p. 425), and the 'simultaneous' instruction of nineteenthcentury elementary schools exhibited certain marked similarities. ${ }^{34}$

Certainly, to anyone schooled within the classroom system, most of Jardine's 
ideas would seem commonsensical. Yet, the fact that his Outlines covered more than 500 pages and ran to two editions, suggests that they contained much that was both new and acceptable. Jardine's blending of naturalistic philosophy and political economy advanced a powerful case for the superiority and efficiency of simultaneous class teaching. Through the agency of colleagues (like John Millar), fellow members of the Glasgow Literary and Commercial Society (like Robert Owen), and pupils (like William Hamilton), Jardine's ideas took on a life of their own and successfully penetrated into the wider educational debates of the early nineteenth century (e.g. university reform, education for the working class, state control of schooling).

Their penetration, however, was far from inevitable. There was still a large gulf, socially and ideologically, between the 'classes' of Glasgow University and the 'classrooms' of a model nineteenth-century elementary school. In particular, why would a form of schooling directed to the promotion of 'learning' have any relevance to elementary schooling - an institution that, historically, went back to the Reformation idea of schooling for virtue? What were the changes in educational climate that allowed such a connection to be made? And who were the educational entrepreneurs who brought them to life?

Many well-intentioned individuals, unaccustomed to witness the conduct of those among the lower orders who have been rationally treated and trained, may fancy such an assemblage will necessarily become a scene of confusion and disorder; instead of which, however, it proceeds with uniform propriety; it is highly favourable to the health, spirits, and dispositions of the individuals so engaged; and if any irregularity should arise, the cause will be solely owing to the parties who attempt to direct the proceedings being deficient in a practical knowledge of human nature.

(Owen 1972: 70)

At first glance, George Jardine seems to have had very little involvement in the schooling of the urban proletariat. Most of his energies were directed towards the reform of Glasgow University and its preparatory institution, Glasgow Grammar School. Nevertheless, there is evidence that, if Jardine did not so much give his ideas to elementary schooling, others were ready to take them. A key figure in this respect was Robert Owen. Besides their concurrent membership of the Glasgow Literary and Commercial Society, Jardine was present in 1812 when Owen made his first major pronouncements on education (at a banquet in Glasgow held to honour the visit of Joseph Lancaster). Jardine's influence is most evident in the organization of Owen's 'New Institution for the Formation of Character' (which was opened at New Lanark after Owen had broken with the monitorial system). Not only was the Institution built with a 'lecture room' as well as various schoolrooms, but older children were taught advanced subjects (natural history, for example) by means of 'Familiar lectures' based on 'sensible signs and conversation' and 'delivered extempore' to 'classes of from 40 to 50' (Owen 1824: 153, 160). 
The link between the systems of Jardine and Owen derives from the fact that, despite their apparent differences, both were organized to foster intellectual growth. Unlike Bell and Lancaster, Jardine and Owen were more interested in teaching their students a mental rather than a corporal discipline. If Bell (1823-7: 67 ) aimed to promote 'virtue' by keeping students 'unceasingly, busily, happily and profitably employed', Owen sought to instill 'character' by more rationalist methods. As far as Owen (1972: 75-6) was concerned, the 'beginning and end of all instruction' was that pupils should understand, as clearly as the 'demonstrations of Euclid', the 'inseparable connection' between the 'interest and happiness of each individual and the interests and happiness of every other individual' (p. 75). For this reason, mentalist concepts like 'understanding', 'perception', and 'attention' found a more important place in the rhetoric of Owen and, to a lesser extent, Stow, than in the writings of Bell and Lancaster.

The rationalist thrust of Owen's thinking was part of an important educational groundswell in the early nineteenth century. Philosophic radicals, like Owen, argued that rationality was as appropriate an educational goal for the lower classes as it was for the upper strata. Unlike the conservatives of the day who assumed that the virtue of the working class could be assured through forms of bodily discipline, the philosophic radicals claimed that a more 'durable' character would be formed when, in Owen's (1972: 67) words, 'the mind fully understands that which is true'.

For such reasons as these a range of 'intellectual' systems of working-class schooling began to appear in the nineteenth century. ${ }^{35}$ Thus, if the history of urban elementary schooling in Britain before 1815 pivots around charity school ideas about the relationship between piety and virtue, the period after that date is marked by the penetration of the new ideas about the relationship between rationality and virtue. In the event, it was from Jardine, Owen, and the Swiss educationist, Pestalozzi (1746-1827), that post-1815 educators took their pedagogic models. Conservative notions of piety, of course, did not die out; as in the different versions of the monitorial system they existed uncomfortably with the meritocratic social-engineering views of the rationalists. Overall, however, the educational rationalists forced the pace in the years after 1830. As political suffrage was extended to larger sections of society, ideological arguments about the ultimate civilizing value of teacher training and higher teacher/pupil ratios carried the day. ${ }^{36}$ Forms of (relatively) small-group instruction were officially endorsed that, in time, were to become the pedagogic mainstay of the classroom system.

When we contemplate the amazing diversity to be found in the laws of different countries, and even of the same country at different periods, our curiosity is naturally excited to enquire in what manner mankind had been led to embrace such different rules of conduct, and at the same time it is evident that, unless we are acquainted with the circumstances which have recommended any set of regulations, we cannot form a just notion of their utility, or even determine in any case, how far they are practicable.

(Millar 1806: 1-2) 
This chapter has tried to go beyond appearances and identify some of the new ideological props that enabled simultaneous instruction to supersede the hitherto dominant forms of individualized domestic production in schooling. For the sake of coherence, the ideas of Adam Smith, Andrew Bell, Joseph Lancaster, George Jardine, and Robert Owen have received particular attention. But, as has been indicated, the development of nineteenth-century elementary schooling was neither restricted to Glasgow, nor was it the responsibility of individual thinkers. $^{37}$

Nevertheless, the relation between Glasgow and elsewhere remains problematic. At one level this chapter can be regarded as a case study of a more general phenomenon - the extension of mass schooling. Within such a framework, then, the choice of Glasgow is purely arbitrary: Manchester, Liverpool, or London would have served the same purpose.

At another level, however, the choice of Glasgow is less than arbitrary. The early appearance of the word 'classroom' in that city allows an alternative reading - that Glasgow's importance as an intellectual and economic centre enabled it not only to invent a solution to the problem of urban schooling, but more important, to export such ideas to all parts of the world. In these terms, then, the ideas of Jardine and Owen were not unique; they merely had a trading advantage over equivalent notions that, elsewhere (for example in The Netherlands and Switzerland), were also emerging from the common European heritage of charity schooling and Enlightenment philosophy. ${ }^{38}$

There is also a third level of analysis embedded in this chapter - the attempt to link schooling and production. Specifically, it is argued that the transition from individualized mass-production (the domestic system) to batch massproduction (the early factory system) can also be followed in the history of schooling and pedagogy. From this perspective, then, the disjunction between monitorial and classroom methods is explicable in the sense that the former were not so much the harbinger of factory production as the last gasp of the domestic system in education.

Overall, this chapter should be read primarily as an essay in the history and theory of pedagogy. It tries to explore, in a complementary fashion, topics that seem to be missing from standard accounts of eighteenth- and nineteenthcentury schooling. ${ }^{39}$ It is hoped in due course to provide a more rounded analysis. ${ }^{40}$ In the meantime, these notes may serve as a preliminary ground-clearing exercise.

\section{Notes}

1 Examination of secondary sources suggests that, among the British universities, only Glasgow used the term 'classroom' in the eighteenth century. The most likely rival contender is Edinburgh: but there is no such usage in the Edinburgh University Senate minutes for that period. An early printed reference to classroom occurs in Gibson (1977: 143). Wider use of the term in education seems to have followed its popularization by Samuel Wilderspin $(1823$ : 18, 26) in the 1820s.

2 Adam Smith's wider contribution to Glasgow College life is documented in Scott 


\section{David Hamilton}

(1937). Joseph Black's attendance at the Glasgow Literary Society is described in Read (1950).

3 The distinction used in this chapter between domestic and factory production is taken, ultimately, from Unwin (1904). In a future paper, it will be argued that Unwin's economic forms have direct pedagogical analogues: that the dominant pedagogic form which preceded the classroom system was akin to the domestic (or workshop) system of production and that the origins of the subsequent dominant pedagogic form (technological progressivism) can be tied into the revolution in scientific management and production that took place in the late nineteenth and early twentieth centuries.

4 For a discussion of some of the political, social and theological disputes over openended lecturing versus closed catechesis in the sixteenth century, see Hill (1969: Chapters 2-3).

5 The expression 'simultaneous instruction' appears in the Minutes of the Committee of Council in Education (Committee of Council 1839-40: 26-32). 'Classroom system' was a later invention. By the end of the nineteenth century, however, the terms were used interchangeably (e.g. 'the simultaneous or class room system' [Landon 1883: $150])$.

6 For the term 'moral economy', see Stow (1850: 22). Stow took the term from his Glasgow patron, Thomas Chalmers. E. P. Thompson's (1971) more recent usage is virtually synonymous.

7 The earliest use of 'system' reported in the Oxford English Dictionary is 1638.

8 For a study of the changing belief systems of the sixteenth and seventeenth centuries, see Thomas (1978).

9 A discussion of the influence of Newton and Locke appears in Buchdahl (1961). The scientific revolution marked by Newton's work was only one of the educational outcomes of the seventeenth century. For complementary studies, see Hill (1975) and Webster (1975).

10 'Sympathy' and the 'propensity to truck, barter and exchange' are discussed, respectively, in the first chapter of $A$ Theory of Moral Sentiments (Smith 1976a) and the second chapter of The Wealth of Nations (Smith 1976b).

11 The original pagination of the constituent pamphlets seems to have been retained.

12 The editors of the Glasgow Edition of The Wealth of Nations (Smith 1976b: 13fnl) suggest that the 'first considered exposition' of the concept of the division of labour occurred in Petty (1690).

13 It has been suggested (Salmon 1904: 2) that Lancaster took the idea of monitorial instruction from his own childhood attendance at a dissenting charity school. Elsewhere, a contemporary review (quoted in McGarry 1966: 14) recorded that the school that Mr. Lancaster himself attended was organized into a plan of divisions into classes each superintended by a monitor'.

14 It has been reported (Armytage 1964: 41) that in the eighteenth century, dissenters set up a school in Southwark in 'direct opposition' to an earlier charity school established by the Jesuits.

15 De la Salle's impact on education is seldom noted in British histories of education. The only accounts that seem available are a chapter in Adamson (1971: 212-36) and Battersby (1949). Neither author discusses the spread of de la Salle's ideas to Britain. A better review of the continental precursors of the monitorial system can be found in Tronchot (1972). Tronchot draws out the similarities and differences between the Conduite des Ecoles and the Bell-Lancaster systems in Chapter 2, pp. 70-3.

16 For details of the plan for reforming education in sixteenth-century Scotland, see Cameron (1972).

17 A discussion of the different forms of charity schooling that emerged in the seventeenth and eighteenth centuries can be found in Simon (1968) and Mason (1954).

18 The conservative standpoint on the monitorial system is clearly revealed by Sarah Trimmer's (1805, in Kaestle 1973) comments on Lancaster's creation of an 'Order of 
merit' for his best pupils. In Improvements in Education, Lancaster (1806: 94-5) argued that such 'distinction' was based on the concept of service which, in turn, was 'the original principle of true and hereditary nobility'. Trimmer (1805, Kaestle 1973: 105-6) found Lancaster's arguments seditious: 'When one considers the bumble rank of the boys of which common Day Schools and Charity Schools are composed, one is naturally led to reflect whether there is any occasion to put notions concerning the "origins of nobility" into their heads... Boys, accustomed to consider themselves as the nobles of a school may in their future lives aspire to be nobles of the land and to take [the] place of the hereditary nobility'.

19 Between 1740-9 and 1790-9 the proportion of matriculated students at Glasgow with fathers in 'industry and commerce' rose from 26 per cent to 50 per cent (Mathew 1966: 78).

20 The use of 'rank', 'distinction' and 'station' to describe the order of society occurs in A Theory of Moral Sentiments (Smith 1976a: 51-2).

21 One of the first persons to use the word 'class' in its modern sense was John Millar a former student of Adam Smith (Morris 1979: 9).

22 See Campbell (1971). Smith's (1976a) discussion of sympathy and emulation occurs in A Theory of Moral Sentiments, especially pp. 62-3.

23 For a discussion of the priority of Smith's notion of sympathy and its consonance with his ideas about self-interest, see Lamb (1974).

24 Locke's discussion of emulation and group teaching appears in Some Thoughts Concerning Education (1880: 138-44; section 7). Bacon's viewpoint appears in De Augmentis: 'I am clearly, in favour of a collegiate education for boys and young men.... For in colleges there is greater emulation of the youth among themselves' (quoted in Armytage 1964: 13).

25 See, for instance, Malthus's (1798) critique of 'Systems of equality' in Book 3 of $A n$ Essay on the Principle of Population. In a later edition, prepared in 1817, Malthus (n.d.: 25) directed certain remarks against Robert Owen: 'a state of equality', he argued, was unsuitable to the 'production of those stimulants to exertion which can alone overcome the natural indolence of man'.

26 Robert Owen's ideas on emulation and sympathy are reported by his son Robert Dale Owen (1824: 175). For an historical review of emulation see Queyrat (1919).

27 For Adam Smith's general influence on nineteenth-century social thought, see Halévy (1955). Many of Smith's ideas were, of course, also carried into educational thought and practice by the generations of schoolmasters who studied at Glasgow University during that period.

28 Other early practitioners of vernacular teaching in Glasgow included the philosopher Francis Hutcheson (in the 1730s) and the chemist William Cullen (in the 1750s).

29 The educational impact of Jardine and the other 'Glasgow men' is discussed in Davie (1964).

30 Comenius's views on perception and attention are well summarized in Charles Hoole's (1970) translation of the preface to the first English language edition of the Orbis Pictus (1659): 'See here then a new help for Schooles, A Picture and Nomenclature of all the chief things in the World... This same little Book will serve to stir up the Attention, which is to be fastened upon things and ever to be sharpened more and more'.

31 Adam Smith (1976b: 20) had expressed a similar view: 'Men are much more likely to discover easier and readier methods of attaining any object, when the whole attention of their minds is directed towards that single object, than when it is dissipated among a great variety of things'.

32 Lancaster (1806: 97), indeed, used classes and divisions synonymously: 'each monitor of a class or division'.

33 Jardine (1825: 464) referring to the teaching of John Millar.

34 The distance between the Glasgow lecture and the elementary schoolroom is also 


\section{David Hamilton}

diminished by the fact that Scottish students in the logic class were, according to Jardine, below the age of 'seventeen or eighteen' (Jardine 1825: 426). Elsewhere, Jardine also refers to his students as 'pupils' (p. 284). English schoolmasters who were aware of Jardine's ideas included Henry Dunn (n.d.: 16-17), Secretary of the British and Foreign School Society, and James Butler (of Handsworth, Birmingham) whose Outlines of Practical Education (1818) may have been deliberately titled to emulate Jardine's Outlines of Philosophical Education.

35 Besides Stow's Training System (1850), Scotland also furnished intellectual schemes in the form of the 'explanatory' system (see Wood 1828) and the 'lesson system' whereby pupils were expected to use 'intellectual' means in the 'concoction' of their answers (see Gall 1830: 58)

36 Robert Owen's arguments against the monitorial system and in favour of higher teacher/pupil ratios occur in the evidence of the Select Committee (House of Commons 1816: 241). Stow's views appear in The Training System (1850: 199-203). For a detailed analysis of the ideological debates surrounding the growth of state intervention in schooling, see Johnson (1970).

37 Some of the more visible aspects of the classroom system are discussed in Hamilton (1978).

38 Some of the European developments in nineteenth-century elementary schooling are described in Pollard (1956).

39 The motivation for writing this chapter stemmed from two sources: (a) curiosity about Adam Smith's and David Stow's homologous use of 'sympathy'; and (b) dissatisfaction with accounts of Adam Smith's influence on education which ignored $A$ Theory of Moral Sentiments, e.g. Szreter (1976) and Higginson (1978). Overall, this chapter may go some way to meeting Harold Silver's (1977: 61) criticism that educational historians of the nineteenth century have ignored the 'relationship between educational and social ideas and ideologies'.

40 Later products of the author's interest in the history of pedagogy are reported in Hamilton $(1989,2001,2002)$. [Endnote added 10 September 2005]

\section{References}

Adamson, J.W. (1971 [1905]) Pioneers of Modern Education in the Seventeenth Century, Classics in Education, No. 45 (New York: Teachers College Press).

Armytage, W.H.G. (1964) Four Hundred Years of English Education (Cambridge: Cambridge University Press).

Battersby, W.J. (1949) De la Salle: A Pioneer of Modern Education (London: Longman, Green).

Bell, A. (1797) An Experiment in Education made at the Male Asylum of Madras (Edinburgh: Cadell \& Davies).

Bell, A. (1808) The Madras School, or Elements of Tuition (London: John Murray).

Bell, A. (1823-7) Brief Manual of Mutual Instruction and Moral Discipline, 10th edn, in A. Bell (1832) Complete Works (Edinburgh: Oliver \& Boyd).

Bell, A. (1832a) Mutual Tuition and Moral Discipline, 7th edn (Edinburgh: Oliver \& Boyd).

Bell, A. (1832b) Complete Works (Edinburgh: Oliver \& Boyd).

Buchdahl, G. (1961) The Image of Newton and Locke in the Age of Reason (London: Sheed \& Ward).

Butler, J. (1818) Outlines of Practical Education (London: Hamilton, Adams).

Camerson, J.K. (1972) The First Book of Discipline (Edinburgh: St. Andrews Press).

Campbell, T.D. (1971) Adam Smith's Science of Morals (London: Allen \& Unwin). 
Comenius, J.A. (1969 [1642]) A Reformation of Schooles, trans. S. Hartlib (Menston: Scolar Press).

Comenius, J.A. (1970 [1659] Orbis Sensualium Pictus, trans. C. Hoole (Menston: Scolar Press).

Committee of Council (1839-40) Minutes of the Committee of Council in Education (London: Her Majesty's Stationery Office).

Davie, G. (1964) The Democratic Intellect: Scotland and her Universities in the Nineteenth Century, 2nd edn (Edinburgh: Edinburgh University Press).

Dunn, H. (n.d.) Principles of Teaching (London: Sunday School Union).

Forbes, D. (1954) “"Scientific” Whiggism: Adam Smith and John Millar', Cambridge Journal, 7 (11), 643-70.

Gall, J. (c.1830) The Effects of the Lesson System of Teaching on Criminals, General Society, and the Lowest Orders of the Human Intellect (Edinburgh: James Gall).

Gibson, J. (1977) The History of Glasgow (Glasgow: R. Chapman \& A. Duncan).

Greer, K. (1979) 'More like a palace: the foundation and early development of the Town's Hospital at Glasgow', Master's thesis, University of Glasgow.

Halévy, E. (1955) The Growth of Philosophic Radicalism, trans. M. Morris (Boston, MA: Beacon Press).

Hamilton, D. (1978) Classroom research and the evolution of the classroom system. Mimeo research report, UK Social Science Research Council, grant HR/5127, ERIC ED 168 139.

Hamilton, D. (1989) Towards a Theory of Schooling (London: Falmer).

Hamilton, D. (2001) 'Notes from nowhere (on the beginnings of modern schooling)', in T.S. Popkewitz, B.M. Franklin, and M.A. Pereya (eds), Cultural History and Education: Critical Essays on Knowledge and Schooling (New York: RoutledgeFalmer), 187-206.

Hamilton, D. (2002) 'From dialectic to didactic', Paradigm (Journal of the Textbook Colloquium), 2 (5), 15-24.

Hamilton, D. and Gibbons, M. (1980) 'Notes on the origins of the educational terms class and curriculum', Paper presented at the Annual Convention of the American Educational Research Association, Boston, USA. ERIC ED 183453.

Higginson, J.H. (1978) 'Michael Sadler on Adam Smith', History of Education Society Bulletin, 21, 39-43.

Hill, C. (1969) Society and Puritanism in Pre-Revolutionary England (London: Panther).

Hill, C. (1975) The World Turned Upside Down: Radical Ideas during the English Revolution (Harmondsworth, UK: Penguin).

Höpfl, H.M. (1978) 'From savage to Scotsman: conjectural history in the Scottish Enlightenment', Journal of British Studies, 17 (2), 19-40.

House of Commons (1816) Reports of the Select Committee on the Education of the Lower Orders in the Metropolis (London: HMSO).

Hutcheson's Hospital (1800) Abstract of the Rules and Regulations by which Hutcheson's Hospital is Governed (Glasgow: Courier Office).

Jardine, G. (1818) Outlines of Philosophical Education Illustrated by the Methods of Teaching the Logic or, First Class of Philosophy, in the University of Glasgow (Glasgow: Printed by A. \& J. Duncan for Anderson \& Macdowell, Edinburgh).

Johnson, R. (1970) 'Educational policy and social control in early Victorian England', Past and Present, 49, 96-119.

Kaestle, C.F. (ed.) (1973) Joseph Lancaster and the Monitorial School Movement: A Documentary History, Classics in Education, no. 47 (New York: Teachers College Press). 
Lamb, R.B. (1974) 'Adam Smith's system: sympathy not self-interest', Journal of the History of Ideas, 35 (4), 671-82.

Lancaster, J. (1806) Improvements in Education (London: The Author).

Landon, J. (1883) School Management (London: Kegan Paul).

Lis, C. and Soly, H. (1979) Poverty and Capitalism in Pre-Industrial Europe (Hassocks, UK: Harvester Press).

Locke, J. (1880) Some Thoughts Concerning Education, ed. R.H. Quick (Cambridge: Cambridge University Press).

Mackie, J.D. (1954) The University of Glasgow 1451-1951: A Short History (Glasgow: Jackson, Son).

Malthus, T. (1798/n.d.) An Essay on the Principle of Population, vol. 2, Everyman edn (London: Dent).

Mason, J. (1954) 'Scottish charity schools of the eighteenth century', Scottish Historical Review, 33 (115), 1-13.

Mathew, W.M. (1966) 'The origins and occupations of Glasgow Students, 1740-1839', Past and Present, 33, 74-90.

McGarry, K.J. (1966) Joseph Lancaster (1778-1838): A Bibliographic Account of his Life and System of Teaching. Thesis submitted for Fellowship of the Library Association.

Millar, J. (1806) The Origins of the Distinction of Ranks (Edinburgh: William Blackwood).

Morris, R.J. (1979) Class and Class Consciousness in the Industrial Revolution, 1780-1850 (London: Macmillan).

Owen, R. (1972) 'A new view of society: third essay (1814)', in B. Simon (ed.), The Radical Tradition in Education in Britain (London: Lawrence and Wishart), 65-89.

Owen, R.D. (1872) 'An outline of the system of education at New Lanark (1824)', in B. Simon (ed.), The Radical Tradition in Education in Britain (London: Lawrence and Wishart), 139-76.

Petty, W. (1690) Political Arithmetick, 3rd edn (London: R. Clavel \& H. Mortlock).

Pollard, H.M. (1956) Pioneers of Popular Education, 1760-1850 (London: John Murray).

Queyrat, F. (1919) L'Emulation et son Role dans l'Education (Paris: Alcan).

Read, J. (1950) 'Joseph Black M.D.: the teacher and the man', in A. Kent (ed.), An Eighteenth Century Lectureship in Chemistry: Essays and Bicentenary Addresses Relating to the Chemistry Department (1747) of Glasgow (1451) (Glasgow: Jackson, Son), 78-98.

Salmon, D. (1904) Joseph Lancaster (London: Longmans).

Scott, W.R. (1937) Adam Smith as Student and Professor (Glasgow: Jackson, Son).

Silver, H. (1977) 'Aspects of neglect: The strange case of Victorian popular education', Oxford Review of Education, 3 (1), 57-69.

Simon, J. (1968) 'Was there a charity school movement? The Leicestershire evidence', in B. Simon (ed.), Education in Leicestershire, 1540-1940: A Regional Study (Leicester: Leicester University Press), 55-100.

Smith, A. (1795) Essays on Philosophical Subjects (London: T. Cadell \& W. Davies).

Smith, A. (1976a [1759]) A Theory of Moral Sentiments (ed.) D.D. Raphael and A.L. MacFie (Oxford: Clarendon Press).

Smith, A. (1976b [1776]) The Wealth of Nations (ed.) R.H. Campbell, A.S. Skinner, and W.B. Todd, 2 vols (Oxford: Clarendon Press).

Stow, D. (1833) Infant Training (Glasgow: William Collins).

Stow, D. (1850) The Training System of Education, Religious, Intellectual and Moral, as established in the Glasgow Normal Training Seminary (London: Longmans). 
Szreter, R. (1976) 'Adam Smith on education: a bicentennial note', History of Education Society Bulletin, 18, 2-5.

Thomas, K. (1978) Religion and the Decline of Magic: Studies in Popular Belief in Sixteenth-and Seventeenth-Century England (Harmondsworth, UK: Penguin).

Thompson, C.R. (ed.) (1978) Collected Works of Erasmus, vol. 24: Literary and Educational Writings, Part 2: De Copia/De Ratione Studii (Toronto: University of Toronto Press).

Thompson, E.P (1971) 'The moral economy of the English crowd in the eighteenth century', Past and Present, 50, 76-136.

Trimmer, S. (1973 [1805]) 'A comparative view of the new plan of education promulgated by Mr. J. Lancaster', in C.F. Kaestle, Joseph Lancaster and the Monitorial School Movement: A Documentary History, Classics in Education, no. 47 (New York: Teachers College Press), 100-8.

Tronchot, R. (1972) L'Enseignement mutuel en France de 1815-1833. Doctoral thesis, University of Paris (Nanterre).

Unwin, G. (1904) Industrial Organization in the Sixteenth and Seventeenth Centuries (Oxford: Clarendon Press).

Webster, C. (1975) The Great Instauration: Science, Medicine, and Reform, 1626-1660 (London: Duckworth).

Wilderspin, S. (1823) On the Importance of Educating the Infant Children of the Poor (London: Goyder).

Wood, J. (1828) Account of the Edinburgh Sessional School (Edinburgh: John Wardlaw). 


\title{
3 The lesson as a pedagogic text A case study of lesson designs
}

\author{
Agneta Linné
}

In order to understand why some educational phenomena appear as givens as natural, obvious or beyond doubt - while others are considered problematic, the analysis of their historical origins and social construction is essential (Popkewitz 1997). Thus, the 'persistence of the recitation' (Hoetker and Ahlbrand 1969) has attained the role of one of the givens of educational history, a 'technology' determined by the framing of the classroom and reproduced almost automatically or unintentionally as a result of the intrinsic qualities of the pedagogic situation. Figure 3.1 shows a classroom of this kind. However, if we presuppose that dominating forms of the pedagogical process take shape and develop - and maybe become redefined - in a social and educational context, which is part of a wider societal pattern, historical studies contribute to a richer understanding of the apparently invariable. This chapter focuses on how the 'lesson', or recitation, as pedagogic text was structured in the early periods of modern compulsory schooling in Sweden. However, the term 'recitation' covers diverse strands of pedagogical thinking (Hamilton 1989); what, then, was its alleged rationale and how can we contextualize its representations?

In the nineteenth century, a shift in classroom technology from monitoring to recitation was staged in several European countries (Hamilton 1989, Hopmann 1990). Westbury (1980) explored the idea that the link between educational goals and the recitation as a classroom technology could be found in an examination of the milieu in which the classroom came into being, and that the recitation was developed as an instructional method well adapted to the transmission of inert information from written texts to the 'minds' of groups of students. The development of ideas of how to structure a lesson and, thus, organize a classroom technology to enhance recitation were powerful steps towards creating the material circumstances that we know as the school - and of the process in which the curriculum was being transformed from an idea to an anchored tradition. My discussion touches upon the ways in which the process of institutionalization creates forms, procedures, and categories which later appear as givens.

The prime source materials for this essay are lesson plans produced by students at teacher training colleges in Sweden in the late-nineteenth and earlytwentieth centuries as part of their final teacher examination. My analysis 


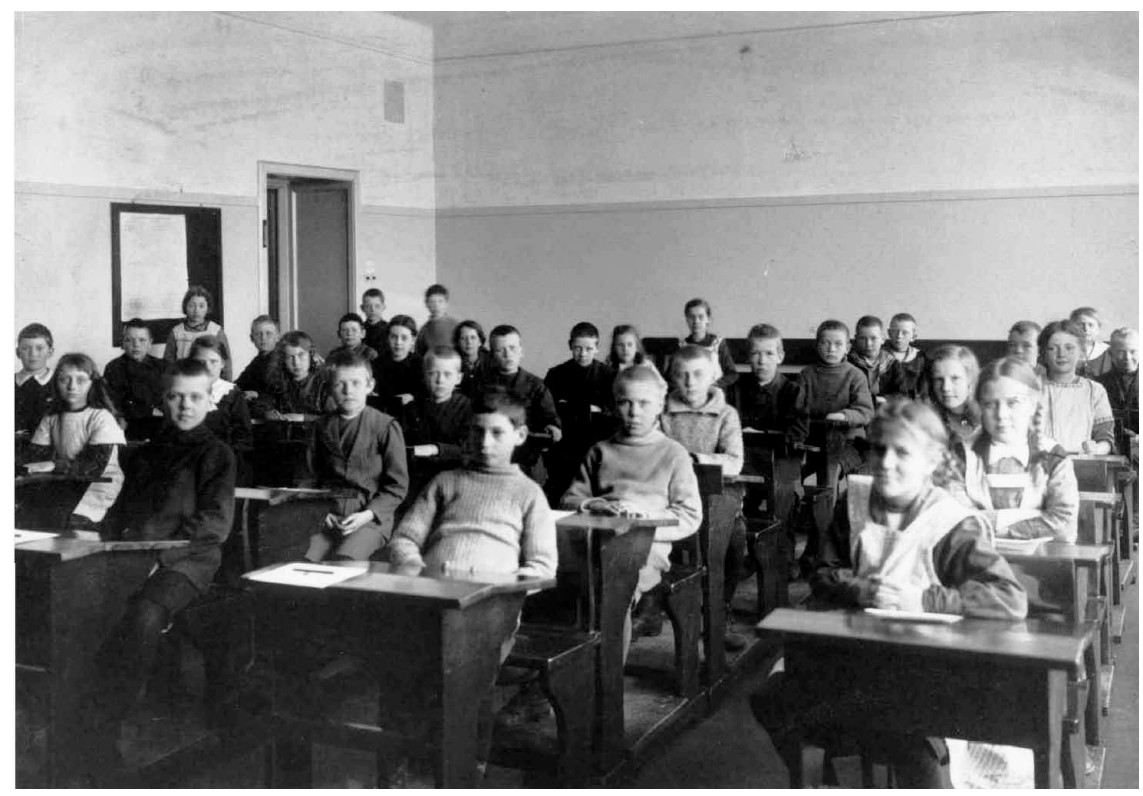

Figure 3.1 Classroom in the practising school of the teacher seminary at Uppsala, 1917/18. The photograph shows a 'modern' classroom of the 1910s. Photographer Julius Grape. From Folkskoleseminariets $i$ Uppsala arkiv [The archive of the teacher seminary at Uppsala], The Regional Archives at Uppsala.

focuses upon the structure of the lesson designs, the discursive pattern of the text, the narrative involved, and the message or moral reflected in the text. As I explore this material, I hope to contribute to the discussion on the formation of a classroom discourse at a time when mass education was being slowly established at a particular social and cultural institution, and when modern ideas concerning education and schooling were on their way to breakthrough. However, my purpose is not to trace the historical roots of what is known as the 'lesson', or to explore the origins of class teaching or grading. Instead, I inquire into the forms and content of a sample of texts representing normative classroom discourses between the 1860s and the second decade of the twentieth century. I use these texts in order to mirror, interpret and analyse some characteristic features of the lesson at that time, and I analyse the texts in relation to their contextual background.

It is important to note that, in Sweden, the change of classroom technology occurred comparatively late - in the decades following 1860 - and at the same time as the school was taking more permanent shape, and being formally regulated as a public institution for mass education. Parallel to this process, seminaries for teacher training were being consolidated, and received their first 
curriculum. As an introduction to this context, I will briefly outline the historical background.

\section{From monitoring to recitation: the Swedish background}

In common with several European countries, the monitorial method was strongly advocated by the founders of the common school in Sweden (Nordin 1973, Isling 1988, Hopmann 1990, Petterson 1992). ${ }^{1}$ And, in the first Swedish legislation on common schooling in 1842, the government stated that pupil teachers were obliged to master the monitorial method in order to be certified as a teacher. However, within a few years, this form of organization of a school was strongly challenged and, interestingly, it was its inadequate provision for moral development that the critics alluded to when they questioned the method.

Following the officially stated norm, the first public teacher training seminaries in Sweden exclusively taught the monitorial method of organizing a school. The method was even promoted by a special association receiving support from the King, The Association of Monitorial Instruction. However, after 1842, the method was challenged by more modern ways of organizing time and space. Influential teachers and school directors made study visits, e.g. to Prussia and Switzerland, where they met with representatives of a different classroom technology. They concluded that teaching ought to be based on personal contact between the teacher and those taught (Aquilonius 1942, Sörensen 1942) and a new Royal Statute of 1864 was to formalize simultaneous instruction as the approved practice. ${ }^{2}$

This presented a great challenge to teacher training. Within the monitorial method, the teacher mainly supervised the monitors and questioned the pupils on their homework. Under the new simultaneous method, the teacher had to master not only the questioning of the pupils' homework, but also teaching the content of the course in advance of application and homework, explaining the meaning of the text, and preparing what the pupils were supposed to read at home. ${ }^{3}$ In addition, the teacher was to direct his or her questioning to the whole class - with everyone expected to listen to the responses of those who were being questioned (Rudenschöld 1856). A tradition slowly developed within which the lesson became structured in more explicit ways, and lesson planning and teaching became the most important activities in teaching practice - as compared to, for instance, the planning for the school day or the school week.

Why did this shift occur, insofar as Sweden was concerned, in such a comparatively short time (Hopmann 1990)? ${ }^{4}$ How should the transformation be seen, what did it signify and how should it be explained? Hamilton (1989) emphasizes the lack of understanding associated with the memorizing practices of the monitorial system, and notes that 'oral' place-taking methods were confounded by the fixed seats and writing desks that accompanied the entry of writing into the curriculum. Hopmann (1990) concludes that the method outlived itself - 
its success brought about its downfall: ${ }^{5}$ as more and more teachers received a more advanced education and/or became more competent, they became more and more dissatisfied with overcrowded schools in which they had to rely heavily on monitors. But, how was the shift materialized into practice?

In the Swedish parliament, the issue of school technology was debated alongside proposals to divide the common school into different departments, i.e. to separate out a minimum course for everyone, to be taught at 'minor schools' by teachers without formal training who were, therefore, cheaper. ${ }^{6}$ The parliamentary committee (Sabeu 1856-58: 21; my translation) $)^{7}$ used the following words in a report:

To bring together large crowds of children of different ages, from 7-15, in our now-existing permanent elementary schools, in cities as well as in the countryside, where often a single teacher is supposed to teach so markedly different pupils everything at the same time, together with keeping order, is an anomaly of the very gravest nature, something which is easily understood by everyone. During such a multifold activity, teaching energy must, to a large extent, be futilely wasted, and teaching, undertaken by hardly capable monitors, be of inferior quality, slow, and unsatisfactory.

Statements like this may be interpreted as tokens of a crisis of legitimacy regarding the old school technology. The elementary school was far from accepted by most parents; teachers who had even a minimum of education were few; and the number of students at the teacher seminaries was decreasing (Arcadius 1911, Aquilonius 1942, Sörensen 1942). And, step by step, eloquent proponents of a different way of ordering, classifying, and framing the context of instruction became more influential - emphasizing the shortcomings of the monitorial school when it came to touching the pupil's mind, and not just attaining a superficial memorization. ${ }^{8}$

The imposed shift of technology did not pass smoothly. However, in the late 1860s and onwards, as the state gradually came to exert a more powerful influence on elementary schooling by way of standardized plans for schools (see Figure 3.2), school inspection, reorganized teacher training, and the production of texts for pedagogy, various measures - not necessarily new as far as educational history is concerned - were advocated in order to enhance the new system.

Dividing the school into various departments was one device used to attain a new order of the school. In Stockholm, a model school was established as elementary schooling was reorganized, beginning after 1861 (Spetze 1992). This model school was set up according to a curriculum plan, with a number of divisions or grades, each having its special content and yearly group of pupils. At a national meeting of inspectors of the elementary school in 1870 (Tidning för Folkskolan 1870: 181-208), a revealing debate took place; it concluded that a division of the children into grades appeared to allow for simultaneous instruction, and that the capability of the teacher was essential in this classification 


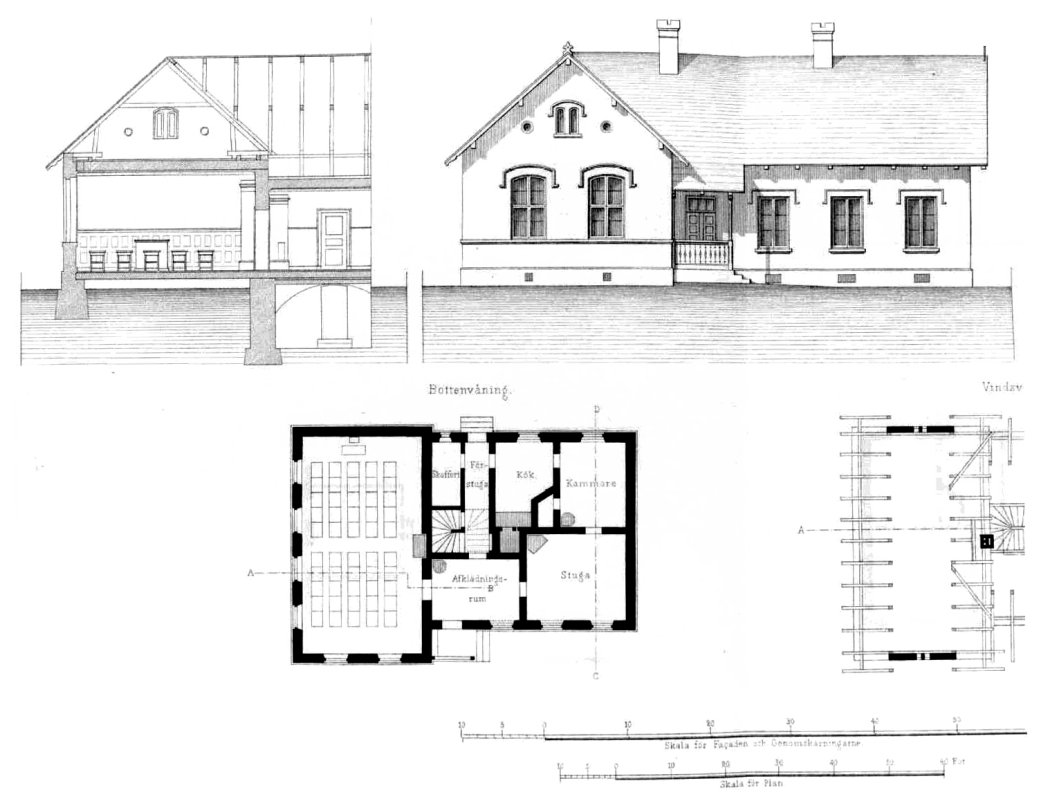

Figure 3.2 Sample design for a village school, 1865. We see the classroom, a room that separated indoors from outdoors for taking off outdoor clothes, and the teacher's lodgings, with a separate entrance, two rooms, kitchen, and pantry. From Normalritningar till folkskolebyggnader jemte beskrifning [Standard guidelines for elementary school buildings] (1865) (Stockholm: Öfverintendentsembetet), Uppsala University Library.

process. ${ }^{9}$ Seven years later, the meeting of school inspectors more explicitly recommended classification as far as grades and courses were concerned. A government committee was appointed and, in 1878, a general curriculum plan ('normalplan') was issued to that effect (Sörensen 1942).

Another device was the model lesson. In the early didactic handbooks, which were being published as simultaneous teaching was on its way to replace the older classroom technology, examples of model lessons were frequent, and exhaustive descriptions of recommended lesson designs were provided. ${ }^{10}$

The issue of the technology of 'transmission' was a critical point in the discursive field of teacher training. In an earlier study (Linné 1999), I have suggested that, as part of the process of creating greater order, the framing (Bernstein 1977, 1990) of the classroom discourse and the boundary-maintenance of contents were gradually changing. Time and space were classified and framed in new ways. The seminaries faced the task of developing a model by which an inexperienced teacher could cope with the situation of simultaneous instruction - meaning that a different but powerful structure for social control of the heterogeneity of the school had to be created. Transforming the lesson into a pedagogic text became part of the solution. The lesson took on a more 
structured, as well as a prescribed and repetitive form, reinforced by the examination system of the seminaries. There is a strong tendency in these lesson plans to assign to children the roles of more or less passive listeners and responders, while the teacher played the leading role, managing the heterogeneity of the classroom through the predetermined manuscript of recitation (Linné 1999).

The meticulously shaped lesson, in fact, appears to have become more pronounced as part of a practical theory of the times. In a situation when teacher training was being reorganized and restructured, and frame factors like time and money were scarce, exercises focusing on holding a lesson, or listening to model lessons conducted by seminary lecturers, were explicitly recommended, instead of practising how to keep a school going and how to teach all of the subjects across a school day. These exercises also served as a way of making clear the extent to which the seminary student had correctly comprehended the instructions, and was able to apply them in a proper way (Tidning för Folkskolan 1871: 155-6).

In his work on the development of the inner process of schooling, Isling (1988) has pointed out the importance of teacher education and its role in forming a long-lasting tradition around the work in the classroom. The goals of the late-nineteenth-century school became materialized into classroom processes, and assumed the shape of material necessities. Isling (1988) suggests that goals and processes of the early schooling can be reconstructed more readily from various teaching manuals or handbooks than from legal statutes and formal curricula. His study focuses on the nineteenth and early years of the twentieth centuries.

In an earlier study, Kaleen (1979) analysed nineteenth-century handbooks and guidelines, as well as collections of lesson plans prepared by seminary students as part of their practicum. He gives numerous examples of early practicum lessons and of the model lessons presented in teaching manuals, in which the exact phrasing of the teachers' talk (i.e. orientations, questions, requests) as well as the children's talk (i.e. answers) are written out in full. The lesson plans or model lessons that are presented by both Isling and Kaleen can be characterized by their formalism, their extremely detailed interrogations, and their meticulous reproduction of short, restricted texts, like a passage of the catechism or the Reader.

The period covered by my study of lesson plans was also a time of great challenge and societal transformation. Profound changes in technical and industrial development, urbanization, power relations and ideas were taking place. At the beginning of the twentieth century, the child made its way into the public scene (Karier 1986, Kliebard 1987). The idea of progress linked a redemption project to a quest for rational change (Popkewitz 1996). A new curriculum was being formed and advocated: more of the Bible itself in place of the catechism; more reading of fiction and studies of the history of literature; a greater space for mathematics, biology, and nature study; the introduction of modern psychology; and more independent study and inquiry methods. The teacher's personality was emphasized as the very core 'instrument' for fulfilling the essential 


\section{Agneta Linné}

goals of the elementary school. However, the tradition of preparing lesson plans continued. ${ }^{11}$

\section{Teacher education and lessons, 1868-1914}

As mentioned, this chapter is based upon filed lesson plans prepared by students at teacher seminaries in Sweden in the late-nineteenth and early-twentieth centuries, mainly as part of their final teacher examination. The legal statute regulating seminary instruction between 1865 and 1885 stipulated that examinees had to present a lesson plan on the teaching of a passage bearing on religious instruction, another lesson plan on the teaching of the Swedish language, and an essay on a subject that was part of the course curriculum of the seminary. The curriculum for the period 1886-1914 stipulated that the final examination must contain an essay on a subject from the course curriculum of the seminary, an essay on the method of instruction of religion, and an essay on the method of instruction of another school subject. These essays on method, however, were often presented in the form of lesson plans.

The drafts I examined come from files of two teacher seminaries - the seminary at Uppsala, at the time an institution for male students only, and the seminary at Falun, then only open to female students. The main material covers the period from 1868 to 1914; however, there are some gaps owing to incomplete filing. ${ }^{12}$ A total of 447 original lesson plans originating from final examinations were analysed. In addition, 77 drafts from practicum lessons were available; these are all from Uppsala and cover the period 1918-26 (see Table 3.1). ${ }^{13}$

The material is rich, the handwriting is meticulous as well as exquisite, and the texts bear evidence of many drafts before the final version - a version of great importance for the future career of the examinee. The lesson plans from 1865-85 mainly focus on passages from the catechism, from a book of biblical stories or the Bible, or from one of the readers for the elementary school. ${ }^{14}$ The plans from the later period also include lessons in other areas such as history, geography, and nature study. This development, and the change in examination regulations, reflect a greater emphasis on school subjects other than religion and the reading, writing, and arithmetic taught at the elementary school. I analysed the lesson plans in terms of their overall structure, their discursive pattern, the narrative involved, and their message or moral.

Table 3.1 Overview of lesson plans

\begin{tabular}{llllllll}
\hline & $1868-9$ & $1870-9$ & $1880-9$ & $1890-9$ & $1900-9$ & $1910-14$ & Total \\
\hline $\begin{array}{l}\text { Male seminary } \\
\text { (Uppsala) }\end{array}$ & 6 & 83 & 29 & 35 & & 102 & 255 \\
$\begin{array}{l}\text { Female seminary } \\
\text { (Falun) }\end{array}$ & & & & & 67 & 125 & 192 \\
\hline
\end{tabular}


A lesson plan is not a real lesson. It is, however, one way of getting close to the normative idea of what was expected to take place in the actual teaching process. ${ }^{15}$ The lesson plans make obvious several distinctive characteristics of the period: we see the lesson as a separate, delimited entity, put in focus in a pronounced and dominating way; we see the lesson being converted into text, into a representation of a real course of events.

\section{The local context of the lesson plans: the teacher seminary}

In the Swedish teacher seminaries of the 1840 to the 1870 s, restriction of knowledge was the norm. A teacher of the common school was not supposed to carry a burden of knowledge heavier than necessary, which meant the core curriculum of the elementary school together with substantial knowledge of the catechism and of biblical history. There were few libraries and textbooks, and the catechism, biblical stories, and the Reader were the central texts. Teaching the method of instruction was the major concern of the seminary (Linné 1999). Seminary instruction was supposed to be based on the principle of teaching by object-lessons. To 'behold the world' had become an important part of the principles of transmission. ${ }^{16}$

The teacher seminaries of 1860-70 were forcefully criticized by the liberal circles of the times because of their alleged formalism, their teaching of religion according to an extraordinarily literal tradition, and their profoundly authoritarian relations between teachers and students (Sörensen 1942, Richardson 1963, Kaleen 1979, Isling 1988). However, teacher training was not uniform. In several teachers' recollections, and in the early works on the history of teacher training (Arcadius 1911, Hall and Liander 1936), as well as in modern studies (Askling and Holm 1985, Elgqvist-Saltzman 1994), it is made obvious that the ethos of the female teacher seminaries deviated from the dominating picture. Overall, the female students carried a higher cultural and social capital than the male students (Gustafsson 1911). ${ }^{17}$

The teacher seminaries were situated in a particular historical context. Thus, they were part of the governing mechanisms being institutionalized in the society as the state, step by step, became increasingly powerful in establishing and controlling mass education (Englund 1986, Florin 1987, Torstendahl 1991, Linné 1996, 1999). Seminary directors and faculties became members of an influential generation of state officials: following a strategy in which the provinces and the capital became linked into a common, and gradually tighter and tighter, network, this generation would cautiously, although in a very significant way, contribute to the reform of Swedish society (Liedman 1991).

At the beginning of the twentieth century, a new generation of teacher educators made their way on to the scene, carrying a capital of academic studies and, sometimes, even ideas of pragmatism and social engineering. Anna Sörensen, who, in 1906, was appointed as a teacher educator at the seminary at Falun, was one of this new generation. Between 1908 and 1912, 
she examined the subjects of pedagogics and geometry (1908), history and church history (1909), history and mother tongue (1910), and history, mother tongue and pedagogics (1910-12). ${ }^{18}$ Later, she became a distinguished writer in the didactical field of religion and a co-editor of a series of volumes on methods of instruction (Nordlund et al. 1924-9) which reflected the new curriculum code of modernity. ${ }^{19}$ In 1919, she was appointed director of the Stockholm Teacher Seminary, a unique achievement for a woman at the time. ${ }^{20}$

Another distinguished representative of the teacher seminary at Falun was Valborg Olander, close friend of Selma Lagerlöf, the writer and Nobel prize winner, and an important renewer of the didactics of literature and the mother tongue. She examined the subjects of the mother tongue, geometry and nature study in 1904-5, geometry and nature study in 1906, and nature study and mother tongue in 1908-9. ${ }^{21}$

While Anna Sörensen may be considered a representative of a new approach to religion and didactics, Wilhelm Norlén, director of the teacher seminary at Uppsala from 1866 to 1896 and a teacher of religion and pedagogics, represents an older tradition (Lundgren 1899). ${ }^{22} \mathrm{He}$ was the author of a widely used handbook on the teaching of religion in the elementary school (Norlén 1884), as well as a textbook of biblical history for the elementary school (Norlén and Lundgren 1885). He was a strong advocate of simultaneous teaching in the way stipulated in the 1864 Act.

\section{Overall structure of the lesson plans}

Let me introduce the content of the empirical source material. The recurrent structure of the lesson is as follows. There is almost always an introduction, in which the teacher in a few words tries to establish a link to something earlier. Thus, a draft on the catechism passage 'Why should we pray?' (Falun 1904) begins, 'Earlier we have talked about the prayer; maybe we wonder why we should speak to God in this way. Therefore we will now think about why we should pray.'

Following the introduction, the text is presented and explained; the teacher's statements or questions are followed by the children's answers, and, in the early lesson plans, questions and responses are quite close to the original text - the passage from the catechism, the biblical story, or the text from the Reader. The children may be asked to give an example, although a certain answer is anticipated, as in this draft (Falun 1904) of a lesson on a passage of the catechism: 'Give an example of something for which we need to pray to God? If we, for example, did not pray for the forgiveness of sins, would God be able to give us this gift of grace?'.

The text is interspersed by reading - catechism passages, Bible verses, and texts from the Reader - and then the children are carefully interrogated on the content of the reading. In the case of a passage from the Reader, a section follows in which the teacher explains or interrogates the children 
on some linguistic problems of the text. Finally, the teacher concludes with some kind of 'application' - a moral address that translates the religious text into a message supposedly relevant to the lives of the pupils, a summary of the earlier parts of the lesson, or by simply giving the children the text as their homework. It is noteworthy that the lessons frequently conclude with a writing exercise.

As is evident from the examples below, the overall structure or disposition of the lessons, as presented by way of introduction, is generally quite brief; however, it is always followed by a full text 'manuscript' in which the teacher's talk - and sometimes even the children's answers - is represented. In other words, not only a disposition or plan was written down in advance, but the whole course of the lesson. ${ }^{23}$

Some typical examples of lesson designs on religion are presented below:

\section{Draft of a lesson on religion: the second prayer}

\section{OUTLINE:}

1 Introduction.

2 The children read the homework, i.e. Luther's explanation of this prayer.

3 The homework is interrogated. Prayer.

(Uppsala 1874; my translation ${ }^{24}$ )

In a lesson plan (Uppsala 1876) on the second prayer, two years later, the third part of the lesson (the 'interrogation') is replaced by an 'introduction to the content'.

\section{Draft of a lesson on a biblical story}

OUTLINE:

1 Introduction.

2 The teacher's narrative.

3 The catechization (i.e. a meticulous interrogation).

(Uppsala 1879)

\section{Draft of a lesson on a catechism passage}

\section{OUTLINE:}

1 Introduction.

2 The Bible verses are read by the teacher, then by the children; meanwhile, in conversation with the children, the teacher explains each verse separately together with the words of the passage.

3 The catechism passage, including Bible verses, is interrogated.

4 The children are given the passage and the Bible verses as homework. 
Draft of a lesson on a passage of the Bible

OUTLINE:

1 Introduction.

2 The text is read by the teacher.

3 (a) Every verse is read by the children, and

(b) interrogated, explained, and applied by the teacher.

4 The text is read by the children.

(Falun 1906)

Not infrequently, the type of plan represented above ends with a fifth part: The text is given as homework.

The following is an early example of a somewhat different outline, representing a lesson on the catechism. This outline anticipates a later, more 'modern' approach:

\section{Draft of a lesson on a passage of the catechism}

OUTLINE:

The catechism passage is formed through conversation with the children on the basis of the Bible verses. Eventually, the children read the passage and the Bible verses according to headings.

(Falun 1906)

A typical structure of a lesson plan on a nonreligious subject is as follows:

\section{Draft of a lesson on a passage of the Reader}

OUTLINE:

1 Introduction.

2 The teacher's exemplary reading.

3 Interrogating the content together with explanations.

4 The children read.

5 Linguistic treatment [of the passage].

6 Dealing with the passage in writing.

(Swedish, Uppsala 1870)

Overwhelmingly, the older outlines focus on the technicalities of the lesson and a similar structure is reproduced, almost totally independent of its content. Some outlines, however, represent a more general approach than the examples above, although they still focus upon technicalities:

\section{Draft of a lesson on history}

OUTLINE:

1 Through questions, the subject of the lesson is placed in its historical context. 
2 The teacher narrates, and while doing this adds some questions to bring along the children and hear if they have understood the narrative.

3 Summarizing questions.

4 Reading the homework in the books.

(Falun 1908)

The dominating guidelines, as well as the textbooks on methods, make the structure for the lesson explicit, and confer on it legitimizing cognitive ideas in terms of the model of 'inner beholding' or visualization. The stage-like structure of the earlier lesson plans resembles simplified versions of the Herbartians' formal stages, but obviously has older roots. ${ }^{25}$ Norlén (1884), for instance, divides the lesson on a catechism passage into 'Introduction', 'Explanation and learning the passage and its Bible verses', and 'Application of the truths of the passage'. In the next lesson, the pupils' oral recapitulations of the passage follow - meaning, to a large extent, the literal memorization of the words of the catechism, reading the Bible verses in their exact wordings, and being able to give the correct answers to the teacher's interrogation. A lesson on a passage of the Bible is structured into 'Introduction', 'Reading', 'Explanation', and 'Conclusion and application of the Bible paragraph', whereas a lesson on biblical history contains 'Introduction and narrative', 'Explanation', and 'Conclusion and application', and is followed by the pupils' oral recapitulation of the biblical story in the next lesson, after reading it at home. Norlén emphasizes that the explanation should be given not by lecturing, but by interrogation, and he highlights narrating and explaining the biblical stories as devices to create clear perceptions (Norlén 1884: 30; my translation):

Teaching becomes perspicuous, not only through displaying external objects, but also through such a narrative, description, representation, or through such a process that overall the phenomenon (the event, the doctrine) appears lifelike to the pupil and inside him may become an inner representation.

A later handbook of elementary school pedagogy (Arcadius 1903), however, presents the ideal progress of instruction by the elements of 'Preparation', 'Representation', 'Association and comparison', 'Recapitulation into concepts', and 'Application and practising'; Arcadius explicitly refers to the Herbartians. ${ }^{26}$

Towards the end of the period, i.e. 1900-14, examples of outlines representing another logic are found - the logic of the content. Apparently, the prospects of this logic were facilitated as the themes of the essays came to represent subjects other than religion or Swedish-language studies. An example:

\section{The centre of gravity of bodies}

OUTLINE:

1 What we mean by centre of gravity of bodies.

2 What is required in order for a body to be in equilibrium. 
3 What is required in order for a body to be in secure equilibrium:

(a) large area of support; and

(b) the centre of gravity should be located low down.

(from the draft of a lesson on physics, Falun 1908)

Examples that might even anticipate the pragmatic 'turn' of the early-twentieth century occur:

\section{The bepatica}

Here you will get one hepatica each. Now, at the very first, look at its root!

- What observations have you made about it? What are roots like these called?...

(from the draft of a lesson on nature study, Falun 1911)

Examples of lesson plans (Falun 1908) from the subject of Swedish-language study (grammar) may contain just (1) 'Examples', and (2) 'Rules', which are induced out of the examples; to this is added some material for teaching by object lessons.

Other lesson plans explicitly focus on the use of material for teaching by object lessons. Instead of giving an overall structure of the lesson, material for teaching by object lessons is presented by way of introduction:

\section{The common swallow}

Material for teaching by object lessons:

1 One stuffed common swallow;

2 One stuffed house sparrow;

3 One swallow's nest;

4 One chart of the common swallow; and

5 One enlarged drawing of the foot of the common swallow.

(from the draft of a lesson on nature study, Falun 1908)

\section{Discursive pattern}

The formation of classroom discourse, as historically and socially constructed, is reflected in the lesson plans. Both what is said and the rules of how it is said the discursive rules - contribute to the creation of the meaning of the text. The classroom may be read as a scene with a stage and prominent and less prominent actors. ${ }^{27}$ The teacher's desk is situated above and in front of all the children. The teacher is the director and also takes the leading role, while the children appear as an abstract collection of silent voices. In these lesson plans, no examples are given of children misunderstanding the original question or delivering contradictory answers - and what the teacher does then. The focus is on teaching, not learning. The children are spoken to; they are not participants 
in a conversation. The pattern of recitation permeates the drafts. Figure 3.3 shows a classroom in a city elementary school of the 1890 s which reflects this scene.

The ritual of reading of text overwhelmingly characterizes the rules of this classroom discourse. The text is read by the teacher, then by one or all of the children, then divided into pieces and read again, and so forth. Reading out loud in the classroom, so that everyone can hear and the teacher can correct possible mistakes, is a core part of this ritual. However, the interrogation is also developed to emphasize the understanding of the text, not memorization alone. ${ }^{28}$ The solemnity of silence is also pointed to as a contrast to the teacher's questions or narrative and the pupils' answers (Rudenschöld 1856). ${ }^{29}$ The text becomes, in a sense, the unifying device within the lesson and is, as such, consecrated as the focus of the lesson and the symbol of the proper ethos of the classroom.

In the early part of our time period, examples of a closed, detailed interrogation dominate:

\section{The migratory birds}

Which birds are spoken about in this passage? - This passage tells about migratory birds. Which birds are called migratory birds? - Migratory birds are birds which... . Mention some migratory birds? In the two first lines of

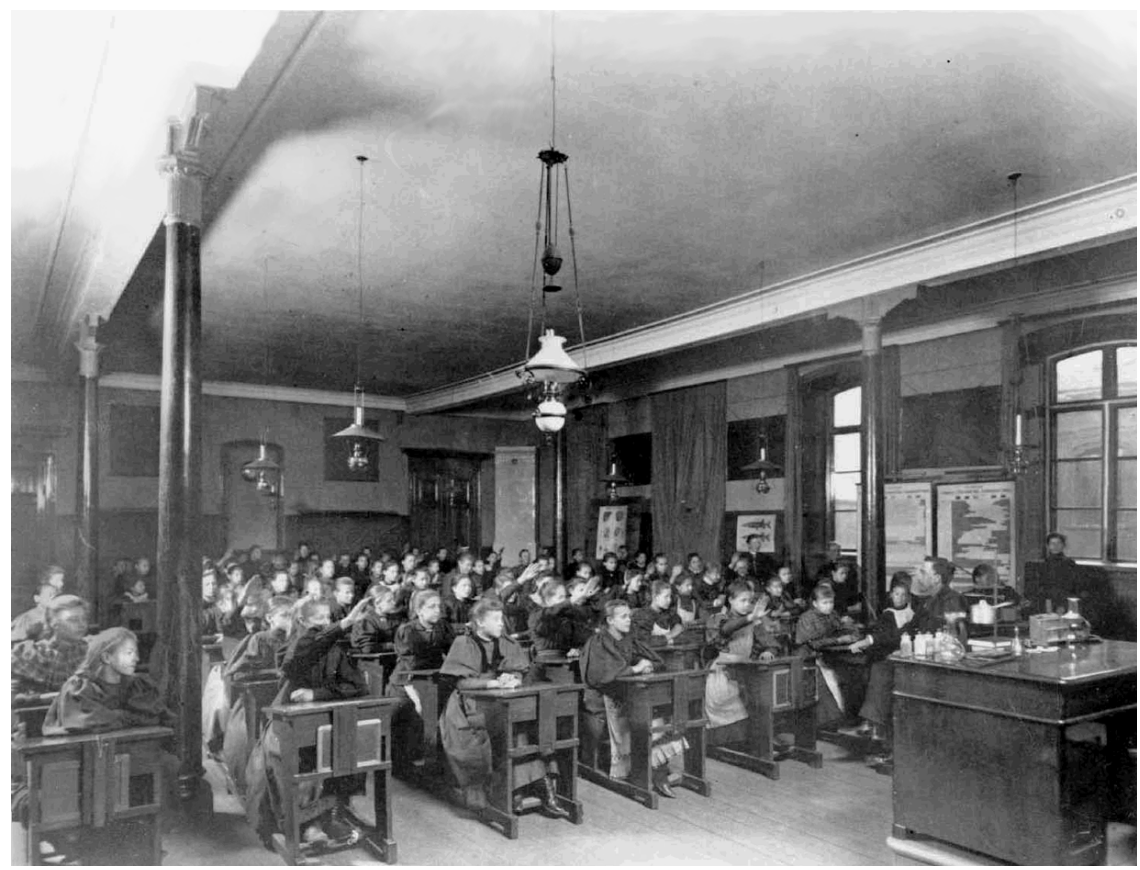

Figure 3.3 Classroom, Klara elementary school, Stockholm, around 1895. Photographer unknown, Stockholm City Museum. 
the first verse, we see the reason why they do not want to remain in the warm countries of the South, and what is said about that? .. .

(from the draft of a lesson on a passage from the Reader containing a poem by a well-known writer, Uppsala 1874)

This painstaking interrogation technique is used for verse after verse!

\section{The eider}

... What do we think the eider should do so that the roaring of the sea would not disturb him in his rest? (Live a long way away from the sea.) But he does not, because what does he think of the roaring of the sea? (Like a song). On a stone slab beside the roaring wave the eider prepares his bed, and out of what? (Seaweed) Seaweed is a sea plant that is thrown onto the shore in large quantities. What did we say seaweed is? ...

(from the draft of a lesson on a passage from the Reader, Uppsala 1875)

As late as 1911, an occasional draft might contain suggested answers linked to the interrogation:

Teacher: How did God bless Abraham and Lot?

Answer: God blessed Abraham and Lot so that they became rich in cattle.

Teacher: How rich in cattle did Lot and Abraham become?

Answer: So rich that their herds could not graze together ...

(from the draft of a lesson on a biblical story, Uppsala 1911)

The catechism tradition cannot be ignored in any discussion of this interrogation technique (Isling 1988, Hamilton 1999). The culture of early Swedish popular education was characterized by a strong integration between learning the catechism and learning to read (Lindmark 1993). In Sweden's Lutheran tradition, the catechism had to be literally memorized and understood by every Christian; this was carefully controlled by the Church (Lindmark 1995, Johansson 1998) and the extent to which the catechism should be taught - memorized - at school was the subject of substantial debate in the decades around the turn of the twentieth century (Sörensen 1942). The catechism allowed no argument; the text was always in focus, and there was always one, and only one, correct answer. This Socratic catechetical tradition was reflected in the exemplar handbooks of German origin used or referred to by the dominating early seminary directors and faculties (e.g. Rambach 1849, Schütze 1865-6). This technology of question-and-answer, using the exact wording of the texts, is reproduced also in the teaching of non-religious school subjects.

Thus, a majority of the nineteenth-century drafts explicitly emphasize an understanding of the meaning of a passage as phrased in the exact wording of the text in question. Meticulous and true-to-the-text interrogations and explanations characterize the content inquiries and the linguistic treatments of a 
passage. But, there are also attempts to interpret an inner content and to synthesize the meaning of the text:

\section{The morning}

No time of the day is as refreshing and pleasant as the morning; nor are the other parts of the day characterized by so much bustling throng as the morning; because then all nature becomes on the move. This is also expressed by the poet Runeberg in his poem The Morning.... We imagine a man who goes out on a summer morning to behold nature; what are his eyes at first fixed upon? What does the sun do? Is this real or an image? ...

(from the draft of a lesson on a passage of the Reader, Uppsala 1870)

It may also be argued that the ritual reading and the painstaking interrogation anticipated a culture based upon the written word. ${ }^{30}$ A lesson preparing the children for writing a short essay (Uppsala 1883) can illustrate this. The theme is 'The oak'; the draft begins with an oral description of the tree, made up from questions and answers: 'All of you children know that the oak is a tree, and where does it most often grow? (In the forest). What kind of tree is the oak then, since she grows in the forest? (A forest tree)'. After this part of the lesson, the children were expected to recite each sentence and insert punctuation marks; later the children might read one sentence or another in chorus, then several individual children were told to represent orally the whole description, and eventually - the next hour - the description would be written down on paper by every child. The teacher put down a disposition of the task on the blackboard: (1) what kind of a tree; (2) roots, trunk, branches, leaves and fruit; (3) usefulness; (4) great age.

A later example (Falun 1913), which was given high marks, ${ }^{31}$ uses the interrogation primarily for enhancing attention and reflection, and for visualizing the narrative, as well as for control. The theme of the lesson is 'The first big industry of Sweden', and the teacher amalgamates narration and questioning. Bringing the children along to an imagined journey in the vast woodlands of northern Sweden, the teacher tells a story of how the large forest companies set out to buy the farmers' land, and how they eventually built large-scale sawmills, making use of new technology:

The companies preferred to buy the forests alongside the rivers. Why? ... For what purpose would the companies use all those forests? Have any of you been at a sawmill? ... Why can't a single person set up a sawmill; he then would earn much more if he got the whole profit himself, wouldn't he?...

Drafts like these contain no ritual reading of a text; rather, the content of the story appears to govern the representation, and the interrogation technique is used as a tool to manage the recitation. 


\section{Agneta Linné}

\section{The narrative}

Almost all the drafts start with an Introduction, in which relations are established to a cognitive content the children supposedly have met earlier. It may be an earlier lesson, a passage of the catechism already known - or, particularly in the twentieth-century drafts, a vivid realization of a scene or a familiar situation narrated by the teacher. Typically, a narrative is created in which a world of representations is introduced by creating a relation to something well known, from which the text is then developed.

Some examples:

Now, when it is summer and green, wouldn't it be nice to make an excursion? Today we shall be able to make such an excursion far, far away, so far, that we can only travel there by thought. You see, we will go to the province that is situated as far north as possible in our country and which borders on Norway. What province is that? .. .

(from the draft of a lesson on geography, Falun 1910)

When you go to church on Sundays, surely you are there from the very beginning of the service. Then you know how the congregation begins its service. How? Well, you want to collect your thoughts through singing a hymn. While the hymn is sung, the pastor approaches the altar, as you know. Then the singing stops and it becomes so silent and quiet in the church. Then, when the pastor begins to speak to the congregation, at first he utters some solemn words which so to say affects your soul and makes you full of reverential worship. Those words go like this: 'Holy, holy, holy the Lord of Sabaoth! All the earth is full of his glory'...

(from the plan for a lesson on religion, Falun 1910)

The recitation then continues with a story of how the Lord summoned the prophet Isaiah, the actual theme of the lesson plan.

Later, explicit recommendations would be made to allow more room for the children's narratives:

At the preparation [of the homework], do not follow the textbook so exactly! You may assume that the children know something about the homework to come. They should be given the opportunity of narrating by themselves. (They have probably heard a great deal at home about strikes and the like.)

(from the lecturer's comments on a draft of a practicum lesson on history,

Uppsala 1918-19)

The narrative seems to have been an instrument well adapted to teaching - and learning - a world of representations. Thus, in having children conceive the essence of the moral of Christian faith through the medium of biblical history, narrative was deliberately used (Norlén 1884). The narrative was explicitly rec- 
ommended in the new curriculum plan ('normalplan') for the elementary school of 1878, and the teachers' capability in handling this 'new' technology was included in the inspectors' evaluations (Mellberg 1996).

In a world becoming more and more invisible to the children, but at the same time a world that must be known - and about which children should have an idea - the narrative became a new device. The teacher's problem was one of representation - a problem of making up for the real world, of making the children imagine what the text was going to be about. The narrative made possible a journey conceived only in thought. A symbolic world was created, a world in which the children were able to make some general judgements from the texts in the Reader or the catechism. The teacher was given a tool to escort the children into a world that was more abstract than their daily lives on farms and in poor urban neighbourhoods. Through the narrative, the teacher was able to create a representation of the world outside, to give the children ideas and conceptions of the ancient world, of the mentality of biblical stories, of distant parts of their own country, of its 'glorious' history, or of the moral aspects of the industrial revolution.

\section{Message and morality}

A technology of the classroom was developed parallel to the formation of the morality - or mentality - of the teacher. The lesson plans I examined are thoroughly impregnated with the ethos of the seminary: biblical faith, the glory of God and His creation, and an urge to make the children of the elementary school understand and confess the true word of Christian belief.

The way the examinees handled the narrative and the technology of question and answer, as demonstrated in the lesson plans, discloses their convictions regarding right or wrong, their worldviews, and their ideas of how to translate the morals of the biblical stories into the contemporary lives of the children in the common school. The lessons were a means by which the teacher professed his or her Christian sincerity and devotion to work (Popkewitz 1996). The narratives created in the texts clearly reflect the dominant themes of the curriculum code and the mentality of the actual period.

The introductory and application parts of the lesson plans strongly reflect the ethos of the seminary:

\section{The fisherman}

From this fisherman we have much to learn, children. We see that, although he was of humble origin and rather poor, he did not grumble and complain, but was always happy and content. And why do thou think, children, that he always could feel happy? He could always feel happy because the Lord was with him, wherever he was. Yes, if thou children always have the Lord as your comfort, then your lives will never feel heavy and hard.

(from the draft of a lesson on a passage of the Reader, Uppsala 1871) 
I wanted so much that we all really could impress this glorious verse in our hearts, so that we always would apprehend, how deterrent the rewards of sin are, but at the same time feel that the gift of God's immense love is enough and is intended even for us.

(from the draft of a lesson on a passage of the Bible, Falun 1911)

Nevertheless, as ideas of the individual becoming competent citizens, able to make their own decisions, became more widespread, the moral development of the child, and the development of their inner person, came to be an essential part of the curriculum. Teaching also had to confront, or at least relate to, social injustice and the living conditions of the working class, to phenomena like strikes and lockouts, to starvation and iniquity. Some attempts to touch upon controversial themes such as these are found in the lesson narratives. ${ }^{32}$

\section{Discourse, narrative, mentality: an example representing the curriculum of modernity}

A few of the drafts are small masterpieces, as far as the narrative and the moral are concerned. An interesting and somewhat atypical draft was produced at Falun in 1910 under the heading "Plan for a lesson on the passage "Saturday evening" in the Reader'. The passage focuses on a poem by the Swedish writer, August Strindberg, still alive at the time, and was illustrated by a portrait painted by Richard Bergh, a well-known 'modern' artist representing the new national romantic style. ${ }^{33}$

The plan or outline of the lesson goes as follows: introduction; something on Strindberg's life and authorship; movement to and dealing with the passage; the passage is first read by the teacher, then by the children (the passage is retold). It seems obvious that the lesson was meant to take place at grade 3 or 4 of the elementary school.

The draft starts by drawing the children's attention to the portrait:

Read what it says under the portrait! You have recently read about the artist who painted it in the magazine Sveriges Var [Spring of Sweden], which most of you have. Tell us something about what was said there about Richard Bergh?

The teacher continues by asking the children to focus on the actual portrait:

If you look very carefully at the picture and focus on the eyes and the forehead, what do you think the portrait may tell us about August Strindberg? Don't you think there is something bold and ruthless over the whole face?

After this introduction, the teacher pictures the writer's life and authorship. The teacher emphasizes his realism as different to earlier writers who would rather have written about what was beautiful; whereas other authors like to paint the 
world as better than it is, Strindberg never shuns the ugly when he considers the ugly picture true. They also point to his national historical writing and conclude: 'And then, he can also write fairy tales, beautiful tales, and curious tales about people and flowers and animals'. The teacher characterizes Strindberg as a true Swedish writer, who writes poetry about the land he sees outside his cottage, in contrast to authors who prefer to write about strange things, often from foreign countries, using 'the most gaudy words and phrases'. Strindberg, the teacher says, writes about the sea, about the garden in which the children have played, about the forests where the flight of woodcocks moves on:

In his poem, Strindberg uses no gaudy, ornate words; he tells us everything straightforwardly, just as he sees it. But, the remarkable thing is that you can really see before you what he has talked about when you have read the piece. Behold that in this poem!

Then the ritual readings of the passage follow, first by the teacher, then by the children - one verse each; unusual or difficult words and expressions are explained, and, finally, one pupil - a good reader - is given the task of reading the whole piece. The teacher concludes:

What kind of an atmosphere is there in these lyrics? Who would like to describe in their own words the picture that Strindberg has painted in this poem?

This draft reflects the idea of Strindberg as a genuinely national writer - he captures nature just as it is; he uses no high-flown phrases; he does not write about what is strange and foreign; he tells the truth, although it may be ugly. The Nation, Swedish nature, truth, simplicity, and sincerity are crucial elements of an inherent ethos or mentality. But, the text also reflects sensitivity to a lyrical atmosphere as well as attempts to explain an individual character and to attribute expressions of personality to a portrait.

In a modest way, this young seminary examinee not only managed to capture and represent a literary movement and style as compared to the earlier dominant school of thought, but also to express some themes of the 'modern' curriculum to be implemented in the 1910s and onwards. ${ }^{34}$ Not only the content, but the address, is different - personal and reflecting an intimate voice, although talking to the whole class. The stereotyped recitations, containing words and phrases directly repeated from the textbook, are less frequent. This voice addresses the inner minds of the children. A portrait no longer merely reproduces a face; it mediates expressions and feelings representing the idea of a patriotic writer - and this is made part of the teacher-pupil dialogue. The symbolic construction of an individual is reflected in the discourse. ${ }^{35}$ 


\section{The lesson, the text and the classroom discourse: towards a culture of symbolic representations}

On the basis of a case study of lesson designs, I have presented some reflections on the classroom processes and the classroom technologies in the decades following the shift from monitorial to simultaneous instruction. I have focused on the character of the lesson as a pedagogic text, formed by the pattern of recitation. The strong emphasis on the structure of the lesson reflects a great need for controlling the heterogeneous classroom context in the shift from one technology to another - and in the light of a growing and more formalized mass education. But, the discursive pattern also reflects a cognitive theory enhancing how to evoke the 'right' idea or perception by the 'right' phrasing of a question. A narrative is articulated, in which a world of representations takes shape in the classroom and in which a mentality of modernity is mediated through the symbolic meaning of the text.

It may be argued that in this process the options open to teachers and pupils regarding classroom content and the boundary maintenance between contents changed when compared with the earlier period that was dominated by the monitorial technology. A technical approach to knowledge was replaced by a more didactical perspective, and a focus on simple replication was developed into a focus on subject matter, framed by school subjects. This process of altered framing and classification (Bernstein 1977, 1990) took place parallel to - or as a consequence of - societal and cultural demands which allowed a greater variation in classroom technology, and prepared the teacher for a new, self-governing role in the new school of modernity (Popkewitz 1996).

The monitorial school displayed older traditions of oral communication, and literally memorizing the catechism rather than the tradition of being able to read and understand a new text. It may be argued that simultaneous instruction developed as the need for a more intrusive moral influence on the children's minds was emphasized. The new classroom technology may also be considered appropriate to a growing urge to teach the children more advanced writing (Hamilton 1989, Mellberg 1996); the ability to write longer sentences and whole passages was not generally included in the early 'literacy' of the common people of Sweden (Lindmark 1995, Johansson 1998). A society more and more based on written texts, a culture in which choices were to be made regarding one's life and one's profession, needed citizens who were able to express their thoughts in writing - not just able to write their name or correctly spell single words.

Memorization may be a distinction which belongs to an oral tradition, whereas the cohesive narrative represents a culture on its way to rely heavily on written texts and symbolic representations. Literary memorization reflects the fact that in order to reproduce the catechism, proverbs, etc. orally, it was necessary to memorize them word by word, by heart (Ong 1982, Mellberg 1996). Clearly, this represents a restriction of thought and shape, while the capacity of advanced writing implies a wider range of possible outcomes and opens the text 
to a variety of mediations. The formation of a more elaborate framing and classification of the classroom was staged parallel to the increasing complexities of the symbolic representations being mediated according to the school curriculum.

What was to be learned, and how this was best done, had begun to be a pedagogical problem that derived from a new concern to educate citizens, not only particular social groups (Lundgren 1983a, b, 1991). When answers to those questions were no longer inherent in the situation, or the context for production, when the curriculum problems of selection and organization of knowledge and its transmission had to be subject to choice and decision, the curriculum had to be abstracted from its immediate context and transmitted through the medium of the pedagogic text. The lesson plans exemplify that, in this process, the pedagogic text was on its way to a change in its character - from one of the simple reproduction and memorization of sentences or passages word by word, into a vivid narrative, creating a new world for the children - a world, however, that was constructed out of recognizable traces of nature, faith, the nation, and the biblical stories.

This inquiry into the territory of lesson plans also demonstrates that a school technology once advocated in order to enhance the teacher's control of all the pupils in the classroom, and at the same time influence the minds, thoughts, and morals of the children, appears to have become an excellent instrument in the creation of a school for social integration and social cohesion, a school for symbolic representation, and a school for meaning-making in a rapidly changing world. Historical studies may well contribute to the understanding of classroom communication in its social and historical contextualization, in its contingency and, hence, also carry the possibility of question, debate and ultimately transformation of the patterns of that communication. ${ }^{36}$

Traditions may turn into frozen ideology (Liedman 1997) or become part of our historical memory (Ödman 1995). The lesson as a pedagogic text - integrated with grading and the division of school subjects - is clearly linked to the development of mass education for the children of the industrial revolution. Redefinitions of manuscript and meaning are being staged in the period of the inquiry. Replication of simple words or phrases in a previously given text, interspersed by closed interrogation techniques, are on their way to be replaced by an intimate, intrusive and personal voice: a voice interpreting a moral wisdom inherent in the world of biblical stories, or representing invisible sceneries of industrial work, the inherent rules of nature, or the glory of the nation, in a personal address to the children of modern society and modern schooling.

\section{Acknowledgements}

I am indebted to Stefan Hopmann, now of the University of Vienna, Austria, for his helpful comments on an earlier version of the chapter and to Ian Westbury for encouraging my further development of a pilot investigation that became this chapter. 


\section{Notes}

1 This appears to have been the case more because of the economy of the method than its alleged pedagogical or didactical advantages. In 1840, the committee responsible for preparing the parliamentary decision on common schooling in Sweden explicitly stated that, under the present circumstances, and because the monitorial system offered an opportunity to teach as many children as the schools could house, the committee would advocate the monitorial method (Linné 1996: 44-5).

2 For the complete text of the statute, see Författningar rörande folkundervisningen (1869).

3 For recollections and descriptions of monitorial schools, see Andersson et al. (1922) and Lindälv (1972).

4 In Sweden, for example, the monitorial method was prescribed by the government in 1842, and, in 1864, it was denounced in favour of recitation. However, this has to be understood in the light of a comparatively late formal regulation of common schooling.

5 In analysing the abrupt end of the twentieth-century progressive movement in the USA, Cremin (1961: 349) suggests, as one of seven reasons, that the movement became a victim of its own success.

6 Women were considered particularly suitable for this. A substantial number of women were employed as teachers of the elementary school in Stockholm as part of a deliberate policy, apparently, because of their capability as teachers (Wilmenius 1999).

7 Sabeu reflects the Swedish name of the committee report: Stats- samt Allmänna Besvärs- och Ekonomi-Utskottens betänkande.

8 Influential school directors, like A.N. Schmidt and H. Ekendahl, both seminary directors, made study visits to schools and seminars in Prussia, Belgium, France, England, or Denmark, where they encountered other forms of school organization (see Hopmann 1990 on the character of the methods of transmission in Prussia). Ekendahl became one of the critics of the monitorial method (Ekendahl 1851-2) and Schmidt made important modifications of the monitorial normal school at the Stockholm teacher seminary in order to enable the teacher at least to get into some contact with each child every day (Spetze 1992). Torsten Rudenschöld developed experimental schools in accord with the principles of recitation and was an important advocate of a stronger classification and framing of schooling (Richardson 1999). Anders Berg, an acknowledged clever teacher and critic of the monitorial normal school of Stockholm seminary, with its several hundred pupils being instructed in one large room, developed model schools organized in grades with a classroom technology based on more direct contact between teacher and pupil (Sörensen 1942).

9 The question was raised as to whether or not the children of each division of the elementary school should in fact be kept together in a permanent group or reading team and be instructed directly and simultaneously by the teacher herself, according to the stipulations of the 1864 Act. The meeting concluded that, whereas a school had been divided into certain divisions following special courses of study, the children of each division usually comprised only one study group. However, whereas the school programme was not classified into grades, the children were usually allocated into one group of abler children and various numbers of other study groups. In the former case, the number of groups became limited enough to allow simultaneous instruction, although in the latter instances this was not always the case. According to the report, it had proved common to divide the school into two larger divisions, each consisting of two or more study groups. Whether or not a well-functioning division into grades was the case had proved to be almost completely due to the teacher's capability.

10 Anjou et al. (1868-9) was one of the most widely disseminated handbooks. The 
structure advocated for a lesson on biblical history in this handbook, for instance, consists of the teacher's preparation, acquisition of the content, preparation of homework, and recapitulation. An example from the study of Swedish, i.e. the mother tongue, or, more precisely, a lesson on a passage of a reader, demonstrates the detailed character of preparation and inquiry. The title of the passage is 'The grateful lion' (a fable). The recommendations go like this:

- the children read the passage as a whole;

- the teacher makes a short introduction, emphasizing the moral of the fable;

- the teacher recapitulates the main idea of the first paragraph of the passage (namely, points out what the first part of the fable suggests);

- the same first paragraph is interrogated and explained;

- the teacher recapitulates the main idea of the subsequent paragraph of the fable;

- interrogation and explanation of this same part;

- the teacher recapitulates the main idea of the next paragraph of the fable;

- interrogation and explanation;

- the teacher recapitulates the main idea of the last part of the fable;

- interrogation and explanation;

- four model questions are written out in full;

- repeated reading of the fable; and

- the children recapitulate the fable.

These elaborated recommendations concern a text - the fable in this Reader version comprising no more than 21 short lines, divided into four short paragraphs. Anjou was director of the teacher seminary at Linköping and heavily influenced by Prussian ideas concerning teacher training, methods of transmission, and evangelical pedagogy (Isling 1988, Hartman 1995, Linné 1996).

11 In a study of the Kalmar teacher seminary between 1925 and 1929 (Askling and Holm 1985: 95-102), based on recollections of former students at the seminary, lesson plans containing every word that was to be said in class were reported to be common in the subject religion; in other subjects, the character of the lesson plans could vary.

12 The majority of the drafts originate from the final examination at the end of the three (until 1877) or four years of studies to qualify for certification as a teacher of elementary schools. The varying numbers over the years may partly be explained by the fact that some of the students chose other available themes for their examination essays.

13 The Uppsala examination material covers the years 1868-97 and 1910-13, and the Falun material the years 1904-14. Throughout the chapter, the source material is referred to as 'Falun' or 'Uppsala' with the year. The drafts are archived in: The Regional Archives at Uppsala Falu folkskoleseminariums arkiv. Skriftliga prov $i$ examen 1904-1914 [Archive of the teacher seminary at Falun. Written examination papers 1904-14]; and The Regional Archives at Uppsala Folkskoleseminariets $i$ Uppsala arkiv. Lektionsuthast 1867-1897. Skriftliga prov $i$ examen 1910-1914 [Archive of the teacher seminary at Uppsala. Lesson plans 1867-97. Written examination papers 1910-14].

14 In 1868, the Swedish state sponsored the publication of a Reader, Läsebok för folkskolan [Reader for the elementary school], which is often referred to as 'The Reader' and which was revised and published in several editions until 1938. It had an encyclopaedic ambition and has been called a late representative of the tradition of Comenius's Orbis pictus of 1658 (Furuland 1979). The first edition comprised 564 pages and covered the content of most school subjects; mathematics was, however, excluded. In most of the cases when the Reader is mentioned in the lesson plans, this reader is being referred to.

15 Other accessible, although disparate, sources for an interpretation are teachers' written recollections or diaries (Ambrosius et al. 1930, Hall and Liander 1936, Kinberg 1961) and inspectors' reports. 


\section{Agneta Linné}

16 The importance of limiting the secular knowledge of the prospective teacher to a minimum was clearly stated in the formal, national curriculum of the 1860s, and has been confirmed by teachers' recollections and diaries (Hall and Liander 1936, Kinberg 1961, Hartman 1995, Ödman 1995). In fact, the curriculum was highly influenced by the Prussian Regulatives of 1854, a conservative reaction to the menace of disorder and upheavals following 1848 (Sörensen 1942, Sjöstrand 1956).

17 It may be assumed that traces of this alleged difference between the male and the female teacher seminaries should appear in the lesson plans; however, comparisons between the two seminaries are rendered difficult due to inconsistencies in subjects chosen and the documents filed.

18 See documents in The Regional Archives at Uppsala Falu folkskoleseminariums arkiv. Handlingar rörande smà- och folkskollärarexamen 1879-1912 [Archive of the teacher seminary at Falun. Documents regarding the examination of junior and elementary school teachers 1879-1912].

19 Sörensen's approach to religion is of great interest and stands in opposition to an older, dominating view of dogmatic evangelical faith. In her work on didactics, she particularly argued that, insofar as religion was concerned, the curriculum of the new century was to be based on a knowledge of the child's nature acquired by scientific research; hence, the selection of content should be determined by the child's susceptibility and needs (Linné 2002). According to the programme of the laboratory school, religious instruction sought to accompany the children into the real world; Sörensen declared that it aspired to give them the matter itself, not just words and phrases. By these means the children would come to know religion not as a doctrine but as living history (Sörensen 1928).

20 In the research project, 'Shaping the public sphere: a collective biography of Stockholm women 1880-1920', supported by the Bank of Sweden Tercentenary Foundation, Anna Sörensen is included among the biographies of influential women. The research group includes D. Broady, B. Englund, I. Heyman, A. Linné, K. SkogÖstlin, A. Ullman, and E. Trotzig.

21 See documents in the file Falu folkskoleseminariums arkiv. Handlingar rörande smaoch folkskollärarexamen 1879-1912.

22 Norlén had been heavily influenced by the evangelical pedagogy that he had encountered during a study visit to Prussia and Switzerland in the 1860s, undertaken at the request of the Minister of Education and Ecclesiastical Affairs, F.F. Carlson (Lundgren 1899).

23 The extent to which the students added a formally written separate schematic outline to the lesson plans varies over the years. At Falun, in 1904, the outlines are supplied as headings in the text, whereas, in 1906, nearly every student added a separate schematic outline of the lesson plan by way of introduction; in 1910, the proportion supplying an outline had decreased to one third (religion). At Uppsala, the majority of the nineteenth-century lesson plans contain a formally written separate schematic outline or disposition, while the extent varies from 1910 to 1914.

24 This applies to all quotations from the lesson plans. I am indebted to Lynn Stevenson for checking the English throughout the essay.

25 Influence from pietists and philanthropists may be traced (Sjöstrand 1956, Kaleen 1979). An introduction to the catechism (Woblunterrichteter Katechet, Swedish edition 1849) by Johann Jacob Rambach (1693-1735), Francke's successor as professor at Halle and influenced by the pietists, was used at several seminaries. Pestalozzi was an important inspiration. Directors of evangelical schools, teacher seminaries and theological institutes in Prussia, Saxony, and Würtenberg directly influenced the Swedish writers of didactical handbooks. Important inspirers were, for example, Christian Heinrich Zeller, influenced by Francke and Pestalozzi; his handbook Lehren der Erfahrung für christliche Land-und Armen-Schullehrer (1827) was published in a Swedish edition in 1868; Christian Palmer, Evangelische Pädagogik 
(1852, Swedish edn 1856); Karl Bormann, Unterrichtskunde für evangelische Volksschullehrer auf Grund der Regulative von 1, 2 und 3 Oktober 1854 (Swedish edn 1866); F.W. Schütze, Evangelische Schulkunde; and K. Kehr, Die Praxis der Volkschule. This literature, however, contains few examples of how to structure lessons - an emphasis on the legitimacy and task of the school in evangelical terms dominate, together with general principles of teaching and organizing a school.

26 The Herbartians appear to have influenced the Swedish scene later than in the other Nordic countries (Kaleen 1979, Stormbom 1986).

27 An intriguing endeavour would have been to analyse the lesson plans according to the categories developed by Bellack et al. (1966) in their classical work on the rules of the classroom language game; however, because of the special qualities of the filed material, a narrative-interpretative approach has been adopted.

28 One of the Prussian representatives of evangelical pedagogy, Palmer (1856 [1852]), explicitly emphasizes the importance of making the children repeat and restate after the text in question; he refers to Pestalozzi when legitimizing this procedure as part of a practical theory.

29 Although, apparently, the practice of silent reading had not yet become a widespread habit.

30 Cf. Westbury's (1980) argument that recitation was well adapted to the transmission of inert information from written texts.

31 The lesson plans from Falun in 1913 are furnished with marks from the examiner; this is, however, exceptional.

32 The draft on the forest industry referred to above (Falun 1913) clearly reflects a moral that legitimized the existing relations between poor agrarian land-owners and large industrial companies - although the text acknowledged that substantial cheating and inadequate payments had been made on the part of the companies.

33 Twenty-five years earlier, a student at the seminary in Uppsala was nearly expelled from the seminary for improper religious beliefs; as one of the indicators of this it was asserted that he had highly recommended non-Christian writers like Strindberg (Lundgren 1899).

34 A few years after her examination, this young female teacher was employed as a member of the faculty of the seminary at Skara, as a teacher at the practice school (Gustafsson 1916: 20).

35 Cf. Hultqvist (1998), who discusses this theme on the basis of historical studies of ideological transformations in the fields of psychology and pre-school development.

36 This theme is further discussed by Englund (1996).

\section{References}

Ambrosius, J.M., Hulthén, T., Lundahl, N., and Nilson, A.B. (1930) Skånska folkskolor [Scanian elementary schools] ÅSU 29 (Lund, Sweden: Föreningen för svensk undervisningshistoria).

Andersson, A.P., Gustafsson, L.J., Hansson, J., Johansson, J., Lindvall, O.D., Malmberg, J.P., Schultz, J., Södergren, L.A., Thunvall, F., and Wensell, E.G. (1922) Lankasterskolor [Lancaster schools] ÅSU 6 (Lund, Sweden: Föreningen för svensk undervisningshistoria).

Anjou, C.L., Kastman, K.W., and Kastman, K.A. (1868-9) Bidrag till Pedagogik och Metodik för Folkskolelärare [Contributions to pedagogics and methodology for elementary school teachers] (Linköping, Sweden: Fridolf Wallin/C.F. Ridderstad).

Aquilonius, K. (1942) Det Svenska Folkundervisningsväsendet 1809-1860. Svenska Folkskolans Historia II [Swedish Popular Education 1809-1860: History of the Swedish Elementary School, vol. II] (Stockholm: Bonniers). 


\section{Agneta Linné}

Arcadius, C.O. (1903) Handledning i Folkskolepedagogik för Seminarier och Lärare [Guide to Elementary School Pedagogics for Seminaries and Teachers] (Stockholm: Norstedts).

Arcadius, C.O. (1911) De Svenska Folkskoleseminariernas Uppkomst och Utveckling [Origin and Growth of the Swedish Teacher Seminaries], in Folkundervisningskommitténs Betänkande I: 3 (Stockholm: Norstedts), 1-186.

Askling, B. and Holm, R. (1985) Undervisningen på Rostad [Instruction at Rostad: On the Education of Female Teachers at Kalmar, 1925-9] (Kalmar and Umeå, Sweden: University College of Kalmar and University of Umeå).

Bellack, A.A., Kliebard, H.M., Hyman, R.T., and Smith, F.L. (1966) The Language of the Classroom (New York: Teachers College Press).

Bernstein, B. (1977) Class, Codes and Control, vol. 3: Towards a Theory of Educational Transmissions, 2nd edn (London: Routledge \& Kegan Paul).

Bernstein, B. (1990) Class, Codes and Control, vol. 4: The Structuring of Pedagogic Discourse (London: Routledge).

Bormann, K. (1866) Pedagogik för Folkskolelärare [Unterrichtskunde für Evangelische Volksschullehrer auf Grund der Regulative von 1, 2 und 3 Oktober 1854] (Göteborg, Sweden: Arwidsson).

Cremin, L.A. (1961) The Transformation of the School: Progressivism in American Education 1876-1952 (New York: Alfred A. Knopf).

Ekendahl, H. (1851-2) Den nya Folkskolan i Sverge I-II [The New Elementary School in Sweden I-II] (I: Jönköping, Sweden: Strehlenert; II: Gefl, Sweden: C.A. Forssell).

Elgqvist-Saltzman, I. (1994) 'Teacher, woman and human being', in G. Bjerén and I. Elgqvist-Saltzman (eds), Gender and Education in a Life Perspective (Aldershot, UK: Avebury), 115-32.

Englund, T. (1986) Curriculum as a Political Problem: Changing Educational Conceptions, with Special Reference to Citizenship Education (Uppsala and Lund, Sweden: Studentlitteratur/ChartwellBratt).

Englund, T. (1996) The public and the text. Journal of Curriculum Studies, 28 (1), 1-35.

Florin, C. (1987) Kampen om Katedern. Feminiserings-och Professionaliseringsprocessen inom den Svenska Folkskolans Lärarkair 1860-1906 [Who Should Sit in the Teacher's Chair? The Process of Feminization and Professionalization among Swedish Elementary School Teachers 1860-1906] (Umeå, Sweden: Acta Universitatis Umensis).

Författningar Rörande Folkundervisningen (1869) [Statutes Regarding Popular Education] (Stockholm: Norstedts).

Furuland, L. (1979) Efterord [Epilogue], in Läsebok for Folkskolan [Reader for the Elementary School] (Avesta, Sweden: Gidlunds), I-XXVII.

Gustafsson, C. (1911) 'Statistiska Utredningar Angående Folkskoleseminariernas Elever under Åren 1866-1910' [Statistical Investigations Regarding Students at the Elementary School Teacher Seminaries 1866-1910], in Folkundervisningskommitténs Betänkande I: 3 (Stockholm: Norstedts), 187-445.

Gustafsson, C. (1916) Svensk Folkskolematrikel [Swedish Elementary School Register] (Uppsala, Sweden: Almqvist \& Wiksell).

Hall, B.R. and Liander, A. (1936) Seminarieminnen [Seminary recollections] ÅSU 47-48 (Lund, Sweden: Föreningen för svensk undervisningshistoria).

Hamilton, D. (1989) Towards a Theory of Schooling (London: Falmer).

Hamilton, D. (1999) 'Frame factors revisited: definition problems surrounding the beginnings of modern schooling', in Pedagogikhistorisk forskning [Research in the history of education: perspectives, importance, and function in today's society. Conference 1998] (Stockholm: Stockholm Institute of Education, Department of Educational Research), 38-48. 
Hartman, S.G. (1995) Lärares Kunskap [Teachers' Knowledge] (Linköping, Sweden: University of Linköping).

Hoetker, J. and Ahlbrand, P.A. (1969) 'The persistence of the recitation', American Educational Research Journal, 6 (2), 145-67.

Hopmann, S. (1990) 'The monitorial movement and the rise of curriculum administration: a comparative view', in H. Haft and S. Hopmann (eds), Case Studies in Curriculum Administration History (London: Falmer), 13-30.

Hultqvist, K. (1998) 'A history of the present on children's welfare in Sweden', in T.S. Popkewitz and A. Brennan (eds), Governing Education: Foucault's Challenge to the Knowledge, Curriculum and Political Projects of Schooling (New York: Teachers College Press), 91-116.

Isling, Å. (1988) Det Pedagogiska Arvet. Kampen För och Mot en Demokratisk Skola 2 [The Pedagogical Heritage: The Struggle For and Against a Democratic School, 2] (Stockholm: Sober Förlags AB).

Johansson, E. (1998) Alphabeta Varia: Orality, Reading and Writing in the History of Literacy, ed. D. Lindmark. Album Religionum Umense 1 (Umeå, Sweden: University of Umeå, Department of Religious Studies).

Kaleen, G. (1979) Fackundervisningen vid Vara Folkskoleseminarier 1865-1914 [Technical Education in Elementary School Teacher Seminaries 1865-1914] ÅSU 142 (Stockholm: Föreningen för svensk undervisningshistoria).

Karier, C.J. (1986) Scientists of the Mind: Intellectual Founders of Modern Psychology (Urbana, IL: University of Illinois Press).

Kinberg, S.A. (1961) S.A. Kinbergs Dagbok [S.A. Kinberg's Diary]. ÅSU 105 (Stockholm: Föreningen för svensk undervisningshistoria).

Kliebard, H.M. (1987) The Struggle for the American Curriculum, 1893-1958 (London: Routledge \& Kegan Paul).

Läsebok För Folkskolan (1979 [1868]) [Reader for the elementary school] (Avesta, Sweden: Gidlunds).

Liedman, S.-E. (1991) Att Förändra Världen - men Med Måtta. Det Svenska 1800-Talet Speglat $i$ C.A. Agardhs och C.J. Boströms liv och verk [To Change the World - but in Moderation: The Swedish Nineteenth Century Reflected in C.A. Agardh's and C.J. Boström's Lives and Deeds] (Stockholm: Bokförlaget A/Arbetarkultur).

Liedman, S.-E. (1997) I Skuggan av Framtiden. Modernitetens Idéhistoria [In the Shadow of the Future: A History of Ideas of Modernity] (Stockholm: Bonnier).

Lindälv, E. (1972) Om Fynden på Vinden i Majornas Växelundervisningsskola [On the Findings in the Attic of the Monitorial School at Majorna] ÅSU 127 (Stockholm: Föreningen för svensk undervisningshistoria).

Lindmark, D. (1993) 'Sann Kristendom och Medborgerlig Dygd'. Studier i Den Svenska Katekesundervisningens Historia ['True Christianity and Civil Virtue': Studies in the History of Swedish Catechism Instruction] Album Religionum Umense 2 (Umeå, Sweden: University of Umeå, Department of Religious Studies).

Lindmark, D. (1995) Uppfostran, Undervisning, Upplysning [Instruction, Education, Enlightenment: Currents in Swedish Popular Education before the Era of Compulsory Schooling] Album Religionum Umense 5 (Umeå, Sweden: University of Umeå, Department of Religious Studies).

Linné, A. (1996) Moralen, Barnet eller Vetenskapen? En Studie av Tradition och Förändring $i$ Lärarutbildningen [Morality, the Child or Science? A Study of Tradition and Change in Teacher Education] Studies in Educational Sciences 6 (Stockholm: HLS Förlag). 


\section{Agneta Linné}

Linné, A. (1999) 'Morality, the child, or science? A study of tradition and change in the education of elementary school teachers in Sweden', Journal of Curriculum Studies, 31 (4), 429-47.

Linné, A. (2002) 'Education of female teachers, modernity and public life', in W. Hörner, D. Schulz, and H.-W. Wollersheim (eds), Berufswissen des Lehrers und Bezugwissenschaften der Lebrerbildung (Leipzig, Germany: Leipziger Universitätsverlag), $105-21$.

Lundgren, F. (1899) Wilhelm Norlén (Stockholm: Aktiebolaget Normans Förlag).

Lundgren, U.P. (1983a) Between Hope and Happening: Text and Context in Curriculum (Geelong, Australia: Deakin University Press).

Lundgren, U.P. (1983b) 'Social production and reproduction as a context for curriculum theorizing', Journal of Curriculum Studies, 15 (2), 143-54.

Lundgren, U.P. (1991) Between Education and Schooling: Outlines of a Diachronic Curriculum Theory (Geelong, Australia: Deakin University Press).

Mellberg, M. (1996) Pedagogen och det Skrivna Ordet [The Teacher and the Written Word: Orality, Literacy and Teachers in the Swedish Elementary School, 1870-1920] (Göteborg, Sweden: University of Göteborg, Department of History).

Nordin, T. (1973) Växelundervisningens Allmänna Utpeckling och dess Utformning $i$ Sverige till omkring 1830 [General Development of Monitorial Instruction and its Character in Sweden until about 1830] ÅSU 130 (Stockholm: Föreningen för svensk undervisningshistoria).

Nordlund, K., Sörensen, A., and Wikberg, S. (1924-29) Arbetssättet $i$ Folkskolan I-VIII [Methods of Instruction in the Elementary School, vols. I-VIII] (Stockholm: Norstedts).

Norlén, W. (1884) Kristendomsundervisningen i Folkskolan. Metodiska Anvisningar [The Teaching of Religion in the Elementary School: Instructional Guidelines] (Stockholm: A.L. Normans Förlags expedition).

Norlén, W. and Lundgren, F. (1885) Biblisk Historia för Folkskolan [Biblical History for the Elementary School] (Stockholm: A.L. Normans Förlags expedition).

Ödman, P.-J. (1995) Kontrasternas Spel. En Svensk Mentalitets- och Pedagogikhistoria [Interplay of Contrasts: A Swedish History of Mentality and Education] (Stockholm: Norstedts).

Ong, W.J. (1982) Orality and Literacy: The Technologizing of the Word (London: Methuen).

Palmer, C. (1856) Evangelisk Pädagogik (Stockholm: C.M. Thimgren).

Petterson, L. (1992) Frihet, Jämlikhet, Egendom och Bentham. Utvecklingslinjer inom Svensk Folkundervisning mellan Feodalism och Kapitalism 1809-1860 [Freedom, Equality, Property and Bentham: Trends in Swedish Popular Education between Feudalism and Capitalism, 1809-1860] (Uppsala, Sweden: Acta Universitatis Upsaliensis).

Popkewitz, T.S. (1996) 'Academic discourse, professionalization, and the construction of the teacher in the USA', in H. Simola and T.S. Popkewitz (eds), Professionalization and Education. Research Report 169 (Helsinki: University of Helsinki, Department of Teacher Education), 2-33.

Popkewitz, T.S. (1997) 'The production of reason and power: curriculum history and intellectual traditions', Journal of Curriculum Studies, 29 (2), 131-64.

Rambach, J.J. (1849) Kort undervisning om rätta sättet att katechisera [Wohlunterrichteter Katechet] (Uppsala, Sweden: P.W. Hörlin).

Richardson, G. (1963) Kulturkamp och Klasskamp. Ideologiska och Sociala Motsättningar $i$ Svensk Skol-och Kulturpolitik under 1880-talet [Cultural Struggle and Class Struggle: 
Ideological and Social Conflicts in Swedish Educational and Cultural Policy in the 1880s] (Göteborg, Sweden: Akademiförlaget).

Richardson, G. (1999) Torsten Rudenschöld [Torsten Rudenschöld: Social Critic and Educational Reformer of the School] ÅSU 189 (Uppsala, Sweden: Föreningen för svensk undervisningshistoria).

Rudenschöld, T. (1856) Svenska Folkskolans Praktiska Ordnande [Practical Order of Swedish Elementary School] (Göteborg, Sweden: Hedlund \& Lindskog).

Sabeu (1856-8) Stats- samt Allmänna Besvärs- och Ekonomi-Utskottens betänkande [Committee report] no. 19. In Bihang till Samtlige Riks-staindens Protokoll vid Lagtima Riksdagen i Stockholm 1856, 1857, 1858. Fjerde samlingen [Appendix to the Minutes of the Parliamentary Sessions of 1856, 1857, 1858 in Stockholm, 4th collection].

Schütze, F.W. (1865-6) Entwürfe und Katechesen über Dr M. Luther's kleinen Katechismus. Für evangelische Volksschullehrer (Leipzig, Germany: Teubner).

Sjöstrand, W. (1956) Pedagogikens Historia, I [Educational History, vol. I] (Lund, Sweden: CWK Gleerup).

Sörensen, A. (1928) Kristendomsundervisningen Enligt 1919 års Undervisningsplan [Teaching Religion According to the Curriculum of 1919]. In K. Nordlund, A. Sörensen, and S. Wikberg, Arbetssättet $i$ Folkskolan VI [Methods of instruction in the elementary school, vol. VI] (Stockholm: Norstedts), 179-90.

Sörensen, A. (1942) Det Svenska Folkundervisningsväsendet 1860-1900. Svenska Folkskolans Historia III [Swedish Popular Education 1860-1900: History of the Swedish Elementary School, Vol. 3] (Stockholm: Bonniers).

Spetze, G. (1992) Stockholms Folkskolor 1842-1882 [The Elementary Schools of Stockholm 1842-82] ÅSU 169 (Uppsala, Sweden: Föreningen för svensk undervisningshistoria).

Stormbom, J. (1986) Pedagogik och Didaktik: Den Herbartianska Grunden [Pedagogics and Didactics: The Herbartian Basis] Studies in Education and Psychology 21 (Lund, Sweden: CWK Gleerup).

Tidning för Folkskolan [Magazine for the elementary school] (1870, 1871).

Torstendahl, R. (1991) Bureaucratisation in Northwestern Europe 1880-1985: Domination and Governance (London: Routledge).

Westbury, I. (1980) 'Schooling as an agency of education: some implications for curriculum theory', in W.B. Dockrell and D. Hamilton (eds), Rethinking Educational Research (London: Hodder and Stoughton), 88-114.

Wilmenius, K. (1999) Folkskollärarinnor $i$ Stockholm [Female Elementary School Teachers in Stockholm] ÅSU 190 (Uppsala, Sweden: Föreningen för svensk undervisningshistoria).

Zeller, C.H. (1827) Lebren der Erfahrung für christliche Land-und Armen-Schullehrer (Basel, Switzerland: Im Verlag des Vereines der Armen-Schullehrer-Anstalt in Beuggen). 



\section{Part II}

Thinking about pedagogy 



\title{
4 Reflectivity and the pedagogical moment
}

\author{
The practical-ethical nature of \\ pedagogical thinking and acting ${ }^{1}$
}

Max van Manen

Sometimes we don't want to know that we don't want to know something. And yet, we may know it. Sartre called this bad faith, lying to oneself. We act as if we have no choice, but, in actuality, we do. A common example is the idea of the hidden curriculum. We teach in a manner that might make us uneasy, if only we would admit to ourselves that what we do contributes to oppressive or repressive structures of the curriculum that we enact in our practices. The premise of the hidden curriculum is that we have been blinded by the prevailing ideology of our profession, our social class, or our culture.

A more subtle and less acknowledged example is the realization that all 'good' teaching (rather than 'mere instruction') is governed by the practicalethical demands of pedagogy. Nothing that teachers say or do (or not say or do) in their interactions with children or students falls outside the boundaries of the pedagogy of teaching. And yet, clarifying what is meant by this practicalethical demand can only be accomplished if we clarify what is meant by the notion of pedagogy. I would need to show that the traditional and still current usage of the notion of pedagogy in European contexts is not easily translated. It is not identical to the concept of 'education' but refers more generally to the task of child-rearing and the upbringing of young people. The challenge is that in the last few decades, the concept of pedagogy has acquired additional multitudinous dimensions of meaning, especially in the English educational and social science discourses. So rather than try to sort through and contrast the earlier with more recent and emergent meanings, I will start with a concrete example as provided by the late Martinus J. Langeveld, who was a famous scholar of pedagogy.

The W.B. Curry Lecture delivered at the University of Exeter (1975) serves as a case to explore the meaning of pedagogical thinking and acting. In this lecture, Langeveld describes an incident to illustrate how our personal response to situations in which we find ourselves with children gives us insight into the sorts of practical-ethical competencies that are required in such situations.

He tells the story of how an accident happens in the street, right in front of him, when a 13-year-old girl calls her father whom she sees on the other side of the street. 


\section{Max van Manen}

'Hello daddy!' she calls out, waving to a man on the opposite side of the road, who waves back to her. He then steps from the pavement to meet his daughter and, before her very eyes, he is run over by a car. He is killed, but she does not yet know. Soon she will: already she cries loudly. Later she'll go on crying and seeing the image of her father's death happening in front of her. She has an irrational feeling of guilt: she knows she is not guilty, but she called his name, she waved to him and then he stepped off the pavement and it happened.

Langeveld asks: What does one do in a situation such as that? Of course, some people may hurry by and not get involved. But Langeveld shows that he cannot help but respond. A 'personal' response is required: to be available to the girl who is in need of help. Langeveld does not use the term 'pedagogical moment' in his texts, but we might say that he found himself in a situation that for him became a pedagogical moment. He experienced a demand. He had to act. Emmanuel Levinas (1981) calls this experience - of an ethical response to the demand issued by the appeal of human vulnerability - responsibility for the other. When Langeveld sees the child's horror, he cannot help but experience his own response to this vulnerable child - he experiences his own responsibility. But at the time that Langeveld gave this Lecture, the French philosopher Levinas had not yet made his impact. So Langeveld uses a different language. He tells how a 'personal response' became a 'pedagogical response':

What, now, did you do walking behind the girl whose father was run over by a car? People ran to the place of the accident. Should this girl see her father crushed and bleeding? Before you knew what you were doing, you had already decided, and you had taken the girl's hand in order to prevent her from approaching that horrible sight. 'Let us go quickly to find your mother ... Where do you live? Where is she?' (emphasis added)

Of course, we can argue about the reasonableness of Langeveld's actions. But judging his response is less important here than noticing that he inadvertently shows us what the structure of a pedagogical moment looks like.

First of all, we can learn from this anecdote that the pedagogical moment is embedded in a situation where something pedagogical is expected of us, and in which we subsequently are oriented to that which is in the best interest or 'good' for this child or these children. We must act. Second, we see that usually the pedagogical moment does not permit us to step back from the situation. In the interactive moment of teaching, there is no time to deliberate rationally and morally, from one point of view and from another, what the various possibilities and consequences are that this situation offers us. Reflective deliberation would require that we use a form of practical reasoning to arrive at a morally and relationally responsible decision about how best to approach the situation, and then to act on this decision.

But practical reasoning - the critical comparing, sorting of alternative means 
and ends, weighing the consequences, and deciding what one should do - can rarely be employed in pedagogically-interactive and relational situations. When we are teaching (discussing, listening, showing, interacting with) a group of children, or dealing with a single child, we tend to be relationally 'captive'. Quite literally our mind is not our own. And thus we can say that 'we give the other(s) a piece of our mind'. Pedagogical moments usually consist of immediate actions and thus it is not surprising that Langeveld says:

Immediately you brought the child into a different life situation: a mother, a house. Immediately you assured her that people were looking after her father: 'Shall I go and have a look?' 'No,' you added immediately, 'no, let us first find your mother, as you live just around the corner'. (emphasis added)

In his lecture, Langeveld does not comment on the curious 'immediacy' of the nature of pedagogical acting. Rather, he uses the anecdote as a basis to reflect on the practical ethics of pedagogy. ${ }^{2}$ He shows how pedagogy demands something of adults. He goes on to argue that it demands reflection on the meaning and significance of pedagogical notions such as the child's experience of and need for 'security, reliability, and continuity'. These demands, he suggests, are basic to the experience of pedagogically-responsive and responsible acting in our everyday relations and situations where we teach or live with children. To a certain extent, children need to be able to experience the world as secure, they need to be able to depend on some adults as being reliable, and they need to experience a sense of continuity in their social relations with those who care for them.

Langeveld also warns that there exists no closed or universally-acceptable rational system that would tell us how we should behave with children in our everyday actions and how we should rationally justify our pedagogical approaches and methods. What is reasonable to one person may appear unreasonable to another person, argues Langeveld. Instead, he attempts to locate phenomenologically the norms of pedagogical acting in the concrete experiences of everyday living with children around the home and at school. In other words, Langeveld (1975) develops the terms of a reflective and moral 'theory' of the practical ethics of pedagogical acting, as he had done extensively in his numerous books and essays.

At this point it is important to make clear that the word 'pedagogy' itself already has the ethical, rational, emotional, normative, and moral aspects built right into its commonly accepted meaning. The meaning of the concept of pedagogy in Dutch, Belgian, German, and Scandinavian languages is almost identical with 'child-rearing' and 'bringing up children', except that it has a slightly more formal usage. As well, it is generally accepted that pedagogy is a central dimension of teaching. The word pedagogiek is so common among Dutch citizens that they immediately understand that it has to do with questions such as what is good for a child, or what is in the child's best interests. And, of course, 


\section{Max van Manen}

teachers too must constantly teach in a manner that is pedagogically appropriate.

A special feature of Langeveld's phenomenological pedagogy is that he wants to show that pedagogical practice is much better understood as an ethical activity than as a rational process. This feature has been a much debated dimension of his approach, since the norms of pedagogical practice are much less easily placed under the control either of the individual human faculty of logic and reason, or under the control of the comprehensive scheme of a social-critical rationality. But, perhaps, what Langeveld shows us between the lines, so to speak, is that his anecdote is no less informative about the nature of the reality of the pedagogical lifeworld than his more explicit reflections afterwards.

So, in his Curry Lecture, Langeveld tells us a plausible story about an event that might happen to any of us. And in the language of the story he shows us more than he actually tells us. He shows that, although we say 'before you knew what you were doing, you had already decided', this is actually not a process of reflective decision-making in terms of which pedagogical acting in the school and in the classroom are usually discussed. And in this feature, our living with children at home or in the community does not differ fundamentally from the more intentionally-structured processes of teaching in the school classroom. In their daily conduct with children, teachers as professional pedagogues, just like parents, are expected to act immediately, though thoughtfully, and in a pedagogically-appropriate manner with children.

Let me sketch a series of situations that are instances of pedagogical life we might recognize in our own everyday experience: Sandra has completed her work and she hands it with visible pride to her teacher. While reading out loud during the class reading lesson, Billy mispronounces several words. Emmy fails to understand when the teacher is trying to get something new across to the students. Adam is quietly reading a book during mathematics class. Sue complains that Jack broke her pencil. Rob refuses to participate in the science lesson since he feels repugnant towards dissecting an animal. All the children are applying themselves to their work in class, but Cathy persistently does not seem to be able to concentrate. After ten years of lessons, Erin announces that she no longer wants to take music lessons or practise the violin. David seems unusually quiet and withdrawn this morning. Mary is in tears; she comes to her teacher and confides that she feels nobody in the class likes her. Mother sees her sevenyear-old son Peter taking money from her purse. Sook asks his mother if he can go to a movie that many of his friends have seen, even though the movie has been rated unsuitable for children of his age.

We could go on indefinitely drawing pedagogical incidents from everyday life. In fact, every instant of our living with children is pedagogically charged. But what constitutes the pedagogical nature of each instance? Let us first notice that each situation is pedagogically charged because something is expected of the adult, the parent, or the teacher. In each situation an action is required, even if that action may be non-action. That active or passive encounter is the pedagogical moment. In other words, a pedagogical situation is the site of 
everyday pedagogical practice. The pedagogical moment is located at the centre of that practice.

Notice that in our daily living with children we must often act on the spur of the moment. The usual case is that we do not have time to sit back and deliberate on what to do in the situation, and even when there is time to reflect on the alternatives and what the best approach is for one to take, in the pedagogical moment itself one must remain relationally present (rather than becoming 'distant') and act, even if that action may consist in sensitively holding back, remaining silent or passive.

Of course, in the cases sketched above, the pedagogical moments have yet to be fulfilled. For the situation to bear a pedagogical moment, the adult must do something that is in the child's best interest: somehow the adult distinguishes what is good from what is less good in his or her relation with this child or these children. In other words, in each situation the adult must show, in actions, what is good (and exclude what is not good) for this or that young person.

Thus pedagogy first of all refers to our active everyday living with children as parents, teachers, school principals or heads, child-care workers, and so on. In everyday life we practise a certain pedagogy, and of course the pedagogy of the home is different from the pedagogy of the classroom. But pedagogy also refers to our need or desire to reflect about our active living with children. In the latter sense, pedagogy refers to our reflective sense-making or theorizing about concerns of education or child-rearing. Naturally, there is value in this pedagogical reflection and everyday theorizing. Pedagogical reflection is oriented toward understanding the pedagogical significance of events and situations in children's lives. It is oriented toward understanding what is pedagogically 'good' or 'right' with respect to the lives of these children (van Manen 1982).

But although we are ongoingly involved, actively and reflectively, as educators with children, it has been very difficult to get a handle on the reflective nature of the pedagogical process. In the next paragraphs I explore the tension between our active living with children and the reflectivity that is prompted by our pedagogical responsibilities.

\section{Forms of reflection and pedagogical action}

Generally, we make a distinction between action and reflection. It is important to keep in mind the difference between being actively engaged in teaching children and being disengaged through reflecting on a past, present, or future situation. Reflection is possible in those moments when we are able to think about our experiences, about what we did or should have done, or about what we might do next.

Reflection is a fundamental concept in educational theory, and in some sense it is just another word for 'thinking'. To reflect is to think. But reflection in the field of education carries the connotation of deliberation, making deliberated choices, coming to decisions about alternative courses of action. It occurs in 
such phrases as 'reflective teaching', 'critical reflective practice', 'reflection in action', and so forth (Calderhead 1989). It is commonly impressed on novice teachers that good teachers are reflective teachers; beginning teachers are taught how to adopt a reflective orientation to their practice. However, beginning teachers are not commonly taught that the daily life of dealing with children is such that there seems little opportunity for reflection - and that this is not the fault of teachers or anyone else. Rather, it is a feature of living together in constant interaction that prevents teachers from critically reflecting on what they are doing while teaching. Even more problematic is the lack of opportunity to reflect thoughtfully with colleagues about the practice and meaning of pedagogical experiences. One of the challenges of the teaching profession is to try to create those spaces and opportunities. This is partly an issue of professional politics.

These considerations lead us to make a distinction between reflection on experiences and reflection on the conditions that shape our pedagogical experiences. It is safe to say that virtually all teachers (and parents too) experience in their lives constraints that frequently seem to make it difficult for them to be a significant influence on the children or young people for whom they feel pedagogically responsible. Many of these constraints have to do with institutional and political factors that operate in people's lives. For example, common concerns for teachers are that many schools are much too large, that educational responsibilities are too specialized, and that modern schools tend to be run like businesses, complete with measurement of 'production performance', 'output figures', 'projected increased rates of success', 'effectiveness of teachers', and 'student standardized test outcomes'. Consequently, the teachers' ability and inclination to reflect thoughtfully on the pedagogical nature of their lives with students are being atrophied by the objectifying and alienating conditions under which they work.

In the attempts by the educational bureaucracy to bring the processes of instruction under increasingly administrative and centralized control, the teachers' tasks have become 'rationalized'. Many feel that the teacher as professional has become increasingly de-skilled as the curriculum has become more and more prescriptive and dictated by centralized control, and as the pedagogical care of students has become highly fragmented ('streamlined') by referrals to resource teachers, psychologists, counsellors, school administrators - many of whom have too little contact with the students to be of much help to them in any sustained way. As the teacher is expected to treat the job of teaching more and more technically, the teacher is less and less able to reflect on the meaning, purpose, and significance of the educational experiences of students whom the school and the curriculum are supposed to serve.

Every situation in which we are to act pedagogically with children is in some sense theory-laden. By virtue of living in a scientifically-advanced society, our everyday experience is shot through with theoretic elements. Accordingly, we may distinguish among several levels or degrees of systematic reflection, some of which fuse into each other. First, there is everyday thinking and acting - partly 
habituated, partly routinized, partly composed of intuitive, pre-reflective, and semi-reflective rationality. This is the level of commonsense thinking and acting in ordinary life. Second, we reflect in an incidental and limited way on our practical experiences in everyday life. We put our experience into language and give accounts of our actions: we recount incidents, tell stories, and formulate rulesof-thumb, practical principles, dos and don'ts, and limited insights. Third, we reflect more systematically and in a more sustained way on our experience and others' experience with the aim of developing theoretical understandings and critical insights about our everyday action. At this level we may use existing theories to make further sense of these phenomena. Fourth, we reflect on the forms of our theorizing, in order to come to a more self-reflective grasp of the nature of knowledge, how knowledge functions in action, and how it can be applied to our active understanding of our practical action. It is important for educators not only to act more thoughtfully and reflectively, but also to understand the nature and significance of reflective experiences and of the types of knowledge they use.

Reflection too is an experience. Some reflection is oriented to future action (anticipatory or pre-active reflection); some of it is reflection on past experiences (recollective or retro-active reflection). But in either case, reflection is a form of human experience that distances itself from situations in order to consider the meanings and significance embedded in those experiences. By reflecting on an experience, I have the experience of grasping and appropriating meanings embedded in that experience. Inevitably, the reflective moments of life involve a temporary stepping back out of the immediate engagement we have with the world. In the words of Dewey (1973: 502) 'Where there is reflection there is suspense'. As we reflect, we suspend our immediate involvements in favour of a more contemplative attitude. And, of course, some active or interactive reflection happens virtually in the midst of life, for example, when we stop and think while we are doing something. All these forms of reflection regularly make up the life we live with children:

i Anticipatory reflection enables us to deliberate about possible alternatives, decide on courses of action, plan the kinds of things we need to do, and anticipate the experiences we and others may have as a result of expected events or of our planned actions. Anticipatory reflection helps us to approach situations and other people in an organized, decision-making, prepared way.

ii Active or interactive reflection, sometimes called reflection-in-action, allows us to come to terms with the situation or problem with which we are immediately confronted. This stop-and-think type of reflection permits us to make decisions virtually on the spur of the moment.

iii Recollective reflection helps us to make sense of past experiences and thus gain new or deeper insights into the meaning of the experiences we have with children. As a result of recollective reflection, we may become more experienced practitioners as teachers or parents because our lives have been 
enriched by the reflective experiences that offered us new or deeper understanding.

iv There is also a common experience composed of the interactive pedagogical moment itself, characterized by a different type of reflectivity: a certain mindfulness. It is this mindfulness that distinguishes the interaction of tactful pedagogy from the other forms of acting described above. While we are interacting (talking, gesturing, listening, working) with people, we usually do not have time or opportunity to reflect on our experience as it is happening. More likely, much of our pedagogical interaction with children is made up of an ongoing rush of pedagogical situations and circumstances. In the immediacy of our actions, reflection does not occur in moments of interrupted stop-and-think action, neither does it occur parallel with our action. In other words, instant action is not usually produced by reflection. Yet this interactive experience or 'rush' itself may be mindful.

\section{The reflective practitioner}

It has been argued that the reflective practitioner is a professional who reflects in action through constant rational-moral decision-making; practical reasoning. In this decision-making, the professional is seen as guided by the theoretical and practical principles of his or her discipline - even though these principles may be operating in a more or less tacit fashion. Thus, some of the theories of the teacher as reflective practitioner try to be sensitive to the intuitive, dynamic, and non-rational features of the act of teaching. They stress that we should not reduce the act of teaching to a simple theory-into-practice model of human action. Teaching is not a technical production process, with inputs, treatments, and outputs. Yet most models eventually seem to offer a reconstructed logic of the interactive moment of teaching that looks surprisingly similar to the process of rational deliberation or rational-moral decision-making. How accurate is the image of the reflective practitioner in comparing, let us say, the family physician and the schoolteacher?

I explain my ailments to the medical doctor: I have experienced a paralysing sensation in my right arm. Although the use of my arm has been restored over a number of weeks, I still suffer from strange and worrying symptoms: weakness, stiffness in muscles and joints, prickling sensations in the fingers, some pain. I still do not have the full use of my fingers, a nuisance when I try to write. The physician listens and writes some things down. He asks more questions and examines my arm. Then he sits down again, and while I am silent, awaiting his diagnosis, I notice that the physician is making columns on his paper. He has quickly drawn vertical lines and is filling in the columns with technical terms. I am sitting back now.

Obviously the physician is reflecting on what to make of my ailments and what possible action to take. I wait a bit longer, and then I clear my throat. I ask the physician what he is drawing and writing on this little notepad. The physician indicates that in the first column he has jotted down the various symp- 
toms that I have indicated: arm weakness, heart palpitations, pain, and loss of sensation. In the next column he has matched the different symptoms with possible diseases. In column three he has entered the tests which would check the likelihood of various diagnostic possibilities. The physician lists in column four the treatments to be suggested in case any of the tests turn out positive. He explains to me that he is trying to decide which diagnostic speculation seems most plausible and thus which tests he should start me on first.

When the physician makes out a referral form for some lab work, it occurs to me that this doctor has just shown me an active and concrete picture of the reflective practitioner at work. In the practice of this medical professional there are evidently moments of detached reflection, deliberation about possible alternatives, deciding on the best course of action, and then acting on this judgement. These are components of a reflective form of acting, which we may see as a kind of deliberative on-the-spot decision-making. Competent, experienced physicians often develop a perceptive and intuitive eye for their patients' ailments. For these physicians the process of reflection is absorbed into a more tacit or intuitive competence that shows itself in the immediacy of acting in the medical situation. But even the latter, more tacit, reflection-in-action process is conditioned by problem-solving behaviour based on medical science. ${ }^{3}$

How does this image of the experience of the reflective practitioner, the physician involved with patients, compare with the teacher who is involved with students? In the example above, the physician is a problem-solver who uses his medical knowledge of the body and its diseases to help restore the patient to a healthy state. Is the teacher or parent a reflective practitioner and problemsolver in the same sense? Sometimes, yes. Obviously, teachers are involved in a wide variety of practices. Sometimes the teacher deals with such problemsolving as how to share insufficient material resources with a large group of students. Sometimes the teacher prepares and plans lessons, assignments, or tests. At other times the teacher is involved in routine or habituated teaching sequences. Periodically, the teacher meets with parents or with resource people to discuss the progress or special needs of selected students.

There is little doubt that when a teacher (or a teaching specialist such as a reading consultant) does diagnostic work with a particular child who seems to have a specific difficulty, as with reading, this diagnostic process may show marked similarities with the practice of the family physician. In fact, the reading problem may sometimes appear to have a physiological base. Thus the reading specialist may typically engage in a process of deliberative-reflective practice. However, here we do not want to address primarily those specialized diagnostic settings. Nor do we want to speak primarily of teaching only when routines and habits are governing the process. Rather, we are interested in this section especially in the interactive reality of the pedagogical moment or situation. Indeed, it is the immediate acting on the spot, in the ongoing flux of pedagogical moments, that is little understood in educational theories.

The situation that parallels best the reflective practice of the medical situation of physician and patient is the pedagogical situation of teacher and student. But, 
unlike the physician, the teacher seems less involved in problem-solving reflection as in reflecting on the pedagogical meaning or pedagogical significance of certain experiences. Problems seek solutions, 'correct' knowledge, effective procedures, solution strategies, productive techniques, or methods that get results! When I consult the physician with a physical ailment, I have a problem that the doctor can hopefully solve and rectify.

But problems of teaching are seldom 'problems' in this sense. Rather, teachers deal with situations, predicaments, possibilities, and difficulties. Situations and predicaments must be handled the best we can, and possibilities and difficulties must be realized and worked through. Ultimately, predicaments and difficulties constitute 'problems of meaning', or rather questions of meaning. For example, when a child is 'difficult' or when a child experiences 'difficulty' (which often means different things), then this difficulty can rarely be 'solved' and done away with. I must ask what the meaning of this difficulty is for the child, and what the pedagogical significance of this is for me as teacher. Meaning questions cannot be 'solved' and done away with once and for all. Few pedagogical problems can ever be eradicated on the spot or overnight. Rather, we must learn to get on and get along with these situations and with each other.

Questions of pedagogical meaning are deeply ethical, ${ }^{4}$ that is, filled with moral, emotional, and normative significance. They are questions that deal with the meaning of experiences that must be better or more deeply understood, so that on the basis of this understanding I may be able to act more thoughtfully and tactfully in this and future situations. But pedagogical problems (questions, predicaments, difficulties) can never be closed down. They always remain the subject matter of conversation. They need to be appropriated, in a personal way, by anyone who hopes to benefit from such insights. In other words, 'difficulty' is something we have to interpret, work at, and remain attentive to.

\section{An example of the pedagogy of teaching}

I have described the pedagogical moment as that situation in which the teacher (pedagogue) does something appropriate with respect to learning in relation to a child or young person. But pedagogical situations usually do not permit the teacher to step back reflectively, analyse the situation, deliberate about possible alternatives, weigh up their consequences, decide on the best course of action, and act on this decision. Some researchers have estimated that teachers, on average, make a decision once a minute. But what does that mean? Are these real decisions in a deliberative sense? No, they mean that the teacher is constantly acting in ever-changing situations. Most often, the pedagogical moment requires the teacher to act instantly. With the hindsight of rational observation, this instant action may look like a kind of decision-making on-the-spot, but it is not really decision-making in the usual problem-solving and deliberative sense. It should be reiterated that all reflection always presumes a certain time element and taking distance from the experience, and the relational interaction that is the object of our reflection. In this distancing we always become aware of our 
actions in some more-or-less objectified manner. The ego mirrors (reflects) the self in an I-me relation. For example, I noticed myself getting confused or irritated.

In pedagogical interactions, we do not commonly experience a splitting between two egos or selves, I and me: one who acts and one who reflects on the action. Of course, we can be thinkingly aware of what we are saying or doing while we interact with children or students. But this awareness is usually volatile and transient. There may even be elements of catching ourselves saying something we feel we should not have said, or catching ourselves and holding back before we do something that we might regret. But these are acts of 'self'consciousness, of embodied mindfulness or tact, that little resemble the decision-making practice of deliberative reflection. (It is significant that selfconsciousness of oneself makes normal social interaction uncomfortable, artificial, or even impossible.) In our pedagogical lives with young people we are actively and immediately involved in a manner of consciousness (with mind and body, head and heart) that only later is open to true reflection. When we are confronted with a child in a situation that demands a response or an initiative from us, the common experience is that we have already acted before we really 'know' that we have acted.

The experience of thoughtful action in pedagogical situations has a peculiar structure. It is neither largely habitual nor problem-solving, neither intellectual nor corporeal, neither purely reflective in a deliberative sense nor simply spontaneous or arbitrary. Thoughtful action differs from reflective action in that is thinkingly attentive to what it does, without reflectively distancing itself from the situation or the relation by considering or experimenting with possible alternatives and consequences of the action. Living the pedagogical moment is, as Langeveld suggested, a total personal response or thoughtful action in a particular situation. So, when we come to tactful action, rather than say that it is 'reflective' we should say that tactful action is 'thoughtful' in the sense of 'mindful'.

Over the weekend I have read a thoughtful interpretation of Rilke's poem, 'The Panther' (Rilke 1982: 24, 25). Now it is Monday morning and I walk into the twelfth-grade classroom totally stimulated and turned on in anticipation of the lesson on 'The Panther'. If I were an inexperienced or naive teacher, then I might have thought that I could just walk in and 'teach Rilke'. As long as I knew it all and expressed it all, the task would be done. The measure of how well it would have been done would depend on how carefully I had thought through what I would need to say and do, and on the extent that the students caught on to what I was trying to do. But now I know that it is not enough just to walk in and expect the students to be ready for Rilke, even with an appropriate motivator. Yes, in part I am positively tense with excitement about this fascinating interpretation of Rilke's 'The Panther'.

But as I walk into the classroom, I intuitively get a sense of where these students are coming from. I know that some of them have been working part-time during the weekend, others have had good or bad experiences on Saturday and 


\section{Max van Manen}

Sunday, and some have had late nights and are not necessarily looking forward to another week of school. Yet all these students have managed to get on the bus or somehow arrive at school, and they have all managed to sit down in their seats at eight this morning. Right now, they could not care about Rilke or poetry. So as I walk into the classroom I am somehow sensitive to the atmosphere and dynamics of the group (even though I do not really make this awareness conscious). I happen to focus on Darryl, whose loud shuffle and laughter somehow seems to flavour the mood of the class. He catches my eye and I smile at him. Somehow he seems to interpret this as an invitation to make a comment about the ice-hockey team that lost in the semi-finals. Hockey is not really my interest but I sympathetically nod, and I crack a joke about it. Some more impromptu comments are exchanged, other kids are tuning in, and the class seems to come together. This is superficial chit-chat. But we need to connect somehow before we can really make a start at anything.

Monday morning classes are often not too difficult to get started because quite literally the students are not yet fully woken up. Just as we slide out of bed on Monday morning and toothbrush our way groggily into the new week, so we ease into the Monday morning lessons at school by warming up our interest and stimulating our readiness to think. On other days of the week the students may show less willingness to slip into a language arts lesson about conjunctions, or metaphors, or a novel, play, or poem.

I had planned to start the Rilke lesson with a question on the board for the class to think and write about before we got started with group discussions about some themes from Rilke's poem. But somehow it does not seem the right starting point just yet, and so I begin with an appeal: 'I would like to read to you a poem by Rainer Maria Rilke, entitled "The Panther" '. (As I am talking I have a feeling already that the mood is not quite right for this sort of thing, and before I can help it, I offer something that almost sounds like an apology.) 'I realize that poetry may not be foremost on your mind this morning.' (A couple of kids look at me askance, and Martha rolls up her eyes as if to say, 'you can say that again!'. But now a feeling of self-righteousness emerges in me. I do not wish to be apologetic and I continue with a bit more zeal.) 'Sometimes it is difficult to do things we set out to do, and "The Panther" poem has a story connected with it that illustrates this point.'

Rilke was a person who lived his life very intensely, and his poetry reflects an incredible commitment to explore life as deeply as possible. To earn money, Rilke had become secretary to the famous French sculptor, Rodin; but working in Paris, Rilke became very frustrated with his inability to write. One day he confided in Rodin that he had been unable for several months to write any poetry. Rodin gave him advice that changed the course of Rilke's poetic development. Rodin suggested that he go to the Paris zoo, select an animal, and look at the animal inside its cage until he could really see it. 'Go and sit in front of a cage. A few weeks wouldn't be too long', said Rodin (Rilke 1982: xxii). Just imagine looking at an animal with that kind of patience and attentiveness! Rilke picked the panther and eventually he wrote the poem by that name. After 
the panther poem he wrote much more poetry based on that type of careful observation. These were later called 'the seeing poems'. In each of the seeing poems it is clear that Rilke saw much more than we ordinarily see when we look at an animal. In the case of the panther, Rilke seems to have captured something of its wild soul.

As I am telling this story to the students, I am constantly aware of who is with me and who is fidgeting or seems preoccupied. This is a teacherly awareness of the contact that one is making with the students individually and as a group. But as the story progresses the whole class seems to come together. The attentiveness of the students prods me to turn a bit more dramatic in my relating of the Rilke anecdote. I ask if anyone has ever seen any sculptures by Rodin, and we talk a bit about the way that creative artists 'see' things. Can artists see things that we cannot see? I tell the students that the panther poem always makes a deep impression on me. 'I have here three translations of this poem, which was originally written in German, and before I give you the texts I would like to read them out loud to you. Afterwards we should try to determine which English translation you find the most evocative and poetically the strongest.'

No matter how well I have planned my lesson, or how enthusiastic I am about the subject matter, the interactive situation in the classroom is such that $\mathrm{I}$ must constantly remain aware of how it is for the students. (In high school you only see the students so many minutes every day or two, and it is easy to slip into a mode of teacher-centred, content-centred thinking and acting that completely ignores the students.) And yet this awareness is more a thoughtfulness than a calculating or deliberative reflectiveness, which would put one equally out of touch with the students, since that would create a distance that accompanies any manipulative interpersonal relationships between teachers and students. So as I interact with the students, I must maintain an authentic presence and personal relationship with them. What the example is meant to show is that life in the classroom is contingent, every moment is situation-specific. And the immediacy of the interactive pedagogical processes is very difficult to describe, since any description tends to place the experience at a reflective distance for our contemplation.

Here is another example, this time from a home situation: Mark is practising his violin. But he is weary, uninspired, and mostly going through the motions. The violin sounds tired, too. The grandmother who is over for a visit at Mark's house peeks into the room. She sees Mark and the sagging violin on his shoulder. Mark's face shows his disheartened mood. Unobtrusively, the grandmother slips into the room and sits down on a chair in the corner. She quietly continues her needlework. But Mark does notice her presence, for his posture straightens, the bow strikes the strings with new vigour, there is a sudden dynamism in the way he is playing the piece. Mark is no longer just practising. He is performing for his grandmother. There is feeling in this music. And she is listening with obvious delight.

It is marvellous how the grandmother instantly knew what to do. Yet if she were later asked to give an account of her action, she might even say that she 


\section{Max van Manen}

did not really decide to try to inspire Mark. She just sat down because the moment seemed to call for it, and her mere presence animated Mark into a musical mood. But in what sense was reflection involved in her action? Did she think of this before she sat down? Perhaps, in some vague sense. More likely, she was aware of the pedagogical benefits of her action just as she sat down. She would also want to say that it could have gone otherwise. Mark might have stopped playing altogether and complained to his grandmother that he just did not feel like practising. What would she have done then? Would she have been able to convert that situation into a pedagogical moment too? Perhaps. In our pedagogical living with children nothing is ever completely foreseeable, predictable, plannable, manageable. And it is usually not until afterwards that we have the opportunity to think reflectively through the significance of the situation.

Just as there are degrees or levels of anticipatory reflection that may range from loose rehearsing to carefully plotted plans, so there are modes of immediate acting that range from the intuitive thoughtfulness of immediate improvisational acting on the one side to the more self-conscious thoughtfulness of mediated improvisational action on the other side. In the self-forgetful intuitive mode, the 'thinking' is truly dialogic or conversational in nature, meaning that we interact in an open, direct, and sharing manner. In the more self-conscious mode of acting, there comes into play a noticeable tension between the conversational I or self, and the reflective I that holds the spontaneous conversational nature of intuitive acting at a distance. In some situations this may be due to the nature of the topic or to the participants in the conversation that force me into a more cautious thoughtful or thinking mood. This happens when I realize in the middle of a conversation that I am not sure of my own view or motive, which leads to an increased self-awareness and attentiveness to detail. In this case I become aware of myself acting while I am acting. In other situations the spontaneous dialogue of immediate acting is somewhat forced when I realize that I do not trust the other with whom I am interacting. And now I pick my way through the situation in the way that I pick my way through a hectic traffic rush-hour. I change lanes to take advantage of the shorter line. But I already know that I am running the risk of getting stuck behind left-turning traffic and thus lose the advantage of having chosen the shorter left lane over the righthand lane. In active on-the-spot judging of traffic situations I am already aware of possible consequences of certain kinds of configurations. I instantly know were something might lead. In rush-hour traffic, too, there is no time for the deliberative process of reflection.

\section{Pedagogical fitness is the mind-body skill of tact}

In the sections above, the main effort has been to determine the nature of action in the thick of dealing with children in pedagogical situations. Of course, in everyday life some teachers may act in ways that are predominantly authoritarian, insensitive, and thoughtless. Other teachers may deal with children in 
ways that students find artificial, affected, stuffy, stilted, inauthentic, or distant. But action that is more in keeping with the pedagogical relation itself is action that involves thoughtful reflection. We have seen that action characterizing concrete experiences between teachers and students in pedagogical situations may not be reflective in a deliberative decision-making sense. Yet this action needs to be mindful and to benefit from reflection. I have referred to this capacity for mindful action as tact-pedagogical tact (van Manen 1984, 1986, 1990, 1991).

Tact is the practical language of the body - it is the language of acting in pedagogical moments. Tactful action is an immediate involvement in situations where I must instantaneously respond, as a whole person, to unexpected and unpredictable situations. Tact as we experience it in our active living with children is a sentient awareness of our subjective self as we act. In other words, while we are acting as teachers or as parents with children we do not usually objectify or take distance from our acting.

Tact as a form of human interaction means that we are immediately active in a situation: emotionally, responsively, and mindfully. Even when as tactful pedagogues we are engaged sensitively, reflectively with a child - searching for the right thing to say or do, we nevertheless are only dimly aware of our actions, unaware of ourselves in a self-reflective sense. ${ }^{5}$ And, therefore, philosophically speaking, our thinking, feeling, and acting is relatively attenuated, drawn in, limited, or restrained by the possibilities of our corporeal being - and therefore also blind to deeper and more far-reaching possibilities.

Of course, our actions are always governed by certain intentions - for example, we are busy restoring order, or we are involved explaining a difficult concept, or we are trying to rouse the children's interest. Yet the reflective component in our immediate interaction with others is limited. When a child 'misbehaves' in class the teacher usually does not have time to reflect on what is the best thing to do. A teacher who paused and privately deliberated at some length about what actions to take about a difficult child's rude comment may be interpreted as hesitant, wishy-washy, and spineless. As a teacher, one simply has to do something, even if it consists of ignoring or pretending that one did not notice the rude remark.

Similarly, when a child, during a lesson, asks a question that shows the child does not understand, the teacher usually does not have the luxury of consulting a text on teaching to deal with this question in just the right way for this child (in any event, a textbook would not be likely to provide such advice). The same is true for parents and other adults with pedagogical responsibilities. When the child falls and hurts him- or herself, or protests the parent's reminder that it is bedtime, there is no opportunity to sit back to figure out what to do in this situation. Where tact is required, there is no chance to reflect in a deliberative, planning manner. Tactful action is always immediate, situational, contingent, improvisational.

Tactful action is always framed by the special orientation or commitment that defines my relation to others: there is tact in friendship, there is tact between lovers, and there is tact in the way that the parent or teacher is 
oriented to the child. The pedagogical orientation to children is conditioned by the intentionality of our love, hopes, and responsibilities. Wherein does pedagogical tact find its resourcefulness? First, we must realize that pedagogical tact is pedagogical understanding in being attentive to young people, through what we notice about them, in the way we listen to them. This is not a detached manner of observing 'behaviour', as a behavioural psychologist might do. Pedagogical understanding, as practised in everyday life, is more common in the natural attitude of everyday acting. ${ }^{6}$

\section{On pedagogical tact}

In general, tact implies sensitivity; a mindful, aesthetic perception. Webster's Dictionary (1985: 1201) defines tact as 'a keen sense of what to do or say in order to maintain good relations with others or avoid offense'. But, as I will try to show, the essence of tact does not inhere in the simple desire or ability to get on well with others, to establish good social relations with them. Tact has interpersonal and practical-ethical properties that appear especially suited to our pedagogical interactions with children. We speak of tact as an instant sense of knowing what to do, an improvisational skill and grace in dealing with others. Someone who shows tact seems to have the ability to act quickly, surely, confidently, and appropriately in complex or delicate circumstances. It is important to state as well that tact does not necessarily connote a soft, meek, acquiescent sensitivity. One can be sensitive and strong. A tactful person must be strong, since tact may require frankness, directness, or candour when the situation calls for it. Tact is always sincere and truthful. And even the tactful 'lie' is ethically never deceitful or misleading.

Tact consists of a complex array of qualities, abilities, and competencies. First, a tactful person has the sensitive ability to interpret inner thoughts, understandings, feelings, and desires from indirect clues such as gestures, demeanour, expression, and body language. Tact involves the ability immediately to see through motives or cause-and-effect relations. A tactful person is able, as it were, to read the inner life of the other person. Second, tact consists of the ability to interpret the psychological and social significance of the features of this inner life. Thus, tact knows how to interpret, for example, the deeper significance of shyness, hostility, frustration, rudeness, joy, anger, tenderness, and grief in concrete situations with particular persons. Third, a person with tact appears to have a fine sense of standards, limits, and balance that makes it possible to know almost automatically how far to enter into a situation and what distance to keep in individual circumstances. Finally, tact seems characterized by moral intuitiveness: a tactful person seems to sense what is good or the right thing to do.

The term tact, like tactile, refers to touch, which, according to Webster's Dictionary (1985: 1201) means to 'handle or feel gently with the intent to appreciate or understand' in more than merely an intellectual manner. We notice that touch can also imply violation or harm, as in the expression 'I 
never touched the child'; we speak of a 'touchy subject'. As for 'a touching scene', something is 'touching' when it is capable of arousing emotions of tenderness.

Tact touches a person with a touch, with a word, with a gesture, with the eyes, with an action, with silence. Etymologically, tact implies physical touch, but the noteworthy fact is that tact carries the ambiguous sense of a non-physical influence or effect of one human being on another. Tact is neither intrusive nor aggressive. Often tact involves a holding back, a passing over something, which is nevertheless experienced as influence by the person toward whom the tactful action is directed. Yet, tact does have a corporeal quality: thoughtfulness incarnates itself in tactful action.

We need to distinguish between tact and tactic. A tactic is a method for accomplishing an end. There is a calculating, planning meaning to tactic, in contrast, tact is essentially unplannable. In fact, tactic and tact are etymologically unrelated. Tactic is derived from Greek, where it referred to military science, the strategic talents of a general in moving his troops in battle. Someone who approaches teaching by way of tactics thinks of manoeuvres, stratagems, and master-minding a programme of directives and objectives. To be good at tactics means that one is good at getting or running an organization to execute some plan of action. Thus, tactics also connote superintendency supervision. The tactics of teaching are strategies, methods, and schema, ways and means that one draws up like a master plan, scenario, outline, blueprint, timetable, schedule, or design.

In contrast, tact derives etymologically from the Latin tactus, meaning touch, effect - from tangere, to touch. A related term is intact: untouched, uninjured. Tactful means fully in touch, and it also suggests being able to have an effect. Some of the synonyms of tact relate closely to what it means to be a good parent or educator: to be tactful is to be thoughtful, sensitive, perceptive, discreet, mindful, prudent, judicious, sagacious, perspicacious, gracious, considerate, cautious, and careful. Would any of these speak badly of an educator? In contrast, someone who is tactless is considered to be hasty, rash, indiscreet, imprudent, unwise, inept, insensitive, mindless, ineffective, and awkward. In general, to be tactless means to be disrespectful, ill-considered, blundering, clumsy, thoughtless, inconsiderate, and stupid.

Finally, there is the term contact, from the Latin contingere, which, according to Klein (1971: 162) means 'to touch closely' - connectedness, being in touch. The Latin prefix con often has the effect of augmenting the term to which it is attached. In other words, contact carries the same meaning as tact but in enhanced, intensified form: it refers to a close human relationship, intimacy, and connectedness. A teacher 'in touch', in 'close contact' with students, implies that the teacher's actions are governed by tactful sensitivity.

Most of us have an appreciation for the value of tact in social life. Often the word tact is used in situations where we are in some way stuck. Someone then says to us 'Well, yes, I guess this situation requires tact'. Saying this, however, is as much to confess one is at one's wits' end as to what exactly to advise. In this 
context tact is sort of a magical term that promises a solution without giving insight into it.

Tactful action is thoughtful, mindful, heedful. But it helps to make a distinction between thoughtfulness and tact. We should see that thoughtfulness and tact go hand in hand. They complement each other. Without thoughtfulness there is no tact, and without tact, thoughtfulness is at best merely an internal state. Thoughtfulness is the product of self-reflective reflection on human experience. In a sense, tact is less a form of knowledge than it is a way of acting. It is the sensitive practice of heedfulness. Tact is the effect one has on another person even if the tact consists, as it often does, in holding back, waiting, remaining passive.

This image of tact as a special interaction between people may be most relevant for education or pedagogy. However, there is an outstanding distinction to be made between, on the one hand, general social tact in the interaction between adults and, on the other hand, the more specific form of pedagogical tact in the interaction between adults and children. This distinction harkens back to the nature and structure of pedagogical relations. General tact in the lives of adults is symmetrical between them, while pedagogical tact is asymmetrical. Among adults we expect tactful behaviour to be reciprocal, in keeping with the nature and circumstances of the situation, and we teach children to practise general social tact towards other children and adults. To be tactful in a general sense means that we respect the dignity and subjectivity of the other person and that we try to be open and sensitive to the intellectual and emotional life of other people, whether young or old.

But as adults we do not have a right to expect from children pedagogical tact. Pedagogical tact is an expression of the responsibility we are charged with in protecting, educating, and helping children grow. Children are not charged with the pedagogical responsibility of protecting and helping their parents or teachers grow and develop. This does not mean, of course, that children do not teach us and do not show us new ways and possibilities of experiencing and being in the world. But children are not there primarily for us, we are there primarily there for them.

It is perhaps surprising that the notion of tact has not been of any systematic interest and study for educational thinkers in the English-speaking world. The person who introduced the notion of tact and tactfulness into educational discourse is the German educator, Johann Friedrich Herbart (1776-1841). In 1802, in his first lecture on education, Herbart told his audience that: 'the real question as to whether someone is a good or a bad educator is simply this: has this person developed a sense of tact?' Herbart posited that tact occupies a special place in practical educational action. The main points of his lecture pertaining to tact were that (a) 'tact inserts itself between theory and practice'; (b) tact manifests itself in everyday life in the process of 'making instant judgements and quick decisions'; (c) tact forms a way of acting which is 'first of all dependent on Gefühl (i.e. feeling or sensitivity) and only more remotely on convictions' derived from theory and beliefs; (d) tact is sensitive to "the uniqueness of the 
situation'; and (e) tact is 'the immediate ruler of practice' (Herbart, in Muth 1982: 54, 55).

However, in spite of this fluid early conceptualization, Herbart's later writings, and especially those of his followers, assumed a more instrumental relation between educational knowledge and practical action. Even in these phrases from Herbart there is evident a somewhat mechanistic concept of the mediating role of tact between theory and practice. But rather than see tact as a device for converting theory into practice, we may see tact as a concept that can help us to overcome the problematic separation of theory from practice. And rather than understand tact as a process of making instant 'decisions', we may reconceive tact as a mindfulness that permits us to act thoughtfully with children and young people.

In Germany, the notion of tact occasionally surfaces in discourse on the nature of pedagogical praxis, ${ }^{7}$ but in the English-speaking world a more technological and pragmatic rationality has governed theories of education and educational competence. The notion of tact has never been systematically studied, and references to tact in English texts about teaching are rare and sporadic. ${ }^{8}$

However, there is one, by the US philosopher and psychologist, William James (1842-1910), in a lecture he gave in 1892. He mentions 'tact' almost in the same breath as he speaks of Herbart. James discusses the relationship between psychology and pedagogy, which in the case of the great systembuilder, Herbart, were developed side by side. In no way, however, was Herbart's pedagogy derived from psychology, says James (1962). Pedagogy cannot be derived from psychology. Knowing psychology is absolutely no guarantee that we shall be good teachers:

To advance to that result, we must have an additional endowment altogether, a happy tact and ingenuity to tell us what definite things to say and do when the pupil is before us. That ingenuity in meeting and pursuing the pupil, that tact for the concrete situation, though they are the alpha and omega of the teacher's art, are things to which psychology cannot help us in the least.

(James 1962: 29)

James provides one brief example of what he understands by tact. He suggests how a tactful teacher can foster an early sense of scholarship in young people by working into school learning the characteristic of almost every child: the desire to collect things. 'Almost all children collect something', James (1962: 29) says. 'A tactful teacher may get them to take pleasure in collecting books; in keeping a neat and orderly collection of notes; in starting, when they are mature enough, a card catalogue; in preserving every drawing or map which they may make.' James's example suggests that the teacher should be sensitive to the child's early impulses and connect these inclinations to the school curriculum.

We should note that there is more involved here than the more commonly agreed-upon challenge for teachers to motivate their students and to make 
things relevant to them. But what exactly is involved in that ingenuity or tactfulness of which James speaks? He professes that this fundamental question lies outside the domain of the psychologist. After thus indicating that psychology has little or nothing directly to say to pedagogy, James makes no further reference to tact.

The important point for us here is that James reminds us that it is tact that is the operative notion that defines what a teacher does in a pedagogical moment. Tact is the pedagogical ingenuity that makes it possible for the educator to transform an unproductive, unpromising, or even harmful situation into a pedagogically-positive event.

Pedagogical thoughtfulness and tact do not of course describe everything teachers (educators or parents) know, are, or do. There are many routine and more technical aspects to teaching and parenting. Teachers must know how to plan lessons, how to fill out report cards, how to make effective use of media; parents must be able to change nappies, keep house, prepare nutritious meals. But the real stuff of teaching and of parenting happens in the thick of life itself when one must know with a certain confidence just what to say or do (or what not to say or do) in situations with children. Therefore, pedagogical thoughtfulness and tact may be seen to constitute the essence and excellence of pedagogy. We might say that thoughtfulness constitutes the internal aspect and tactfulness the external aspect of pedagogy. Pedagogy is structured like tact. And at the heart of teaching lies pedagogy.

\section{Tact as improvisational acting}

Herbart was by no means the only scholar to use the notion of tact in referring to a special quality of human interaction. ${ }^{9}$ Gadamer (1975: 17) refers to the work of a near-contemporary of Herbart, the physiologist Hermann Helmholtz (1768-1834), to bring out two aspects of tact: tact as one aspect of human interaction and tact as social-science scholarship. In the first sense, tact is commonly understood as 'a particular sensitivity and sensitiveness to situations, and how to behave in them', but for which 'we cannot find any knowledge from general principles'.

In the second sense, tact is practised through scholarship - such as developing a sense of the aesthetic or the historical - that the social scientist uses to do his or her interpretive work. The scholar demonstrates the measure of his or her tact by insights that he or she is able to produce with respect to the meaning of a text or a social phenomenon. In making this distinction, Helmholtz had suggested that tact is not simply a feeling or unconscious inclination, but rather that tact is a certain 'mode of knowing and of being' that encompasses the important human science notion of Bildung (formation or education) (Bollnow 1987). There is an implication, therefore, that tact is not a simple affect or learnable habit, but that it can be fostered through the more profound process of humanistic growth, development, and education. In passing, we should note that the notion of 'tact in scholarship' is exercised in a different modality from 
tact in human interaction. Tact in scholarship is usually practised while reading or writing texts. This is a highly reflective human activity. In contrast, tact in human interaction is usually practised on the spur of the moment where one is required to act in an instant or immediate fashion.

The German philosopher Friedrich D.E. Schleiermacher (1768-1834) has also written on the substantive aspects of tactful action (Muth 1982). Schleiermacher employed the notion of 'tone' to describe that special quality in human interaction that allows a person to behave with sensitivity and flexibility toward others. In ordinary present-day language, we still say of a tactful person that he or she is able to 'strike a good tone', thus creating a warm social atmosphere. When we walk into different schools or classrooms, we are often struck by the presence or absence of this tone or atmosphere that somehow hovers in the social environment. This is not just a matter of how teachers and students speak to each other. A 'good tone' comprises more than linguistic intonation or tone of voice. It is accomplished through such communicative devices as a 'meaningful' wink or word, glance or gesture, smile or silence, posture or presence.

Appropriately, the notion of 'tone' refers also to music, from where the concept of tact was originally derived. In music, Takt is German for 'beat', the unit of musical time. The German word for the conductor's baton is Taktstock, the stick that beats time. The Latin tactus is a fifteenth- and sixteenth-century term for 'beat', both with temporal meaning and as in 'conductor's beat'. The musical notion of beat refers to the 'pulse' underlying a musical work - beat or pulse are elemental in the rhythmic quality of a work. The rhythmic beat or pulse in music is the heart of music. The musician knows that beat, pulse, or rhythm can exist without melody, as in percussion ensembles or in the drumbeats of African music, but melody cannot exist without rhythm.

Shifts periodically occur in the application of rhythm to music. Such a shift took place between the Baroque and Rococo period on the one hand, and the Classical and Romantic music that followed them on the other hand. The already strict rhythmic modes of the thirteenth century and the oratorical speech chants of the Renaissance were followed by the strong body rhythms of Baroque musicians such as Bach, Vivaldi, and Handel. In this music, the beat was more vigorous or even mechanical, not unlike the role of the rhythm section in jazz. So important was this strong, ever-present beat that the conductor of a musical group at the time of the Renaissance and the Baroque commonly would conduct a piece of music by banging his stick on the ground. Jean-Baptiste Lully, the French composer and conductor, died of blood poisoning in 1687 when he accidentally stabbed himself in the foot with his stick while banging the beat during a musical performance at the court of the French King Louis XIV (McLeish and McLeish 1982). When later conductors stopped banging the beat with a stick, this may have had something to do with the changing function of Takt in music. With the Classical masters (such as Haydn, Mozart, the early Beethoven) and the Romantic masters (such as Chopin, Schumann, Liszt, and Brahms) the beat that organizes the music grew more subtle, retreating somewhat and becoming less ever-present to the ear. This shift of 


\section{2}

Takt from the regular, mechanical, vigorous mode to more subtle and restrained forms may have contributed to the application of the notion of tact to the social sphere, where it acquired the meaning of subtle sensitivity and of restraint or holding back in human relations and interaction.

It is thought that Voltaire was the one who, around 1769 , imported the notion of tact from the musical domain into the social sphere (Onions 1979: 899). The Germans, Dutch, and English adopted this usage from the French. But only in German educational theory has there been an articulation and discussion of tact in a pedagogical sense. Moreover, the German Taktgefübl expresses a more subtle sentient quality than the English 'tactfulness'. The term Gefübl means feeling, sensitivity, sentiment, the sentient quality of having a 'feel' for something. Thus, to be tactful with another person one must be able to 'hear', 'feel', 'respect' the essence or uniqueness of this person. The English 'tactful' means having the quality of tact and literally being full of tact. The German word Taktgefübl has the additional connotation of having a feeling for tactfulness. There is a hint here that the quality of tact is somewhat like talent. We often think of talent as a fortuitous gift - either you are or you are not blessed with a 'feel' or talent for the violin, the canvas, or the stage. But, of course, talent must be recognized, developed, nurtured, and disciplined. Similarly, pedagogical tact, although a gift in some sense, needs to be prepared and practised as a special 'feel' for acting tactfully.

Naturally, musical 'tact' is at best a metaphoric referent or analogy for social tact. It is usually misleading to try to follow the many possible implications of metaphoric comparisons, but it is tempting to venture a few steps further with the musical metaphor. In music, the basic chords, beat, and pulse are the elements on which the melody can be improvisationally created. It should be realized that Takt and melody are not mutually exclusive however - they need each other. Yet, Takt (beat, pulse) needs to retreat to the background and loosen its grip on the total musical situation for the more subtle improvisations of melody to become possible. And rhythm can even become the organizing element in the performance of musical improvisation. So the existence of the musical metaphor of Takt may prompt us to wonder: what are the organizing elements that make tact in social life possible?

The tact that adults are able to show with children is a function of the nature of pedagogy itself. In other words, pedagogical tact is made possible by the nature of the pedagogical moment, the values and orientation of pedagogical reflection, the conditions of pedagogy, the elements of pedagogical understanding, the structures of pedagogical situations and relations, and so forth (van Manen 1991). What needs to be elaborated, however, is how tactful pedagogical acting itself is structured: what is pedagogical tact? And what is false tact? How does it manifest itself? What does pedagogical tact do? How does pedagogical tact do what it does? 


\section{Ethical aspects of tact}

As we have seen, pedagogical tact is a special case of general social tact. Tact is certainly not an esoteric theoretical phenomenon. We recognize it as a common feature of everyday social life. We know in a way what tact is, yet we rarely reflect on its meaning. More often we may become aware of tact only when we experience situations where tact was sorely missed.

'Just look at that! That's no way to treat a child!' Who has never said something like this? It is what we exclaim when we see or hear of cases of child-abuse or neglect. And sadly enough, physical, psychological, and sexual abuse of children appears to occur all too commonly. We even feel disturbed or aghast when we observe an adult demonstrate insensitive behaviour toward a child who is at play, in need, or somehow getting in the way of an adult's activity.

When one adult insults another adult or hurts the other's feelings, we may consider such person ill-mannered or boorish. But when an adult hurts a child's feelings we tend to become even more deeply upset. We realize that in certain respects children are more vulnerable than adults - they may experience fear or terror that is more terrible than it would be for adults. In short, most adults recognize that children require different treatment from adults. For example, babies seem fragile and seem to require tenderness; adults will even adjust their tone of voice to the child's size and produce 'motherese' or 'parentese' chatter for the benefit of the infant. (In my experience, very young children respond positively to 'motherese' talk and seem to prefer it to normal talk.) When we sense that a child is fearful or anxious about something, we may try to alleviate the fear or calm the child down. Some things we won't talk about in the child's presence because we feel that the child is not yet old or mature enough to deal with such matters.

In other words, we all know about tact and the need for it in our dealings with children. Yet we do not speak of it. Theories of education are surprisingly silent about the practical significance of the ethical quality of tact and its behavioural manifestations. Is it because we assume that tact is merely an extra, something desirable perhaps, but in truth superfluous to the real business of educating children? Or is it because tact is so self-evidently part of everyday life that we do not tend to wonder about its meaning?

There is a meaning to tact that distinguishes it from associated behaviours, such as 'diplomacy', 'courtesy', 'savvy', 'address', 'poise', 'savoir faire', or 'finesse' - even though these are terms often provided as synonyms of tact. For example, a diplomat is 'diplomatic' for the purpose of manipulating perceptions for political ends. This does not necessarily mean that a diplomatic person would lie or be deceitful, but while diplomacy may not involve telling untruths, it may involve withholding truths that should actually be told. A diplomat is ultimately motivated by self-interest, or by the interest of the party that he or she is representing. Tact, in contrast, is always in the service of the person towards whom the tact is directed. Without pursuing these distinctions much further, we might briefly note that tact avoids the political motivation and 
conciliation of 'diplomacy', it lacks the implication or it does not stress the idea of dexterity and preoccupation with success in trying circumstances as does 'address', it lacks the calculating cleverness of 'being savvy', tact is not self-conscious of its own social bearing and self-possession as is 'poise', it does not emphasize worldly experience and a sure awareness of expediency as does 'savoir faire', and it is more concerned with what is ethical or good than with refinement of approach like 'finesse'. In the following sections some aspects of the nature of tact are further examined, with a particular focus on pedagogical tact.

\section{Tact means the practice of being oriented to others}

To exercise tact, one must be able to overcome an orientation to the world that seems to come 'naturally' to human beings, the attitude of seeing oneself at the centre of all things. Every child, every adult experiences the taken-for-granted relation of self to the world: I live my life; this is my world in which I live. I am at home in my world. 'I live here' means I exist here and I belong here. When I speak or interact with others, I am constantly the subject of my discourse and my actions: $I$ think, $I$ see, $I$ feel, $I$ hear, $I$ understand, $I$ love, $I$ do, $I$ play, $I$ wonder about things. I am involved in projects in the world that define my relation to the world, and which show who I am in the world. I make a meal. I favour certain foods. I enjoy reading a book. I have an opinion about certain people or about what they do. I work at certain things. I am proud of my accomplishments or I feel dissatisfied or unhappy with what I have done or what others do to me. I may go to watch a movie, to the pub, or to church. The point is, I am the centre of my universe. I am my world.

When things go well I may feel 'on top of the world'. Everything seems just right. The things in the world exist as if they are there just for me. This world is my home, my kingdom. I belong here. Sometimes this experience of the centrality of the 'I' can turn existentially oppressive for the individual. I cannot help but feel that ultimately I am alone in the world. When I undergo a crisis or when I suddenly face serious illness, then I feel forsaken, shaken. This will be my death. In the awareness of my mortality and of my impending end, my world can shrink into a small circle of despair.

This experience of the primacy of the 'I' in my world is neither good nor bad. It is the way human beings may experience the world, know the world, recognize the world as theirs. But of course this is not the whole of human experience. The human being is not alone. Some people may prize aloneness, independence, separateness; others may suffer from loneliness and alienation from others. Yet in these experiences, the felt absence or presence of others is already implicit. In the world, we experience the other person. There are other people who live beside me. There are others whom I encounter in the world. The question is: how do the others appear to me? Are they there simply for me, as parts of my larger world? Are the others only important for me insofar that they add to or subtract from my world? Are the others just there as objects for the satisfaction of my wants and needs: to be used, manipulated, made available by me and to me? 
I do not really experience the subjectivity of the other until I am able to overcome the centredness of myself in the world. The fascinating fact is that my possibility of the experience of the otherness of other resides in my experience of the vulnerability of the other. ${ }^{10}$ It is when I see that the other is a person who can be hurt, distressed, pained, suffering, anguished, weak, in grief or in despair that I may be opened to the essential being of the other. The vulnerability of the other is the weak spot in the armour of the self-centred world. I see a child who is hurt or who is in agony and, temporarily at least, I forget my present preoccupations. No longer am I driven by my personal agenda. For the moment I am just there for this child, for this other person. With this recognition of the other comes the possibility of acting for the sake of the other. So when a child is hurt and I actually 'see' this child in his or her vulnerability, then I am in a position to do something for this child. In fact, most probably the situation is such that I find myself oriented to the child before I even think about it.

A mother has just received a telephone call from the physician: the results of a medical test, that had seemed to indicate the presence of a terrible malignancy, have turned out on retesting to be benign. The relief of pent-up anxiety is so strong that the woman breaks down in tears. When the six-year-old enters the room and sees his mother wipe away the tears he asks, 'What's wrong, Mum?'. 'It is nothing, dear', the mother smiles. 'You know, sometimes I feel so lucky to have you that I cry from happiness. Come and let me give you a hug.' The mother feels that she cannot tell the young child about her own fears and vulnerabilities. Rightly or wrongly, she instantly senses that the thought of his mother's fear of dying is too much to burden this young child with. But there is something else she now knows. She knows that she values life, but that she would sacrifice it for her child.

A young, single mother of a three-year-old son is interviewed on television. She knows that she carries the AIDS virus and that she will probably die from the disease. One cannot help but feel deeply moved for this young woman. How terrible to be so young and to know oneself to be so near death. But the mother speaks with remarkable strength and hope. 'All I hope for', she says, 'is that I will live long enough, long enough to give my child a good start in life.'

We are all vulnerable. And yet we know that children are vulnerable in ways that adults are not. Especially with very young children (and even with young animals) it is quite common for adults to experience this sense of disarming vulnerability. Naturally, this vulnerability on the part of the child can be abused by the adult who may feel self-important and powerful in the face of the child's need for protection or help. Yet the adult feels disarmed and mellowed when he or she sees the child making mistakes or doing things that seem awkward and so 'typical of children'. Think of the laughter that children get on the occasion of the 'not always perfect show' during the Christmas performance in front of the parents and the community. It is not a mocking or derisive impulse that moves adults to laughter when children unintentionally behave drolly or comically. The good-natured laughter is indicative of the adults' knowledge of the difference between being an adult and being a child. 
It is in the face of the child's defencelessness and vulnerability that adults find it easy to be generous and giving. But what happens when a child turns rightfully self-righteous and demanding? How well can the adult still see the child's vulnerability and the child's otherness when the adult is too selfpossessed, too preoccupied with the projects and concerns of the self?

Of course, in a real sense every human being is vulnerable; every human being is mortal and subject to fears and dangers. Every human being is my other. The other is actually or potentially weak and vulnerable, just as I know myself to be actually or potentially weak and vulnerable. However, the existence of the other does not merely manifest itself as my feelings of pity or compassion for the hurt or suffering of this other person. More pointedly, I experience the other as a voice, as an appeal to me. And this is what we mean when we speak of our living with children as a vocation, a calling.

The experience of the other is the breaking of the silence of my world, which is centred in the ' $\mathrm{I}$ '. The voice of the other de-centres my universe. In this sense we may say that the newborn child de-centres the 'self' of the world of the woman and the man. The child changes the world of woman or man into the world of mother or father, and thus the woman is transformed into mother and the man is transformed into father. Of course, not every man or woman experiences the coming of a child as a transformation into parenthood. Some have great difficulty accepting responsibility by making room in their lives for their children. But luckily it is common that sooner or later the new mother or father experiences the birth of their child as an appeal. The new-born in its vulnerability calls on me to care for it. And the experience of this appeal transforms me from woman into mother or from man into father. I now must act in thoughtful attunement to the other for the other. In this sense, tact is the practice of being oriented to others.

\section{Tact is governed by insight while relying on feeling}

It is generally impossible to plan a tactful action or response. We become aware of the unplannable nature of tact when, for example, we have the unpleasant task of breaking bad news to a person for whom we care. Beforehand, we may find ourselves rehearsing the kinds of things we feel we should say. We need to be gentle. We don't want to create unnecessary hurt by being too blunt or saying something insensitive. We want to do what is right for the other person. But then, when we find ourselves in the situation, we usually let go of our mental script, for fear of being artificial. We meet the other person and with our eyes we search the person's face for the right words - which usually come forth. Tactful action cannot be planned or charted out beforehand - it always realizes itself in concrete and unexpected or unforeseeable situations in which one finds oneself and in which one must serve, help, or respond to another person. But even though tact is unplannable, one can prepare for it - one can prepare the heart and mind.

In teaching it is often the unsteady, unstable, inconsistent, variable moment 
that requires tactful action of a sort that is essentially unplannable. And these unstable moments are not accidents in teaching but rather are essentially an integral part of teaching.

We think of tactfulness as a caring orientation to others. On the one hand, 'caring' is the willingness to take on burdens, trouble, or grief for others. On the other hand, to be caring is to be heedful, affectionate, loving, tender. The term caring connotes an attitude and feeling rather than an ability or skill. I may care about something or somebody but not know what to do, or be incapable of doing what I should do. By contrast, although it seems appropriate to say that 'tact' also implies a sense of caring, yet tact is more complex than the notion of caring. To be tactful is to be able to take other people's feelings into account. Tact is being sensitive to delicate situations; having a feel for what other people require. But tact is not merely a feeling or a sentiment. So it would not be right to say that tact belongs to the affective rather than to the intellectual or cognitive domain, an artificial distinction commonly made in education. Rather, tact is the expression of a thoughtfulness that involves the total being of the person, an active sensitivity toward the subjectivity of the other, for what is unique and special about the other person.

Tact is a kind of practical intelligence that is governed by insight while relying on feelings. Tact is possible because human beings are capable of exercising the complex faculty composed of perceptiveness, sensitivity, insight, and being attuned to each other's experience. This is true for adults as well as for children. Children are often quite sensitive to the mood, disposition, or authentic spirit of the adults in their shared lives. Children are often capable of remarkable tactfulness in their interactions with other children or adults. But as they get hardened and dulled by the process of growing up, children may become increasingly insensitive to the subtleties of other people's experiences.

To exercise tact means to see a situation calling for sensitivity, to understand the meaning of what is seen, to sense the significance of this situation, to know how and what to do, and to actually do something right. To act tactfully may imply all these, and yet tactful action is instantaneous. The perceptiveness needed, the understanding and insight required, the feeling for the right action are not necessarily separate stages in a sequential process. Somehow, insight and feeling are instantly realized in a mode of acting characterized by a certain thinking attentiveness.

\section{The tactful structure of pedagogical action}

There are no rules to follow for being tactful. There are no theories or models that explain the principles for behaving tactfully. It is impossible to reduce tact to a set of techniques or skills for acting predictably and consistently in situations calling for tact. In spite of this uncontrollable nature of tact, it must be said that tact expresses itself in a positive and normative manner in practical situations. At the basis of tact lies a certain thoughtfulness or mindfulness that animates tactful behaviour. 
A comparison of tact with social custom or etiquette may be instructive. Tact is not the same as etiquette. To know etiquette is to know what social rules or manners to use in particular circumstances (as with table manners, for example). On the surface, tact may look like etiquette, since etiquette is concerned with what to say or how to behave in order to maintain good social relations. But etiquette deals with prescribed conduct or procedures required in social and official situations. Practising etiquette may suggest a sign of good upbringing. The rules of etiquette are laid down by tradition or authority. Etiquette is in the end predictable, rule-governed behaviour. Tact lacks such a set of definite rules. Instead, tact is improvisational.

In certain areas of everyday life - such as in living with children - tact may be the basic feature of human interaction. In this sense, tact rules praxis (defined as 'action full of thought, thought full of action'). Tact rules practice, although tact cannot be reduced to rules. Yet tact is not in itself unruly. In other words, tact is not arbitrary, it does not operate randomly. Tact demands a delicate discipline. Tact requires that one can 'read' or interpret social situations for what actions or words are appropriate. Tact requires that one knows how a situation is experienced by the other person.

Everyday practical action is carried by our orientation to life rather than determined by a particular set of technical skills or competencies (van Manen 1977). In acting tactfully I demonstrate unwittingly what I can do as a pedagogue with children. In thoughtful reflection I later discover what I have done, what tactful action I am capable of demonstrating. As I reflect pedagogically on my daily living with children I discover my pedagogical nature, its present limits and possibilities.

Thoughtful reflection discovers where unreflective action was 'thoughtless', without tact. Thus the experience of reflecting on past pedagogical (teaching) experience enables me to enrich, to make more thoughtful, my future pedagogical experience. This is not just an intellectual exercise, but a matter of pedagogical fitness of the whole person. What we might call 'pedagogical fitness' is a cognitive, emotional, moral, sympathic and physical preparedness. Indeed, as I have already proposed, acting tactfully is very much an affair of the whole embodied person: heart, mind, and body.

We can speak of pedagogical thoughtfulness as a form of knowledge; and yet pedagogical thoughtfulness is less a body of knowledge than a mindfulness oriented toward children. To think of thoughtfulness as an oriented mindfulness may remind us of the etymological connection between thought and mind; the word mind shares roots with the term man, human. Originally man did not refer only to the male half of the human species. It meant 'human being' as in the German term Mensch and the Dutch mens. Klein (1971: 466) suggests that the roots of both mind and man stood for the 'one who thinks', 'who remembers'.

The term mind is also related to minne, which originally meant 'loving memory', while the Greek etymology of the term includes 'desire, ardour, spirit, passion'. Now, if thoughtfulness has a spiritual quality of 'minding', then tact- 
fulness is its concrete equivalent. As we saw earlier, the term tact carries this physical reference to 'touch', 'body', 'tactile'. To be tactful is to be physically mindful of the person toward whom one is oriented; to be tactful is to incarnate one's reflective thoughtfulness in concrete and contingent situations. If we were to epistemologize the relation between reflective thoughtfulness and tactfulness, we might say that tact is the embodiment, the bodywork, of thoughtfulness.

By stressing the embodied quality of tact I do not mean to suggest that the mind is less involved in this knowledge, but rather that tact is a more than intellectual knowing. Often there exists a wide gap between what we know intellectually or theoretically and our practical actions. For example, I may know intellectually that smoking is bad for me, but I continue to smoke. I may know theoretically that children learn best if provided with positive encouragements, but I continue to criticize. In contrast, tact integrates in more intimate ways mind and body, intellect and heart, reason and emotion. For example, a teacher spontaneously raises her voice enough so that her praise of a student who had not experienced much success is overheard by others - and the student glows with pride. A parent automatically draws a child's attention away from a situation that could be emotionally disturbing. A teacher unconsciously glances with admonishment at a student who is about to ridicule another student in class.

These tactful gestures of encouraging, shielding, admonishing children are thoughtful even though the gestures were sudden, unanticipated, impulsive, and spontaneous. This shows that thoughtfulness is a quality that can characterize immediate action as well as meditative reflection. We can become more thoughtfully tactful through thoughtful reflection on the pedagogical significance of children's experience. There is a difference between the artificial thoughtfulness that is created by the mechanical application of an external technique or skill and the authentic thoughtfulness of true tact. Tact is not a skill we use, it is something we are. Thus, when we speak of the embodied thoughtfulness, mindfulness, heedfulness of tact we point at the way a person is in mind and body.

Tact is a kind of embodied knowledge. We all know that the human body acquires or learns certain bodily skills and habits that become like second nature in our living. When I am thirsty I take a cup from the usual place, I turn the tap on, and then 'thoughtlessly' tighten the tap. In a way, I leave this routine behaviour almost blindly to my skilled and habituated body. This does not mean that I am not aware of what I am doing, but that I can do habituated bodily things without having to do them attentively and consciously. Only when the tap won't open or when the water smells foul would we probably break our routinized behaviour.

For many things in life we rely on our body's knowledge to perform certain tasks. Where is the light switch? How do you tie a knot? Which way does the tap turn on? We may have to simulate the gesture to discover what our body already knows. A variety of intellectual tasks too rely on this kind of body skill: 'How do you spell "lieutenant"?' Sometimes we may have to write the word on 
paper to discover what our fingers already know. Our body skills also permit us to perform actions that require flexibility and spontaneity, as when we drive a car or a bike across town. Once at our point of destination we may remember little of all the stops we made - our skilled body guided us through the hectic traffic.

Thoughtfulness and tact are not identical to skills and habits, yet they are like this constellation of embodied skills and habits that have become second nature and determine to an extent who we are, who we have become, what we are able to perceive, understand, and do. According to Klein (1971: 688) the word skill is related to the term skilja, the ability to discriminate, to distinguish, to separate between things that make a difference. Etymologically, skill means 'to have understanding', 'to make a difference'. So the notion of bodily skill is an unexpected ally in our exploration of the nature of thoughtful pedagogical perceptiveness.

When I teach a group of children and I notice that some children experience shyness, exuberance, frustration, animation, boredom, wonderment, curiosity, puzzlement, confusion, or insight, then what I see is less given by a technical instructional skill that I may have learned in a teacher-effectiveness workshop than by a more embodied orientational pedagogical skill that I have acquired in a more experiential and reflective manner. However, this skill of perceptiveness (of sensing, for example, what a situation means for a child) is something I cannot practise to do in the same way that I may be able to practise a skill such as lesson-planning, classroom management, or even story-telling.

Pedagogical perceptiveness relies in part on a tacit, intuitive knowledge that the teacher may learn from personal experience, or through apprenticeship with a more experienced teacher. Most human activities that depend on knowledge and skills involve tacit or intuitive complexes. For example, medical doctors confronted with certain symptoms may intuitively sense what is wrong with a patient on the basis of such tacit understandings - even though the symptoms may not be that easy to pinpoint or articulate. ${ }^{11}$ Just so, a teacher who senses that a child has certain difficulties in dealing with a problem may not be able to identify exactly on what clues the perceptive understanding was based. The tacit or intuitive nature of our bodily skill and bodily knowledge is learned in subtle ways by attuning ourselves to the concrete particulars of situations.

The skill of pedagogical perceptiveness inheres in the thoughtfulness and tact that we learn through the practice of teaching, but not simply by teaching itself. We come to embody tact by means of past experiences coupled with thoughtful reflection on these past experiences. We reflectively acquire intuitive sensitivities and action-sensitive insights in various ways - as through literature, film, stories by children, stories about children, and childhood reminiscences.

Of course, the processes of thoughtful reflection are also experiences. Thoughtful reflection may constitute a kind of experience that gives significance to or perceives meaning in the experiences on which it reflects. So the significance that we attribute through thoughtful reflection to past experience can leave a living memory that is no less embodied knowledge than are the physical 
skills and habits we learn and acquire in a less reflective manner. And this thought-engaged body knowledge of acting tactfully attaches an attentive or thinking quality to our ordinary awareness of our everyday actions and experiences. $^{12}$

\section{Notes}

1 For this text I have borrowed selected passages from van Manen (1991).

2 I use the words 'ethical', 'moral', and 'normative' here where Langeveld usually employed the Dutch term ' $z e d e$ '. The term 'zede' has some associations with the idea of what is valued as acceptable and customary in a specific human community. Although the terms 'practical ethics', 'morality', and 'normativity' are not perfect translations, in this context, they refer to considerations of everyday practical acting where we have to distinguish what is appropriate from what is less appropriate or inappropriate in our dealing and living with children. Langeveld's basic argument was that the 'zede' rather than the 'rede' (ethics rather than reason) determines everyday pedagogical actions, that is, how we bring up children around the home and in schools.

3 It is fascinating how some of the dominant models of 'reflective teaching' or 'teaching as reflection-in-action' curiously wind up resembling the process of scientific inquiry itself, complete with 'rigour in on-the-spot experiment', 'hypothesizing', and 'testing'. See, for example, Schön $(1983,1987)$.

4 Of course, medical situations are often ethical (moral) as well. However, the medical question of whether to perform an amputation of a gangrenous leg, for example, is a purely medical decision for the specialist to the extent that the specialist must know what alternative procedures are available and what consequences and possible risks are involved in the decision to amputate a diseased portion of a limb. The ethical or moral dimensions of medical decisions usually have to do with considerations that non-specialists can participate in as well.

5 This awareness may not be completely unlike the kind of check on the acting 'self' that characterizes the work of the stage actor. Stage actors often report that they somehow remain transiently aware of their acting behaviour even though the acting itself should be a total immersion into the spirit of the role that they are creatively assuming. But in acting, a role or persona is in some way, of course, an assumed and 'false' self. In contrast, the pedagogue (teacher or parent), in acting with children, needs to remain true to his or her own being.

6 For further explanation of pedagogical understanding see van Manen (1991).

7 The best reference is probably a small but comprehensive book on tact in German educational theory by Jakob Muth (1982).

8 I thought that I had coined the notion of 'pedagogical tact' (see, for example, van Manen [1984, 1986]). However, I later became aware of the discussion of pedagogical tact in the older German literature, especially after my friend and colleague, Helmut Danner, sent me a booklet by Jakob Muth (1982). Muth's text proved useful for the historical background and formulations on some aspects of pedagogical tact further developed in this essay. In Muth's review of the notion of tact I subsequently found the 1802 Herbart lecture.

9 Muth (1982) cites from the early works of predecessors of Herbart to show that the feeling of 'sensitivity' and the attitude of 'holding back' in tactful acting was already being discussed.

10 For a discussion of the nature of otherness and the human responsibility that flows from the experience of otherness see especially Emmanuel Levinas $(1969,1981)$.

11 Michael Polanyi (1958) has argued that while we learn all kinds of details about ordinary things, these details form a silent or 'tacit' knowledge. We have a hard time 


\section{Max van Manen}

expressing how we know these things. For example, I recognize the face of a friend out of a crowd of passers-by, and yet I would have difficulty telling what it is about my friend's face that makes it possible for me to identify this person as my friend. And Polanyi argues that this proves that 'we know more than we can tell'. Somehow we are able to integrate our many impressions and particular experiences into holistic intuitions; and these intuitions Polanyi calls 'personal knowledge' that each individual must acquire in order to gain competence at certain tasks. For example, a medical doctor cannot just learn from a book how to recognize certain symptoms. The physician has to learn these often subtle diagnostic skills through experience or through apprenticeship. Personal knowledge is a process of moving from a subsidiary awareness of particulars to a focal awareness of an integrated whole. Polanyi distinguishes between four analogous structures of tacit knowledge: understanding physiognomies, performance of skills, the use of the senses, and the mastery of tools. Although Polanyi's analysis of personal knowledge as a from-to function of the relation between particulars and whole may be somewhat mechanistic, his notion of tacit knowledge is experientially appealing. It is comfortably similar to the idea of bodyknowledge and body-skills that also emphasizes the importance of the personal or embodied nature of knowledge.

12 For a more detailed exploration of how tact operates in teaching see van Manen (1991).

\section{References}

Bollnow, O.F. (1987) Crisis and New Beginning: Contributions to Pedagogical Anthropology, trans D. Moss and N. Moss (Pittsburgh, PA: Duquesne University Press).

Calderhead, J. (1989) 'Reflective teaching and teacher education', Teaching and Teacher Education, 5 (1), 43-51.

Dewey, J. (1973) 'Experience and thinking', in J.J. McDermott (ed.), The Philosophy of John Dewey (New York: G.P. Putnam's Sons), 494-506.

Gadamer, H.-G. (1975) Truth and Method, trans W. Glen-Doepel, eds G. Barden and J. Cumming (New York: Seabury Press).

James, W. (1962) Talks to Teachers on Psychology (New York: Dover).

Klein, E. (1971) A Comprehensive Etymological Dictionary of the English Language (Amsterdam, The Netherlands: Elsevier).

Langeveld, M.J. (1975) Personal Help for Children Growing Up: The W. B. Curry Lecture Delivered at the University of Exeter on 8 November 1974 (Exeter, UK: University of Exeter).

Levinas, E. (1969) Totality and Infinity: An Essay on Exteriority, trans A. Lingis (Pittsburgh, PA: Duquesne University Press).

Levinas, E. (1981) Otherwise than Being: or, Beyond Essence, trans. A. Lingis (The Hague: Martinus Nijhoff).

McLeish, K. and McLeish, V. (1982) The Oxford First Companion to Music (London: Oxford University Press).

Muth, J. (1982) Pädagogischer Takt (Essen, Germany: Neue Deutsche Schule).

Onions, C.T. (ed.) (1979) The Oxford Dictionary of English Etymology (London: Oxford University Press).

Polanyi, M. (1958) Personal Knowledge: Towards a Post-Critical Philosophy (Chicago: University of Chicago Press).

Rilke, R.M. (1982) The Selected Poetry of Rainer Maria Rilke, ed. and trans S. Mitchell (New York: Random House). 
Roth, H. (1964) Pädagogische Psychologie des Lehrens und Lernens (Hanover, Germany: Schroedel).

Schön, D.A. (1983) The Reflective Practitioner: How Professionals Think in Action (New York: Basic Books).

Schön, D.A. (1987) Educating the Reflective Practitioner: Toward a New Design for Teaching and Learning in the Professions (San Francisco, CA: Jossey-Bass).

van Manen, M. (1977) 'Linking ways of knowing with ways of being practical', Curriculum Inquiry, 6 (3), 205-28.

van Manen, M. (1982) 'Edifying theory: serving the good', Theory into Practice, 21 (1), 44-9.

van Manen, M. (1984) 'Theory of the unique: thoughtful learning for pedagogic tactfulness', in G. Milburn and R.J. Enns (eds), Curriculum Canada VI: Alternative Research Perspectives: The Secondary School Curriculum: Proceedings of the Sixth Invitational Conference of the Canadian Association for Curriculum Studies (Vancouver, BC: University of British Columbia, Centre for the Study of Curriculum and Instruction), 63-80.

van Manen, M. (1986) The Tone of Teaching (Richmond Hill, ON: Scholastic-TAB; Portsmouth, NH: Heinemann).

van Manen, M. (1990) Researching Lived Experience: Human Science for an Action Sensitive Pedagogy (Albany, NY: State University of New York Press; London, ON: Althouse Press).

van Manen, M. (1991) The Tact of Teaching: The Meaning of Pedagogical Thoughtfulness (Albany, NY: State University of New York Press; London, ON: Althouse Press).

Webster's Ninth New Collegiate Dictionary (1985) (Markham, ON: Thomas Allen). 


\title{
5 Didaktik analysis as the core of the preparation of instruction
}

\author{
Wolfgang Klafki
}

The following chapter was first published in the journal Die Deutsche Schule in $1958^{1}$ and later appeared in several editions of collected papers on instructional preparation, as well as in my book Studien zur Bildungstheorie und Didaktik (1963). The concept I developed was used for about two decades in pre-service teacher education at many universities and colleges in what was then West Germany and, particularly, in the second, school-based phase of initial training. It is still in use in places today.

The concept drew on and developed theory of education (Bildungstheorie) from the field of human-science pedagogy (Geisteswissenschaftliche Pädagogik), especially Didaktik, the theory of contents and curriculum (Theorie der Bildungsinhalte und des Lehrplans), as developed, in particular, by Erich Weniger. My formulation of the concept incorporated experience I gained as a teacher in primary and secondary modern schools and at the teachers' college in Hanover from 1956, supervising student teachers on teaching practice in schools in different types of localities.

When I later came to develop the human-science theory of education (Geisteswissenschaftliche Bildungstheorie) and Didaktik into a critical-constructive theory of education from the end of the 1960s onwards, I also began to revise my concept of instructional preparation. This work led first to the essay Probleme einer Neukonzeption der didaktischen Analyse (1977) and then to the paper 'Überlegungen zur Unterrichtsplanung im Sinne kritisch-konstruktiver Didaktik' (1980; reprinted in Adl-Amini \& Künzli 1980). The most recent version is contained in the essay 'Zur Unterrichtsplanung im Sinne kritisch-konstruktiver Didaktik' in my Nene Studien zur Bildungstheorie und Didaktik: Zeitgemäße Allgemeinbildung und kritisch-konstruktive Didaktik (1993). ${ }^{2}$

There is scope here to cite only the salient points that influenced the revision of my concept of instruction planning:

- My earlier position was rooted in the human-science pedagogy (Geisteswissenschaftliche Pädagogik) of Erich Weniger, Theodor Litt, Herman Nohl, Eduard Spranger, and Wilhelm Flitner. My exploration of the basic ideas of the Frankfurt School of social philosophy (as propounded by Adorno, Horkheimer, and Habermas) as well as the dialogue with educational theorists 
working, like myself, on a critical revision of traditional German pedagogy led me, from the late 1960s onwards, to evolve a draft for a 'critical-constructive science of education' and, within this framework, a system of 'critical-constructive Didaktik'. In this context, 'critical' is to be understood in the sense of 'social criticism', which in terms of Didaktik implies constant reflection on the relations between school and instruction on the one hand (their goals, contents, forms of organization, and methods) and social conditions and processes on the other. 'Constructive' continues to indicate an emphasis on practice, on 'reform' - but more decisively than before it refers to a shaping of school and instruction in keeping with humane and democratic principles (selfdetermination, participation in decision-making, solidarity).

- A second element is the expansion of my previous, narrower concept of Didaktik (as theory of contents and curriculum, Didaktik als Theorie der Bildungsinhalte und des Lehrplans). I now use Didaktik generically for both the dimension of objectives and content and the dimension of methods, taking the preconditions given at both the personal and institutional level into account. Now I emphasize the primacy of objectives against all other dimensions of instruction.

The most crucial stimulus for this expansion of my conception of Didaktik came from the criticisms and suggestions of the 'Berlin School of Didaktik' (Heimann, Otto, Schulz) in the forms developed from 1972 onward, later integrated by Wolfgang Schulz and Gunter Otto into their 'Hamburg Didaktik'.

- In my current concept of instructional planning I stress, more emphatically than in the earlier essay, that teaching and learning must be understood as processes of interaction, that is, as processes in which relationships between people - between teachers and learners, and between the learners themselves play a central role. These processes must therefore be comprehended not only as processes of acquisition in which subject matter and problems are confronted, but also as social processes or processes of social learning.

This new emphasis on the relationship question was influenced in particular by the discussion of social learning which has intensified in Germany since the 1970s, and the ideas of 'communication-centred' or 'critical-communicative' Didaktik.

In presenting the older text 'Didaktik Analysis as the Core of the Preparation of Instruction' for renewed discussion, this time in an abridged, English version, I see the justification in the fact that the central ideas of the earlier concept with its five basic questions have not been supplanted, but continue to be valid in an expanded, in places modified, and in a more differentiated form.

\section{The question}

Preparing lessons is one of those tasks of the teacher in which the basic pedagogical problems of the school converge. It is the place where the interactive relationship between theory and practice fundamental to all education, the 
interplay between experience and reflection, must be concretized in the form of reflective decisions for planning instruction and learning. Good preparation for a lesson, for a sequence of lessons, or for an instructional unit is always a new, small-scale, and provisional construction as well as a synthesis of prior experience. If we make the 'draft character' of good preparation clear enough to ourselves - because any planning of instruction can be only provisionally valid then it is quite consistent to rate the instructional planning process highly whilst at the same time recognizing that, in the end, each and every lesson holds in store myriad unforeseeable possibilities and that the openness of teachers' minds to new situations, impulses, and the difficulties arising from the moment is a criterion of their pedagogical competence.

The principal purpose of instructional preparation can be summarized as follows: Preparation is intended as the design of one or several opportunities for children to make fruitful encounters with certain contents of education (Bildungsinhalte).

But, even with this interpretation in view, there is a danger that the task will be understood primarily, or indeed exclusively, as a preliminary reflection about the 'how' of the encounter to be engendered; in other words, preparation may be regarded first and foremost, or even wholly, as a question of methods. Usually the reflections of those who hold such a conception are dominated by a methodological principle (such as self-activity) or practice (such as learning in small groups), and the question is then how the material can be dealt with in keeping with this principle or this practice. (Basically, it is of no importance whether the principle of method or the form of instruction is a formal sequence [cf. Herbart: Formalstufe] or a matter of 'hands-on activity', 'self-activity', 'classroom discussion', and so on.)

With respect to this misinterpretation, the specialist literature has repeatedly pointed out that the search for method must be the final, albeit necessary, step in good instructional preparation and is, in a manner of speaking, the crowning element. The working out of method is contrasted again and again with the first step of preparation, which is the preoccupation with the subject matter to be conveyed or acquired in the lessons. This throws up a crucial question that will, in the course of the argument, reveal itself as the core issue of the whole spectrum of preparation. What comprises 'the matter'? What is the nature of this 'lesson content'?

Let us proceed from the ordinary situation of teacher. (Ordinary refers here to the situation of a teacher who is not also a curriculum developer or educational theorist.) With this normal situation in mind, let us ask ourselves what kind of 'matters' the teacher encounters as objects of preparation:

1. First, we can observe that the framework is, in the main, delineated by the curriculum or syllabus. This is no less applicable if the latter has assumed the desirable form of a set of guidelines that do not explicitly set out the individual items of subject matter but give basic issues or thematic areas, mostly with supporting examples, leaving the selection of suitable details up to the school or the teacher. 
Our question as to the nature of the 'objects' of preparation can now be brought more sharply into focus: what is the nature of the subject matter or topics of the curriculum?

2. This is not the place for a detailed critique of the different answers to this question that have been put forward, and that are still being offered today, either expressly or implicitly. They include, for example, the opinion that the specific nature of curriculum contents lies in their 'scientific-ness', or that curriculum contents are cultural contents, more precisely the contents of the various authorities that are vehicles and sources of culture such as the church, the judicial system, science, art, commerce, or professional structures. The specifically pedagogical answer to that question would have to be, we feel, that the subject matter in the curriculum is characteristically seen by curriculum designers as contents of education (Bildungsinbalte). This is, then, how the subject matter must be regarded, and validated as such, in the classroom.

A decision has thus been made long before our teacher begins to tackle the business of preparation. From among the wealth of the conceivable contents yielded by our civilization, certain contents or thematic areas have been selected as contents of education (Bildungsinbalte). The teacher is not 'unprejudiced' when approaching the curriculum contents. He or she is aware of the prior decision reflected in these contents - or at least should be aware of it. Now we can bring our question about the nature of the 'matters' that the teacher engaged in preparation has first to deal with even more sharply into focus: the first step in preparation is the understanding of the contents of education (Bildungsinhalte). The teacher must re-enact the pedagogical decision made by the curriculum designers and embedded in the curriculum contents, must reflect which considerations must have led to the inclusion of a particular item or a particular basic issue, that is, why these were selected as possible contents of education (Bildungsinbalte) that the practical work of instruction must bring back to life?

We believe that it would be demanding too much of teachers in terms of time and mental energy to expect them to 'rationalize' about the contents in a pre-pedagogical context whenever they set out to prepare themselves for teaching. This would involve, for example, adopting the role of a scientist who sees the contents in question as a research exercise in a specific field. And we are of the opinion that this applies not only to teachers at primary, junior secondary, and vocational level, but also to those at senior secondary level! Admittedly, the teacher engaged in preparation must first concentrate on the 'matter' at hand, on what is to be taught. But this 'matter' is from the very beginning an 'object' seen through a pedagogical lens that a young person's mind is to 'possess'. It is, in short, content of education (Bildungsinbalt). The task is to elucidate which aspects of the content contribute to Bildung, to explore what it contains that can or should comprise education, Bildung.

The term analysis of subject matter (Sachanalyse), which in the relevant literature has become the common term for the first phase of instructional preparation, is not, therefore, particularly apt. Indeed, it could be misconstrued as 


\section{Wolfgang Klafki}

referring to a pre-pedagogical, scientific analysis of the subject matter, making this the basis of instruction and thus losing sight of the specifically pedagogical nature of the task.

3. The 'objectivity' demanded of the teacher in preparation requires a certain type of questioning. The teacher must adopt two positions, and must be able to assimilate both. He or she represents on the one hand the 'lay-person' the students will later become, and on the other hand the young people themselves and their individual potential. As a lay-person, the teacher represents, for instance, the democratic citizen who is to be aware of his or her responsibility for our society and our state, the committed member of the religious community to which both teachers and students belong, or the 'consumer' who should be able to choose critically and with taste from among the wide range of opportunities for experiencing and forming culture. And so the list could continue. In this perspective, teachers must be willing to be moved by the subject matter during preparation - honestly and seriously. They can fulfil their task of educating and instructing their children only if they represent the content that is to be acquired by education or instruction, if they themselves personify it and credibly reflect it. The poem the teacher is to present the next day, and which he or she will interpret with the children and render with the feeling it inspires, this poem must 'enchant' anew the teacher herself, shake her up, delight her, affect her. The physics problems that will occupy the next few physics lessons must stimulate the teacher once again, like an unsolved puzzle, causing wonder, questioning, experimenting, advance hypothesizing, as a piece of reality with a bearing on, and significance for, the common person - for that is what we all are outside our own specialized field of work.

In the second position, as a representative of the young person, the teacher must view the capacity for understanding and questioning of the 'educated layperson' (gebildeter Laie) from the perspective of the child or youth at a particular level, must recreate with vitality the particular questions, interests, and attitudes of the students, and explore them for their deeper educational potential (Bildungsmöglichkeiten).

The 'matter' the teacher is wrestling with in order to comprehend and exploit its educational substance (Bildungsgehalt) is a peculiarly dynamic complex. It is to be absorbed by and fill the young mind while, at the same time, pointing forward to future tasks and opportunities of a mature life.

4. If we adopt the term Didaktik as a subsumption of all mental effort directed at aspects of content, at the 'what' of instruction and Bildung (as distinguished from the concentration of the 'how', a topic of a theory of teaching and learning methods, i.e. Methodik), the first task of a teacher engaged in preparation can be termed Didaktik analysis. It is evident that we must first clarify our terms if we wish to get closer to the nature of Didaktik analysis. And although we are dealing here with a truly practical problem of schoolwork, we must not allow ourselves to shy from the 'effort of terminology', from confrontation with the difficult, fundamental theoretical questions that the problem poses. 


\section{Contents of education and educational substance (Bildungsinbalt and Bildungsgehalt)}

1. A speaker who uses the term contents of education (Bildungsinhalt) tacitly acknowledges Bildung as a basic term of pedagogy. But it would be wrong to assume that everyone using the expression invests it with a clearly defined idea of what it comprises, inevitably infusing it, though perhaps implicitly, with their own metaphysically-founded ideal or with ideals derived from their own worldviews. On the other hand, we believe that the term can be usefully employed if the controversial issues of ideals are set aside and a broad - not simply formal understanding of Bildung is agreed on; as broad, for example, as that expressed by $\operatorname{Litt}(1963: 11)$ :

When we refer to a person as educated (gebildet) ... we mean at least that this person has succeeded in establishing a certain degree of order in the whole of his existence, in the wide variety of gifts, opportunities, drives, and achievements he incorporates, linking the one to the other in the appropriate relationship, guarding against overemphasis, but also against suppression of the particular. However, a person can never, never create order within himself, unless he has regulated his relations to the world in an appropriate manner. If we regard the one side by side with the other, we may use the term Bildung for any state of mind of a person that puts him in a position to impose order on himself, as well as on his relations to the world.

Weniger, in his essay 'Bildung und Persönlichkeit' (1958), put it more cautiously: Bildung remains 'in essence in the forecourt of life. It only prepares for the decisions of life through which a person will become a "personality"' (p. 138). With reference to Bildung as a result of the educational process, Weniger described it as 'the state in which one can assume responsibility'. An interpretation of the term, as recommended by the statements of Litt and Weniger, is adequate for our purposes as we now try to find a more precise definition of the terms 'content of education' (Bildungsinhalt) and 'substance of a content of education' (Bildungsgehalt).

2. How does a content become a content of education? Otto Willmann (1957) in his Didaktik als Bildungslehre, gave the general answer that it is the educational substance (Bildungsgehalt) of the subject matter. He explained this statement as follows:

Within the whole of the contents to be acquired [we must distinguish between] the essential and the inessential, fruit and leaves, the interior and the exterior. As the learners process the matter, differences emerge.... There are different degrees of internalization of what is presented: some matter penetrates through to the roots of inner growth, the rest remains peripheral. From among the whole of an object of instruction, we 
distinguish its educational substance (Bildungsgehalt) and comprehend the latter as those elements of the former where the subject matter can begin to take root and be internalized, and on whose retention the value of the learning and the practising essentially depends.... Teach in such a way that what is given is learned ... and that its substance (Bildungsgehalt) can take effect.

Content of education is not, therefore, an externally-given matter, but there is 'rather an organic power contained in the content itself, which has a determining influence on the conceptions and thoughts during assimilation by the mind, bringing them into conformity with itself, and thus effecting internal organization' (Willmann 1957: 324). In this interpretation, content of education appears, by virtue of its intrinsic substance (Bildungsgehalt), as something 'wise', something vital, something invisible but objective that needs to be grasped if the matter is to be mastered. A system of Didaktik based on this view explores the particular objects and items of subject matter in order to ascertain their structure and organization, their 'ideal content' or the 'wisdom' they contain, 'their germinative forces and their productive drives' (Willmann 1904: 59).

Willmann's concept of substance (Bildungsgehalt) and his interpretation as sketched out here represent a crucial discovery in the history of Didaktik. But in this most general form, Willmann's definition does not yet give the elucidation necessary for our purposes. We must therefore press on and go beyond Willmann.

3. After Willmann, the terms content of education, education substance (Bildungsgehalt), and educational value (Bildungswert) were increasingly incorporated in the theory of education (Bildungstheorie). But Willmann's interpretation suggested the notion that objective contents per se, independent of the persons who assimilate them, have a certain substance or value contributing to education (Bildungsgehalt, Bildungswert). [Henceforth substance may be taken to refer to Bildungsgehalt where no other attribute is given: translator's note.] Until Kerschensteiner's Theorie der Bildung (1926), all attempts to explore the problems associated with the terms remained within the framework of this basic conviction.

It was the proponents of human-science pedagogy (Geisteswissenschaftliche Pädagogik) who made the decisive move on to new ground. Herman Nohl and Erich Weniger in particular saw, in contrast to the objectivism of Willmann and Kerschensteiner, that a double relativity constitutes the very essence of contents of education, in other words their substance or value. What constitutes content of education, or wherein its substance or value lies, can, first, be ascertained only with reference to the particular children and adolescents who are to be educated and, second, with a particular human, historical situation in mind, with its attendant past and the anticipated future.

The first point of relativity is emphasized when Nohl (1949: 427) described the adjustment to the life of the student as 'the pedagogical criterion': 
Whatever demands are made on the child by the objective culture and the social relationships, they must tolerate a transformation that proceeds from the questions: What is the sense of this requirement in the context of the child's life, for its development and the increase of his or her faculties? and What potential does the child have for coping with the demands?

This is a concrete interpretation of Martin Buber's (1953: 23) thesis that conscious and volitional education is always 'selection of the active world'. Peter (1954: 72, 75) had the same sort of thing in mind when he said that 'the object of teaching is dependent on the Didaktik aims of the teacher'. 'The concept of the object of instruction thus also contains an objective'.

The second, historical relativity in what can be regarded as content of education, substance or value, was emphatically underlined by Weniger (1952). Reference to assets of education (Bildungsgüter) or contents of education means first that:

The speaker has gained formative (bildende) impressions in contact with a substance of the human world, with a component and detail of culture, with particular poetry, painting, music, constitutional doctrine, or with an historical or religious personality. He now possesses them; figuratively speaking, they now belong to him. The very fact that this is possible is the peculiarity of the human mind: an entity complete in itself, such as a sonata, an historical life, a poem, a cultural epoch ... can be grasped and possessed by a person and yet remains unspent and independent. But for the person 'educated' by this entity (der durch dieses Gebilde Gebildete), it has become his property: he has experienced the values concealed therein as educational values (Bildungswerte) and possesses them. Now he learns that others have also experienced the formative force (bildende Kraft) of these contents, such as those with a similar educational career or interests, those with the same work and the same social class, in the same region or the same tribe. Thus we learn to term something an asset that is generally experienced by larger groups as formative (bildend).

(pp. 48-9)

But that is only one facet of the historical character of all contents of education. The other side becomes visible as soon as one recognizes that 'historicity, not only looks backwards, but also points towards the future'. It is an unreflected and by no means self-evident assumption

that something, that for a person speaking about substance has become an asset (Bildungsgut) in the course of his own experience of education (Bildungserfabrung) and what he experienced with his generation, must for future generations also become an asset, that is, will evoke the same experiences of education and must produce the same figure of an educated person (gebildeter Mensch), German, Christian.

(Weniger 1952: 49) 
If we remain with the orientation to the life of the student as our pedagogical criterion, then we must agree with Weniger's (1952) hypothesis that:

Posing the problem of selecting and concentrating the contents of education means ... reflecting on the existential concentration in which the human, historical world is given to us in our life-context, from the perspective of the tasks that arise in our specific and individual situation. For a people, a group or the individual, as life progresses, particular challenges are always present.

This means, therefore, that everything that claims to be content of education must also have a significance for the future of those to be educated - the future for which education is supposed to equip the young people and that it must thus anticipate (vorwegnehmen), without being falsely premature and without narrowing the students' future scope for decision-making.

4. Those contents of education, therefore, that present themselves to the teacher in the form of curriculum and the substance (or value) of which must be tracked down by 'Didaktik analysis' must be comprehended as a selection made in a particular human, historical situation and with specific groups of children in mind (according to environment, school types, grade level). Curriculum designers assume that these contents, once the children or adolescents have internalized and thus acquired them, will enable the young people to 'produce a certain order' (Litt) in themselves and at the same time in their relation to the world, to 'assume responsibility' (Weniger), to cope with the requirements, and take the free chances of life. The contents of teaching and learning will represent such order, or possibilities for such order, such responsibilities, inevitable requirements, and opportunities, and that means at the same time opening up the young people to systems of order (legal, social, moral, etc.), responsibilities (such as human welfare or politics), necessities (such as the mastery of cultural skills, a minimum of vital knowledge, etc.), and human opportunities (e.g. to enjoy and be active in leisure time, e.g. in the arts, in the choice of profession, etc.).

This form of opening up, of rendering the learners open to contents and values, can be achieved only by what we call contents of education because they have a particular characteristic: they are always specific contents, are examples that represent a larger set of cultural contents. A content of education must always make fundamental problems, fundamental relations, fundamental opportunities, general principles, laws, values, and methods understandable. Such elements that effect understanding of the general in or through the medium of the specific are conveyed in the term educational substance (Bildungsgehalt). Any specific content thus contains general substance.

The task of Didaktik analysis as the first and most important step in the preparation of lessons is, therefore, 'to bring out the substance of the objects of learning' (Willmann 1957: 460), to establish as the pedagogically crucial ele- 
ments of the material those parts 'on which its internalization [that is, its power to penetrate] depends or, inversely, in which the form of subjective Bildung becomes fulfilled and perfected' (Nohl 1949: 144). In other words, Didaktik analysis is to indicate wherein the general substance of specific content of education lies. The substance almost always proves to be 'a network of relations' (Peter 1954: 72, cf. p. 77), a 'nexus, a complex of connections, which is itself set in a wider . . . context' (Petzelt 1947: 78).

\section{Didaktik analysis}

Only after these preliminary fundamental reflections on the content of education and substance can the task of Didaktik analysis be more precisely defined. We make our general question more precise through the medium of five general questions that, together, should yield a definition of substance. It will be immediately clear that the answers to these questions can usually be obtained only from the specific situation, of the specific school class in question. Thus, our examples always remain distanced from the particular reality of school.

As the five basic questions, which we in turn break down into sections, are mutually dependent, the order in which they appear is not necessarily obligatory for Didaktik analysis in practice. Each question carries tacit overtones of the other four, and the answer to each individual question only becomes fully comprehensible in the light of all five answers.

What questions, therefore, should a teacher ask in the preliminary phase of instructional preparation, that is, Didaktik analysis, in view of the concrete topics/themes proposed by the curriculum or planned by the individual teacher?

\section{What wider or general sense or reality does this content exemplify and} open up to the learner? What basic phenomenon or fundamental principle, what law, criterion, problem, method, technique, or attitude can be grasped by dealing with this content as an 'example'?

\section{$i$ What does the planned topic exemplify, represent, or typify?}

The automobile engine stands for all gasoline engines, the cherry blossom for the basic biological phenomenon of blossom, a particular incident from the colonization of the eastern European regions by Germans for eastern European colonization in general, the painting theme 'Hurrah, it's snowing!' for creative use of spray techniques in art, these specific arithmetic tasks from the field of banking, for the calculation of interest in general, and so on. The 'exemplary' significance depends to a large extent on the teacher's goals. One and the same item of content can in some cases exemplify a variety of general subjects. 


\section{Wolfgang Klafki}

ii Where can the knowledge to be gained from this topic be picked up on and used at a later date, either as a whole or as individual elements insights, conceptions, conceptions of values, work methods, techniques?

When a child in the second grade learns to change small denomination money into larger denominations, the process will later reoccur as an 'element' in understanding basic arithmetical operations in written form. The basic terms of, for example, history and science that the child learns at elementary school will later be applied in high school classes....

2 What significance does the content in question, or the experience, knowledge, ability, or skill to be acquired through this topic already possess in the minds of the children in my class? What significance should it have from a pedagogical point of view?

It is crucial that this question should not be understood purely in terms of method. This is only its secondary sense. First and foremost, it is a matter of whether the content in question, that is, the substance to be investigated in it, can and should be an element in the present education of young people, that is, in their lives, in their conception of themselves and the world, in their areas of competence. Moreover, the term Bildung of the child or adolescent does not primarily mean 'school' or 'education' as a definable, special area of knowledge, ability, attitude, or behaviour, but the world of the mind and the habits of the young person as a whole. Within this mental world, school should be understood as a place of clarification, purification, consolidation, expansion, and stimulus. In this perspective, the foremost criterion of a school's efforts should be the query whether the activities can come alive and be effective outside the school's walls. Thus we ask what importance electricity, animals, foreign lands, music, crafts, stories, church, faith, religion, and so on have for the child outside school, and in what sense they could or should become significant.

To clarify: has the planned topic already come up in questions occurring in class? Is the topic familiar to these children (to some? to all?) in their out-ofschool experience? Does it play a vital role in their school or out-of-school life? Must the children first be acquainted with the questions from which this topic is to develop - perhaps by shattering certain conceptions they take for granted or can the familiarity be presupposed? (bicycles, automobiles, fruit trees, the lives of knights, calculation of interest, letter-writing, water-cycle, trade-union movement, multiplication and division of fractions by fractions, punctuation in direct speech). From which angles do the students already have access to the topic? Which angles are still unfamiliar? (In the case of the topic 'local birds', for example, the children might know birds as song-birds, as cherry and grain thieves, but they may not know of the economic benefits birds can have for humans.) 


\section{What constitutes the topic's significance for the children's future?}

With this question we formulate more specifically the perspective of the layperson, mentioned earlier, which the teacher has to anticipate for the student.

To clarify: does this content play a vital role in the intellectual life of the adolescents and adults the children will become, or is there justification to assume that it will, or should, play such a role? (e.g. coming to terms with our recent history, securing the foundations of our democracy, the problem of communism, the question of European unity, the double role of women, the organization of leisure, getting to grips with modern art, and so on). Is this content a genuine element of general education, Allgemeinbildung, of all-round, foundational Bildung in its positive sense, or does it pre-empt some sort of specialized education (Spezialbildung), such as vocational training? If the answer to this is yes, then it should be rejected! Are the children already aware of the content's relevance to the future? Can it be made clear to them, or is it so difficult to understand that it cannot be explained to the children?

\section{How is the content structured (which has been placed in a specifically pedagogical perspective by Questions 1, 2, and 3)?}

It is vitally important to remember that the question about the structure of the content can only be properly asked, pedagogically, in the light of the first three basic questions. Detached from the perspective created by these questions, the structural question becomes a pre-pedagogical 'subject analysis', that is, a theoretical-scientific question - at least by intention - that yields corresponding answers. The question about the structure of the content 'electricity', for example, can be answered by key words such as 'atomic theory', 'electron current', 'Ohm's Law', and so on. Responses of this kind can be educational (bildend) only if and when the question and comprehension level of the students matches them, as would be the case, for example, in the highest grades of general secondary education or in the final grades of particular vocational schools. A teacher wishing to deal with this topic in grade 7 or 8 , however, will be forced to conclude, after reflecting on the present meaning of this topic for his average students (i.e. from the point of view of what children in puberty can comprehend and how they regard the world), that the model constructs of atomic theory, the mathematical formulation of Ohm's Law, and so on, cannot (in general) be grasped in their inner meaning by these children, cannot be knowledge that contributes to Bildung. Any teacher, therefore, who believes the students must still be presented with these theoretical elements courts the danger of inducing misconceptions (such as confusion of the atomic model with reality) or mere rote learning that will play no functional role in the subsequent intellectual life of the young person in question (Ohm's Law). Physics at this level will have to be phenomenonoriented (Wagenschein). It will have to confine itself to those phenomena of electricity to which the students have ready access, either through their everyday experience or through simple experiments, and that interest them. This 


\section{6}

means that it will be first and foremost the practical effects and technical applications of electricity that create the framework within which electricity can be taught at this level.

With regard to these conditions, the basic question about the structure of a particular content can be broken down as follows:

\section{$i$ What are the individual elements of the content as a meaningful whole?}

In the case of the petrol engine, this would be, for example, (a) expansion of gases on heating, (b) low ignition temperature of a spark-plug, (c) technical transmission of upward-and-downward motion into rotary motion (crankshaft), and (d) simple gear connections for transmitting the direction of mechanical movement.

\section{ii How are these individual elements related?}

(a) Do they form a logically 'obvious' series? (Mostly in arithmetic and in mathematics, in the natural sciences.) In this case, a certain order of logical steps must be adhered to. Or (b) do they form an interdependent structure, where all or some elements are interrelated, so that the order in which they have to be examined is not necessarily given by a unilinear 'logic', but characterized by the reciprocal effects of some or several factors (such as the relationships of plants and animals in symbiotic systems, the geomorphological factors essential to a particular landscape, geographical relations, etc.)?

\section{iii Is the content layered? Does it have different layers of meaning and significance?}

In the case of a reading text, for example, either a complete text or an extract, this would involve, first, the layer of the narrated events and actions; second, the layer of inner experiences of the protagonists not expressly described; third, the (possible) symbolic meaning of the phenomena and relations ascertained in the first and second layers. To take another example, in geography, with the topic 'Africa', it would involve the basic layer of knowledge about climatic and vegetation zones; then the layer of specialized and specific knowledge, including the anthropological, geographic, economic factors, and so on. In the case of a history topic, such as the 1917 Bolshevik Revolution in Russia, it would involve, first, the layer of essential historical facts; second, the layer of political ideology; third, the layer of fundamental historical, political, and sociological phenomena and basic concepts such as state, government, tsar/king, class, revolution.... Can the layers be understood in relative independence of each other? Or is knowledge of one layer a prerequisite for the understanding of another (as in our geography and history examples)?

iv What is the wider context of this content? What must have preceded it?

The study of magnetism, for example, would need to precede the study of the electric motor. 
$v$ What peculiarities of the content will presumably make access to the subject difficult for the children?

Examples: In science topics, it is not only common sayings such as 'the sun rises' that mislead the children, but also terms commonly used in instruction and even in science textbooks, such as 'centrifugal force', 'the flow of electric current', which either have caused or presumably will cause the children to make false analogies. The idea of electric current 'flowing', for instance, immediately evokes the conception of flowing water, which moves as a result of differences in altitude. (There is a so-called 'illustration' that is still used, even in science textbooks today, where water is watched as it flows from one vessel into another placed at a lower level. Even for primary science, this attempt at analogy is unsuitable or, more precisely, not isomorphic, inadequate, because it misrepresents the essence of electrical 'current', which is a circuit. No phenomenon of electricity can be made comprehensible by means of that analogy with flowing water.)

In history instruction, the difficulty constantly reoccurs that the children project their notions, which are anchored in their present experience, onto previous periods of history, and thus make it harder to understand historical phenomena and processes.

vi What is the body of knowledge that must be retained ('minimum knowledge') if the content determined by these questions is to be considered 'acquired' as a 'vital', 'working' human possession?

5 What are the special cases, phenomena, situations, experiments, persons, elements of aesthetic experience, and so forth, in terms of which the structure of the content in question can become interesting, stimulating, approachable, conceivable, or vivid for children of the stage of development of this class?

This final query of the five must be developed in three sections:

$i$ What facts or states of affairs, phenomena, situations, experiments, controversies, and so forth - in other words, what experiences - are appropriate for exciting in the pupils' minds an interest in, and a positive attitude towards, developing questions oriented to deciphering the structure of the given problem?

It is this questioning that is to drive the course of the teaching-learning process. Heinrich Roth (1983: 123-4) formulated the problem as follows:

How do I bring the object within the scope of the child's ability to question? How can I make it worthwhile for the child to ask questions? How do I transform it again into a question, an object that arose as an answer to a question?

In reply he gave the following answer as a matter of principle: 
Child and object interlock when the child or adolescent can sense the object, the task, the cultural asset in the nearness of its processes of development, in its 'original situation', from which it has become an 'object', 'task', 'cultural asset'.... By analyzing ... the object in its genesis, I recreate the original human situation with respect to it and thus the vital interest from which it once stemmed.

Such a pedagogical 'return to the original situation' strives to 're-transform dead subject matter into the vital actions that engendered it: physical objects into inventions and discoveries, works into creations, plans into worries, treaties into decisions, solutions into tasks, phenomena into basic phenomena' (p. 124).

Copei (1963) gave us a good example involving a can of condensed milk. His students begin to ask questions directed at the effects of air pressure after observing, first, that the contents of a can of condensed milk cannot be poured out of one hole and, second, when two holes are punched, that the milk can be poured only if the can is held obliquely. The observation, in early spring, that children from a village on a hillside can still go sledding whereas their schoolfellows from a village down in the valley cannot because all the snow has melted there, can induce questions directed at a basic issue of climate. The juxtaposition of different songs that the children perceive as 'sad' and 'gloomy' or 'bright', 'happy', or 'light', and so on, can provoke questions that lead to a consciousness of the dominant sound character of major and minor keys.

ii What pictures, hints, situations, observations, stories, experiments, models, and so on, are appropriate in helping the children to answer, as independently as possible, their questions directed at the essentials of the matter?

The answer here as a general principle can be summed up as 'the model character of the elementary case' (Roth 1964: 125) or 'the fruitfulness of the elementary' (cf. Spranger 1954: 87ff.). For all contents that are themselves the product of a process of thoughtful development, the appropriate and adequate form of illustration is the 'return to the original situation', a term that here is not primarily meant in an historical sense, but refers instead to the systematic origin. This is a principle with which we are familiar as a means of inducing a genuine process of questioning in the children and, at the same time, as the right way of adequate illustration.

After, for example, a story from before the time of steamships (e.g. about a becalmed vessel) has brought up the question of how the trade winds occur, the students can develop their answer using air movement in a heated room as a model. In the case of a question about German colonization of eastern Europe - prompted by the issue of German refugees after the Second World War - the teacher can present the material required to formulate the answers by, for example, recounting a story in which the various motives are 'symbolically concentrated' ('symbolische Verdichtung:' Heimpel), made obvious by vividly charac- 
terized historical persons or groups. The theme 'winter landscape' is appropriate to stimulate creative efforts in which the aesthetic quality of black-and-white colour contrast and plane-line form contrast is strikingly illustrated.

iii What situations and tasks are appropriate for helping the principle of content grasped by means of an example, of an elementary 'case', become of real benefit to the students, helping to consolidate it by application and practice (immanent repetition)?

Modern theories of language instruction justifiably demand 'practice with a purpose' appropriate both to the subject and to the child. Once, for instance, the pattern of concessive clauses has been introduced using an appropriate example, the next step should be to seek situations in the life of the child where concessive clauses are required to verbalize the subject matter, and not, as is still so often the case, simply to set the task, 'Write 10 sentences using although.' A similar principle applies in arithmetic. And in science, for instance, the aim would be for the laws of radiation worked out with one or two examples to be discovered in other cases. Or the characteristics of an animal community could be first studied by using the example of bees, and improved with the students subsequently doing work of their own on ant communities.

\section{Planning of the methodical arrangement of teaching and learning}

The second step of instructional planning, planning of teaching methods, can proceed only from Didaktik analysis. Methods planning is concerned with the 'how' of teaching, more precisely with the questions 'Which ways can lead to the fruitful encounter between the children and the content?' (the pedagogical significance and structure of which have been established by Didaktik analysis) and 'What can follow for a fruitful encounter between the two to be achieved?' This interpretation of planning for methods clearly shows its dependence on Didaktik reflection.

The transition from Didaktik reflection to the planning of method has already been indicated several times in our sketch of Didaktik analysis (in the narrow sense of the term Didaktik): first, in the remarks on the introduction of initial questions and, second, in the reflections on the problems of illustration. Nevertheless, we consider it of utmost importance that these very problems contrary to common belief - must be seen primarily as Didaktik issues (and not in the narrow sense), that is, as problems of content.

The depth of Didaktik analysis required as a first step in preparation will, of course, always depend on the chosen theme. This may be an instructional unit stretching over several months, but could equally be the topic for a week, or just for one lesson. Didaktik analysis is the foundation, not only for the introduction of a new theme, but for all teaching activity dedicated to this particular content. Thus, even the design of a practice or revision lesson - as such mainly a matter of method - depends on the results of Didaktik analysis. In the end, the 
only way of determining whether this or that form of practice or revision would be pedagogically right or wrong in a particular case is by ascertaining whether it is appropriate to the contents.

This is not the place for a detailed discussion of the second step for planning of methods of instruction. Suffice it to say that this phase of planning and preparation must, we feel, concentrate on four areas above all:

- the organization of instruction or learning into sections or phases or steps;

- the choice of forms of teaching, work, play, practice, and revision;

- the use of classroom aids (teaching and learning aids);

- the achievement of organizational prerequisites for instruction and learning.

Ideas about method will naturally occur to the classroom practitioner in the course of Didaktik analysis. Nonetheless, method planning, which is, after all, the outline of the lessons themselves, can really take place only after Didaktik analysis. This is an essential point, particularly because the outline of the questions as set out previously is by no means identical to the chronological order of the methodical steps. Thus, the outlooks or applications that children can be shown on the basis of the ideas set out under Question 3 of the Didaktik analysis (relevance for the future) come, when method is under consideration, after the practical conclusions to be drawn from the considerations set out under Question 5 (exemplary cases, phenomena, etc. as 'entries' to the processes of understanding structures). In short, the order of methodical steps obeys a different set of rules from those determining Didaktik reflection (in the narrower sense). The former is governed by practical considerations, whereas the order of Didaktik reflection follows theoretical-systematic norms.

\section{Acknowledgements}

This abridgement and adaptation of 'Didaktische Analyse als Kern der Unterrichtsvorbereitung' draws heavily on an initial translation of the paper prepared by Gillian Horton-Krüger. The adaptation incorporates the comments of Peter Menck of the University of Siegen and the corrections of Wolfgang Klafki on the translation. Support for both the translation and adaptation was provided by the Institut für die Pädagogik der Naturwissenschaften (IPN) at the ChristianAlbrechts Universität, Kiel, through its 'Didaktik Meets Curriculum' group consisting of Kurt Riquarts, Roland Lauterbach, and Stefan Hopmann.

\section{Notes}

1 Didaktische Analyse als Kern der Unterrichtsvorbereitung. Die Deutsche Schule (1958; 450-71), and later in Auswahl (1962), a collection of essays edited by H. Roth and A. Blumenthal. Some of the changes I made to the essay in this version were influenced by W. Kramp, Hinweise zur Unterrichtsvorbereitung für Anfänger, Die Deutsche Schule (1962), and in the collection, Auswabl, mentioned earlier. 
2 W. Klafki, Zur Unterrichtsplanung im Sinne kritisch-konstruktiver Didaktik. In my Neue Studien zur Bildungstheorie und Didaktik: Zeitgemäße Allgemeinbildung und kritisch-konstruktive Didaktik; first edition (Weinheim: Beltz Verlag 1985); considerably expanded for the second edition (Weinheim: Beltz Verlag 1991); now in its fifth edition (Weinheim: Beltz Verlag 1996).

3 Translator's notes: Bildungsgehalt - the substance of a content based on the content's history and current importance and use; limited by the curriculum, it is transformed by the interests and experiences vested in it by the teacher and the learner. As such, the notion of substance is a holistic concept. In Klafki's model, the search for the substance is practically focused on the question of what educating (bildend) potential the content is reckoned to have (e.g. by curriculum authors, teachers) and how this potential can be realized. In this practical sense, the content of 'substance' is close to Shulman's notion of 'pedagogical content knowledge' (L.S. Shulman [1987] Knowledge and teaching: foundations of the new reform. Harvard Educational Review, 57 [2], 1-22).

Geistig: (Following the translation of Wilhelm Dilthey's [1989] Introduction to the Human Sciences, eds R.A. Makkreel and F. Rodi [Princeton, NJ: Princeton University Press]) 'human', of the 'human world', with few exceptions.

\section{References}

Adl-Amini, B. and Künzli, R. (eds) (1980) Didaktische Modelle und Unterrichtsplanung (Munich, Germany: Juventa Verlag).

Buber, M. (1953) Reden über Erziehung (Heidelberg, Germany: Schneider).

Copei, F. (1963) Der fruchtbare Moment im Bildungsprozess (Heidelberg, Germany: Quelle \& Meyer).

Kerschensteiner, G. (1926) Theorie der Bildung (Leipzig, Germany: B.G. Teubner).

Klafki, W. (1963) Studien zur Bildungstheorie und Didaktik (Weinheim, Germany: Beltz Verlag).

Klafki, W. (1977) Probleme einer Neukonzeption der Didaktischen Analyse Schriftenreihe des pädagogischen Instituts der Landeshauptstadt Düsseldorf, vol. 34 (Düsseldorf, Germany: Pädagogisches Institut der Landeshauptstadt Düsseldorf).

Klafki, W. (1980) 'Zur Unterrichtsplanung im Sinne kritisch-konstruktiver Didaktik', in E. König, N. Schier, and U. Vohland (eds), Diskussion Unterrichtsvorbereitung. Verfahren und Modelle (Munich, Germany: W. Fink), 13-44.

Klafki, W. (1996) 'Zur Unterrichtsplanung im Sinne kritisch-konstruktiver Didaktik', in W. Klafki Neue Studien zur Bildungstheorie und Didaktik: Zeitgemäße Allgemeinbildung und kritisch-konstruktive Didaktik (Weinheim, Germany: Beltz Verlag), 251-84.

Litt, T. (1963) Naturwissenschaft und Menschenbildung (Heidelberg, Germany: Quelle \& Meyer).

Nohl, H. (1949) Die pädagogische Bewegung in Deutschland and ihre Theorie (Frankfurt, Germany: G. Schulte-Bulmke).

Peter, R. (1954) Grundlegender Unterricht (Bad Heilbrunn, Germany: Klinkhardt).

Petzelt, A. (1947) Grundzüge systematischer Pädagogik (Stuttgart, Germany: Kohlhammer).

Roth, H. (1983) 'Die “originale Begegnung” als methodisches Prinzip', in H. Roth, Pädagogische Psychologie des Lehrens und Lernens (Hanover, Germany: Schroedel), 116-26.

Spranger, E. (1954) Die Fruchtbarkeit des Elementaren. In E. Spranger, Pädagogische Perspektiven (Heidelberg, Germany: Quelle \& Meyer), 87-92.

Weniger, E. (1952) Didaktik als Bildungslehre. Teil 1: Theorie der Bildungsinbalte und des Lehrplans (Weinheim, Germany: Beltz Verlag). 


\section{Wolfgang Klafki}

Weniger, E. (1958) 'Bildung und Persönlichkeit', in E. Weniger, Die Eigenständigkeit der Erziehung in Theorie und Praxis (Weinheim, Germany: Beltz Verlag).

Willmann, O. (1904) Aus Hörsaal and Schulstube. Gesammelte kleinere Schriften zur Erziehungs- und Unterrichtslehre, 2nd edn (Freiburg im Breisgau, Germany: Herder).

Willmann, O. (1957) Didaktik als Bildungslehre nach ibren Beziehungen zur Sozialforschung und zur Geschichte der Bildung (Freiburg im Breisgau, Germany: Herder). 


\title{
6 Effect of questions in education and other enterprises
}

\author{
J.T. Dillon
}

Asking and answering questions are among the most common human activities, yet it is remarkable how little is known, in a systematic way, about the effect of questions on a respondent. Nonetheless, a great deal of literature exists. Asking questions characterizes practice in several fields, such as education and survey interviewing. Analysing questions characterizes recent theoretical work in other fields, such as logic and linguistics. It would seem useful to understanding and practice to bring together the contributions of these various enterprises.

This review examines only part of the literature on questions. ${ }^{1}$ The general topic is restricted to the effect that putting a question has on a respondent. That is to omit the entire other side of the coin, namely how questions come to be conceived and spoken. Concern is further limited to practitioner questions: a teacher's or an interviewer's. That is to omit questions put by the student or client. Lastly, interest focuses on one aspect of practitioner questions, namely their effect on cognitive and expressive processes; for example, the extent to which teacher questions stimulate student thought and discussion. On this issue, different fields will be seen to take different positions, but all of them contrast with that taken in education.

The first part of the review describes the emphasis on questions in education. The next part sets up a series of contrasts between education and three groups of other enterprises. One group is characterized by theoretical analysis of questions - the fields of logic, linguistics, and philosophy. Another is characterized by the practical pursuit of questions - opinion-polling and cross-examination. A third is characterized by the tactical avoidance of questions - personnel interviewing, psychotherapy, and group discussion. The last part summarizes research on response to questions.

By relating the various fields, by contrasting the divergent theories, practices and research findings, this review might serve to introduce scholars to conceptions perhaps unfamiliar in their own field. As a result it might stimulate inquiry into the effect of questions, as well as into alternative means of enhancing expression of student thought. 


\section{J.T. Dillon}

\section{Emphasis on questions in education}

\section{Classroom practice}

It is a well-documented fact that teachers traditionally ask a lot of questions. Beginning with a study by Romiett Stevens in 1912, teachers have regularly been observed to ask several, and even many questions per minute (see, for example, Gall 1970, Hoekter and Ahlbrand 1969, National Education Association 1976). Recently, with the introduction of the 'new' curricula, they have been asking even more questions than before (see, for example, Wilson 1969).

Observers from various perspectives have described classroom discourse as a series of three-part exchanges, principally a teacher question, a pupil response, and a teacher comment - plus a further question (Bellack et al. 1966, Sinclair and Coulthard 1975, Mehan 1979). Sociolinguistic research has formulated this practice as 'an exponential law of successive questioning', whereby the chances at any point are two to one that a teacher will ask a question (Mishler 1975a). In 85 per cent of exchanges observed in primary classrooms, teachers put a further question after the pupil had responded; in 67 per cent of the classes, they replied to a pupil question by asking another question (Mishler 1975b). Thus, questions are the predominant technique for initiating, extending, and controlling the conversational exchange in classrooms.

At least in part, this use of questions is deliberate and purposive, representing a choice among alternative means (see, for example, Shavelson 1976). Among other purposes, questions are used 'to stimulate thinking as well as to facilitate class discussions':

Through the use of questions, teachers make decisions concerning which pupils will participate in the verbal classroom activity, when they will participate, how often they will be allowed to participate during a given class period, how long they will participate at any one time, the form of pupil participation, and the level of thinking at which students need to function in order to respond.

(Blosser 1973: 52, 57)

This review will refer to this practice as the use of questions in order to stimulate student thought and discussion.

To characterize classroom practice, therefore, it is not enough to note that teachers typically ask a lot of questions. Questions are not only a frequent but a predominant technique; they are also the preferred technique for stimulating student thought and discussion.

\section{Pedagogical theory}

A long tradition upholds this preference for questions. 'To know how to question is to know how to teach' was a favourite adage years ago (see, for example, 
DeGarmo 1902, Betts 1910). Recently one reads: 'To question well is to teach well' (Weaver and Cenci 1960: 72). 'Good questions are vital to good teaching' (Auerbach 1977: 204). Questions are traditionally described in superlative terms, such as: the most influential single teaching act; the most valuable of all teaching devices; the greatest medium of instruction (see, for example, Landon 1899, Stevens 1912, Taba 1964). Today one reads: 'It is impossible to conceive of teaching without asking questions' (Hyman 1979: 1).

An unmistakable surge of emphasis on questions has marked recent decades. The pedagogical literature now includes scores of question-classification schemes and observation devices, dozens of manuals, mini-courses, and selfinstructional booklets, and a mass of commentary in the journals. Book-length manuals on questioning are devoted to inquiry-discovery approaches, to humanistic-affective education, to creativity programmes, and to highercognitive emphases (see, for example, Sanders 1966, Torrance and Myers 1970, Hunkins 1972, Carin and Sund 1978). Other manuals are devoted to questioning in specific subject areas such as social studies and science (Groisser 1964, Intermediate Science Curriculum Study [ISCS] 1972). This remarkable surge in theory is reflected in classroom practice. For instance, science teachers using a discovery approach have been observed to ask 50 per cent more questions than their traditional colleagues. 'The art of questioning is the essence of discovery teaching' (Wilson 1969: 3).

Recent emphases are, at bottom, traditional. Page (1847) held that questions could 'wake up mind' and in 1912 Stevens (in Wilson 1969: 7) put it that 'the purpose of the question is to provoke thought and evoke expression'. Today, questions are held to do the same things, but the claims are put in more modern terms: they 'trigger thinking' (Aschner 1961), 'ignite creative processes' (Carin and Sund 1978), and 'establish a dialogue relationship' (Hough and Duncan 1970). While still proposing that questions stimulate student thought and response, the current literature now stresses their use in discussion in contrast to recitation, and higher-order questions in contrast to factual ones. Questions are held to generate more discussion, and higher-order questions are presumed to stimulate higher-order thought and longer responses (ISCS 1972, Blosser 1973).

Thus, in contrast to the former emphasis on factual knowledge elicited of yore by factual questions, modern preference is for higher-cognitive processes, now presumably elicited by higher-cognitive questions. Accordingly, a proliferation of classification schemes have been devised, a dozen in the 1970s alone, some for particular subject areas (see, for example, Tinsley and Davis 1971), others for teacher questions generally (Riegle 1976). This particular emphasis too has its counterpart in practice. Teachers of the new 'inquiry' curricula are observed to ask a greater proportion of higher-order questions than their traditional colleagues do (Sloan and Pate 1966, Moon 1971, Bruce 1971, Porterfield 1974). In accord with theoretical emphases, then, "the "new" science teachers are asking more and better questions' (Wilson 1969).

To characterize pedagogical theory, therefore, it is not enough to note that 


\section{J.T. Dillon}

questioning has traditionally been regarded as distinctive of good teaching. Now increased questioning is distinctive of better teaching. Traditionally questions have been said to stimulate student thought and response. Now higher questions stimulate greater thought and response. Hence pedagogical theory sustains the characteristic reliance on questions in classroom practice. In view of the prominence of questions, it is pertinent to inquire whether they have been observed in research to achieve that which they are presumed to achieve in theory and in practice.

\section{Educational research}

In research, as well as pedagogy, teacher questions have been traditionally prominent and have recently become more salient. The tradition dates, as we have noted, at least from Stevens (1912), and within decades had deserved an excellent review (Horn 1937). Recently the research has grown to such an extent that reviews alone are starting to appear biennially. ${ }^{2}$

Since Stevens's study, the research has persistently described the teacher's use of questions - their frequency, rate, type, etc. Just as persistently, it has neglected to examine their effect. For example, only 18 experiments - all but three unpublished - could be found on the effect of questions on achievement (Winne 1979). Scarcely a handful can be found exploring their effect on participation. There is a great deal of literature on other aspects of teacher questions, and on other sources of questions - student questions (e.g. Susskind 1969), textbook questions (Davis and Hunkins 1966), children's questions (Meyer and Shane 1973), and adjunct question (Anderson and Biddle 1975), but contrary to what might be presumed, the volume of research has not to any extent investigated, much less demonstrated, the effect of teacher questions.

Inevitably, therefore, many claims are available but little evidence is extant. Moreover the evidence does not support the claims. Regarding the frequency of questions, reviewers characterize the prevailing wisdom to run: 'After all, the more one asks questions, the more pupils are encouraged to think and to respond' (Dunkin and Biddle 1974: 369). But as for research: 'The evidence is ambiguous, to say the least' (Rosenshine 1976a: 357). Studies repeatedly present a 'pattern of inconsistent results'. Regarding particular kinds of questions: 'The effects of higher-order questions are nowhere to be seen, nor are the effects of lower-order questions as clear as one would wish' (Rosenshine 1976a: 358). 'The conceptual definition of higher cognitive questions', concludes a recent reviewer, 'has not yet been sufficiently demonstrated empirically' (Winne 1979: 44).

Of all that remains unknown or undemonstrated, the major part had already been specified at the outset of research 70 years ago:

Naturally, the majority of teachers ... ask questions for months and years without ever taking into account what mental changes a question calls 
forth, what emotional states it arouses in the pupil's mind, how such resulting states influence the course of ideation and thinking, and so forth.... Thus it is of prime importance for educators to study the influence of questioning upon answers and upon the mental development of the child.

(Yamada 1913: 129)

This neglect of 'the influence of questioning' is traditional and is characteristic of research. As a result, little empirical knowledge supports classroom practice. 'The research base for our practice is woefully thin' (Rosenshine 1976b: 61). Little empirical knowledge supports pedagogical theory. 'We have only a slim basis for asserting that any questioning strategy affects student behaviour positively' (Gall 1973a: 39).

In what manner, then, is it known that questions stimulate student thought and discussion? This knowledge can be characterized as received opinion, conventional wisdom, or presumptive knowledge. The effect of questions comes down to rest on assertion in theory, on belief and habit in practice, and on neglect and uncertainty in research. Hence the emphasis on questions in education may be characterized as presumptive practice.

The matter invites critical views and counter-arguments (see, for example, Dillon 1978, 1979a, 1981a). It becomes all the more problematic when questions are seen to hold no comparable place in any other enterprise. In fields in which there is theoretical analysis of questions, the conclusions contradict pedagogical theory. In fields in which there is a practical pursuit of questions, the practice is similar to education, but the purposes it serves are opposite. In fields in which there is a tactical avoidance of questions, the purpose is similar to education but the practices are opposite. These contrasts are exhibited in the three following sections.

\section{Theoretical analysis of questions}

One turns to logic, philosophy, and linguistics for analyses of the nature of questions, their relation to answers, and their function in discourse, that is, for a theory of questions. By contrast to the substantial body of opinion in education, nothing known about questions from this theoretical analysis gives us reasons to conclude that they might stimulate student thought and response.

The study of questions in these fields is of recent origin, as are some of the very fields themselves (cf. Prior and Prior 1955). But the literature is already quite large. Apart from numerous articles, several books have elaborated impressive theoretical-analytic systems. ${ }^{3}$ A recent review and an anthology are also available (Kearsley 1976, Hiz 1978). The major part of this literature is technically sophisticated, but the details, issues, and controversies need not be of concern here. This section will survey the theoretical perspectives and conclusions from these fields only to contrast them to educational thought and practice. The contrasts may conveniently be reviewed according to various aspects of questions, beginning with their function as sentences. 


\section{J.T. Dillon}

\section{Question-functions}

Although everyone demonstrably recognizes a question when they hear one (Uldall 1962), it is oddly difficult even for erotetic logicians, philosophers, and linguists to state just what a question is and to agree on what it does (see Llewelyn 1964, Kearsley 1976). There are several kinds of things called 'questions' and several functions which any one question can serve. It is useful to begin analysis by distinguishing between a question as a sentence and as a social act, to examine question-sentences first alone, and then in relation to answers.

Considered alone as a sentence, a question has first an expressive function, serving to state something on the part of the asker. For example, a questionsentence may be said (in some cases) to express perplexity and to state a request for information. On grounds of this ipsative function, questions have long been held functional in the thinking process - of the questioner (see, e.g. Fahey 1942, Clark 1972). They would not, however, on that account be said to stimulate thinking in the respondent, versus: 'Individual [teacher] questions spur students to think' (Hyman 1979: xii). Similarly, various kinds of questions may function to express given kinds of perplexity, to motivate given kinds of thinking, and to request given kinds of information. But they would not be said to cause given kinds of thinking in the respondent, versus: 'Different questions not only seek different answers, but they also cause the students to go through different mental processes in responding' (ISCS 1972: 2-4).

From an analytic viewpoint, then, $A$ 's question functions to stimulate $A$ 's thought. How might it function to stimulate $B$ 's thought? Analysis does not have a ready account for that case, versus this account:

Since thinking begins with a problem, one way for the teacher to encourage pupils to think is to pose a problem in the form of a question. Thus, the aim of teaching is to stimulate and shape the pupil's cognitive responses. The teacher stimulates and directs the response by posing a problem that initiates the pupil's thinking; that is, he asks a question that requires an answer.

(Bellack et al. 1966: 249)

But, since thinking begins with a problem, student thinking begins with a student's problem since questions stimulate thought, student questions stimulate student thought. How might the teacher's question become as well the student's question, so that its ipsative function has a causal effect? Analysis readily accounts for this case. To share the same question, both parties would have to experience the perplexity which it expresses and feel the same need for the information which it requests. The act of merely hearing another party's question does not of itself entail experiencing the perplexity; neither does the fact of not knowing the answer of itself entail needing the information (Dillon 1980a). In any event, teachers are rarely perplexed about the questions they ask, so there are small grounds available for sharing the question and little chance of stimulating anyone's thought on either side. 
Research would determine the still unresolved empirical matter (Winne 1979): whether, as presumed in pedagogical theory, higher-level teacher questions stimulate higher-level student thought. Logico-linguistic theory does not presume them to have this effect. Analysis of the procedures which manuals use to classify teacher questions reveals a matrix of displaced inferences among question and response; function and effect; expression and cognition; teacher and student. Beginning with some question-sentence, one procedure first projects a hypothetical response; next it makes an inference as to the cognition of any student who might speak it; and then, by retrojection, attributes to the question the quality of the presumed response. In this fashion questions are labelled 'thought-provoking' because they are presumed to provoke thought (Torrance and Myers 1970). Taking the same question-sentence, another procedure first posits a hypothetical questioner; next takes a guess at the intents and meanings of any teacher who would speak the question; and then, by projection, assigns to the putative response the inferred cognition of the hypothetical questioner. In this fashion questions are labelled 'creative' because they encourage creative answers, or 'convergent' because, having only one thing in mind, they can only be answered in one way (see, e.g. ISCS 1972). The first procedure defines the function of a question by presuming its effect; the second defines the effect of a question by presuming its function. Having thus circularly erected a linear taxonomy, the manuals propose to use questions as 'cognitive levers' (Rogers 1972) for moving at least a third of student thought to successively higher rungs (Sanders 1966). Ask a foolish question, get a foolish answer; 'ask a higher-level question, get a higher-level answer' (Lamb 1976). From an analytic perspective, a high-level question would characterize the talk, perhaps the thought, of the questioner, not the respondent. It makes a request, not elicits a response, for information, not for cognition. It might be said to express a highlevel thinking, but it does not cause it in the respondent. Thus, teacher questions would not be said to stimulate student thought, nor higher questions higher thought.

\section{$Q^{-R}$ (questioner-respondent) relations}

Question-sentences can further be analysed in relation to answer-sentences. The two are typically found together, but their relations are uncertain.

A question expresses the questioner's $(Q)$ particular concerns and 'epistemic interests' in the matter specified (Harrah 1969). As events go, the respondent $(R)$ too is absorbed with topics, concerns, and interests. A fair presumption is that $Q$ disrupts these, and not that $Q$ stimulates them. Questions are intrusive: in order to stimulate $R$ 's thinking, a question must entice $R$ away from his own pursuits, engage him to entertain other concerns, and motivate him to satisfy someone else's interests. Anyone can be interrupted, and subordinates can be made to perform some action in another's favour, for example, to answer a question; yet this could not be said to stimulate their mental processes. Moreover, a question-sentence specifies the topic, kind, and amount of information 
to be supplied. It is implausible that the circumscribed task set by such an intrusive request can be thought to stimulate in $R$ energetic mental activity, and to elicit from $R$ sustained production of speech. How is it that teacher questions can stimulate student thought and discussion?

People do indeed respond to questions. It is socially difficult, almost impermissible, to withhold response (Labov 1970, Mishler 1975a). Hence $R$ does speak. Yet $R$ need not give the information requested by $Q$ nor even an answer, but only a reply: 'a term covering the host of more-or-less responsive noises that can follow upon a question' (Belnap and Steel 1969: 15). The reply can be an indirect answer, an incorrect answer, a partial answer, a false answer, or a refusal to answer; it can evade the question, parry it, reject, correct or repeat it; it can be an exclamation, a command, and even a question (Hamblin 1958, Harrah 1963, Katz 1972). Any of these can constitute a response. Some of them constitute an answer. None of them is the answer $Q$ wants, though all of them respond to $Q$ 's question. Although $Q$ wants a correct, direct, true, complete, informative answer, such a response is by no means even probable. 'A question has no greater logical - even pragmatic - relation to its correct answer than to any incorrect one' (Harrah 1963: 63). That is, $Q$ 's intent does not ensure a like response to $Q$ 's question.

From the fact that $Q$ desires an answer and that convention requires a response, it does not follow that $R$ will be stimulated to discourse upon the topic. As to the desired answer, how is it that $R$ is to divine precisely what $Q$ means and wants? And once divined, why is it that $R$ should make fulsome efforts to satisfy these? As for a required response, on what grounds is $R$ presumed to fulfil the requirement? The very fact that response is required would seem to suggest that minimal rather than effusive responses would more likely be forthcoming. In that event, $Q$ can thereupon put another question. A series of questions has already started, in response to each successive one of which $R$ may give out just one more bit of information. That is to require and not to stimulate the extended, not extensive, participation of $R$ in $Q$ 's pursuit.

In socio-linguistic terms, 'questioning is one of the ways through which one speaker attempts to exert control over another. For us, it is a realization or an expression of authority relationships' (Mishler 1975b: 105). $Q$ is the superordinate partner in the exchange. $Q$ assumes the right to ask the question; $R$ assumes the obligation to respond; $Q$ reserves the right to speak again (Mishler 1975a). In 'an exercise of social power', $Q$ may speak again by putting a further question and thus maintain control of the conversation; again $R$ is obliged to respond and again $Q$ has the right to speak thereafter. If $R$ in turn puts a question, $Q$ will reply with a question, in 'an act of counter-control' (Mishler 1975a: 106). Thus in a $Q-R$ relationship, $R$ is established in a subordinate, reactive role. $R$ does not initiate the exchange and does not choose the topic; $R$ does not extend the conversation and cannot redirect it to $R$ 's concerns; $R$ does not terminate the exchange. $Q$ literally has the final say.

The $Q-R$ relationship, especially when prolonged and more especially when $Q$ enjoys additional attributes of status, power, and authority relative to $R$, is 
not a circumstance ordinarily stimulating to $R$. Response becomes at once more certainly required but less probably expansive; $R$ 's participation is constrained, not encouraged. To the extent that this circumstance describes observed classroom practice, teacher questions can only with generous rhetoric be said to stimulate student thought and discussion. All they do is demand and get replies.

\section{Standard presumptions}

Under certain conditions, the social act of uttering or hearing a question constitutes what is termed the 'standard' question-situation. Its formal components consist of 'standard presumptions', of properties attributed to the act by both $Q$ and $R$. These are pragmatic properties of the questioning act, as distinct from logical properties of the question-sentence (for example, presuppositions). Such presumptions may be found in any number of sources in these various disciplines (Knight 1967, Belnap 1969, Labov 1970, Katz 1972, Harrah 1973).

When $Q$ puts a question, $Q$ and $R$ agree to these five presumptions, in each case the reverse of those found in teacher-student questioning.

\section{(A) QDOES NOT KNOW THE ANSWER AND THINKS THAT $R$ DOES KNOW IT}

But the teacher typically knows the answer and thinks that the student does not or might not know it. The student presumes that the teacher knows it.

\section{(B) $Q$ DESIRES AND NEEDS TO KNOW THE ANSWER}

But it is evident that the teacher does not desire or need the answer, since he already knows it. He attributes to the student the need to know and desires that the student know it. What is left unaccounted for is whether the student feels the need to know, even when he or she does not know the answer. (One can not know the price of tea in China and still not desire or need to know it.)

\section{(C) QREQUESTS THE INFORMATION SPECIFIED BY THE QUESTION}

But teachers do not request that information, since they already have it. They request display and proof of student knowledge of that information. Although students must provide this proof, neither they nor the teacher doubt, desire, or need that information; what the teacher desires and what the student needs is an 'answer'.

\section{(D) $Q$ BeLIEVES AND ATTESTS THAT THE PRESUPPOSITION TO THE QUESTION IS TRUE}

But teachers frequently know the presupposition to be false and attest it to be true. Students must believe it true. The belief is a misfortune: some poor soul must give the inevitably wrong answer, thereby permitting the teacher to make 


\section{J.T. Dillon}

the point. The teacher's intent is not at all malicious but, on the contrary, 'educative'. Yet the effect may be otherwise. The respondent will have been shown foolish or ignorant, thus reduced in status and perhaps in consequence reducing his and other students' participation.

\section{(E) $Q$ BELIEVES THAT THERE IS AT LEAST ONE TRUE DIRECT ANSWER AND EXPECTS $R$ TO GIVE IT}

But teachers know there is often no such answer to many of their questions; are sure an incorrect one will be given; they expect at times that an answer not be given; and at other times they themselves supply the answer. These are the rhetorical, leading, loaded, trick, trap, test, or tough questions put 'to make students really think'. No matter what students think, the answer to such questions is necessarily wrong. Hence students will give cautious, minimal responses if they give any at all. 'After a certain number of bad experiences, many students learn not to volunteer answers to riddles, “come-ons”, or invitations' (Labov 1970: 58-9).

These points are evident enough, but their implications may be less clear. In recognizing that teachers already know the answer to their questions, an old manual called Teaching to Think (Boraas 1922) adverted in a reverse way to the non-stimulating effect such questions must have: 'What a stimulating thing it would be if the teacher did not know before asking what the answer should be but really asked a pupil for information' (p. 99). In logical terms when the answer is known, or if unknown is not needed, the question does not arise (Belnap 1969). Thus, questions might well not be arising in minds of either teacher or students, even though everyone is busy with asking and answering them. To philosophers, questions which fail to meet these presumptions 'must be considered non-inquisitive or meaningless for purposes of inquiry' (Knight 1967: 571). Thus, teacher questions cannot be held to have a stimulating effect on inquiry. There is no inquiry involved in asking them, and none in answering them; there is only interrogative form and declarative effort. It is not stimulating but deadening to supply information to someone who already is known to have it, and to go about seeking information that one does not, of one's self-doubt, need or desire. Yet these otiose questions are conceived of as making students think, inquire, and discuss.

Teachers are of course not alone in putting non-inquiring questions, nor do they put only this kind of question. But they are perhaps alone in believing that non-inquiring questions stimulate inquiry. Although they are aware that such questions can scarcely stimulate the teacher's own thought, the manuals nevertheless urge ever more and higher questions to stimulate greater student thought and discussion. No such conclusion can be derived from the theoretical analysis of questions.

\section{Adult-child questioning}

Everyday experience reveals the observation that an adult will speak to children primarily in questions, but rarely use questions in conversation with other 
adults. In group conversations, adults will sanction someone who continually asks questions; the behaviour is not appropriate to the process or the status of participants. In dyadic exchanges, a partner will answer only a very few questions before interrupting with: 'Say, who do you think you are, asking all these questions?'. Often even a single question will meet with: 'Why do you ask?'. Hence, at times the questioner quickly appends the phrase, 'The reason I ask is ...' The convention is that permission to ask must first be sought, whether implicitly or explicitly (for example, 'Say, can I ask you a question?'), whether situationally or verbally ('Pardon me, boy, is that the Chattanooga choochoo?'); otherwise the partner may refuse the role of respondent. Thus, questions are not usually effective for stimulating adult conversation. With children on the other hand, one can burst in at any time and ask all the questions one wants. And children will respond to every question - but to all of them briefly.

Socio-linguistic studies reveal how briefly children do respond to adult questions. When one researcher realized that Hawaiian schoolchildren were giving only minimal responses to his questions, he decided to try other means of eliciting needed samples of speech. From this 'inadvertent experiment', he discovered that responses to questions proved on the average almost three times briefer (1.0 versus 2.7 lines). 'Questions are less likely to elicit narratives than are other verbalizations'. Far from stimulating response: 'It is hard to escape the conclusion that individually-directed questions inhibit response in the child addressed'. Far from enhancing conversation: 'It might follow that attempts at conversation made up entirely of questions should fail to produce much response at all' (Boggs 1985: 307, 312). This study is significant not only for the contrast it offers to educational thought, but also for being one of the few studies in the whole of the literature surveyed to examine the amount of response to questions by comparison with other techniques.

Another study done in primary classrooms found that the great majority of responses consisted of only a single word or phrase, and gradually diminished as successive questions were put (Mishler 1975a, b, 1978). By contrast, the children gave longer and more complex responses to children's questions. This finding held for closed, yes/no questions as well as for the more open ' $w h$ 'type. That is, to the adult's question, children would give a yes/no and stop; with a child's question they would go on to elaborate. 'Even when they ask this type of response-constraining question they elicit a more complex response'. Hence the investigator concluded: "The "appropriate" response of children to adults both in their role as adults and to the adult manner of questioning, is a relatively short response' (Mishler 1978: 290, 294).

In summary, the conclusions from theoretical and empirical analyses in these fields either contradict or fail to support the notion that questions stimulate student thought and response:

In one way or another, teacher questions are often conceived of as ways of getting students to talk. In socio-linguistic research, we also use questions to obtain speech - as much as possible - and we have therefore given a 
great deal of attention to the form of questions, their underlying presuppositions, and the kind of question that gets the most results.... But, on the whole, it appears that questions may not be very good means of getting people to talk.

(Labov 1970: 57)

As is shown next, various fields of practice have also reached that same conclusion reworded as: questions are a very good means of keeping people from talking.

\section{Practical pursuit of questions}

One looks to opinion-pollsters and cross-examiners less for their theoretical views than for their practice. They do scarcely anything else but ask questions. In one way or another they rely on questions to delimit their client's thinking and speaking. Whereas their practice of questioning is similar to that in education, the purposes it serves are the opposite.

Of all the literatures on questioning, survey research is the next largest to education. Several manuals and research compendia are available (see, for example, Payne 1951, Sudman and Bradburn 1974). Research and field experience appear by and large to have settled the major issues for practice, including the issue of the response-effects of various question formats and wordings.

To obtain reliable and comparable results, survey research has a need for respondents not to give wide-ranging answers. Surveys elicit opinions as well as facts, but the opinion poll is a 'limited response' interview. 'The great majority of questions implicitly instruct the respondent to limit the length of his response to a few words' (Richardson et al. 1965: 260). The respondent cooperates by giving the information as specified and then awaits the inevitable follow-up question; for the question-sequence has been carefully designed to direct the conversation, to control its flow, and to constrain its content. Although surveys ask opinion questions and open-ended questions, analysis reveals them typically to contain twice as many closed questions as open ones (Richardson et al. 1965: 259).

This approximately describes classroom practice as well. Teachers also speak predominantly in questions, about two-thirds of which are closed-ended; students give limited responses; further questions follow, directing and controlling the course of conversation. But whereas teachers rely on questions to enhance thought and response, pollsters use them to delimit thinking and speaking.

Much the same contrast is afforded by courtroom cross-examination. To be sure, this enterprise too differs in important respects from opinion-polling as well as from teaching. Yet cross-examiners share with pollsters the characteristic tactical pursuit of questions in order to delimit client thought and response.

The literature on cross-examination is old and large enough, but it does not constitute a corpus of the kind which characterizes disciplines of study. The 
field exhibits neither theoretical nor empirical concerns; of all fields surveyed, this one is the most practical in emphasis. Authoritative sources include a classic treatise (Wellman 1937), a standard textbook (Keeton 1954), and transcripts of 'notable cross-examinations' (Fordham 1970). Applied psychology has regularly contributed studies of the effect of variously-worded questions on eye-witness testimony (see, for example, Muscio 1916, Loftus 1979). But there are few debatable issues of technique, for the results of cross-examination are immediate and conclusive; one soon knows whether practice has been effective or not. Thus this field is characterized by rules of practice, informed by the tradition of experience and constrained by judicial procedure and laws of evidence. Perhaps in consequence, authorities are unusually clear and agreed upon essentials of practice. Even in legal education, the same questioning techniques proven effective in courtrooms tend to characterize law-school classroom (Dillon 1980b).

More so than opinion-pollsters, cross-examiners have the purpose of preventing respondents from thinking and talking too much. Effusive responses may yield unreliable results in an opinion poll, but definitive and disastrous results in a court trial. The cross-examiner's case is endangered when a witness begins to think, to elaborate, to explain, to clarify, and to speculate (Keeton 1954, Busch 1961, Schwartz 1973). 'Under proper questioning, his opportunity to help establish that side of the case is limited to relating specific facts called for by the questions' (Keeton 1954: 132). The witness responds much like an interviewee or, indeed, a pupil, giving brief, limited answers as specified by the question and then silently awaiting the next question. A witness who knows better or more than asked is not permitted by the court to give additional information but only 'to give answers to those questions he is asked in a way that is short, direct, and to the point' (Tierney 1971: 43). The cross-examiner is especially cautious of volunteered information. A famous adage runs: if the witness wants to be asked a question, don't ask it (Tierney 1971: 33). In the face of a verbose witness the advice is: step up the questioning (Schwartz 1973). Curiously, that same advice has been given to teachers faced with a hesitant student (see, for example, Carin and Sund 1978). The questioning is held to delimit the witness's output and to enhance the student's.

Trial lawyers must be finely attentive to characteristics of a question - its wording, sequence, and presupposition. One wrong question from self or from opposing counsel can damage or lose the case. For example, the assessment of counsel's questions 'must be instantaneous and well nigh instinctive. The objection to a question must be made in the split second between the completion of the question and the start of the answer. After that it may be too late' (Schwartz 1973: 209). The consequences of one's own questions must also be appreciated. For example, like teachers, lawyers always know the answer in advance. The authorities are unanimous in warning: never ask a question unless you already know the answer. Behind this rule of thumb 'there is the logic of much tragic experience' (Busch 1961: 221).

By comparison with other practitioners, cross-examiners ask the most 
questions and probably the most effective ones. Opinion-pollsters ask nearly as many and as effectively. Their purpose is to delimit client thinking and speaking. Teachers too ask many questions, of a similar type, with predetermined answers. But their purpose is to enhance student thinking and speaking: the practice is similar, the purposes opposite.

\section{Tactical avoidance of questions}

Here, the purpose is similar to that found in education, but practices are opposite. The avoidance of questions characterizes just those enterprises where, as in classroom discussion, it is essential to enhance the expression of client thought. Personnel interviewing, group discussions and conferences, and psychotherapy, like education, focus upon the client's cognitive and expressive processes; they proceed by interaction and exchange of information; they entail exploration and inquiry. To be sure, there are all manner of important differences among these enterprises, as well as between them and education. Yet in each case it is the immediate purpose of the practitioner to enhance the client's participation. Hence one presupposes that these other practitioners, like teachers, might well use questions. But they do not. They deliberately avoid asking questions. They also avoid answering questions (see, for example, Maier 1958, Lowental 1972). Moreover, they substitute other techniques to achieve the very effect which educators attribute to questions. Thus, the whole of this stance is the reverse of that of conventional teaching. The contrasts will be described under three headings: avoidance of questions; use of statements; use of silences.

\section{AVOIDANCE OF QUESTIONS}

Where educators emphasize the use of questions, other practitioners avoid using them. In personnel interviewing, for instance, 'The use of direct questions is to be avoided wherever possible' (Lopez 1965: 252). Whereas educators hold questions in high esteem, in counselling: 'Generally, questioning is of doubtful value' (Arbuckle 1950: 106). If a question constitutes 'the most influential single teaching act' (Taba 1964: 53), in psychoanalysis it is 'a deviant technical intervention' (Olinick 1954: 60).

The general use of questions is thought to have opposite effects on students and other clients. As to thought processes, teacher questions 'stimulate and encourage inquiry' (ISCS 1972); a therapist's questions, however, 'produce blocking' and prevent the client from making 'penetrating analysis of problems' (Curran 1952: 241). As to expression of feeling, teachers are told that by questioning students they can learn 'what they know and how they feel' (ISCS 1972: 1-6). Group leaders are warned that questioning is not conducive to finding out how participants feel' (Maier 1963: 114); and counsellors are told that by asking a question, 'the chances of a true expression of feeling are restricted' (Arbuckle 1950: 108). As to amount of response, teachers rely on questions 'to increase pupil talk' and 'to facilitate discussion' (Blosser 1973). 
But in personnel interviewing: 'Primary reliance on questions as a means of stimulating conversation can lead to reduced input from the applicant' (Drake 1972: 76).

Specific techniques of questioning are also held to have divergent effects. Education manuals urge putting questions to individual students who are not participating or who are drifting out of the discussion (see, for example, Carin and Sund 1978). But leaders of group discussions are told: 'Generally speaking, this is not a good procedure' (Maier 1963: 116). Probing and follow-up questions are urged upon teachers because they get longer responses (Gall 1973b), and keep students involved in the lesson (Gage and Berliner 1975). Interviewers are cautioned against asking questions one after the other, for 'the likelihood is that shorter and shorter responses will be made to each succeeding question' (Drake 1972: 76). Far from involving, probing 'drives the interviewee away' (Weinland and Gross 1952: 204), and 'may be resented, feared, and resisted' by the analysand (Olinick 1954: 61). 'Probing inquiries' in psychotherapy 'restrict interaction, circumscribe response, and encourage passivity' (Hammond et al. 1977: 340).

To account for these depressive effects, authorities specify that questions make clients defensive and/or passive. As to defensiveness, 'merely asking a question produces a threat to the well being, or stress' (Royal and Schutt 1976: 146). Questions can be threatening, paralyzing, and interpreted as an attack (Merton 1956, Maier 1963, Bradford et al. 1964). 'At its worst, questioning can become an inquisition and cut off almost all conversation. At its best, questioning tends to arouse caution in the applicant' (Drake 1972: 76). As to passivity, a question-answer relationship removes initiative, responsibility, and a kind of energy from clients. Those who do start off expressing their ideas soon perceive the questioner as telling them: 'Look, if I want to know what you're thinking, I'll ask you' (Drake 1972: 76). The course of conversation is rightly supposed to be determined by the one party, the one who asks the questions; the other party follows along by giving the answers and then co-operatively and silently - awaiting the next question. 'He answers when asked and otherwise keeps his mouth closed - and undoubtedly his mind and heart as well' (Benjamin 1974: 66). To what extent might that also describe the effect of teacher questions put to open minds and mouths and hearts?

Beyond practice and theory, little research seems available on the avoidance of questions. One study of therapy sessions concluded that 'the asking of direct questions is usually rather unfavourably received by the client' (Snyder 1945: 214-15). Another found that questions increased clients' 'unpleasant affect', and decreased their 'understanding and insight' (Frank and Sweetland 1962). A third found that when therapists answered questions, clients abandoned 'selfexploration' (Bergman 1951). The remaining evidence, such as it is, consists of critical glosses on therapy protocols (Arbuckle 1950, Curran 1952, Snyder 1963, Benjamin 1974). For example: 'This whole section of the interview is much less profitable because of two directive questions' (Rogers 1942: 280).

In these fields, questions are held to inhibit expression of thought. Since 
practitioners desire to enhance it, they avoid questions or use them sparingly. Instead they use declarative statements and deliberate silences.

\section{USE OF STATEMENTS}

Statements are not merely used, but substituted for questions, on the grounds that they more effectively enhance client participation. In personnel interviews, for example, substituting statements for questions 'subtly invites the interviewee to speak more freely' (Lopez 1965: 119). In counselling sessions, a counsellor's neutral or accepting response 'probably would have obtained much more information than he received from his direct question, "How do you explain that?"' (Curran 1952: 240). One would not imagine that much could be made of the use of declarative statements. Yet the contrast between education and other enterprises over declaratives and interrogatives is literal; it is not merely that education emphasizes the one and other fields the other; the contrast involves an explicit reversal of major and minor accents.

Regarding general technique, a manual for teachers recommends that interrogatives be used more frequently than declaratives. 'Teachers should develop a speech pattern in which the interrogative sentence is as important and as frequently used, if not more so, than the declarative statement' (Weaver and Cenci 1960: 63). A manual for interviewers recommends the reverse. 'Rather than asking questions. the interviewer substitutes, wherever possible, declarative statements' (Lopez 1965: 119).

Regarding the specific technique for following up a contribution during discussion, a manual for teachers recommends using an interrogative in place of a declarative; a manual for group leaders again recommends the reverse, again for the reverse reasons. The teacher is told: 'Whereas a declarative statement sounds critical and omniscient, a question or request makes the speaker think a little more' (Moffett and Wagner 1976: 79). The group leader is told: 'It is important not to put these rephrased statements in the form of questions. This same restatement expressed as a question would indicate doubt or disapproval. Questions can be threatening, and cause answers to be brief and guarded' (Maier 1963: 114). These examples may represent isolated instances. Yet it is a wonder that such literal reversals should be found at all.

Apart from practice and opinions, only three empirical studies have been found that compare response to questions and statements. All report that questions receive the lesser response. In a socio-linguistic study already noted, children's response to questions was nearly three times briefer (1.0 versus 2.7 lines). 'Questions are less likely to elicit narratives than are other verbalizations' (Boggs 1985: 312). In an experimental psychoanalytical situation, response to statements was longer than to questions (26 versus 19 sentences), and more relevant to the topic ( 58 per cent versus 49 per cent). The statements proved 'significantly more effective in amplifying free association', and therefore 'might represent a more effective heuristic in clinical discourse' (Colby 1961: 238). And if we reframe our concern to ask, which type of teacher intervention might 
prove more effective in amplifying student discussion?, the third study, done in high school discussion classes, found that response to teacher questions was, on average, slightly briefer than response to statements (14 versus 16 seconds). This finding held for various types of questions and comparable types of statements; for example, factual questions and statements (10 versus 13 seconds), and opinion ones (15 versus 18 seconds). Analysis of class mean response revealed no significant difference between the two (Dillon 1981b).

In accounting for such findings, a psychoanalytic investigator advanced a suggestive viewpoint from information theory. A question is designed to elicit information, whereas a statement offers information. The respondent is instructed, 'supply the information requested' or 'accept/reject the information offered'. That would appear to make questions more effective in enhancing response, since accept/reject is a one-word or even a one-nod task. But a statement has more informational 'surprise-value' and is more ambiguous with respect to response beyond accept/reject. 'What direction to develop and when to terminate are less clearly defined than in the case of an interrogative' (Colby 1961: 237, 238). In accepting/rejecting the information, respondents bring to bear information and experience which they already possess, together with the structure and organization of what they know. They are left free to adduce all manner of justifications, to make comparisons and adjustments, to give supportive data, examples of counter-instances, and so forth. But respondents are less free to do any of that when answering a question. A question specifies the topic, the type of information to be supplied, and also the amount of response that is adequate (Richardson et al. 1965). That is: 'Supply the information requested, then stop'. Thus a question may be said comparatively to circumscribe response and to delimit inquiry.

The respondent to a question is limited because, as further revealed by linguistic analysis, $Q$ and $R$ have agreed by convention that $R$ will answer the question and that $Q$ will speak again. In this temporary status as respondent (not 'interlocutor'), $R$ does not have the option to go on speaking at will, nor to alter the topic; he has agreed to use his turn to perform the task which has been specified by $Q$. After $Q$ has subsequently commented on the response, the exchange ends and the partners may negotiate another - including a non-question, non $Q-R$ exchange. However, if $Q$ uses his right to speak again for putting another question, $R$ again comes into play. And that is how teachers maintain question-answer exchanges. Hence, by using questions, teachers may unwittingly constrain expression of student thought, all the while hoping to enhance it. Especially during discussion classes, alternatives to questioning would appear more effective in stimulating student cognitive and expressive processes. ${ }^{4}$

\section{USE OF SILENCES}

Deliberate silent pauses are also substituted for questions, again on grounds of enhancing participation. For example, a counsellor's 'dubious' use of the question, 'What makes you feel that?' is criticized because 'a pause would probably have elicited further attitudes from the client' (Rogers 1942: 289). 
The use of silence must be deliberate in that all practitioners seem to assume entire responsibility for the flow of conversation, experience unease when the conversation halts, and tend to put a question at that juncture in order to keep it going (Arbuckle 1950, Merton 1956, Richardson et al. 1965, Matarazzo et al. 1968). When silence threatens, teachers, too, may put a question, thinking to stimulate more response. 'Silence per se is a threat to the teacher's wellbeing. Student response, no matter how trivial, assures the teacher that "everything is okay"' (Brophy and Good 1974: 30). However, in interviewing: 'Breaking the silence by another question could inhibit the further response that would otherwise have been forthcoming' (Richardson et al. 1965: 204). When a student pauses, teachers are advised to probe for further response, especially to encourage hesitant or reticent students to speak their thoughts. But psychotherapists speak of the 'futility' and 'negative effects' of probing with questions when the client pauses (Weisman 1955, Zeligs 1960). "What are you thinking?" usually evokes the reply, "Nothing", followed again by continued silence' (Zeligs 1960: 409).

In recent years, a few educators have also recommended the use of silence (Rowe 1974). However, three marked differences may be cited between education and these other fields.

The use of silence is not emphasized in education but is of major emphasis in other fields. There are as many reviews on silence in other fields as there are individual articles on silence in education. ${ }^{5}$

b The use of silence supplements the teacher's question whereas it substitutes for the clinician's. Educators regard silence as a sort of passive adjunct to the primary techniques of questioning. It is referred to as 'wait-time' and 'lapse time interval' (Arnold 1974, Rowe 1974), a kind of grace-period or empty wait during which the effect of the question presumably makes itself felt. In other fields, silence itself constitutes a distinct technique with a primary, active role. It is called 'a positive force', an 'intervention', a 'stimulus', an 'intentional response' (see, for example, Gorden 1954, Lief 1962, Benjamin 1974).

c The effects of silence in other fields are just those which education attributes to questions. The interviewer's use of silence is said to assist the respondent to express an idea, to make inferences and judgements, to encourage him to continue his story, and to become more willing to talk and to rephrase previous statements (Gorden 1954, Bruneau 1973, Benjamin 1974, Penland and Mathai 1974). The therapist's silence is held to facilitate the patient's communication, to elicit further attitudes, and to help the taciturn to verbalize (Rogers 1942, Zeligs 1960, Lief 1962).

No study has been found that compares questions to silences. In the absence of comparative evidence, some findings on silence alone can be outlined. Generally, the research has demonstrated that pausing during speech is positively related to the amount of speech production and quality of cognitive activity (see 
Rochester 1973). Studies conveniently divide into those examining silent pauses within an individual's utterances and between two speakers' utterances.

Within utterances, silent ('unfilled') pauses have been found more frequent and more lengthy: (i) before high-information rather than low-information words (Eisler 1968); (ii) during abstract rather than concrete sentences (Taylor 1969); (iii) during explanation and interpretation of events rather than during description (Levin et al. 1967, Eisler 1968). Of considerable significance is the finding that silence during interpretation and explanation as compared to description - namely during higher versus lower cognitive activity - is twice as long for the same amount of speech, i.e. per word produced (Eisler 1968). 'In short, to think results in slow, pause-filled, hesitant speech' (Levin et al. 1967). These findings suggest that if teachers were to forebear speaking at the moment when a student pauses (ostensibly terminates) they would likely bear further expression of higher thought.

Studies of between-speaker silences suggest that practitioner silence does enhance the amount and quality of response. To put it simply, silence has been found positively related to: (1) frequency of response (Gorden 1954, Matarazzo et al. 1968, Jaffe and Feldstein 1970); (2) length of response (Gorden 1954, Matarazzo and Wiens 1972, Rowe 1974); (3) cognitive level of response (Rowe 1974). In class, for example, as the teacher increased pausing time during and after student response from one to three-plus seconds, mean response increased from seven to 28 words (Rowe 1974). These studies vary in details of method, context, and results. But, taken together, they make a fair case that practitioner silence has a positive effect on participation.

In summary, enterprises characterized by the tactical avoidance of questions maintain a stance entirely at variance with education. But by no means does this contrast of itself invalidate education's stance. Yet it does make for curiosity, raising more than one issue for theory, practice, and research. In this circumstance one turns to research, wondering what response do clients in fact give to practitioner questions?

\section{Research on response to questions}

When attention turns away from theory and practice to research, the most striking impression is one of sudden smallness of view. In contrast with the proliferation of opinions and the extent of practice, the foundation in research appears restricted and tentative. This last section summarizes what is known empirically of the extent to which questions in general, and selected types, enhance client participation.

\section{Questions in general}

The use of questions appears to have a relatively limiting and depressing effect upon expression of client thought. That statement summarizes a variety of findings from a limited number of studies done in several contexts, including 


\section{J.T. Dillon}

classrooms (Stevens 1912, Yamada 1913, Susskind 1969, 1979, Mishler 1975a, b, 1978, Rowe 1974, Santiesteban 1976, Susskind 1979, Boggs 1985) and therapy sessions (Snyder 1945, Bergman 1951, Colby 1961, Frank and Sweetland 1962).

The findings from these studies are as follows. Responses to questions are brief, typically a single word or phrase. As further questions are put, responses become shorter. Responses to teacher questions are shorter and simpler than they are to questions asked by other pupils. Responses to questions are shorter than to other verbalizations such as declarative statements. High rates of questioning are associated with low rates of student questions and voluntary contributions, apart from answers. By comparison with other techniques, the use of questions is associated with more inaccuracies of report and more unpleasant affect; less free-association, self-exploration, understanding and insight; and fewer respondent questions and fewer statements of problems and feelings.

Beyond the findings themselves are the terms in which researchers have couched their observations. Noting the high frequency of questions in classrooms, early investigators spoke of 'highly strung nervous tension' and a 'highpressure atmosphere' (Stevens 1912); to rely on questions alone 'is to make children passive and halting in their self-expression and independent mental activity' (Yamada 1913). Recent observers suggest that a high frequency of questions may yield 'negative affective outcomes' (Santiesteban 1976), make the class appear an 'inquisition' rather than a reasonable conversation (Rowe 1974), and encourage student passivity, dependency, and reactivity (Susskind 1969).

Clearly, findings such as these do not support the supposedly stimulating effect of questions. They would support the contrary notion: questions tend at the least not to stimulate expression of student thought, and perhaps to depress it (Dillon 1978). Nonetheless, the evidence is limited; the studies are few in number and entail a variety of methods, purposes, perspectives, and contexts. A body of studies is required that would directly examine the characteristics of response to teacher questions (for example length, affect, cognitive quality).

One of the first requirements should be to stipulate a definition of the questions being studied. Lack of definition is the most remarkable deficiency of studies reviewed; consequently it is difficult to compare studies and even to grasp the results of an individual study. Often the reader cannot be sure as to what has been counted as a question, and what has not. In one study it turns out that imperatives were counted as questions, whereas many interrogatives were not, if they did not begin with 'Why?' (Gall et al. 1970). In other studies it turns out that the questions are declaratives (see, for example, Frase 1971). In a study comparing questions to statements, the 'questions' are completely identical to the statements save for exclusion of the key response term (Bruning 1968). Other sources do not actually discriminate questions but include them with various other 'solicitations to respond' (Bellack et al. 1966) or 'intellectual exercises calling for a response' (Sanders 1966). Especially when comparing questions to other utterances, it might be useful to restrict the term question to interrogative utterances. 


\section{Content of questions}

The most pronounced emphasis in the educational literature is upon asking questions of a higher-cognitive order than fact, memory, and knowledge. Higher types presumably elicit more complex thought-processes and consequently longer responses (Gall et al. 1970, Blosser 1973). Yet the effect of such questions on complex thought-processes remains undemonstrated. 'None of the experiments reviewed here have documented that higher cognitive questions actually promote the assumed cognitive processes in students' (Winne 1979: 44). The associated issue of response length has been examined by only a few studies, but they all report that higher questions do elicit longer responses. Using number of words as a measure of length, studies have found longer responses for 'higher' versus 'knowledge' questions (Gall et al. 1970); for 'interpretive' versus 'factual' (Smith 1977); and for 'broad/higher' versus 'narrow/lower' (Smith 1978). A study which categorized responses by number of words found that 73 per cent of responses to 'memory' questions were one to three words long, whereas 71 per cent for 'divergent/evaluative' questions were 10+ words long (Cole and Williams 1973). Finally, a study measuring duration of response in seconds observed longer response to 'opinion' than to 'fact' questions (Dillon 1981b).

A contrary, and suggestive, finding comes from survey research: longer responses came to factual rather than opinion questions (both in 'open' form), 'possibly because respondents resist subjective questions more than objective questions' (Richardson et al. 1965). Indeed, one of the classroom studies incidentally noted that 'valuing questions about personal feelings' were a type of higher question which, in fact, got brief responses (Smith 1978). Thus, researchers might find it more informative to classify questions into a differentiated scheme instead of a mere dichotomy.

A further suggestion is to distinguish content from structure, since any type of factual or higher question can exhibit a closed or open structure. Many schemes appear to confound these two dimensions (for example, identifying higher with open questions), and to confound the two further with yet other dimensions (for example, defining 'open' now by cognition, now by syntax, now by number, length, or level of possible responses). Hence a final suggestion is to decide clearly whether question content is to be distinguished by type of inferred cognition, syntactic structure, intended meaning, and expected response, or yet by type of information entailed. It appears more direct, more objective, and more reliable to classify questions according to the type of information which they can be seen to contain. In general, the study of question types would benefit from more precision in defining categories and more clarity in reporting them.

\section{Sequence of questions}

A second technique emphasized in the educational literature is to follow up a student's initial response with another, probing question. A probe or follow-up 


\section{J.T. Dillon}

question 'will take an initially weak response and improve its quality, as measured by length' (Gall 1973b: 4). Although reviewers have placed 'high priority on investigations of question sequence' (Gall 1973a: 8), there appear to be few studies in education which directly address this issue. A technical report on teacher training (Gall 1973b) incidentally presents data which can be analysed to show a longer response for probe than for initial questions (14 versus eight words). Other studies contradict this view. A socio-linguistic study done in primary classrooms found that responses to a second question is shorter, 42 per cent of answers consisting of a single word (Mishler 1978). In a psycho-linguistic study of hesitation phenomena, experimenters asked questions of those children who were 'especially hesitant, spoke slowly, or paused a great deal' while trying to explain a curious event the child had just described. 'Nevertheless, these probes did not have the effect of increasing the child's fluency compared to his performance during description' (Levin et al. 1967: 563). In a study done in high-school classes, response to initial questions in a series was on average longer than for subsequent questions put to the same student (16 versus 11 seconds). No difference was observed in class mean response to these questions (Dillon 1981b).

Issues in the study of question sequence remain to be defined. Evidently there are various kinds of sequence and various sorts of functions that questions of various types can serve in any one position. For example, it is not immediately clear in which way a question constitutes either a probe or a follow-up. One teacher question can follow another without necessarily relating to the previous question or respondent or response. Future studies might usefully distinguish between (a) questions asked singly and questions in a series; for those within a series, between (b) initial and subsequent questions; within subsequent questions, between (c) those put to the same and different respondents; and for same-respondents, between $(\mathrm{d})$ those which relate to the previous response and those which do not. The issues are susceptible to direct, and relatively easy to test, once the sequence is: first, clearly defined, and second, carefully related to other question-dimensions. Whatever a question's sequence, its effects might yet be mediated by its content and structure (cf. factual versus high probe, open versus closed). Given present confusion, it is little wonder that the effects of probing are obscure.

\section{Structure of questions}

Considerable emphasis is given to the teacher's use of open-ended over closed questions. Open questions are presumed to produce longer responses (see, for example, Blosser 1973). Similarly, in survey interviewing, response length is thought to be 'most directly controlled' by the choice of open versus closed, 'open questions obtaining longer answers' (Richardson et al. 1965: 256). There seems to be little educational research on this matter. In survey research, responses to open questions were found longer than for closed ones in 29 of 40 interviews analysed; and, in experimental interviews, mean response to open 
questions was found three times longer (nine versus three lines). 'The results confirm what might reasonably be expected: open questions do elicit longer responses than closed questions' (Richardson et al. 1965: 148). Nonetheless, a synthesis of survey research has concluded otherwise: 'Contrary to our hypothesis, whether the question is closed-ended or open-ended seems to have no general effect on responses' (Sudman and Bradburn 1974: 35-6). Exploratory research in classrooms might yield altogether different results again. For example, a study in primary classes found that responses to closed questions asked by other children was longer than to open questions asked by the teacher (Mishler 1978). A study in high-school classes found that closed questions received nearly twice the amount of class mean response as open ones (12 versus 7 seconds). Closed questions were defined as so linguistically structured that a single word or phrase in response was sufficient on grammatical grounds; open questions were structured so as to require at least several phrases or a sentence (Dillon 1981b). It should be noted that the definition is not in terms of the questioner's intent but of the question's structure. These findings exemplify the possible differences between intended answers and expressed questions, and between expected and observed responses.

Future studies might usefully distinguish between three elements of structure: (a) What kind of structure is to be examined? for example, syntactic or semantic; (b) What relation does that structure bear to the response? for example, requiring or permitting a certain kind or amount; (c) Which quality of response is entailed? for example, length, content, variety. A direct approach would be to examine syntactic structure in relation to the minimum number of words sufficient for response on grammatical grounds. The resulting types of structure should then be examined in conjunction with various types of content (for example, open-factual, open-opinion).

\section{Length of question and silence}

Little if any theoretical emphasis is placed on the length of questions, except perhaps to keep them brief. Nonetheless, length is of some interest both for research and for practice.

Experimental and correlational studies of teacher, interviewer, and therapist questions report that, on average, the longer question gets the longer answer (Matarazzo et al. 1962, Koomen and Dijkstra 1975, Dillon 1981b) - suggesting that questions should not be kept brief. These studies measured length by duration in seconds. By contrast, a synthesis of survey research found 'no general effect related to the number of words in the question' and it called for more work to be done on measuring the effect of length in words (Sudman and Bradburn 1974: 146). However, a study of spontaneous conversations suggests that different results are obtained from measuring length by duration, as compared to number of words; and from distinguishing between vocalizations and silent pauses within an utterance. When length was measured by words, no relationship was found between the two parties' utterances. When measured by 
duration, the relationship observed in other studies between the two parties' utterances (namely vocalizations) vanished; there emerged instead a relationship between their pauses within utterances $(r=0.43)$ (Jaffe and Feldstein 1970: 48-9). Future studies might well adopt this duration-strategy in order to compare the effects of teacher questions and silences at the juncture where the student stops speaking.

Two issues emerge for studying response to silence: (a) whether or not the student resumes speaking; (b) the duration of resumed speech. Research findings are unclear. For length of silence and proportion of silences responded to, certain studies have found a direct positive relationship (Matarazzo et al. 1968), others a direct negative one (Gorden 1954). For duration of response, it has been found to increase (Rowe 1974), but also to decrease as the silence is prolonged (Gorden 1954). Perhaps some range or threshold effect is involved, such that silences shorter than 3-5 seconds and longer than 10-15 seconds might have little or no effect upon participation (Gorden 1954, Cook 1964, Matarazzo et al. 1968). Even so, both the limits of the range and the effects within could well differ for classrooms as compared to individual therapy and interview settings (Hammer 1975). Intriguing and useful though it appears to be, silence remains as undervalued and neglected in educational research as it is in classroom practice.

\section{Conclusion}

No other enterprise but education holds that questions enhance cognitive, affective, and expressive processes. In fields emphasizing theoretical pursuits, the theory of questioning either fails to yield that notion or contradicts it. In fields emphasizing practical pursuits, where the practice of questioning is similar to education, the purposes it serves are opposite; and where purpose is similar to education, the practices are opposite. Only in education are questions asked in the belief that they will stimulate thought and encourage expression.

Research offers few grounds in support of this stance and relatively strong grounds both against it and in support of its contrary. It suggests that questions at least do not stimulate and might well depress the expression of student thought, whereas alternative techniques such as declarative statements and deliberate silences might enhance it. Overall, however, the evidence is limited and there is ample room for systematic inquiry. Amidst the vast structure of the literature one wanders in search of empirical foundations, wondering always at the mass of pedagogical theory and the weight of classroom practice. What certainties sustain these? Much remains to be known about the effect of questions.

\section{Acknowledgements}

Frederick F. Lighthall, Harold B. Dunkel, and anonymous referees made welcome suggestions on various drafts of this review. 


\section{Notes}

l For a comprehensive bibliography see Dillon (1981a); for further literature see Dillon (1982).

2 For example, Hoekter and Ahlbrand (1969), National Education Association (1976), Rosenshine (1971, 1976a), Dunkin and Biddle (1974), and Winne (1979).

3 See, for example, Harrah (1963), Belnap and Steel (1969), Robinson and Rackstraw (1972), and Hintikka (1976).

4 For alternative techniques, see Dillon (1979a, 1981c).

5 See, for example, the reviews by Weisman (1955), Bruneau (1973), and Rochester (1973).

\section{References}

Anderson, R.C. and Biddle, W.B. (1975) 'On asking people questions about what they are reading', in G.H. Bower (ed.), Psychology of Learning and Motivation, vol. 9 (New York: Academic Press), 89-132.

Arbuckle, D.S. (1950) Teacher Counseling (Cambridge, MA: Addison-Wesley).

Arnold, D.S. (1974) 'Questions and response levels and lapse time intervals', Journal of Experimental Education, 43 (1), 11-15.

Aschner, M.J. (1961) 'Asking questions to trigger thinking', NEA Journal, 50 (6), 44-6.

Auerbach, S. (1977) Teaching science. In J.F. Callahan and L.H. Clark (eds), Teaching in the Elementary School: Plannning for Competence (New York: Macmillan), 193-215.

Bellack, A.A., Davitz, J.R., Kliebard, H.M., and Hyman, R.T. (1966) The Language of the Classroom (New York: Teachers College Press).

Belnap, N.D. (1969) 'Questions: their presuppositions, and how they can fail to arise', in K. Lambert (ed.), The Logical Way of Doing Things (New Haven, CT: Yale University Press), 23-37.

Belnap, N.D. and Steel, T.B. (1969) Logic of Questions and Answers (New Haven, CT: Yale University Press).

Benjamin, A. (1974) The Helping Interview, 2nd edn (Boston, MA: Houghton Mifflin).

Bergman, D.V. (1951) 'Counseling method and client responses', Journal of Consulting Psychology, 15 (3), 216-24.

Betts, G.H. (1910) The Recitation (New York: Houghton Mifflin).

Blosser, P.E. (1973) Handbook of Effective Questioning Techniques (Worthington, OH: Education Associates).

Boggs, S.T. (1985) The meaning of questions and narratives to Hawaiian children. In C.B. Cazden, V.P. John, and D. Hymes (eds), Functions of Language in the Classroom (Prospect Heights, IL: Waveland), 299-327.

Boraas, J. (1922) Teaching to Think (New York: Macmillan).

Bradford, L.P., Gibb, J.R., and Benne, K.D. (1964) T-Group Theory and Laboratory Method: Innovation in Re-education (New York: Wiley).

Brophy, J.E. and Good, T.K. (1974) Teacher-Student Relationships: Causes and Consequences (New York: Holt, Rinehart \& Winston).

Bruce, L.R. (1971) 'A study of the relationship between the SCIS teachers' attitude toward the teacher-student relationship and question types', Journal of Research in Science Teaching, 8 (2), 157-64.

Bruneau, T.J. (1973) 'Communicative silences: forms and functions', Journal of Communication, 23 (1), 17-46. 
Bruning, R.H. (1968) 'Effects of review and testlike events within the learning of prose materials', Journal of Educational Psychology, 59 (1), 16-19.

Busch, F.X. (1961) Trial Procedure Materials (Indianapolis, IN: Bobbs-Merrill).

Carin, A.A. and Sund, R.B. (1978) Creative Questioning and Sensitive Listening Techniques, 2nd edn (Columbus, OH: Merrill).

Clark, M. (1972) Perplexity and Knowledge: An Inquiry into the Structure of Questioning (The Hague: Martinus Nijhoff).

Colby, K.M. (1961) 'On the greater amplifying power of casual-correlative over interrogative inputs on free association in an experimental psychoanalytic situation', Journal of Nervous and Mental Disease, 133 (3), 233-9.

Cole, R.A. and Williams, D.M. (1973) 'Pupil responses to teacher questions: cognitive level, length and syntax', Educational Leadership, 31 (2), 142-5.

Cook, J.J. (1964) 'Silence in psychotherapy', Journal of Counseling Psychology, 11 (1), 42-6.

Curran, C.A. (1952) Counseling in Catholic Life and Education (New York: Macmillan).

Davis, O.L. and Hunkins, F.P. (1966) 'Textbook questions: what thinking processes do they foster?', Peabody Journal of Education, 43 (5), 285-92.

DeGarmo, C. (1902) Interest and Education: The Doctrine of Interest and Its Concrete Application (New York: Macmillan).

Dillon, J.T. (1978) 'Using questions to depress student thought', School Review, 87 (1), $50-63$.

Dillon, J.T. (1979a) 'Defects of questioning as an interview technique', Psychology in the Schools, $16(4), 575-9$.

Dillon, J.T. (1979b) 'Alternatives to questioning', High School Journal, 62 (5), 217-22.

Dillon, J.T. (1980a) 'Curiosity as a non sequitur of Socratic questioning', Journal of Educational Thought, 14 (1), 17-22.

Dillon, J.T. (1980b) 'Paper Chase and the Socratic method of teaching law', Journal of Legal Education, 30 (4/5), 529-30.

Dillon, J.T. (1981a) 'Categories of literature on questioning in various enterprises: an introduction and bibliography', Language Sciences, 3 (2), 337-58.

Dillon, J.T. (1981b) 'Duration of response to teacher questions and statements', Contemporary Educational Psychology, 6 (1), 1-11.

Dillon, J.T. (1981c) 'To question and not to question during discussion', Journal of Teacher Education, 32 (6), 15-20.

Dillon, J.T. (1982) 'The multidisciplinary study of questioning', Journal of Educational Psychology, 74 (2), 147-65.

Drake, J.D. (1972) Interviewing for Managers: Sizing Up People (New York: American Management Association).

Dunkin, M.J. and Biddle, B.J. (1974) The Study of Teaching (New York: Holt, Rinehart \& Winston).

Eisler, F.G. (1968) Psycholinguistics: Experiments in Spontaneous Speech (New York: Academic Press).

Fahey, G.L. (1942) 'The questioning activity of children', Journal of Genetic Psychology, $60(2), 337-75$.

Fordham, E.W. (1970) Notable Cross-Examinations: chosen and annotated by Edward Wilfrid Fordham (Westport, CT: Greenwood).

Frank, F.H. and Sweetland, A. (1962) 'A study of the process of psychotherapy: the verbal interaction', Journal of Consulting Psychology, 26 (2), 135-8.

Frase, L.T. (1971) 'Effect of incentive variables and type of adjunct question upon text learning', Journal of Educational Psychology, 62 (5), 371-5. 
Gage, N.L. and Berliner, D.C. (1975) Educational Psychology (Chicago: Rand, McNally). Gall, M.D. (1970) 'The use of questions in teaching', Review of Educational Research, 40 (5), 707-21.

Gall, M.D. (1973a) 'The Use of Questions in Teaching Reading', ERIC ED 067650.

Gall, M.D. (1973b) 'What effect do teachers' questions have on students?' Paper presented at the Annual Meeting of the American Educational Research Association, New Orleans, ERIC ED 077882.

Gall, M.D., Dunning, B., Galassi, J., and Banks, H. (1970) Main Field Test Report: Minicourse 9 - Thought Questions in the Intermediate Grades (San Francisco, CA: Far West Laboratory for Educational Research and Development).

Gorden, R.I. (1954) An Interaction Analysis of the Depth-Interview. Doctoral dissertation, University of Chicago.

Groisser, P.L. (1964) How to Use the Fine Art of Questioning (Valley Stream, NY: Teachers Practical Press).

Hamblin, C.L. (1958) 'Questions', Australasian Journal of Philosophy, 36 (3), 159-69.

Hammer, G.J. (1975) 'An experimental study of prolonged teacher silence', Research in Education, no. 15, 73-7.

Hammond, D.C., Hepworth, D.H., and Smith, V.G. (1977) Improving Therapeutic Communication (San Francisco, CA: Jossey-Bass).

Harrah, D. (1963) Communication: A Logical Model (Cambridge, MA: MIT Press).

Harrah, D. (1969) 'Erotetic logistics', in K. Lambert (ed.), The Logical Way of Doing Things (New Haven, CT: Yale University Press), 3-21.

Harrah, D. (1973) 'The logic of questions and its relevance to instructional science', Instructional Science, 1 (4), 447-67.

Hintikka, J. (1976) The Semantics of Questions and the Questions of Semantics: Case Studies in the Interrelations of Logic, Semantics, and Syntax. Acta Philosophica Fennica, 28, no. 4 (Amsterdam, The Netherlands: North-Holland).

Hiz, H. (ed.) (1978) Questions (Dordrecht, The Netherlands: D. Reidel).

Hoekter, J. and Ahlbrand, W.P. (1969) 'The persistence of the recitation', American Educational Research Journal, 6 (2), 145-67.

Horn, E. (1937) Methods of Instruction in the Social Studies (New York: Scribner).

Hough, J.B. and Duncan, J.K. (1970) Teaching: Description and Analysis (Reading, MA: Addison-Wesley).

Hunkins, F.P. (1972) Questioning Strategies and Techniques (Boston, MA: Allyn and Bacon).

Hyman, R.T. (1979) Strategic Questioning (Englewood Cliffs, NJ: Prentice Hall).

Intermediate Science Curriculum Study (ISCS) (1972) Questioning (Morristown, NJ: Silver Burdett).

Jaffe, J. and Feldstein, S. (1970) Rhythms of Dialogue (New York: Academic Press).

Katz, J.J. (1972) Semantic Theory (New York: Harper \& Row).

Kearsley, G.P. (1976) 'Questions and question asking in verbal discourse: a crossdisciplinary review', Journal of Psycholinguistic Research, 5 (4), 355-75.

Keeton, R.E. (1954) Trial Tactics and Methods (Boston, MA: Little, Brown).

Knight, T.S. (1967) 'Questions and universals', Philosophy and Phenomenological Research, 27 (4), 564-76.

Koomen, W. and Dijkstra, W. (1975) 'Effects of question length on verbal behavior in a bias-reduced interview situation', European Journal of Social Psychology, 5 (3), 399-403.

Labov, W. (1970) The Study of Nonstandard English (Urbana, IL: National Council of Teachers of English). 
Lamb, W.G. (1976) 'Ask a higher-level question - get a higher-level answer', Science Teacher, 43 (4), 22-3.

Landon, J. (1899) The Principles and Practice of Teaching and Class Management, 4th edn (London: Alfred M. Holden).

Levin, H., Silverman, I., and Ford, B.L. (1967) 'Hesitations in children's speech during explanation and description', Journal of Verbal Learning and Verbal Behavior, 6 (4), $560-4$.

Lief, H.I. (1962) 'Silence as intervention in psychotherapy', American Journal of Psychoanalysis, 22 (1), 80-3.

Llewelyn, J.E. (1964) 'What is a question?' Australasian Journal of Philosophy, 42 (1), 69-75.

Loftus, E.F. (1979) Eyewitness Testimony (Cambridge, MA: Harvard University Press).

Lopez, F.M. (1965) Personnel Interviewing: Theory and Practice (New York: McGrawHill).

Lowental, U. (1972) 'On the use of questions in psychiatry', Comprehensive Psychiatry, $13(1), 19-23$.

Maier, N.R.F. (1958) The Appraisal Interview: Objectives, Methods, Skills (New York: Wiley).

Maier, N.R.F. (1963) Problem-solving Discussions and Conferences: Leadership Methods and Skills (New York: McGraw-Hill).

Matarazzo, J.D. and Wiens, A.N. (1972) The Interview: Research on its Anatomy and Structure (Chicago: Aldine-Atherton).

Matarazzo, J.D., Hess, H.F., and Saslow, G. (1962) 'Frequency and duration characteristics of speech and silence behavior during interviews', Journal of Clinical Psychology, 8 (4), 416-26.

Matarazzo, J.D., Wiens, A.N., Matarazzo, R.G., and Saslow, G. (1968) 'Speech and silence behavior in clinical psychology and its laboratory correlates', in Shlien, J. (ed.), Research in Psychotherapy, 3 (Washington, DC: American Psychological Association), 347-94.

Mehan, H. (1979) Learning Lessons (Cambridge, MA: Harvard University Press).

Merton, R.K. (1956) The Focused Interview: A Manual of Problems and Procedures (Glencoe, IL: Free Press).

Meyer, W.J. and Shane, J. (1973) 'The form and function of children's questions', Journal of Genetic Psychology, 123 (2), 285-96.

Mishler, E.G. (1975a) 'Studies in dialogue and discourse: an exponential law of successive questioning', Language in Society, 4 (1), 31-51.

Mishler, E.G. (1975b) 'Studies in dialogue and discourse: II. Types of discourse initiated and sustained through questioning', Journal of Psycholinguistic Research, 4 (2), 99-121.

Mishler, E.G. (1978) 'Studies in dialogue and discourse: III. Utterance structure and utterance function in interrogative sequences', Journal of Psycholinguistic Research, 7 (4), 279-305.

Moffett, J. and Wagner, B.J. (1976) Student-centered Language Arts and Reading, K-13: A Handbook for Teachers (Boston, MA: Houghton Mifflin).

Moon, T.C. (1971) 'A study of verbal behavior patterns in primary grade classrooms during science activities', Journal of Research in Science Teaching, 8 (2), 171-7.

Muscio, B. (1916) 'The influence of the form of a question'. British Journal of Psychology, $8(3), 351-89$.

National Education Association (1976) Higher Cognitive Questioning (Minicourse 9): Description of Teacher Inservice Education Materials (Washington, DC: National Edu- 
cation Association, Project on Utilization of Inservice Education R \& D Outcomes), ERIC ED 167530.

Olinick, S.L. (1954) 'Some considerations of the use of questioning as a psychoanalytic technique', Journal of the American Psychoanalytic Association, 2 (1), 57-66.

Page, D.P. (1847) Theory and Practice of Teaching (Syracuse, NY: Hall and Dickson).

Payne, S.L. (1951) The Art of Asking Questions (Princeton, NJ: Princeton University Press).

Penland, P.R. and Mathai, A. (1974) Interpersonal Communication: Counseling, Guidance and Retrieval for Media, Library and Information Specialists (New York: M. Dekker).

Porterfield, D. (1974) 'Influence of inquiry-discovery science preparation on questioning behavior of reading teachers', Reading Teacher, 27 (6), 589-93.

Prior, M. and Prior, A.N. (1955) 'Erotetic logic', Philosophical Review, 64 (1), 43-59.

Richardson, S.A., Dohrenwend, B.S., and Klein, D. (1965) Interviewing: Its Forms and Functions (New York: Basic Books).

Riegle, R.P. (1976) 'Classifying classroom questions', Journal of Teacher Education, 27 (2), 156-61.

Robinson, W.P. and Rackstraw, S.J. (1972) A Question of Answers (London: Routledge \& Kegan Paul).

Rochester, E.R (1973) 'The significance of pauses in spontaneous speech', Journal of Psycholinguistic Research, 2 (1), 51-81.

Rogers, C.R. (1942) Counseling and Psychotherapy: Newer Concepts in Practice (Boston, MA: Houghton Mifflin).

Rogers, V.M. (1972) 'Modifying questioning strategies of teachers', Journal of Teacher Education, 23 (1), 58-62.

Rosenshine, B.V. (1971) Teaching Behaviours and Student Achievement (Slough, UK: National Foundation for Educational Research).

Rosenshine, B.V. (1976a) 'Classroom instruction', in N.L. Gage (ed.), The Psychology of Teaching Methods. 75th Yearbook, Part 1, of the National Society for the Study of Education (Chicago: National Society for the Study of Education), 335-71.

Rosenshine, B.V. (1976b) 'Recent research on teaching behaviors and student achievement', Journal of Teacher Education, 27 (1), 61-4.

Rowe, M.B. (1974) 'Wait-time and rewards as instructional variables, their influence on language, logic, and fate control. Part one - wait-time', Journal of Research in Science Teaching, 11 (3), 81-94.

Royal, R.F. and Schutt, S.R. (1976) Gentle Art of Interviewing and Interrogation: A Professional Manual and Guide (Englewood Cliffs, NJ: Prentice Hall).

Sanders, N.M. (1966) Classroom Questions: What Kinds? (New York: Harper \& Row).

Santiesteban, A.J. (1976) 'Teacher questioning performance and student affective outcomes', Journal of Research in Science Teaching, 13 (6), 553-7.

Schwartz, L.E. (1973) Proof, Persuasion and Cross-examination (Englewood Cliffs, NJ: Executive Reports Corporation).

Shavelson, R.J. (1976) 'Teachers' decision making', in N.L. Gage (ed.), The Psychology of Teaching Methods. 75th Yearbook, Part 1, of the National Society for the Study of Education (Chicago: National Society for the Study of Education), 372-414.

Sinclair, J.Mch. and Coulthard, J.M. (1975) Towards an Analysis of Discourse: The English Used by Teachers and Pupils (London: Oxford University Press).

Sloan, F.A. and Pate, R.T. (1966) 'Teacher-pupil interaction in two approaches to mathematics', Elementary School Journal, 67 (December), 161-7. 


\section{J.T. Dillon}

Smith, C.T. (1977) 'The relationship between the type of questions, stimuli, and the oral language production of children', Research in the Teaching of English, 11 (2), 111-16.

Smith, C.T. (1978) 'Evaluating answers to comprehension questions', Reading Teacher, $31(8), 896-900$.

Snyder, W.U. (1945) 'An investigation of the nature of non-directive psychotherapy', Journal of General Psychology, 33 (October), 193-224.

Snyder, W.U. (1963) Dependency in Psychotherapy: A Casebook (New York: Macmillan).

Stevens, R. (1912) The Question as a Measure of Efficiency in Instruction: A Critical Study of Class-room Practice Contributions to Education, no. 48 (New York: Teachers College, Columbia University).

Sudman, S. and Bradburn, N.M. (1974) Response Effects in Surveys: A Review and Synthesis (Chicago: Aldine).

Susskind, E.C. (1969) 'The role of question-asking in the elementary school classroom', in F. Kaplan and S.B. Sarason (eds), The Psycho-Educational Clinic: Papers and Research Studies from the Department of Psychology, Yale University Psycho-Educational Clinic, in conjunction with the Massachusetts Department of Mental Health (Boston, MA: Department of Mental Health), 130-51.

Susskind, E.C. (1979) 'Encouraging teachers to encourage children's curiosity: a pivotal competence', Journal of Clinical Child Psychology, 8 (2), 101-6.

Taba, H. (1964) Thinking in Elementary School Children Co-operative Research Report, no. 1574 (San Francisco, CA: San Francisco State College), ERIC ED 003285.

Taylor, I. (1969) 'Content and structure in sentence production', Journal of Verbal Learning and Verbal Behavior, 8 (2), 170-5.

Tierney, K. (1971) How To Be a Witness (Dobbs Ferry, NY: Oceana Publications).

Tinsley, D.C. and Davis, O.L. (1971) 'Questions used by secondary student teachers to guide discussion and testing in social studies: a study in planning', Journal of Teacher Education, 22 (1), 59-65.

Torrance, E.P. and Myers, R.E. (1970) Creative Learning and Teaching (New York: Dodd, Mead).

Uldall, E.T. (1962) 'Ambiguity: question or statement? Or "are you asking me or telling me?"' in A. Sovijärvi and P. Aalto (eds), Proceedings of the Fourth International Congress of Phonetic Sciences Held at the University of Helsinki, 4-9 September, 1961. Janua Linguarum, Series Maior 10 (The Hague: Mouton), 779-83.

Weaver, G.G. and Cenci, L. (1960) Applied Teaching Techniques (New York: Pitman).

Weinland, J.D. and Gross, M.V. (1952) Personnel Interviewing (New York: Ronald Press).

Weisman, A.D. (1955) 'Silence and psychotherapy', Psychiatry: Journal for the Study of Interpersonal Processes, 18 (3), 241-60.

Wellman, F.L. (1937) The Art of Cross-Examination, 4th edn (New York: Macmillan).

Wilson, J.H. (1969) 'The "new" science teachers are asking more and better questions', Journal of Research in Science Teaching, 6 (1), 49-53.

Winne, P.H. (1979) 'Experiments relating teachers' use of higher cognitive questions to student achievement', Review of Educational Research, 49 (1), 13-49.

Yamada, S. (1913) 'A study of questioning', Pedagogical Seminary, 20 (2), 129-86.

Zeligs, M.A. (1960) 'The role of silence in transference, countertransference, and the psycho-analytic process', International Journal of Psychoanalysis, 41 (July-October), 407-12. 
Part III

Thinking about curriculum work and

curriculum change 



\title{
7 'There's always another agenda' Marshalling resources for mathematics reform
}

\author{
Jeremy N. Price and Deborah Loewenberg Ball
}

This chapter takes up the puzzle of mathematics reform in the US, examining the gap between reputation and reality in the efforts to change the teaching and learning of mathematics. With its ambitious and articulate vision of mathematics instruction for all students, mathematics reform appears to be ahead of other curricular areas in terms of direction, clarity, and vision. In fact, educational leaders in other areas frequently look to the mathematics education community as a model for animating a successful reform.

Yet a closer look inside classrooms reveals that the headlines of success for the mathematics reforms are premature. In spite of the publication of numerous reform documents (California State Department of Education 1985, 1992, National Council of Teachers of Mathematics 1989, 1991, National Research Council 1989) many students continue to experience a traditional mathematics curriculum of memorization and procedures and classrooms where teachers talk and students listen and practise. Even when students find the materials and terms of mathematics changed, observers note that the changes often appear little more than cosmetic. Students may use manipulatives instead of just paper and pencil, they may talk and work in groups instead of working alone, but they still continue with a steady diet of computation and number work (see, for example, Cohen 1990, Weiss et al. 1996). Even when the calculations are dressed up in word problems (Butts 1980), the fundamental curriculum - what students learn and how they learn it - remains largely unaltered (Cohen 1990, Wilson 1990, Weiss et al. 1996). We ask the question: why, after over a decade of serious effort, has so little changed in many US mathematics classes?

Analysts have helpfully examined the puzzle of why some reforms flourish while others fail (Cuban 1992, Mirel 1994, Tyack and Tobin 1994, Tyack and Cuban 1995). We offer another perspective on this puzzle, one grounded in a set of assumptions specific to the mathematics reforms and what their realization would require. We interpret the mathematics reforms as pressing for deep changes in mathematics teaching and learning. Whereas current practice is dominated by drill and practice of basic skills and manipulation of symbols, punctuated by word problems that 'apply' skills in instructional contexts, the reforms promote a broadening of the curriculum to include topics such as probability, geometry, and number theory. Reformers envision teachers telling 
less and children engaging in complex thinking more, the curriculum focusing less on speed and memorized recall and emphasizing more the meaning of mathematical ideas.

These visions represent a dramatic shift in what is taught, how it is offered to students, and what students should do and learn. The idea of mathematics as a collection of rules, mathematics instruction as showing students how to follow those rules, mathematics learning as rapid and accurate computational skill - all of these are deeply rooted in US schools. This is the mathematics experience of teachers and administrators who face making the changes promoted by the reforms. It is the experience of a public which expects schools to produce mathematical competence, defined as speed and calculational skill. Hence, we argue that for these reforms to take hold, teachers and others - administrators, parents, students - have a great deal to learn (Wilson $e t$ al. 1996). They would need opportunities to learn mathematical content and ways of thinking that they themselves never learned, and to develop different ideas about what mathematics is and what its contributions might be to a broader view of literacy (Paulos 1988, 1995). They would need opportunities to expand and change their ideas about how mathematics is done and learned. And they would need to see mathematics being taught in ways different from what they remember, ways that promote mathematical thinking and reasoning along with skill and definitions.

This is a collective challenge, not just an agenda for individuals. Such learning would require substantial intellectual resources - ideas, images, materials, time - to provide opportunities to learn about mathematics, students, and pedagogy. Mathematics does not typically garner a giant share of such investment. Although it is an elite field, mathematics in the US is not held as essential to everyday life, to literacy, or to most conceptions of 'education' (Ball and Cohen 1995, Paulos 1988). Instead, simple arithmetic, such as that required to balance a cheque book, is what most people think of when asked about the importance of mathematics to their lives. Hence, it seems likely that making changes of the sort envisioned by the reforms would require an enormous shift in what is construed as mathematics and its importance in a broad equation of literacy or education. A big question is whether and how the mathematics reforms can compete for serious attention among the multiple agendas pressing on schools. To what extent can mathematics muster unusual force among other more traditionally dominant missions, such as literacy? What are some of the factors that support or impede the marshalling of needed resources for mathematics reform?

\section{Resources for mathematics reform: a case of one district}

In our study of a small group of teachers in a mid-sized US urban district over the past three years, we have been keeping our eye on the marshalling of resources for mathematics instruction and teacher change. While all our teachers were using a new 'reform-oriented' mathematics textbook, and most were 
inclined to add some manipulatives and 'problem-solving' to their mathematics teaching, only one of our 11 focal teachers seemed to have become deeply involved in the ideas of the mathematics reforms. Our interest was piqued when we noticed that the resources for learning available in reading and language arts seemed dramatically greater than in mathematics. Few resources existed to support real change. While we acknowledge that the resources to support literacy were also in many cases inadequate, we argue in this paper that the contrast in resources between mathematics and literacy was striking, especially when examined from a perspective of what deep change would require.

The idea that the 'subject matters', as Stodolsky (1988) has said, is not a new one. Shulman (1986), pointing to what he called a 'missing paradigm' in educational research, called for increased attention to subject-specific aspects of teaching. Since then, many have followed, especially in studies of teaching and teacher education. But policy research has failed to probe how the 'subject matters' in reforms and their enactments. In fact, the standard efforts that have characterized both state and national attention to curriculum - in many ways presumed more similarity than difference.

The story of the Mapleton ${ }^{1}$ district's mathematics programme reveals a critical gap between national visions, state curriculum guidelines, and local agendas. Examining this gap helps to explain why the mathematics reforms may actually have little chance to germinate. This paper appraises the resources afforded by the district to the mathematics reforms and offers an argument for why the resource patterns look as they do. Our analysis is premised on the idea that principals and other district leaders are crucial in the recruitment of resources to particular efforts. Although some might see local districts as conduits of state and national policies and agendas - primarily as implementers (Berman and Pauly 1975, Gross et al. 1971, Smith and Keith 1971, Crandall 1982) - we base our work on the assumption that districts are active policy-making contexts. We assume that district staff members shape priorities, agendas, and directions, and that they do so in light of the specific ideas and commitments that they bring to any particular set of initiatives (Spillane 1993). Beyond these kinds of individual readings of and responses to the reforms, however, we also conjecture that the substance of the policy may affect local reactions and responses, and that there may be systematic subject matter or other area differences. In this case, we investigate the marshalling of resources for mathematics and examine factors that may shape the comparatively thin allocation of resources for mathematics as compared to reading.

We begin by introducing the district, including an orientation to the context and demographics of the district in general, as well as a brief history of emphases and changes in mathematics instruction and the curriculum. We also provide an overview of the current agenda in mathematics. Then, for a closer view of practice, we pay a brief visit to the classrooms of our teachers. This snapshot illustrates the relatively modest influence of the reforms in the classrooms we have been studying. Moving back outside the classroom, we examine district resources available to marshal and support an agenda for change in mathematics 
teaching. Given what Mapleton teachers and administrators bring to the challenge of reforming mathematics education, we argue that these resources are inadequate in crucial ways and, further, that these inadequacies stand in contrast with comparable resources available for the reform agenda in written literacy. While some might see as reasonable a policy decision to allocate more resources to reading and language instruction than to mathematics, we propose that this contrast in resources represents a paradox in the effort to effect reform: a vision that ambitiously challenges not only modal school practice but also societal assumptions about literacy (Paulos 1988, 1995, Spillane 1993) would require considerable support and attention in order to be realized. Yet, because of the traditionally less central role occupied by mathematics in US society, in conceptions of what it means to be educated, and in the school curriculum, mathematics tends to be of less central concern in the schools. Underattended to, it is poorly positioned to garner adequate resources for reform. We argue that this paradox is an important factor in the weak shape of change in mathematics.

\section{Mapleton: a mid-sized urban district}

Mapleton is situated in a US metropolitan area of almost a quarter of a million people. Settled in the mid-nineteenth century, the city has a downtown district encircled by sprawling residential neighbourhoods, business strips, and shopping centres. Together, heavy manufacturing and public sector employment form the principal economic base of this mid-western city. Although unemployment rocketed in the 1980s, presently it stands at around 6 per cent. About 20 per cent of the city's residents are African American; approximately 5 per cent are Latino (people of Latin American and Caribbean heritage). In the early 1970s, Mapleton introduced busing in response to court-ordered desegregation; current school boundaries are in many cases the same as those drawn then, producing results not always congruent with the aims of those who mandated busing. ${ }^{2}$

With over 20,000 students, Mapleton is one of the state's ten largest school districts. Approximately one-third of the students are African American, over a tenth Latino, and about half are white. A small percentage of the students speak English as a second language; their primary languages include Hmong (Laos), Spanish, and Vietnamese. While the district is primarily middle-class, as many as one-third of the families live in poverty.

Our work has been focused in three of the district's elementary schools: Burnside, McKinley, and Remington. These K-5 buildings are all among the poorer, more ethnically-diverse of the district. Burnside is the only school which has no busing. Located in an older part of the city, the school's population is about half white, one-third African American and one-sixth Latino. Almost half of the children come from families on welfare. McKinley, located in an uppermiddle-class neighbourhood, buses one-third of its students from a poor area about a mile away. Remington's population, almost two-thirds African American, is highly transient. Over 70 per cent of the children qualify for free 
lunches. Each of these three schools enrols about 300 students. In all three buildings, there has been a turnover in administration over the last four years. As a consequence, we have been involved with six principals in three buildings over the course of our study. We were told by central-office administrators that this mobility of principals is quite typical within Mapleton.

The district administration is headed by a superintendent and two deputysuperintendents, one responsible for instruction and the other for operations (e.g. transportation, food services, business office). A cadre of 'directors' under the deputy-superintendent for instruction share the central responsibilities of the district's instructional programme. Figure 7.1 illustrates the nominal distribution of responsibilities among these directors. Although the titles suggest a unique division of responsibilities among departments, in fact, many key functions are under the purview of more than one director. For example, staff development is a matter of concern for four different departments: elementary and secondary education, instructional support, and staff development and curriculum. Leadership in specific curricular areas is provided by subject-area 'coordinators' who currently report to the director of staff development and curriculum (although this has changed three times over the course of our study). These co-ordinators work with steering groups of teachers to make curricular decisions, such as textbook adoption. The scope of their responsibility is enormous: the mathematics co-ordinator, for example, is responsible for

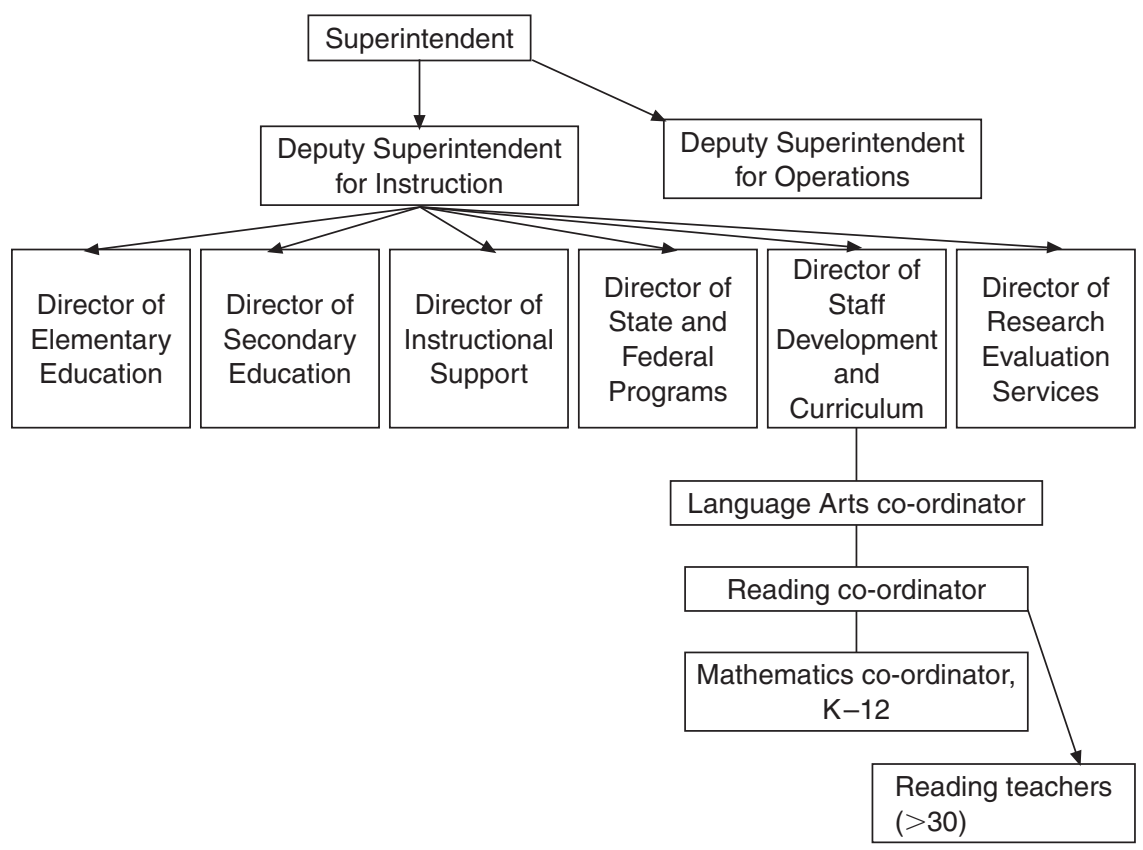

Figure 7.1 Mapleton's administrative structure. 
providing leadership and support for the K-12 curriculum and staff development for over 400 teachers. In addition to representing the spread and scope of responsibilities, Figure 7.1 also shows the difference in staffing for reading and mathematics: in reading/language arts, there are two subject-area coordinators, who in turn work with over 30 reading teachers in the district. Mathematics has one co-ordinator at the administrative level and no specialist resource teachers.

\section{Mapleton's agenda for mathematics instruction}

Just before we began our study, the Mapleton school district had finished rewriting its mathematics curriculum statements - the documents that specify the district's goals and objectives. While this revision process was part of the regular curriculum 'updating', it occurred at a time of considerable ferment in mathematics education at the national level. Just two years earlier, the National Council of Teachers of Mathematics (NCTM) had published the Curriculum and Evaluation Standards (1989), and the year before the state had revised and reissued its Goals and Objectives for Mathematics and had redesigned the state assessment to test students on problem-solving and mathematical concepts. The revision of Mapleton's mathematics goals was led by the retiring mathematics co-ordinator, a man who had guided the district's mathematics curriculum for over 25 years, but who was not active in the current mathematics reform movement.

Modestly revised, the new district guidelines did not attract major attention nor generate noticeable controversy. The new guidelines closely followed the new state Goals and Objectives for Mathematics, even using some of the same examples and illustrations. Copies of the curriculum statements were distributed to the buildings. Without fanfare, they found their way into teachers' loose-leaf binders of district curriculum guides. Although more than one of the centraloffice administrators told us how these objectives functioned to guide teachers' decisions and plans on a day-to-day basis, we encountered a different story when we were in schools. One day, when we were meeting with one of the building principals, we glimpsed the archaeology of these cycles of curriculum updating. Ms. Young, at Remington, had requested that her teachers turn in their binders to her. As she leafed through different notebooks, she showed us packets of curriculum objectives from other subject areas and other years still tightly shrink-wrapped in plastic, as well as layers of previous editions now supposedly outdated and replaced. One binder contained the last three sets of curriculum statements, each one filed after the other. And in talking with our teachers, we learned that not one used the district curriculum statements as a close guide for their practice.

While the district curriculum guide did not seem to be a powerful signal for mathematics reform in Mapleton, the next two events - hiring a mathematics co-ordinator with both energy and vision and adopting a new 'reform-oriented' textbook - sounded a somewhat louder call. The year after the curriculum state- 
ments were completed, Mapleton's veteran mathematics specialist retired, and the district appointed a dynamic new mathematics co-ordinator, Lydia Jackson. Active in the state Council of Teachers of Mathematics organization, Jackson had also worked closely with several prominent university mathematics educators. She was unimpressed with the district's revised mathematics curriculum statements: 'Granted, there's some improvement in these statements, but they're not ... significantly different than the statements that they had the previous year'. She went on to explain that although the people who had worked on the revisions believed that the statements were now aligned with the NCTM Standards, she was unconvinced. And the central-office administrators, she argued, were inattentive to, and unconcerned with, the NCTM reforms.

Jackson turned her energies to making more substantial changes in line with the mathematics reform movement. Her own efforts, while not at odds with the state Goals and Objectives, were directly oriented around the national reforms in particular, the NCTM Standards. Under her leadership, the district steering group sponsored a year of textbook piloting (1991-2). Teachers from every elementary building tried out different textbook series in their classrooms, seeking the one that best supported the district's mathematics agenda - as they interpreted it. Jackson worked actively to bring key elements of the mathematics reforms to the fore: more emphasis on problem-solving, use of concrete materials, and classroom discussions, less emphasis on skill practice, computation, and algorithms. Still, her colleagues interpreted these ideas in light of their own past experience, understandings, values, and beliefs. Given the limited opportunities Jackson had to help them explore the reform ideas and to learn things they might need in order to delve into them, teachers' interpretations of the reforms tended to be more superficial than she wanted - expressed in terms of 'handson', 'manipulatives', and 'active learning'.

Commenting on the district's awareness of the reforms, Jackson expressed frustration:

It's a nightmare because people are not informed about the reform movement. They do not know what ... the Curriculum and Evaluation Standards are all about. They haven't a clue ... [but] our steering committee meetings are tied up this year in dealing with this [textbook] pilot.

The first two meetings, she told us, were focused entirely on details such as how to distribute the evaluation forms and what was to be the procedure for voting on the textbook selection. This was not what she had envisioned:

So we spent a lot of time on these kinds of issues instead of the issues about changing the way in which we teach mathematics, changing our views and perceptions of what does it mean to do and teach mathematics. I had ideally thought about using the steering committee time to show and demonstrate how ... [these ideas work] in the ... classroom. But there's no time to do it. There's always another agenda. 
Still, Jackson distributed copies of the NTCM Standards to all the buildings, and made copies of the K-4 section for all the pilot teachers. Although the former mathematics specialist had set the wheels in motion for this piloting, and had already chosen three textbooks to be piloted, Jackson added a fourth texbook series to the menu of alternatives. She held meetings after school for teachers who were participating in the pilot; the Standards figured prominently in the focus of these sessions. In some measure, Jackson's efforts paid off: near the end of the year, participating pilot teachers voted to select the series she herself preferred (though not wholeheartedly) - Harcourt Brace Jovanovich's Mathematics Plus (1992 edition).

Remillard's (1996) examination of this particular series suggests that it includes more attention to problem-solving, places more emphasis on traditionally marginalized topics (such as probability and data), and uses manipulatives quite heavily throughout. She claims that exploration and investigation of mathematical ideas are stressed, as opposed to the traditional explanation and practice that filled the pages of the former textbook. Filled with ideas, suggestions and guidance for a more conceptually-oriented curriculum, this textbook series is the major tool in which the district invested for 'updating' the mathematics programme. Jackson had mixed feelings about this reliance on textbooks in teaching mathematics. But, she acknowledged that a textbook with good information in it was what was required for many teachers who did not have sufficient mathematical background. A big question that remained was what teachers 'without mathematical background' could make of 'good information'. What kind of resource could a new textbook series be?

By 1992, Mapleton had completed the formal revision of its mathematics curriculum. The district's mathematics agenda, consistent with - if not directly shaped by - the state's Goals and Objectives for Mathematics, was officially launched in the direction of a more conceptual and problem solving-oriented curriculum. With a dynamic and knowledgeable mathematics co-ordinator at the helm, Mapleton seemed to have marshalled strong resources in support of the mathematics programme. In the cycle of curriculum revisions, the district moved on to the next curriculum area - computer education.

To get a glimpse of what many Mapleton teachers did in the wake of this recent wave of curricular redefinition and revision, we turn next to the classroom of Dave Burch, a fifth-grade teacher at Burnside Elementary. Like other teachers in Mapleton, Mr. Burch spent the year making his way through the new textbook, and reconstructing his mathematics teaching in, through, and around it. In spite of Jackson's visions, the lesson we describe below was typical not only of Dave Burch's teaching, but of what we saw in most classrooms instruction that continued to be both closely tied to the textbook and teachercentred. By paying a visit to his classroom, we aim to show an example of what close following of the new textbook looked like and what the role of the textbook was in change. Only by looking at this closely is it possible to get a finegrained view of the ways in which the new textbook affected, and did not affect, mathematics curriculum and instruction. 


\section{A visit to Mr. Burch's fifth grade}

This was Dave Burch's first year (1992-3) at Burnside as well as his first year teaching fifth grade. When he compared Burnside with his previous school, where he had taught third grade, Burch saw it as an inner-city school whose students were academically behind and who encountered many social problems. The mix of students in his class included 11 white, nine African American, six Latino, one Vietnamese, and one Iranian. Of these students there were three whom Burch labelled 'special ed', one labelled 'learning-disabled', and two who had 'trouble with English' and participated in the school's bilingual programme for most of the day. Because Burch believed that mathematics was not language-based like other subject areas, it was in fact the only subject in which he taught all of his students together.

Burch's classroom was bright and spacious. The bulletin boards, as well as the wall spaces throughout the room, contained handwritten posters with slogans conveying expectations about behaviour: 'Respect Diversity', 'What Active Listening Looks Like', 'Rules of the Classroom', and lists of student jobs. Underneath the windows were shelves of trade books, sets of dictionaries, and individual boxes where students deposited their work. In the front corner of the room stood an unused Apple II computer. The front and back walls of the classroom each had a large chalkboard and a smaller bulletin board. Burch often conducted lessons from his desk which sat at the front of the room. Students' desks were clustered in groups of three, four, and five, and were not all facing the front of the room. Burch's instruction often required students to turn their chairs to face him.

Mr. Burch was directly involved in the mathematics textbook-adoption process. In his third-grade classroom, he had piloted two of the candidate textbook series. He recounted that 80 per cent of the piloting teachers, himself included, had favoured the book chosen over the other three series. Nonetheless, he had criticisms of the new series. He believed that the book was difficult for students to read because there was so much textbook before the actual exercises. He also believed that there were not enough practice exercises for each concept in the textbook, and that students must practise in order to learn. He compensated for this by supplementing the new textbook with practice from the old.

Mr. Burch's views of the textbook were pertinent because the textbook was the core of his mathematics teaching. Leading students through the book's pages one problem at a time, he rarely deviated from what was written in the text. The following segment from a lesson on measurement was typical of $\mathrm{Mr}$. Burch's mathematics teaching, as well as that of most of the other teachers we observed, with the textbook providing both setting and script. Burch used the book's examples, asked its questions, and assigned its problems. The students' role was to respond to the teacher's directions and questions.

On this particular day, Mr. Burch began the lesson by writing the following on the board: 
MILLIMETRE

CENTIMETRE

DECIMETRE

METRE

KILOMETRE.

He then directed students to get out their 'new math books' and, after waiting for a lot of shuffling to end, began the lesson. Engaging in little interaction with students, Burch marched through the textbook page, explaining the various units of measurement listed on the top right-hand corner:

Page 350. Look at the chart. Look at that chart on the right-hand corner where it says units of length in the blue. It tells you how many millimetres make a metre, how many centimetres equal one metre, and how many decimetres make a metre and how many metres are in a kilometre. So this is how they go as far as size. Is everyone with us yet? 350 ? This is from the smallest to the largest. Millimetres, then centimetres, decimetres, then metres. Kilometre or kilometres as some people call it - doesn't matter to me either way - okay - so, it takes 1000 millimetres to equal one metre. And a metre, if you look, is about the width of a doorway. So, this is the metre. It's 100 centimetres in a metre, 10 decimetres in a metre, and it takes a 1000 metres to make a kilometre.

Using the example from the textbook, Burch said, 'So a paper clip is about one centimetre in width'. He then moved to the classroom door and announced, pointing at the doorframe, 'It'll take 100 of those - if you lay them side by side, to go from here to there. That gives you some idea of how long things are'. Continuing, he paraphrased the caption from the next illustration in the book: 'A thickness of a dime is one millimetre'. He held a dime up in the air and informed students it would take 1000 of them to go from one side of the door to the other.

As Burch moved through the sections 'Talk About It', 'Check for Understanding', and on to 'Practice', the class appeared to be attentive. He and his students played their familiar roles well: the teacher asked questions, the students answered, the teacher affirmed or corrected. There was little side conversation among students, and no interruption from students asking questions.

Burch seemed to control much of the discourse in the classroom. For example, he would call on students and ask them to read from the textbook. Frequently, he repeated what they read, adding emphasis. On another occasion, when he got to the 'Talk About It' section of the textbook, he changed his role to that of questioner, reflecting the switch in the book's format at this point. For instance, he called on Barry who read the question, 'Which units are smaller than a metre?'. Burch then restated the question and asked Amy for an example. 'Centimetre', she offered. And so Burch moved on. 
The class continued moving swiftly through the questions in the order they appeared on the pages in the book. Indicating the top of page 351, Burch asked firmly,

Number five. Length of a spelling book. Your spelling book. Would you use millimetre, centimetre, kilometre, or -? You need to look at page 350 to give you a clue. Liesha, what would you pick? Think about it before you answer, don't just babble.

He paused.

When you have an answer - anybody here have an answer yet? Raise your hand when you think you know the answer. How about anybody at the back table yet? Anybody at that back table with an answer to number 5? Now we're waiting on Janeya, Liesha.

When most hands were raised, he asked Liesha for the answer. Hearing the right response, he said 'correct' and then moved on to number 6. 'The distance from the earth to the moon?' he asked, looking out at the children.

In 'Mixed Applications', the last section of the lesson, a student was called on to read number 18: 'Franklin and Candy cut 12 pieces of wire that were each 20 point 5 centimetres long. How many centimetres of wire did they cut?'

Burch: Okay, what's the numbers we have in this problem? Derek?

Derek: 20 and 5?

Burch: 20 point 5 is one number. What's the other number? Any other number?

Derek: 12

Burch: What do we do with those? Raise your hand and tell me.

A student yelled out, 'Times!!'. Burch said, 'Twenty point five times twelve. How do you come up with an answer?' Without waiting for a response, he swiftly did the multiplication on the board. Turning back to the class, he asked where the decimal point goes. 'After the 6', someone offered. Without comment, Burch put it on the board.

Through demonstrating for the students the procedures and operations to solve the problems in the textbook, he finished working through the remaining problems. The students observed, and were to learn what to do from following his steps. To ensure that students knew what they were responsible for, Mr. Burch concluded the lesson by instructing them to memorize the chart on page 350. He announced that they would be asked to know these metric equivalences on a class test. And, he added, 'These are things you're gonna have to know on the SAT test'. Raising scores on the SAT college-admissions test, typically taken in the eleventh grade, was one of the main aims of the district, according to Burch. And he was committed to do his part to achieve that goal 
with his students, a commitment that leads him to make sure students are practising and memorizing.

The textbook was indisputably central in Mr. Burch's teaching. He used the examples, questions, and exercises the textbook's authors had included in the section. Therefore, Mr. Burch's practice would at times reflect elements of the reforms, to the extent that the new textbook series itself embodied them. But the textbook was by no means the single determinant of what Burch did in his classroom. In following the textbook, his teaching was also significantly shaped by conventional habits, orientations, and beliefs.

His own knowledge of mathematics affected the way in which he read and used the book. In this lesson, as in all of Birch's lessons we observed, he had the reins and controlled the talk; what was talked about centred on small facts and right answers to be memorized. Neither teacher nor students discussed the ideas or raised questions of their own; instead, they followed the textbook's script together. And students' turns were short and constrained.

Burch's views of learning, his notions about mathematics and measurement, his perceptions of his students and what they needed - all these interacted in his practice. These views were important influences on what he did as a teacher, and they affected how he made use of the textbook. They directly affected what kind of a resource the textbook was for him. A teacher with a deeper, more connected understanding of measurement might possibly be able to adapt and use the textbook's ideas in a more productive way. Neither were his ideas idiosyncratic; rather, these beliefs are conventional and deeply rooted in our society (Paulos 1988, Cohen 1989). That he may not have deep understandings of mathematics is also not unique, but a predictable result of his own experiences in mathematics classes (Ball 1990, Simon 1993).

Despite the district's efforts to bring mathematics instruction in step with current reforms, Dave Burch was more concerned with other issues. Asked about the NCTM Standards, Burch recalled hearing that it was a new test. Although he was one of the 80 Mapleton teachers who participated in piloting mathematics textbook options, he was unaware of the thrust of the reforms and unfamiliar with the reform rhetoric. He did not even clearly remember Lydia Jackson, the mathematics co-ordinator. Changing mathematics instruction, curriculum, and learning were simply not central to Mr. Burch's agenda. Mathematics reform was not on his mind.

\section{Resources for reform: promise and limits}

Our observations of other Mapleton teachers' classrooms suggest that $\mathrm{Mr}$. Burch's classroom, and Dave Burch himself, are quite typical. With the textbook providing questions and examples, practice and review, teachers and students move together through the curriculum materials. The mathematics they do is for the most part a mathematics of procedures and exercises, the discourse decidedly teacher-centred, and the environment right answer-oriented. No big surprise here. This is what they experienced in school themselves; most have 
never seen mathematics teaching built on the commitments of the Standards. Sitting through years of mathematics classes where memorization was key and understanding beside the point, they have not had opportunities to explore mathematical ideas in any depth. While they may remember particular algorithms, their own understandings of core ideas are often thin and unconnected.

The glossy new mathematics textbook series, selected as a vehicle for Mapleton's curriculum guidelines and updated to incorporate the Standards' emphases, was indisputably an important resource for teachers like Dave Burch. Underlying ideas are stressed, both for the teachers and for the students. And Burch, consistent with habit, followed it faithfully. But the textbook also had limits. Pages 350 and 351, from Burch's lesson, provide a glimpse of the modest ways in which publishers have tended to interpret and respond to the reforms. While students were asked to make estimates of distance and length, they did not actually engage in measuring anything. Measurement remained inert, pictured on the pages of the book, not as a mathematical topic with important applications in the real world, and involving judgement, estimation, and physical skill. Measurement is instead represented as an abstract matter of equivalences and facts. In her analysis of this textbook series, Remillard (1996) notes:

The text includes many characteristics that fit with the ideas of the reforms, but little of the 'old stuff' has been let go, allowing teachers to choose the items that best fit their orientation toward teaching. Long-held goals and perceptions of mathematics, such as computational mastery and traditional content organization, are still prevalent, thus it appears very familiar. The publishers have managed to fold in a range of possible alternatives to traditional practices without upsetting the status quo.

And, with hundreds of pages intertwining old and new, the textbook offers little guidance about emphasis. Lydia Jackson, the district mathematics coordinator, was sharply aware of the limits of the new textbook to effect major change. She could have been talking about Dave Burch when she remarked:

There are more chapters instead of fewer. The teachers are still faced with this awesome task of 'what is it I'm going to really teach?'. Because they still start at the beginning [of the book] and they work through till the end. I have teachers who say they skip around but ... not that many teachers ... do that. So I have also the job and responsibility of helping teachers make decisions of what to leave out. That's a big responsibility.

The process of textbook revision means that this textbook, like most series, is in many ways quite similar to previous editions. Further, since the reform ideas include not just attention to content but also to the environment and discourse of classrooms, a textbook may not be the best lever to stimulate and support all aspects of the reforms. A textbook is better as a guide for what to teach and 
how to model or represent ideas than as a guide for the discourse of a class, or its culture and norms. Texts are maps of curriculum and activities, not plans for instructional conversation and improvisation (Tharp and Gallimore 1988, Yinger 1988). As a result, while the textbook can offer some new ideas and new approaches, it was not enough to lead Burch to change dramatically what he taught or how he taught it.

Other researchers have documented the possibilities and limits of textbooks as levers for teachers' learning. In a ground-breaking study of fourth-grade teachers' curricular decisions, for example, Schwille et al. (1983) found that teachers exercised significant discretion as 'policy brokers', making key decisions about coverage and emphasis that resulted in differences in the enacted curriculum, even when they used the same textbook in the same district or school. And a study of two of Burch's colleagues' first year of using the same textbook found that the teachers' beliefs and understandings shaped their reading of the textbook, and the teaching that they did with it. In both cases, the textbook influenced the teacher's practice. In both cases, the teachers' own assumptions and aims were also central in shaping what they paid attention to, what they emphasized, and what they omitted (Remillard 1996).

Shaping a mathematics curriculum in response to the national and state-level reform agenda requires careful thought, active work, and opportunities for reflection. It also requires ongoing learning. For teachers to change their mathematics instruction in the direction of the reforms would entail more than packing up their old textbooks and unpacking their new ones (Cohen and Ball 1990). Teachers also need to understand and be committed to the new goals. They need opportunities to learn more mathematics in depth themselves, to look closely at their students' thinking about that mathematics, to explore ways to respond to students' ideas, and to talk with others who are trying to make these changes in their practice (Schifter 1995a, b). They need time, ideas, and images. They need both sustained opportunities to learn, and support to experiment in practice.

Mr. Burch's principal, the administrator with whom he has the most contact, could play a role in helping to get mathematics and the reform of mathematics teaching more squarely in view. Perhaps a mathematics specialist-teacher could help him know about the agenda for mathematics instruction in Mapleton, as well as about the mathematics reform movement and its central aims and ideas. Perhaps someone else, for example a workshop leader, could also inspire him to care about the mathematics agenda, and support him in being a learner as he considers how the ideas fit in his classroom, what he might try with his students. Mr. Burch has been to some meetings with Lydia Jackson, meetings centred on the textbook piloting and selection process, but such contact has been too minimal to make a difference. Jackson, alone responsible for the entire district's mathematics curriculum - for the work of over 400 teachers - did not have substantial contact with Burch, even though he was one of the pilot teachers. In fact, later he could not even recall who she was.

For Burch, the selection of a new textbook seemed little more than normal 
district 'updating'. In fact, language about problem-solving and other 'new' aspects of the textbook series only served to reinforce a sense that this change was little more than routine curriculum revision to make the district nominally more current. Moreover, the conversation seemed centred on content - what to teach. None of this impressed on him that his mathematics instruction was to undergo any substantial change.

Repeatedly, Jackson told us that she alone could not accomplish this ambitious reform in Mapleton. With all of K-12 to worry about, her job was vast:

And I'm in a position that I cannot dictate what you will do in your elementary buildings. I can't dictate it. I cannot dictate what the curriculum is going to be. If the teachers are not in agreement ... just because I put it on paper is not going to make it [happen].

Neither can a new textbook alone meet the challenge of change. As Mr. Burch's teaching shows, teachers' existing beliefs and understandings will shape their use of even well-designed and reform-oriented textbooks (Rickard 1993, Remillard 1996). And no commercially-available textbook will divert dramatically from modal practice in any case.

Although mathematics is considered to be an important subject area, and the national agenda for reform is ambitious, the local resources allocated to supporting change in mathematics seem meagre. To expect to effect change in a complex curricular area in a district the size of Mapleton with one staff co-ordinator and a new textbook series seems simplistic. Indeed, in reading and language arts, the resource allocations were much more generous. At the central office level, two staff members were playing Lydia Jackson's role. In addition to a new literature-based textbook, multiple copies of trade books and other instructional materials had been purchased, and every building had a full-time reading teacher and an instructional aide.

It seemed there was more district interest in reading, and consequently more attention to it. Some might argue that this is a natural consequence of the fact that reading dominates the elementary curriculum. Mapleton district guidelines specify substantially more time to be spent on the teaching of language arts. One hundred and fifty minutes of instruction are required per week in mathematics, just slightly less than the amount of time required per day in reading, writing, and language arts. Hence, perhaps it is reasonable that resources - staff, materials, connections with others - for professional support and development in reading and language arts far outstripped what was available in mathematics. However, the traditional imbalance in instructional time can also be seen as a reflection of widely-held societal assumptions about mathematics and its lack of importance, at least in comparison with reading (Ball and Cohen 1995). American society has never developed a robust view of the place of mathematics in literacy and education. In school, that elementary teachers are asked to allocate dramatically different amounts of time to reading and to mathematics not only communicates priorities, but in itself shapes teachers' opportunities to develop 
their practice. More time spent teaching reading means greater attention to, and concentration on it, and thus less on mathematics. Time spent also precipitates more need to talk about the teaching of reading with colleagues. An apparently simple thing like instructional time allocations can contribute to the creation of opportunities for teachers to learn, and hence, to acquire resources.

In the section that follows, we explore the role played by district administrators in the allocation of resources for mathematics instructional improvement.

\section{District administrators and the allocation of resources}

Just as teachers' ideas and commitments shape how they interpret and approach the reforms, so, too, do administrators' concerns and understandings influence their practice. What administrators care about influences their practice. What administrators care about influences their priorities and attention. What administrators understand shapes what they do. Moreover, administrators' decisions shape local policy, explicitly through what they do and implicitly by the ways in which their decisions communicate priorities or focus. ${ }^{3}$ We turn next to a closer look at the administrators who provide leadership for curriculum and instruction in Mapleton. Our analyses probe the work of central-office administrators and principals who make decisions, shape instructional agendas, and marshal resources within the district. We ask to what extent are these district leaders equipped to assist teachers in remodelling Mapleton's mathematics curriculum? To investigate this question, we examine the ideas and orientations administrators bring to the agenda for mathematics reform: What do they know and believe about the mathematics reforms, such as those promoted by Mapleton, the state, or the NCTM Standards? Because we want to set their ideas about mathematics instruction in context, we also explore their own agendas as building or district leaders. What do they hold as central to the improvement of Mapleton schools? What is the relative place of mathematics and literacy in these agendas? The purpose of such comparisons is not to make claims about other areas, such as reading and language arts, but merely to place the mathematics reform issues in a broader context.

We turn first to consider several of the building principals, including Burch's own former and current principals.

\section{Principals' orientations to the mathematics reforms}

In the main, the principals' ideas about mathematics instruction seemed meagre, and they did not talk much about mathematics instruction or about the reforms, even when we asked them directly. They seemed to know little about the changes in the mathematics curriculum. In fact, many of the principals tended to side-step our attempts to initiate conversations about mathematics instruction, and to turn the conversation to another subject area, usually reading. Of the six principals whom we were studying, not one had a background in mathematics or special expertise or experience with mathematics 
instruction. Two of the six principals, however, were highly regarded former reading teachers: Oletha Young at Remington, and Barb Norris at McKinley. Young said, chuckling, that she is 'not as comfortable with math, but nobody else is right now because it's new'. Barb Norris was perhaps the most forthright about her knowledge of mathematics instruction and curriculum: 'Like I said, math is not my area, if I'm going to pick up an article, I'll pick it up on language arts and not math, when I should be doing more of the math (laughs)'.

The principals' knowledge of the mathematics reforms was represented through phrases such as 'manipulatives' or 'problem-solving', with little elaboration. Only one of the six principals - Joan Underwood of Burnside - talked at any length about mathematics instruction, and particularly the reform of mathematics instruction and curriculum. Still, although Underwood disclosed that the district had distributed the NCTM Standards documents to all buildings, and that she had read the documents, she did not seem very familiar with many of the key aspects of the reform agenda. She characterized the change in mathematics as a generic change in 'teaching strategies'. 'A lot of the process you use in mathematics resembles and is a part of what you do in reading as a process', she told us. Continuing her explanation of the connections between mathematics and reading, she argued that the reforms in both mathematics and reading represent:

the wholeness of reading and math coming together as processes again.... It's just a way of thinking. It's a more holistic way of thinking. . . So what stands out for me is the compatibility to reading, in the sense that you need to move to a higher level of thinking, it's not surface, it's not what you see is what you get, not really. It leads to discovery and investigation on behalf of the learner. It doesn't put the teacher in a position of talking and teaching the whole time, but basically allows for more interaction between the learner and the material. It allows for a multitude of solutions.

Although Underwood used similar language to describe the teaching and learning of both mathematics and reading as processes, she seemed to elaborate less on her ideas about the teaching of mathematics as a process. Her focus on the process of learning new ideas seemed strongly linked to her role prior to assuming the principalship at Burnside when she was a staff-development co-ordinator focused primarily on the process of learning. While Underwood talked eloquently about processes of learning and unlearning ideas, she was less specific about particular new ideas in mathematics instruction and curriculum.

Barb Norris's sense of the new ideas in mathematics also emphasized process. Norris characterized the change in mathematics within the district as essentially a move to 'hands-on' activities in mathematics. She suggested the district was 'trying to use the manipulatives'. Although Norris argued that 'hands-on' teaching was central to the mathematics reform in the district, she was vague about what 'hands-on' meant to her: 
I don't know, I think that there have just been a lot of studies done where, you know, the styles kinds of things, but kids need to have some hands-on kinds of things because they're not learning in the way that we're teaching them now, we need to look at how we can change that.

Norris essentially characterized the changes in mathematics as the introduction of manipulatives in the classroom, but could not elaborate further. She also talked about mathematics teaching that would promote problem-solving, but admitted that she was not well prepared to engage in such teaching:

And I think looking at myself, if I were to go back to the classroom now, and I taught sixth grade for quite a while, and if I were to teach math, I would have to take some workshops on how to use manipulatives, because I'm not quite sure how I would go about doing that. ... I think problemsolving is really important and as I look back on myself when I was teaching math, I didn't really know about, you know, teaching strategies for problem-solving.

Oletha Young mirrored Norris's orientations to the mathematics reforms. For Young, the new changes in mathematics were like the changes in reading, and manipulatives were central to these changes: 'It's like the new reading. We're talking about comprehension, understanding, manipulatives, more time spent working with the child rather than lecture and paper-and-pencil and what math has been forever'.

The principals whom we interviewed also did not seem to place a priority on developing a better grasp of the mathematics reforms. Young argued that principals 'don't have an opportunity' because the district-office personnel 'don't want you out of the building very much, so we don't have an opportunity for in-servicing'. Even when occasional workshops were available within their own buildings, other commitments prevented the principals from attending. Young, for example, was unable to participate in a special in-service session in her building because she was with 'the lunch group' during the time of the workshop. None of the principals with whom we spoke felt they had received any signals from the district leadership that they should organize themselves to make time to learn about the mathematics reforms. And, from the principals' own accounts, only rarely was there substantive talk about mathematics instruction at their own district-level meetings. Underwood described how principals were provided with information about the changes in mathematics:

The district made available to us, the standards and criteria for the National Council of Teaching of Mathematics $[$ sic $]$... . They bought both books for each building .... and they provided a 30-minute overview of what those changes would be and what we can anticipate. And then along the way, they have provided for teachers and staff, a number of mathematics work- 
shops.... The steering committee is sponsoring like hour-and-a-half workshops every so many weeks that deal with various phases.

Underwood continued to describe the process, arguing that few principals would take advantage of the district mathematics steering committees and argued that most of the building principals in the district would more than likely learn about new ideas in mathematics from a teacher in their building:

It's not mandated for administrators at all. As a matter of fact the administrators who are not on the steering committee probably won't attend. It'll come as another layer ... it's a matter of how much do you yourself as an administrator care to know about it. It's available but it isn't mandated that you know. I believe the district's approach for administrators is basically you need to have an awareness and then anything beyond ... will be fine for you but we're certainly not mandating it.... Probably of the 33 elementary principals ... I would make a broad assumption that eight will go on to learn more about it and the others will drift along and as their staffs bring them along, they'll probably lean on one of the teachers within their building to guide and direct that rather than leading it themselves.

According to Underwood, how the principals involved themselves in the agenda for mathematics reform was left to their discretion. Principals' involvement in mathematics reforms was not required, or even urged, by central-office administrators. 'Awareness' of the reforms was enough. Why would Ms. Underwood pursue mathematics reform beyond a 'basic awareness' under these circumstances? It is not surprising then that few principals initiated any sustained investigation of the mathematics reforms given these weak signals from the central office about the centrality of mathematics reform among the principals' myriad responsibilities. Further, all our principals admitted that they were not oriented towards mathematics in the first place. Given the minimal support and opportunities to learn about the new reforms, it may be of little surprise that the principals chose not to embrace and immerse themselves in the mathematics reform agenda.

\section{Principals' own primary agendas}

The principals whom we interviewed all had clear professional agendas that did not focus on the mathematics reforms. While they attended to the improvement of instruction and curriculum in a general sense, mathematics curriculum and instruction was not the priority of a single principal. Those who did prioritize instructional and curricular reforms tended to prioritize language arts and reading more than any other content area. Other principals, notably the three principals of colour, were dedicated to issues of multiculturalism, respect for diversity, and building stronger links between their school and the immediate community. 
Attending to their personal agendas was not an easy task. These principals all expressed concern about the amount of time they dedicated to organizational issues in their buildings, making it difficult for them to find the time to pursue an instructional agenda. In particular, Hyde and Norris characterized the time they spent on organizational leadership as time taken away from providing instructional leadership (Cusick 1983, Gronn 1983, McNeil 1986). Hyde, a former principal at Remington, explained, wryly:

When you try to be building manager and an instructional leader, at a shop like this shop and a good third of the shops in Mapleton, you can't do both jobs. It's not possible. It's time-and-a-half as a building manager. Forget instructional design and all that other stuff.

While Hyde and Norris argued that they spent sizable portions of their daily work dealing with organizational issues, and this was echoed by the other principals, two principals did develop and promote an instructional agenda.

Norris and Young dedicated a considerable amount of time to providing support for reading instruction and curriculum in their buildings. With their background and experience as reading specialists, they drew upon this expertise to provide guidance and support for teachers. 'I'm really big on language arts and reading and writing, we have a writing and publishing centre here', Norris told us with pride. Young, too, spent considerable time working on developing new ideas about reading. For Young and Norris, reading instruction was their passion, and the area to which they devoted their attention when not involved in other activities. Young argued, however, her focus on reading instruction reflected a broader current found in the district:

People have always looked at reading as being the end all. I mean that's the most important thing, and in some ways I guess it is, if you can't read I guess you can't do some math.

Young's view was a common one. Literacy tended to be seen as the primary subject, the vehicle on which other subjects depended. Doing story-problems, for example, would require that students be able to read. Despite the central place given to discourse in the current mathematics reforms, we encountered no principal who spoke of the role of oral language in learning or doing mathematics, or of the connections between language and communication and the development of students' mathematical literacy. Instead, other subjects required language. Lack of ability to read would impede students' progress in mathematics, it was argued.

While Norris and Young focused on reading instruction and curriculum in preference to mathematics, we note that they were the only two of the six principals who focused on an agenda related to curriculum and instruction. The roles these two principals crafted were complex and linked not only to their beliefs about their role, but also to their prior experiences and commitments as 
educators. The press for time saw each of these principals and others making decisions that prioritized some agendas over others.

Amidst the daily challenges of co-ordinating their respective buildings, each of the six principals has developed a personal agenda which does not include the reform of their school's mathematics instruction and curriculum. This is not necessarily because they are not concerned about mathematics, but rather because, as they themselves explained, they have been provided with few opportunities as principals to be connected to mathematics communities and to encounter new ideas and experiences around mathematics that are central to the mathematics reform activity. This leads us to look more closely at the centraloffice leadership, and to ask: How are the reforms in mathematics in the district, as well as at the state and national levels, viewed and understood by district leaders - the people responsible for influencing principals' priorities and opportunities to learn? How do the mathematics reforms figure in the agendas of the central-office staff and their visions for the district's directions?

\section{Central-office administrators' orientations to the mathematics reforms}

The central-office administrators whose responsibilities included mathematics in some way were the assistant superintendent for instruction, the directors of elementary education, state and federal programmes, instructional support, curriculum, and evaluation (Figure 7.1). ${ }^{4}$ Although they shared key responsibilities for the curriculum, staff development, and evaluation in mathematics, few of them had much depth of knowledge about the mathematics reforms. All were aware of current efforts to shift the emphasis in the direction of 'manipulatives' and 'problem-solving', as reflected in this administrator's comment:

Youngsters will not be spending as much time doing paper-and-pencil computations, you know. They will really be engaged more in problemsolving, use of manipulatives, and figuring out things, as opposed to sitting down, computing, and you know, getting all the addition and subtraction facts. It's really more oriented towards actually solving problems.... That's a thrust from the state, there's a thrust from the National Council of Teachers of Math, the standards that they publish.

Like at least two of the principals, the central-office administrators saw the changes as similar - and therefore generic - across language arts, science, and mathematics. The reforms, to them, promoted a focus on thinking and problem-solving - on processes rather than on facts or isolated skills. The director of elementary education emphasized to us: 'There is a thread, a thread that runs through basically all of these subject areas. The focus is on problem-solving and higher-order thinking skills.'

Several others commented on the new centrality of 'applications' - a notion that seemed only vaguely articulated. For example, one director who was 
convinced that this lay at the heart of the changes that were 'coming down from the state' and from the national organizations, declared:

Application's the name of the game now. It's not the knowledge, it's the application of the knowledge. And the only way you're going to know whether a student can apply the knowledge is to let him do it.

Thinking about the reforms of subject-area instruction as generic, as about process, makes it difficult to attend to some crucial aspects of the reform. For example, for a mathematics teacher to hold a good discussion about fractions, she needs to understand a great deal about fractions herself. She also needs to know what counts as evidence for, proof of, or refutation of a mathematical claim. To conduct such a discussion solely on the basis of a general sensitivity to classroom discourse and a commitment to problem-solving, for instance, would make it difficult to facilitate students' progress with the mathematical ideas. Moreover, the directors lacked specific ideas about what this shift in emphasis really meant for goals or instruction.

Most were also aware that there had been changes in the state assessment but were only vaguely familiar with the specific nature of those changes. One director, predicting that 'the [state assessment] is the engine that is driving curriculum in this state', described the emphasis:

It's testing more process. I mean, it's an extension. Maybe not an extension but it's, it's in the same spirit as the new definition of reading and the direction that the science [test] is headed. Where kids are going to have to demonstrate the skills that are necessary to solve a problem, to follow a process rather than to fill in a blank or make an arbitrary choice.

One notable exception was the deputy superintendent, who herself took the tenth-grade state assessment examination in mathematics. She described for us one of the items, a problem involving rotations. Clearly she had been challenged and was still not entirely sure of her answer. 'Those are not basic skill concepts', she remarked. Commenting on the fourth-grade-level test, she had less detail about the nature of the items, although she emphasized that what counted was 'if they can apply the applications to solve problems'.

Although the directors seemed aware of a broader national agenda for mathematics reform, they cited the district's curriculum revision cycle as the impetus for updating the Mapleton agenda. One director explained:

It's a cycle. Every five years, a subject area will come into focus. That was established some years ago through another committee that set this up as a way to really review the curriculum on an ongoing cycle. And, um, math came in ... as [its time in the cycle].

The mathematics co-ordinator, she continued, participated on one of the state committees - 'and brings in all of the new stuff that's coming down from the 
state' - and this provided the information link between the state and the district. Another director corroborated this relationship to the state's goal statements as well as the national agenda - 'what's being done at the national level plus what's being done at state level. And out of that meld you've gotta come up with something that works for your kids'.

Overall, our interviews with the central-office staff suggested to us that their familiarity with the mathematics reforms was modest, and often represented in slogans such as 'hands-on' or incorporated into generic ideals such as 'process' or 'higher-order thinking' or 'applications'. They had taken little opportunity to delve into the nature of the national recommendations for mathematics curriculum and instruction, and therefore were unable to talk in any detail about the nature of the reforms or the implications for curriculum, instruction, or staff development. Although many of the pedagogical goals were generic, and in common across subject matters, pursuing them in the context of any particular subject would mean looking more specifically at what these ideas might mean or entail in that content.

\section{Central-office administrators' other agendas}

Although mathematics was not an area on which many administrators had a lot to say, they, like the building principals, had many issues that did matter deeply to them. In no case was the agenda of one of the central-office administrators focused on mathematics. Their concerns ranged from raising test scores, to improving programmes and outcomes for disadvantaged students, to revising assessment. And, in most cases, reading and language arts were their foremost curricular priority.

Out of her understandable frustration to manage the task of leading a large district's mathematics agenda, Jackson often commented to us that mathematics was a low priority for Mapleton. Once she related a conversation she remembered having with the then-director of curriculum:

In reality, I don't believe mathematics is a priority because I can remember years ago, before I ever got this position, that I went to the curriculum director and I asked him if he would be an advocate for mathematics in this district. I needed someone in this district who was willing to write a grant so that we could have some much better staff-development programmes going on. And he said he could not be an advocate for mathematics. He didn't have the time to do that.

This interpretation fits with what other administrators themselves said to us in interviews. Just as we saw in our conversations with principals, reading seemed a much higher priority than mathematics. ${ }^{5}$ When pressed as to why the district hires dozens of reading teachers and hires no mathematics specialists, the same director of curriculum to whom Jackson had referred said that we had 
'touched a nerve'. He went on to explain that elementary teachers are well-paid professionals and that with increasing specialists to teach the curriculum, classroom teachers are barely responsible - in his view - for anything any more. It was only reasonable, he argued, that they teach something on their own. When we queried as to why not hire mathematics specialists instead of reading, he told us that, with the increasing emphasis on process and problem-solving, 'if you can't read, you won't be able to perform successfully in mathematics'. This notion of reading being fundamental to everything else, and particularly to mathematics, was echoed by many of the other administrators. Another director, when asked if the district placed a higher priority on reading than on mathematics, replied, 'Reading is so basic and fundamental to everything else that youngsters do and they have to know how to read in order to do math'. To her it was obvious that reading should receive the lion's share of the attention funding, staffing, and staff development - for the ability to read was prior to everything else, including mathematics.

Another central-office administrator justified the priorities differently. She remarked that making changes in reading was much more challenging than in mathematics, because

the content of mathematics is ... less ambiguous ... it's easier to give students things that they need to apply in mathematics until the concepts get in, until you get into trig problems sometimes there isn't an answer, you know.... But I think mathematics as a content is more exact than language. Because language brings all of the cultural dimensions and subcultures. ... So language is a little different. We don't really know how kids read, learn to read, and we don't really know if kids learn anything, quite frankly. But we know that somehow or another it happens in the human mind because we're capable of it, intrinsically the human body is capable of doing it, the human body is capable of taking in stuff. But I think it's easier for a math teacher than a language teacher.

For her, teaching and learning in reading were more complex than in mathematics, and so justified the differential allocation of resources.

\section{The paradox of mathematics reform: low in priority, high in need}

Administrators - at the central office or in buildings - are in positions of power to affect the marshalling of resources around particular agendas. They allocate funds for materials, professional development, and staff. They influence teachers' priorities, in the form of concern and time. Thus, what they care about and understand can have crucial consequences for the development of any particular reform agenda - either because of the direct messages they send or because of resources that they make available.

Our analyses suggest that, in Mapleton, both building principals and central- 
office administrators were relatively unfamiliar with the mathematics reforms. When they described the district's agenda, they emphasized generic processes and they seemed to have thought little about the shape these ideas might take in classrooms or what, specifically, teachers might need help with. Although they were vaguely familiar with the state and national reform agenda, their understandings were similarly thin and unfocused. They used common buzzwords like 'manipulatives', 'problem-solving', and 'application', but had little to say that went beyond identifying these as core elements of the reforms. This stood in contrast to what we saw in some administrators' articulateness regarding curriculum and instruction in reading. Although not all principals or central-office administrators were knowledgeable about reading and language arts, several were well-versed in the latest theories and directions.

That administrators, both at the building level and in the central office, were unconnected to the mathematics reforms and the ideas about improving mathematics instruction seemed to have important consequences for the district's agenda in mathematics. The administrators had little involvement in the ideas and their underlying rationale, and mathematics was lower in overall district priorities - certainly much lower than, for example, reading and language arts. Mathematics did not seem to be of central concern for them, as was made evident by the lack of time they spent talking about the mathematics curriculum, professional development, and the new textbooks. Mathematics was only on the principals' agenda very occasionally, whereas reading was discussed frequently. The enormous discrepancy in staffing for reading and language arts versus mathematics was another obvious case in point. In reading and language arts, Mapleton had on staff over 30 specialist teachers, as many instructional aides, and two subject-area specialists, whereas in mathematics, Lydia Jackson was the mathematics staff for the entire district. This contrast was quite dramatic. In Mapleton, one person was expected to launch, promote reform in mathematics, and create professional development opportunities in mathematics for the entire district in elementary, middle, and high schools. Yet there were over 30 specialists in elementary schools alone who undertook such responsibilities in reading and language arts.

Essentially, Mapleton administrators' lack of familiarity with the mathematics reform agenda meant that they were less inclined to allocate resources crucial to making the kinds of changes Jackson envisioned. They were also less likely to provide more than superficial support for teachers, to explain and justify the reforms to parents, and to lobby for additional resources from the community or the school board. With no special personal interest in making ambitious mathematics reforms happen, the routine revision of the district objectives and the adoption of a new textbook seemed sufficient to most administrators. And having a dynamic new mathematics co-ordinator, who was energetically dashing around the district, only served to animate the belief that mathematics was 'taken care of'. 


\section{Mathematics: high in need}

The paucity of local resources for mathematics reform presents a paradox for reformers. For a district to make the changes envisioned by the NCTM Standards would be an unusually challenging task, requiring exceptional resources. Teachers would need access to images of approaches to mathematics teaching consistent with the reforms. They would need opportunities to investigate such practices, to explore them with others and in their own classrooms. They would need opportunities to deepen and extend their own mathematical understandings. Yet when those in positions of power lack understandings of and commitments to the reform agenda, as in Mapleton, they are unlikely, in the face of fiscal and political pressures, to allocate adequate resources for mathematics.

Making change in mathematics presents unusual challenges for a number of reasons. First, the mathematics reforms are far from a blueprint for action, a plan to be implemented. A blend of vision and commitment, the reform agenda sets out instead a direction for focused development and invention. The current patterns of mathematics teaching and curriculum are deeply rooted in schools (Cohen 1989); changing from a curriculum of algorithms and calculation would take extended effort.

Second, elementary teachers and administrators are less well prepared in mathematics than in many other subject areas - certainly less well prepared than in reading. Their formal mathematics education is typically thin, and they often do not feel mathematically competent or confident. Developing the visions of reform to engage children in intellectually-serious mathematical work is a task for which most teachers would need significant opportunities to learn as well as substantial support. When the Mapleton teachers worked across an entire school year to select a new textbook series, they were making a choice that would, in this case, shape their principal opportunity for learning. And yet, at this point, they could not fully comprehend the vision that they were being asked to use to guide their work; thus, their preferences were shaped as much by their existing understandings and commitments as by those that reformers were promoting. Ultimately, this would limit the kinds of opportunities the selected textbook was likely to offer. Although the mathematics co-ordinator preferred the textbook that was selected, she believed that none offered a well-developed programme consistent with the reforms.

Third, working to educate and inform the public about the nature and rationale for mathematics reform is no simple matter. Community interest in mathematics instruction is not high, and perspectives on what students need to know are, for the most part, conservative, comprising basic skills and computational prowess. Lacking deep mathematical literacy themselves, most people remember being stung by the last wave of mathematics education reform - 'the new math' (Sarason 1982, Romberg 1992) - and are not convinced that a curriculum focused on 'reasoning' and 'thinking' will equip students with what they need to learn. That the reform agenda is underdetermined and uncertain - in need of continued development and revision - makes the task of communicating with and convincing the public that much harder. 


\section{Comparing mathematics with reading: a paradoxical inversion of resources and needs}

Both by interest and by default, reading is central to the elementary curriculum. Among Mapleton administrators, some brought to their work extensive background and experience with reading and language arts. They were connected to the reading reforms, had ideas about what they implied for classroom practice, and were inclined to allocate resources in support. Even when reading is not an area of expertise or special interest, it remains, perhaps by convention, a high priority. Attention and concern seem tilted by default toward reading. Those who told us that reading was fundamental to everything else expressed a widelyshared belief. The expertise and assumptions that administrators bring to making decisions about reading mean that they are likely to be concerned with providing resources for the district's language-arts programmes. Our colleagues' work investigating the evolution of state reading policy shows that, at the district level, different commitments and interpretations of reading and of reading reform lead to different decisions about the nature of resource allocations. But no matter what, reading seems consistently to be centrally on the agenda (Spillane 1993, Cohen et al. 1996, Jennings 1996).

Mathematics enjoys no such automatic attention or interest. Lower in priority than reading, mathematics instruction is often weakly supported. With less support, mathematics instruction is difficult to change. In many classrooms, the curriculum and students' experiences with it, are much the same as they were 50 years ago (Welch 1978, Cuban 1984, Goodlad 1984, Weiss et al. 1996) despite much rhetoric and concern. Students still spend most of their time practising algorithms and developing computational skill. This is the mathematics that most parents recognize, and the mathematics that most teachers teach. Without substantial effort, the pedagogy and curriculum of mathematics is likely to continue to reproduce itself, for it is traditional views, knowledge, and practices that are recycled.

That mathematics is usually less well supported than reading is understandable when one examines closely what Mapleton administrators brought to their work: mathematics was not a central area of interest or expertise for any of them. It was not surprising that they did not accord substantial attention or resources to mathematics. And yet, one could argue that mathematics reform is more in need of significant support than is reading because it will take more to make change.

This raises a fundamental paradox about the allocation of essential resources for reform in mathematics: if people who are in positions of power are themselves not oriented to the specific challenges of the mathematics reforms, they are less likely to make it a high priority. Further, if the defaults of schooling are more strongly set on reading and language arts, it would take extraordinary effort to reverse this natural pattern of priorities. And if extraordinary - not just basic - resources are not levied in support of efforts to make change in mathematics teaching and learning, the promise of deep reform is dim. 
Paradoxically, those responsible for allocating resources are themselves more familiar with and committed to reading and language arts and yet, without opportunities to examine and learn about a host of ideas related to mathematics teaching and learning, and about mathematics itself, they are unlikely to shift their priorities. Could something be done to change this paradoxical inversion of resources and needs? Could fundamental patterns that prioritize reading and marginalize mathematics be altered? District leaders must somehow themselves have opportunities to learn and become committed to mathematics in ways that would incline them to commit resources more adequately, in a more appropriate relationship to need. This would not be easy, for in times of fiscal cutbacks, increasing attention to mathematics might be seen as decreasing concern for literacy. The continued need for resources in literacy in tandem with a need for an increase of resources in mathematics presents schools with a dilemma. Managing such a dilemma seems to require more creative ways of identifying, allocating, and using resources. Managing ambitious reform in a time of overall reductions in resources presents a set of puzzles that complicates the already difficult problems of change. Allocating resources to mathematics need not automatically lead to decreasing support for literacy. Doing so would make little sense. Thinking more carefully about the allocation of resources to both these areas should take account of the centrality of both, and not pit one against the other in a fruitless competition in which there can be no winners.

Understanding in this way the crucial role played by districts in marshalling resources for reform illuminates the gap between the proudly heralded mathematics reforms and their disappointing failure to take root in classrooms. Taken seriously, the mathematics reforms point to fundamental revisions in views of knowledge, of learning, and of the relationship of teachers and students in classrooms. Without dramatically different local policy-making about resources available, however, the rhetoric of mathematics reform has little chance to comprise more than superficial shifts in the surface features of classrooms and a splash of new slogans. Doing so would require administrators to have opportunities to learn about - not just be updated on - the substance of the mathematics reforms and about what it might take to realize these ideas in classrooms. And it would require them to make different choices about the allocation of resources to mathematics reform, both in terms of kind and extent.

\section{Acknowledgements}

Work on this chapter was supported by the Education Policy and Practice Study (EPPS), which is funded in part by Michigan State University, and by grants from the Pew Charitable Trust (Grant no. 9104343000); the Carnegie Corporation of New York (Grant no. B 5638); the National Science Foundation (Grant no. ESI9153834); and the Consortium for Policy Research in Education (CPRE) and the National Center for Research on Teacher Learning (NCRTL), both of which are funded by grants from the US Department of Education, Office of Educational Research and Improvement (Grant no. 
OERIG008690011 and no. OERIRI17G1001194). The views expressed in this chapter are ours and are not necessarily shared by the grantors.

We gratefully acknowledge the helpful criticisms and comments that we received from David Cohen, James Spillane, and Robert Calfee. We would also like to thank our colleagues who are also working on the role of local districts in state policy and reform for their helpful comments: Jennifer Borman, Nancy Jennings, Penelope Peterson, and Richard Prawat. In addition, we wish to thank other researchers on the EPPS project who work with us in studying the Mapleton district: Carol Barnes, Susan Luks, Steve Mattson, Sue Poppink, Janine Remillard, Peggy Rittenhouse, and Karl Wheatley. They helped to collect the data on which this chapter is based and also participated in the development of the argument. We would especially like to thank Susan Luks for her assistance in earlier versions of this chapter. Finally, we gratefully acknowledge the assistance of Kara Suzuka in the preparation of this chapter.

\section{Notes}

1 Mapleton is a pseudonym, as are the names of all people who appear in this chapter.

2 For example, at one of the schools where we have been working, poor African American children are bused from the other side of town to be with the poor African American children in the school neighbourhood, while the middle-class white children in the neighbourhood attend a different nearby school.

3 James Spillane's (1993) study of the role of districts in a state reading reform illustrates the powerful role played by individuals at the district level, and the ways in which their own commitments shape their interpretation and enactment of the reform.

4 Because our analysis of the central-office administrators' understanding of and concern for the mathematics reform agenda is not centred on differentiating among these individuals, we have chosen not to refer to them by name or title. Doing so necessarily would compromise our commitment to confidentiality in ways that referring to teachers or principals does not, and it is not necessary to distinguish among these people for the claims we make here with respect to the relative lack of attention accorded to mathematics among the central-office administrators. The point is a more general one concerning them as a group, and the district as a whole.

5 Our claims do not address the nature or depth of these administrators' attention to reading and language arts. Instead, we claim that with greater interest in and valuing of reading, and more resource allocation of all kinds, there is greater opportunity to consider issues related to teaching and learning. By comparison, the opportunities to even begin to explore issues of curriculum and pedagogy in mathematics are slim.

\section{References}

Ball, D.L. (1990) 'Breaking with experience in learning to teach mathematics: the role of a preservice methods course', For the Learning of Mathematics, 10 (2), 10-16.

Ball, D.L. and Cohen, D.K. (1995) 'What does the educational system bring to learning a new pedagogy of reading or mathematics?' Paper presented at the annual meeting of the American Educational Research Association, San Francisco (East Lansing, MI: College of Education, Michigan State University).

Berman, P. and Pauly, E.W. (1975) Federal Programs Supporting Educational Change: Factors Affecting Change Agent Projects, vol. 2 (Santa Monica, CA: Rand). 


\section{J.N. Price and D.L. Ball}

Butts, T. (1980) 'Posing problems properly', in S. Krulikand and R.E. Reyes (eds), Problem Solving in School Mathematics: 1980 Yearbook of the National Council of Teachers of Mathematics (Reston, VA: NCTM).

California State Department of Education (1985) Mathematics Framework for California Public Schools, Kindergarten through Grade Twelve (Sacramento, CA: California State Department of Education).

California State Department of Education (1992) Mathematics Framework for California Public Schools, Kindergarten through Grade Twelve (Sacramento, CA: California State Department of Education).

Cohen, D.K. (1989) 'Teaching practice: plus ça change', in P.W. Jackson (ed.), Contributing to Educational Change: Perspectives on Research and Practice (Berkeley, CA: McCutchan), 27-84.

Cohen, D.K. (1990) 'A revolution in one classroom: the case of Mrs. Oublier', Educational Evaluation and Policy Analysis, 12 (3), 311-30.

Cohen, D.K. and Ball, D.L. (1990) 'Relations between policy and practice: a commentary', Educational Evaluation and Policy Analysis, 12 (3), 249-56.

Cohen, D.K., Spillane, J.P., Jennings, N., and Grant, S.G. (1996) 'Reading policy: policy and practice in Michigan reading reform', Working paper (University of Michigan, School of Education).

Crandall, D. (1982) People, Policies, and Practice: Examining the Chain of School Improvement (Andover, MA: The Network).

Cuban, L. (1984) How Teachers Taught: Constancy and Change in American Classrooms, 1890-1980 (White Plains, NY: Longman).

Cuban, L. (1992) 'Why some reforms last: the case of the kindergarten', American Journal of Education, 100 (2), 166-94.

Cusick, P.A. (1983) The Egalitarian Ideal and the American High School: Studies of Three Schools (New York: Longman).

Goodlad, J. (1984) A Place Called School: Prospects for the Future (New York: McGrawHill).

Gronn, P.C. (1983) 'Talk as work: the accomplishment of school administration', Administrative Science Quarterly, 28 (1983), 1-21.

Gross, N.C., Giacquinta, J.B., and Bernstein, M. (1971) Implementing Organizational Innovations: A Sociological Analysis of Planned Educational Change (New York: Basic Books).

Jennings, N.E. (1996) Interpreting Policy in Real Classrooms: Case Studies of State Reform and Teacher Practice (New York: Teachers College Press).

McNeil, L. (1986) Contradictions of Control: School Structure and School Knowledge (New York: Routledge \& Kegan Paul).

Mirel, J. (1994) 'School reform unplugged: the Bensenville New American School Project, 1991-1993', American Educational Research Journal, 31 (3), 481-518.

National Council of Teachers of Mathematics (1989) Curriculum and Evaluation Standards for School Mathematics (Reston, VA: NCTM).

National Council of Teachers of Mathematics (1991) Professional Standards for Teaching Mathematics (Reston, VA: NCTM).

National Research Council (1989) Everybody Counts: A Report to the Nation on the Future of Mathematics Education (Washington, DC: National Academy Press).

Paulos, J.A. (1988) Innumeracy: Mathematical Illiteracy and Its Consequences (New York: Hill \& Wang).

Paulos, J.A. (1995) A Mathematician Reads the Newspaper (New York: Basic Books). 
Remillard, J. (1996) Changing texts, teachers and teaching: the role of curriculum materials in mathematics education reform. Doctoral dissertation, Michigan State University.

Rickard, A.D. (1993) Teachers' use of a problem solving-oriented sixth-grade mathematics unit: two case studies. Doctoral dissertation, Michigan State University.

Romberg, T.A. (1992) “"New math” was a failure - or was it?’, UME Trends: News and Reports on Undergraduate Mathematics, 2 (6), 1-3.

Sarason, S.B. (1982) The Culture of the School and the Problem of Change, 2nd edn (Boston, MA: Allyn \& Bacon).

Schifter, D. (1995a) Constructing New Practices/Reconstructing Professional Identities: Teacher Narratives from the Mathematics Education Reform Movement (New York: Teachers College Press).

Schifter, D. (1995b) Voicing the New Pedagogy: Teachers Interpret the Rhetoric of Mathematics Education Reform (New York: Teachers College Press).

Schwille, J., Porter, A., Floden, R., Freeman, D., Knapp, L., Kuhs, T., and Schmidt, W. (1983) 'Teachers as policy brokers in the content of elementary school mathematics', in L. Shulman and G. Sykes (eds), Handbook of Teaching and Policy (New York: Longman), 370-91.

Shulman, L.S. (1986) 'Those who understand: knowledge growth in teaching', Educational Researcher, 15 (2), 4-14.

Simon, M.A. (1993) 'Prospective elementary teachers' knowledge of division', Journal of Research in Mathematics Education, 24 (3), 233-54.

Smith, L.M. and Keith, P.M. (1971) Anatomy of Educational Innovation: An Organizational Analysis of an Elementary School (New York: Wiley).

Spillane, J.P. (1993) Interactive policymaking: state instructional policy and the role of the school district. Doctoral dissertation, Michigan State University.

Stodolsky, S.S. (1988) The Subject Matters: Classroom Activity in Math and Social Studies (Chicago: University of Chicago Press).

Tharp, R. and Gallimore, R. (1988) Rousing Minds of Life: Teaching, Learning, and Schooling in Social Context (New York: Cambridge University Press).

Tyack, D. and Cuban, L. (1995) Tinkering Toward Utopia: A Century of Public School Reform (Cambridge, MA: Harvard University Press).

Tyack, D. and Tobin, W. (1994) 'The "grammar" of schooling: why has it been so hard to change?', American Educational Research Journal, 31 (3), 453-79.

Weiss, I., Lawrenz, F., and Queitzsch, M.L. (1996) 'The elementary and secondary learning environment', in L. Suter (ed.), Indicators of Science and Mathematics Education (Arlington, VA: National Science Foundation), 33-71.

Welch, W. (1978) 'Science education in Urbanville: a case study', in R. Stake and J. Easley (eds), Case Studies in Science Education (Urbana, IL: University of Illinois at Urbana-Champaign, College of Education).

Wilson, S.M. (1990) 'A conflict of interests: constraints that affect teaching and change', Educational Evaluation and Policy Analysis, 12 (3), 293-310.

Wilson, S.M., Peterson, P.L., Ball, D.L., and Cohen, D.K. (1996) Learning by all. Phi Delta Kappan, 77 (7), 468-76.

Yinger, R. (1988) 'The conversation of practice', in P.P. Grimmet and G.L. Erickson (eds), Reflection in Teacher Education (New York: Teachers College Press), 73-94. 


\title{
8 Towards a theory of leadership practice
}

\section{A distributed perspective}

\author{
James P. Spillane, Richard Halverson, and \\ John B. Diamond
}

Leadership is thought critical to innovation in schools. We know that schools matter when it comes to improving student learning and we know a considerable amount about the organizational structures, leadership roles, and conditions of schools that contribute to innovation (Newman and Wehlage 1995, Hallinger and Heck 1996). We know, for example, that schools with shared visions and norms around instruction, norms of collaboration, and a sense of collective responsibility for students' academic success create incentives and opportunities for teachers to improve their practice (Bryk and Driscoll 1985, Newman and Wehlage 1995). We know that principals' leadership is important in promoting these conditions (Rosenholtz 1989). Furthermore, there is evidence to suggest that principals' leadership, as mediated through the development of these school-level conditions and processes, has an effect on student learning (Hallinger and Heck 1996).

However, while it is generally acknowledged that where there are good schools there are good leaders, it has been notoriously difficult to construct an account of school leadership, grounded in everyday practice, that goes beyond some generic heuristics for suggested practices. We know relatively little about the how of school leadership, that is, knowledge of the ways in which school leaders develop and sustain those conditions and processes believed necessary for innovation. While there is an expansive literature about what school structures, programmes, roles, and processes are necessary for instructional change, we know less about how these changes are undertaken or enacted by school leaders. A recent review of the North American literature by Hallinger and Heck (1996, 1998, see also Bossert et al. 1982 ) identified many 'blank spots', i.e. shortcomings of the research, and 'blind spots, i.e. areas that have been overlooked because of theoretical and epistemological biases, in the understanding of leadership. These authors argue that an important blank spot centres on in-depth description of how school leaders sustain those in-school conditions that foster successful schooling. Sustained, narrowlyfocused inquiry is necessary to fill this blank spot in the knowledge-base (Heck and Hallinger 1999). With respect to blind spots, they note that the focus on 'documenting if principals make a difference reinforced the assumption that school leadership is synonymous with the principal', resulting in researchers for the most part ignoring other sources of leadership in schools. 
We agree, and consider an account of the how of leadership, grounded in the day-to-day practice of school leaders, as essential to understanding leadership in schools. ${ }^{1}$ However, to study leadership activity, it is insufficient to generate thick descriptions based on observations of what school leaders do. We need to observe from within a conceptual framework if we are to understand the internal dynamics of leadership practice. However, because of the inattention to leadership practice, frameworks for studying leadership activity are scarce, and those that exist tend to focus chiefly on either individual agency or the role of macrostructure in shaping what leaders do. (Indeed, investigations of work practices in general require the development of new conceptual frameworks, 'frameworks built out of concepts that speak directly to practice' [Pickering 1992: 7].) Hence, our goal in this chapter is to develop a conceptual framework - a distributed perspective on leadership - for investigating leadership practice.

The distributed leadership perspective developed here is designed to frame a programme of research that will analyse leadership activity and generate evocative cases for practitioners to interpret and think about as part of their ongoing leadership practice. By identifying dimensions of leadership practice and articulating the relations among these dimensions, we hope that the distributed leadership framework can enable leaders to reflect on and analyse their practice. Moreover, it offers a framework for those interested in studying the practice of leadership.

Consider, by way of example, monitoring instruction, which the research informs us is important for the successful enactment of instructional innovation (Firestone 1989). However, although this research documents the importance of 'monitoring' behaviours for successful innovation, it tells us relatively little about the how of monitoring. Without a rich understanding of how leaders monitor, it is difficult to develop a perspective on the leadership practice of monitoring that can provide helpful information for school leaders in their practice. By framing an analysis of leadership practice - and developing rich case studies of that practice - the distributed leadership perspective is a tool that can enable change in leadership activity. A conceptual framework for leadership practice is likely to yield more insight into the relations between leadership and innovation in schools than theories that focus exclusively on organizational structures and leadership roles, because leadership practice is a more proximate cause of that innovation.

We begin with a brief retrospective on research into school leadership, paying particular attention to some recent North American work that has attempted to document and describe leadership practice, that is, work that begins to address Heck and Hallinger's (1999) 'blank spot'. Next, we outline the theoretical underpinnings for our distributed leadership framework. Specifically, we use distributed cognition and activity theory, perspectives that have proven especially generative in understanding human action, as the theoretical foundations for framing a distributed conception of leadership practice. We use these literatures to re-approach the subject of school leadership and to reinterpret the relevant literatures. We then develop our distributed leadership perspective around four 
central ideas - leadership routines, tasks and functions, the enactment of routines and tasks, social distribution, and situational distribution.

In summary, we argue that investigating leadership practice is essential to understanding leadership in organizations. However, such investigations have to be undertaken within a conceptual frame and we develop a distributed framework for such work. In developing a distributed perspective on leadership, we move beyond acknowledging leadership practice as an organizational property in order to investigate how leadership might be conceptualized as a distributed practice, stretched over ${ }^{2}$ the social and situational contexts of the school. Leadership is not simply a function of what a school principal, or indeed any other individual or group of leaders, knows and does. Rather, it is the activities engaged in by leaders, in interaction with others in particular contexts around specific tasks. We conclude by considering what our distributed leadership perspective might entail for research on school leadership and innovation.

\section{School leadership: a retrospective}

Our intent here is not to undertake a comprehensive review of scholarship on leadership, but rather to briefly overview some major lines of work relevant to school-leadership practice. While acknowledging the contribution of different lines of research to our understanding of leadership, we identify several challenges that must be addressed in order to develop a conceptual framework for investigating school-leadership practice.

The literature on leadership, regardless of tradition, has focused mostly on those in formal leadership positions, chiefly on the chief executive officer or in the case of schools, the school principal. For example, the 'leaders' traits' approach defines leadership chiefly as a function of individual personality, ability, traits, and style - and the focus on the venerable 'great man' theories of leadership continues unabated (Burns 1978). This approach has a long history and marked influence on leadership research, focusing on the identification of leaders' personality traits, and in some cases relating these traits to leaders' effectiveness (Stogdill 1948, 1950, Yukl 1981). Traits such as self-confidence, sociability, adaptability, and co-operativeness, among others, are thought to enable leaders to inspire others, and thus get others to follow; and empirical work suggests that such leader traits do indeed increase the likelihood of a leaders' effectiveness (Yukl 1981).

Responding in part to criticisms levelled at the 'leaders' traits' tradition for its silence about what leaders do, other researchers began to investigate leadership as a set of behaviours (Hemphill and Coons 1950, Kunz and Hoy 1976, Mouton and Blake 1984). Such research, which documented the behaviours of 'successful' leaders, has generated taxonomies of behaviours, including 'monitoring', 'consulting', and 'delegating' (Hemphill and Coons 1950, Hallinger and Hausman 1993). Other work in this tradition has identified broad styles of behaviour, including autocratic, democratic, and laissez-faire (Lewin et al. 
1939, White and Lippitt 1960), employee-oriented and directive (Mouton and Blake 1984), and task-oriented and relationship-oriented (Likert 1967), at times showing a relationship between these behaviours and effectiveness.

While providing valuable insight, the focus in these traditions on positional leaders is problematic because other research underscores the need to move beyond those at the top of organizations in order to understand leadership (Barnard 1938, Katz and Kahn 1966, Heenan and Bennis 1999). Thus, critics of the solo decision-maker model have argued for giving attention to the shifting coalitions of decision-makers in organizations in which preferences and coalition membership are neither stable nor unified (Cyert and March 1963, March and Olsen 1984). Research on schools has suggested that leadership is not the sole purview of the school principal; teacher-leaders and other professionals also play important roles in leading instructional innovation (Smylie and Denny 1990, Heller and Firestone 1995).

In other words, if leadership is an organizational quality (Pitner 1988, Ogawa and Bossert 1995), then investigations of leadership practice that focus exclusively on the work of individual positional leaders are unlikely to generate comprehensive understandings of the practice of school leadership. Indeed, in schools, teacher-leaders often assume leadership roles from a perspective that is distinct from that of positional leaders, and the character and structure of these interactions are vital to understanding leadership practice (Leithwood et al. 1997, Urbanski and Nickolaou 1997).

Seeking to address the inattention to context or situation, another line of research on leadership, contingency theory, has focused on the relations between the situation of leaders' work and their actions, goals, and behaviours (Fiedler 1973). Contingency theory assumes that there is no one best approach to organizing, that organizational structure matters when it comes to organizational performance, and that the most effective method of organizing depends on the organization's environment (Galbraith 1973, Lawrence and Lorch 1986). While some researchers have concentrated on such situational aspects as relations between leaders and followers and the extent to which the leadership task is structured (Fiedler 1970), others have focused chiefly on followers' readiness to achieve the leader's goal (Hersey and Blanchard 1977). Effective leaders draw on a repertoire of styles, and the effectiveness of particular styles is dependent on both the leadership task and the context (Stogdill 1974). For example, a task-oriented style is more effective when followers have limited experience and competence (i.e. 'immature' followers); a blend of taskand relationship-oriented styles works best with more mature groups; and a delegating-style of leadership appears most effective when working with very mature groups (Hersey and Blanchard 1977).

Leaders' thinking about their work is largely ignored in behavioural studies of leadership, with the research focusing attention on documenting macro- or micro-leadership behaviours or styles. The cognitive tradition of research on decision-making in organizations has focused on leaders' and followers' thinking about their situation and work, and the relations between these cognitive 
processes and their behaviour (Simon 1976, Pfeffer 1977, Weick 1979, 1995). Recent work in this tradition investigates how school leaders use mental representations to understand and order their repertoire of responses to experience (Bolman and Deal 1991, Gardner 1995). Comparing the problemsolving strategies of 'expert' and 'typical' principals (as identified by school boards, administrators, and interviews with subjects), researchers have shown that 'experts', when compared to 'typical' principals, are better able to identify the problem situation and to detect features of the problem that are similar to past problems (Leithwood and Steinbach 1990, 1995). However, with its focus on the thinking of individual leaders, this work continues the tradition of seeing leadership chiefly as a function of individual personality, ability, cognition, and style. If school leadership involves a range of administrators and teachers in a given school, this focus has limitations. Another caution to be levelled at the cognitive research on leadership is that by concentrating on administrators' intentions, values, and beliefs, cognitive approaches run the risk of ignoring organizational, cultural, and political factors that also influence what school leaders do (Cuban 1993). Work on leaders' cognitive scripts has and will continue to make important contributions to our understanding of leadership, but other perspectives are also needed.

In contrast to the traditional cognitive perspective, institutional theory attempts to situate individual sense-making in institutional sectors, challenging 'models of social and organizational action in which relatively autonomous actors are seen as operating with unbounded rationality' (Rowan and Miskel 1999: 359). From an institutional perspective, the thinking and action of social actors is situated in institutional sectors that provide norms, rules, and definitions of the environment, both constraining and enabling action (Powell and DiMaggio 1991). These tacit schemata define appropriate structures and give meaning and order to action in institutional sectors (Scott 1995). In this scheme, leadership is about preserving institutional legitimacy in order to maintain public support for the institution.

From this perspective, leadership, and leaders' cognition cannot be understood apart from the contexts in which they are embedded. This perspective provides insight into the implications of structure for leaders' cognition and action, suggesting that cognition itself can be constrained by institutional context. However, although not inherent in the approach, institutional theorists have tended to overplay aggregation and determinism (DiMaggio 1988), curtailing the frame's usefulness for investigating leadership practice. Focusing on populations of organizations - institutional sectors - institutional theory has stressed the emergence of dominant organizational forms rather than the leadership practices or activities that may be particular to individual organizations (Whittington 1992). Further, the overemphasis on the role of institutional schemata tends to smother human agency. As a result, institutional theory runs the risk of being overly deterministic by not attending to how social actors make sense of, and shape, their environments (Giddens 1984, Weick 1995). To enhance its relevance to scholarship in educational leadership, insti- 
tutional theory needs to more closely address issues of school learning, educational practice, and institutional change (Rowan and Miskel 1999).

Drawing on this previous research, we contend that, in order to understand leadership practice, leaders' thinking and behaviour and their situation need to be considered together, in an integrated framework. We argue that understanding the what of leadership is essential; but that without a rich understanding of how leaders go about their work, and why leaders do and think what they do, it is difficult to help school leaders think about and revise their practice. Further, from a research perspective, we contend that attention to how leadership practice is undertaken by multiple leaders in diverse contexts will establish a cogent framework for a more careful consideration of the why of school leadership. Building on recent work in distributed and situated cognition and activity theory, we argue that leaders' practice (both as thinking and activity) is distributed across the situation of leadership, that is, it emerges through interaction with other people and the environment. Hence, to frame a study of leadership practice, we propose an integrative conceptual model that explores the interaction of leaders' thinking, behaviour, and their situation.

\section{Conceptual underpinnings}

Distributed cognition and activity theory, the conceptual foundations for our distributed leadership perspective, have proven especially fruitful in understanding human activity in complex, emergent, and discretionary environments. This emergent perspective within psychology is recognizing how social context is an integral component of, not just backdrop or container for, intelligent activity. We appropriate several concepts from this work.

The study of human cognition has undergone something of a revolution in the past few decades, as scholars have focused on understanding the thinking process in situ rather than in vacuo (Rommetveit 1980). Recent investigations of human intelligence and cognition, rooted in Heidegger's (1962) emphasis on the 'in-the-worldness' of human experience, aim to situate thinking in the context in which it occurs (Lave and Wenger 1991). In this context, it does not seem satisfying or relevant to talk about thinking as a ' $y$-factor', independent of the context or action in which it is exercised, because intelligence is not encountered apart from the occasions in which it is displayed. In this view, investigating purposeful activity in its 'natural habitat' is essential for the study of human cognition (Leont'ev 1981, Hutchins 1995b). Cognition cannot be understood merely as a function of mental capacity because sense-making is enabled (and constrained) by the situation in which it takes place (Resnick 1991).

Thus, because of the mutuality of the individual and the environment, human activity is distributed in the interactive web of actors and artefacts, and situation is the appropriate unit of analysis for studying practice. Because cognition is distributed situationally in the physical environment, that is, through the material and cultural artefacts in an environment, it is also distributed socially, 
through other people in collaborative efforts to complete complex tasks (Latour 1987, Pea 1993).

Recent investigations in distributed cognition have focused on ways in which cognition is distributed across or 'stretched over' material and cultural artefacts (Rogoff 1990). Artifacts include language, notational systems, tools of various sorts, and buildings (Gagliardi 1990). For example, Hutchins (1995a) documents how the task of landing a plane can be best understood within a framework that includes the manufactured tools and social context of the cockpit which situate a pilot's activity. These features of the environment are not, argues Hutchins, merely 'aids' to the pilot's cognition, rather they are best understood as essential features of a composite which has the cockpit as the basic unit of analysis. Similarly, tools such as calculators enable students to complete computational tasks in ways that are difficult without tools (Pea 1993); in these cases, cognitive activity is also 'stretched over' actors and artefacts (Lave 1991). Thus, the unit of analysis for examining cognition in practice is actors in situations working with artefacts, rather than actors abstracted from situations or artefacts.

The technological or material aspects of the situation are not the only relevant means of distribution. Language, number systems, theories of action, and interpretive schemata provide also 'mediational means' that enable and transform intelligent social activity (Vygotsky 1978, Leont'ev 1981, Brown and Duguid 1991, Wertsch 1991). Such material and cultural artefacts, seen as products of particular social and cultural situations, form identifiable aspects of the 'socio-cultural' context. Actors have or develop common understandings, and draw on cultural, social, and historical norms in order to think and act. Thus, even when a particular cognitive task is undertaken by an individual, apparently in solo, the individual relies on a variety of socio-cultural artefacts, such as computational methods and language, that are social in origin (Vygotsky 1978, Wertsch 1991).

While much of the work in distributed cognition and activity theory emphasizes how context enables action, we recognize that it can also constrain it. Thus, our conceptual frame must address the relations between structure and human agency. 'Structure' refers to the various elements which individuals must contend with when forming action, from the tangible to the intangible, from things like classroom lay-outs to world-views and cultural dispositions. 'Human agency' refers to the actions of individuals within the context of (and, in fact, through) structure.

There are different perspectives on the relations between agency and structure - from objective structural determinism where all 'agency' is ultimately predicted by the structure in which it is embedded (Althusser 1971), to phenomenology which emphasizes the agentive, subjective, social construction of reality by agents (Berger and Luckmann 1966). While these approaches view structure and agency as a dualism, we conceptualize structure as a duality. Following Giddens (1979, 1984), we view structure as both the medium and the outcome of action, i.e. agency. Structure constitutes agency, providing the 
rules and resources upon which it is based; however, structure is also created, reproduced, and potentially transformed by the actions of human agents. The structural properties that enable human activity exist only as they are 'instantiated in activity' or remembered as rules of conduct or 'rights to resources' (Whittington 1992: 696).

In other words, a distributed perspective on human activity presses us to move beyond individual activity to consider how the material, cultural, and social situation enables, informs, and constrains human activity. In this view, activity is a product of what the actor knows, believes, and does in and through particular social, cultural, and material contexts. Taking a distributed and situated perspective does not mean that the individual is somehow irrelevant in an investigation of human cognition and activity. What the individual thinks and knows is still relevant (Salomon 1993). In adopting a 'person-plus' perspective on human activity, we acknowledge that individual cognition is distributed in the material and social situation, but also that some intelligent activity may be distributed more than others (Perkins 1993).

\section{Leadership: a distributed perspective}

In keeping with the theoretical underpinnings for this work, our perspective on school-leadership practice focuses on leaders' thinking and action in situ. For us, the appropriate unit of analysis is not leaders or what they do, but leadership activity or practice. We argue that leadership practice is constituted - defined or constructed - in the interaction of leaders, followers, and their situation in the execution of particular leadership routines and their component tasks. As illustrated in Figure 8.1, in this view leadership activity involves three essential constituting elements - leaders, followers, and situation. It does not reside in any one of these elements, and each is a pre-requisite for leadership activity. Our perspective shifts the unit of analysis from the individual actor or group of actors to the web of leaders, followers, and situation that give activity its form. We explore each of these elements separately below; however, it should understand that we view leadership practice as constituted in the interaction of all three.

In other words, rather than seeing leadership practice as solely a function of an individual's ability, skill, charisma, and/or cognition, we argue that it is best understood as a practice distributed over leaders, followers, and their situation. Attending to situation as something more than a backdrop or container for leaders' practices, we consider socio-cultural context as a constitutive element of leadership practice, an integral defining element of that activity.

\section{Leadership in schools}

Although the distributed perspective we develop here is applicable to leadership in general, we use examples of leadership practice related to curriculum and instruction to illuminate our argument. Our perspective is premised on two assumptions: 


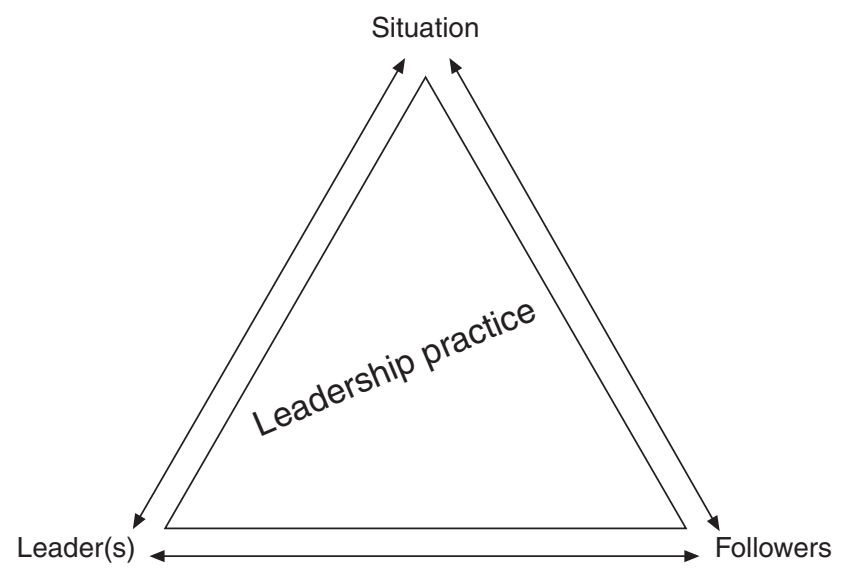

Figure 8.1 Constituting elements of leadership practice.

- School leadership is best understood through considering leadership practice in the execution of routines and enactment of tasks; and

- Leadership practice is distributed in the interactive web of leaders, followers, and the situation.

We begin our discussion with a consideration of the routines and tasks around which school leaders organize their practice. We consider the functions as well as the routines and tasks that are intended to address these functions. We next consider the distribution of leadership practice in routine execution and taskenactment.

'Leadership refers to activities tied to the core work of the organization that are designed by organizational members to influence the motivation, knowledge, affect, or practices of other organizational members or that are understood by organizational members as intended to influence their motivation, knowledge, affect, or practices' (Spillane 2006: 11-12). It involves efforts to mobilize school personnel to notice, face, and take on the tasks of changing instruction as well as attempts to harness and mobilize the resources needed to support the transformation of teaching and learning. School leadership involves the identification, acquisition, allocation, co-ordination, and use of the social, material, and cultural resources necessary to establish the conditions for the possibility of teaching and learning.

An issue here concerns the relationship between leadership and management. While 'the essence of organizational leadership [is] the influential increment over and above mechanical compliance with routine directions of the organization' (Katz and Kahn 1966, cited in Bass 1990: 14), management involves 'maintaining efficiently and effectively current organizational arrangements' (Burns 1978, Cuban 1988). Many have noted how the 'managerial imperative' 
often dominates the work of school leaders, while instructional activities receive limited attention (Peterson 1977). Managerial routines, which are designed to produce stability, may differ substantially from 'leadership' routines designed to promote change (Firestone 1996). However, what leaders do in the managerial and political realms, though often not directly and explicitly connected to changing some aspect of school life, may be an essential component of leadership in general, and leadership for instruction in particular (Lee 1987, Leithwood 1994). Indeed, efforts to change and efforts to preserve are often blended in the practice of leaders as routines serving multiple agendas and functions. For example, maintaining scheduling arrangements for teachers that create opportunities for them to meet can enable instructional innovation. Leaders who neglect managerial concerns, such as respecting the constraints on the daily schedule resulting from, e.g. collective-bargaining arrangements (i.e. de facto limitations on what can be asked of teachers), may have difficulties performing leadership routines and tasks.

Without attention to stability and the maintenance of organizational structures and routines, it can be very difficult to understand the significance of particular leadership tasks. Thus, efforts to transform teaching and learning that are guided by a technical logic are likely to depend in some measure on preserving the legitimacy of the institution by maintaining the confidence of external constituents, efforts which are informed by an institutional logic (Meyer and Rowan 1978). In other words, routines and tasks designed to encourage others to change may depend, in substantial measure, on the successful execution of routines and tasks designed to preserve the status quo.

\section{Leadership routines, tasks and functions}

Breaking leadership practice into component tasks is an elusive activity because, as Mintzberg (1973: 31; see also Leithwood and Steinbach 1995) puts it, the work of administrators is characterized by 'brevity, variety, and fragmentation'. The disjointed, discretionary, and emergent work of school leaders, their 'firefighting' (Weick 1996), results in a decision-press which can lead to a focus on short-term resolutions of problems rather than long-term planning (Peterson 1977). However, because school leaders do not work solely in reaction to their environment, our analysis of their practice is tied to an understanding of the routines and their component tasks that, over time, structure their work. ${ }^{3}$ Pursuing a routine and task-centred approach, grounded in the functions of leadership within the school, offers a means of accessing leadership practice. While others focus on the 'networks of roles' that exist between multiple actors and make up organizational leadership (Ogawa and Bossert 1995), our perspective centres on the interdependencies between leadership activities or practices rather than focusing chiefly on social interaction among individuals. Hence, the distributed frame allows us to examine how aspects of the situation simultaneously constitute leadership practice.

Routines including grade-level meetings, mathematics curricular committee 
meetings, formative evaluations of classroom instruction, and teacher professional development sessions are commonplace in schools. These routines involve repeated and recognizable interactions among two or more staff members and typically are made up of a number of tasks. For example, a routine such as formative evaluations of classroom instruction typically involves tasks such as observing a classroom, taking notes on the observed practice, conferencing with the teacher about the observed lesson, drawing conclusions about the quality of the instruction, providing feedback to the teacher about the instruction, and establishing remediation plans where necessary. Routines and tasks differ in terms of their grain-size. Routines can serve multiple organizational functions. For example, formative evaluations of classroom instruction can be designed to serve the function of monitoring instruction and at the same time can serve the function of supporting teacher growth and development.

The literature documents a variety of school-level functions that characterize successful, well-run schools. For example, Purkey and Smith (1983) note that school-site management, planned curriculum co-ordination and organization, linking staff development to the expressed concerns of the staff, and a strong sense of order and discipline are some key characteristics of effective school communities. An extensive literature identifies and describes the school-level functions that are thought essential for innovation and improvement (Leithwood and Montgomery 1982, Firestone and Corbett 1988, Blasé and Kirby 1992, Louis and Kruse 1995, Sheppard 1996, Blasé and Blasé 1999). Synthesizing this literature, we can identify several functions that are important for instructional leadership:

- constructing and selling an instructional vision;

- developing and managing a school culture conducive to conversations about the core technology of instruction by building norms of trust, collaboration, and academic press among staff;

- procuring and distributing resources, including materials, time, support, and compensation;

- $\quad$ supporting teacher growth and development, both individually and collectively;

- providing both summative and formative monitoring of instruction and innovation; and

- establishing a school climate in which disciplinary issues do not dominate instructional issues.

These leadership functions provide a framework for analysing leadership routines and tasks and exploring their relation to instructional innovation. Focusing on functions alone, however, will not enable us to understand leadership practice - where we must also identify and analyse the routines and their component tasks that either by design or default contribute to the execution of the organizational functions. However, because of the fragmentary nature of leadership practice in schools, tasks often appear to have little connection either with one another or with the school's instructional goals (Lee 1987). Thus, the research 
challenge in understanding leadership practice is to reconstruct, through observation and interview, whatever links exist between organizational functions and the leadership routines and tasks. For example, creating opportunities in the school day for teachers to work together, e.g. shared planning time, helps school leaders build norms of collaboration within the school (Goldring and Rallis 1993). Similarly, the execution of routines such as frequent classroom observations with attention to distinguishing summative and formative evaluation and establishing professional relations between the observer and the observed helps realize the functions of both supporting teacher growth and monitoring instruction (Little and Bird 1987). Our earlier discussion suggests that routines and their component tasks can also be sorted into instructional, managerial, and political categories, although these categorizations are not mutually exclusive (Cuban 1993).

We contend that research on the analysis of leadership routines and tasks should be extended to focus on dimensions that include complexity, ambiguity, and the knowledge-entailments of a routine or its component tasks. For example, the cognitive skills of framing and resolving non-routine tasks, as distinct from routine tasks, differentiate expert from novice principals (Leithwood and Steinbach 1995). We also know from research in organizations in general and schools in particular that the clarity and complexity of the core technology (in the case of schools, instruction) influence the behaviour of managers (Thompson 1967). For example, greater clarity, i.e. specificity, with respect to instructional practices, enables closer supervision of teaching by school leaders. Furthermore, in-depth analyses of leadership routines and tasks are important: routines and tasks that appear similar can turn out, on careful scrutiny, to be very different.

\section{Enacting leadership routines and tasks}

However, to develop a framework for analysing leadership practice, it is necessary to move beyond the identification and analysis of routines and their component tasks to explore their enactment. Indeed, the ways in which leadership routines and tasks are enacted may be most important when it comes to influencing what teachers do (Blasé and Kirby 1992, Lambert et al. 1995, Elmore et al. 1996, Smylie and Hart 1999).

There is often a difference between what people do and what they say about what they do, a distinction that can be maintained without duplicitous intent. Organizational policies can reflect ideal or desired tasks rather than what people actually do (Orr 1996), and personal accounts of action often reflect post facto sense-making efforts that refine the complexities of the experience (Weick 1996). Thus, the 'espoused theories' of practice (Argyris and Schön 1974) or the 'canonical practice' (Brown and Duguid 1991) found in formal accounts, official policies, and job-descriptions are often abstracted from day-to-day practice to provide over-rationalized portrayals of an ideal practice in which the challenges and uncertainties of unfolding action are smoothed-over in the 
telling (Weick 1979, Brown and Duguid 1991). Research suggests substantial differences between the espoused theories and the 'theories-in-use' that guide day-to-day practice (Argyris and Schön 1974). For example, Orr (1996) shows how the espoused theories (i.e. the training manuals, trouble-shooting guides, and decision-trees) of a copy-machine repair organization tell a fundamentally different, more rationally-ordered story of work than the emergent, discretionary work of the repair technicians. He found that repair workers supplement espoused practices with a rich, shared cultural library of case-stories used to diagnose and resolve problems. Thus, espoused practices, while often readily accessible, serve as insufficient road maps to practice. To gain insight on practice, we need to understand routines and tasks as they unfold from the perspective and through the 'theories-in-use' of the practitioner.

Analysing leadership practice involves understanding how school leaders define, present, and carry out their routines and tasks. 'Expert' principals are better able to regulate their own problem-solving processes and are more sensitive to the task demands and the social contexts (Leithwood and Steinbach 1995). We suspect, however, that a greater range of processes influences how school leaders enact their routines and tasks.

Recently, some scholars have worked to understand the enactment of tasks and routines through documenting the day-to-day practices of school leaders, exploring their relationship to the school functions considered essential for innovation (Goldring and Rallis 1993) and their effects on teachers' work (Blasé and Blasé 1999). For example, routines such as frequent classroom observing and distinguishing summative and formative evaluation help realize the function of supporting teacher growth (Little and Bird 1987). Blasé and Blasé's (1999) study of teachers' perspectives on principals' day-to-day leadership behaviour identified six strategies that principals use in executing routines to promote teacher reflection, including making suggestions, giving feedback, modelling, using inquiry, soliciting advice and opinions, and giving praise (p. 359).

While such work has contributed in significant ways to our understanding of the everyday enactment of routines and tasks by principals, it has shed limited light on the beliefs and experience that leaders bring to their work and, in some cases, the influence of context on leaders' practices. For example, when it comes to enacting routines and tasks considered essential for instructional innovation, school-leaders' subject-matter and pedagogical knowledge, coupled with their beliefs about teacher learning and change, may influence how they present and carry out these tasks. Nelson (1999), for example, has suggested that administrators' assumptions about teaching and mathematics instruction influence what they notice and how they evaluate mathematics lessons. The enactment of routines becomes more complicated if one assumes a distributed perspective, that is if one assumes that human activity is not simply a function of individual skill and knowledge but is stretched over people and situations. 


\section{Routine enactment and social distribution}

A distributed perspective presses us to identify and explore the enactment of leadership routines and tasks as these are performed by multiple formal and informal leaders. Consistent with the research which suggests that school leadership reaches beyond those in formal leadership positions (Heller and Firestone 1995, Ogawa and Bossert 1995), a distributed view of leadership incorporates the activities of multiple individuals in a school. Thus, our distributed perspective focuses on how leadership practice is distributed among positional and informal leaders as well as their followers. Understanding how leaders in a school work together, as well as separately, to execute leadership functions and tasks is an important aspect of the social distribution of leadership practice.

We argue that the social distribution of leadership means more than acknowledging the division or duplication of labour - although that is an important aspect - in the enactment of leadership functions and tasks (Heller and Firestone 1995). A distributed perspective presses us to consider the enactment of leadership tasks as potentially stretched over the practice of two or more leaders and followers. Hence, the social distribution of leadership practice involves more than developing additive models that capture the 'amount' of leadership or that are inclusive of the work of all leaders in a school (Pounder et al. 1995). It also involves understanding how leadership practice is stretched over the work of various school leaders and exploring the practice generated in the interactions among these individuals. In this view, leadership practice might be 'in-between' (Salomon and Perkins 1998) the practice of two or more leaders. From a distributed perspective, a multiplicative rather than additive model is most appropriate because the interactions among two or more leaders in carrying out a particular routine or task may amount to more than the sum of those leaders' practice.

In other words, we argue that leadership activity is constituted in the interaction of multiple leaders (and followers) using particular tools and artefacts around particular leadership tasks. In this scheme, what is critical are the interdependencies among the constituting elements - leaders, followers, and situation - of leadership activity.

One way of understanding interdependencies in leaders' practices would centre on the ways in which two or more leaders jointly enact school-leadership practice. For example, in one of our schools, Carson, a core organizational routine involves using standardized test scores and a breakdown of student performance in particular skill areas to focus instructional improvement efforts on specific student learning needs. This strategy involves a number of interdependent tasks and actors, each building on resources produced through the completion of prior tasks. First, the tests must be administered to students, requiring scheduling and co-ordination. Second, the test results must be received, analysed, and interpreted by school personnel. Third, based on this analysis, instructional priorities must be identified and disseminated, and their implementation monitored throughout the school. And, finally, classroom 
teachers must participate in professional development and implement the instructional changes in classrooms.

This example illuminates how leadership practice is distributed across people while adding a temporal dimension to jointly enacted leadership routines. Taking into account the multiple tasks involved in this routine of using student test scores to lead instructional improvement at Carson, we observe an interdependency among various tasks. In this case, one leadership task - determining instructional priorities - depends upon the completion of another task - interpreting student results. The vignette illuminates how the enactment of certain leadership tasks depends upon resources generated from prior tasks.

A second sort of distribution across leaders occurs when a routine involves two or more tasks that are performed separately by two leaders. At Ellis school, the principal and assistant principal work separately but interdependently on the routine of evaluating instruction. The assistant principal, who maintains a friendly and supportive relationship with teachers, visits classrooms frequently and engages in formative evaluation by providing regular feedback to teachers on instructional issues. The principal, on the other hand, functions more as an authority figure and engages in summative evaluation. She visits the classrooms once or twice a year and makes final determinations on the quality of teachers' instructional practices. The assistant principal shares his learning with the principal, and the two use their collective observations to develop an understanding of teachers' instructional practices. In other words, the routine of evaluating instruction involves two actors who work separately on two separate tasks; however, their work is interdependent in producing the teacher evaluation routine at Ellis. Moreover, sharing a common goal of improved instruction, their work is co-ordinated as they communicate with each other. While some observers might see the practice of these two leaders as independent, one can only understand evaluation routine at this school by factoring in the practices around the two tasks. The assistant principal's practice only makes sense when considered in relation to the principal's practice. And, while some might view this practice as a division of labour, we argue that these leaders are not engaged in discrete tasks but that leadership activity, the practice of evaluating instruction in this case, is stretched over their work.

Finally, interdependency emerges when the enactment of a leadership routine depends on the interplay between two or more actors (and, as discussed below, two or more aspects of the situation). Consider the following example. At monthly planning meetings, the mathematics co-ordinator, fourth-grade lead-teacher, and the assistant principal were working together to co-ordinate the work of a curriculum committee made up of the teachers from each grade level who were redesigning the elementary school mathematics curriculum for the following academic year. The mathematics co-ordinator, with a master's degree in mathematics, was recognized by her colleagues for her knowledge of mathematics. The assistant principal had a keen understanding of state and district curriculum standards and accountability measures, especially the learning priorities established by the mandated state and local district standardized tests. 
The fourth-grade lead-teacher, who recently completed a master's degree in curriculum and instruction, had a keen interest in and knowledge of mathematics pedagogy.

The practice of facilitating the curriculum committee routine was constituted in the interaction of these three leaders, the teachers, and the material artefacts they used. For example, at one meeting, the assistant principal argued that fourth-grade teachers should teach multiplication of fractions in the fall semester, so that the students could have a mastery of that skill for the standardized test given in February. The mathematics co-ordinator noted that this would only work if the children had already mastered multiplication facts and multiplication situations (word-problems) and developed a working understanding of fractions. She pointed out that these are prerequisites for understanding multiplication of fractions and gave the group a few examples to indicate why these topics are important. At this point, the fourth-grade lead-teacher interjected, arguing that all of these topics cannot be covered prior to the winter break. Hence, it would not be possible to cover multiplication of fractions by February. Most of the teachers agreed, and marshalled considerable evidence to support the lead-teacher.

Initially, the assistant principal insisted that multiplication of fractions must be covered. She suggested that either the bare essentials could at least be covered in all four pre-requisite areas or, alternatively, perhaps they could skim over the pre-requisite concepts. The mathematics co-ordinator reminded her that some of the questions in the 'new' format for the mandated tests require students to explain their answers, and that this would be difficult for students if they did not have a firm grasp of the key mathematical principles involved in these topics. Memorizing procedural knowledge alone would not serve. As the conversation proceeded, the group decided to teach the meaning of fractions and multiplication facts in the spring semester of the third grade, so that students would be better prepared when they reach fourth grade to take up multiplication of fractions.

In this example, leadership practice was constituted in the interaction among these three leaders, the teachers, and the material artefacts. There was also a reciprocal relationship between the practice of these leaders. Each required input from the others to facilitate the activity. In such reciprocal interdependencies, individuals play off one another, with the practice of person A enabling the practice of person B, and vice versa. Hence, what A does can only be fully understood by taking into account what B does, and vice versa. Such collective leading depends on multiple leaders working together, each bringing somewhat different resources - skills, knowledge, perspectives - to bear. Of course, individuals can also work together in place and time, but work toward different, or even conflicting goals. Leaders don't have to see eye-to-eye to lead a routine (Spillane 2006).

In the scenario described above, the group (or the group of individuals) performing the routine had cognitive properties that exceeded those of any one member - 'the cognitive properties of groups are produced by an interaction 


\section{Spillane et al.}

between structures internal to individuals and structures external to individuals' (Hutchins 1990: 306). We contend, in other words, that the collective cognitive properties of a group of leaders working together to enact a particular task leads to the evolution of a leadership practice that is potentially more than the sum of each individual's practice. Consequently, to understand the knowledge needed for leadership practice in such situations, one has to move beyond an analysis of individual knowledge and consider what these leaders know and do together. Depending on the particular leadership task, the knowledge and expertise of school leaders may be best explored at the group or collective level rather than at the individual leader level.

A final aspect of the social distribution of leadership practice concerns the ways in which a leader's practice is distributed among leaders and followers. Previous work underscores the relational nature of leadership, suggesting that leaders not only influence followers, but are also influenced by them (Dahl 1961, Hollander 1978, Cuban 1988). As Barnard (1938: 163) put it, 'Whether an order has authority or not lies with the persons to whom it is addressed'. The emphasis here is on the development of a negotiated order between leaders and followers: leaders are dependent on the followers they lead (Smylie and Hart 1999). Research in micro-politics suggests that, while leaders can often draw on their positional authority to support the beliefs and actions they advocate, followers can influence leaders by drawing on personal characteristics, access to information, or special knowledge or expertise (Bacharach and Lawler 1980). Finally, followers may influence leadership strategies by finding subtle ways to resist administrative controls through 'creative insubordination' (Crowson and Morris 1985, Blasé and Anderson 1995).

A socially-distributed perspective on leadership practice extends these arguments by suggesting that the role of followers in leadership practice involves more than influencing the actions taken by formal leaders or the effects of formal leadership. From a distributed perspective, followers are an essential constituting element of leadership practice. Rather than a variable outside of leadership practice that influences what leaders do or mediates the impact of what they do, followers are best understood as a composing element of leadership practice.

Consider an example. An assistant principal and lead reading teacher were working to foster reflective dialogue among the fifth-grade teachers in their school using the 'Writer's Workshop', which the fifth-grade teachers had been using for a semester. To facilitate the dialogue that they sought, the teachers' accounts of their enactment of the Writer's Workshop, as well as some of the stories fifth-graders composed in the programme, became the focal points of biweekly meetings convened by the assistant principal and lead-teacher to promote the teachers' reflection about reading instruction. The followers in this situation - the teachers - in interaction with the two leaders and a variety of artefacts, contributed to defining the leadership practice through the accounts of practice they shared and their discussion of these accounts. 


\section{Routine enactment and situational distribution}

In our view, leadership practice is situated. Acknowledging the mutuality of the individual and the environment, the distributed view underscores that activity is distributed in the interactive web of actors, artefacts, and situation.

Prior research has established the importance of situation to leadership arrangements in organizations. Contingency theorists argue that the most effective or appropriate organizational structure depends on the nature of the work, i.e. the technology, being undertaken by the organization and the environmental demands the organization has to negotiate (Fiedler 1973, Lawrence and Lorch 1986). Aspects of the situation, including the complexity and uncertainty of the work performed by the organization, its size, and the complexity of its environment, influence an organization's structural arrangements and performance (Scott 1995).

Work on schools illuminates how the circumstances of leadership influence what leaders do as well as the effects of what they do on followers (Bossert et al. 1982, Murphy 1991). For example, the clarity and complexity of the instructional technology influences the extent to which school administrators coordinate and control the work of teachers (Cohen and Miller 1980). Other situational variables, including district-office support, e.g. provision of resources and technical assistance and priorities, staff composition, e.g. age, educational level, stability, and the school's social or community context, e.g. SES of parents, have also been examined (Dwyer et al. 1983). Such work finds, for example, that, in order to lead effectively, leaders must adapt their behaviours to the characteristics of their staff. Schools with more mature and stable staff are likely to have principals with more indirect leadership styles compared with schools with younger and less stable staff (Dwyer et al. 1983). However, while we agree that such aspects of the situation are important in studies of school leadership and its effects, our treatment of situation differs in a number of respects.

Thus, our approach to situation differs from contingency theorists in at least four ways - the positioning of situation vis-à-vis leadership activity, the relations between situation and leadership, the aspects of the situation that are critical, and the aspects of leadership that merit attention. In contingency theory, situation or context is treated chiefly as something that is outside and working independently or interdependently to influence leadership activity. Aspects of the situation are treated as independent or interdependent variables that shape leadership behaviour and/or mediate the effects of leadership on teachers or other organizational members. For example, Hallinger and Murphy (1987: 182) talk about situation (no doubt reflecting the state of the literature) as creating 'a context within which principals act' and 'its influence on the actions of school leaders'. In other words, situation, as manifested in organizational size and staff characteristics among other factors, is treated as something impacting leadership practice from outside the practice. However, in keeping with activity theory and distributed cognition, our distributed perspective argues that 


\section{Spillane et al.}

situation is not external to leadership activity, but is one of its core constituting elements (see Figure 8.1).

As indicated above, studies within activity theory and situated cognition contend that situational elements are constitutive of human practice, and thus highlight how difficult it is to separate the capacity for action from the context of action (Pea 1993). Situation or context does not simply 'affect' what school leaders do as some sort of independent or interdependent variable(s); it is constitutive of leadership practice. Because situations offer particulars - e.g. tools of various kinds, organizational structures, and language - that are part and parcel of leadership practice, as these particulars vary, so too will the how of leadership practice. In other words, we mean by 'situated' that leadership activity is, to varying degrees, distributed or stretched over various facets of the situation, including tools, language, and organizational structure. Situation is part of practice and works to influence leadership activity from within the activity.

A second distinction concerns the somewhat deterministic treatment of social structure in contingency theory. Contingency theorists tend to view structure as a determining rather than constraining, or indeed enabling, human activity (Child 1972, Pfeffer 1981). Our distributed perspective, as we will elaborate below, suggests that aspects of the situation enable or constrain leadership activity, while that activity can also transform aspects of the situation over time. As argued earlier, situation is both constitutive of and constituted in leadership activity.

A third distinction we draw concerns the aspects of the situation that are important in investigating leadership activity. While we agree with contingency theorists that aspects of the situation, such as staff size and stability, environmental complexity, and task-complexity and task-certainty, are important, other aspects of the situation are also especially critical in studying leadership practice. Specifically, in our framework the symbols, tools, and other designed artefacts that are part and parcel of day-to-day leadership practice, and mostly taken-forgranted, are integral to investigations of leadership activity. Further, by 'structure' we mean not only organizational structures (Ranson et al. 1980) but also broader societal structures, including race, class, and gender (Abolafia and Kilduff 1988, Filby and Willmott 1988), and the manner in which these manifest themselves in interactions among leaders and followers in the execution of leadership tasks.

Finally, while contingency theory tends to focus chiefly on the effects of situation on broad leadership styles and organizational forms, we are concerned with day-to-day leadership activity, not just broad styles of leadership or organizational structures and roles.

Thus, by situation, we mean the socio-cultural context (including artefacts) that can embody the stable practices - the 'crystallized operations' (Leont'ev 1981) or the 'reifications of practices' (Wenger 1998) - in work such as leadership. It is important to keep in mind that these stable practices are inventions, and frequently they wear out, and are re-designed or reinvented over time. As integral constituting elements of human activity, artefacts of various sorts are 
not just sources of ideas and guidance for action but vehicles of thought (Perkins 1993). Hence, the introduction of new tools or artefacts does not merely make the work of leaders more efficient, but can transform the nature of the leadership activity.

The challenge for a distributed leadership framework is to identify those aspects of the situation that are critical in constituting leadership practice. We have already brought to the fore the tasks of leadership as the thread that winds through leadership practice. Here, we turn to some of the significant aspects of the socio-cultural context that are constitutive of that practice. To develop this point, we consider some aspects of the situation, emphasizing the structural context of leadership as mediational means (Wertsch 1991) that serve both as the medium and outcome of human action (Giddens 1979). To illuminate these ideas, we then consider how leadership practice might be spread out across three dimensions of the situation: designed artefacts, language, and organizational structure.

Our conception of situation draws heavily on the work of Giddens (1979, 1984), Wertsch (1991), and Swidler (1986). We argue that leadership practice cannot be extracted from its socio-cultural context - that it is situated in cultural, historical, and institutional settings (Wertsch 1991).

Drawing from Giddens (1979: 66), we distinguish between structure, the rules and resources that provide the medium and outcome of social action, and system, the 'reproduced relations between social actors or collectives organized as regular social practices'. 'System' refers to the social institutions, like work, family, school, or other constellations that we recognize as having some level of stability and regularized patterns of social interaction. 'Structure', on the other hand, represents the properties of social systems that enable and constrain social action. So, for example, within a school (i.e. a social system) the organization of grade levels (i.e. a structure) shapes social interaction, while language provides a medium of action in this social system as a structural property constitutive of human action in schools. Our use of structure as the medium of human interaction in social systems is similar to Wertsch's (1991) conception of the 'mediational means' which he argues enable and shape human action in important ways. To understand human activity, we must investigate individuals 'acting in conjunction with mediational means' (Wertsch 1991: 33). In other words, our framework includes structure, or the rules and resources that are the medium and outcome of social relations within social systems, and system, which refers to reproduced relations between social actors.

We have argued above that human agency is embedded in the situation. We need, therefore, to illuminate how we see structure and agency interacting in the construction of leadership practice. While we assign a central role to structure, we are not advancing a structural-determinist argument where all 'agency' is ultimately predicted by the structure in which it is embedded (Althusser 1971). Structure is both constitutive and constituted: the structural properties of social systems can be conceptualized as a 'tool-kit' of rules and resources that may facilitate action. Here, we borrow from Swidler (1986), who 
argues that culture provides a tool-kit through which social actors deploy strategies of action. These strategies are informed by the repertoires of skills and resources to which people have access. We argue that structures, as mediational means, provide a basis for action from which people pick and choose in an effort to accomplish desired ends. Thus, we avoid structural determinism while recognizing how structure is constitutive of human action.

It is also important to note that we recognize the unequal distribution of resources and the differential implications of rules for different social actors. For example, organizational arrangements that inhibit communication among teachers might constrain leadership practice for instructional innovation. Likewise, adversarial relationships between home and school might work against home-school collaboration and undermine instructional innovation.

Having considered the conceptual issues with respect to relations between situation and leadership activity, we now explore how leadership practice might be stretched over its situation or context. Specifically, we want to illuminate the ways in which the situation might be constitutive of day-to-day leadership practice. We consider how leadership practice might be distributed across the dimensions of the situation, including designed artefacts and organizational arrangements. While other dimensions of the situation may also be important, a consideration of these two will enable us to articulate in more specific ways what we mean when we argue that the situation of leadership practice is constitutive of that practice.

\section{Designed artefacts}

Designed artefacts are constitutive of leadership practice. Leadership practice is situated in an environment composed of artefacts that represent, in reified forms, the achievements and problem-solving initiatives of previous human action. We use the term 'artefacts' here to refer to externalized representations of ideas and intentions that are constitutive of leadership practice. A leader's thinking and practice is mediated by these artefacts: they serve as constituting components of leadership practice, not simply as devices or means that allow individuals to do what they want to do. However, while artefacts form tangible features of the school environment, the ways in which they are utilized also depend upon the agency of social actors and the situation in which they are introduced. In other words, artefacts are constitutive of and constituted in human activity.

Leaders do not work directly on the world; their actions in and on the world are mediated by a continuum of artefacts (Wertsch 1991). At one end of the continuum are tools, ranging from material artefacts such as memos, meeting agendas, computer programs for analysing test data, and district policies (e.g. teacher evaluation protocols) to such more abstract artefacts as the temporal arrangements of the workday. These artefacts represent identifiable created or emergent entities or routines that both define and are re-defined by leadership practice. At the other end are symbols, that is language-based systems, rhetorical strategies, and vocabularies, that constitute artefacts that are difficult to pin 
down in both their origins and specific effects but are pervasive in their cumulative defining of practice.

Both tools and symbols are kinds of artefacts, that is, created entities either designed by individuals or gradually defined by multiple audiences in order to enable particular practices. A distributed perspective on leadership seeks both to articulate the range of these artefacts as they constitute leadership practice, and to characterize the ways in which such artefacts define and are defined by leadership activity. On one end of the continuum, designed material artefacts such as forms, memos, and agendas constitute the material context in which schoolwork is done.

Forms, as designed artefacts, serve as mediational means for leadership activity. Investigating leadership practice involves understanding leaders' practice as both enabled and constrained by forms of various sorts. Consider, for example, the practice of teacher evaluation. Many school systems in the US mandate that school leaders use particular forms when undertaking summative evaluations of teaching practice. Understanding the practice of teacher evaluation involves exploring the mediational properties of these evaluation protocols, that is how these forms are constitutive of leadership activity.

If we consider two very different evaluation protocols, the importance of the tool in understanding leadership practice will be further illuminated. Imagine protocol A, consisting of a checklist of generic teaching processes, including items such as wait-time and teachers' use of praise, of the sort identified by the process-product research tradition. In contrast, protocol B is subject-matter specific, including, for example, such items for mathematics teaching as 'how the classroom task represented "doing mathematics"', and 'how students were required to justify their mathematical ideas'. These different forms draw the observers' attention toward different aspects of the teaching situation, thereby resulting in potentially different kinds of observation practice. Leaders may negotiate with forms in order to identify the aspects of practice they see fit to note, but the point still remains that the forms act as a defining element of the observation practice. The form or protocol is not simply an accessory or aid that the leader uses to execute the evaluation task in an a priori manner. Further, because evaluation tools represent teaching and what it means to be competent in teaching in different ways (as our two hypothetical examples illuminate), changing the protocol may contribute to changes in the practice of evaluating teaching.

Memos represent artefacts designed to address particular issues of communication in schools. The subjects of memos can range from information dissemination to individualized messages regarding specific events in the school. For example, some leaders use informal, hand-written memos to congratulate faculty members on work well done, to offer reminders about following through on responsibilities, or to check in on relationships. Others use memos in lieu of faculty gatherings to make sure that the school community is up to date on current events. Such memos can convey a message of encouragement, interest, or surveillance, and are often regarded by both parties as a 


\section{Spillane et al.}

non-threatening means of communication. However, when problems about instruction, compliance, or conduct escalate, more formal memos serve notice that binding communication procedures have been initiated. These formal memos can establish conditions of firing or instances of discrimination, and are often written with an eye toward the legal weight that they may have to shoulder. However, especially in the latter case, the nature of the formal memo is an intrinsic property of the disciplinary activity. The memo of reprimand, for example, replaces an often difficult face-to-face conversation between a leader and a teacher or staff member, serving as an extension of the leader's authority as well as a statement of administrative intent. These memos also serve as legal artefacts with the potential to represent the communication between the parties in the event of a claim by either party. Memos, then, are artefacts that not only convey messages within the school, but their form represents a crucial tool that contributes to defining leadership practice. The practice of leadership in these situations is best understood by viewing the memo as a constitutive element.

Finally, meeting agendas provide a good example to illustrate how material artefacts are constitutive of leadership activity, especially when it comes to determining the legitimate issues of discussion (and contention) in the school. Thus, one important constituting element of leadership practice is the meeting agenda, and because of its power for shaping meeting conversation agendasetting is an influential tool available to leaders.

Thus, the use of agendas varies both within and across leadership activity. In some activities, agendas become powerful formal artefacts to collaboratively shape the instructional agenda of the school, while in other activities the agenda emerges with the issues currently faced by the school community. For example, consider the differences in agenda-setting by the same leadership team for different occasions. At a preliminary planning-session meeting, the leadership team purposely constructs and distributes an under-specified agenda in the interest of communicating to participants that their contributions will be an integral aspect of the meeting time. On the other hand, when calling a meeting to outline the results of its planning process, the agenda is presented as a highly structured artefact intended to inform the audience while inviting little comment. In both cases, the agenda is a constituting element of the leadership activity. Similarly, a request for an agenda on the part of faculty and staff-members could indicate a need to clarify why valuable time is being spent on faculty meeting issues. At Ellis school, the agenda for the professional development sessions held through the next school year are collaboratively developed among leaders and teachers every spring, and are firmly connected to the instructional agenda of the school improvement plan. Agenda-setting and agenda-distribution are, thus, seen as a key artefact through which leadership actions are distributed throughout a school community. Such practices, enabled by the agenda artefacts themselves, communicate a strong sense of instructional direction to the school community and beyond. Examining the use of meeting agenda, or planning agenda more broadly, provides an artefact through which the practice of leadership becomes clearer. 
Designed artefacts, however, are not limited to tangible, at-hand material items. More abstract artefacts such as the schedule of the school day and yearly calendars establish the 'hidden rhythms' of school life (Zerubavel 1981). These artefacts collectively form representational schemata within which time-usage and action in the school are structured. Yearly school calendars and faculty schedules shape the space and temporal resources available to the costly and time-consuming process of changing teaching.

District and school policies, learning technologies, and the school plant itself also represent key artefacts that contribute to defining leadership activity. Many of these artefacts are experienced as 'givens' by school leaders, as constraints that afford little opportunity for agency. And, in fact, designed artefacts, such as district policies, often do not bear the imprint of local actors and, while designed, are received in the context of schools as constraints on practice. However, the consideration of how leadership activity is constitutive of and constituted by artefacts can highlight the interactive nature of the use of designed artefacts in schools. For example, many school leaders in the US feel that their district's yearly schedule constrains the range and depth of professional development opportunities that can be offered to teachers. They feel that district-mandated hours and times for professional development limit the possibilities for creative leadership in the school. However, other leaders see these same constraints as opportunities for collaborative staff negotiations about how this time should be, or might better be, spent. Leaders who construct meaningful incentive systems to exploit the time set aside for district-mandated development can create, over time, a professional community of practice within the school.

These contrasting stories illustrate both how artefacts constitute leadership practice in schools and how they are constituted by that same practice when they are taken as an opportunity to work on building a professional community. Considering the artefacts apart from practice may allow us insight into the intentions of the artefact designers, but considering the artefacts as they enable and constrain leadership practice provides a lens into leadership as a distributed practice in schools.

\section{Organizational structure}

In a way that is similar to the use of designed artefacts, leadership practice is also stretched over organizational structures. A distributed perspective presses us to consider organizational structures as more than vessels for leadership activity, and more than accessories that leaders can use to execute a particular task using some pre-determined strategy or practice. For example, the prevailing 'egg-carton' organization of schools isolates teachers in their classrooms, providing them with few opportunities to discuss instructional issues with peers (Lortie 1975). Such individualized and privatized arrangements for teachers' work can inhibit the dissemination of ideas about professional practice among teachers in schools. However, these organizational arrangements are 
constitutive of leadership practice, not simply hurdles external to that practice that leaders must overcome in order to enact a particular task using some predetermined practice. In other words, the 'egg-carton' school structure is an essential constraint in the composition of leadership practice, fundamentally shaping how school leaders enact their tasks. Likewise, research from the institutional perspective informs us that schools 'decouple' formal structure, e.g. administration and management, from core activities, e.g. teaching (Weick 1976). Minimizing inspection of the uncertain core activities of schooling enables schools to maintain the confidence of their external constituents (Meyer and Rowan 1978).

In proposing that organizational structures are constitutive of leadership practice we are not arguing that they determine that practice. School leaders are another constituting element. They notice, apprehend, and use organizational structures in a variety of ways. Thus, while organizational structures are constitutive to the activity of school leaders, it is also the case that these structures are created and recreated by the actions of leaders and others who work in schools. For example, in one of the elementary schools in our study, which had been characterized by limited dialogue among teachers and mostly privatized classroom practice, the principal established breakfast meetings in order to create a forum for teachers to exchange ideas about their instructional practices. According to the staff at this school, over time this opportunity for dialogue contributed to breaking down the school's 'egg-carton' structure, creating new structures that supported peer-communication and information-sharing, arrangements that in turn contributed to defining their leadership practice.

In other words, leadership practice is extended through organizational structures that enable the movement and generation of knowledge and incentives in the organization. In this case, the leader's practice both redefined and was defined by organizational structure. Research on schools as professional communities illuminates how alternative organizational arrangements can provide forums for teacher conversations and contribute to de-privatizing practice (Louis and Kruse 1995). From a distributed perspective, what is paramount is understanding the extent to which, and how, organizational arrangements are constitutive of leadership practice, not simply ancillary.

In summary, mediational means, while shaping human action, are also reshaped through human activity. A tool is, to some extent, a bundle of dispositions or potentials that shape leadership practice under certain circumstances, but that can also be reshaped by that practice.

\section{Discussion and conclusion}

We have developed a perspective on the practice of school leadership that centres on the how and why of leadership practice. We contend that, to understand leadership practice, it is essential to go beyond a consideration of the roles, strategies, and traits of the individuals who occupy formal leadership positions to investigate how the practice of leadership is stretched over leaders, fol- 
lowers, and the material and symbolic artefacts in the situation. The situation of leaders' practice, material artefacts, tools, language, etc., is not simply an appendage but, rather, a defining element of that practice. Leadership practice (as both thinking and activity) emerges in the execution of leadership tasks in and through the interaction of leaders, followers, and situation.

The distributed leadership perspective has implications for research on school leadership and efforts to improve the practice of leadership. Thus, the framework provides some important leverage with respect to empirical research on leadership. First, it offers theoretical grounding for studying day-to-day leadership practice, enabling investigations of practice to go beyond documenting lists of strategies that leaders use in their work. In other words, it frames inquiry into leadership activity in ways that move beyond leaders' and teachers' accounts to develop more integrative understandings of leadership as a practice. Second, it suggests that leadership activity at the level of the school, rather than at the level of an individual leader or small group of leaders, is the appropriate unit of analysis in studying leadership practice. To study leadership practice, we need to study leaders in interaction with others and their situation. Focusing either exclusively on one or more formal leaders, or on teacher-leaders, is unlikely to generate robust insights into school leadership practice.

Third, our distributed frame also specifies an integrative model for thinking about the relations between the work of leaders and their social, material, and symbolic situation, one in which situation is a defining element in leadership practice. For example, one consequence of treating situations in this way is that the tools leaders use become central in the study of leadership practice. Forms, curricular documents, tools for representing test-score data, and other material artefacts have rarely received systematic and in-depth attention in studies of leadership. We contend that systematic attention to these artefacts is essential in studying leadership practice.

Fourth, our distributed perspective suggests the need for a wider array of approaches to studying the expertise of leaders. From a distributed perspective, expertise is not simply a function of a leader's thinking and mental schemata. Viewing skill and expertise exclusively as a function of individual traits, styles, and schemata obscures how what leaders do is a function of their situation. A 'person-plus', as distinct from a 'person-solo' perspective (Perkins 1993), is necessary in order to understand leadership expertise as something extending beyond the mind of individual leaders. Studies of leadership expertise must also investigate how, and the extent to which, the expertise essential for the execution of particular leadership tasks is stretched over different leaders as well as over the tools with which they work. In other words, investigating purposeful activity in its 'natural habitat' is important to understanding leadership expertise. Of course this is not meant to suggest that studying how leaders think is irrelevant. We do not mean to suggest that the distributed perspective developed here offers the only fruitful frame for a study of leadership practice, 
though we are convinced it offers substantial theoretical leverage in studying leadership activity.

We believe that a distributed leadership perspective, and the knowledge generated from empirical studies within that framework, can give insights and leverage on the improvement of school leadership. It offers a new meta-lens for thinking about a familiar activity - leadership practice - by mobilizing a language and a set of analytical tools for reflecting on that activity. Understanding the distributed practice of school leadership will help to build legitimate stories of practice, grounded in the interaction of people and contexts in school environments - and that will be recognizable to practitioners as evocative sounding boards for their own work. By providing a frame that helps researchers build cases for practitioners to interpret and think about in their on-going leadership practice, the distributed perspective offers a tool to help researchers and practitioners to change that activity. For example, cases of how leadership is stretched over individuals in schools in a variety of ways that vary depending on the particular leadership tasks and situations might help leaders to think about the enactment of leadership tasks in new ways. Similarly, thinking about material artefacts as critical elements of leadership practice might press school leaders to consider the tools they use, and how these tools both enable and constrain their practice.

The distributed perspective also suggests some ways of thinking about intervening to change school-leadership practice. Rather than proposing to develop, articulate, and disseminate a context-neutral, task-generic template outlining the moves that leaders should make, it argues for the development of rich theoretical knowledge based on studies of practice that are contextsensitive and task-specific. We believe that such knowledge can be useful in helping leaders reflect on their practice and conceptualize their work in realistically-complex ways. By making the 'black box' of school-leadership practice more transparent through the generation of rich knowledge about how leaders think and act to change instruction, a distributed perspective can help leaders identify the dimensions of their practice, articulate the relations among these dimensions, and think about changing their practice. Further, the distributed perspective also suggests that intervening to improve school leadership by focusing exclusively or chiefly on building the knowledge of an individual formal leader in a school may not be the optimal, or the most effective, use of resources. If expertise is distributed, then the school rather than the individual leader may be the most appropriate unit for thinking about the development of leadership expertise. In addition, reformers might also think about how the tools they design represent expertise for leadership, enabling or constraining leadership activity.

In Sense-making in Organizations, Weick (1995) claims that 'it takes a complex sensing-device to register and regulate a complex object'. We propose the distributed leadership framework as a sensing-device for registering the complex practice of school leadership. If theory is to be more influential in guiding leadership practice, it will need to provide a frame, informed by practice, that helps leaders interpret and reflect on their day-to-day practice. The 
distributed leadership perspective promises to establish a rich knowledge-base upon which we can build such a theoretical frame.

\section{Acknowledgements}

The writing of this chapter was supported by the 'Distributed leadership project', funded by research grants from the US National Science Foundation (REC-9873583) and the Spencer Foundation (200000039). Northwestern University's School of Education and Social Policy and Institute for Policy Research also supported work on the chapter. All opinions and conclusions expressed herein are those of the authors and do not necessarily reflect the views of any funding agency.

\section{Notes}

1 The lack of attention to work-practices on the part of scholars is not unique to education. Wellman (1995; cited in Suchman 1995) sums the situation up aptly when he noted that 'how people work is one of the best-kept secrets in America'. Wellman goes on to argue that 'the way in which people work is not always apparent. Too often, assumptions are made as to how tasks are performed rather than unearthing the underlying work practices'. Some scholars of business management and organizations have also noted this inattention to the activity of leadership (Tucker 1981, Eccles et al. 1992, Heifetz 1994). Eccles et al. (1992: 13) argue that an 'action perspective sees the reality of management as a matter of actions and processes'. They encourage an approach to studying leadership that centres on action rather than exclusively on structures, states, and designs.

2 We view 'distributed' and 'stretched' as complementary terms. 'Stretched over' provides a more visual representation of what we mean by 'distributed'.

3 All names of schools and people used in this chapter are pseudonyms.

\section{References}

Abolafia, M.Y. and Kilduff, M. (1988) 'Enacting market crisis: the social construction of a speculative bubble', Administrative Science Quarterly, 33 (2), 177-93.

Althusser, L. (1971) Lenin and Philosophy and Other Essays, trans B. Brewster (London: New Left Books).

Argyris, C. and Schön, D.A. (1974) Theory in Practice: Increasing Professional Effectiveness (San Francisco, CA: Jossey-Bass).

Bacharach, S.B. and Lawler, E.J. (1980) Power and Politics in Organizations: The Social Psychology of Conflicts, Coalitions and Bargaining (San Francisco, CA: Jossey-Bass).

Barnard, C. (1938) The Functions of the Executive (Cambridge, MA: Harvard University Press).

Bass, B.M. (1990) Bass and Stogdill's Handbook of Leadership: Theory, Research and Managerial Applications, 3rd edn (New York: Free Press).

Berger, P.L. and Luckmann, T. (1966) The Social Construction of Reality: A Treatise in the Sociology of Knowledge (New York: Doubleday).

Blasé, J.J. and Anderson, G.L. (1995) The Micropolitics of Educational Leadership: From Control to Empowerment (New York: Teachers College Press). 


\section{Spillane et al.}

Blasé, J.J. and Blasé, J.R. (1999) 'Principals' instructional leadership and teacher development: teachers' perspectives', Educational Administration Quarterly, 35 (3), 349-78.

Blasé, J.J. and Kirby, P.C. (1992) Bringing Out the Best in Teachers: What Effective Principals Do (Thousand Oaks, CA: Corwin Press).

Bolman, L.G. and Deal, T.E. (1991) Reframing Organizations: Artistry, Choice, and Leadership (San Francisco, CA: Jossey-Bass).

Bossert, S.T., Dwyer, D., Rowan, B., and Lee, G.V. (1982) 'The instructional management role of the principal', Educational Administration Quarterly, 18 (3), 34-63.

Brown, J.S. and Duguid, P. (1991) 'Organizational learning and communities-ofpractice: toward a unified view of working, learning, and innovation', Organizational Science, 2 (1), 40-57.

Bryk, A.S. and Driscoll, M.E. (1985) An empirical investigation of the school as community (Chicago: University of Chicago, Department of Education).

Burns, J.M. (1978) Leadership (New York: Harper \& Row).

Child, J. (1972) 'Organizational structure, environment, and performance: the role of strategic choice', Sociology, 6 (1), 1-22.

Cohen, E.G. and Miller, R.H. (1980) 'Coordination and control of instruction in schools', Pacific Sociological Review, 23 (4), 446-73.

Crowson, R.L. and Morris, V.C. (1985) 'Administrative control in large-city school systems: an investigation in Chicago', Education Administration Quarterly, 21 (4), 51-70.

Cuban, L. (1988) The Managerial Imperative and the Practice of Leadership in Schools (Albany, NY: State University of New York Press).

Cuban, L. (1993) 'Foreword', in P. Hallinger, K. Leithwood, and J. Murphy (eds), Cognitive Perspectives in Educational Leadership (New York: Teachers College Press), ix-xi.

Cyert, R.M. and March, J.G. (1963) A Behavioral Theory of the Firm (Englewood Cliffs, NJ: Prentice Hall).

Dahl, R.A. (1961) Who Governs? Democracy and Power in an American City (New Haven, CT: Yale University Press).

DiMaggio, P.J. (1988) 'Interest and agency in institutional theory', in L.G. Zucker (ed.), Institutional Patterns and Organizations: Culture and Environment (Cambridge, MA: Ballinger), 3-21.

Dwyer, D.C, Lee, G., Rowan, B., and Bossert, S. (1983) Five Principals in Action: Perspectives on Instructional Management (San Francisco, CA: Far West Laboratory for Educational Research), ERIC ED 231085.

Eccles, R.G., Nohria, N., and Berkeley, J.D. (1992) Beyond the Hype: Rediscovering the Essence of Management (Boston, MA: Harvard Business School Press).

Elmore, R.F., Peterson, P.L., and McCarthey, S.J. (1996) Restructuring in the Classroom: Teaching, Learning, and School Organization (San Francisco, CA: Jossey-Bass).

Fiedler, F.E. (1970) 'Leadership experience and leader performance: another hypothesis shot to hell', Organizational Behaviour and Human Performance, 5 (2), 1-14.

Fiedler, F.E. (1973) 'The contingency model: a reply to Ashour', Organizational Behavior and Human Decision Processses, 9 (3), 356-68.

Filby, I. and Willmott, H. (1988) 'Ideologies and contradictions in a public relations department: the seduction and impotence of living myth', Organization Studies, 9 (3), 335-49.

Firestone, W.A. (1989) 'Using reform: conceptualizing district initiative', Educational Evaluation and Policy Analysis, 11 (2), 151-65.

Firestone, W.A. (1996) 'Leadership roles or functions?' in K. Leithwood, J. Chapman, D. Corson, P. Hallinger, and A. Hart (eds), International Handbook of Educational 
Leadership and Administration, vol. 2 (Boston, MA: Kluwer Academic Publishers), 395-418.

Firestone, W.A. and Corbett, H.D. (1988) 'Planned organizational change', in N.J. Boyan (ed.), Handbook of Research on Educational Administration (New York: Longman), 321-40.

Gagliardi, P. (1990) Symbols and Artifacts: Views of the Corporate Landscape (New York: Aldine de Gruyter).

Galbraith, J.R. (1973) Designing Complex Organizations (Reading, MA: AddisonWesley).

Gardner, H. (1995) Leading Minds: An Anatomy of Leadership (New York: Basic Books).

Giddens, A. (1979) Central Problems in Social Theory: Action, Structure, and Contradiction in Social Analysis (Berkeley and Los Angeles: University of California Press).

Giddens, A. (1984) The Constitution of Society: Outline of the Theory of Structuration (Berkeley and Los Angeles: University of California Press).

Goldring, E.B. and Rallis, S.F. (1993) Principals of Dynamic Schools: Taking Charge of Change (Newbury Park, CA: Corwin).

Hallinger, P. and Hausman, C. (1993) 'From Attila the Hun to Mary had a little lamb: redefining principal roles in restructured schools', Paper presented at the Annual Meeting of the American Education Research Association, Atlanta, GA, ERIC ED 359647.

Hallinger, P. and Heck, R.H. (1996) 'Reassessing the principal's role in school effectiveness: a review of the empirical research', Educational Administration Quarterly, 32 (1), 27-31.

Hallinger, P. and Heck, R.H. (1998) 'Exploring the principal's contribution to school effectiveness: 1980-1995', School Effectiveness and School Improvement, 9 (2), 157-91.

Hallinger, P. and Murphy, J. (1987) 'Instructional leadership in the school context', in W. Greenfield (ed.), Instructional Leadership: Concepts, Issues, and Controversies (Boston, MA: Allyn and Bacon), 179-203.

Heck, R.H. and Hallinger, P. (1999) 'Next generation methods for the study of leadership and school improvement', in J. Murphy and K.S. Louis (eds), Handbook of Research on Educational Administration, 2nd edn (San Francisco, CA: Jossey-Bass), 141-62.

Heenan, D.A. and Bennis, W. (1999) Co-Leaders: The Power of Great Partnerships (New York: John Wiley \& Sons).

Heidegger, M. (1962) Being and Time, trans J. Macquarrie and E. Robinson (New York: Harper \& Row).

Heifetz, R.A. (1994) Leadership Without Easy Answers (Cambridge, MA: Bellknap Press). Heller, M.F. and Firestone, W.A. (1995) Who's in charge here? Sources of leadership for change in eight schools. Elementary School Journal, 96 (1), 65-86.

Hemphill, J.K. and Coons, A.E. (1950) Leader Behavior Description (Columbus, OH: Ohio State University, Personnel Research Board).

Hersey, P. and Blanchard, K.H. (1977) Management of Organizational Behavior: Utilizing Human Resources, 3rd edn (Englewood Cliffs, NJ: Prentice Hall).

Hollander, E.P. (1978) Leadership Dynamics: A Practical Guide to Effective Relationships (New York: Free Press).

Hutchins, E. (1990) 'The social organization of distributed cognition', in L.B. Resnick, J.M. Levine, and S.D. Teasley (eds), Perspectives on Socially Shared Cognition (Washington, DC: American Psychological Association), 283-307.

Hutchins, E. (1995a) 'How a cockpit remembers its speed', Cognitive Science, 19, $265-88$. 


\section{Spillane et al.}

Hutchins, E. (1995b) Cognition in the Wild (Cambridge, MA: MIT Press).

Katz, D. and Kahn, R.L. (1966) The Social Psychology of Organizations (New York: Wiley).

Kunz, D. and Hoy, W.K. (1976) 'Leadership style of principals and the professional zone of acceptance of teachers', Educational Administration Quarterly, 12 (3), 49-64.

Lambert, L., Walker, D., Zimmerman, D.P., Cooper, J.E., Lambert, M.D., Gardner, M., and Slack, P. (1995) The Constructivist Leader (New York: Teachers College Press).

Latour, B. (1987) Science in Action: How to Follow Scientists and Engineers Through Society (Philadelphia, PA: Open University Press).

Lave, J. (1991) 'Situating learning in communities of practice', in L.B. Resnick, J.M. Levine, and S.D. Teasley (eds), Perspectives on Socially Shared Cognition (Washington, DC: American Psychological Association), 63-82.

Lave, J. and Wenger, E. (1991) Situated Learning: Legitimate Peripheral Participation (New York: Cambridge University Press).

Lawrence, P.R. and Lorch, J.W. (1986) Organization and Environment: Managing Differentiation and Integration (Boston, MA: Harvard Business School Press).

Lee, G.V. (1987) 'Instructional leadership in a junior high school: managing realities and creating opportunities', in W. Greenfield (ed.), Instructional Leadership: Concepts, Issues and Controversies (Boston, MA: Allyn \& Bacon), 77-99.

Leithwood, K. (1994) 'Leadership for school restructuring', Educational Administration Quarterly, 30 (4), 498-515.

Leithwood, K. and Montgomery, D.J. (1982) 'The role of the elementary school principal in program improvement', Review of Educational Research, 52 (3), 309-39.

Leithwood, K. and Steinbach, R. (1990) 'Characteristics of effective secondary school principals' problem solving', Educational Administration and Foundations, 5 (1), $24-42$.

Leithwood, K. and Steinbach, R. (1995) Expert Problem Solving: Evidence from School and District Leaders (Albany, NY: State University of New York Press).

Leithwood, K., Begley, P.T., and Cousins, J.B. (1992) Developing Expert Leadership for Future Schools (London: Falmer Press).

Leithwood, K., Jantzi, D., Steinbach, R., and Ryan, S. (1997) 'Distributed leadership in secondary schools', Paper presented at the Annual Meeting of the American Educational Research Association, Chicago, IL, ERIC ED 407411.

Leont'ev, A.N. (1981) Problems of the Development of the Mind (Moscow: Progress Publishers).

Lewin, K., Lippitt, R., and White, R.K. (1939) 'Patterns of aggressive behavior in experimentally created "social climates", Journal of Social Psychology, 10, 271-99.

Likert, R. (1967) The Human Organization: Its Management and Value (New York: McGraw-Hill).

Little, J.W. and Bird, T. (1987) 'Instructional leadership "close to the classroom" in secondary schools', in W. Greenfield (ed.), Instructional Leadership: Concepts, Issues and Controversies (Boston, MA: Allyn \& Bacon), 118-38.

Lortie, D.C. (1975) Schoolteacher: A Sociological Study (Chicago: University of Chicago Press).

Louis, K.S. and Kruse, S.D. (1995) Professionalism and Community: Perspectives on Reform in Urban Schools (Thousand Oaks, CA: Corwin).

March, J.G. and Olsen, J. (1984) 'The new institutionalism: organizational factors in political life', American Political Science Review, 78 (3), 734-49.

Meyer, J.W. and Rowan, B. (1978) 'The structure of educational organizations', in M. 
Meyer and Associates (eds), Environments and Organizations: Theoretical and Empirical Perspectives (San Francisco, CA: Jossey-Bass), 78-109.

Mintzberg, H. (1973) The Nature of Managerial Work (New York: Harper \& Row).

Mouton, J.S. and Blake, R.B. (1984) Synergy: A New Strategy for Education, Training, and Development (San Francisco, CA: Jossey-Bass).

Murphy, J. (1991) Restructuring Schools: Capturing and Assessing the Phenomena (New York: Teachers College Press).

Nelson, B.S. (1999) Building New Knowledge by Thinking: How Administrators Can Learn What They Need to Know about Mathematics Education Reform (Newton, MA: Education Development Center, Center for the Development of Teaching), ERIC ED 431630.

Newman, F. and Wehlage, G.H. (1995) Successful School Restructuring: A Report to the Public and Educators by the Center on Organization and Restructuring of Schools. (Alexandria, VA: Association for Supervision and Curriculum Development; Reston, VA; National Association for Secondary School Principals).

Ogawa, R.T. and Bossert, S.T. (1995) 'Leadership as an organizational quality', Educational Administration Quarterly, 31 (2), 224-43.

Orr, J.E. (1996) Talking About Machines: An Ethnography of a Modern Job (Ithaca, NY: Cornell University Press).

Pea, R.D. (1993) 'Practices of distributed intelligence and designs for education', in G. Salomon (ed.), Distributed Cognition: Psychological and Educational Considerations (New York: Cambridge University Press), 47-87.

Perkins, D.N. (1993) 'Person-plus: a distributed view of thinking and learning', in G. Salomon (ed.), Distributed Cognition: Psychological and Educational Considerations (New York: Cambridge University Press), 88-110.

Peterson, K.D. (1977) 'The principal's tasks', Administrator Notebook, 26 (8), 1-4.

Pfeffer, J. (1977) 'The ambiguity of leadership', Academy of Management Review, 2 (1), 104-12.

Pfeffer, J. (1981) Power in Organizations (Marshfield, MA: Pitman).

Pickering, A. (ed.) (1992) Science as Practice and Culture (Chicago: University of Chicago Press).

Pitner, N.J. (1988) 'The study of administrator effects and effectiveness', in N.J. Boyan (ed.), Handbook of Research in Educational Administration (New York: Longman), 99-122.

Pounder, D.G., Ogawa, R.T., and Adams, E.A. (1995) 'Leadership as an organizationwide phenomena: its impact on school performance', Educational Administration Quarterly, 31 (4), 564-88.

Powell, W.W. and DiMaggio, P.J. (eds) (1991) The New Institutionalism in Organizational Analysis (Chicago: University of Chicago Press).

Purkey, S.C. and Smith, M.S. (1983) 'Effective schools: a review', Elementary School Journal, 83 (4), 427-52.

Ranson, S., Hinnings, B., and Greenwood, R. (1980) 'The structuring of organizational structures', Administrative Science Quarterly, 25 (1), 1-17.

Resnick, L.B. (1991) 'Shared cognition: thinking as social practice', in L.B. Resnick, J.M. Levine, and S.D. Teasley (eds), Perspectives on Socially Shared Cognition (Washington, DC: American Psychological Association), 1-22.

Rogoff, B.M. (1990) Apprenticeship in Thinking: Cognitive Development in Social Context (New York: Oxford University Press).

Rommetveit, R. (1980) 'On the meanings of acts and what is meant by what is said in a 


\section{Spillane et al.}

pluralistic social world', in M. Brenner (ed.), The Structure of Action (Oxford: Blackwell), 108-49.

Rosenholtz, S.J. (1989) Teachers' Workplace: The Social Organization of Schools (New York: Longman).

Rowan, B. and Miskel, C.G. (1999) 'Institutional theory and the study of educational organizations', in J. Murphy and K.S. Louis (eds), Handbook of Research on Educational Administration, 2nd edn (San Francisco, CA: Jossey-Bass), 359-84.

Salomon, G. (1993) 'No distribution without individual cognition: a distributed interactionist view', in G. Salomon (ed.), Distributed Cognition: Psychological and Educational Considerations (New York: Cambridge University Press), 111-38.

Salomon, G. and Perkins, D.N. (1998) 'Individual and social aspects of learning', in P.D. Pearson and A. Iran-Nejad (eds), Review of Research in Education, vol. 23 (Washington, DC: American Educational Research Association), 1-24.

Scott, W.R. (1995) Institutions and Organizations (Thousand Oaks, CA: Sage).

Sheppard, B. (1996) 'Exploring the transformational nature of instructional leadership', Alberta Journal of Educational Research, 42 (4), 325-44.

Simon, H.A. (1976) Administrative Behavior: A Study of Decision-making Processes in Administrative Organizations (New York: Macmillan).

Smylie, M.A. and Denny, J.W. (1990) 'Teacher leadership: tensions and ambiguities in organizational perspective', Educational Administration Quarterly, 26 (3), 235-59.

Smylie, M.A. and Hart, A.W. (1999) 'School leadership for teacher learning and change: a human and social capital development perspective', in J. Murphy and K.S. Louis (eds), Handbook of Educational Administration, 2nd edn (San Francisco, CA: JosseyBass), 421-42.

Spillane, J.P. (2006) Distributed Leadership (San Francisco, CA: Jossey-Bass).

Stogdill, R.M. (1948) 'Personal factors associated with leadership: a survey of the literature', Journal of Psychology, 25, 35-71.

Stogdill, R.M. (1950) 'Leadership, membership, and organization', Psychological Bulletin, 47 (1), 1-14.

Stogdill, R.M. (1974) Handbook of Leadership: A Survey of Theory and Research (New York: Free Press).

Suchman, L. (1995) 'Making work visible', Communications of the ACM, 38 (9), 56-64.

Swidler, A. (1986) 'Culture in action: symbols and strategies', American Sociological Review, 51 (2), 273-86.

Thompson, J.D. (1967) Organizations in Action: Social Science Bases of Administrative Theory (New York: McGraw-Hill).

Tucker, D.J. (1981) 'Voluntary auspices and the behavior of social service organizations', Social Science Review, 55 (3), 603-27.

Urbanski, A. and Nickolaou, M.B. (1997) 'Reflections on teachers as leaders', Educational Policy, 11 (2), 243-54.

Vygotsky, L.S. (1978) Mind in Society: The Development of Higher Psychological Processes (ed.) M. Cole (Cambridge, MA: Harvard University Press).

Weick, K.E. (1976) 'Educational organizations as loosely coupled systems', Administrative Science Quarterly, 21 (1), 1-19.

Weick, K.E. (1979) The Social Psychology of Organizing (Reading, MA: Addison-Wesley).

Weick, K.E. (1995) Sensemaking in Organizations (Thousand Oaks, CA: Sage Publications).

Weick, K.E. (1996) 'Fighting fires in educational administration', Educational Administration Quarterly, 32 (4), 565-78. 
Wenger, E. (1998) Communities of Practice: Learning, Meaning, and Identity (Cambridge: Cambridge University Press).

Wertsch, J.V. (1991) Voices of the Mind: A Sociocultural Approach to Mediated Action (Cambridge, MA: Harvard University Press).

White, R.K. and Lippitt, R. (1960) Autocracy and Democracy: An Experimental Inquiry (New York: Harper).

Whittington, R. (1992) 'Putting Giddens into action: social systems and managerial agency', Journal of Management Studies, 29 (6), 693-712.

Yukl, G.A. (1981) Leadership in Organizations (Englewood Cliffs, NJ: Prentice Hall).

Zerubavel, E. (1981) Hidden Rhythms: Schedules and Calendars in Social Life (Chicago: University of Chicago Press). 



\section{Part IV}

Thinking about futures 



\title{
9 Designing diversity Globalization, textbooks, and the story of nations
}

\author{
James Andrew LaSpina
}

\section{The mediated native, and where in the world is Parramatta?}

At the climax of the opening ceremony of the 2000 Olympic Games in Sydney, Australia, Cathy Freeman stood waiting. Surrounded by a ring of fire, Olympic torch in hand, she held it aloft with a global audience watching. Freeman, the young Aborigine woman athlete and national hero, was cast to represent all of Australia on the world stage. But something was amiss. The immense bowl now lit with the Olympic flame, which had been passed from nation to nation to Freeman, was not moving up the track to its final resting place high above the Olympic stadium in Parramatta, ${ }^{1}$ a suburb of Sydney. For several interminable minutes engineers struggled to get the huge dish moving as Freeman stood patiently waiting, torch still raised above her. A major embarrassment seemed to loom in the hushed air of the stadium. Finally, the flaming bowl she had lit lurched forward, rising above the crowd, reaching its destination. Fireworks ensued. The ceremony came to a dramatic conclusion fitting for such programmed events.

But that interminable pause, in which Freeman held her pose for nation, network, and the International Olympic Committee, could also serve as a symbolic snapshot illustrating the gap between the ideal image Freeman was intended to present and the more troublingly complex political reality for Australia's indigenous people, past and present. In attendance at the opening ceremony was Prime Minister John Howard. The Howard government, first elected in 1996, has been the bane of the Aboriginal rights movement in contemporary Australia. Like that nation, which is presently suspended, at least in public opinion, between a monarchy and a republic, Aborigines, with Howard's approval, have been suspended between token recognition ('reconciliation', as it is called in Australia) and substantial redress in the courts. Howard has been the prime mover of government policy away from the official multiculturalism of the last decades (referred to as the 'M' word), as he has from indigenous rights, calling for a return to an Anglo-British cultural mainstream, a twenty-firstcentury version of the 'White Australia policy', which was one of the cornerstones of the country's founding in 1901. For Howard, Aborigines like Freeman suit the public relations needs of the government, because, although 


\section{James Andrew LaSpina}

they may be activist, they do not openly challenge its policies. Their visibility is not of the 'black armband' sort, radically vocal urban Aborigines politically aligned with White activists, which Howard has often railed and fumed against. 'Black armband historians', 2 in Howard's mind, dredge up a past mainstream Australians would simply like to forget and, he would argue, are not responsible for in the present. One reason perhaps Freeman is so popular: light-skinned, urbane, and assimilated, a stellar world-class athlete, whose selfeffacing public persona tends to reflect an ideal present, her country at its best, unburdened by any troubling historical baggage. The paradox of such notoriety is that by being a highly visible, successful Aborigine in Australian society, her presence alone calls attention to the deeply problematic status of her people in that country.

Rather than look at late-twentieth-century gold-seeking (later in the Olympic Games Freeman won a gold medal), my focus here will be on the latenineteenth-century Pacific Rim region, and what one might describe as an earlier phase of globalization. The temporal coincidence of multiple gold rushes occurring during the closing decades of the nineteenth century in the USA, Canada, Australia, and New Zealand forms a common narrative thread to be used as the transnational setting and topical point of departure in this chapter. If the closing of the frontier in each country reflects a critical stage in national development, it was also imagined as a symbolic zone of encounter, where the indigenous presence would give way to civilization. How that contact and its denouement have been conceived of in contemporary school textbooks may be less a story recounted than a 'usable past', a textual past, fitted to that story of progress (Brooks 1968), one designed to reinforce a common national faith in 'progress', where even Freeman's indigenous presence might be put at the service of civilization - even carry its torch.

\section{Absent natives: the story of nations in California and Canada}

The red Indian in North America ..., the Tasmanian, Australian, and New Zealander in the southern hemisphere, die out, not from any one special cause, but from the inevitable effects of an unequal mental and physical struggle.

(Wallace 1891: 177)

In the spring of 1999 the California State Board of Education (CSBE) made public their recommendations of primary and secondary school history and social studies textbooks, which were in conformity with its California History-Social Science Framework [California Framework] (California Department of Education [CDE] 1987). That document, originally adopted by CSBE in July 1987 and re-affirmed with newly-added appendices in 1996 (CDE 1996), initiated one of the most controversial curriculum reforms of the past two decades, restoring history to the centre of the social studies curriculum 
(Gitlin 1995). It was also the first major attempt to define for the US textbook market what a multicultural history of the USA for schoolchildren should look like. The California Framework's vision of a national identity called for the recognition of the 'pluralistic and multicultural' nature of a society that stressed its 'special role in world history as a nation of immigrants' and their respective contributions to that nation (CDE 1987: 20-1). That alignment of multiculturalism with the ongoing process of nation-building by immigrants, always emphasizing the collective contribution their respective heritages made to this process, echoes the multicultural policies of the US neighbour to the north, Canada, as well as their antipodean cousins to the far south, Australia and New Zealand.

Following the California Framework's appearance, CSBE adopted a series of history textbooks that became equally controversial. Given the conservative nature of US textbook publishing in general, this new textbook programme was, like California, a trend-setter, the state being the second-largest textbook market, next to Texas, in the USA. California state law, which requires adoption only for K-8 instructional materials (grades 9-12 are at the discretion of local districts), asks that the textbook that publishers submit for adoption first be evaluated by state-appointed review panels and then by the public, before the CSBE votes on adoption. During these public reviews in 1990, this new K-8 textbook programme submitted by the Houghton Mifflin company came under attack by various racial, ethnic, and religious groups who found their representation in these books inadequate. Yet, despite these attacks, the textbooks were approved by CSBE in 1991 with minor editorial changes (Cornbleth and Waugh 1995).

In 1994, Houghton Mifflin published a revised edition, and in 1999 CSBE re-approved a new twenty-first-century edition (Armento 1994a, b, c, 1999a, b, c). Comparison of the first edition with the newly adopted versions is one way to look at how historical representation from a multicultural perspective has recently progressed. In 1999, CSBE also approved a number of other textbook programmes submitted by other educational publishers - and I will comment on several of these programmes. Part of the controversy surrounding the Houghton Mifflin series was that in 1991 it was the only textbook programme submitted for adoption which went on to be approved by CSBE.

During that first adoption, one of the more controversial multicultural hot spots that was changed in the revised 1994 edition centred on a small photograph found in the third-grade textbook, From Sea to Shining Sea (Armento 1991: 21). In the opening chapter of a special feature on the Grand Canyon, there appears an oval-shaped black-and-white photograph of a Native American and a bearded White man. In the first edition the caption identified the bearded man as John Wesley Powell (1834-1902), the first American to explore the Grand Canyon, but said nothing of the other presence in the picture (Grand Canyon National Park 2003). The more obvious connotations burdening this nameless Other escaped Houghton Mifflin editors until it was discovered by critics who opposed the adoption of the textbooks (LaSpina 1998). This 


\section{6}

omission was corrected in the 1994 revised edition (Armento 1994b). John Wesley Powell, it is noted, stands next to Tau-Gu, who was chief of a Paiute tribe, which lived along the Colorado River.

But apart from the addition of a name, the elliptical frame of this photograph suggests far more about the space indigenous peoples occupy in national history. The actual photograph taken during Powell's 1869 exploration of the Grand Canyon can be found in the archives of the Smithsonian Institution in Washington (Grand Canyon National Park 2003). Juxtaposing an $8 \times 11$ rectangular copy of the original image against a much-reduced $2 \times 1$ elliptical oval found in the Houghton Mifflin text is a highly suggestive exercise. Not only does it offer a reader a better sense of the actual space where the photograph was taken, but it also suggests a much larger story, far exceeding the cropped hole in time that Powell and Tau-Gu inhabit in this feature. Further commentary and another photograph of Powell can be found in the fifth-grade text, America Will Be (Armento 1994a), but in effect it merely expands upon the information of the controversial caption, with great emphasis placed upon the geological survey Powell was conducting for the federal government in the southwest USA, noting how he later went on to found the National Geographic Society.

However much heat multicultural critics expended over the omission of TauGu's name, they entirely missed the larger cultural significance implicit in the framing of this photograph. Nowhere do readers learn that Powell went on, after his successful mappings of the Southwest frontier, to head the newly formed Bureau of American Ethnology in Washington, DC. Neither his worldview, philosophical or otherwise, nor the motives driving his exploration, enter the picture. None of these elements enters the narrative presentation. However, their elaboration would render clearer the larger philosophical underpinnings driving the formation of an Anglo-American national history. And what little information in this textbook representation readers will find on John Wesley Powell is more than they can ever possibly recover about Tau-Gu. Yet a fuller exposition of Powell's life might not only shed light on Tau-Gu's apparent marginality but also offer instructive lessons about the inherent limitations of a multicultural national history, especially one that attempts to represent indigenous peoples.

Powell's explorations of the Southwest strategically mark the closing of the last US frontier. In a sense, he can be taken as a vanguard for progress. But at the time, the territorial advance of civilization ('From sea to shining sea') was viewed as the evolutionary displacement of one culture over another. Upon his return east several years later, he informed the US Congress that, 'There is now no great uninhabited and unknown region to which the Indian can be sent. He is among us, and we must either protect him or destroy him' (Hinsley 1981: 146). The belief that Aboriginal cultures were disappearing was common not just in the USA, but, as noted above, was a popularly held view in the British settler colonies of Australia, Canada, and New Zealand. Indeed, Powell's mission, as head of the new Bureau of American Ethnology, was to amass as 
much ethnographic data and artefacts as possible before Native Americans became extinct (Berkhofer 1979). The photograph of Powell and Tau-Gu can be properly viewed in this light. In the late-nineteenth century, the photographic recording of vanishing Aborigines was in high demand as a popular art form. Assuming their imminent demise, Australian Aborigines were romantically recuperated as noble savages and 'their photographs in combination with artifacts found large audiences in the many international exhibitions of the midto-late-nineteenth century' (Troy 1988: 21).

Whether in the Americas or the Antipodes, in the late-nineteenth century the actual territorial frontier enters the symbolic lexicon of nation-building. Spurring this transformation was Frederick Jackson Turner's definitive essay of 1893, 'The significance of the frontier in American history' (Turner 1985). The key to Turner's conception of the frontier is his characterization of indigenous people: 'The frontier is', he says, 'the outer edge of the wave - the meeting point between savagery and civilization' (p. 3). In more positive terms, it is also 'the crucible [where] immigrants were Americanized, liberated, and fused into a mixed race, English in neither nationality nor characteristics' (p. 3). Thus, the advance of civilization is also the march of liberal democracy, though one characterized by the highly individualized ethos of the lone frontiersman mastering the wilderness. ${ }^{3}$

It should not go unnoticed that Turner's 'crucible' bears a strong symbolic resemblance to another turn-of-the-century symbol - the 'melting-pot' (taken from a popular US stage play by Israel Zangwill [1909]) - which served until the Civil Rights era as the common-sense explanation for the rite of passage immigrants make as they assimilate into Anglo-American society (Gordon 1964). Given the structural divide equating civilization solely with Europe and its US progeny, Turner's nation-building crucible serves only one inexorable telos, and that is to exclude the native, in effect rendering him or her dross, unsuitable for national history. Similar formulations of the frontiersman reappear in Australia where he becomes the 'noble bushman'. Thus, in The Australian Legend, Russell Ward (1958) appropriates Turner's basic dichotomy of immigrant British settlers facing down 'indigenous influences'. For Ward, 'the frontier was a forcing-ground for the growth of distinctive national habits and sentiments' which in the late-nineteenth century 'promote[d] national unity and nationalism', thus providing a distinctive impetus to the formation of the Australian state in 1901 (Lawson 1980: 584).

While the immigrant is key to the Australian conception of a multicultural nation, it is also central to the California Framework (CDE 1987). Its basic chronological orientation is a progressive telos ideally presented as a metanarrative of a 'story well told'. Interestingly enough, Turner's thesis is considered to be integral to this unfolding story. In the grade 3 course of study, the theme of local history is framed in terms of continuity and change. 'American Indians who lived in the region should', the California Framework emphasizes, 'be authentically presented'. And that should include 'their tribal identity; their social organization and customs' (p. 41). Studies of these 'customs' and 
lifestyles should be organized around a timeline that illustrates the ongoing sequence of newcomers into the region. This would include explorers, then settlers, with attention given to 'their impact on the American Indian of this region', along with those 'who have continued to come into this region, and the rich legacy of cultural traditions that newcomers brought with them' (p. 42).

While the frontier zone of 'impact' in grade 3 is largely implicit, by grade 5 actual conflict is explicitly noted. In that year's course of study, 'students should learn about the resistance of American Indian tribes to encroachment by settlers and about the government's policy of Indian removal to lands west of the Mississippi'. Tecumseh's 'resistance' on the Indiana frontier is highlighted. The 'tragic story of the Cherokees' Trail of Tears' is also prominent (CDE 1987: 54). By grade 8, the last year covered in the California Framework's curriculum, the frontier is conceived as the nexus of both growth and conflict. However, here the geographic West serves as a symbolic stand-in for the frontier's enduring importance. At this grade level, students should study 'the West for its deep influence on the politics, economy, mores, and culture of the nation.... It offered new frontiers ... [which] provided a folklore of individualism and rugged frontier life that has become a significant aspect of our national selfimage' (p. 70).

In the textbooks that follow these course descriptions, representations of indigenous cultures in frontier zones, like Turner's thesis, paradoxically tend to reveal as much as they conceal, eliding the larger historical forces at play. In their text presentations, the stunning visuals tend to keep the narrative on the surface. The synoptic accounts are generally shaped by neutral description. Readers can see the artefacts of history. To a greater extent this follows the line developed by the grade 3 course description, which calls for 'authentically presented' cultures, because 'authentic' is being subtly redefined in the terms of a museum-like tableau.

In Houghton Mifflin's textbook for grade 3, From Sea to Shining Sea (Armento 1999b), there is a chapter on the Kwakiutl people, entitled 'By the shining sea'. In this text one would be hard-pressed to describe what should rightfully be seen. For a grade 3 child, this is an exquisitely designed presentation of the Canadian Northwest coastal tribal culture. Stunning, full-colour reproductions of native artefacts - a Kwakiutl mask, a totem pole, clothing - are juxtaposed with text and famous photographs of tribal ceremonies. There are simple but exacting descriptions of Kwakiutl lifestyle and ritual (referred to as a ceremony) interspersed with other appropriate artefacts, maps, and timelines (pp. 62-7). In the fifth-grade textbook, America Will Be (Armento 1994a), the most important ceremony of the Kwakiutl, though not alluded to in 'By the shining sea', is introduced. But here, another tribe, the Makah, who lived on what is now known as the Olympic Peninsula of Washington, celebrate the potlatch ceremony.

How can a teacher, knowing little about the cultural significance of the potlatch ceremony for Northwest coastal tribal cultures, explain such an odd dis- 
placement in the transition from one grade to the next? As delightful to the eye as the museum-like quality of ethnographic presentation is, it is woefully stripped of historical context. A timeline for the lesson, recounting the imagined life of a fictional Kwakiutl boy named 'Weesa', is set between 1700 and 1709, a time frame, because of its remoteness, more mythic than historical. Even the teacher's edition of the text (Armento 1999b: 68-9) adds little beyond additional superficial information on the Kwakiutl ceremonial woodcarving, yet this is 'authentic' presentation of indigenous culture.

Nowhere to be found is any account of the more profound cultural forces at work surrounding the potlatch ceremony - nothing outlining the basic historical context of early British settlement and the colonial policy of the 'Douglas system' (Tennant 1990: 27), which proposed in 1858 to assimilate gradually 'the Indians into English-style villages' (p. 27) (with the larger intent of 'diffusing the blessings of the Christian Religion and civilization among the natives' [p. 29]). Nor can teachers find how these earlier benevolent policies were superseded by the more aggressive policy of dispossession that took effect in 1870, which presumed the more widespread view that, because Indians were 'primitive savages', they could have no understanding of property, which fed the equally popular settler myth 'that British Columbia had been in essence an empty land, devoid of society, government, or laws' (p. 41). And critical to understanding the potlatch was its banning in 1884. The Potlatch Law, a statute not amended until 1951, was sponsored by Protestant missionaries who correctly saw its banning as the best way to destroy native culture. Enforcement placed the native in 'wardship', and would serve, it was hoped, as a 'programme of gradual preparation for Canadian citizenship' (LaViolette 1961: 31-45). But equally important to understanding the Potlatch Law is that it inspired 'the first modern Indian political action', which was mounted by 'north coast chiefs in 1887' to counter this government prohibition, thus beginning a long campaign of struggle to retain native identity and regain sovereignty over their lands (Tennant 1990: 68-83).

To move from surface to depth, historical representation obviously requires basic facts. The anthropologist Franz Boas believed that cultural artefacts like the Kwakiutl's should be placed in 'the setting of its generating culture ... before its true meaning could be understood' (Jacknis 1996: 185). But 'authentic' representation needs more than just 'setting', it needs historical context, one that illuminates the struggle of the Kwakiutl by placing it within the national story, but also a view of that struggle that indicates its connection to larger global processes.

Basic facts about the potlatch ceremony are presented in Canada: The Story of a Developing Nation (Deir et al. 2000a: 293), the McGraw-Hill Ryerson textbook, which is in conformity with the Ontario Curriculum for history and geography in grade 8 (Ontario Ministry of Education and Training [OME] 1998). The text surveys nineteenth- and early-twentieth-century Canadian history from 1850 to 1918 , Confederation to World War I. The struggle over potlatch is presented as one of many during this period in a chapter titled 'The struggle for 
rights'. The timeline on the opening pages of the chapter begins in 1876 when the Indian Act was passed, and amended in 1884 when 'Aboriginal cultural ceremonies' were outlawed, i.e. the Potlatch Law (Deir et al. 2000a: 290-1). Further elaboration, however brief, on the potlatch appears in the chapter's opening section, 'The good old days?'. The text informs the reader that:

In British Columbia, in August 1889, a Kwakiutl, Hemasak, was sentenced to imprisonment for six months for holding a potlatch. For Aboriginal groups of the Northwest Coast, a potlatch is an important traditional ceremony. The ceremony involves formal dances, songs, and the giving of gifts to guests.

Hemasak's struggle is almost a historical footnote in the larger political and cultural struggles of the time, with the greater emphasis in the chapter given to the nascent women's rights movement in Canada. Still, a later section of the chapter, 'Aboriginal struggles', discusses the assimilation of Aboriginal children in government residential schools, the loss of land, and the opposition of Aboriginal peoples to those changes (pp. 306-10).

This candid, however fragmented, factual accounting of the indigenous presence within the national story is also evident in US history textbooks. In the revised edition of the Houghton Mifflin textbook, America Will Be (Armento 1994a) for grade 5, the growth in population during the California Gold Rush, 1848-52, is captured by a simple line graph plotting the massive upward growth of gold-seekers into the state. But in the new twenty-first-century edition (Armento 1999a), recently adopted by California, that population graph is nowhere to be found. In its place is a stark paragraph describing the 'harsh injustice' faced by California Indians and Chinese immigrants:

As the number of Chinese immigrants grew, discrimination against them increased. Many Chinese would later be injured or killed helping to build the transcontinental railroad. Now they faced harsh discriminatory laws, such as the Foreign Miners' Tax. ${ }^{4}$ Also, California's Indian population was being wiped out by hunger, violence, and disease. Indians living on the land purchased by a white settler became slaves by law.

(pp. 386-7)

Such graphic accounts are also evident in the twenty-first-century Houghton Mifflin edition of Oh, California (Armento 1999c). Whereas in the previous edition a graph, similar to the one in the earlier grade 5 text, marked the rapid influx of 100,000 into the state 'from around the world', the authors now note instead that during this time over 100,000 Indians had been killed (p. 129). Similar accounts noting the apparent genocide can be found in McGraw-Hill's submission, California: Adventures in Time and Place (Banks 2000: 184), for grade 4, and Prentice Hall's submission, The American Nation (Davidson et al. 2000: 297) for grade 8. 
Images of Kwakiutl ceremonies and artefacts, like the photograph of John Wesley Powell and Tau-Gu, have a story to tell, but one that often exceeds the reduction necessary to fit the streamlined narrative of nations. Even when the text passes beyond the image to actual historical accounts of Aboriginal struggles, as in Canada: The Story of a Developing Nation (Deir et al. 2000a), the story tends to be fragmented, and the indigenous presence is set within the progressive pattern of national development. But is there something wrong with progress? Gold-seeking and the closing of the frontier in British Columbia and California have a downside that undercuts the apparent objectivity of graphs plotting limitless growth.

When the British explorer Captain James Cook first sailed along the coast of Vancouver Island in the 1770s, he was hailed by descendants of the Kwakiutl, the 'Nuu'chah'nulth'. In that first encounter his translators aboard ship heard the 'Nuu'chah'nulth' shout out the phrase, 'Nootka, Nootka ...', and believed that they were simply declaring who they were, failing to realize that 'Nootka' was instead 'a warning to watch out for underwater rocks' (Tennant 1990: 4). Perhaps there is a deeper narrative structure of 'underwater rocks', which regulates the surface flow of national history. Similarly, the frontier is more than an 'imaginary line dividing the pioneer settlements from the area where the Indians lived'. ${ }^{5}$ In effect, then, crossing that line, like navigating these underwater rocks, may be less an act of translation than of recognizing the limits to understanding the story of nations can itself impose.

\section{Fields of gold: the USA and the Antipodes}

A war of extermination will continue to be waged between the two races until the Indian race becomes extinct.

Governor Peter H. Burnett (1851), address to the California legislature (Hurtado 1988: 135)

In less than twenty years we have nearly swept them off the face of the earth. We have shot them down like dogs. In the guise of friendship we have issued corrosive sublimate in their damper [i.e. bread] and consigned whole tribes to the agonies of an excruciating death. We have made them drunkards and infected them with disease. ...

Edward Wilson, editor of the Argus, a Melbourne, Australia, newspaper, March 1856 editorial (Goodman 1994: 17)

In the teachers' edition of the Prentice Hall grade 8 textbook, The American Nation (Davidson et al. 2000), as a suggested 'Connections with the world activity', students are asked to research gold strikes in Australia, New Zealand, South Africa, and Canada, which occurred at roughly the same time as California's. Obviously, the 'world' referred to is to be understood in a more general geographic and international sense. Less obviously, gold seems to connect these same frontier societies to a greater world of Anglo-European empires, although 


\section{James Andrew LaSpina}

in the late-nineteenth century this 'world' was in transition to modernity. These nation-states were being 'pulled together in one international market' (Hofstader 1955: 51). Frontiers were consolidated and new nation-states were emerging. But such consolidation characteristically 'assumed the elimination of the former indigenous population' (Hobsbawm 1987: 24). Even as settlerstates such as Australia and New Zealand fashioned government charters based upon advanced forms of social democracy, like the USA, both countries had race-based notions of who was a native.

In Call to Freedom (Stuckey and Salvucci 1999), the Holt, Rinehart \& Winston US history textbook also adopted by California in 1999, the California Gold Rush appears to serve as a site for national self-definition in collective as well as individual terms: 'The Yankee regarded every man but a native American as an interloper, who had no right to come to California and pick up the gold of free and enlightened citizens' (p. 535). Of course, 'native American' here, the teachers' edition announces, means only 'white U.S. citizens'. In California at the time, Chinese immigrants, like indigenous natives, could not give testimony in a trial, although in Australia for a time they could (Markus 1979: 16). Yet in California and Australia, the Chinese, unlike the Aborigines and Indians, were regarded as civilized and not about to disappear. Although gold-seekers in California were attacked by remnants of local tribes, no such resistance occurred in the goldfields of Victoria and New South Wales (Markus 1979: 37).

Reaction to the Chinese during the 'gold strikes' in the Americas and the Antipodes marks a textual shift in nation-building narratives from the consolidation of internal frontiers of 'exploitation' and 'settlement' to the formation of external national boundaries (Nugent 1994). Although there is some debate about how 'attitudes held toward Aborigines influenced attitudes to nonEuropean immigrants' (in this case the Chinese), there is no doubt that nationbuilding in its frontier phase appears to depend upon an evolutionary racism, typical of the late-nineteenth century, in which history is made by the displacement of primitive cultures (Markus 1979: 236, Reynolds 1982). As the California Gold Rush population graph in the Houghton Mifflin grade 5 textbook reveals (Armento et al. 1994: 386), the tragic aspect of such displacements can be registered as it is reduced to a statistical advance.

It might be said that the reaction to the Chinese gold-seekers in California and Australia marks a change in the pattern of nation-building narratives. With the consolidation of territorial frontiers after this period, the symbolic force of civilization/savagery is turned to the formation of national identity and the policing of racial boundaries, excluding or including incoming immigrant groups. Given the historical interaction between California and Australia during that period, perhaps the California Framework's conception of a multicultural immigrant nation should be seen as a twice-written script. The 'orthodoxy' of the immigrant model connects the USA to that 'Other America' down under (Bell and Bell 1993). This script, which has striking similarities with its Australian counterpart, becomes evident as the national story is placed in a comparative global context. 
Opening a recently published history textbook, To Be Australian (Newman and Sawyer 1997), published by McGraw-Hill Australia for New South Wales school years 7-10, one encounters an antipodean question about nationality rather than the self-assured nationalism of the California Framework. Moving chronologically, Chapter 1 begins by subtly posing the question of Aboriginal origins, 'A nation of immigrants?', and ends with 'A multicultural nation', which presents a statistical chart accounting for population trends of 'settler arrivals' since the 'Whitlam era', 1971-75. The opening sentence of To Be Australian invokes Manning Clark, a traditional Australian historian whose work is firmly rooted within a British colonial perspective. Clark describes all Australians as 'immigrant people':

Is this the way all Australians see themselves - as a nation of immigrants? Or has 'being a migrant' come to mean being a member of a special group in our society?

(Newman and Sawyer 1997: 1)

Clark's assertion is next juxtaposed with a quote by Silas Roberts, 'an Aboriginal Australian from Arnhem Land' in the Northern Territory:

Aborigines see themselves as part of nature. We see all things natural as part of us.... All the things on earth we see as part human. This is told through the idea of dreaming. By dreaming, we mean the belief that long ago, these creatures started human society, in special places and special roads or tracks or paths.... My people believe this and I believe this. Nothing anyone ever says to me will change my belief in this.

This is followed by a series of questions embedded in several illustrative sources: a painting titled '40,000 Years (Awakening)' (p. 2), which shows an Aborigine face emerging out of a tree; a map of the Australia-South-East Asia land-bridge in the Ice Age; and a photograph of a rock engraving that is reported to be 75,000 -years-old. On the basis of these sources the student is asked to decide if Aborigines are migrants.

This dialogue on national origins and identity is continued in another recent McGraw-Hill textbook, Identity: Images of Australia (Kruse 1998). This issuesoriented topic booklet designed to conform to the national statement and profiles and state curricula variants, particularly those for civics and citizenship education, looks at the question of identity from various perspectives which are developed along a timeline that runs from $3.5 \mathrm{~m}$ years ago to 1997 , the year of the Aboriginal Reconciliation Conference. Other dates important to contemporary Aborigine history appear on the timeline, e.g. the Wik High Court decision in 1996 and the 'Mabo' decision in $1992 .{ }^{6}$

The five thematic parts of Identity: Images of Australia (Kruse 1998) unfold along this timeline. Aboriginal identity is followed by the White-settler bush 


\section{James Andrew LaSpina}

legend, then the transition from colony to nation. It concludes with a section on 'What symbols of Australian identity could be used for the future?' (p. 44). An excerpt from the 1997 Australia Day Address given by Sir William Deane, then Governor-General of Australia, is used to frame this concluding section. In his speech, Deane notes the still-marginal status of Aborigines in mainstream society, particularly their 'appalling health conditions'. Yet he is still 'happy' because of the 'uplift' provided by 'multiculturalism' (p. 44).

The Deane speech has an unintended irony:

Apart from the Aborigines, we Australians are all immigrants or descended from immigrants.... The essence of that multiculturalism is mutual respect and tolerance for all our different cultural, ethnic, national, and religious backgrounds.

(Kruse 1998: 44)

'These differences', he suggests, 'unite us as a single nation'. Multiculturalism is 'not only our Australian way - It's what we are' (p. 44).

Typically then, the Aborigine, like the Native American, occupies a paradoxical place in the national narrative. They are both set apart, not considered citizens, yet migrants from a primordial time. Ice-Age land-bridge theories, which frame the opening discussion of To Be Australian (Newman and Sawyer 1997), also are in evidence throughout US history textbooks. ${ }^{7}$ While there is now extensive coverage of Native American culture and lifestyle and the Indiansettler contact in US textbooks, minimal coverage of the Aborigines' place in Australian history textbooks tends to be the norm, usually confined to the opening chapter of the textbook, with the emphasis placed on their ancient, primitive origins.

In Shaping a New Nation: Australian History to 1901 (Howard 1993), published by Longman, the 'Original Australians' briefly share the stage just before 'European Discovery'. Here, as elsewhere, there is a concerted effort to place the Aborigine within a 'national heritage' perspective. Yet even the second edition, which is a revised version of the 1984 text, fails to catch obvious anachronisms, like viewing Aboriginal culture as a 'continuation of Stone Age culture' (p. 9). In another recent Longman publication, Checkerboard: Themes and Skills in Australian History (Pyne 1993), the heritage theme has two major features, Australia's natural and multicultural heritage. According to this text, 'Our multicultural heritage' has three strands: 'Aboriginal, British, and heritages from other cultures' (pp. 71-2). Complementing this national heritage is the 'National Estate' which is graphically described through a Venn diagram (p. 73) as three intersecting ellipses: Aboriginal, natural, and historic. The tripartite diagram represents geographic 'places of value', like Kakadu, an Australian National park outside Darwin, and Uluru, i.e. Ayers Rock, both located in Australia's Northern Territory. However, this alignment, which connects indigenous peoples to their ancestral lands, also tends to suggest that they are more part of nature than history. 
In Australia the study of history generally falls within 'Studies of Society and the Environment' (Australian Curriculum, Assessment and Certification Authorities 1995: 9). For example, in the history strand of 'Studies of Society and the Environment' for Years 5-10, the state of Victoria calls for an 'inclusive curriculum' that 'includes within it the important perspective of Australia's first peoples' (Victorian Curriculum and Assessment Authority 2002). It should not go unnoticed that, unlike Canada's 'first nations', the curriculum framework refers to 'first peoples'. Apart from the required study of history in the recent K12 curriculum framework, 'Human Society and Its Environment', the New South Wales Board of Studies (2002) offers a special elective sequence for grades 7-10 for Aboriginal Studies.

State school systems in Australia also have programmes in the area of legal studies, with courses that specifically address the rights of indigenous peoples within the context of international law. ${ }^{8}$ In this subject area, Australian cultural and historical realities intersect in new ways where one's deposit of the national heritage gives way to the possibility of post-colonial self-definition. Here, the colonial term 'Aborigine' is dropped, and tribal names such as Koori, Murri, Yolngu, or Anangu are used, prompting another reading and the possibility of a history from the other side (Miller 1985).

\section{Changing places in Perth}

They were nothing more than people, by themselves... . But all together, they have become the heart and muscles and mind of something perilous and new, something strange and growing and great. Together, all together, they are the instruments of change.

(Hulme 1994, quoted in Howitt et al. 1996: 1)

Up to this point, the question of what a multicultural history might look like has revealed that nation-building is structured by the narrative norm of progress. But just as this norm is woven with a strand of 'metropolitan racial ideology', a worldview that a John Wesley Powell would be quite comfortable with, it also has a more up-to-date strand. That other face of progress is evident in the multicultural textbooks examined so far (Reynolds 1974: 53). The new family of the nation fronts a liberal rejection of prejudice and preaches inclusion, but it really tells readers little about the 'other side of the frontier' (Reynolds 1982). Stanner (1991) was perhaps one of the first Australians to recognize how national culture produces its own kind of historical blindness. History in an Anglo-European mode works from basic structural assumptions, which produce:

a view from a window which has been carefully placed to exclude a whole quadrant of the landscape. What may well have begun as a simple forgetting of other possible views turned under habit and over time into something like a cult of forgetfulness practised on a national scale. 
Because I have relied in part on the device of framing, readers might ask what the window of history looks like from outside in. The Fremantle Arts Centre Press in Western Australia produced one textbook that attempted such a view. Changing Places (Kenworthy and Kenworthy 1997) is not so much a local history of Perth, the present city, the cosmopolitan outpost in Western Australia facing the Indian Ocean; rather, it is a deconstructive study of historical accounts concerned with 'Aboriginality'. Two parallel stories recounting the settlement of the Swan River Valley of Perth are presented to the reader. By placing these divergent stories together, Changing Places poses questions about the constructed nature of 'Aboriginality'. Whereas the majority of US history textbooks sampled in this chapter place native peoples within the larger narrative flow of progress, Changing Places presents dual accounts of settler and Aborigine. Suggestive of a global context, these stories are prefaced with an extract from President Andrew Jackson's Message to the Nation of 1830, which talks about 'the passing of the Red Indian' from the American continent (p. 18).

Unfortunately, this division into colonizers (settlers) and colonized (Aborigines), however appropriate, tends to reduce each account to stereotypical terms, reflecting a veritable post-colonial pedagogy of the oppressed, and in the process diminishes historical complexity. One of the more provocative chapters, 'Settlement and invasion', can be read as an official settler history of the Swan River Valley. The timeless Aboriginal landscape is irrevocably changed with the arrival of Europeans. The city of Perth gradually emerges from an initial cluster of farms and homesteads along the river. The hinterland surrounding the city is domesticated, becoming a major farm belt. Industry arrives. Modern-day Perth and its bustling suburbs gradually emerge, replacing farmland.

This account is read against a collection of indigenous sources, which strip away the progressive facade, undercutting its naturalism. Margin rewrites centre. Oral histories of the local Nyoongar peoples fill in gaps and silences that a White version of local Aboriginal history effaces. Subsequent chapters discuss the construction of Aboriginality, identifying the subtext of racist discourse that underlies this process. A later section takes the reader to Rottnest Island off the coast of Fremantle, a city south of Perth. Once the island was the only prison where local Aborigines could be incarcerated; the mainland jail was only for Whites. It is now a national heritage site and holiday getaway. The concluding chapter on 'Aboriginal voices' poses the problem of how Australian literature can move beyond 'Aboriginality' to recognize indigenous voices. Changing Places ends on the hopeful note of reconciliation with a poem titled 'Integration', which suggests that these nations within may someday come together, ultimately joining the Australian mainstream.

\section{Double-talk on New Zealand's last frontier}

Changing Places (Kenworthy and Kenworthy 1997), however burdened by its heavy-handed pedagogy of oppression and resistance, still poses the essential question: How does the nation accommodate the 'native' to let them speak and 
render their own story? Multiculturalism in its national variants is in an odd dilemma. The founding White majority has fashioned through trial and error a canonical national story, which incorporates immigrant newcomers, giving them a stake in the family of the nation. But historical encounters of first peoples run counter to the inclusiveness of this story. And the establishment of an indigenous voice is not necessarily about coming together within the imagined unity of an immigrant nation. Perhaps the best that can be hoped for is dialogue, and here there is a foundational nation-building script, New Zealand's Treaty of Waitangi. ${ }^{9}$ The biculturalism enshrined in the Treaty may be the only sure path to balancing the tendency to separateness or domination by one side. Less a path and more a legal bridge, the Treaty compels recognition, pressing each side into an on-going process of self-representation and negotiation.

But how do textbook publishers represent the terms set for this national dialogue posed by the Treaty? It has only been in the last few decades that the Treaty became more than a 'historical curiosity'. ${ }^{10}$ With the exception of Australia (until the Mabo court decision in 1992), treaty-making with indigenous peoples was a common practice of the British in many of its colonies, particularly North America (Sorrenson 1998). And since the institution of the Waitangi Tribunal in 1975, the larger socio-cultural implications of the Treaty have been felt across New Zealand society. Well beyond the official commemorations sponsored by the government - which had hoped that 'the Treaty could be used as a unifying symbol for a multicultural society' - it has set in motion a process of legal and economic redress which has forced New Zealanders to acknowledge the pronounced economic disparities in contemporary society between Maoris and 'Pakehas', i.e. Whites (Orange 1990: 97).

The Treaty has also had an impact on New Zealand national history and its traditional configurations, which in its own way recalls the warning to Captain Cook to watch out for underwater rocks. The Treaty represents a lesson writ large, basic to the process of intercultural communication. With the 1985 amendment to the Treaty of Waitangi Act, the legal work of hearing claims done by the Tribunal began to force major concessions from the national government, and also inspired a 'radical reinterpretation of New Zealand history' (Sorrenson 1989). How it was originally understood by Maori and Pakeha was never about creating a national 'Unum', i.e. one, similar to the USA. Rather, the Treaty was intended to provide a legal ground of sanction for cultural recognition in its widest sense.

The snapshots of national history sampled here through the textbooks of Australia and the USA represent the native as subject to nature or the state, or both. The progress of nations carries with it the presumption of dominion. But with the Treaty of Waitangi, this presumption led well beyond the textual problem of double readings, even to actual war. Over time, multiple versions of the Treaty - there have been 'at least five' - have been reduced to two nearly irreconcilable interpretations (Belich 1996: 194).

Whereas the Maori version is about the continuity of their tradition and culture, the Pakeha version, which history bears out, is about its abrogation. ${ }^{11}$ 


\section{8}

Nevertheless, as Kelsey (1990: 5 ) points out, 'the essence of the Maori position' has been consistent from the beginning of the Pakeha state in 1840, which enshrined the English version of the Treaty. 'It is te tino rangatiratanga o te iwi Maori - [which translated means] the absolute authority of the Maori people collectively over their lives and resources' (p. 5). With the statutory recognition of the two Treaties and the continued work of the Tribunal, McHugh (1997: 55) has observed that a new 'historiographical and constitutional ethos of difference' has appeared, which he argues 'may be more suitable' than the Whiggish fiction of national 'harmony and progress' (p. 50). Consequently, the co-ordinates of national history have been reset on the contested terrain of Aotearoa/New Zealand. But how is this competition between Crown sovereignty and Maori mana represented by mainstream history and social studies textbooks in New Zealand?

In Talking About the Treaty (Wark and Frood 1994), like Changing Places (Kenworthy and Kenworthy 1997), the student encounters a set of historical primary-source documents framed in the light of contemporary public opinion. According to the back cover of the text, Talking About the Treaty is designed as 'a discussion document' for high school social studies. But like its title, instead of facing the historic problem of multiple conflicting versions of the Treaty, which bears directly upon present legal fights wrought by the Tribunal, students get to talk about one Treaty, thus from the outset maintaining a historical fiction.

Talking About the Treaty is organized around the famous exchange of two letters in 1847 by Henry Williams, principal translator between the Crown and the Maori, and Bishop Selwyn, an advocate for Maori land-rights. But the main body of the text for discussion is a series of interviews done in 1993, which generally represent a 'wide cross-section' of New Zealand society (back cover). Yet aside from the wide range of honest opinion, in some cases from Maori, it appears that the 'radical reinterpretation' of New Zealand history, and its implications, brought about by the Waitangi Tribunal have barely filtered down to the mainstream.

This is most evident in the use of the two letters used to preview the interviews, and appearing in their entirety in the Appendix (Wark and Frood 1994: 37-9). The letters act as a focusing device, but also serve to foreground a very traditional interpretation of the Treaty's significance for New Zealand as a settler-nation. Henry Williams viewed the Treaty as 'the Magna Carta of the aborigines of New Zealand', a document 'they [i.e. the Maori] must read with a clearer understanding' (p. 2). But the Treaty version Williams refers to is, of course, only the English one. Apart from a segment of the Maori text on the critical section on sovereignty in Article One, the Treaty as it is framed here is a 'Hobbesian contract between Crown and subject', finalized for all time, rather than a 'conditional' one more in keeping with Maori understanding (McHugh 1997: 46). Following the letters, the lesson engages students in a typical social studies inquiry strategy. In therapeutic tones, they are asked how they 'feel about the Treaty of Waitangi now!' (Wark and Frood 1994: 1). Students are 
then asked to register their feelings, negative or positive, on a seven-point scale. After reading the letter fragments and going over the interviews, they test their feelings again.

But the deeper social paradox embedded in these interviews eludes this simplistic instrument. Wholly subjective, these opinions reflect a complex range of ambivalence, misunderstanding, and ignorance. In fact, even the more insightful interviews are hard to interpret as pro or con. And, as with generic social studies exercises, intractable complex issues tend to get flattened out and reduced to the terms of a high-school debate, resolved with a formulaic feelgood consensus. The stories of actual history, the competing versions of rights and obligations which sparked a bitter and brutal war and which have produced simmering racial divisions in present-day New Zealand, are nowhere in evidence (Belich 1986). Talking About the Treaty, however, toes the line and is in conformity with New Zealand's state-approved social studies curriculum, where 'programmes emphasize learning about [its] peoples, cultures, and groups'. And key to 'such learning includes the development of understandings of the Treaty of Waitangi, of New Zealand's bicultural heritage, and of the multicultural nature of society' (Ministry of Education 2002).

But in keeping with the present-tense orientation typical of social studies, Talking About the Treaty maintains, right from the opening page, the monologue of modernity and progress. At least Changing Places (Kenworthy and Kenworthy 1997), in its hope for reconciliation of Aboriginal margin to the Australian mainstream, clearly distinguishes past and present by giving voice to another side of progress. Talking About the Treaty is right for the progress of nations, but tone-deaf to the deep-seated conflict underlying New Zealand's 'bicultural heritage'. To explore the notion of bicultural dialogue, students must listen to voices past in order truly to engage the 'strange multiplicity' of incommensurable cultures (Tully 1995).

\section{Globalization, textbooks, and the story of nations}

On 1 April 1999 the newly formed province of Nunavut ('our land' in Inuktitut) joined the Canadian federation. The story of how Inuit First Nation peoples came to found their own self-governing territory is told in the concluding chapter of the grade- 8 history textbook, Canada: The Story of a Developing Nation (Deir et al. 2000a), published by McGraw-Hill Ryerson. The tragic arc of nineteenth-century Aboriginal dispossession, displacement to tribal reserves, and forced assimilation, which began with the Indian Act of 1876, has come full circle. 'The story today', the title of the concluding section, is a hopeful one. As the chapter overview ('Setting the focus') states: 'The story of Canada is ongoing. Our system of government allows for new provinces and territories. Such changes make us stronger.' The Canada of today, the text goes on to say, can right 'past wrongs', recognize native title to 'traditional lands', and affirm their right to self-determination (pp. 345-7).

But this opening section, which highlights 'Canada's new treaties with 
Aboriginal peoples', is only one of five themes explored in this concluding chapter (Deir et al. 2000a: 345). Like the placement and all-too-brief mention of the potlatch ceremony and suppression of the Kwakiutl in a preceding chapter, the indigenous presence is fitted within a larger theme of 'The struggle for rights', where women, Chinese immigrant labourers, and children's-rights advocates contribute to the story of national development. This embedding of the potlatch in an overarching thematic order and structure, effectively stripped of historical context, is illustrative of an editorial-containment publisher's exercise in designing for diversity. But a diversity that conforms to a national framework, where the symbolic logic of the story is guided by the dominant myth of modernity itself: progress.

The narrative form of that logic is perhaps most evident in the titles of McGraw-Hill's history textbooks for grades 7-10, where Canada's story progresses from Canada: The Story of Our Heritage (Deir et al. 2000b) to Canada: The Story of a Developing Nation (Deir et al. 2000a), and then to Canada: A Nation Unfolding (Newman 2000). The linear convention of a nation's past, present, and future is graphically reinforced by the chronological organization of the chapter-openers, and rhetorically emphasized throughout to maintain narrative continuity by the feature, 'The story so far'. Less obvious but more revealing of this inexorable logic of progress and modernization is indicated in the concluding chapter of 'The story today'. In the opening paragraph on Canadian technology, the entire history of Canada's national development parallels developments in transportation (and again Native Americans are fitted into the pattern of progress):

First Aboriginal Peoples fastened birch bark over a wooden frame. Later voyageurs navigated Canada's waterways in canoes to the farthest reaches of the land. Next the builders of canals, steamships, and railways brought millions of immigrants into the heart of the country, to settle and cultivate the land. More recently bush pilots opened up the vast northland. Today Canada's astronauts are pushing back the frontiers again.

(Deir et al. 2000a: 352)

That this study of textbooks ends as it began with an invocation of the frontier perhaps speaks in part to its resilience as a standard trope in the collective national imagination. Yet, whatever connection a frontier of the nineteenth century may have with that of today might be less important than its persistence as a symbol, which tends to obscure more than it reveals about the actual processes of history. And that question of connection in this instance, especially as it pertains to the history of indigenous peoples, cannot be properly posed by considering a particular nation in isolation.

The coincidence and commonality of gold-seeking with the closing of frontiers, and the respective treatment of indigenous populations by Anglo-settler nation-states, are historical phenomena that only come into focus full-force when considered comparatively and in their global dimensions. As such, the 
larger point of this comparative exercise is not only to suggest a nineteenthcentury parallel with the present-day phenomenon of globalization, but also to propose that the very fact of globalization demands that people view the nation idea differently. This global network of indigenous sites of cultural encounter points to historical realities beyond the temporal co-ordinates and mythos of the nation-state.

Just as present-day recognition of indigenous peoples has compelled the rethinking of the nation-state to what has been characterized as a 'nationswithin' model of political and cultural sovereignty, globalization has wrought a similar perceptual shift in the way nations are viewed in terms of the wider world (Deloria and Lytle 1998). If people can now acknowledge the reality of nations (whether ethnic or indigenous) within nations, they are equally compelled to view nations as neither entirely sovereign nor autonomous, but instead caught up in a world-system of increasing complexity. So common has this perception become, that one might infer that a paradigm shift in popular understanding about the nation-idea, this 'imagined community', was forthcoming (Anderson 1991). But if the selection of textbooks considered herein is any indication, that change may be only in a potentially formative stage.

Globalization presents a host of problems for the consensus that has maintained the narrative conventions of the typical national history textbook in the USA. That 'consensus' is reflected in the general education curriculum. Normally, the order of things is that students should study the history of their nation first, then the western world, as traditionally embodied in the heritage of western civilization. After the Second World War, additional study of the East and its ancient civilizations (i.e. India, China, Japan, etc.) became acceptable, but not widely adopted (Wallerstein 2000). Underlying this 'consensus', and readily confirmed in any standard social studies textbook in the USA, at least until recently, was the inevitability of modernization and progress (Lockard 2000).

That 'consensus' held, at least among professional historians, until the 1960s, when it was challenged by movements in social history. Innovative, path-breaking studies in race, class, culture, ethnicity, and gender, that were heavily influenced by work done in England and France, largely overturned this long-standing 'consensus' (Novick 1988, Kessler-Harris 1990). These 'new histories' were influential in shaping an emerging multicultural model of representation that served to sharpen debates over inclusion in the liberal arts curriculum at the university level. Similarly, they were a catalyst in the US 'culture wars' over the role of history education in the public school curriculum (Nash et al. 1997). As evident from the examples presented from the Houghton Mifflin textbooks, this debate was particularly heated in California (Cornbleth and Waugh 1995, Gitlin 1995). But like other curricular controversies over multiculturalism, voices calling for inclusion wanted in on the national story. Then, as now, 'The story today' is still largely about nations.

But the problem with this 'story' today presents an interesting and perhaps overlooked paradox. As textbooks embrace diversity and the 'story' becomes 


\section{James Andrew LaSpina}

more inclusive, breadth tends to cancel-out depth, and content becomes fragmented and bit-like, self-contained as a graphic advertisement. Potentially, the 'story' becomes as thin as the page it is printed on. No more telling example of this dilemma can be viewed than 'The story today' in Canada: Story of a Developing Nation (Deir et al. 2000a). Other story elements that share representational space after the First Nations' peoples of Nunavut take the stage are the multicultural character of current immigration ('Diversity encouraged here' [p. 350]), Canadian Technology (p. 352) (and its development as recapitulated in the Aboriginal canoe above), the impact of Americanization ('How Canadian is Canada?') (p. 355), and Québécois separatism ('One nation - or many?') (p. 358). No doubt this is an elegant design solution, one that appears to strike just the right balance, giving voice to all and presenting the crucial issues that will make or break the nation: 'Canada's future may hang on the answers to these questions. It's a story that is still being written' (p. 361). But the larger irony of these 'questions' is that the national story is already being overwritten, because together these same elements can be read as characteristic of a larger unfolding story - globalization.

As a consequence, the basic problem with the nation-story is how to situate it within a broader context of a world system. Where, for instance, do the ' 50 cultural neighbourhoods', which make up present-day Toronto, described as 'the city of the future' (again in this case starting with Canada's 'Aboriginal Peoples'), come from (Deir et al. 2000a: 350-1)? How can the warp and weft of Toronto's cosmopolitan 'tapestry' be made comprehensible? Where is the loom and who is the weaver? Here the global contours of this paradox come into view. Globalization is localism with a vengeance. The world is everywhere already here; yet the manifold historical process that makes it visible, discernible, remain outside the text. But this global story has no outside.

The crux of the problem is how to get inside this totality by placing the nation within it and by drawing pathways from it to other nation-states, presenting the patterns of their mutual interconnection and dependence, to articulate a constructive curriculum of 'system effects' (Jervis 1997). But as long as textbooks tend to re-inscribe thematically the path of progress and its apogee, 'that entity the West', its 'myth-making' apparatus remains obscure (Wolf 2000: 133), and in doing so the 'large[ $\mathrm{r}$ historical] processes' which structure the local story of nations will remain safely at the margins of an emerging global context (Tilly 1984).

The dilemma of the present nation-story is aptly posed in Canada: A Nation Unfolding (Newman 2000). The thematic tension pulling apart the fictive national unity is reflected in the titles of its two concluding chapters: 'Canada: A community of communities', followed by 'The search for Canada within an emerging global community'. Given the political realities of Québécois separatism, the over-arching metaphor of nation as community is stretched to its imagined limits. Extending this schema to a global level might appear to isolate and insulate further this community, safely reducing it to a 'static disconnected thing' (Wolf 2000: 133). But the 'emerging global community' is anything but a static order. The real 'search' is less for community than for global context. 
How, then, to move to a transnational context? Recent curriculum reforms in the USA and Canada may serve as cautionary lessons. Even when vision exists that points to other ways of world-making, institutional constraints still tend to dispose people to think and act locally in terms of modernity - that is, seeing the nation-state, the west, and progress as the natural order of things.

\section{USA's world}

A controversial culture war over a US history curriculum occurred when the first federally-funded national standards for K-12 history were released by the National Center for History in the Schools (1996) at the University of California, Los Angeles. Condemned by the US Senate and widely trashed by conservatives in the press and media, most of the firefight was over the K-12 standards for US History, which were considered 'politically correct', presenting a lessthan triumphalist history of the nation (Symcox 2002). But the Center also developed national standards for world history (grades 5-12). Although igniting much less public debate, the standards nevertheless were criticized by Lynne Cheney, former chair of the National Endowment for the Humanities, who originally approved funding for their development. Cheney faulted the world history standards because they departed from a framework that highlighted the western foundations of world history:

By deciding not to give any emphasis to Western civilization, they lost any organizing principle. If you look over history for the last 500 to 600 years, the rise of the West is the organizing principle and the key to the rise of democratic standards.

(Gugliotta 1994)

The structure that organized the world history standards was both traditional and radical. Nine eras for study were set along an evolutionary timeline that ran from 4000 BCE to the post-Second World War world of the twentieth century. The focus in each era was on large-scale 'world circling developments', looking at 'particular regions and societies' and 'broad patterns of change'. The 'shape of world history' was found in 'big stories'. In such a scheme, western civilization, as Cheney conceived it, only came into focus in a broader context, in effect a local history subsumed by a global process of change (National Center for History in the Schools 1996).

A world history curriculum that met Cheney's approval was produced by the state of California in 1987, and was the deciding factor in the selection of the Houghton Mifflin K-8 textbooks in 1990, discussed at the outset of this chapter. In 1998, CSBE approved a set of standards based upon the California Framework, also discussed above. The standards codified a K-12 scope and sequence that required one year of state history in grade 4 , three years of US history in grades 5, 8, and 11, and world history in grades 6, 7, and 10, with each year of history integrated with the study of geography (CDE 1998). 


\section{James Andrew LaSpina}

But the three years of world history in the California Framework followed the typical general education format. The USA was characterized as an immigrant nation, the progressive fulfilment of western civilization, and Europe. Even though ancient civilizations are studied in grades 6 and 7, the emphasis is placed on the Judeo-Christian roots of western civilization. And with the history of the modern world in grade 10, the study of regions and other countries like Africa, Southeast Asia, China, etc., was selective and optional.

Even as the new California History-Social Science Standards (CDE 1998) confirmed a more traditional world-making model of history, it also provided a level of specificity for local histories which acknowledged the indigenous presence. The standards for 'California: A changing state' (pp. 42-6), prompted the editorial revisions, which removed the Gold Rush population graph. That chart, noted earlier and found in the Houghton Mifflin grade 5 textbook, America Will Be (Armento 1994a: 386), marked only the massive White-settler growth in the new state, a graphic symbol thoroughly in keeping with the idea of progress. Its replacement with a benign but candid historical summary of the Gold Rush's more devastating effects on the remnant of California's indigenous population is indicative of design that moves beyond diversity to difference, and in so doing, suggests a recognition that the incommensurable difference of peoples and cultures in history has had tragic effects and often time-persistent consequences.

\section{Canada's connected curriculum}

Curriculum guidelines suitable for a transnational framework, one that provides a curricular lens for First Nations as it does globalization, may be found in the recent Ontario Curriculum, grades 1-12. The Ontario Curriculum guidelines, initially approved by the Ministry of Education in 1998, have a three-part scope and sequence: Social Studies, for grades 1-6, History and Geography, for grades 7 and 8, and Canadian and World Studies, for grades 9-12 (OME 1998, 1999, 2000). If the shape of a transnational framework is discernible in the California Standards (CDE 1998), the Ontario Curriculum presents an advanced articulation of its basic contours. At each grade level, Canada's connection to the world is the overarching theme organizing each course of study, with special 'emphasis ... placed on relating social studies, history and geography to the world outside the classroom' (OME 1998: 3). History and geography are required in grades $7-10$, and are optional in grades 11 and 12 .

As in the early grades, emphasis is placed on viewing Canada as a multicultural community that 'may be viewed from local, regional, national, and world perspectives' (OME 1999: 25). The study of history, the overview for Canadian and World Studies, grades 9 and 10 suggests (OME 1999: 25), can render important insights:

The better we understand history, the easier it becomes to understand other times and places. Such knowledge teaches us that our particular 
accomplishments and problems are not unique - an important lesson in a world in which the forces of globalization are drawing people of different cultures closer together.

At the local level, that difference in culture is a recurring strand at every grade level in the curriculum organized around the theme of 'heritage'.

Students, for example in grade 2 , focus on 'the wide variety of cultures and traditions in Canada' and how each 'contribute[s] to society' (OME 1998: 17). In grade 3 they are expected to 'identify the contributions of Aboriginal peoples to early settlement', in terms of 'medicine, food, and exploration' (p. 19). By grade 6, students are expected to study the contribution of Aboriginal peoples and their contact with European explorers for the entire school year. In grades 7 and 8 this study continues where they look at 'the early settlements of North America [i.e. New France, the British] and their impact', in terms of 'conflict and change', on Aboriginal peoples (OME 1998: 42).

Like the California History-Social Science Framework and Standards (CDE 1987, 1998), this historical study of the indigenous presence in Canadian society is integrated with the study of geography ('Canada and World Connections'). By grades 9 and 10 the curricular goal of this study is meant to 'help [students] to perceive Canada in a global context and to understand its evolving role in the world community' (OME 1999: 2). In the concluding years of high school, the study of history (as noted above) becomes optional and the curriculum for grades 11 and 12 is tracked along two general paths: university/college and workplace preparation. Canadian and World Studies for grades 11 and 12 (like 9 and 10) 'encompasses five subjects: economics, geography, history, law, and politics’ (OME 2000: 3).

The history courses that can be elected in these last two years again reflect the same local/global dynamic structuring the entire scope and sequence of the Ontario Curriculum. In grade 11 a student can take 'American History', 'World History to the Sixteenth Century', 'Canadian History and Politics Since 1945', and 'Twentieth-Century History: Global and Regional Perspectives' (OME 2000: 116-62). There are two capstone courses for grade 12: 'Canada: History, Identity, and Culture' and 'World History: The West and the World'. If there is one 'Place' where the Ontario Curriculum fails to sustain a 'World Connection' equal to the local/global dynamism of the preceding grades, it is in the overarching thematic structure of these two courses. In the course 'Canada: History, Identity, and Culture', a student can 'learn how modern Canada was shaped by the interaction among Aboriginal peoples, the French, the English, and subsequent immigrant groups' (OME 2000: 163). Of these respective groups, only Aboriginal peoples appear consigned to their 'heritage' and the 'contributions' they have made.

But if one looks again at the three McGraw-Hill Ryerson history textbooks (Deir et al. 2000a, b, Newman 2000) considered above, which appear to model explicitly their unit book design on the Ontario Curriculum, a curious displacement of the indigenous presence can be noted. Most of the historical content 
about Canada's native peoples is found in Canada: The Story of Our Heritage (Deir et al. 2000b). As one moves from past to present, and closer to Confederation in the next two textbooks: Canada: The Story of a Developing Nation (Deir et al. 2000a) and Canada: A Nation Unfolding (Newman 2000), the coverage, as noted in the opening discussion in the section above on 'Globalization, textbooks, and the story of nations', becomes fragmented, tends to jump ahead, resuming in the concluding chapters to the present-tense discussion of 'The story today'.

A different kind of displacement occurs with the other course. 'World History: The West and the World' appears to be caught in a paradigm shift. Not properly a 'world history' course as the discipline might conceive it, the grade-12 capstone course is more like a traditional course in Western civilization with global aspirations. A survey of 'major trends ... from the Sixteenth century to the present' (OME 2000: 174), the 'Overall Expectations' cannot get beyond the reductive perspective of conceiving the course in terms of 'the West and the rest' (p. 179), an unfortunate phrase which places 'the West' into a reified category resistant to the kind of broader comparative analysis fitting to the study of world history (OME 2000).

\section{Meta-text for a transnational story}

Conceiving of the world today as a 'community' of interacting 'local, regional, and national communities' largely brought together by the phenomenon of globalization, the Ontario Curriculum with its rigorous breadth, depth, and specificity falters only when it ethnocentrically frames the world as a mere accompaniment to its presumed centre, 'the West'. But imagine what kind of global community might come into view had the word 'and' been changed to 'in': what possible world, or worlds, might emerge had the course been conceived of as 'The West in the world'? Similarly, how might the local history of Nunavut appear when the indigenous presence is not relegated, as is the tendency with the Ontario Curriculum, the California History-Social Science curriculum, or the Australian and New Zealand textbooks mentioned herein, to the museum-like anteroom of 'heritage', where their past contributions to the national story can be safely discussed, once the nation is placed on the path of progress?

As textbook publishers accommodate the imagined needs of nations, diligently following the expert lead of state curriculum developers, less attention is taken to a wider world not in the story. That world in all its complexity exceeds the conventional form imposed on it by the story of nations. The paradox globalization presents is one of 'complex connectivity', a 'condition' in which all nations and the world, as Tomlinson (1999: 2) observes, are caught up in a 'rapidly developing and ever-densening network of interconnections and interdependences'. In that sense, to get inside the history of the Kwakiutl or the Inuit today, people should look at that history globally and comparatively. That 'condition' does not only apply to the present. The Kwakiutl of the nineteenth 
century are intimately connected to the Inuit of the twenty-first. The same global force of nationalism that suppressed the potlatch ironically affirms the new nation of Nunavut. Similarly, the progress of a John Wesley Powell, albeit modified of its racism, can be re-invoked on the new symbolic frontier of multicultural diversity, where the voice in the margin enters the mainstream textbook.

But as textbooks go, such connections require a model of design capable of an order of exposition and explanation, which can adequately frame the local-global dynamism of the emerging world system. To have an outside-in view of nations suggests moving beyond a linear view of time, as it does narrative. A transnational framework suggests a need for new metaphors, a 'meta-text' suitable to unlocking a global context (Chamblis and Calfee 1998: 261). A global context should be capable of 'multidimensional' representation and 'plural perspectives', one that Waldman (2000: 91-2) has said:

can capture simultaneity and exchange, not just sequence and effect, that can trace the delicate filigree and articulation of boundaries and borders, that can fit things together in such a way as to ... generate complexities adequate to the messiness of human phenomena distributed over time and space.

Any transnational framework equal to framing an indigenous present or the story of nations might emerge along four points of paradoxical tension:

- Roots/routes

- Bits/nodes

- Homogeneity/heterogeneity

- Difference/diversity.

Nations, first, immigrant, or ethnic, all have a point or place of origin, that can be symbolic, geographic, or both. Whether a people or an individual trace their roots to a home country or region, a tradition or cultural heritage, often it is the point of origin that is emphasized. But globalization shifts the emphasis on roots to an awareness of the route travelled (Clifford 1997) - not only the route marking how a people migrated to their adopted country but also the historical process tracing how their identity was constructed from past to present. Similarly, nations, like ethnic groups, can be viewed as autonomous bits, territorially and culturally, having distinct identities and an ethos that separates them from others. But in a global context, nations are enclosed within a complex network of node-like relations.

Culturally, modernization, mass-production, and media have produced a lifestyle homogeneous in pattern, largely reflective of western values, and presently dominated by US influences. This process of Americanization has accelerated under the present regimes of economic globalization, although this homogeneity arguably is superficial, sharing a contested ground where more 


\section{8}

complex heterogeneous patterns of cultural hybridity are in play. Within this larger cultural field, the political relations of multicultural nations like Canada have fashioned a tenuous unity and national identity. The cultural and ethnic nationalism of the Inuit and the Québécois have strained the inclusive mosaic of diversity. But in the bicultural dilemma of Canada, and for that matter New Zealand, lies the key to understanding that nations rarely recognize difference as they are successful in containing it.

Briefly sketched, these four heuristic co-ordinates are at the crux of an emergent global context. Reflecting the local/global tensions of globalization, and perhaps fundamental to the condition of postmodernity, they are basic to developing a transnational framework that connects the story of nations to a world without borders.

Perhaps the more provocative lesson of this comparative chapter is that indigenous First Nations may also be the last. The temporal line of events connecting nineteenth-century nation-building with twenty-first-century globalization are strikingly bold and clear. Set on the path of progress and modernity, the indigenous presence in national history sits as a crucible at the intersection of political and cultural forces inevitably compelling recognition and change. That change is to some extent evident in the contemporary textbooks reviewed here. That the social and economic displacements wrought by globalization in the borderlands of the present world may have their precedent in the indigenous struggles a century past does not mean that the articulation of a transnational context for tomorrow's textbooks is a sure thing. The discipline of world history, largely a by-product of the 'new' history movements noted above, is still emergent, fluid, and without a dominant consensus. ${ }^{12}$ If the curriculum frameworks reviewed here are any indicator, the nation-idea still centres the world, and the new histories decentring the dominant western orientation of that world have yet to make a substantial impact with state educational institutions, even though their perennial mandate is curriculum reform. And, adding to this conservative inertia, although publishers take their corporate citizenship seriously, their overriding commitment is always the market, a market vision that in design delicately balances the best of the nation with the text of progress. $^{13}$

To that end, I conclude as I began: in the story of nations today, the progress that Cathy Freeman represents for mainstream Australia is no doubt incalculable, though the torch she raised sheds little light on her country's indigenous realities past and present. Although the Olympic internationalism she represented does indeed represent an ideal world, it is one that appears to be far from a transnational vision necessary to move beyond the surface-spectacle of that global event.

\section{Notes}

1 Parramatta was the site of the first Crown Colony school set up to educate and, ostensibly, to civilize Aboriginal children (Fletcher 1989). 
2 The Australian historian Geoffrey Blainey coined the expression. For a recent discussion of its larger significance to race and politics in Australia, see Markus (2001).

3 Turner (1985). Perhaps one need look no further than the US Declaration of Independence to locate the palimpsest for Turner's formulation of savagery/ civilization. In that most revered nation-building document in the section on 'Colonists' Complaints Against the King', 'the merciless Indian Savages' are already positioned against the colonial 'inhabitants' on America's 'frontiers'.

4 A similar tax, modelled on California's, was imposed on Chinese immigrants by the Australian government (Markus 1979: 34).

5 This definition of the frontier is from the fifth-grade textbook, America Yesterday and Today (Endsley 1991: 187). Scott, Foresman is now a division of Addison Wesley Longman.

6 Eddie Koiki Mabo, a Mer (Murray) Islander, Queensland, brought suit against the Queensland government to Australia's High Court, which claimed Mer Islander Aborigines had traditional tribal rights (native title), which gave them ownership over the Islands and control of its resources. After a ten-year court battle, the High Court in 1992 ruled in the Mabo decision that Aborigines did under certain circumstances have native title which overrode what may have happened to their lands after British colonization. In 1996, the Wik court decision followed. The Wik people, of Cape York Peninsula, Queensland, also claimed native title to their lands. Wik set out the legal conditions under which native title cases could proceed (Brennan 1998).

7 For example, see The American Nation: Independence Through 1914, Grade 8 (Davidson et al. 2000: 30-1), and America Will Be, Grade 5 (Armento 1999a: 80-1).

8 See, for example, Cunneen and Libesman (1995) and Scott-Murphy and Jones (1996).

9 Located on New Zealand's North Island in the area known as the Bay of Islands, well to the north of New Zealand's largest city, Auckland, Waitangi was originally an old whaling port settled in the 1700s by, among others, New England whalers from New Bedford, Massachusetts. The port was one of the first chief points of exchange with Northland Maori tribes.

10 See McHugh (1997) for a critical overview of how the Waitangi Tribunal's legal deliberations have had a profound impact on traditional Whig models of New Zealand national history.

11 In fact, as Williams (1989) points out, there were several English versions of the Treaty, only one of which became the official version, in contrast to the one reconstructed Maori text, the original irrevocably lost. Apart from the long-standing 'invisibility' of the Maori text, Williams notes that the two versions have always 'been talking past each other', with the Pakeha version basically a document legitimizing a transfer of power, while the Maori text affirms their continued sovereignty.

12 See Dunn (2000) for an important overview of these issues and trends.

13 Addison Wesley Longman of Australia and New Zealand was part of the Londonbased Pearson International Media Group. In 1999, on their now withdrawn website, the company reported that its educational mission involved a commitment 'to the support of active learning, critical thinking, co-operative learning, problem solving and multicultural awareness for primary school students via traditional and non-traditional avenues'. Similar commitment to cutting-edge pedagogy and global corporate citizenship and diversity can be found in the annual reports of McGraw-Hill Ryerson, the largest educational publisher in the USA, Canada, and Australia. In their Letters to Shareholders of 1997, the company reported:

a world-wide surge in spending for financial services, education and media - our company's core products. As the globalization of business has marched on and free market principles have spread, recognition that information, knowledge and a well-educated population are vital for prosperity and growth has broadened. 
Such a progressive outlook is equally shared and easily found in curriculum documents such as the Ontario Curriculum. Given the global reach of McGraw-Hill and its potential influence in the classroom, one need look no further for reasons why this paper was undertaken - and no more compelling rationale for research and study, especially given its global implications, with publishers serving as the prime agency of mediation for curriculum and culture in a post-national world.

\section{Textbooks}

Armento, B.J. (1991) From Sea to Shining Sea, lst teachers' edn (Boston, MA: Houghton Mifflin).

Armento, B.J. (1994a) America Will Be, revised, teachers' edn (Boston, MA: Houghton Mifflin).

Armento, B.J. (1994b) From Sea to Shining Sea (Boston, MA: Houghton Mifflin).

Armento, B.J. (1994c) Oh, California, revised, teachers' edn (Boston, MA: Houghton Mifflin).

Armento, B.J. (1999a) America Will Be, 21st-Century, teachers' edn (Boston, MA: Houghton Mifflin).

Armento, B.J. (1999b) From Sea to Shining Sea, 21st-Century, teachers' edn (Boston, MA: Houghton Mifflin).

Armento, B.J. (1999c) Oh, California, 21st-Century, teachers' edn (Boston, MA: Houghton Mifflin).

Banks, J.A. (2000) California: Adventures in Time and Place (New York: McGraw-Hill).

Cunneen, C. and Libesman, T. (1995) Indigenous People and the Law in Australia (Sydney, Australia: Butterworths).

Davidson, J.W., Stoff, M.B., and Castillo, P. (2000) The American Nation: Independence Through 1914, teachers' edn (Upper Saddle River, NJ: Prentice Hall).

Deir, E., Fielding, J., Brune, N., Grant, P., and Abram, S.S. (2000a) Canada: The Story of a Developing Nation (Toronto, ON: McGraw-Hill Ryerson).

Deir, E., Fielding, J., Brune, N., Grant, P., and Abram, S.S. (2000b) Canada: The Story of Our Heritage (Toronto, ON: McGraw-Hill Ryerson).

Endsley, P.T. (1991) America Yesterday and Today (Glenview, IL: Scott, Foresman).

Howard, M. (1984) Shaping a New Nation: Australian History to 1901 (Melbourne, Australia: Longman, Cheshire).

Howard, M. (1993) Shaping a New Nation: Australian History to 1901, revised edn (Melbourne, Australia: Longman, Cheshire).

Kenworthy, C. and Kenworthy, S. (1997) First Australians: New Australians Part II Changing Places: Aboriginality in Texts and Contexts (Fremantle, Australia: Fremantle Arts Centre Press).

Kruse, D. (1998) Identity: Images of Australia (Sydney, Australia: McGraw-Hill).

Miller, J. (1985) Koori: A Will To Win - The Heroic Resistance Survival and Triumph of Black Australia (London: Angus \& Robertson).

Newman, G. (2000) Canada: A Nation Unfolding, Ontario edn (Toronto, ON: McGraw-Hill Ryerson).

Newman, H. and Sawyer, R. (1997) To Be Australian (Sydney, Australia: McGraw-Hill).

Pyne, M. (1993) Checkerboard: Themes and Skills in Australian History (South Melbourne, Australia: Longman Cheshire).

Scott-Murphy, J. and Jones, J. (1996) A Question of Justice, Challenge: Indigenous Peoples, 3 Unit Legal Studies (Sydney, Australia: McGraw-Hill). 
Stuckey, S. and Salvucci, L.K. (1999) Call to Freedom: Beginnings to 1914, teachers' edn (Austin, TX: Holt, Rinehart \& Winston; Harcourt Brace).

Wark, J. and Frood, H. (1994) Talking About the Treaty (Auckland, New Zealand: Longman Paul).

\section{References}

Anderson, B. (1991) Imagined Communities: Reflections on the Origin and Spread of Nationalism, revised and extended edn (London: Verso).

Australian Curriculum, Assessment and Certification Authorities (1995) Mapping curriculum in the final year of secondary schooling across Australia (MCFYSSA), Project Report, Victorian Board of Studies, Melbourne, Australia.

Belich, J. (1986) The New Zealand Wars and the Victorian Interpretation of Racial Conflict (Auckland, New Zealand: Auckland University Press).

Belich, J. (1996) Making Peoples: A History of the New Zealanders: From Polynesian Settlement to the End of the Nineteenth Century (Honolulu, HI: University of Hawaii Press).

Bell, P. and Bell, R.J. (1993) Implicated: The United States in Australia (Melbourne, Australia: Oxford University Press).

Berkhofer, Jr., R.F. (1979) The White Man's Indian: Images of the American Indian from Columbus to the Present (New York: Vintage).

Brennan, F. (1998) The Wik Debate: Its Impact on Aborigines, Pastoralists and Miners (Sydney, Australia: University of New South Wales Press).

Brooks, V.W. (1968 [1918]) 'On creating a usable past', in C. Sprague (ed.), Van Wyck Brooks: The Early Years: A Selection from his Works, 1908-1925 (New York: Harper Torchbooks), 219-26.

California Department of Education [CDE] (1987) California History-Social Science Framework (Sacramento, CA: California Department of Education).

California Department of Education [CDE] (1996) California History-Social Science Framework (Sacramento, CA: California Department of Education).

California Department of Education [CDE] (1998) History-Social Science Content Standards for California Public Schools (Sacramento, CA: California Department of Education).

Chamblis, M.J. and Calfee, R.C. (1998) Textbooks for Learning: Nurturing Children's Minds (Malden, MA: Blackwell).

Clifford, J. (1997) Routes: Travel and Translation in the Late Twentieth Century (Cambridge, MA: Harvard University Press).

Cornbleth, C. and Waugh, D. (1995) The Great Speckled Bird: Multicultural Politics and Education Policymaking (New York: St. Martin's).

Deloria, V. and Lytle, C.M. (1998) The Nations Within: The Past and Future of American Indian Sovereignty (Austin, TX: University of Texas Press).

Dunn, R.E. (ed.) (2000) The New World History: A Teacher's Companion (Boston, MA: Bedford/St. Martin's).

Fletcher, J.J. (1989) Clean, Clad and Courteous: A History of Aboriginal Education in New South Wales (Sydney, Australia: Southwood Press).

Gitlin, T. (1995) Twilight of Common Dreams: Why America is Wracked by Culture Wars (New York: Metropolitan Books).

Goodman, D. (1994) Gold Seeking: Victoria and California in the 1850s (St. Leonards, Australia: Allen \& Unwin). 


\section{James Andrew LaSpina}

Gordon, M.M. (1964) Assimilation in American Life: The Role of Race, Religion, and National Origins (New York: Oxford University Press).

Grand Canyon National Park (2003) Tau-Gu, Chief of the Paiutes, overlooking the Virgin River with J.W. Powell, Age 39, Circa 1873. John Wesley Powell Photographs/no. 17229. Grand Canyon National Park Museum Collection, Grand Canyon, Arizona, USA.

Gugliotta, G. (1994) 'World history teaching standards draw critics. As with American guidelines last month, dissenters say Western contributions shortchanged', The Washington Post, November 11, A4.

Hinsley, C.M. (1981) The Smithsonian and the American Indian: Making a Moral Anthropology in Victorian America (Washington, DC: Smithsonian Institution Press).

Hobsbawm, E.J. (1987) The Age of Empire, 1875-1914 (New York: Vintage).

Hofstader, R. (1955) The Age of Reform: From Bryan to F.D.R. (New York: Vintage).

Howitt, R., Connell, J., and Hirsch, P. (1996) 'Resources, nations and indigenous peoples', in R. Howitt, J. Connell, and P. Hirsch (eds), Resources, Nations and Indigenous Peoples: Case Studies from Australasia, Melanesia and Southeast Asia (Melbourne, Australia: Oxford University Press), 1-30.

Hurtado, A.L. (1988) Indian Survival on the California Frontier (New Haven, CT: Yale University Press).

Jacknis, I. (1996) 'The ethnographic object and the object of ethnology in the early career of Franz Boas', in G.W. Stocking, Jr. (ed.), Volksgeist as Method and Ethic: Essays on Boasian Ethnography and the German Anthropological Tradition (Madison, WI: University of Wisconsin Press), 185-214.

Jervis, R. (1997) System Effects: Complexity in Political and Social Life (Princeton, NJ: Princeton University Press).

Kelsey, J. (1990) A Question of Honour? Labour and the Treaty, 1984-1989 (Wellington, New Zealand: Allen \& Unwin).

Kessler-Harris, A. (1990) 'Social history', in E. Foner (ed.), The New American History (Philadelphia, PA: Temple University Press), 163-84.

Laspina, J.A. (1998) The Visual Turn and the Transformation of the Textbook (Mahwah, NJ: Lawrence Erlbaum).

LaViolette, F.E. (1961) The Struggle for Survival: Indian Cultures and the Protestant Ethic in British Columbia (Toronto, ON: University of Toronto Press).

Lawson, R. (1980) 'Towards demythologizing the "Australian legend": Turner's frontier thesis and the Australian experience', Journal of Social History, 13 (4), 577-87.

Lockard, C.A. (2000) 'Global history, modernization, and the world-system approach: a critique', in R.E. Dunn (ed.), The New World History: A Teacher's Companion (Boston, MA: Bedford/St. Martin's), 230-41.

Markus, A. (1979) Fear and Hatred: Purifying Australia and California 1850-1901 (Sydney, Australia: Hale \& Iremonger).

Markus, A. (2001) Race: John Howard and the Remaking of Australia (Crows Nest, Australia: Allen \& Unwin).

McHugh, P.G. (1997) 'Law, history and the Treaty of Waitangi', The New Zealand Journal of History, 31 (1), 38-57.

Ministry of Education (2002) Social Studies in the New Zealand Curriculum (Wellington: Ministry of Education).

Nash, G.B., Crabtree, C., and Dunn, R. (1997) History on Trial: Culture Wars and the Teaching of the Past (New York: Knopf). 
National Center for History in the Schools (1996) World History Standards for Grades 5-12 (Los Angeles, CA: University of California, Los Angeles, Department of History). New South Wales Board of Studies (2002) Human Society and Its Environment Life Skills Years 7-10, Draft Writing Brief(Sydney, Australia: Board of Studies, New South Wales).

Novick, P. (1988) That Noble Dream: The 'Objectivity Question' and the American Historical Profession (New York: Cambridge University Press).

Nugent, W. (1994) 'Comparing wests and frontiers', in C.A. Milner II, C.A. O'Connor, and M.A. Sandweiss (eds), Oxford History of the American West (New York: Oxford University Press), 803-34.

Ontario Ministry of Education and Training (OME) (1998) The Ontario Curriculum: Social Studies, Grades 1 to 6; History and Geography, Grades 7 and 8 (Toronto, ON: Queen's Printer for Ontario).

Ontario Ministry of Education and Training (OME) (1999) The Ontario Curriculum: Grades 9 and 10; Canadian and World Studies (Toronto, ON: Queen's Printer for Ontario).

Ontario Ministry of Education (OME) (2000) The Ontario Curriculum: Grades 11 and 12; Canadian and World Studies (Toronto, ON: Ministry of Education).

Orange, C. (1990) An Illustrated History of the Treaty of Waitangi (Wellington: Allen \& Unwin).

Reynolds, H. (1974) 'Racial thought in early colonial Australia', Australian Journal of Politics and History, 20 (1), 45-53.

Reynolds, H. (1982) The Other Side of the Frontier: Aboriginal Resistance to the European Invasion of Australia (Ringwood, Australia: Penguin).

Sorrenson, M.P.K. (1989) 'Towards a radical reinterpretation of New Zealand history: the role of the Waitangi Tribunal', in I.H. Kawharu (ed.), Waitangi: Māori and Pākehā Perspectives on the Treaty of Waitangi (Auckland, New Zealand: Oxford University Press), 158-79.

Sorrenson, M.P.K. (1998) Indigenous rights: restitution and reparations. Draft paper, Department of History, University of Auckland, Auckland, New Zealand.

Stanner, W.E.H. (1991) After the Dreaming, with a foreword by H.C. Coombes (Sydney, Australia: Australian Broadcasting Commission).

Symcox, L. (2002) Whose History? The Struggle for Standards in American Classroom (New York: Teachers College Press).

Tennant, P. (1990) Aboriginal Peoples and Politics: The Indian Land Question in British Columbia, 1849-1989 (Vancouver, BC: University of British Columbia Press).

Tilly, C. (1984) Big Structures, Large Processes, Huge Comparisons (New York: Russell Sage Foundation).

Tomlinson, J. (1999) Globalization and Culture (Chicago, IL: University of Chicago Press).

Troy, J. (1988) 'Nineteeth century visual images of Australian Aborigines', in J. Jupp (ed.), The Australian People: An Encyclopedia of the Nation, Its People and Their Origins (North Ryde, Australia: Angus \& Robertson), 19-22.

Tully, J. (1995) Strange Multiplicity: Constitutionalism in an Age of Diversity (Cambridge: Cambridge University Press).

Turner, F.J. (1985 [1920]) The Frontier in American History (Malabar, FL: Krieger).

Victorian Curriculum and Assessment Authority (2002) Studies of Society and Environment (East Melbourne, Australia: Victorian Curriculum and Assessment Authority).

Waldman, M. (2000 [1988]) 'The meandering mainstream: reimagining world history', in R.E. Dunn (ed.), The New World History: A Teacher's Companion (Boston, MA: Bedford/St. Martin's), 87-97. 


\section{James Andrew LaSpina}

Wallace, A.R. (1891) Natural Selection and Tropical Nature: Essays on Descriptive and Theoretical Biology (London: Macmillan).

Wallerstein, I. (2000) 'World-systems analysis: five questions in search of a new consensus', in R.E. Dunn (ed.), The New World History: A Teacher's Companion (Boston: Bedford/St. Martin's), 241-5.

Ward, R.B. (1958) The Australian Legend (Melbourne, Australia: Oxford University Press).

Williams, D.V. (1989) 'Te Tiriti o Waitangi - unique relationship between Crown and Tangata Whenua?', in I.H. Kawharu (ed.), Waitangi: Māori and Pākehā Perspectives on the Treaty of Waitangi (Auckland, New Zealand: Oxford University Press), 64-91.

Wolf, E.R. (2000) 'Connections in history', in R.E. Dunn (ed.), The New World History: A Teacher's Companion (Boston, MA: Bedford/St. Martin's), 131-7.

Zangwill, I. (1909) The Melting-Pot: Drama in Four Acts (New York: Macmillan). 


\title{
10 Meta-scientific criticisms, curriculum innovation, and the propagation of scientific culture
}

\author{
Joan Solomon
}

\section{The predicament of science education}

There are practical problems in several countries with the perception of science among young people, and a correspondingly low uptake of physical sciences in schools and colleges - all of which suggest that we take a fresh look at the curriculum. Criticisms emanating from the fields of metascience and postmodern philosophy may be relevant to some of this dissatisfaction. But that alone would probably not have been enough to stimulate the present glut of changes to the science curricula in many countries if it were not also the case that many countries felt the need for a broader scientific education among their population. This brings us to the last term in the title of this chapter, scientific culture, which is beginning to replace both 'public understanding of science' and 'scientific literacy' in some European documents. But the term 'scientific culture' includes in particular the connotations of culture as a kind of knowing which is familiar to many, of general popular esteem, but hard to specify exactly. None of these notions describes the common objectives of science education at the present time: 'esteem' and 'familiarity' are new and uncertain goals, and it is far from clear how any school curriculum might support them.

The immediate stimulus for the curriculum innovators in Britain is a crisis in the number of students opting to study science. At the present time the number of students electing to continue with the study of physics and chemistry after the age of 16 is either diminishing, or failing to increase in step with the expansion of tertiary-level education. The reason why this should be so is not clear. Neither of the two world wars of this century - sometimes called the Chemists' War and the Physicists' War respectively because of the new and dreadful technologies each of them employed for mass slaughter - caused any immediate decrease in the popularity of science subjects at school. Indeed, during the 1950s and 1960s the number of British pupils choosing to study physics increased four-fold, despite vocal public fears and demonstrations against nuclear weapons. Previously, in the 1930s, when the wheezing of old soldiers who had been gassed in the trenches of the First World War was still to be heard in British streets, there was no diminution in the popular respect paid to chemistry, or science in general. On the contrary, the 1930s was a time of 
popularization of high science through books for self-education, like Hogben's (1938) Science for the Citizen (in the series 'Primers for the Age of Plenty').

It is worthwhile studying this movement for self-education in some detail, and what it tried to achieve in terms of the popularization of science, in order to compare it with the problems of today. Lancelot Hogben and other scientists of his time launched a movement called scientific humanism dedicated to the opposition of religion, and to the spreading of scientific education so that workers could both understand the impact of science on society and participate in decision-making concerning its use. In his introduction to Science for the Citizen, Hogben expressed trenchant views on the poor quality of school education, the lack of scientific knowledge among politicians, and the low standard of popular scientific writing, which he described as 'weak-kneed and clownish' because it lacked scientific rigour. Few could accuse Hogben's heavy volumes on popular education in mathematics and science of the same fault! He entertained no doubts at all about his own ability to educate, despite an admission that only 20 students came to the series of 100 lectures on science that Sir William Beveridge, the designer of the social provisions of the post-war British welfare state, had asked him to deliver at the London School of Economics. He attributed this entirely to the students' false belief that economics itself was a science. However, it is certainly possible that this failure to attract young people because of his style of scientific instruction is not without relevance to our problems today.

It is easy to react against Hogben's arrogance and his derogatory comments directed at the social sciences and old scientists who 'wasted their time' on theology, ethics, or other unscientific pastimes. More attractive, however, was his hope of being instrumental in founding both a new social contract and a scientific culture for all the people, although what he meant by this may have been very different from our interpretation. Add to this Hogben's unaffected love of science, despite a conflation of all that is not-science with magic, and it becomes possible to match his views with those of several modern scientists:

science makes stringent demands on our willingness to face uncomfortable views about the universe... . Human nature, deeply rooted in its unsavoury past is on the side of vitalistic theories. When the spirit of intellectual adventure dies and with it the courage to face the austere neutrality of the universe ... it becomes all too easy to find a formula which provides a compromise for the conflicting claims of magic and science.

(Hogben, quoted in Werskey 1978: 112)

Science is a special way of knowing and investigating and the only way of appreciating the process is to do it. Only in this way can people come to recognize a key feature of science - there is only one correct explanation for any one set of phenomena. Finding that correct explanation can be difficult, painful exhilarating, exhausting, frustrating, fun, and ultimately very rewarding.

(Wolpert 1997) 
These scientists of two different periods, who represent the views of many others, wanted to, and want to, change science education so that it can offer a deeper and more rigorous treatment of the discipline, even if this is at the expense of breadth of context. They both personally enjoyed and enjoy science hugely, and were and are sure that it is the only way to reach the truth about what they see as our unquestionably mechanistic universe.

It is not only the philosophers and sociologists of science who wince at these confident scientistic views; many others do so. For reasons which need to be understood, the students of our era seem more repelled by these attitudes than were their parents and grandparents. The Cold War is over, diminishing numbers of our young people are committed to any organized religion, and yet it seems that they are turning away from science to other ways of thinking about our world which might be called 'magical or enchanted', to use Holton's term, or, in more philosophical terms, postmodern.

These opening considerations show that the comments of Hogben or, for example, Wolpert about how to treat the problem of 'science' do not stand up well to inspection. Neither claims about the intellectual superiority of science nor those about the benefits that science can bestow inspire the reluctant students of today. But the suggestion of teaching less content in a more rigorous fashion, which is common to Hogben and Wolpert, is even echoed, rather surprisingly, by some contemporary science educators: 'Given the evidence of students' lack of understanding in so many basic areas, the guiding principle as regards curriculum content must surely be: do less but do it better' (Millar 1996: 12). This is reminiscent of the nursery ruling that if you haven't eaten your greens yet, you will just sit there until you do! It addresses neither the students' difficulties, nor their lack of interest, nor the broad sweep of scientific issues in the public arena. Given the interest of the young in the more humanistic sciences such as psychology and sociology, this repetition of a small range of abstract content, without the essential humanist detail, might well induce more all-consuming boredom.

The malaise afflicting education in the physical sciences is so deep-seated that it seems better to begin with an analysis of the many criticisms levelled at scientific knowledge itself, and to winnow from them those which appear to address the less well articulated difficulties that our young students commonly exhibit. Only then can we derive a sense of what a more popular education in the physical sciences might possibly be like.

\section{Relativism, postmodernism, and other criticisms}

Science engenders not only enthusiasm in its practitioners, but also a rather naive certainty. Too often they tend to write of science, as Wolpert does, as being the one and only road to truth, and of its concepts as being certain and enduring. Some of those who argue against this are the philosophers who point out, as David Hume did two centuries ago, that the process of induction which science uses can never achieve such certainty. However good the experimental evidence may be, the resulting theories must be 'underdetermined'. Of course 
there are some theories which seem more certain than others, such as the kinetic theory of gases as opposed to the still humming background microwaves of the Big Bang of creation. In fact, so much evidence in terms of confirmed deductions and new observations may be built upon the basis of one particular idea that it is only reasonable to consider it more probable than others.

This kind of mild philosophical criticism probably upsets neither the bench scientist who should understand about induction and consequent tentativeness (but often chooses to ignore it) nor the school pupil who almost certainly does not understand it at all. But many practitioners have shown that it is possible to teach the history of science within school in a way that shows that current explanations and theories have superseded older ones. The corollary that these too may one day be discarded in favour of better ones is not lost on most secondary school students. In my experience (Solomon et al. 1992), this casts no slur on science - and indeed may add a measure of excitement to learning a subject which is not closed to further discovery by a framework of finished certainty. It also brings into focus the more humanistic characteristics of those who laboured and failed, many times, before succeeding.

Another level of this kind of criticism of science knowledge comes from social researchers such as Latour and Woolgar (1979) who observe and analyse the processes of experimenting, intuiting, and predicting in normal laboratory settings, or in the context of paranormal science, of uncertainty, or of failed science. Scientists work in groups to 'construct' theories which they then talk up until they are often ready to stand by them through thick and thin, instead of remaining cautious and sceptical as their own propaganda suggests they do. In the course of their work the scientists have to model these new concepts or physical entities, and manipulate them in their minds, in order to make explanations for observed phenomena. It is not surprising, then, that the tentative entities soon become real for them. Philosophers call this attitude 'naive realism'. But these sociologists of science, the relativists, go further - claiming that scientists are riddled with preconceptions about the reality of their constructed images, and do not practise their craft in 'the proper' objective spirit. Hence, some say, scientific theories are no more to be trusted than any maxim of folklore.

Do these local disagreements, the so-called 'Science wars' (Midgley 1997), mean that science education should be fundamentally changed in order to take the new points into account? Should we teach that electrons, the energy concept, and the colliding molecules of a gas, which we have such difficulty making real and believable to our students, are not real at all?

And which should we teach first - their reality or their unreality? Put like that, the answer seems obvious to most science teachers. Science simply cannot be taught at all if the students are to be told that there is no point in believing what is being said. A few relativist ideas have crept into outlying regions of science education practice, but there is no strong movement towards this kind of change in science education. Indeed there is, not surprisingly, considerable antagonism to it from teachers and science practitioners alike.

A more serious threat to the integrity of science arises from its deep special- 
ization and from its increasingly close, even cosy, relationship with industry and government. Lancelot Hogben, and many who followed him in proposing a science for democratic participation, advocated the popularization of scientific knowledge so that people could be protected against the introduction of malign technology by their own informed participation. In his The Consequences of Modernity, Anthony Giddens (1990) argued that the increasing sophistication and specialization of modern science has inevitably led to a situation where the 'weak inductive knowledge of lay people' cannot hope to follow it. Morris Shamos (1995) made much the same point when pointing out that the boast of 'scientific literacy' - its empowerment of the citizen to assess the validity of expert advice - is unattainable in practice. New and unforeseen threats lying on the frontiers of what is known, such as BSE (i.e. mad cow disease), bewilder most other scientists too. Since the new science-based technologies, from modern agriculture to gene therapy, clearly present us with possible risks which may be personal and intimate, this forced dependency on scientific experts is not at all trivial. Risk itself, as opposed to the older idea of hazard or chance, is redolent of our new age. We need to trust not only the experts' understanding of what is incomprehensible to us, but also to trust that science itself has uniquely correct answers. All of us have evidence that the uniquely correct answer does not appear to exist when we most want it. Scientific experts wrangle and disagree in public. Even expertise is contested!

There are a number of possible reasons for this perplexing and frightening knowledge dilemma. The most innocent is that the topics that raise the issues are so new that there exist, as yet, no agreed-upon, correct answers. But if we dig deeper, the question of who it is that agrees to the correctness of scientific answers, who certifies the expert, opens up a whole new field of the sociology of science. Thus, while the relativists look cynically at the construction of scientific knowledge from the outside, others have studied its processes for producing reliable knowledge from inside the science machine. Though some aspects of this look a little like the policing of the publication of results, and other parts seem almost too liberally high-minded (e.g. the norm of complete disinterestedness), the worrying aspect of this is not the ideal norms, but that both industry and government (e.g. the pharmaceutical and agricultural firms and the relevant government departments) are big employers of scientists. At times, all of them have certainly prevented that free publication of scientific results which is so essential if other researchers are to have access to them to stimulate the growth of expert knowledge. The link between the norms of scientific practice and its philosophical principles is so close that it is not even clear which comes first. If there is secrecy or censorship where there should be sharing and open publication, and the seeking of material rewards where there should be only a search for explanation, science may indeed lose its objectivity, its integrity and its very purpose. It is also clear that our lay people will have lost their impartial experts.

All of this impinges on both the public and the school science student. When young people talk about disagreement among scientists, they often attribute this to bias in favour of their employers' interests. The young students may be too 
ignorant about scientific knowledge to satisfy those who measure their understanding in tests, but they do recognize common human failings! A variety of studies from the UK and from Canada, among many others, have shown that the public are becoming cynical about the reliability of scientists' reassurances.

Finally, we need to face up to the more difficult and slippery criticisms of postmodernism. At the time of the Enlightenment, a century or so after the work of Galileo and following the hideous atrocities in the name of religion during the Thirty Years War, the cool rationale of science seemed to offer an escape route into an intellectual heaven. Many of the arguments of the postmodernists hinge on a contention that this intellectualism is now out of date and inappropriate.

There is only enough room here to provide the briefest sketch of the considerable postmodernist protest against the claims of science.

- It denies that there is just one valid way of knowing. The catchphrase is that there is no 'meta-narrative' which is an objective overarching search for truth. Science is, of course, almost the prototype of all meta-narratives.

- Postmodernism insists that the context does make a substantial difference to the argument. In moral or ethical cases in particular it would seem quite absurd to insist that the details of personal or cultural circumstances have no relevance. Could it be that context even makes a difference within science itself? An example of this, which became important to the emerging feminist movement in science, was the Nobel Laureate Barbara McClintock's comment that it was important to 'get a feeling for the organism' in its environment, in order to understand its genetic coding. Contemporary inheritors of reductionism, like Richard Dawkins (1989), insist that we humans are mere vehicles exploited for and by our genes. This anti-humanist trend tries to eliminate all but the most reductionist of descriptions, and it is not just the feminists and multiculturalists who are offended by it.

- The hegemony of scientific knowledge, the postmodernists claim, is no longer tenable. Not only is there public controversy among scientific experts, as we have seen, there is also an underlying 'rage against reason', as Bernstein (1991) puts it. In anti-nuclear, environmental, and other specialissue circles, adherents claim the right to decide for themselves on very different grounds from expert logic. They want to use their feelings for the rights of animals, their respect for our planet, or just their aversion to any new technology which is beyond their comprehension or evaluation.

- Finally, there is a growing rejection of the notion of holding a uniform, and rather blinkered, world-view. Richard Rorty (1989: 40) has elegantly described how we change our own past by what he calls 'the final victory of metaphors of self-creation over metaphors of discovery'. In one sense this is just another aspect of the meta-narrative already rejected, but it applies also to the creation of our personal vision, and even our selfhood and identity. While it is tempting to believe that we, each of us, have a heroic adherence to a single view of the world which we stick to through thick and thin, soci- 
ologists and anthropologists see little evidence for this. Sociologists point to the way we adjust our meanings to the meanings and points of view of those speaking to us.

The Scientific Renaissance may have been the first cause of 'modernism' which glorified logical thinking to the exclusion of moral evaluation, but science as research has suffered very little from the postmodern revolution. By its very nature, the scientific quest cannot but be optimistic. Even if some observations are acknowledged to be problematic and subject to experimental error or uncertain interpretation, researchers will still argue that they are resolutely searching for the truth as best they can, by the best of available methods. Commitment to science in the 'context of discovery' has probably not changed since the days of Galileo and his stirring claim that scientific truth was to be read in the 'open book of heaven'. It is the meta-scientific context of justification which has been injured.

Science education, however, is a different matter. In 1792, at the time of the French Revolution and when the Enlightenment project was fresh and new, the Marquis de Condorcet claimed specifically that science education could form a basis for secularism to the exclusion of religion, metaphysics, and the moral and social sciences. He planned out a sketch of what that would imply which was implemented some hundred years later: 'Let us therefore hasten to prefer reasoning to eloquence, and books to speakers, and bring at last to the moral sciences the philosophy and method of the physical sciences' (Condorcet 1990).

Rigorous science education, as Hogben and Wolpert implied, was good for young people, if rather painful - as things that are good for us usually are. Indeed school students do find the physical sciences difficult as compared with other subjects, and British comparisons of examination results show there is substance in this claim. This difficulty, and the youngsters' opposition to science, has to do with many of those aspects of scientific thinking which the postmodernists specifically attack - logic and mathematical abstraction, lack of context, and the rejection of any alternative considerations which are not certified by science. This opposition is what Gerald Holton (1992), in his analysis of anti-science, called the 'enchanted' thinking evoked by contemporary Green issues, such as emotive attitudes towards animals and the environment. Rigorous science education insists on a complete abjuration of all that is not logical, but most of our young people want to claim a more varied attitude. Perhaps even the steeply growing numbers of our school students who choose to study an unorthodox mixture of subjects may indicate an aversion to tying oneself down to any single perspective, in common with postmodern thinking.

Caring young people who are still uncertain about where they stand on environmental issues remain susceptible to feelings of peer-group solidarity during adolescence. This is another feature not based on logic but well described by postmodern philosophy (Rorty 1991: 21):

There are two principal ways in which reflective human beings try, by placing their lives in a larger context, to give sense to those lives. The first is 


\section{Joan Solomon}

by telling the story of their contribution to a community.... The second way is to describe themselves as standing in immediate relation to a nonhuman community ... the desire for objectivity.

This last is tougher on the young school students of science than on the practising scientists. Scientists form part of a working community sharing an enthusiasm for science, as well as participating in the professional practices of publication, lectures, and peer review. In the classroom, on the other hand, that community is not present. A science student is not a situated peripheral participant in a community. To be a lone objective thinker may court ridicule or unpopularity.

Opposition to the notion that science must be carried out with no regard to evaluative ways of thinking is heating up in Britain, fuelled by some rather crass comments from a small vocal group of scientists. Within the last year, an eminent British biologist proclaimed on a $\mathrm{BBC}$ radio programme that 'Ethics is to biology as pornography is to sex'. With such statements the schism between scientific and evaluative thinking becomes wider. From France comes a blast from the Nobel Laureate Pierre de Gennes (1996) placing 'la didactisme' in science as the latest enemy to be attacked in the name of Marxism and psychoanalysis. There is little support from the science community for any change to science education during this time of the science wars, when the next generation of potential scientists is at stake.

\section{Curriculum considerations}

Our tour through the criticisms of science knowledge designed to identify any features for a radical new curriculum has not produced a very rich haul.

- Teach using stories from the history of science to gain some understanding of the tentative and humanist nature of its theories;

- Discuss contested knowledge in the context of democratic issues and personal risk;

- Place human contexts first when teaching the physical sciences;

- Use a range of ethical and social considerations, and even New Age approaches, as well as the explanatory rationale of science;

- See an easy familiarity with science and its concepts, rather than correct definition, as the important educational goal.

None of these specify a content, but all may be considered as steps along the road to a popular scientific culture. This is not at all the same as the popularization of (high) science. It will aim to show young people a science which is lighter on logic and abstraction, stronger on involvement and active evaluation, and intimately woven into the aspirations and concerns of citizens.

Most theoretical analyses, like the one in this chapter, offer far too little guidance for immediate classroom introduction. Even the content of the new 
curriculum is not specified because it depends so strongly upon joint teacher and student perceptions of importance and situation. Students may, for example, be taught ecology in their school science lessons, but out of school it may carry a quite different label. Renate Bader (1993: 49) has written about the adult perception of science in Germany in the following terms:

Ecology is not necessarily seen as a science, but as a new holistic approach to all aspects of life and nature. It is precisely those most disenchanted with and critical of traditional research and its applications who are drawn towards the Greens. Science for them equals risk; ecology is the saviour.

This kind of reaction makes the choice of science curriculum content especially difficult. Potentially attractive and important topics, from medicine to new plastic materials and animal behaviour, may be reconstructed in a hostile manner by the public. Medical advances are often compared unfavourably with acupuncture or herbal remedies which seem mystical and are believed to have few side-effects. The making of new plastics only serves to remind some of our youngsters of industrial pollution; animal behaviour studies conjure up images of tortured rabbits or protesting monkeys in laboratory cages.

As recently as the 1970s the purpose of the British school curriculum as being the simple transmission of knowledge was so widely accepted that the study of the curriculum was almost completely devoted to identifying suitable categories of knowledge. There was some argument about what might be meant by a working-class or middle-class curriculum, but this was conducted within the confines of a conception of appropriate knowledge. Bernstein (1975), whose thinking was so influential at this time, was writing angrily that curriculum itself was defining what counts as valid knowledge, and adding that schools in working-class districts were exploding in a crisis of confidence about this validity. Malcolm Skilbeck (1982: 12), still working in the old liberal tradition, saw rationalism rather than content as underpinning the science curriculum.

Science ... needs play only a relatively minor part in the process.... From an educational standpoint what is important is not the production of scientific élites or even the training of the whole people in scientific techniques, but the deliberate cultivation of rationality, of problem-solving procedures, adaptability and flexibility and a generalized capacity to face up to the problems of practical life.

But the link between science and rationality on the one hand and practical problems on the other has been a continual impediment to the study of science. There was nothing here of the imaginative, or the humanistic. Skilbeck does go on to claim that open and flexible thought would enable people to consider a wide range of influences and new possibilities for action - but by this time his argument has left the sphere of science. There is no doubt that he wanted to 


\section{Joan Solomon}

prepare our young people to continue the process of reconstructing their society through political action, if and when they so wished. Indeed his three requirements specify, in broad terms, the guidelines he laid down for those seeking to design and write a new curriculum. When translated into our terms for a more radical curriculum, they have immediate implications for science education:

- The transmission of a scientific culture.

- The development of the cognitive and evaluative skills of learners.

- Enabling young people to take part in the reconstruction of their society with respect to technical and scientific issues (STS).

The first of these makes an ambiguous claim. Curriculum theorists, like Peter Hirst and Howard Gardner, have always bargained for the inclusion of their favourite brands of knowledge on the grounds of their contribution to 'culture'. Some fight for Shakespeare, or a classical language, on grounds which seem closer to culture defined as élitist knowledge than to culture as the network of contemporary concerns and meanings. In science, however, the older theories have no special prestige, and soon get superseded by new ones. Modern concepts - DNA, the Big Bang, plate tectonics, Gaia theory, and plastics for medical implants - are the stuff of relevance and their use may well be involved in societal reconstruction. The extent to which they have entered the common culture will depend not on how many people can define them in abstract ways but on their familiarity.

Studies of the public's understanding of science have shown that most adults are not curious about scientific explanations, but we also know that some of the images and metaphors of science do achieve public currency. John Major, the former British prime minister who was not famous for his understanding of science, proclaimed several times as he returned triumphantly from Northern Ireland after negotiating the first IRA ceasefire, that he had made 'a quantum leap forward'! If he was referring to a sudden transition to a new political situation the metaphor was very apt. Likewise, 'DNA fingerprints', another new metaphor, is the stuff of everyday talk, as are genes and clones, light years, and black holes. Even the disturbance produced by the beat of a butterfly's wing in some prehistoric forest is becoming a new image-gift from chaos theory, as seen, for example, in the film Jurassic Park. This is not so much a question of a hard-nosed increase in scientific knowledge, as one of light metaphor, general meaning, and popular culture.

Translating these kinds of considerations back into curriculum-speak shows that what we need in scientific culture for the majority of students who will not become research scientists, is a wide but not necessarily deep knowledge of science and an enthusiasm for it which will breed confidence in using easy and vivid parts of its language. This is precisely the kind of understanding which has been shown by research to be essential for enabling young people to take part in the discussion of social issues. Youngsters will/can only discuss the social issues 
of science and technology if the language is familiar to them. If it is not, the students stop discussing, demanding 'Why don't they [the scientists] speak English?' This implies that it is not abstract theory but an engagement with the general ideas of science in context which is required. Such a transmutation of science - once precise, hard to comprehend and known only to a few - into general knowledge, the stuff of topical and changing metaphors, commonplace and familiar, is a barter in which school education and the general public would be the winners. Those few of our pupils who become future scientists are also likely to be excited and intrigued by these ideas and images, so that their higher education can take place on well-prepared ground.

There have been other analyses of science education which have arrived at roughly similar prescriptions for curriculum change, as has this argument. These have been labelled Science, Technology and Society, or Science and Technological Literacy, and date back to a time and place when educated citizen knowledge and action was thought to provide a strong shield against further disasters such as nuclear warfare and the ruination of the environment. The unfolding of history has now shown that nuclear warfare is not the global threat that we once believed, and that the ruination of the environment is inevitable in the face of industrial development and landless farmers. This is not to deny the value of discussing these issues in the classroom, but it shows that rigorous knowledge, e.g. about the structure of the atomic nucleus and the dynamics of habitats, need no longer be the ultimate goal of science education for the citizen. For every science-based issue which is troublesome, teachers can begin, rather than end, with a discussion of the civic issues involved.

\section{Curriculum innovation and political action}

Science education is currently being re-examined in many countries, in Europe and the rest of the world. Some nations want more practical work to illustrate the nature of scientific evidence, others simply want to shine in the international league-tables. For many countries there is the naive hope that better science education will bring technical innovation, and hence an increase in national economic wealth.

But once curriculum action is seriously proposed, a whole nexus of practical problems arises. As Douglas Roberts (1980: 67) pointed out, science curriculum development is an aspect of the more general problem of 'putting theory into practice' which always proves far more difficult than it sounds. Theoreticians and teachers inhabit rather different spheres of power and realms of values. None of these coincide perfectly, and the resulting mismatch may effectively prevent any curriculum change:

The requirement that a teacher's actions be defensible is a matter of practical ethics, not of theoretical consistency. It is a matter of weighing up the relative value of pupil outcomes, and there comes a point in the weighing where further research information simply does not help ... where the 
teacher has to take a stand, and 'consistency with research' does not constitute adequate grounds for such a stand.

Teachers, as Donald Schön (1983) observed, reflect best while they are interacting with their pupils. Despite any original intention to follow the theoretician's diagnosis, value judgements about one or more pupils' understanding and learning take priority almost involuntarily. If university lecturers and political advisers decide that they want more practical work to be designed and carried out by the pupils, they may run in-service courses for the teachers to show them just how this should be done, but still it rarely happens with any consistency. Profound changes in ways of teaching are needed, and this means that there needs to be a corresponding and persistent change in the teachers' values which will reflect not so much the findings of research as the mood of the nation to which we all belong. Even at the best of times, change like this will happen slowly.

Curriculum innovation calls not just for teaching professionalism of a high order, but also for a generosity of spirit which goes far beyond what has previously been expected. Within the network of honour and status which is a part of any national culture, the public needs to acknowledge this professional generosity of their teachers by the respect and also the autonomy to which they accord them. Outside the school there are many other actors in the innovation process - politicians, local educational advisers, universities, parents, and employers. Do the universities, who may well be looking for more or better trained students, or the parents who harbour ambitions for their children to become doctors and engineers, really want any more than just the old prestigious form of Enlightenment education? For a curriculum change which affects the substance of national culture, the wider the support obtained the more likely the change is to happen.

Historically there have been four main models for putting curriculum change into action.

(1) Top-down, 'teacher-proof', initiatives These are best known from the Sputnik-era when the politicians and science educators of the US decided that science education had failed their nation. The principal scapegoat for this was identified, as usual, as the constituency least able to defend itself - the teachers. So little respect was accorded them that the new educational resources were written in such a way that (it was hoped) the instruction could pass directly from the professors to the students, completely by-passing the teachers. Research has shown that these initiatives failed because they were simply not put into practice.

(2) Top-down 'cascade' training initiatives These curriculum reforms originate in decisions taken at the top, like those in the previous category, but they encourage and enable the teachers to take part by training them in both the new subject matter and in their values behind its introduction. The injection of 
science into the British National Curriculum belongs to this type of innovation. For the first time science was introduced into the primary schools where most teachers knew little or no science. Not all primary teachers could be prepared for the change because of the large numbers involved, so each trained teacher had then to train the others in their own school.

This rarely worked well since the conviction, knowledge, and practice of the rather hurriedly prepared teachers was severely strained in the cascade process. Major problems arose when primary teachers tried to pass on to others as a basis for teaching action the limited knowledge they had acquired in their 20-day courses, not because it was hard to understand, but because the new values in which it was rooted did not transfer so easily. Teaching is a travesty of professional action where it is not based upon conviction and values.

(3) Teacher-led initiatives These happen in a small way on a daily basis in the classroom. They may once have been more common in England than in other countries, and even now, after ten years of the government-imposed, top-down, National Curriculum changes, writers still naively commend the teacher action-research model of curriculum change. A variant of this, the 'periphery to centre' model, was first tried nation-wide by the British School Science Curriculum Review (Ditchfield et al. 1985) during the 1980s in a way quite similar to the Ciencia Viva initiative which is underway in Portugal today. These initiatives provide a very happy initial scenario, which resembles a great optional INSET programme, although only a minority of excellent teachers take part. The British initiative did not succeed in changing the curriculum, and one can speculate that the reason for its failure was that none of the other powerful agents for change were involved in the process.

(4) Democratic curriculum initiative It has been argued that there need to be new ways of thinking about science education for a popular scientific culture, because the expression of its culture is of deep and broad importance to the whole nation. If curriculum change is able to find the right conditions under which science can be introduced into the national culture then many players on the scene will need to give it their backing. Ultimately it is a function of democracy.

This last model of curriculum innovation is echoed in the thinking of the Swedish curriculum theorist Tomas Englund (1986: 253) who struggled with this problem over a decade ago. He wrote that 'whether a syllabus finds general acceptance depends on whether or not the existing hegemony in society as a whole moves in line with this dominant ideology'. The Swedish national curriculum has now been reformed and we can read about both its reliance on teachers and the inside politics of the process. It is significant that, as Carlgren (1995) points out, the new national curriculum contains a mixture of old and new values. It mentions Christian ethics and Western humanism as any traditional programme might do; and yet it also states that the activities of the school must develop the pupils' ability to take personal responsibility and 
perform social action. This links it with the requirements for a science curriculum for societal reconstruction. It is by the results of this programme, Carlgren writes, and not by some simplistic measure of their pupils' learning published in league tables, that the school's effectiveness should be judged by parents as a basis for choice about their children's education.

Englund's (1997) analysis of research didactics in Sweden is also valuable because it shows the tasks still awaiting teacher educators and the range of analyses which are possible. No modern curriculum innovation can take place without concomitant evaluation and research. Englund argues that whether there is a narrow cognitive focus on instruction and learning, or a broader sociological focus on reasons for the choice of teaching methods and special content, there is an important role for teacher educators in ensuring that attitudes towards science education accord with the demands of our pluralist society and the meanings to be attached to the learning of science.

If this analysis is correct there is no longer a special case to be made for science education in terms of its logical power or its economic importance. Its value now relies on the social salience of the issues of new technology in our culture to which it would be linked. Like education in history or in a modern language, science education must depend on cultural arguments rather than on technical know-how. Its task is the making and passing-on of a new cultural scientific heritage, the development of contemporary ways of thinking in science which need not be abstracted from context, and a preparation which will enable our young people to evaluate scientific issues from a personal and cultural point of view. It follows that curriculum innovation in science is no longer a technical matter for science education experts or teachers alone. George DeBoer (1991: 240 ), who wrote what is probably the first history of ideas in science education, concluded that cultural values and socially-relevant science should be at the heart of science instruction for the future, and imagined its operation in the following way:

There would be frequent discussions about the relationships between the principles of science and the events of the day. Nuclear power plants, recycling, birth control, losses to the gene pool when species become extinct, the ozone layer, and genetic engineering would be part of the daily interaction between student and teacher and between student and student. Students would be alerted to read about these issues in magazines and newspapers and to discuss them with family and friends. As John Dewey (1938) told us years ago, isolation in all forms is the thing to be avoided: connectedness is what we should strive for.

What is most attractive about this vision of a new science education is that the 'connectedness' it advocates links so convincingly with a concept of familiar science which is so well embedded within a culture that its present alien nature would be totally forgotten. It seems, if DeBoer's rather utopian ideas could be realized, that this might amend the unpopularity of the physical sciences with 
our young people, who so often prefer to study the more socially-oriented sciences which give meaning to their everyday lives and concerns.

\section{References}

Bader, R. (1993) 'Science and culture in Germany: is there a case?', in J.-M. LévyLeblond, J. Durant, and J. Gregory (eds), Science and Culture in Europe (London: Science Museum), pp. 47-52.

Bernstein, B.B. (1975) Class, Codes and Control (London: Routledge \& Kegan Paul).

Bernstein, R.J. (1991) The New Constellation: The Ethical-Political Horizons of Modernity/Postmodenity (Oxford: Basil Blackwell).

Carlgren, I. (1995) 'National Curriculum as social compromise or discursive politics? Some reflections on a curriculum-making process', Journal of Curriculum Studies, 27 (4), 411-30.

Condorcet (1990 [1792]) 'Rapport et projet de décret sur l'organisation générale de l'instruction publique', in C. Hippeau (ed.), L'Instruction publique en France pendant la Répolution: discours et rapports de Mirabeau, Talleyrand-Périgord, Condorcet, Lanthenas, Romme, Le Peletier de Saint-Fargeau, Cales, Lakanal, Daunou et Fourcroy (Paris: Klincksieck), 105-51.

Dawkins, R. (1989) The Selfish Gene (Oxford: Oxford University Press).

DeBoer, G.E. (1991) A History of Ideas in Science Education: Implications for Practice (New York: Teachers College Press).

Ditchfield, C., Hornsby, J., Thompson, J., and West, R. (1985) 'The SSCR: an interactive and evolving model', School Science Review, 66 (237), 628-33.

Englund, T. (1986) Curriculum as Political Problem: Changing Educational Conceptions, with Reference to Citizen Education. Uppsala Studies in Education, 25 (Uppsala and Lund, Sweden: Studentlitteratur/Chartwell-Bratt).

Englund, T. (1997) 'Towards a dynamic analysis of the content of schooling: narrow and broad didactics in Sweden', Journal of Curriculum Studies, 29 (3), 267-87.

Gennes, P.-G. de and Badoz, J. (1996) Fragile Objects: Soft Matter, Hard Science, and the Thrill of Discovery, trans A. Reisinger (New York: Copernicus).

Giddens, A. (1990) The Consequences of Modernity (Cambridge: Polity Press).

Hogben, L.T. (1938) Science for the Citizen: A Self-educator Based on the Social Background of Science Discovery (London: George Allen \& Unwin).

Holton, G. (1992) 'How to think about the anti-science phenomenon', Public Understanding of Science, 1 (1), 103-28.

Latour, B. and Woolgar, S. (1979) Laboratory Life: The Social Construction of Scientific Facts (Beverly Hills, CA: Sage).

Midgley, M. (1997) 'Visions of embattled science', in R. Levinson and J. Thomas (eds), Science Today: Problem or Crisis? (London: Routledge), 35-50.

Millar, R. (1996) 'Towards a science curriculum for public understanding', School Science Review, 77 (280), 7-18.

Roberts, D. (1980) 'Theory, curriculum development, and the unique events of practice', in H. Munby, G. Orpwood, and T. Russell (eds), Seeing Curriculum in a New Light: Essays from Science Education (Toronto, ON: OISE Press), 65-87.

Rorty, R. (1989) Contingency, Irony and Solidarity (Cambridge: Cambridge University Press).

Rorty, R. (1991) Objectivity, Relativism and Truth (Cambridge: Cambridge University Press). 


\section{Joan Solomon}

Schön, D.A. (1983) The Reflective Practitioner: How Professionals Think in Action (New York: Basic Books).

Shamos, M.H. (1995) The Myth of Scientific Literacy (New Brunswick, NJ: Rutgers University Press).

Skilbeck, M. (1982) 'Three educational ideologies', in T. Horton and P.C.M. Raggatt (eds), Challenge and Change in the Curriculum: A Reader (Sevenoaks, UK: Hodder \& Stoughton), 7-19.

Solomon, J., Duveen, J., Scott, L., and McCarthy, S. (1992) 'Teaching about the nature of science through history: action research in the classroom', Journal of Research in Science Education, 29 (4), 409-21.

Werskey, G. (1978) The Visible College: The Collective Biography of British Scientific Socialists in the 1930s (New York: Holt, Rinehart \& Winston).

Wolpert, L. (1997) 'In praise of science', in R. Levinson and J. Thomas (eds), Science Today: Problem or Crisis? (London: Routledge), 1-21. 


\title{
11 A curriculum for the study of human affairs
}

\author{
The contribution of Lawrence \\ Stenhouse
}

John Elliott

\section{The humanities in the innovatory secondary modern school}

In the early 1960s I was teaching religious studies in an English secondary modern school (Evans 2005), ${ }^{1}$ a type of school that admitted all those pupils who had failed the entrance test into grammar (i.e. academic secondary) schools. At first, secondary modern schools offered a diluted, watered-down version of the grammar school curriculum plus an additional diet of practical subjects such as wood and metalwork, needlecraft and cookery, rural studies, etc. By the time I began teaching in one, the alienation of the pupils was becoming increasingly clear to the majority of teachers. Some responded by adopting evermore repressive measures of control. Some secondary modern schools became little more than concentration camps in which to contain, rather than educate, the vast majority of the nation's children. As one senior teacher instructed me when I was a student teacher, 'Your job is to keep the lid on the garbage can'. Other teachers responded to the alienation they faced daily by asking the question, 'What does it mean to educate these pupils?' The answers they generated created the 'innovatory secondary modern school'. I taught in one and it was a formative experience.

The key ideas underlying the curricular reforms the other teachers and I introduced into the secondary modern school were those of 'relevance' and 'responsible judgement'. The curriculum area on which we embarked became known as 'the humanities': that group of subjects which carried such labels as English, history, geography, and religious studies. All of these subjects dealt with some aspect of human experience and activity but tended to be presented didactically as discrete bodies of inert factual information, the products of work in academic disciplines, unrelated to the lived experience of those required to memorize and recall them in classrooms. It was the organization and transmission of knowledge about human affairs in traditional academic categories that we began to challenge for the sake of 'relevance' and 'responsible judgement'. We tried to reorganize knowledge about human affairs in categories that expressed human experience as it was lived or anticipated by the pupils themselves; for example, 'The Family', 'Industry and Work', 'Relations Between the Sexes', 'Law and Order', 'Poverty', etc. Such a reconceptualization of 
curriculum content arose out of a concern to make curriculum content relevant to 'the lives of pupils' here and now. But this implied a corresponding shift in pedagogy to allow the pupils to exercise their own judgement with respect to the significance (for the way they lived their lives) of the information presented. We embarked on an attempt to move away from an instruction-based towards a discussion-based classroom. Information was no longer to be transmitted as a body of inert facts, but as a conveyor of personal meaning - as something to be interpreted, evaluated, and personally appropriated in the light of the experience of the pupils. This, at least, was the aspiration.

In my school, this reconceptualization of curriculum content and the pedagogy appropriate to it began within the traditional academic timetable. But, gradually, specialist subject teachers realized they were handling the same topics in similar ways, largely because the pupils began to complain they were doing the same things under different subject labels. As a result we gradually began to abandon the traditional practice of teaching different subjects in separate timeunits and by implication started to undermine the idea of the teacher as an expert on a specialist body of knowledge. Topic-centred team-teaching organized in substantial blocks of time under the general label of 'the humanities', co-ordinated by someone called 'head of humanities', became the order of the day in the innovatory secondary modern school during the latter half of the 1960s.

However, the curricular reforms initiated within the innovatory secondary modern school by no means constituted an undistorted realization of the aspirations teachers expressed in terms of ideas like 'relevance' and 'responsible judgement'. Teachers found it difficult in practice to leave the security of seeing themselves as subject experts. Even within the organizational framework of topic-centred team teaching a pattern of 'key lessons', differentiated along subject lines, evolved. Typically, a topic might last for four or five weeks, and each week's time allocation would be devoted to looking at the topic from the point of view of a particular subject. For example, I remember one school taking the topic 'communication'. It went something like this: the work for week 1 was initiated by a key lesson in which the historian talked about the development of communication systems through the ages. It was the geographer's turn for the key lesson in week 2 , and it focused on present transportation systems in the UK. In week 3 an English literature specialist talked about 'inter-personal communication in contemporary literature'. Then in week 4 the religious studies teacher explained how God communicated with man through the medium of angels. On each week the 'key lesson' was succeeded by 'discussion' and 'follow-up work' in small groups. All too often the 'discussion' took the form of teacher question - pupil answer - teacher question - pupil answer, etc. Rather than constituting a free and open exchange of ideas about the moral, social, or political significance of the information transmitted in the 'key lesson', it functioned as an exercise in establishing the teacher's understanding of the significance of the facts in the minds of the pupils. 'Follow-up' written work played a similar role. 
Little attention was given to the logical interrelationships among the various bodies of knowledge presented, or to how they were to be integrated psychologically within the lived experience of the pupils. It was just assumed that, given the 'relevance' of the content, the pupils would be able to make the psychological connections with their own experience for themselves. And of course many did not, remaining in their previous state of boredom and alienation.

In some schools the attempt to link existing factual knowledge with the lived experience of pupils was abandoned altogether. 'Discussion' in the classroom was conceived as a 'debate' about human issues grounded solely in the existing experience of pupils. The more 'heated' the argument, the better the discussion - from the teacher's point of view. It indicated that the pupils were 'involved', 'motivated', and no longer bored, and therefore signalled some kind of progress. But, like the 'key lesson' approach, it failed to address the central problem of how pupils could extend their understanding of their lived experience'. All too often in my experience, such discussions went round in circles; each pupil merely affirming in the face of opposition their existing interpretations of experience. Teachers provided little that might throw new light on the experience of each pupil and thereby move their 'understanding' forwards. Although the teachers who adopted this approach left the security of their 'subject expertise', they resorted to a familiar pattern of human interchange in both academic and everyday life, namely, that of a point-scoring argument, the purpose of which is to undermine the position of those one disagrees with rather than reflect about one's own.

The innovations within the humanities curriculum of the English secondary modern school were, in my view, distorted by a failure on the part of teachers to realize an adequate theory of understanding in the teaching of human affairs. Our practice, if not our aspirations, remained trapped in an 'objectivist' theory of understanding. While it allowed us to organize knowledge content in topic categories and find some room for 'discussion' in classrooms, it also left room for the teacher to operate in the comfortable securities of the subject expert and the didactic pedagogy this status implies.

The theory was as follows: one understands a human act or situation when one knows the relevant facts about it. It is only after it has been so understood that one is in a position to interpret its moral, social, or political significance correctly. The latter 'insights' can then be applied by pupils to extend their insights into their own experience, and thereby serve as a basis for responsible judgements about how they ought to conduct their lives. Understanding, interpretation, and application to experience (judgement) are thus conceived as quite distinct cognitive processes, but linked in a logically-necessary pedagogical sequence.

This theory shaped classroom practice as follows. First, pupils were instructed in the facts, and only then allowed to 'discuss' their moral, social, or political significance. If time then permitted, they were allowed to explore the implications of the 'insights' they gained to their own lives.

How could teachers of the humanities in the innovatory secondary modern 


\section{John Elliott}

school of the 1960s have made a better job of their attempt to translate their aspirations into practice? Well, for a start they could have had better support from educational theorists and philosophers who spent a considerable amount of intellectual energy sniping from academia. Many of their criticisms of emerging practice - 'sloppy thinking on the part of teachers', 'the lack of intellectual discipline and rigour which the new curricula provided for pupils' - were often quite valid. But what the theorists consistently failed to do was to indicate to teachers how the theories of knowledge and education they employed in criticism could be translated into a form of practice from which pupils in secondary modern schools would benefit. In other words, the theorists failed to offer teachers a translation of their theories into a form of practice that indicated how the problem of pupil alienation from the traditional humanities subjects might be solved.

What the humanities teachers of the 1960s needed were practical procedures that addressed the problem of how to make established knowledge in the human field relevant to the life experiences of pupils in terms of a novel theory of understanding; that is, one which significantly differed from the theory informing established practice. I will call such a procedural expression of ideas a praxiology. The function of a praxiology is to mediate between ideas and attempts to actualize them in practice. By shaping ideas in a practical form it not only assists the realization of ideas in practice, but also allows them to be tested and modified in the light of practice. A praxiology supports the art of translating ideas into action without restricting the practitioner's judgement about how this is best done.

Most humanities teachers in English secondary schools had to wait until the early 1970s before such a praxiology was available to them. It came in the form of the Schools Council/Nuffield Foundation Humanities Curriculum Project (1967-72), directed by Lawrence Stenhouse. I was fortunate enough to have been a member of the team that helped Stenhouse in this enterprise. What emerged was a curriculum conceived as a praxiology (although Stenhouse, to my knowledge, did not call it such). Because this was, and still is, a rather novel conception of what a curriculum is, I want to digress a little in the next section and explore its rationale and implications more fully before moving on to look at the Humanities Project as an example.

\section{Curricula as praxiologies}

Lawrence Stenhouse introduced a radically different theory of knowledge to teachers of the humanities, which challenged them to view understanding, interpretation, and application in personal judgement as a unified process. His views were first fully articulated in abstract form in Culture and Education (1967). To my knowledge, few teachers read the book. Retrospectively, Stenhouse may have been more disappointed about its impact on professional educational theorists than on teachers. For he believed that educational theories only fostered the professional development of teachers when they were given 
practical shape in the form of a curriculum teachers could use in their classrooms. Stenhouse (1980: 41) wrote:

all educational thinkers ... should pay teachers the respect of translating their ideas into curriculum. And that means enough contact with classroom reality or enough consultancy with teachers to discipline all ideas by the problems of practice.

Only in curricular form can ideas be tested by teachers. Curricula are hypothetical procedures testable only in classrooms. All educational ideas must find expression in curricula before we can tell whether they are day dreams or contributions to practice. Many educational ideas are not found wanting, because they cannot be found at all.

If someone comes along asking you to adopt an idea or strive after an objective: political maturity or basic literacy, ask him to go away and come back with a curriculum. Or give you a sabbatical to do so for him.

Taking his own advice, Stenhouse shaped the theories articulated in Culture and Education into the practical form of the Humanities Project.

What Stenhouse offered teachers of the humanities was 'a curriculum' conceived as a set of hypothetical classroom procedures they could experiment with as a basis for the reflective translation of educational ideas into educational action. From this conception of a curriculum, Stenhouse derived his now famous idea of the 'teacher as a researcher'. If curriculum is the medium through which educational ideas are tested and developed then teachers must be viewed as having a central role in theory generation. Their reflections about the problems of implementing the theories embodied in curricula should, Stenhouse argued, lie at the heart of all curriculum research.

According to Stenhouse, the 'research' role of the teacher is not merely concerned with the development of theories about methods conceived instrumentally as technical rules for bringing about preconceived learning outcomes. He not only rejected the traditional view that a curriculum was simply a syllabus - a list of content to be covered - but also mounted a penetrating critique (Stenhouse 1970) of the now popular idea that it is a 'rational plan' of content and methods conceived in terms of their instrumentality for bringing about preconceived knowledge in the learner. Stenhouse's ideas of a curriculum and of the teacher as a researcher are grounded in a theory of the educational process which is radically different from the technological model that underlies the notion of a 'rational curriculum plan'. For him, education was not a process of social engineering in which ends and means could be clarified independently of each other. He was very much influenced by R.S. Peters's (1963) view that ideas about educational ends refer not so much to quantifiable products of an educational process as to qualities to be realized in, and constituted by, the process itself. Conceptions of educational ends refer to ideals, values, and principles, to be realized in the way teachers proceed to relate pupils to the content of education and not to the extrinsic outcomes of this process. Educational 
ends constitute intrinsic criteria for judging what is to count as a worthwhile educational process.

This distinction between an educational and a technological process reflects Aristotle's $(1954)^{2}$ distinction between praxis and poiesis. The latter refers to a set of operational procedures for producing quantifiable consequences that can be specified clearly in advance, whereas the former refers to the realization of an ideal way of life - to the actualization of certain ethical qualities in the way people conduct their lives with others. Praxis is a matter of actualizing our ideals and values in an appropriate form of action, and it is always an unfinished enterprise requiring continuous self-reflection and analysis. Moreover, it implies that means cannot be reflected upon independently from ends. By reflecting about the extent to which we have actualized our ideals in action, we not only develop new understandings of how to act, but also deepen our understanding of the ideals themselves.

More than any other contemporary educational theorist, Stenhouse grasped the pedagogical significance of viewing education as a form of praxis rather than a technological process. He understood that good teaching was an art rather than the mastery of techniques. In art, Stenhouse (1980: 42) argued:

Idea and action are fused in practice. Self-improvement comes in escaping from the idea that the way to virtuosity is the imitation of others - pastiche - to the realization that it is the fusion of idea and action in one's own performance to the point where each can be 'justified' in the sense that it is fully expressive of the other. So the idea is tuned to the form of the art and the form used to express the idea.

Thus in art ideas are tested in form by practice. Exploration and interpretation lead to revision and adjustment of idea and of practice. If my words are inadequate, look at the sketchbook of a good artist, a play in rehearsal, a jazz quartet working together. That, I am arguing, is what good teaching is like. It is not like routine engineering or routine management.

...[T] he process of developing the art of the artist is always associated with change in ideas and practice. An artist becomes stereotyped or derelict when he ceases to develop. There is no mastery, always aspiration. And the aspiration is about ideas - content - as well as about performance - execution of ideas.

By viewing curricula as praxiologies - as hypothetical strategies for realizing ideas in practice - Stenhouse posited them as both expressions and objects of practical judgement. As expressions of other people's practical judgements educational theorists, for example - they are a source of ideas. Every attempt by a teacher to translate a curriculum into action involves asking the question, 'What is the meaning or point of doing this?'. In this way, the teacher is forced to grapple with the ideas underlying the judgements that shape the curriculum. But this does not imply that teachers are thereby compelled to accept passively 
the ideas which confront them. By rendering the practical judgements that shape curricula problematic, Stenhouse made them objects for personal critique by teachers.

Curricula foster improvements in educational practice not because they compel teachers to implement their underlying ideas but because they create a framework within which teachers can extend their own ideas by bringing them into a dialectical relationship with other people's. The insights or understandings that emerge and get translated into action 'go beyond' not only teachers' previous ideas but also those they confront in the curriculum. Curricula for Stenhouse were the media through which teachers developed their own insights and learned to translate them into practice. But the understandings and skills so developed always involve 'going beyond' the curriculum. Hence, curricula need to be continuously revised in the light of teachers' judgements. As I shall show later, this view of professional learning expresses the same theory of understanding that Stenhouse applied to education generally.

The Humanities Project is best understood as the medium through which Lawrence Stenhouse conducted a dialogue with the teaching profession. For years after the project team disbanded, some people were keen to point to evidence - for example, from the Schools Council's 'Impact and take-up' research published in 1978 - that the Stenhouse materials and teaching strategies as he conceived them were rarely used in secondary schools. At best they saw this as a sign that an interesting, and even novel, educational innovation failed to 'take' on a large scale in schools. But this constitutes a serious misunderstanding of Stenhouse's conception of the role of the educational theorist as a curriculum developer. For him, the success of his dialogue rested not so much on whether teachers are still using his curriculum as on the extent to which those that did have deepened their own insights into the nature of education, teaching, learning, and knowledge, and with them the capacity to translate them into forms of action within their classrooms.

Writing about the fashionable idea which he himself helped to generate - no curriculum development without teacher development - Stenhouse (1980: 40) warned:

that does not mean, as it often seems to be interpreted to mean, that we must train teachers in order to produce a world fit for curricula to live in. It means that by virtue of their meaningfulness curricula are not simply instructional means to improve teaching but are expressions of ideas to improve teachers. Of course, they have a day-to-day instructional utility: cathedrals must keep the rain out. But the students benefit from curricula not so much because they change day-to-day instruction as because they improve teachers. 


\section{Towards a vernacular humanism: the Humanities Curriculum Project}

The problem Stenhouse addressed through the Humanities Curriculum Project 'rang bells' with a number of us teaching the humanities in the innovatory secondary modern school. He took it from the Schools Council Working Paper no. 2 on Raising the School Leaving Age (1965: 14):

The problem is to give every man $[$ sic $]$ some access to a complex cultural inheritance, some hold on his personal life and on his relationships with the various communities to which he belongs, some extension of his understanding of, and sensitivity towards, other human beings. The aim is to forward understanding, discrimination and judgement in the human field it will involve reliable factual knowledge, where this is appropriate, direct experience, imaginative experience, some appreciation of the dilemmas of the human condition, of the rough hewn nature of many of our institutions, and some rational thought about them.

Reviewing this passage later in an essay entitled 'Towards a vernacular humanism', Stenhouse (1983a: 167) remarked that 'I still find this a moving statement of an aspiration towards a humanistic education for all'. And it was a humanistic aspiration not simply because it emphasized the study of human affairs, but because it restated the importance of individual judgement as against rule by authority in the conduct of life. A humanistic education was concerned with the emancipation of the individual. And for Stenhouse it rested 'upon the passionate belief that the virtue of humanity is diminished in man when judgement is overruled by authority' (p. 163). He defined the 'most civilized state' as the one whose 'citizens are successfully trusted with the responsibility of judgement' (p. 163).

Stenhouse (1983a) wanted to extend the type of education he had received in a school for the élite - Manchester Grammar School - to all. In that school he claimed his teachers had presented knowledge as intrinsically problematic and invited their pupils to question and judge it. Looking at the educational system as a whole he wrote: 'We are still two nations, because we produce through education a majority ruled by knowledge, not served by it, an intellectual, moral and spiritual proletariat, characterized by instrumental competencies rather than autonomous powers' (p. 166). He saw the majority of schools operating with an arid scholastic view of knowledge, conceiving it 'as a matter of law rather than speculation, of assertion rather than enquiry, and of style' (p. 166). So, given a commission by the Schools Council (Plaskow 1985) to construct a humanities curriculum for adolescent pupils of average and below-average academic ability, most of whom were still housed in secondary modern schools, he set about helping teachers to become the instrument of a redistribution of the means of autonomy and judgement.

His point of departure was to define the humanities as the study of human 
issues which were of universal concern within society to pupils and to their parents and teachers. They constituted human acts and social situations which are empirically controversial in our society, e.g. abortion, divorce, the roles of men and women in society, streaming by ability in schools, war and pacifism, and nuclear weapon production. In addition, they are areas of experience where society acknowledges the right of individuals to disagree and exercise their own judgement.

The project redefined the subject-matter of the humanities in terms of its relevance to areas of human experience in which pupils would be expected to exercise judgement. It then specified a general aim to orientate the teaching of humanities so defined: to develop an understanding of social situations and human acts and of the controversial value issues that they raise.

I can remember being rather puzzled as to precisely what this formulation of Stenhouse's meant. He not only resisted the 'rational planning' procedure of operationally defining general aims in terms of measurable learning outcomes, but also politely ignored my attempts to sharpen the concept of 'understanding' through philosophical analysis. However, he did submit the idea to a type of analysis which was at the time quite unique in the field of curriculum development. Drawing on Richard Peters's (1963) claim that educational aims imply process rather than outcome criteria, he proceeded to analyse the idea of 'understanding' into principles of classroom procedure. In other words, from a general aim, he generated what I have called a praxiology. But let him (Stenhouse 1971: 155) describe this process:

To abandon the support of behavioural objectives is to take on the task of finding some other means of translating aim into practice. We attempted to analyze the implications of our aim by deriving from it a specification of use of materials and a teaching strategy consistent with the pursuit of the aim. In other words we concentrated on logical consistency between classroom process and aim, rather than between predetermined terminal behaviours and aim.

Given this basic view that general aims in education imply the kind of classroom conditions that are necessary for their realization, Stenhouse felt little need for sophisticated philosophical analyses conducted from the armchair. Greater clarity about the project's general aim, he argued, would emerge from teachers' attempts to translate its principles of procedure into action. The argument exactly mirrored Aristotle's view that in praxis, as opposed to instrumental action, ends cannot be reflected upon independently from means.

The procedural principles that emerged constituted a 'theory of understanding' rendered in the form of a praxiology for teachers of the humanities. It was something which, in my view, teachers had needed for some time, but it was not widely accessible until after the initial trial phase of the project in schools. The project's official handbook (Stenhouse 1983b: 8) asserts the following principles: 
1 that controversial issues should be handled in the classroom with adolescents;

2 that teachers should not use their authority as teachers as a platform for promoting their own views;

3 that the mode of enquiry in controversial areas should have discussion, rather than instruction, as its core;

4 that the discussion should protect divergence of view among participants, rather than attempt to achieve consensus;

5 that the teacher as chairman of the discussion should have responsibility for quality and standards in learning.

These principles are not so specific as to tell teachers what to do. In other words they are not rules. Exactly how they are to be translated into classroom action remains an open question. They leave room for practical deliberation and reflection by teachers. This is a point I shall return to later.

For Stenhouse (1983b: 14), these principles, which he summarized as the 'demand that the teacher should be neutral on the issues under discussion but committed to certain procedural values' - in authority but not an authority meant that it was not possible for the teacher to be a source of information 'in his own person' because this way of transmitting information 'will inevitably be coloured or at least limited by his own views'. Yet, he argued, to expect students (as pupils were significantly called in the project) 'to be the sole source of information in a discussion group of adolescents seems unwise' (p. 14). So he solved this problem by conceptualizing relevant information as material evidence. The project produced packs of materials on such themes as 'War and Society', 'The Family', 'Relations Between the Sexes', 'Education', 'Poverty', 'People and Work', 'Living in Cities', and 'Law and Order', which were revised and commercially published after the trial phase (1967-70) by Heinemann Education. The 'evidence' was produced in the form of multi-media materials including print, photographs, tape-recordings, and film. It consisted of 'factual' material drawn from the behavioural sciences and history, as well as experiential material drawn from the arts - poetry, literature, song, music, paintings, etc.

For Stenhouse, this material constituted evidence of human ideas, which were relevant to the discussion of human issues. Even the 'factual' statements drawn from the social sciences and history were to be treated as such. They were not to be treated simply as evidence of social facts, but as evidence of the theories and values that entered into people's interpretations of the social facts. This was a position Stenhouse held about facts in general; it was not merely related to those of the social studies. It runs throughout his argument in Culture and Education and is the basis of his general conception of knowledge as intrinsically problematic. If facts are not just inert 'things out there' to be passively observed, but dynamic interpretations of the world in the light of people's theories and values, then they are objects for discussion and judgement.

Stenhouse's position is very much in tune with that of the great philosopher of science, Karl Popper. In his intellectual autobiography Unended Quest (1976: 
180-7), Popper makes a distinction between World 1 - of things and objects, World 2 - of subjective experiences like thought processes, and World 3 - the ideas and theories that constitute the content of experience and thought. He writes:

It is clear that everybody interested in science must be interested in World 3 objects. A physical scientist, to start with, may be interested mainly in World 1 objects - say, crystals and X-rays. But very soon he must realize how much depends on our interpretation of the facts, that is, on our theories, and so on World 3 objects.

Popper's distinctions offer a better grasp of Stenhouse's view of how information generally should be handled in classrooms - as evidence of World 3 and not simply of World 1 objects. He called this third realm 'Culture'.

And so teachers of the humanities had the important role of mediating 'culture' to students, and this meant treating the material evidence or information in which it was embedded as open to discussion and individual judgement in classrooms. Their task was to introduce this evidence in terms of its relevance to the issue being discussed, and in accordance with the principles of procedure laid down. The pedagogic style was to be responsive to the views being expressed by students. 'Evidence' was to be 'fed into the process' and not used to predetermine it. This approach demanded great skill, because it involved a radical departure from the traditional procedure of presenting information merely as evidence of facts about the world of objects and things. It also involved a radical shift from the traditional role of the teacher as an authority, who by transmitting information via his or her own person endorsed its status as fact.

This conception of classroom information as providing access to the realm of culture was difficult for pupils as well as teachers to translate into action. One of my major tasks as a member of the project team was to help teachers reflect about the implementation problems in the classroom. I remember being called into a school in which the pupils were failing to discuss 'evidence' the teachers were putting before them. The teachers wondered whether 'the reading level' required by the material was not too high. This was a common complaint which often resulted in teachers carrying out a comprehension exercise 'before the pupils were able to discuss'. I observed a lesson in this school, and true enough the students remained silent when faced with the evidence. After the lesson I interviewed them. The conversation went something like this:
J.E.: $\quad$ You didn't say very much?
Student: No, we don't like the readings.
J.E.: Why not?
Student: We disagree with them.
J.E.: $\quad$ Fine, why don't you say what it is you disagree with, in the class- room?


Student: The teacher wouldn't like it.

J.E.: Why not?

Student: The teacher agrees with them.

J.E.: How do you know?

Student: He wouldn't have given them to us if he disagreed with them, would he?

What the teachers had failed to clarify to the students was the different conception of classroom knowledge they were now attempting to operate with. Role change on the part of the teacher depends upon a corresponding change on the part of students. This can only be accomplished by clarifying and discussing the new expectations with students. And this in turn rests upon teachers grasping the theories of schooling that students have developed from years of classroom experience, and which enter into and prejudice their interpretations of the 'new situation'.

The implementation of the project's innovatory procedures for handling information in classrooms ultimately rested on teachers' research into the ways students interpreted and responded to their actions in the classroom. In helping teachers in the trial schools to do this - through tape-recording their lessons, interviewing their students, and then analysing these data - the now extensive 'teachers as researchers' movement was born (Nixon 1981).

During the trial phase of the project, members of the central team and teachers collaboratively gathered, shared, and analysed classroom data. From this process, common understandings were developed about the problems of translating the project's principles for handling evidence into action. At the dissemination phase these 'insights' were offered as hypotheses for teachers to test in relation to data drawn from their own classrooms. In order to avoid any suggestion of prescription they were posed as a series of questions for teachers adopting the project to answer.

\section{POINTS TO BEAR IN MIND WHEN PLAYING BACK AND} ANALYSING TAPES OF DISCUSSIONS:

1 To what extent do you interrupt pupils while they are speaking? Why and to what effect?

2 Do you press individuals to take up moral positions? If so, what is the effect on the individual concerned?

3 Reflective discussion can often be slow-paced and contain sustained silences. What proportion of these silences are interrupted by you? Is your interruption ever simply a matter of breaking under the strain rather than a real contribution to the task of the group? If the teacher gives way under the strain of silences and inevitably comes in to talk, the students can use silence as a weapon to make him take over the task they should face as a group.

4 Are you consistent and reliable in chairmanship? Are all the students 
treated with equal respect, and are all views, including those with which you sympathise, critically examined?

5 Do you habitually rephrase and repeat students' contributions? If so, what is the effect of this?

6 Do you press towards consensus? For example, 'Do we all agree?' If so, what is the effect of this type of question? Compare this with the effect of: 'What do other people think?' 'Does anyone disagree with that?' 'Can anyone see another possible view or interpretation?'

7 To what extent do you confirm? Do you for example, say: 'Yes' or 'No' or 'An interesting point' or 'Well done' or 'That's interesting'? What is the effect of this on the group? Is there any trace of students looking for rewards to you rather than to the task?

8 To what extent do you ask questions to which you think you know the answer? What is the effect of such questions on the group? What is the effect of questions to which you do not know the answer?

9 What prompts you to provide the group with a piece of evidence? Was the piece of evidence in practice helpful? If so, why? If not, why not?

10 Are you neutral on controversial issues? Do you disclose generalised moral judgements? For example, do you make it apparent that you think war is justified or not justified or that you think comprehensive schools are better - or worse - than grammar schools? Are values implicit in the question you ask? Are they implied in the words, gestures or tone of voice with which you follow a student's statement? Are you careful to maintain balance in clarifying or summarising a position or point of view? Are you scrupulous not to feed into the discussion evidence intended to push the group towards a view you yourself hold? Do you draw attention by questions to certain parts or aspects of a piece of evidence which seem to support a viewpoint with which you agree? Do you always encourage minority opinions?

11 Do you attempt to transmit through eliciting questions your own interpretation of the meaning of a piece of evidence such as a poem or a picture?

(Stenhouse 1983b: 30-1)

In the first section of this chapter I argued that what innovatory teachers of the humanities lacked in the 1960s was a theory of understanding articulated as a praxiology. This is precisely what the Humanities Project provided them with for the 1970s. And during its trial phase, several teachers proved that, given opportunity and support for reflective analysis, they could use it to improve the match between their aspirations and practice. The project, in my view, proved that, although it was difficult, teachers could develop a pedagogy that went some way towards realizing their dreams.

For the rest of this section on the Humanities Project I want to 'abstract' the theory of understanding embedded in its praxiology for handling evidence in classrooms. 


\section{John Elliott}

I will begin with the principle that discussion rather than instruction should be the core activity in the classroom.

The project did not see discussion as the only classroom activity. Creative and essay writing, drama, expressive art, etc., all had a function as outcomes from, and inputs into, discussion. As such, they constituted the students' creation of additional evidence to be looked at. The packs of materials produced by the project were only conceived as a foundation collection to get the process underway. But then it was expected that the need for additional evidence, either created or discovered by the students through their own 'research', would be generated from the discussion group. Thus discussion was conceived as the core activity which co-ordinated and fostered a more general process of inquiry into an issue. Such an inquiry could last for weeks. This principle of discussion as the core activity highlighted the failure of previous attempts to make discussion anything more than peripheral to instruction in classrooms.

The principle flows from Stenhouse's conception of the 'knowledge' to be transmitted by teachers as intrinsically problematic. As such, it invites individual judgements and promotes an exchange of views. In attempting to translate this principle into action, teachers are confronted with a view of classroom learning radically different from the one they have traditionally operated with. The established theory was that information had to be understood before it was judged; hence the problem trial-school teachers had in resisting comprehension exercises when students responded to evidence with silence. But by conceptualizing information as evidence for discussion, Stenhouse rejected the established theory and reinstated judgement. This assumed that understanding cannot be achieved independently of judgement. It is only by evoking students' judgements - in effect, their prejudices - that they develop an understanding of human acts and situations.

This view is very similar to Gadamer's (1975: 236-7) theory of interpretation (hermeneutics). He argues that every act of interpretation, whether it be of a linguistic text or some other human act, involves bringing our fore-conceptions or prejudgements to bear on the evidence. This is a condition, not a barrier, to understanding, because we can only grasp meanings that derive from other people's experience in terms of the meanings we give to our own. There is no such thing as a bias-free interpretation. The danger lies in the workings of unconscious bias, because this prevents us from being open to other people's meanings. However, once we become aware of our prejudices, we can control them to establish a dialectical relationship with the evidence. The meanings that emerge as a result lie neither objectively in the evidence nor subjectively in the prejudgements brought to bear on it. They emerge from within the dialectical process itself. Thus the development of understanding is a working out of, and extension of, one's prejudices in relation to evidence of other people's meanings. In explaining his mentor, Heidegger's theory of understanding, Gadamer (1975: 236-7) writes:

The process ... is that every revision of the fore-project is capable of projecting before itself a new project of meaning, that rival projects can emerge 
side by side until it becomes clearer what the unity of meaning is, that interpretation begins with fore-conceptions that are replaced by more suitable ones. This constant process of new projection is the movement of understanding and interpretation. A person who is trying to understand is exposed to distraction from fore-meanings that are not borne out by the things themselves. The working-out of appropriate projects, anticipatory in nature, to be confirmed 'by the things' themselves, is the constant task of understanding. The only 'objectivity' here is the confirmation of a foremeaning in its being worked out.

Within the Humanities Project it is the teacher's transmission of evidence as 'problematic knowledge' which enables students to make their prejudices explicit and thereby become aware of them. But this kind of transmission also allows a variety of prejudgements to emerge. And so the process of knowledge transmission is such that, in Gadamer's (1975: 236) words, 'rival projects can emerge side by side'. The importance of alternative viewpoints emerging from the confrontation with evidence is underlined by the principles that the teacher should protect divergence of view and refrain from using his or her authority position to promote his or her own views. The former principle should not be confused, as we often had to point out, with 'promoting divergence'. The point of 'protecting divergence' is to allow the full range of existing unconscious biases to emerge, and not to manipulate biases into existence for the sake of divergence. And this is obviously inconsistent with the teacher who uses his or her authority position to promote his or her own views. Such a strategy inevitably imposes a constraint on the conscious expression of biases when they contradict the teacher's own.

Many teachers have interpreted the principle of procedural neutrality as the teacher not presenting his or her own views to the class, and Stenhouse himself tended to promote this interpretation. However, I would argue that if a teacher gave his or her own views, having made it clear that they should be treated as equally problematic to those expressed by students, and subsequently handled the discussion impartially, then his or her conduct would have been procedurally neutral. Because in practice it is so difficult for students to disassociate a teacher's authority position from his or her 'personal knowledge', neutrality will normally involve refraining from expressing his or her views in person; at least in the early stages of the work with students.

Now the teacher's role in introducing evidence is not simply to stimulate rival judgements, but also to discipline the discussion which emerges as a result. Hence, the principle that as chairman the teacher is responsible for quality and standards in learning. After the initial stage of eliciting divergent views had successfully emerged in trial-school classrooms (where teachers were advised to work with half-classes), the project team noticed a tendency for the discussion to take the form of a hot and heated argument in which each student merely 'dug in' and defended his or her views by attempting to undermine other people's. Although teachers often perceived this as an indicator for a 'good 
discussion', because the pupils appeared 'involved', the project team felt it indicated little development of understanding. Such development seemed to imply a degree of openness towards having one's judgements modified. We began as a result to draw a distinction between argumentative and reflective discussion.

The significance of the emergence of alternative views is that it gives each individual an opportunity to look at an issue from a variety of perspectives and therefore adopt a more open attitude towards his or her own judgements. Teachers can help each student in this respect by ensuring that they listen to the words - the evidence - in which other students express their views, and attempt through asking questions to grasp something of other ways of looking at a situation - of the criteria and standards others employ for evaluating it. By ensuring that students listen to, and ask questions of each other, teachers exercise responsibility for the quality and standards of learning, because this kind of reflective discussion establishes the dialectic of meanings through which understanding - what Gadamer (1975: 236) describes as 'the unity of meaning' - is developed.

But, as Stenhouse realized, teachers not only exercised this responsibility by getting students to listen and ask questions of each other's views. In order to provide conditions for developing understanding of an issue, they needed to widen the discussion by introducing relevant evidence from our rich cultural inheritance. And here, too, the procedure is one of establishing a dialectical process between evidence and individual judgement by ensuring that students listen to, and ask questions of, the evidence.

I hope I have done sufficient to indicate something of the theory of understanding embedded in the Humanities Project's pedagogical procedures for handling information in classrooms. It is a theory that posits understanding, interpretation, and judgement as different aspects of a unified learning process. In the project's handbook for teachers, Stenhouse (1971) wrote: 'The insight into a situation offered by evidence can be grasped only by the exercise of judgement in its interpretation'. In order to understand facts about a human act or situation we need to interpret them (including facts about human artefacts like works of art) in terms of the theories and ideas which underlie their construction. But we cannot do this without bringing our prejudgements about these acts and situations to bear in our interpretations. By becoming aware of our own prejudgements we become more open to the meanings the facts express. Out of the dialectical process that emerges, our understanding of the facts is extended, and our judgement of the act or situation to which they refer modified. It is in, not as a result of, the development of understanding that the capacity for responsible judgement is extended.

Within the praxiology of the Humanities Project, Stenhouse embedded a theory of understanding that coherently demonstrated how information about human acts and situations could be made 'relevant' to the 'responsible judgement' of individuals. In Culture and Education (1967: 18) he summarized his position as follows: 
We are faced with the fact that we interact with the past through an immense store of written records and works of art. These stored ideas allow us to bring 'the best that has been thought and said' into a dialogue with our contemporary culture. Interaction with the past is an element in our own cultural development; and it is of course a major role of the educational system to keep going this conversation of past with present.

Although there are many teachers in the UK today who would claim that the Humanities Project helped them radically to improve their professional practice, the winds of political change were blowing through secondary education in the early 1970s. The growth towards comprehensive schools speeded up considerably. It was politically justified by the claim that they could do as good a job as the grammar schools, and for a wider range of the population. The criterion of success was taken from the grammar school; namely, pupil pass rates in public examinations. David Hargreaves (1982: 66) has argued that: 'Leading members of the Labour Party, from Hugh Gaitskell to Harold Wilson, proclaimed to the public that the comprehensive schools would be "grammar schools for all" '. And so, according to Hargreaves, through the growth of comprehensive reorganization and people's attempts to legitimate it in terms of a grammar school education for all, secondary education in England became 'grammarized'. He points out that this led to the death of the innovatory aspirations of many teachers in secondary modern schools. The emphasis increasingly during the 1970s was on maximizing every pupil's chances of examination success. 'Subjects' came back and with them a concept of knowledge as a body of inert factual information to be recalled and comprehended, but rarely problematic enough to discuss.

In my view the Humanities Project is no longer to be found in the majority of secondary schools because it was 'killed' soon after it was born by the demise of the 'innovatory secondary modern' school, whose aspirations for the teaching of humanities Stenhouse so creatively articulated.

\section{Notes}

1 In this version of the paper, some references have been updated and the syntax revised, where appropriate.

2 Books 3 and 6 of Aristotle (1954) refer.

\section{References}

Aristotle (1954) Nicomachean Ethics, trans. D. Ross (Oxford: Oxford University Press). Evans, N. (2005) Curriculum Change in Secondary Schools, 1957-2004: An Educational Roundabout (London: Routledge).

Gadamer, H.-G. (1975) Truth and Method (London: Sheed and Ward).

Hargreaves, D.H. (1982) The Challenge for the Comprehensive School: Culture, Curriculum and Community (London: Routledge \& Kegan Paul).

Nixon, J. (ed.) (1981) A Teachers' Guide to Action Research: Evaluation, Enquiry and Development in the Classroom (London: Grant McIntyre). 


\section{John Elliott}

Peters, R.S. (1963) Authority, Responsibility and Education (London: Allen \& Unwin). Plaskow, M. (ed.) (1985) Life and Death of the Schools Council (London: Falmer).

Popper, K.B. (1976) Unended Quest: An Intellectual Autobiography, revised edn (La Salle, IL: Open Court Publishing).

Schools Council (1965) Raising the School Leaving Age: A Co-operative Programme of Research and Development, Working Paper no. 2 (London: Her Majesty's Stationery Office).

Schools Council (1978) Impact and take-up project: First interim report. Schools Council, London.

Stenhouse, L. (1967) Culture and Education (London: Nelson).

Stenhouse, L. (1970) 'Some limitations of the use of objectives in curriculum research and planning', Pedagogica Europaea, 6, 73-83.

Stenhouse, L. (1971) 'The Humanities Curriculum Project: the rationale', Theory into Practice, 10 (3), 154-62.

Stenhouse, L. (1980) 'Curriculum research and the art of the teacher', Curriculum, 1 (1), 40-4.

Stenhouse, L. (1983a) 'Towards a vernacular humanism', in L. Stenhouse, Authority, Education and Emancipation (London: Heinemann), 163-77.

Stenhouse, L. (1983b [1970]) The Humanities Curriculum Project: An Introduction, revised by J. Rudduck (Norwich, UK: School of Education, University of East Anglia, for Schools Council). 


\title{
12 Learning for anything everyday
}

\author{
Shirley Brice Heath and \\ Milbrey Wallin McLaughlin
}

In the USA, numerous developments in curriculum studies in the 1980s focused on authenticity in classrooms. To bring students to a sense of ownership in their learning, educators proposed that 'hands-on' projects, portfolios, and performance-based learning complement direct instruction of discrete skills, or segments of knowledge (Peters 1991, Mitchell 1992). Such activities involved collaborative and co-operative learning that assumed distribution of expertise across the classroom. While acknowledging continuing public demands for accountability, educators and policy-makers endorsed goals of integrating evaluation of student achievement with instruction and increasing opportunities for authentic tests of students' abilities (Archbald and Newmann 1988, Frederiksen and Collins 1989, Wiggins 1989, Berlak 1992, Educational Leadership 1992). The situations for such authentic assessment ranged from oral history projects for local archives to programmes that brought business representatives into classes to hear panels, read papers, and engage students in discussion.

Along with such changes in curricular design and assessment came the call for restructuring schools and classrooms to enable them to incorporate such innovative curricula (Newmann 1990, Smith and O'Day 1991). Old roles and relationships - between students and teacher, principal and teachers, school and community - stood firmly in the way of redistribution of agentry and access to knowledge. Old expectations of what schooling should be about and how outcomes should be measured impeded attempts to bring instruction and assessment closer together and to shift some attention to having students know that rather than know what. Pressures for authenticity pushed changes in materials, methods, and organizational structures in order to reshape the curriculum into tasks and tests that more closely resemble everyday learning than past instantiations from teachers' editions of textbooks, fixed lesson plans, and standardized tests (Leinhardt 1992).

But, curiously enough, with all these emphases on curricular and structural changes believed to be mutually supportive of each other, neither educators nor policy-makers gave any attention to where, when, and how learning to learn or learning for anything - takes place under what young people regard as everyday conditions. Ironically, educators have attempted to create 'authenticity' 
artificially rather than study contextually-authentic curricula - authentic to youth - in supportive organizational structures.

What are authentic curricula and the organizational environments that support them? This chapter offers insight for these questions by considering the embedded and mutually-constituting structure and curriculum of youth organizations - such as Boys and Girls Clubs, Girl Scouts, and grass-roots athletic groups that serve as learning environments for some inner-city adolescents. The research on which this chapter draws was carried out over five years in inner-city neighbourhoods of three major US metropolitan areas and focused on the daily life of those organizations judged effective by local youth. ${ }^{1}$

Participating in these institutions are young people who in most cases feel they have no place in school, and they are attracted to these youth organizations because they want 'something to do to stay off the streets'. The development of a sense of membership within these organizations depends on intense involvement in collaborative work toward a project or performance bounded in time and prepared for outside audiences or evaluators. Apprenticeship, peer learning, authentic tasks, skill-focused practices, and real outcome measures permeate these organizations that shape 'everyday' learning for inner-city youth between the ages of eight and 18 into cognitive and social apprenticeships.

It is particularly critical to study the engagement of these young people, since American inner-city youth is so often represented as unreachable by any reasonable educational means. We explore the extent to which the curricular means and ends of these groups are interdependent with the strong sense of belonging and working upon which these institutions depend. What makes them authentic from youth's perspective?

What follows is first a discussion of where the notion of authenticity currently sits within learning theories. Next is a delineation of the features of those youth organizations that their young members regard as places in which they can be safe, have fun, be with their friends and get 'to do something'. We illustrate these features in practice from a detailed analysis of one Girls Club planning meeting and retrospective on this meeting by its members. Finally, we compare the conditions for apprenticeship and guided learning through the different frames of participation that schools and youth organizations offer.

\section{Learning theories and authenticity}

Educators' advocacies of curricular changes that might effectively target students' everyday experiences and resemble authentic daily tasks received considerable support from simultaneous new research directions in cognitive and developmental psychology and cultural anthropology during the 1980s (Shweder 1991, Leinhardt 1992). Studies of practical knowledge and thought for action contributed significantly to understanding ways in which we learn in everyday activities. ${ }^{2}$

Central theoretical support for scholars who reject the separation of cerebral, 
emotional, and bodily involvement has come from philosophy, the social sciences (including psychology), and cognitive science (Goodnow 1990a, 1990b). Those particularly interested in enculturation or socialization have searched for ways to account for the interdependence of individual mind, interpersonal relations, and social situations that enable 'learning' or 'development'. Influenced by tenets that John Dewey put forth in Democracy and Education and that Soviet psychologists Leont'ev and Vygotsky proposed, social scientists began as early as the 1970s to try to relate individuals and culture in order to account for how habits, beliefs, and problem-solving circulate, evolve, and are added to by creativity. Numerous methods of teaching drew from cognitive science encouragement for making learning more real for children through efforts such as reciprocal teaching (Palincsar and Brown 1984). All these pedagogical approaches stressed both the metacognitive dimensions of learning and the effects of the embeddedness of tasks in a culturally-constituted world in which all members see themselves as participants (Tharp and Gallimore 1988, Newman et al. 1989).

This pedagogical work received strong impetus from interdisciplinary social science research studying interactional contexts beyond the dyad and involving highly complex non-discrete learning situations. The work of Lave (1988) and Lave and Wenger (1991) on apprenticeship, and the importance of access to ongoing communities of practice to build a sense of value and identity as learner, contributed substantially to frameworks for a theory of learning. Cultural psychology increasingly struggled to find ways to bring studies of mind, self, and emotion together to help explain development and adaptability in learning (Shweder and LeVine 1984, Stigler et al. 1990).

Rogoff (1995) brought much of this work together to consider the ongoing dynamic of development through participation, of learning as transformation of learner as well as skills and knowledge. Moving beyond the stand-alone ideas of legitimate peripheral participation (Lave and Wenger 1991), apprenticeship (John-Steiner 1985), and guided participation (Rogoff 1990), Rogoff (1995) integrated these ideas in three planes of analysis to account for development through socio-cultural activity. Here, learners in groups have access to the social distribution of knowledge and skills through personal, interpersonal, and community working together. Critical to this reinterpretation of earlier considerations of ways to account for development beyond a mere system of 'individual somehow linked to culture in learning' is the view that the planes are not hierarchically ordered, but are mutually constituting and inseparable. Rogoff illustrates this work through her study of a group of girls selling Girl Scout cookies, i.e. biscuits, showing how the girls learn from each other and from their experiences such details as how to fill out order forms, develop strategies for selling cookies, and deliver cookies in the most efficient way.

Within Rogoff's proposed framework of three planes of analysis, apprenticeship includes more than the customary expectation of novice and expert conjoined as dyad as the novice acquires skills to accomplish particular tasks or levels of achievement. The community, taken here to mean the socio-historical 
institutions, beliefs, and norms of a constituted group, involves individuals in relationships, communication, and social and technological interactions that bear multiple and overlapping functions. For example, Girl Scouts have to learn how to handle the order forms for the cookies, and though leaders give instructions before the girls go out for door-to-door sales, the girls must work out their own uses of these 'on the job'. Such involvement makes the collective experience and sense of direction or goal perceptible to members by means of demonstration, mediated representations (with language, pictorial art, gesture), and trial-and-error participation by degrees.

Guided participation similarly comes not simply in dyadic, purposive interactions, but in a mutuality of directional involvement that ensures access to experts and to chances for practice without threat. Here participation by any one individual may be more or less involved at any point in time, but observation as well as joining in can be shared because the coming event - whether cookie-sale finale, or, in the case of other youth groups, dramatic performance, or basketball tournament - moves everyone along toward the inevitability of a deadline. An intention toward meaning animates learning, since the final experience means something to participants and moves them along the way toward a shared goal. In addition to demonstration and voluntary participation, learners are also motivated through the verbal directions of their peers, who not only give specific guidance, but also offer meta-level comments on processes, norms, and goals (e.g. 'It's quicker if you write down the orders over here and then move them all later to that column' or 'We can't get behind just because it's raining', or 'We'll never catch up to where we need to be Saturday, if we want to go to Sue's birthday party').

Participatory appropriation refers to the actual process of participation that enables meaningful interpersonal activity to be transformative for individuals. What comes from such participation is not the simple transmitting of skill, knowledge, or attitude from others or even from the interaction. Instead, it is the transisting and transforming that come through being in a participatory role.

Implicit, then, within Rogoff's three-planed model is the power of roles that are directly or indirectly revealed in the dynamic nature of events. Roles are not rigidly prescribed, hierarchical or predetermined, as are those of 'teacher' and 'learner' within conventional school settings. The motivating intimations of roles and performance cut through the three planes of personal, interpersonal, and community, and energize their interdependence. Roles are constituted through combinations of skill, attitude, and symbolic means, and the taking on of roles is made possible by the expectation of performance. Participants observe and take part in activities with a sense of fit between their current attitude and abilities and possible roles they may play within a situation or slice of action within an episode. Individuals then take part by taking a part or role, mentally or physically, in events that surround them and that they now contribute to a resulting performance. 


\section{Inner-city youth organizations}

Youth organizations bear little resemblance to most contexts of shared situations or institutional life usually studied for evidence of learning and insight into the nature of guidance in scaffolded problem-solving. To the short-term observer, Boys and Girls Clubs, Little League (i.e. youth baseball) teams, or grass-roots youth-theatre groups represent chaos, with young people of all ages running back and forth, shouting and singing, talking over each other, and appearing never to settle into any identifiable task. Long-term participation and observation, in addition to transcripts of audiotapes of the language of several participants, can, however, lead to the sorting out of actions, artefacts, and agents to see what is happening and how what happens gets carried on into other situations. ${ }^{3}$ What we offer here are the features of these organizations that provide multiple roles through which the young enter into apprenticeship, guided participation, and appropriation through involvement.

Within US inner cities, the young have few choices of places to be - both spatially and in terms of how they identify themselves. Once school closes for the day, they face only home, which, if they are fortunate, offers a safe haven from the streets, but little else except household and childcare responsibilities for either single parents or households in which both parents are at work. The after-school activities of their mainstream counterparts - music lessons, sports teams, children's theatres, or volunteer or paid jobs - are not there for them, nor are safe parks and streets in which they can congregate. In this void, some few youth organizations struggle against the odds to maintain community centres, nationally affiliated youth programmes (of groups such as YMCA, Boys and Girls Club, etc.), and grass-roots basketball teams or theatre groups. These organizations reflect the following array of structural and curricular features.

1 Border zones: They offer a place for inner-city young people not only to be but to take an active role in a variety of situations within the institutions while they look both ways, to their own streets of the inner city and to the mainstream institutions of employment and education.

2 Youth as resources: Adult leaders who are successful in creating environments which attract and engage inner-city youth value young people's diversity of age, experience, and talent, which contributes to organizations that are constantly underfunded and overburdened.

3 Seasonal cycles of plan, prepare, practice, and perform: Major activities - athletics and the arts, especially drama - engage youth from beginning to end as full thinking and acting members.

4 Imagined family: Youth speak of those youth organizations they regard as effective most often as an ideal family. Youth organizations assign responsibilities and chores, run homework sessions and study groups for standardized tests, and require accountability to the group. Youth organizations expect housekeeping chores from those in building-based programmes, clean-up of neighbourhood courts or fields for those without 
buildings, and involvement by both types of groups in discussions of group financial needs. Youth organizations offer safe places, mutual monitoring and support, and structures of give-and-take in work and play.

5 Minimal rules with maximal impact - strictly upheld: Once within these groups, young people must adhere strictly to what are usually only a few rules, some of which they can contribute at the beginning of each cycle. Breaking the rules often means exclusion from the group. Rules leave room for considerable negotiation: a stricture such as 'nobody gets hurt here' ensures members ample opportunity for multiple interpretations.

6 Outside evaluation and self-assessment: Youngsters work within what soon becomes a predictable cycle of practice that culminates in performance before outsiders - dramatic performances for video production or before live audiences or games with other athletic teams that lead to league playoffs. Moreover, they must continuously assess themselves, for they know they will be called on to teach others. Young people seldom learn something just for individual gain; ever-present is the expectation of group improvement and the need for older youth to help guide younger members to new skills.

Inner-city youth comes to be involved in these organizations largely through serendipity - a friend's recommendation, strong urging from a parole officer, or a need to be off the streets until gang tensions cool. Some are school drop-outs, some have children of their own, some hang with gangs on occasion, some have had their share of encounters with legal authorities. Almost all have trouble with learning in school and see themselves as unsuccessful there.

Adult leaders of youth organizations see themselves as creating arenas of practice and performance that are at once real and imagined. The 'everyday' skills of negotiation, planning ahead, and coping to navigate inner-city streets without harm are, in many ways, those that youth leaders see as evidence of the 'working intelligence' (Scribner 1984) of the young. But their everyday knowhow and social skills as practised only within situations of the inner city cannot serve them well if transferred intact to mainstream institutions of education and employment. Theirs is, then, a task of adaptation. Youth organizations offer a nearby and safe arena for this task, with guidance from mediators who know their world as well as that of the mainstream and have their interests at heart sufficiently to hold them to high standards of performance.

Youth organizations create an ever-regenerative present of an up-close and tangible possible world. Not only through their dramatic productions, but also within their member roles in these institutions, young people have to learn to perform as though they were in 'outside' mainstream institutions. The coach of a grass-roots basketball team successful enough to play in tournaments in distant cities puts the players in charge of telephoning travel agencies to check on schedules and figure out restrictions associated with certain price structures. The director of a youth centre asks some members of his club to calculate the cost of painting a large game room and to compare the prices of different hard- 
ware stores and paint companies. Youngsters act as receptionists, clerks, hall monitors, and visitor guides in building-based programmes. End-of-season banquets and programmes engage them as greeters, heads of table, actors, singers, speakers, and general public-relations agents for their organization.

Opportunities to play roles and perform for outside, evaluating audiences are as much the curriculum of youth organizations as are components of their central activities of athletics or the arts. Fundamentally, the curriculum is about membership and what it takes to be part of an ongoing community motivated by a sense of direction and purpose. Here, the authenticity of planning, preparation, practice, and performance comes through interpersonal conjoined goalachievement and the inevitability of deadlines. The months of practice and gradually increased frequency of ball games will roll by and the play-offs will come. Similarly, for projects and performances, the deadline for final exhibition before outside audiences determines the pace of practice and the planned degree of complexity of final outcome. If, within only six weeks, a youth theatre has to work up four programmes to perform for the city's Parks and Recreation summer camps, the frame of what is possible looms over planning and practice.

The strong directionality of youth organization activities also motivates the amount and type of language that surrounds participation. Throughout planning, leaders and older members remind newcomers to restrain their ideas to the realities of budget, time, and feasibility of available personnel, space, and equipment resources. The language of directives, encouragement, comparison, and conditionality mark practices; leaders and older members reinforce demonstration, drawings and musical props with frequent questions of 'What are we doing here?'; 'Josie, do that again; hold it; now tell us what you did'. Members across groups are enlisted as explicators, critics, and sometime demonstrators for others of the group.

Written language in a range of genres goes along with much of what youth organizations do. A youth theatre group keeps a journal throughout their six weeks of practice and performance for the Parks and Recreation programme; they also keep human physiology charts to supplement their daily records of sore muscles as they intensify warm-ups and increase the level of difficulty of dance routines. Youth drama groups write their ideas for scripts and take notes on presentations that outsiders come to give them on topics related to themes of their scripts. Finally, they write their scripts and prepare the programmes and advertising materials for final performances.

\section{At the Girls' Club}

In 1990 the Boys and Girls Club of America was formed from the formerly separate organizations; the all-girl organizations that did not join the merger became instead Girls Inc. One such organization was located in a major metropolitan area of the Southwest of the US. The director, a young European American woman, and her staff continued their dawn-to-dusk programming for girls, remaining at their old centre, and retaining many aspects of the nationally 
developed curriculum of the former Girls Club. Staff and members include Latinas, African-Americans, and European Americans.

Working mothers drop their daughters at the centre by 6 a.m. to have breakfast, go over their homework, and take a bus to nearby schools. During the day, girls too young to go to school stay at the centre with staff members. Mid-afternoon, girls begin coming in by bus from their schools, separate into small groups of a dozen or so girls of about the same age, have snacks and begin their small-group, family-like activities. These include projects to entertain nearby senior citizens, sessions centred around reading children's literature and playing games, life-skills courses that cover birth control and prenatal and infant care, cooking projects, and party-planning. Each afternoon, all members must attend at least two small-group sessions, and in their remaining time, after they complete their homework, they can watch videos, play games, read or just sit and visit among themselves. Most of them leave the club between 6 and 8 p.m. each evening; many come to the club for most of the day on Saturdays.

At the start of each project, many of which stretch over several weeks, staff lay out the general objective and then sit with the girls while they launch into the actual planning. The general cycle runs from planning, preparing (and practising if need be), to performing for final exhibition, usually before parents and an outside group, such as a senior citizens' centre. Through their long-running projects, they keep journals and read from these from time to time.

\section{The egg project}

One afternoon late in February, Francine, a young African-American staff member, gathers with her own two children, 15-year-old Nikki, and 12-yearold Ginny, in the Science Club room. Her small groups of girls, ranging in age from 11 to 16, join her following their after-school snack. She explains that their next project is to be 'the egg project', and they will need to take care of an egg as their 'baby' for five weeks, when they will present their ideas and thoughts about the project in a skit.

Anyway, you're gonna go to WIC [the local welfare commission] and if you're not married, so um uh, you have to if you're gonna stay in school, get a job, or do both. Keep a diary and the diary will tell us day to day, if you keep up with it, what you, hey, what you're doing towards taking care of your baby. If you need to find someone to baby-sit going to work or ... someplace like that. Bring me a note. Just in case our babies become abused or broken you'll go to trial. Anyway, it's a lot of things that you're gonna have to plan today. You need to keep like a little financial thing of how much the baby's costing you starting with the day of delivery. And that means hospital costs and stuff like that.

The girls respond immediately by giving aloud their scenarios of what could happen: 'I hope I don't put the egg in my pocket and forget it's there'; 'How 
much it costs to deliver a baby at the hospital? I have no idea'; 'I'm not gonna be a single parent'.

Francine laughs and gives some answer to each of their projections, and reminds them: 'You know, I was married when I got this [hand on Nikki's back] and I'm a single parent now. So, but I'm talking about before marriage, you know, and all this kind of stuff'. The girls continue talking among themselves, until Merlyn announces loudly: 'I'm going back to school'. Francine turns to her and asks:

You goin' back to school? Ya, well it's not that easy to go back to school and it's not that easy to go out and find a job and take care of a kid, so you got to sit down with somebody, me or your mom or somebody, and say, you know, well, this is what I want to do or this is what I need to do. And all mothers are not going to stay home and take care of the baby for the simple reason that they gotta work to take care of the baby and you, too.

Merlyn responds with 'Oh', and the other girls jump in with their ideas of all the places in town where mothers can both work and leave their children in nurseries.

Nikki: $\quad$ I want the kind of job that I can take my own baby with me.

Francine: You got your own business, right?

Nikki: Yes, ma'am.

Lelab: You can do that, You can do that at the Saints=

Chris: $\quad=$ at All Saints, if you work at All Saints, they got a nursery

Lelab: =you can work at the Tan Hane. If you have your baby, you can bring it up there, because my momma can.

Nikki: There some other places you can bring your baby to work/

Francine: /so you going to school and to work, right? Can you take your baby to school?

Lelah: No.

Francine: So your momma's going to have to keep the baby while you're in school?

Lelab: Right.

The girls then pursue the problem of working mothers who do not work at businesses that have nursery facilities and schools that do and do not allow young mothers to bring their children. Once they have generated such a list, they move on to costs of medical care: delivery, paediatrician, medicine, and days missed from work and school when the baby is sick.

At several points during the conversation, Francine asks the girls 'What are we doing now?'. Their answers range from 'planning' to 'imagining'. Francine herself injects into their talk 'Now we're imagining' several times. She explains that they have to be able to 'think ahead', 'put themselves out there in what it might be like'. She requires the girls to write down the results of their research 
on institutions and their childcare policies as well as their own calculations of projected expenses.

Staff members explain that in all they do with the girls, they want them to be involved and to use what goes on in their activities to learn to consider the consequences of their actions. When the girls begin to have trouble thinking of all they will have to do in the first week of the 'birth' of the egg, Francine comments: 'And it's real hard for you to use your imagination. And I'm talking about a little bit more reality on this thing, right'. Here she emphasizes with them that what she wants them to imagine is reality.

The girls then take charge of the 'reality' they want to define. They rebel against the idea that the egg is 'real'. They propose instead that they all bring their dolls and use these as babies instead of the eggs. Francine tries to object, but they drown her out with requests such as 'Excuse me, Miss Francine, but I was talkin'. They take over the discussion by tossing out all the ways in which taking care of dolls will accomplish all that they could learn from carrying an egg around. All of the girls have dolls, and they talk at considerable length about dressing the dolls. Francine listens for a while and then asks if just dressing a baby is all there is to having a baby. She pushes the point that the fun of having a doll is in dressing it and then being able to put it away or leave it behind. Having an egg removes the fun and etches in the realities. After several such interjections, a few girls take over elaborating Francine's points:

Natasha: OK. OK, like, with a doll you can, like, um, you know, you can, well [another girl giggles] I can't explain. You know, there's just certain things, like, with an egg you have to be extra careful cause if you don't then you'll break the egg, but with a doll you can set it down, you can drop it, you know.

The girls soon concede that dolls cannot replace eggs and move on to discuss what they must do during the second week. Francine asks them what the local welfare commission is, for it is there that they must register. The girls share their knowledge about registering there, services possible, where it is located, and what papers are needed to get properly registered.

Francine keeps reminding them that they must enter their plans and decisions in their notebooks, and they cover the list of choices they must make:

- the economic class to which they wish to belong when they have their baby;

- whether or not they will go on welfare;

- relationship with baby's father;

- welfare penalties if a mother and baby live with a father;

- costs of child care, clothing, medical services;

- problems of sending a sick baby to the doctor with someone else; need for mother's signature;

- problems of having an 'ugly' baby; 
- child support/amount, how to be sure to get it, what to do when you don't.

Contributions of needed information move back and forth among the girls, from Francine, and from written information they know exists and to which they can refer. They name individuals they know who could give them information, negotiate contradictions in the information they have from different people, and propose ways to clear up their confusions.

Francine's goal is to involve the girls in thinking hypothetically and in planning so that they will come to engage this process when they consider opportunities for the future. Across the group the knowledge is distributed also through the various types of sources of information they call upon. In sessions such as this one, the girls' sense of agentry within the current discussion initially exceeds their reflection of self-agentry within the future scenario of keeping the egg. As they move through the discussion, Francine guides them into several occasions of considering the need to be flexible and to plan for the unexpected as well as for the specifics they project for the future. For those who announce they will return to school, go to work, or leave the baby with their mother, Francine raises possible obstacles to these plans. She calls on them to imagine with some foresight not only their choices, but the particular circumstances that may affect their ability to follow through on those choices.

Throughout the discussion, it is the community or the group as a whole that engages in the planning, distribution, testing, and application of information. Together they guide each other toward the central goal or purpose of the smallgroup meeting; if they do not stay on course with the planning that must be done at this session, they will not be able to achieve the next step of the project - the assignment of the eggs. In that first week, Francine tells them they must accumulate - in imaginary terms - all that the baby will need, record the costs, make medical appointments and cope with few hours of sleep. This session, like any small-group session, has a sub-goal that is clearly necessary to the achievement of the overarching goal of the project before them for the next few weeks.

They allow few detours around achievement of the sub-goal of this session. ${ }^{4}$ The primary detour comes in their proposal that dolls substitute for eggs. When Natasha brings the group back to acceptance of the egg idea, she calls up the particular features of keeping an egg that relate to the realities of having to care for a baby. The detour thus mediates for the group their central goal of considering what will be involved in the weeks ahead of caring for their eggs.

\section{Who really knows here?}

Several days after the session discussed above, the field-site worker, a young member of our research team whose long-term presence around Girls Inc. had made her something of a fixture, sat out on the fire-escape in the late afternoon with six of the girls who had been in Francine's group. Talk moved across the usual topics of friendships, life in the summer, and boys. 
During their conversation, they bring up a curricular guide, Choices, designed by the national headquarters of Girls' Club for use in centre programmes. They had used the book last year and hated it because 'it felt like we were comin' to another school. You know, coming to school again, because we had to DO this and had to WRITE this'. Several point out that this year's sessions have been different:

Natasha: With just talkin' about it in a way that, that WE would say. Just come and talk about it as it comes to our mind. Instead of saying, 'What would you do in this situation? What would you do in this situation?'. Well, you know, we, it's obvious what we're gonna say, what we're goin' to do is the RIGHT [said sarcastically] thing, but we don't really know what we're goin' to do until we come to that point $=$

Monica: =like teenagers gettin' pregnant and all. Most of them/

Natasha: /yeah, like what would you do if a boy said he loved ... he's sayin', you know, all this kind of stuff. Well, of course in the book, you're gonna write down, 'I would say no. I would say no.' But if you came to the part, you know, to really doin' it. You'd say, you know, 'Hmm, I don't know'. You wouldn't say, you know, just right off your part, cause $=$

Monica: $\quad=$ he'd try to sweet talk you.

The girls point out that their earlier curriculum, which prescribed activities and asked them to write answers in a workbook, kept them from bringing up all the obstacles to decisions they could in the ideal way they would make in facing problems ahead.

They go on to elaborate on how this year is different, not only because of opportunities to talk about problem-solving among themselves, but also because Francine sometimes brings in boys who join the group's talk. One girl offers: 'I've learned how to communicate with people differently. Even with boys. Even with boys I can see.... And I didn't really know how, you know, boys thought about things'. The girls also role-play interviews with various agencies, such as the local welfare commission, Social Security office, employment office, counsellors at school, etc. Other girls point out that talking in the kinds of situations they have at Girls Inc. gives them a sense of being able to control what comes up, even though several agree 'I haven't had any crisis problems in my life YET! ... and I don't think, I'll ... I don't PLAN on havin' any'.

Their talk indicates their sense of self-agentry, as they move to discussing 'crisis problems' other friends have had and their own thinking about 'if I was in her shoes, I don't know what I'd do. I don't know if I'd do the same thing she's doin' or...' Being in Girls Inc. gives them access to authoritative information - from Francine, the other girls' experiences and reported stories from their friends, and the knowledge from reading that each girl carries around 
in her head. When they speak of Natasha, one of the older girls in the group, they elaborate:

Aya: $\quad$ She reads all these books and everything, and soon as we start havin' discussion, 'I know. I know'. And SHE knows it.

Natasha: It's, no, I like to, I like you know, all those pamphlets back there. I have read all of them. And it's like, so when we have discussions and stuff, it's like all of it, cause ... they're havin' a discussion and nobody's sayin' anything. Then I'll come and I'll say something, 'Oh, yeah, that's right', or 'Oh, yeah, yeah', and the girls really open up. It's like I know what they're thinking. If somebody tries to say something and Francine's goin' 'I don't understand what you're saying'. I understand what she's sayin'. She's sayin'... .

The girls go on to compare their body of experiences and their abilities to talk and give advice with those of Dr. Ruth, a national public media expert on sexual behaviour and reproductive health. The girls elaborate on what it means to have knowledgeable people with whom they can talk within their own group and close to their own age. The central theme of their talk is the relevance of being believed and trusted to being able to listen and to be listened to by others. Deception, falseness, inconsistency, and 'two-facing' come in for hard criticism before they retreat inside at 6 p.m. to wait to be picked up from the centre.

\section{Schools as authentic?}

This look inside Girls Inc. illustrates the many ways youth organizations serve as border zones for inner-city youth. Here cross-age groups engage in complex projects and performances that require considerable planning and consistent reporting and self-assessment. Motion and action, along with oral and written language, drawings, charts, schedules, and maps are constant within organizations such as Girls Inc. where small groups meet and plan, prepare or practise through time-limited cycles that always drive toward immovable, real performance deadlines.

We have detailed here one girls-only planning session specifically designed to enable 11- to 16-year-olds to take on possible future roles as mothers, students, and employees. We have delineated the extent of meta-language of one planning session and the girls' verbalized apperception of themselves in the ordinary work of planning and preparing for the egg project. The close-up look at the role of language within action illustrates the extent to which both the adult leader and older members call on their own experiences, those they have heard from others, and from verifiable authoritative sources (such as printed materials in their organization, as well as those collected on their visits to agencies) in writing. Sessions such as this one are constructed around the idea of making possible maximal participation through highly engaging joint projects and performances. 


\section{S.B. Heath and M.W. McLaughlin}

Careful description and analysis of participants' interactions during occasions of planning suggest the intricacy of doing and thinking in an ever-regenerative present that finally emerges as yet another present. Their planning and shuffling with their planning session gives them practice in examining the transitions and the implications of their own process of planning. The ongoing dynamism of one instance of planning provides in microcosm the ways in which new information, from any of a variety of sources, leads the group to certain detours and resumptions of earlier routes. The present of their discussion includes the past and future, and cannot be separated from them. To the extent that they call up the past through their own or others' experiences, they do so as a present fact, relevant for the ongoing transformations in the flow of their discussion.

But can the features of institutional life and leadership that characterize youth organizations such as Girls Inc. be recreated or shifted to schools? In light of the collaborative calls for restructuring, along with expansion of authenticity within the curricula of US public schools, it is worth comparing how the structures of inner-city youth organizations and those of schools facilitate development at the three planes of authentic socio-cultural activity - personal, interpersonal, community - illustrated here, particularly in planning behaviour.

\section{Time}

Youth organizations use time to their advantage in two primary ways. First, projects and performances must fit within strict time periods with a fixed deadline for performance and evaluation. Second, most individual sessions have no absolute time for closure. Ample time across a season and within each session allows for the building of trust and confidence that must underlie the distribution of knowledge across the group.

Schools, on the other hand, face multiple constraints on time. Individual sessions are often limited to less than one hour; each day is determined in length by bus schedules, safety requirements that regulate who can be on school grounds, and when. Cycles of evaluation are arbitrarily set according to grading periods and the number of days of each academic term. The artificial boxes of time bear no relationship to a task. The time-segments are therefore isomorphic with almost everything except the learning work at hand.

\section{Talk}

Leaders of youth organizations expect talk to do the bulk of the work of planning, preparing, and practising, and talk that results from distributed time cannot be controlled a priori. Leaders expect sources of knowledge, and thus plans and preparations, to emerge from the group's expertise and their knowledge of access to resources. Co-participating through talk is their primary means of constructing their shared knowledge, especially during planning sessions when the pools of knowledge they use as the starting points for their projects must become evident to all. 
Within schools, moving learning along primarily through talk robs teachers of permanent records of display of knowledge. Speech is ephemeral, is distributed usually beyond a single speaker, and does not move, particularly in planning sessions, in a definitive direction. A driving sense that a group must reach a particular point within a set period of time can be assured only through hierarchical leadership and imposition of rules extraneous to the task of the talk and the distribution of knowledge. Moreover, classrooms far exceed in number the discussion groups of most youth organizations, and without some reorganization into small within-class groups, opportunities for talk are very limited.

It is also the case that schools prefer as sources of knowledge those that are verifiable - usually written. The very glue of conversation and oral distributions of knowledge - personal experiences and those reported from others - appear antithetical to the idealized expertise that comes from recitation of written sources of knowledge. The question of whose voice is speaking in schools matters a great deal, and when students do get to speak, whose voice is it that gains the greatest praise and reinforcement? Seldom does it belong to youth.

\section{Choice}

Young people who belong to youth organizations volunteer their participation; they vote with their feet. Effective youth organizations situate their curricula within the youth and not within external rules or mandates. Even those groups, such as the American Campfire Girls and the Scouts which have national curricula, modify these in format and presentation for local needs. Their rules of operation - location and timing of field trips, range of activities pursued, timing of activities - are not dictated by any external authorities except those of the state and city that relate to health and safety codes. Hence, their choices of time, space, travel, activities, uniforms, equipment, etc. are limited primarily by financial and staff resources, and almost any topic of interest to youth can enter the youth organization.

Youth organizations are not totally without constraints on programme or focus, however. Funders, policy-makers, and the public hold consequential views about 'what works' or about the most important goals for youth organizations to pursue. These conceptions of programme and of youth's best interests change dramatically over time - the arts programme favoured last year loses out to this year's interest in academics; athletic teams scramble for support while public and private dollars move to encourage new programmes in drug- or drop-out prevention. The dependence of youth organizations on externally-defined tastes and allocation choices makes them extremely vulnerable and fragile. The genius of youth organizations lies in their ability to remain youth-based, none the less, and to manage these constraints while still providing curricula that attract youth.

Schools face imposing constraints of structure, disposition, resources, and externally-imposed guidelines for curricula and outcomes. But they can try in particular niches and types of activities within particular subject areas to provide for some authentic learning, regardless of their many constraints. 


\section{S.B. Heath and M.W. McLaughlin}

Subjects of study aligned with disciplines determined by institutions of higher learning dictate arenas of topics. Within each of these, teachers have to neutralize their methods and materials to satisfy a constituency of wide-ranging interests. The 'facts' of authoritative sources and incontrovertible evidence must stand as that to be learned and tested in contexts that exclude the person and the personal of the student. Schools have to operate not only under specific curricular guidelines and conceptions of knowledge, but also within the context of laws and regulations regarding aspects of daily school-life such as classroom hours per year, age- and ability-grouping for activities, types of materials for use within classrooms, bus schedules, and teacher assignment. The constraints with which schools must wrestle and within which they must define practice make deep inroads into educators' autonomy, especially in areas most central to authentic curricula.

\section{Cross-age resources}

Discussion, preparations, and performances can draw on experienced resources that extend well beyond the adult leader. 'Seniors' in youth organizations assume responsibility not only for information and know-how, but also for socializing new members into norms of interpersonal interactions, observance of group rules and norms, and representing the organization on the outside. These responsibilities recognize the special status and expertise of older youth, while integrating them into the community. Ages are not artificially segregated but grouped according to their appropriateness for the task or project undertaken. Cross-age communities of practice enhance everyone's role, since everyone has an opportunity to be both apprentice and expert, teacher and learner.

Schools segregate learning challenges according to age. Access of younger students to the experience of their older peers is unavailable during times of 'serious' learning. During recess and 'playtime' for younger children, their interactions are strictly controlled through segregation that is based on spaceusage, gender, and type of activity. As students reach the teenage years, their access to younger students becomes impossible, because the locations of their schools are usually at some considerable distance from each other.

\section{Goal agreement}

Membership within a youth organization implies agreement to participate in the broad direction of the institution as well as in its specific activities. Hence, joining a baseball team means accepting that the coach sees his group as set apart from the violence and grime of the neighbourhood and also as a winning team. These dual goals mean clean-up duty at playing fields, care of uniforms, no use of 'foul' language, respect for women and participation in service projects at local senior citizen centres. Participation means becoming part of the very fibre of the organization and thus enhancing one's access to the pervasive socialization of the group's routines and actions. 
The goals of schools and of schooling are imposed on youth, and are at once highly specific and abstract, ranging from 'to get good grades so as to go to college' to 'getting an education'. The interdependence of schools with close institutional relatives - family and employment - is contentious and distancing. Schools want and need support from families, until such support merges into interference. Schools need to be places where students learn to 'work', but they extol 'academic work' that leads to further education as the ideal and ignore or disparage that work which appears to have no kinship with further education.

\section{Assessment}

Youth organizations integrate assessment throughout all phases of the cycle from planning to final performance. Essential assessment criteria along the way come from older members of the group who report their experiences with outside audiences of the past: last year's Little League players tell new recruits just how they must handle the left-handed pitcher of a particular opposing team. The ultimate assessment is that of the strangers - the outsiders as audience or as opposing teams - who judge, sometimes fairly, sometimes not so fairly, the results. Self-assessment is modelled throughout the season. Have I improved over my own past performance? Assessment counts in real ways in youth organizations: poor performance in the play-offs will cut out possibilities of trophies, travel, and special celebrations; a half-hearted job on the end-ofsummer dramatic performance before funders, friends, and representatives from other youth groups may mean losses of funding, moral support, and local reputation.

Schools both create their own assessment tools and have them mandated by outsiders. The evaluation of student work rests almost entirely outside the student, rather than within the learner's sense of criteria against which to be measured and process of doing so. Distanced from the student are both what counts as evidence and who the critical judges are. So-called authentic assessment attempts to move inside and represent students' work in context. Ironically, however, 'authentic assessments' prove difficult to sustain in practice because of all of the 'inauthentic' pressures in the school and classroom.

\section{Authenticity to the fore}

Key to all these differences is the central fact that youth organizations can and do put youth at the centre (Carnegie Council on Adolescent Development 1992, Heath and McLaughlin 1993). Young people learn quickly in these groups that they are needed resources and not problems in need of fixing. Selfreliance along with the social control of being within a community that sees itself often as being under siege from the outside world stimulates the voluntary spirit that brings young people to these groups. Whereas they must attend school, their participation in youth organizations is entirely of their own free will. Thus those who choose to do so from the inner city are self-selected, to a 
great extent, according to their desire and ability to function within the apprenticing and guided participation that sustain youth organizations.

Youth organizations, through the enablement of these key structural features, represent what are, in many ways, ideal aspects of current curricular reforms. Their programmes cross the lines of many disciplines, draw on an array of sources, engage the young in projects and performances, and exhibit authenticity in numerous ways. Topics and activities are those of interest to the young. Involvement with these meshes oral and written language across a range of genres and forms of representations (journals, charts, graphs, etc.). Members take part in the full cycle of planning, preparing, practising, and performing, knowing that their final assessment will be by outsiders and not by their trusted intimates of the youth organizations. Along the way, their own self-assessments, as well as group sessions taking account of how they are doing, occur as normal parts of the development of their collective activity.

Youth organizations successful in attracting young people and fostering their development illustrate that authenticity must be pervasive, not just here or there. Their structures, mediating tools, and activities sustain participatory appropriation, guided participation, and apprenticeship, all of which are animated through the members' sense of the many roles they can play within the group. Enhancing the playing out of their many roles across their span of time in the organizations is their immersion in meta-language - talk about the roles they play, performances they give and stages on which they will have to play elsewhere. Talk about talk, as well as talk about being a part of a collective activity and playing particular organizational roles as individuals, goes on continuously in the self-conscious atmosphere of an effective youth organization.

These institutions portray themselves as different - from schools, jobs, streets, and other youth organizations that are programme-centred rather than youth-centred. Uniforms, mottos, collective memories, and daily reminders leave no possibility that anyone who comes in contact with them will fail to notice their sense of difference. Youngsters within these organizations absorb a strong sense of distinct identity for their group as well as for themselves as individuals in the broader community. Members repeatedly talk of occasions when people outside the organization comment about them as 'being different' from 'what you'd expect around here', from 'the guys who have just given up'.

\section{Learning from experience: learning for anything everyday}

Proposals of curricular reform that promote authenticity and call for school restructuring may benefit from comparative studies such as ours which examine institutions of curricular authenticity. The voluntary contexts of development that demand authenticity - that enable learning for anything everyday - and thereby make possible the guided participation, apprenticeship, and appropriation of knowledge and experience gained through playing 'real' roles, may require structural readjustments far beyond those currently considered for schools. Imaginative new proposals seem necessary, starting from the premise 
that authenticity in development opportunities for youth ultimately rests in the view that young people are resources. Looking at instances where we find those young most often rejected by schools willingly undertaking challenges of apprenticeship and participation can give us incentives to rethink imposed authenticity in comparison with structure and curriculum grounded in the everyday realities of communities of learners.

\section{Acknowledgements}

We want to thank Rebecca Carver, Stanford Graduate School of Education, for her careful reading of an earlier version of this manuscript and Carol Smith for her editorial assistance.

\section{Notes}

1 This research comes from a study, 'Language, socialization, and neighbourhood-based organizations: moving beyond dependency of family and school', funded by the Spencer Foundation. In addition to principal investigators Heath and McLaughlin, senior associates on the project were Merita A. Irby and Juliet Langman. The judgements by local youth of the effectiveness of the youth organizations studied in this project were reinforced by oversubscriptions, long waiting lists, and facilities booked for youth activities 12-16 hours a day.

2 The term activity has come to symbolize new directions in pedagogy, though the term retains specific meaning for those who associate it with the Soviet theory of activity, in which thinking is 'acting' in a socio-culturally constituted world.

3 A data bank of transcribed talk by leaders and performers during planning sessions, practices, and performances totals more than a million words. Ethnographic field notes and interviews supplement these data. Discourse analysis aided by statistical representations indicates the extent to which certain types of language use conveyed to the youth the philosophy of the organization. Transcription conventions used in language data given here show overlaps between speakers [/ at break-in point of one speaker over another]; latching, occasions when a second speaker completes an utterance of another $[=]$; and pauses $[\ldots$ for pauses exceeding three seconds].

4 The view of planning as a developmental process within socio-cultural activity theory is elaborated in Baker-Sennett et al. (1993). For another example of collaborative planning and problem-solving in an open-ended project, see Baker-Sennett et al. (1992).

\section{References}

Archbald, D.A. and Newmann, F.M. (1988) Beyond Standardized Testing: Assessing Authentic Academic Achievement in the Secondary School (Reston, VA: National Association of Secondary School Principals).

Baker-Sennett, J., Matusov, E., and Rogoff, B. (1992) 'Sociocultural processes of creative planning in children's playcrafting', in P. Light and G. Butterworth (eds), Context and Cognition: Ways of Learning and Knowing (New York: Harvester Wheatsheaf), 93-114.

Baker-Sennett, J., Matusov, E., and Rogoff, B. (1993) 'Planning as developmental process', in H. Rese (ed.), Advances in Child Development and Behaviour, vol. 24 (New York: Academic Press), 254-81. 


\section{S.B. Heath and M.W. McLaughlin}

Berlak, H. (ed.) (1992) Toward a New Science of Educational Testing and Assessment (Albany, NY: State University of New York Press).

Carnegie Council on Adolescent Development, Task Force on Youth Development and Community Programs (1992) A Matter of Time: Risk and Opportunity in the Nonschool Hours (New York: Carnegie Council on Adolescent Development).

Educational Leadership (1992) Using performance assessment, 49 (8).

Frederiksen, J.R. and Collins, A. (1989) 'A systems approach to educational testing', Educational Researcher, 18 (9), 27-32.

Goodnow, J.J. (1990a) 'The socialization of cognition: what's involved?', in J.W. Stigler, R.A. Shweder, and G.H. Herdt (eds), Cultural Psychology: The Chicago Symposia on Human Development (New York: Cambridge University Press), 259-86.

Goodnow, J.J. (1990b) 'Using sociology to extend psychological accounts of cognitive development', Human Development, 33 (2/3), 81-107.

Heath, S.B. and McLaughlin, M.W. (eds) (1993) Identity and Inner-city Youth: Beyond Ethnicity and Gender (New York: Teachers College Press).

John-Steiner, V. (1985) Notebooks of the Mind: Explorations of Thinking (Albuquerque, NM: University of New Mexico Press).

Lave, J. (1988) Cognition in Practice: Mind, Mathematics, and Culture in Everyday Life (New York: Cambridge University Press).

Lave, J. and Wenger, E. (1991) Situated Learning: Legitimate Peripheral Participation (New York: Cambridge University Press).

Leinhardt, G. (1992) 'What research on learning tells us about teaching', Educational Leadership, 49 (8), 20-5.

Mitchell, R. (1992) Testing for Learning: How New Approaches to Evaluation Can Improve American Schools (New York: Free Press).

Newman, D., Griffin, P., and Cole, M., with Broyles, S., Petitto, A.L., and Quinsaat, M.G. (1989) The Construction Zone: Working for Cognitive Change in School (New York: Cambridge University Press).

Newmann, F.M. (1990) 'Linking restructuring to authentic student achievement', Paper presented to Indiana University Education Conference, Bloomington, IN (School of Education, University of Wisconsin, Madison).

Palincsar, A. and Brown, A. (1984) 'Reciprocal teaching of comprehension-fostering and comprehension-monitoring activities', Cognition and Instruction, l (2), 117-75.

Peters, C.W. (1991) 'You can't have authentic assessment without authentic content', Reading Teacher, 44 (8), 590-1.

Rogoff, B. (1990) Apprenticeship in Thinking: Cognitive Development in Social Context (New York: Oxford University Press).

Rogoff, B. (1995) 'Observing sociocultural activity on three planes: Participatory appropriation, guided participation, apprenticeship', in J.V. Wertsch, P. del Rio, and A. Alvarez (eds), Sociocultural Studies of Mind (New York: Cambridge University Press).

Scribner, S. (1984) 'Studying working intelligence', in B. Rogoff and J. Lave (eds), Everyday Cognition: its Development in Social Context (Cambridge, MA: Harvard University Press), 9-41.

Shweder, R.A. (1991) Thinking through Cultures: Expeditions in Cultural Psychology (Cambridge, MA: Harvard University Press).

Shweder, R.A. and Levine, R.A. (eds) (1984) Culture Theory: Essays on Mind, Self, and Emotion (New York: Cambridge University Press).

Smith, M.S. and O'Day, J. (1991) 'Systemic school reform', in S. Fuhrman and B. Malen 
(eds), The Politics of Curriculum and Testing: The 1990 Yearbook of the Politics of Education Association (Philadelphia, PA: Falmer Press), 233-67.

Stigler, J.W., Shweder, R.A., and Herdt, G.H. (eds) (1990) Cultural Psychology: The Chicago Symposia on Human Development (New York: Cambridge University Press).

Tharp, R.G. and Gallimore, R. (1988) Rousing Minds to Life: Teaching, Learning, and Schooling in Social Context (New York: Cambridge University Press).

Wiggins, G. (1989) 'A true test: toward more authentic and equitable assessment', Phi Delta Kappan, 70 (9), 703-13. 


\title{
13 Curriculum forms \\ On the assumed shapes of knowing and knowledge
}

\author{
Brent Davis and Dennis J. Sumara
}

\section{Mapping experience}

During the 1980s, when we were both practising public school teachers, we were required to complete 'year plans' that were to be submitted for the principal's approval at the beginning of each school year. Regardless of grade level or discipline, these plans were expected to obey a very specific format: three columns, the first of which listed all the school days that year, the second identified the sequence of curriculum 'strands' to be followed, and the third parsed those strands into specific, single-lesson topics that corresponded with the dates in the first column. The sense we made at the time was that such 'maps' of teaching and learning were intended to assure relatively seamless and orderly progressions through fields of knowledge for students.

Although we and our colleagues never looked forward to these tasks, we rediscovered every year that it was a relatively simple matter to create such structures of predicted experience. Armed with monthly and weekly timetables, sequentially organized curriculum guides, and corresponding publisher's materials, even the most inexperienced teacher could create these required plans to everyone's satisfaction. It involved little more than matching boxes on calendars to boxes in programmes of study.

Curiously, however, while we both imagined the task might become even easier as we gained experience, the opposite seemed to be the case. As we moved further away from our student teaching experience (with its 1970s emphasis on behaviourist, psychologistic doctrine and methods), we found this annual task more difficult and frustrating. As we each learned more about working with different groups of students, in different schools and communities, amid tremendous social, economic, and political change, it became obvious that learning outcomes could not be contained by orderly boxes, and teaching intentions refused to be bounded by the tidy grids we had been asked to create.

Our experience is hardly unique. The kind of mapping required during our experiences as public school teachers continues to be demanded of teachers and teachers continue to point to the limited and limiting impact of these habits. But, it has proven difficult to offer alternative ways of thinking about the necessary process of preparing for the year (or the unit, or the lesson) ahead. 
Why? Part of the reason seems to be that orderly, sequential, grid-like structures are easy to make. More subtly, perhaps, they are commonsensical, familiar, reassuring. They adhere to a familiar pattern of organization, one used to structure a good part of the Western world. As any airline traveller passing over inhabited parts of North America - urban and rural spaces alike - will affirm, Canada and the US (more so than territories 'tamed' by humanity prior to the modern era) have been dissected into rectangles. Apart from grudging accommodations made to rivers, forests, and other terrains that refuse the straight line, the aerial viewer is often struck by the very specific and regular ways in which natural forms have been organized into grids.

In familiar terms, one might suggest that the human-arranged territory has been structured 'geometrically', whereas the more natural spaces and forms are not given to any sort of pattern or order. Although the former can be easily depicted using a ruler to measure and draw straight lines, any attempt to represent the latter requires a departure from classical forms and techniques. In particular, it is also easy to measure accurately the distance between one point and another among human-built forms. The same is not true of the more unruly natural form, however. How long is a river? What is the perimeter of a forest? How long is a shoreline?

Until recently, these sorts of questions were examined through a strategy that involved a certain amount of straightening, of attending only to distances between specific points rather than to the actual forms of the bodies being measured. Instead of tracing out every meander or branch or bulge, the measurer would assume them to consist of a series of smooth or flat edges - that is, the measurer would work from the premise that the object under study could be treated as a classical geometric figure.

Such a reduction can be useful and adequate (for building roads that parallel rivers, etc.). It can also be extremely problematic. Reflective of the same mindset that infused our efforts to map out learning outcomes and curriculum sequences, it demands and compels an ignorance of the texture of highly irregular, always-changing forms. Structuring and measurement are perplexing when one understands that there are no smooth or flat edges to complex phenomena and events.

This difficulty in measuring and describing the 'shapes' and 'character' of natural landforms is not unlike or unrelated to the discomfort that teachers experience in having to manufacture long-term plans. This is particularly true for teachers who understand knowledge as socio-culturally and ecologically emergent. If knowledge is to be considered inextricable from the complex relations among representations of past knowledge, current social and cultural relations, and biospheric ecology, it becomes ludicrous to attempt to map the inevitable bumpiness of detail that emerges from these interacting phenomena in a form as arcane as a year plan.

We contend, herein, that the images and metaphors that have guided and that continue to guide curriculum theory, planning and development, tend to be organized by a particular 'geometry', namely Euclidean. Despite the now 
longstanding postmodern critiques of modernist epistemological beliefs incorporated into formal education for the last few centuries, there have been relatively few challenges to the classical Euclidean forms used to organize curriculum and to structure schools. We attempt to uncover some of these forms and to explore the figurative possibilities of an alternative geometry, one more reflective of the unruliness of learning and teaching.

\section{Classical geometries}

For most people, the word 'geometry' evokes images of triangles, circles, and so on - those forms that serve as the foci of one of the less popular strands of traditional high school mathematics. Such forms were first gathered together into a coherent field of study by Euclid in the third century BCE.

Euclid did not invent geometry. In fact, in retrospect, his contribution was actually a narrowing of a somewhat richer and broader understanding of the term. A century earlier, Plato had identified geometry, then understood as the logico-deductive argument, as the hallmark of scholarly thought. Plato's geometry was not focused on figures drawn on the plane, but on a mode of reasoning that he thought could be used to uncover the deepest secrets of the universe. Specifically, geometry was understood as a manner of inquiry that aimed at a total understanding of the universe through the systematic reduction of all phenomena to fundamental particles, root causes, and original principles.

Euclid's major contribution was to assign a visual form to this manner of inquiry with the refinement of the case of planar geometry. Using 23 definitions (e.g. 'a point is that of which there is no part') and five axioms (e.g. 'a straight line can be drawn from any point to any point'), he demonstrated the power of logical argument for deriving and linking a diversity of known forms. In so doing, he contributed to a transformation of the meaning of geometry.

From a current perspective, Euclid seems to have hijacked the term. However, the transition in meaning did not in any way diminish the place of Plato's geometry. On the contrary, Euclid's contributions helped to entrench the formal logical argument in Western mind-sets - to the point that it has become the invisible backdrop of most claims to knowledge, at least in academia.

This point has been thoroughly developed within and across certain postmodernist, feminist, ecological, critical, and culturalist discourses. What has been less well developed is the manner in which Euclid's geometry continues to structure contemporary thinking, even when the pervasiveness of Plato's geometry has been uncovered. Many alternatives to logical argumentation have been presented, including narrative, metaphoric, analogical, and metonymic possibilities. Yet, for the pervasive imagery of classical geometry, few alternatives have been proposed and even fewer have been developed in ways useful to discussions of learning and teaching.

This is not a small point. Human thinking is enabled and constrained by the available conceptual tools - and, in terms of the visual referents that are most 
often used, one need only glance at living spaces to see that the forms of classical geometry are overwhelming in their presence. The influence of Euclid is perhaps most obvious in homes and offices, in rectangulated cities, in linearized conceptions of time and development, and so on. In schools, Euclid is present in the grids used to lay out curriculum, order the school day, organize learners in rooms, structure their experiences, mark their progress, and so on. So dominant is this geometry that the unruly and organic are often surprising and even unwelcome. What tend to be preferable are narratives of control, predictability, and efficiency, such as is demanded by Plato's logic and embodied in Euclid's images.

Several alternatives to Euclid's geometries have arisen over the past few centuries, most of which play on the fact that a change in definition or axiom can prompt a new set of forms and assertions. Such developments, however, have often served to bolster the logical argument rather than to disrupt it, as the resulting systems continue to obey the rigid logical architecture of Plato's geometry. Recently, however, fractal geometry has risen to prominence, both within mathematics proper and across scholarly and popular domains. As we suggest herein, fractal geometry seems to reflect emerging changes in cultural activities and sensibilities - changes that parallel the dramatic shifts which marked the start of the modern era (e.g. capitalism, empirical science, industrialization, urbanization, and print communication).

Although new, fractal geometry is utterly reliant on what has come before. It is not a break, but a dramatic elaboration. That being said, it also interrupts much of what preceded it by presenting a very different sort of object. In particular, the fractal image seems in many ways to be more closely aligned with and illustrative of postmodern sensibilities than with its own modern roots. We examine some key aspects of this geometry and show how some of its associated notions might be useful in rethinking curriculum and schooling.

\section{Fractal geometry}

Reflective of the unpredictable and surprising images of many fractal images, the history of fractal geometry is one of sudden turns and unexpected developments (Gleick 1987). Among their unusual qualities, fractal figures are scaleindependent. That is, whether one moves in on or pulls back from a fractal image, the bumpiness of detail stays the same. Whereas the figures associated with Euclidean geometry become simpler under closer inspection (e.g. a portion of a circle appears more and more like a line segment as it is magnified), fractal images do not give way to simpler forms as one closes in on them. In this way, they generally serve as better representations of natural forms which, for the most part, display striking levels of complexity at all the levels of magnification and reductions that humans have been able to impose (see Figure 13.1). ${ }^{1}$ As such, a fractal image might serve as an apt visual metaphor for those emergent conceptions of knowing and knowledge that pull away from classical logic and its implicit linearities. In particular, such images as foundations, structures, 

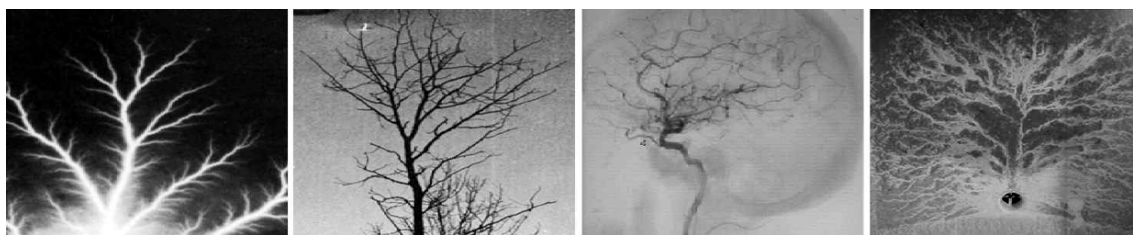

Figure 13.1 Fractal images are scale-independent, meaning that the same bumpiness of detail presents itself whether magnified or reduced. Closing in on these forms does not lead to simpler patterns or structures. Some natural forms that illustrate a high degree of scale independence include coast lines, clouds, and various tree-like phenomena (such as, illustrated here, electrical discharges, trees, arteries, and sludge from a drainage tub).

and hierarchies are challenged by notions of infinite regress, nestedness, and implicate orders. Moreover, fractal geometry presents an alternative to the often unquestioned assumption that complex phenomena can be reduced to root causes - a notion that is associated with an image of basic components, as embodied in Euclid's geometry. There is no 'simplest level' in a fractal image. Each is as complicated as the one that preceded it and the one that follows it.

Partly because of this quality, fractal geometry has been described as 'far closer to the flexibility of life than it is to the rigidity of Euclid' (Stewart 1998: 23). This description is also prompted in part by the uncanny resemblance of many fractal images to natural forms - which, in turn, highlight a second important quality of fractal images. Such forms tend to demonstrate some degree of self-similarity, meaning that the form might be seen as being assembled of reduced copies of itself (see Figure 13.2). Riverbeds, clouds, trees, mountains, skin - along with virtually every natural form or structure - demonstrate some sort of self-similarity.

The qualities of scale-independence and self-similarity raise the possibility of regarding any aspect of a fractal image as a whole with its own proper integrity, as an element of a larger whole, or as a collectivity of smaller forms. Within this frame, such oppositional dyads as part versus whole or simple versus complex are untenable. Rather, what is highlighted is an inevitable partiality in the act of viewing, where partiality is understood both in terms of the fragmentary nature of any observational act and in terms of the biases implicit in all events of perception. (As we shall show, these qualities prompt us to offer fractal images as visual metaphors for the integration of recent but varied discourses on knowing and knowledge, most of which rely on very similar dynamics while focusing on very different levels of organism or social organization.)

Fractal geometry has been embraced by researchers from many domains, from physics to the humanities, as being descriptive of the sorts of phenomena that are now being studied (Capra 1996). Awareness of scale-independence and self-similarity seems to have opened up possibilities for seeing a broader range 


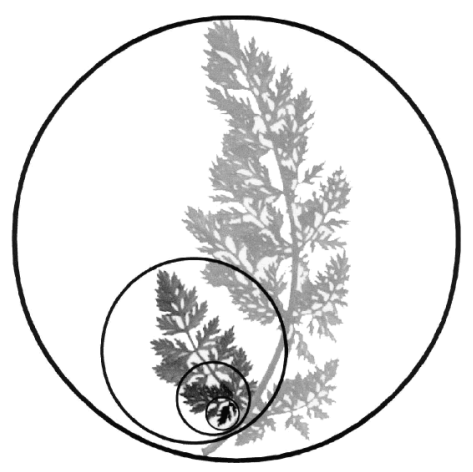

Figure 13.2 A figure is self-similar if, under magnification, a portion of it resembles the whole. Appropriate enlargements of the parts of the fern frond contained in the successively smaller circles, for example, would generate images that are reminiscent of the entire frond.

of phenomena as patterned - literally ranging from subatomic space to the distribution of matter in the universe. Phenomena previously thought to be random and formless - i.e. forms that did not conform to Euclid's geometry are now coming to be seen as elegantly patterned.

This is not to say that such patterns are determinable and, hence, reducible. On the contrary, they are seen as irreducible unfoldings, forms subject to incomprehensible arrays of both subtle and imposing influence. What fractal geometry brings is not a renewed effort to colonize the disorderly, but an appreciation of the universe as complex, ever-unfolding, self-transcending, and relational.

Such dynamic complexities may well spring from surprisingly simple beginnings, and fractal geometry has helped to illustrate how this might happen without invoking a reductive logic or causal notions of development. Fractal images are the products of particular sorts of recursive or iterative procedures. Briefly, a recursive process is a repetitive one in which, at any particular level of computation, the new input is the output from the previous level (and the subsequent output is the input for the next round). A familiar example of a recursive process is the calculation of compound interest. Interest earned in one term is dependent on interest earned in previous terms and will affect interest earned in later terms. Although recursive, however, this particular example is not fractal, as it lacks an important quality.

Those recursive processes that lead to fractal images differ from other repetitive calculations in that there are no shortcuts for determining the outcomes for fractals. The calculations are non-reducible; there is no compact process or theory that can anticipate the details of the unfolding. (In contrast, compound interest many seasons hence can be calculated directly.) Figure 13.3 offers a visual example of a non-compressible recursive process that leads to a treelike 


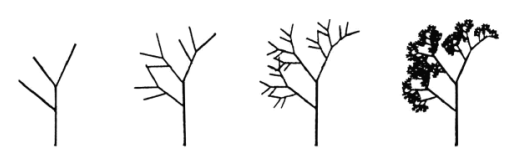

Figure 13.3 Fractal images are generated by recursive or re-iterative processes, whereby the starting place in one stage of the process is whatever was generated at the previous stage. In the case of this fractal tree (or, perhaps more appropriately, fractal parsley), for example, at each iteration, the same pattern of 'shoots' are drawn onto the branches that appeared in the previous iteration. The end result is scale-independent and self-similar.

image, in this case by repeatedly grafting reduced images of an original figure onto itself.

Diverse applications have been developed for such processes. Within popular media, for example, convincing imitations of dinosaur skin, planet surfaces, cloud formations, and mountain vistas have been created by mimicking nature's habit of (recursively) playing on what has already been generated. Medicine, economics, chemistry, and other domains are also finding productive uses of such recursive processes as they seek to address complex, emergent problems in their respective domains.

The discovery that certain recursive functions can give rise to cryptic order and, moreover, that such order often resembles very familiar forms - has come as a surprise to many people. It has also supported the use of fractal patterns as important visual metaphors in the recently emergent field of complexity theory. Focused on the ways that order often emerges for free when dynamic forms are allowed to interact with one another, complexivists have demonstrated that life itself seems to be organized fractally.

Put somewhat differently, complexivists have problematized a modern-day habit of drawing analogies between mechanical objects and living forms. The former obey a Euclidean geometry, both structurally (in terms of the familiar classical shapes of their components) and operationally (in terms of the logical interconnections of those components). Machines are the sums of their parts, designed deliberately to fulfil particular functions in particular ways.

Living systems, as suggested, seem to adhere more to a fractal geometry again, both structurally (in terms of the characters of their subsystems) and operationally (in terms of the sorts of rules that guide the interactions of these systems). Like a fractal image, the aspects of a living system seem to be hazily bounded and nested. A human, for example, might be seen as a coherent unity, as a higher-order form that emerges in the joint activity of subsystems with their own particular integrities, or as a form that participates in such transcendent forms as social grouping, cultures, and so on. To understand the nature of a human, then, would require one to look across such nested levels as biological constitution, context, society, and so on. 
On the rules that guide the interactions of a complex form (as well as their sub- and super-systems), a fractal image can also be illustrative. In fact, a somewhat surprising suggestion arises when a more recursive logic is applied to the interactions of complex forms. Departing from the Platonic/Euclidean notion that complete knowledge of an event relies on the possibility of reducing it to its most basic parts, a more holist sensibility is suggested. Stewart and Cohen (1997: 76), a mathematician and a biologist, describe the shift in thinking in this way:

Traditional science saw regularities in nature as direct reflections of regular laws. That view is no longer tenable. Neither is the view that the universe rests upon a single fundamental rule system, and all we have to do is find it. Instead, there are - and must be - rules at every level of description.... The universe is a plurality of overlapping rules.

In other words, as might be illustrated with reference to a fractal image, emerging views of the universe suggest that it is scale-independent. It does not matter much which order of phenomenon one chooses to study, the same bumpiness of detail will present itself.

Conversely, with a reconceptualization of the relationships between part and whole - again supported by a fractal image - one is freed from having to study everything in order to understand something. The part is not simply a fragment of the whole, it is a fractal out of which the whole unfolds and in which the whole is enfolded.

This different imagery has proven a fertile source for rethinking the natures of time, memory, identity, words, and so on. Understood not in terms of isolated elements, such phenomena are coming to be discussed in terms of nodes in webs of possibility that, when examined more closely, are shown to be, themselves, similar webs of possibility, and so on.

In the next section, we invoke fractal imagery to develop the suggestion that there are some deep intertwinings across theories of cognition now rising to prominence in discussions of education. This discussion is a preamble to an examination of some implications of thinking in terms of fractals rather than Euclidean forms when studying curriculum.

\section{Current geometries of knowing and knowledge}

The nature of cognition has received a great deal of attention over the past few years. Once considered an aspect of psychology, at least in the educational literature, cognition is now routinely taken up by those whose interests are more neurological, sociological, anthropological, or ecological. A main contribution of these varied discourses to understandings of cognition has been the realization that such phenomena as thought and learning are not strictly brain-based events. Rather, they are caught up in layers of dynamic process that range at least from the sub-cellular to the planetary. 
At first glance, many current theoretical offerings seem disparate, even contradictory - as illustrated by continuing efforts at reconciling individualistic and collectivist accounts of knowing (Cobb 1994). A suspicion of incongruity is quite justified: discourses that derive from Piaget's genetic epistemology, for example, focus on quite different organismic and organizational phenomena from those that draw more on Vygotsky's more social concerns.

Behind such obvious differences, however, there is significant common ground to much of the current wave of theoretical offerings. Specifically, the assumption of a complex evolutionary dynamic pervades most of the current thinking. Departing from traditional interpretations of evolutionary processes, by which change was usually seen in terms of progress toward perfection, current perspectives tend to characterize moments of evolution more as unfolding choreographies than as directed marches. Elaborating the popular assumption that evolution occurs as an organism or species adapts itself to the constraints on its context (i.e. a theory in which an unchanging context exerts selective pressure), current accounts of evolutionary dynamics tend to highlight the role of mutual affect or co-adaptation as forms and contexts evolve together.

Such co-emergent processes give rise to much more complex arrays of possibilities than was once assumed. Whereas earlier accounts of evolution were associated with quite linear images (most commonly, a lineup that begins with a scrambling simian and ends with a weapon-toting Caucasian male), current accounts tend to draw on more fluid, diversified images such as a stream breaking into a myriad of rivulets as it flows downhill or a tree whose branches sometimes branch wildly and sometimes are lopped off suddenly.

In effect, this change in defining imageries amounts to a shift from Euclidean-based to more fractal-based sensibilities. In the flowing-water image, for example, as the possible paths that the stream might take down a mountainside are traced out, it becomes clear that each bit of movement opens up a range of new possibilities. The resulting image - the 'phase space' of the system - is actually fractal (as is, for that matter, the surface on which it is drawn) (see Figure 13.4).

This change in image, as applied to complex evolutionary processes, highlights a different set of concerns than has been typical of much of educational discourse. In particular, projects that have been characterized more in terms of Euclidean forms (i.e. lines, grids, spirals, and so on) might be seen as incommensurate with the diversity and complex texture of activity present in any learning setting. Such imperatives as the pre-specification of learning outcomes and the articulation of comprehensive lesson plans, we suggest, can eclipse the richness embodied in any moment of engagement with a subject matter.

To set the stage for a discussion of curriculum, we focus on current discussions of cognition viewed through the lens of fractal geometry. The intention here is not to fully describe these new orientations. Such a goal may well be impossible, as the discourses are hardly unified - even within a category like constructivism. Rather, our purposes are twofold. First, we point to some ways 


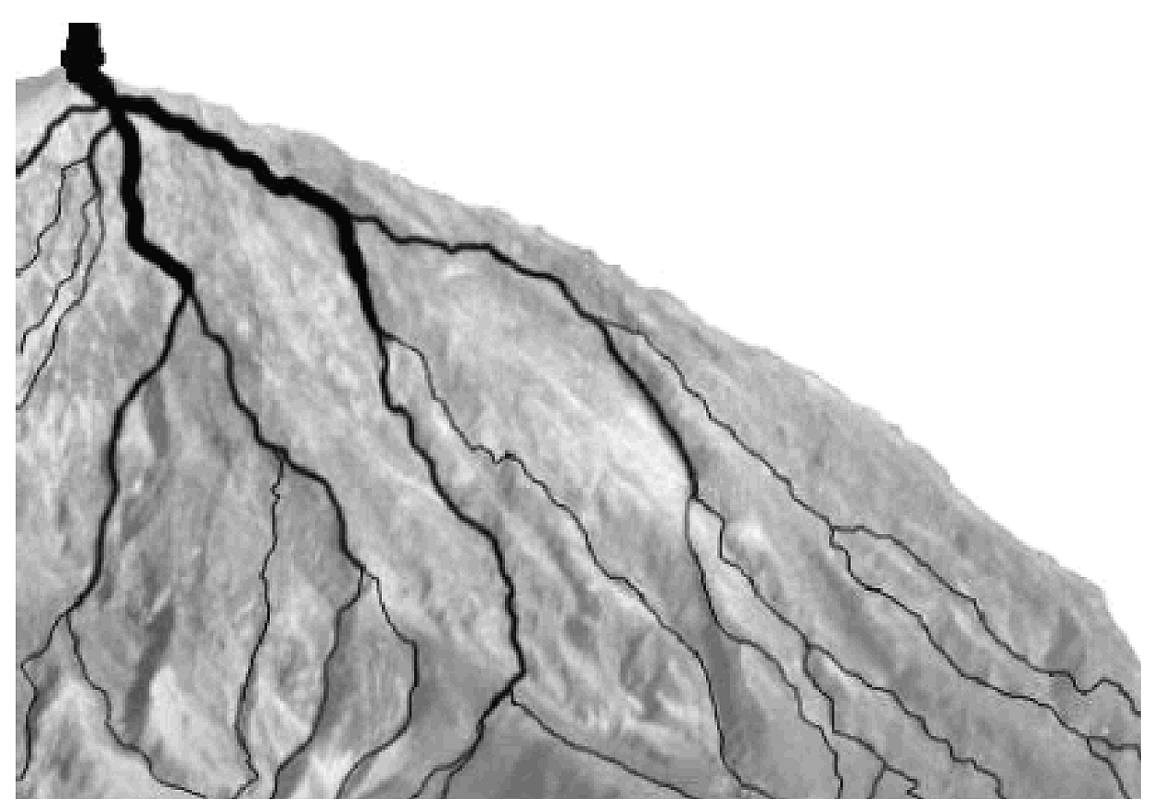

Figure 13.4 The phase space of a system is the array of possible paths that might be followed. In most complex systems, the phase spaces are fractal.

in which these theories intertwine and overlap, more often on the level of tacit assumption than explicit assertion. Second, we interpret these commonalities in terms of fractal geometric principles - that is, as nested recursions rather than as intersections of discrete (Euclidean) regions.

\section{Subject-centred constructivisms}

A first category of current discourse focuses on issues of individual cognition. Working from the premise that the learner's basis of meaning is found in her or his direct experience with a dynamic and responsive world, these subject-centred constructivisms challenge such dichotomies as mind/body and knower/ knowledge. In particular, these discourses tend to replace the language of Newtonian mechanics with more complex notions drawn from biology, ecology, and evolution.

In this way, cognition is understood as a process of maintaining an adequate fit with one's ever-changing circumstances, as opposed to progressing toward an optimal internal representation of an external world. Although these theories are generally regarded (and, for that matter, self-identified) as subjective, there is a clear acknowledgement that the knowing agent is coupled to her or his context - affecting and being affected. Hence, these constructivisms are subjective in the sense that they focus on the activities of individuals, but not in the 
solipsistic sense of regarding cognition as fully autonomous or strictly internal (von Glasersfeld 1995).

Cognition, for constructivists, is embodied. That is, the biological body is not a structure through which one learns, but a structure that learns. Formal learning, thus conceived, is a matter of interpreting and reinterpreting one's primal body experiences, a continuous process of reorganizing what is known. Each act of (re)cognition compels an assimilation or accommodation of what was known. This is an endlessly recursive, irreducible, creative process - one that is much better illustrated through reference to the generation of a fractal image than to the logical processes of classical geometry. Knowing is fractal-like: a continuous, reiterative event through which one knits together one's history, one's immediate situation, and one's projects. Such knowing is never fixed, never stable.

Implicit in this conception of embodied knowing is an acknowledgement that bodily action is not simply an external demonstration of internal understanding. Rather, bodily action is understanding, as the knower seeks to maintain fit with circumstances. Of course, the context is as dynamic as the agent's knowings or doings, and this realization has prompted some to suggest that, just as cognition is spread through one's body, so it is distributed across the objects in one's world. That is, departing from the commonsensical notion that thought and memory reside in the brain, cognition is stretched beyond neural processes and bodily action to include both natural and human-made forms. Human technologies such as language and tools, for instance, are not merely products of intelligence, but bestowers of intelligence as well. Once available, they make it possible to draw on the insights of others in ways that, for example, enable high-school students to perform feats that were beyond the best minds only a few generations ago.

\section{Social constructionisms}

This extension of cognition beyond the skin marks the overlap of constructivist and social constructionist discourses - the latter of which focus more on some sort of collective corpus (e.g. a pair of students, a teacher-learner interaction, a classroom grouping) or on bodies of knowledge as knowing agents build understandings and come to shared ${ }^{2}$ conclusions. Elaborating the interest in individual sense-making, these discourses are centrally concerned with analyses of conversation patterns, relational dynamics, and collective characters. Cognition, for the social constructionist, is always collective: embedded in, enabled by, and constrained by the social phenomenon of language; caught up in layers of history and tradition; confined by well-established boundaries of acceptability.

In spite of the differences in their objects of inquiry, subject-centred constructivisms (with their focus on the biologic body) and social constructionisms (with their focus on some collective corpus) have a great deal in common. Most obvious is the shared use of evolutionary and ecological metaphors - and, in particular, the notion of viability or adequate fit with prevailing circumstances as 
the measure of (individual or collective) knowledge. In mathematics, for example, collective knowledge is not cumulative, it does not emerge along a linear path, and it does not proceed toward a specifiable goal. Rather, it unfolds in fits and starts, subject to individual insights and cultural contingencies. The key point of departure of social constructionisms from constructivisms, then, is not on matters of process of product, but on the phenomenological and biological order of the object of inquiry.

'Understanding', considered on the level of social accord, is different from individual understanding. But, these phenomena are also inextricably intertwined. Furthermore, the relationship between individual cognition and groupprocess is not a simple matter of dialectical causality. Rather, the individual is embedded in the collective - and, hence, these 'bodies' might be seen as different levels of the same fractal image. As with a fractal, there seems to be a certain self-similarity. Depending on one's point of reference, each level has its own particular integrity. And, in the same way that one moves from one iteration to the next in the constructions of a fractal image, the same evolutionary dynamics and the same complex emergent qualities seem to be at play in the cognitive processes of individual and collective. A Euclidean geometry (of discrete, discernible regions) breaks down here, whereas a fractal geometry neither allows one part to be considered as independent of another, nor privileges one level of analysis as more informative, as more encompassing, or as explaining another. As such, this geometry recalls the hermeneutic notion that the whole is enfolded in and unfolds from the part: (subjective/individual) knowing and (objective/collective) knowledge are inseparable (Gadamer 1990).

\section{Cultural and critical discourses}

The topic of cognition has also been prominent among educational researchers working from critical and socio-cultural perspectives. Shifting the focus from the individual's efforts to shape an understanding of the world, and broadening the social constructionist's interest in the collective character of cognition, these discourses tend to emphasize how the world shapes the understanding of the individual.

Generally speaking, cultural and critical discourses are rooted in critical and interpretive philosophic traditions - domains that announced their suspicion of classical geometries and that inquired into the complex characters of culture and identity well before fractal geometry became a field of study. Critical theorists have long been arguing for very fractal-like notions to trouble the rigidly logical and linear geometries of Western thought. On formal schooling, some of the prominent points of critique have included the ideal of individual autonomy, the creation and maintenance of societal norms (gender, race, class, sexuality, etc.), and the privileging of certain domains of knowledge (mathematics and the sciences, in particular).

Although the term is rarely invoked - perhaps because it arrives from the very disciplines, mathematics and the sciences, most subject to critique - a 
certain self-similarity among social forms has been highlighted by critical theorists. It has been shown that structures of social organization, together with hierarchies and inequalities that support such structures, are present at every level of human activity, from the macro (e.g. the systemic exclusion of racial minorities from the academy) to the micro (the less obvious diminution of minorities within discursive practices). This self-similarity is reiterated across all levels of social organization, and an important assertion of cultural theorists is that perceived injustices can only be reconfigured when there are deliberate, sustained, and simultaneous interruptions across individual, social, and cultural domains of activity.

Within such assertions, it is clear that culturalist discourses are using evolutionary and ecological notions, albeit that such notions are not often made explicit and tend to be coupled to one or more critical discourses (e.g. Marxism, feminisms, psychoanalysis, post-colonialism, queer theory). As such, cultural discourses often draw similar-sounding conclusions to subject-centred constructivisms and social constructionisms, although such conclusions are usually applied to the body politic rather than to a particular collective corpus or to the body biologic. The same metaphors of bodily dynamics are used (adaptation, evolution, fitness, dynamic unfolding, and so on).

\section{Commonalities}

This metaphoric commitment to the body across interpretive frameworks is vital to understanding the shared logic of subject-centred constructivisms, social constructionisms, and cultural/critical discourses. In particular, it highlights that each is, in some sense, 'holistic'.

The defining assertion of holism is that a phenomenon can only be understood if examined in its wholeness, which includes an appreciation of the interdependencies of the parts comprising the whole and the context in which that whole comes to form. Such is certainly the case for each of the discourses on cognition, albeit that the 'whole' (or body) is different in each case.

Although most holistic philosophies represent an important response to reductionist and mechanistic mindsets, they continue to share some aspects of a classically geometric worldview. Holists, in fact, often offer contradictory responses to the question of what counts as 'whole', as exemplified in the attention given to the imperatives for student-centred instruction in recent decades. Such discourses often treat the individual learner as a whole, but simultaneously as a fundamental particle of sorts. The learner is seen as interactive, but as autonomous. In effect, such moves displace rather than replace a reductionist habit.

A more complex view embraces holist philosophy, but also prompts attention to varied levels of functioning and organization. As such, whether one selects the individual, the social unit, or a culture as the site of contest, one must realize that each level is embedded in social and natural environments, both affecting and being affected by. Such extensions are, at times, intimated by 
cognitive discourses, but they are rarely taken up in earnest. In contrast, a view of cognition supported by fractal geometric notions of recursive and reflexive embeddedness actually compels these extensions.

Put somewhat differently, four common themes emerge across these discourses. First, as just mentioned, each discourse regards a body (biological, epistemic, or politic) as the site of contest. Second, each draws on (or is readily aligned with) complexity and evolutionary theories in characterizing the activities of these bodies. More specifically, in each case, the dynamics of cognition/ knowledge are seen in much the same terms as the procedure used to generate a fractal image. It is seen as a matter of recursion, of elaborating what has come before, subjected to emergent contingencies, embedded in and part of a similarly recursive context. Third, at every level, processes of cognition are seen as broadening the agent's flexibility. It is a creative event, directed towards being able to deal with a wider range of contingencies, not a zeroing-in on ideal or fixed forms. Fourth, combining these points, cognition is not seen as located in a body, but as a means of describing the dynamics and the relationships that afford a body a coherence, or that enable that body to retain its viability and integrity within a larger context. Individual knowing, collective knowledge, and cultural identity become three intertwining, self-similar levels of one phenomenon - ones which, as with the fractal image, can only be understood in relation to one another.

In noting these commonalties across discourses, we do not mean to suggest that the same rules can be applied across personal and collective domains. Nor do we mean to imply that these domains can be collapsed into or explained in terms of one another. On the contrary, fractal geometry does not compel this manner of reductive assertion. Rather than seeking out a single fundamental system of laws, it is recognized that the 'rules' are specific to the level of description. And, rather than regarding collective phenomena as inevitable consequences of individual dynamics, or vice versa, the specificities of the particular bodies that comprise grander bodies are recognized and embraced. Indeed, the dynamic characters of bodies are seen as utterly dependent on (but not determined by) the diversity that is present within those bodies.

Bodily identities and their associated knowledge - whether at individual, communal, or cultural levels - are, thus, never unitary, never stable, never neatly bounded, and never able to be fully represented. As Capra (1996: 35) claims:

the web of life consists of networks within networks. At each scale, under closer scrutiny, the nodes of the network reveal themselves as smaller networks. We tend to arrange these systems, all nesting within larger systems, in a hierarchical scheme by placing the larger systems above the smaller ones in pyramid fashion.... In nature there is no 'above' or 'below', and there are no hierarchies. There are only networks nesting in other networks.

What people call a 'part', then, is only a pattern within a web of relationships a notion that should prompt rethinkings of the 'things' that tend to get 


\section{4}

separated into the mental (e.g. thought, knowledge, and the mind) and the physical (activity, representations of knowledge, and the body). Knowledge comes to be comprehensible only in terms of an active body. More specifically, knowledge is that which affords a body - whether a person, a social group, or a culture - a coherence through which that body maintains viability. Knowledge is the space of the possible. It is necessarily embodied. It is necessarily contextual.

Stated somewhat differently, within these discourses it is apparent that a new metaphor for knowledge is needed, one that replaces the classical geometry of foundations, buildings, and linear progress, one that takes up notions of relational networks nested within one another. Paradoxically, even though contemporary discussions of cognition have pulled away from Platonic logic and Euclidean architectures, a reliance on classical geometries continues to be announced by their self-chosen titles. 'Constructivism' and 'constructionism', in particular, call to mind a Euclidean mindset, both in terms of the straight lines, right angles, and discrete spaces typical of Western buildings, and in terms of the solid foundations, vertical growth, and static product derived from Plato's and modernist conceptions of knowledge. Moreover, such titles reveal a narrow scope of interest: humans construct and are constructed by knowledge. A tacit but impassable border thus seems to be drawn around discussions of cognition and knowledge, one that separates the realm of human interest from the rest of the universe, from nature.

A more fractal geometry addresses such concerns. For example, organic and recursive notions are used to uncover and problematize pervasive architectural metaphors. As well, the scale-independence of a fractal image - whereby the same bumpiness of detail is presented whether one magnifies or reduces the image - prompts further iterations of conventional discussions of cognition.

Such extensions have been undertaken, both to sub-human processes and beyond the human species, and the resulting discussions are leading to important new thinking about thinking. As Capra (1996: 37) explains, new insights seem to be a result of a recognition of a different geometry: 'Throughout the living world we find systems nesting within systems, and by applying the same concept at different levels - for example, the concept of stress to an organism, a city, or an economy - we can often gain important insights'. Similarly, Kauffman (1995: 191), a medical researcher, notes that it is difficult not to see parallels among the evolutions of organisms and human artifacts, despite their being 'so different in scale, complexity, and grandeur, so different in the time scales over which they evolved'.

\section{Cognition on the sub-subjective level}

On the sub-human level, much of recent medical research has been developed around a conception of the body's organs as relatively autonomous and cognitive. In particular, HIV/AIDS-prompted studies have demonstrated the inadequacy of pervasive, mechanically-based conceptions of the immune system 
(Kauffman 1995). That system is a complex one that learns, forgets, hypothesizes, errs, recovers, recognizes, rejects, and projects in a complex dance with other (bodily and non-bodily) systems. As well, as part of its functioning, the immune system is constantly transforming itself. Neither fully autonomous nor a mere mechanical component of a larger whole, one's immune system is related to oneself in the same way that the individual is related to the collective - and it is this insight, perhaps more than any other, that has encouraged AIDS/HIV research in the past few years.

Bodily systems are themselves composed of subsystems that are fractal-like in their functioning. For example, Stewart and Cohen (1997: 204) suggest that 'the brain seems more like a chamber orchestra in which each player is reacting to others, but not under central direction', an analogy that fits well with Dennett's (1996) suggestion that the mind is a conglomerate of loosely knit processes, each of which is semi-independent of the others.

The fractal character of personal cognition is not merely evident in different levels of functioning, but is also apparent in the brain's organization. As Calvin (1996: 120), a neurologist, explains:

[The] factor of a hundred keeps recurring: a hundred neurons to a minicolumn, roughly a hundred minicolumns to a macrocolumn, a hundred times a hundred macrocolumns to a cortical area ..., and there are just over a hundred Brodman Areas when you total those in both cerebral hemispheres.

Calvin also describes the activities at each level as resembling those at every other level, and he draws on chaos theory in his descriptions. Such analysis renders inadequate the Euclidean model of a pyramid-shaped hierarchy (with neurons at the base and cognition at the apex), because each level of functioning is similar to every other level. The implication is that individual cognition is not merely a global process emerging in the amalgamated activities of neurons, but a nested process embodied in each element (be it neuron, minicolumn, etc.).

Calvin (1996: 7) explicitly invokes evolutionary theory in describing these cognitive processes: 'the same Darwinian process ... shapes a new species in millennia ... or a new antibody during the several weeks of an immune response'. In this formulation, he joins with many others who are seeking to articulate a link between the micro and the macro. A common conclusion of scientists working at one or the other of these levels is that the evolutionary processes at work tend to lead to a maximum possible diversity within a cell, organ, organism, collectivity, or species. The agent must be able to respond to the broadest possible range of contingencies; overspecialization can quickly lead to extinction within dynamic contexts - a conclusion that is as relevant on the level of schooling as it is on the levels of a bacterium, an ecosystem, or a multinational corporation.

Another important insight of researchers working across levels of organization is that processes of affect are not unidirectional. That is, for example, 
DNA does not determine the shape of an organism or its behaviour. Nor is the opposite true. Rather, there is a complex, mutually affective dynamic that is constantly occurring. Context and activity prompt changes at the molecular level (although these changes are much too complex to unravel); events at the molecular level participate in the unfolding of possibilities at higher levels. Notions of nature versus nurture are demonstrated to be naive and lacking here, replaced by a realization that the phenomenological and the biological are inextricable. Similarly, the role of bodily needs and physical drives - phenomena that tend to be disregarded, reduced to social constructions, or seen as base instincts to be overcome within those discourses that restrict their interests to human activity - play a renewed and vital role.

Such realizations reveal the inadequacy of current orthodoxies around knowledge. The popular assertion that all knowledge is socially constructed, for example, is shown to ignore the fact that cells and organs and bodies know a great deal - and continue to learn more - that is never brought to formulation. In this argument, knowledge is revealed to be more vast, more dynamic, more embodied than most previous and popular epistemologies are able to accommodate.

\section{Cognition on the supracultural level}

This idea is not limited to those phenomena that are explicitly recognized as biological. Consider, for example, Stewart and Cohen's (1997: 213, 287) assertion that 'cells are more like miniature cities than diminutive lumps of jelly' and 'cultures are not replicative systems, but reproductive ones. They do not copy themselves inflexibly from each generation to the next: they modify themselves.'

This thinking is perhaps most clearly articulated by those interested in global ecology. Once scorned, but rapidly achieving broad acceptance, the 'Gaia Hypothesis' (Lovelock 1979) posits that the human species is a mere subsystem of a larger and more complex web of relations - that is, invoking a fractal image, human activities are embedded in and part of a grander body whose cognitive processes are seen by humans as co-evolutions of species and habitats. Thompson (1996: 79) asserts that 'the biosphere is an extended body politic; properly speaking, it is part of our incarnation'.

Maturana and Varela (1987), both biologists, sum up such thinking with their assertion that living systems are cognitive systems - or, phrased differently, living is a process of cognition. This notion is coupled to a recognition that the variety of living forms cannot be mapped out in a two-dimensional mosaic, but must be thought of in terms of a fractal-like, multi-dimensional structure branching radiations through time and space and of systems within systems. In effect, this sort of thinking represents a radical rejection of boundaries. More precisely, these ideas amount to a recognition of the permeability of those membranes that are perceived to separate agents (e.g. cell versus cell, organ versus organ) or levels of organization (e.g. cellular versus organismic, personal versus social) from one another. Cognizing bodies are seen as complex collec- 


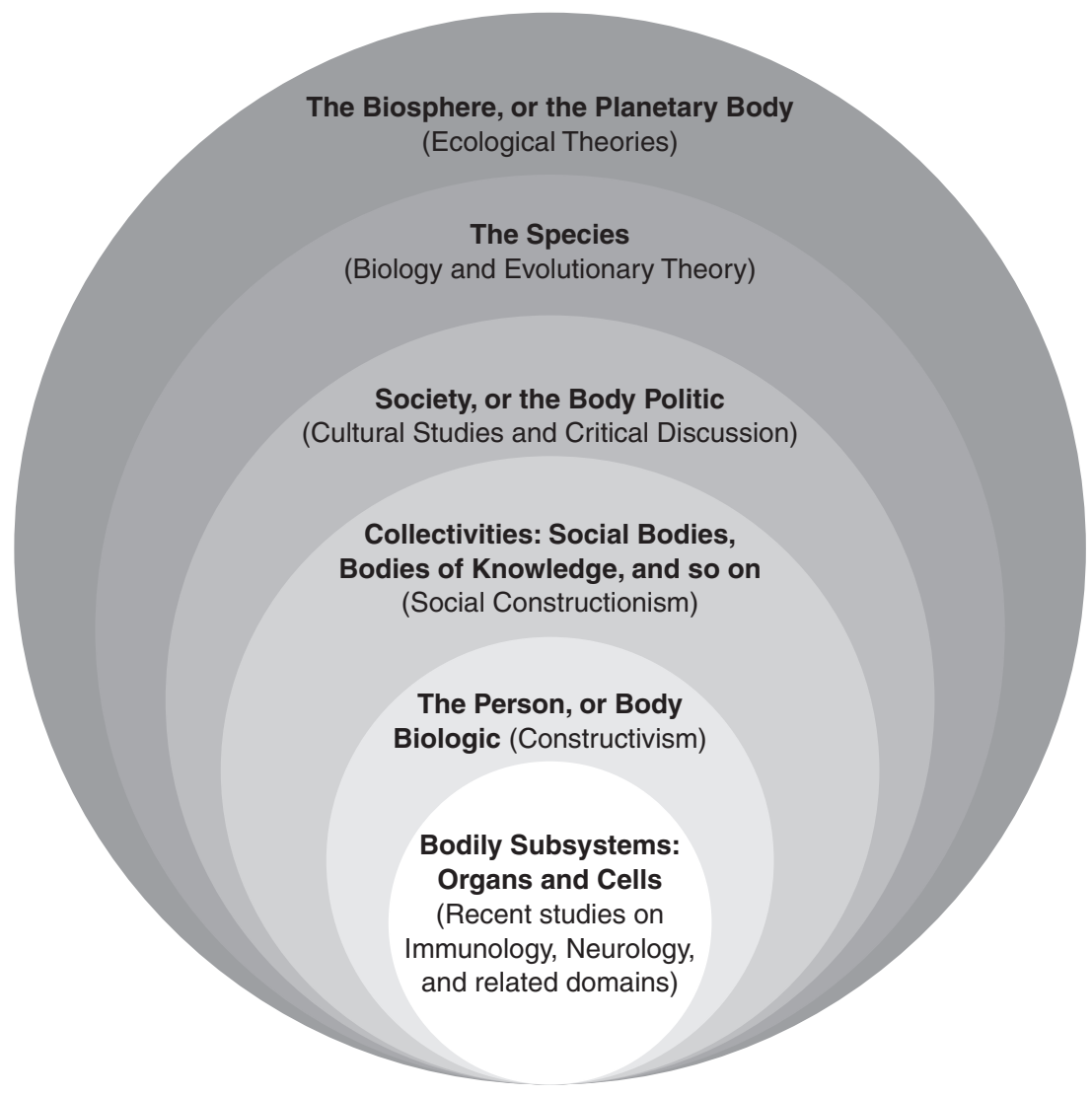

Figure 13.5 A visual interpretation of the nestedness of bodies (and the discourses that address these bodies). The image is intended to highlight the self-similarity of the complex evolutionary dynamics at play across the levels and the scaleindependence of the forms that emerge at each level.

tives whose boundaries are never tidy or fixed. Although each can be seen as having its own identity and subject to its own rules, there are no rigid breaks among these perceived bodies.

Visually, this assertion might be represented by a series of nested, similar forms, each of whose boundaries melt into the layers that surround it (see Figure 13.5). This image demands a much more complex understanding of what it means to know, one that allows a separation of knowing from consciousness. This is an idea that may well be unsettling for many, given that knowing and knowledge are usually only considered in explicit and formulated terms - that is, as conscious or at least accessible to consciousness.

Forty years of neurological evidence suggest otherwise, however. It appears, 
for example, that consciousness exerts very little control over what is perceived, what is learned, or how one acts. These categories of knowing are given over to sub-processes outside conscious awareness and conditioned by cultural and environmental circumstances. In other words, as knowing agents, people have explicit awareness of only a tiny fraction of human knowledge (Norretranders 1998). The bulk of an agent's knowing is simply enacted, invisible to the actor. (Of course, humans, along with a few other species, have the capacity to draw aspects of their unformulated knowledge into conscious awareness. This ability is clearly vital to individual and collective capacities to elaborate knowledge into more powerful knowings. Nonetheless, human capacities in this regard appear to be greatly constrained, more by biological constitution than by social conditioning.)

A dramatic break with modernist thought is represented here. Analytic philosophy is explicitly deductive, seeking to articulate all knowledge claims in the formal terms of Plato's geometry. Among the core distinctions of this philosophic orientation is the separation of ontology from epistemology. Since Descartes, it has been generally assumed that what exists and what people can know about it are two different things.

Taking up a different geometry compels a very different attitude toward this issue - as it points to the fact that humans are dynamic aspects of what is. Cognition is not seen to be something that occurs in a differentiated mental realm, but as part of the physical universe. A thought is a physical event - one that, like any other physical event, represents a change in conditions, a transformation of the universe. For those interested in deliberate efforts to produce and maintain knowledge, this notion should prompt a very different attitude towards those activities that define educational projects. Far from the inert and amoral status that ideas are often ascribed, our knowings are implicated in the unfoldings of personal, collective, cultural, species and planetary integrities. Given increasing concern over planetary conditions (and recognition of the role of humanity's knowledge in provoking these conditions), this insight is of increasing relevance.

\section{Enacting a different geometry of curriculum}

As other scholars have suggested (e.g. Pinar et al. 1995), two very different sensibilities are represented in conventional curriculum discourses. At the risk of oversimplifying, on one hand curriculum is seen as a straightforward project of selecting outcomes and parsing those outcomes into incremental learning trajectories. In our terms, this attitude toward curriculum is Euclidean, aligned with images of lines and discrete regions, concerned with trade-offs of breadth and depth of understandings, and reliant on a conception of knowledge as edifice - set on firm foundations and erected in careful sequences.

On the other hand, over the past three decades in particular, considerable work has been done to introduce sensibilities that might be better described as fractal-like. These discourses have tended to highlight the complexities of the 
classroom situation, its possibilities for surprise, its dependence on the particularities and diversities represented, its propensities for reflecting and reenacting broader social dynamics, and so on - in brief, the scale-independence and the specificity of the moment of teaching. Grumet's (1988: 172) characterization of curriculum using a waterfall image, which is itself fractal in structure, is a cogent example of this attitude:

Curriculum is a moving form. That is why we have trouble capturing it, fixing it in language, lodging it in our matrix. Whether we talk about it as history, as syllabi, as classroom discourse, as intended learning outcomes, or as experience, we are trying to grasp a moving form, to catch it at the moment that it slides from being the figure, the object and goal of action, and collapses into the ground for action.

In the face of rapidly changing social and environmental circumstances, this fractal-like sensibility, with its emphases on attentiveness and responsiveness to the immediate, is the one that must be embraced. The still-prevalent Euclidean geometry of most curriculum projects is proving problematic in a context of rapid change. Whereas Euclid's forms once provided a powerful means of organizing and representing thought, they are now proving an impediment to meaningful transformation.

For instance, curriculum projects that employ linear (or curvilinear, such as spiral) images have supported a 'bit-at-a-time', accumulative or learnerindependent sort of instruction, a structure that is perhaps best illustrated by the classic mathematics textbook. The linear or spiral trajectory is a particularly useful way to organize information for quick access and for ease of use when deep understanding or flexible application are not key worries. However, as has been amply demonstrated by educational researchers, such structures can be highly problematic when learners are expected to extend their understandings to messier, less delineated situations.

A fractal image of a curriculum structure supports quite a different approach, one that might better be characterized as 'all at once' or interpretive. For example, students learning about fractions could be engaged in the interpretation of varied experiences of folding, cutting, and assembling - which, inevitably, would involve all of the basic operations. ${ }^{3}$

What is being suggested here is in essence a redefinition of 'structure' - or, more appropriately perhaps, a reclaiming of its original meaning. Conventionally, the word 'structure' tends to carry with it a sense of intentionality, deliberateness. Educators, for example, often aim to structure learning events, to structure arguments, to structure curricula, to instruct and so on - following a sense of structure that draws from modern architecture. There is a sense of preplanning, deliberate implementation, step-following, and direct progress towards specific goals.

Biologists also use 'structure' a good deal, but in a very different sense. When they talk about an organism's structure, they refer to the complex web of 
events that contribute to an entity's current form. Structure is both consequence and accident, inevitable and unrepeatable, familiar and unique, biological and experiential. Structure implies a recursivity, an embeddedness, an inseparability of the particular and the general - notions that might be illustrated in reference to the qualities of a fractal image.

The biologist's use of the term is more faithful to its origins. Sharing the same roots as 'strew' and 'construe', structure originally referred to the way things 'fall', 'spread out', or 'pile up' in a way that is not quite predetermined, but not quite random either. (Importantly, such patterns of distribution have been demonstrated to be fractal-like.) When the notion of structure was first applied to buildings, it made perfect sense. Such forms, for the most part, were not pre-planned. Rather, they unfolded over years and uses as parts were added, destroyed or otherwise altered. One built according to need, opportunity or whimsy. The resulting edifices were thus not seen as permanent, but in flux, evolving - that is, they were structures in the biological sense of a form's immediate state of being.

For the most part, there is now a very different attitude to architecture. Whereas the notion of 'pre-specified structure' would have been an oxymoron only a few centuries ago, today it makes perfect sense. Unfortunately, that modern, deliberate sense has slipped into other uses of the term. The centuriesold notion of 'structure of knowledge', for instance, today invokes a sense of carefully articulated order, rather than the perhaps more appropriate senses of unpredictable unfolding or complex emergence. This, unfortunately, is especially true of the structure of knowledge, as popularly understood. Most often and this is especially true in circles where mathematics and science learning are discussed - such bodies of knowledge are treated as if they were pristinely structured in the modern architectural sense of hierarchical arrangement, welldefined boundaries, and predictable development. Any close examination of the history of these bodies would suggest that a more biological interpretation is in order. That is, people are not fumbling along a more-or-less straight road toward a totalized and self-contained knowledge of the universe. Rather, they are all taking part in structuring knowledge - spreading out, piling up; and this requires a completely different image.

A similar, rigid notion of structure is often assumed in such phrases as 'personal knowledge structure'. One's sense tends to go toward modern buildings and, once there, attracts such complementary notions as foundations, platforms, planks, scaffolds, building blocks, hierarchies, frameworks, and so on. Such habits of association are a stumbling block in current discussions of cognition where 'structure' is intended in the biological sense, but is heard by audiences who work from more modern, technocratic sensibilities.

It is here that we believe fractal geometry might be used to interrupt resilient habits of thought. The possibility of thinking about curriculum structures as recursive events, as illustrated with a fractal image, opens a space to talk about events simultaneously unique and familiar, uncontrollable and ordered. Instead of focusing on steady progressions toward optimality, the more unruly, strewing 
fractal image might support a space to think about the importance of false starts, surprise turns, and ever-mounting complexity. Conceived in terms of the generation of a fractal image, the product of a curriculum engagement cannot be predicted or controlled - but that does not mean that it defies comprehension. It just means that the structure that emerges or the path that unfolds has to be lived through for its endpoint to be realized. Rather than thinking in terms of a pre-specified structure, one might think of a myriad of potentialities, one of which will be pulled into existence - but only by living through the event.

These sorts of images highlight the impossibility of predicting or controlling complex events. Even in this situation, which is vastly simpler than, say, a mathematics lesson, it is impossible to anticipate outcomes. People simply cannot expect to know in any definitive way where a particular droplet might go as it begins its way down a mountainside. Where it ends up depends on a host of uncontrollable events - including the influence exerted by the droplet on the surface that it passes over. Clearly, people can prescribe no outcomes in this situation. However, they need not throw up their hands in despair. Although the actual outcome is unpredictable, the range of possibilities is not. That is, the domain of potentialities is proscribed by the qualities of the system - the droplet must move downhill, it cannot leap, and so on. This compromise of the unknowable and the knowable - which supplants images of progress along lesson trajectories, through concept maps, along roads of life, or up evolutionary ladders - is thus supplanted by a different geometry of existence, a different shape to life.

The unpredictability, yet inevitable familiarity, of a fractal landscape presents an interesting contrast to current metaphors of 'obstacles' and 'stumbling blocks' to understanding. Such images presume a knowable goal, and contingencies must thus be cast as impediments and resistances to be overcome in a grand competition. Fractal sensibilities suggest that contingencies must be anticipated, but, beyond a general expectation, cannot be predicted in any dependable way. Although metaphors of competition can be read into this image, one's movement might just as well be described in terms of mindful attendance to the texture of existence.

This shift is an aspect of what might be considered a rethinking of the notion of 'route', implicit in most discussions of curriculum. The popular habit of thinking of curriculum as the route to be followed brings with it desires for the most direct course, the smoothest path, etc. A consideration of the notion of route in terms of the fractal texture of experience, while not discounting the importance of goals and focus, prompts a shift in attention onto the bumps and turns and distractions. It is these features, as much as anything else, that gives the route - that is, the curriculum - its form. In effect, we are arguing here what was suggested by Pinar and Grumet (1976: 18) some time ago in the development of the notion of currere, the verb form of 'curriculum'. Currere refers to the running of the course rather than the 'course to be run, or the artifacts employed in the running of the course'. It is a call to attend to the complex, organic character of the learning engagement. 


\section{Reiterating}

There has been a rapid evolution of sensibilities among educators in recent years. In particular, epistemologies, methodologies, and reporting strategies have been the topics of intense debate and reformulation. Much of this discussion, we believe, has been prompted by realizations that the complexity of educational phenomena cannot be understood through strategies of reduction, nor do holist theories provide an adequate alternative. Within such realizations, philosophies of middle ways have arisen - mind-sets that endeavour to consider whole and part simultaneously, recognizing the impossibility of any sort of totalized understanding.

In terms of developing this mind-set, a powerful metaphor - both visually and procedurally - has arisen in mathematics: fractal geometry. Demonstrating how simplicity can give rise to complexity and how complexity can give rise to simplicity, realizing that bumpiness of detail is not a function of scale, compelling in the observer an awareness of her or his partiality in viewing; demonstrating the manner in which forms can be part of larger forms without flattening their own unique integrities; prompting analyses that offer description in terms of relationships and ecologies rather than linear causality; presenting accounts of growth in terms of dynamic recursivity rather than direct progress these are some of the qualities of a fractal-informed sensibility.

Indeed, these qualities are actually manifest in the emergence of the field of fractal geometry. It is itself a complement of previous geometries. Neither a denial, a replacement, nor a correction, fractal geometry is a further iteration, an elaboration of what has come before. It is an elaboration that enables thinking to become more complex, and also that reveals much of what has been allowed to slip into transparency in terms of the assumed structure of knowledge and the taken-for-granted criteria for claims to truth.

Fractal geometry, we suggest, offers a useful interpretation of emerging sensibilities. We believe that it can contribute to a new habit of mind, one that is more tentative, more attentive. Our own reading of current happenings and crises, on levels ranging from the personal through to the global, is that this manner of thinking is crucial if educational research is to continue to generate different ways to understand learning and teaching. In this we join with Berry (1990: 22):

Understand that no amount of education can overcome the innate limits of human intelligence and responsibility. We are not smart enough or conscious enough or alert enough to work responsibly on a gigantic scale. In making things always bigger and more centralized, we make them both more vulnerable in themselves and more dangerous to everything else. Learn, therefore, to prefer small-scale elegance and generosity to large-scale greed, crudity, and glamour.

In enabling a conceptual reunification of part and whole, fractal geometry might also enable this sort of change in thinking. It might even help to shift the 
goals of formal education from universal principles and narrow expectations of the future toward recognitions that the contextual and the immediate are more than fragments. They are fractal. As novelist Anne Michaels (1996: 19) notes, 'Any given moment - no matter how casual, how ordinary - is poised, full of gaping life'.

\section{Notes}

1 Ideally, we would have preferred to print a range of fractal images for inspection. Unfortunately, we are limited by space, image resolution, and copyright regulations. There are, however, thousands of websites (e.g. Fractal Website 2005) devoted to the display of fractal images. Most search engines will generate extensive lists of possibilities for the search terms 'fractal geometry' or 'fractal images'.

2 'Shared' is not used here to suggest identical subjective interpretations. It is, rather, intended to suggest the participatory nature of understanding. To draw a loose analogy, understandings are shared in the way that conversations and responsibilities are shared.

3 More detailed examples of the sensibilities announced here see Davis (1996) for mathematics instruction, Sumara (1996) for reading education, and Davis and Sumara (1997) for teacher education.

\section{References}

Berry, W. (1990) 'The futility of global thinking', Harper's, June, 16-22.

Calvin, W.H. (1996) How Brains Think: Evolving Intelligence, Then and Now (New York: Basic Books).

Capra, F. (1996) The Web of Life: A New Scientific Understanding of Living Systems (New York: Doubleday Anchor).

Cobb, P. (1994) 'Where is the mind? Constructivist and sociocultural perspectives on mathematical development', Educational Researcher, 23 (7), 13-20.

Davis, B. (1996) Teaching Mathematics: Toward a Sound Alternative (New York: Garland).

Davis, B. and Sumara, D.J. (1997) 'Cognition, complexity, and teacher education', Harvard Educational Review, 67 (1), 105-25.

Dennett, D.C. (1996) Kinds of Minds: Toward an Understanding of Consciousness (New York: Basic Books).

Fractal Website (2005) IFD: Internet Fractal Database. www.ba.infn.it/ zito/project/ gallerie.html (accessed 15 August 2005).

Gadamer, H.-G. (1990) Truth and Method, 2nd edn, trans. W. Glen-Doepel, trans. rev. J. Weinsheimer and D.G. Marshall (New York: Continuum).

Gleick, J. (1987) Chaos: Making a New Science (New York: Viking).

Grumet, M.R. (1988) Bitter Milk: Women and Teaching (Amherst, MA: The University of Massachusetts Press).

Kauffman, S.A. (1995) At Home in the Universe: The Search for Laws of Self-organization and Complexity (New York: Oxford University Press).

Lovelock, J.E. (1979) Gaia, A New Look at Life on Earth (New York: Oxford University Press).

Maturana, H.R. and Varela, F.J. (1987) The Tree of Knowledge: The Biological Roots of Human Understanding (Boston, MA: Shambhala). 


\section{B. Davis and D.J. Sumara}

Michaels, A. (1996) Fugitive Pieces (Toronto, ON: McClelland \& Stewart).

Norretranders, T. (1998) The User Illusion: Cutting Consciousness Down to Size (New York: Viking).

Pinar, W.F. and Grumet, M.R. (1976) Toward a Poor Curriculum (Dubuque, IA: Kendall/Hunt).

Pinar, W.F., Reynolds, W.M., Slattery, P., and Taubman, P.M. (1995) Understanding Curriculum: An Introduction to the Study of Historical and Contemporary Curriculum Discourses (New York: Peter Lang).

Stewart, I. (1998) Life's Other Secret: The New Mathematics of the Living World (New York: Wiley).

Stewart, I. and Cohen, J. (1997) Figments of Reality: The Evolution of the Curious Mind (New York: Cambridge University Press).

Sumara, D.J. (1996) Private Readings in Public: Schooling the Literary Imagination (New York: Peter Lang).

Thompson, W.I. (1996) Coming into Being: Artifacts and Texts in the Evolution of Consciousness (New York: St. Martin's Press).

von Glasersfeld, E. (1995) Radical Constructivism: A Way of Knowing and Learning (London: Falmer). 


\section{Index}

Aboriginals, Australian 233-4, 237, 243-6 activity theory 213-14

administrators, educational 180, 185-9

agency as distinct from structure $202-3$, 215

alienation 281, 284

America see United States

architecture 17-20,340

Australia 233-4, 237, 242-8

Ball, Deborah L. co-author of Chapter 7 vii, 5

Bildung 118-19, 123-5

blackboards 27

California State Board of Education (CSBE) and California Framework 234-5, 242-3, 253-5

Canada 239, 249-58

caring attitudes and feelings 107

citizenship education $65-6,69$

classroom discourse 60-3, 68, 134

classroom layout 61

classroom system, evolution of 14-17, $26-8,31-2,36-41,48-9$

cognition and cognitive science 199-201, 301, 327-38; see also distributed cognition

comprehensive schools 297

computers, use of 23

constructivism 330-4

contingency theories 199, 213-14

currere concept 341

curriculum: definitions of 13-14; geometry

of 321-2, 338-41; historical viewpoint on 4 ; need for 285 ; origin of $12-13$; as a practice 2 ; strange types of $4-5,9-11$, $14,17,23$

curriculum development 116-17, 122,
$178,210-11,253-6,267,272-8$, 281-7, 299, 316-17

curriculum guidance 170-2, 177

Davis, Brent co-author of Chapter 13 vii, 5-6

decision-making: and leadership 205; in organizations 199-200; by teachers 90-1

'designed artefacts' in leadership practice 216-19, 222

Dewey, John 87, 278, 301

Diamond, John B., co-author of Chapter 8 vii, 5

Didaktik analysis 114-15, 118-30

Dillon, James T., author of Chapter 6 vii, 4

discourse, cultural and critical 331-2; see also classroom discourse

distributed cognition 201-3, 213-14

distributed leadership see leadership

division of labour 34,38

Elliott, John, author of Chapter 11 vii, 5 embodied knowledge, skills and habits 109-11

'espoused' theories and theories-in-use 207-8

ethical considerations $83,103-4$

Euclid and Euclidian geometry 322-31, 334-5, 338-9

'everyday' learning 300

evolutionary processes 328,335

factory system 29-30, 41

fractal geometry $6,323-43$

'Frontier' conception 237-8, 241, 250

Gadamer, H.-G. 100, 294-6 
geometry 322-3; of the curriculum 321-2, 338-41; see also fractal geometry

Germany 99, 114-15

Giddens, Anthony 202, 215, 269

globalization 234, 251-8

grading of pupils 51-2

grammar schools 35-6

Halverson, Richard R., co-author of Chapter 8 vii, 5

Hamilton, David, author of Chapter 2 vii, $4,12,50$

Heath, Shirley Brice, co-author of Chapter 12 viii, 5-6

history of science 268,272

history teaching $234-5,243,245,251-5$

HIV/AIDS 334-5

humanities teaching and the Humanities

Curriculum Project 281-97

human-science theory of education 114 , 120

indigenous peoples see Aboriginals; Maoris; Native Americans

inner-city communities 303-4

in-service training for teachers 182 , 276-7

institutional theory 200-1, 220

interrogation technique used in teaching 61-3

\section{Journal of Curriculum Studies (JCS) 1-4}

Klafki, Wolfgang, author of Chapter 5 viii, 3-4

knowledge, structuring of 340

Langeveld, Martinus J. 81-4, 91

LaSpina, James A., author of Chapter 9 viii, 5

leadership 196-223; definition of 204; distributed 5, 197-204, 208-22; enactment of 107-8; instructional 206; and management 204; practice of 206-8; research on 198-201; role of followers in 203, 212; routines, tasks and functions of 205-9; in schools 196-8, 203-5; situated nature of 213-14, 221; styles of 199, 214

lectures 38

lesson plans 48-70, 116, 129-30

Linné, Agneta, author of Chapter 3 viii, 4

literacy 184, 192
McLaughlin, Milbrey Wallin, co-author of Chapter 12 viii, 5-6

Maoris 247-8

mathematics teaching 165-92, 208-11; educational administrators' attitudes to 185-9; need for and priority of reform in 188-90; resources needed for 166-8, 176-80, 189-92; school principals' attitudes to $180-5,188-9$

memorization $68-9,177$

memos, use of 217-18

Milburn, Geoffrey, co-editor and coauthor of Introduction viii mindfulness $88,91,107-9$

monitorial system 29-30, 36, 39-41, $50-1,68$

multiculturalism 233-7, 242-9, 252, 257

narrative, use of 64-6, 68-9

National (US) Council of Teachers of Mathematics (NCTM) 170-2, 180-1, 190

National Curriculum (British) 23, 276-7

Native Americans 236-4, 250

New Zealand 242, 247-9, 258

Ontario Curriculum 254-6

organizational structures 219-20

pedagogical fitness 94-6, 108

pedagogical moments and pedagogical action 82-6, 89-91, 95, 100-2, 107-11 pedagogy: concept of 81,83 ; ethics of 83 perceptiveness, pedagogical 110 phenomenology 202, 331, 336 postmodernism 270-1, 321-3 practical reasoning $82-3$

praxiology 284, 286, 289, 293, 296 praxis 286, 289

Price, Jeremy N., co-author of Chapter 7 viii, 5

principals of schools: attitudes to mathematics teaching $180-5,188-9$; leadership role of 196, 198; primary agendas of 183-5

problem-solving: as an orientation in teaching 185-8, 273; by school principals 200 ; by teachers $89-90$ psychology in education 99-100

questions 133-56; asking of 133-6, 282-4, 296; avoidance of 146-8; effect of 136-7; follow-up 153-4; higherorder 135-6, 139, 142, 153; length of 
155-6; open-ended or closed 154-5; practical pursuit of 144-6; purposes of 134,138 ; research on response to 151-6; theoretical study of 137-44

recitation as a form of pedagogy 48 reflection 85-91, 94-5, 108-10; forms of $87-8$; promotion of 208

reflective practitioners $88-90$

Reid, William A., author of Chapter 1 ix, 4 research: on use of questions 136-7,

151-6; on school leadership 198-201 roles in teaching and learning $302-5$

school design 52

schooling, concept of 39

Schools Council 284, 288

science: history of 268,272 ; sociology of 269-71

science education $5,265-79$

scientific culture $272-4,277-8$

secondary modern schools $281-4,288$, 297

silences, use of $149-51,156$

social constructionism 330-2, 336

social learning 115

Socratic tradition $62-3$

Solomon, Joan, author of Chapter 10 ix, 5

Spillane, James P., co-author of Chapter 8 ix, 5,204

sport in schools 18,21

statements used instead of questions $148-9$

Stenhouse, Lawrence 5, 284-97

structural determinism 202, 215-16 structure: and agency 202-3, 215; alternative definitions of 339-40; and system 215

subjects, academic, construction and reconstruction of 5

Sumara, Dennis J., co-author of Chapter 13 ix

Sweden 13, 48-69, 277-8

tact: definitions of 96-7, 100-2; ethical aspects of $103-4$; musical 102 ; and orientation to others 104-6; pedagogical 95-102; and pedagogical action 107-11; in relation to insight and feeling 106-7; in scholarship 100-1

'teachers as researchers' movement 285 , 292

teacher training $50,53-6,182,276-7$

textbooks 12-13, 18, 177-9, 190, 235-58, 339

thoughtfulness 98-100, 107-10

United States 13, 23, 165-92, 219, 234-5, 246-7, 253-4, 299-312

'upbringing' of children 3

van Manen, Max, author of Chapter 4 ix, $3-5,108$

vulnerability of children $103-6$

Westbury, Ian, co-editor and co-author of Introduction ix, 13, 48

youth organizations 303-17; differences from schools $313-17$ 

eBooks - at www.eBookstore.tandf.co.uk

\section{A library at your fingertips!}

eBooks are electronic versions of printed books. You can store them on your PC/laptop or browse them online.

They have advantages for anyone needing rapid access to a wide variety of published, copyright information.

eBooks can help your research by enabling you to bookmark chapters, annotate text and use instant searches to find specific words or phrases. Several eBook files would fit on even a small laptop or PDA.

NEW: Save money by eSubscribing: cheap, online access to any eBook for as long as you need it.

\section{Annual subscription packages}

We now offer special low-cost bulk subscriptions to packages of eBooks in certain subject areas. These are available to libraries or to individuals.

For more information please contact webmaster.ebooks@tandf.co.uk

We're continually developing the eBook concept, so keep up to date by visiting the website. 






